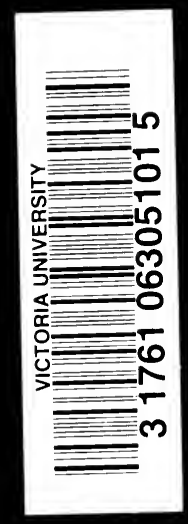


Geonge \&. Blewett. fondon, Eng.

[sett. 10,1900]

Plat* aris. Kant:

$31-83$

$-33-37$

$38+41$ 



\section{LECTURES AND ESSAYS}

$$
\text { ON }
$$

NATURAL THEOLOGY AND ETHICS 
HEN RY FROWDE, M.A.

PUBLISHER TO THE UNIVERSITY OF OXFORD

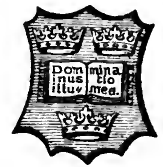

LONDON, EDINBURGH, AND NEW YORK 



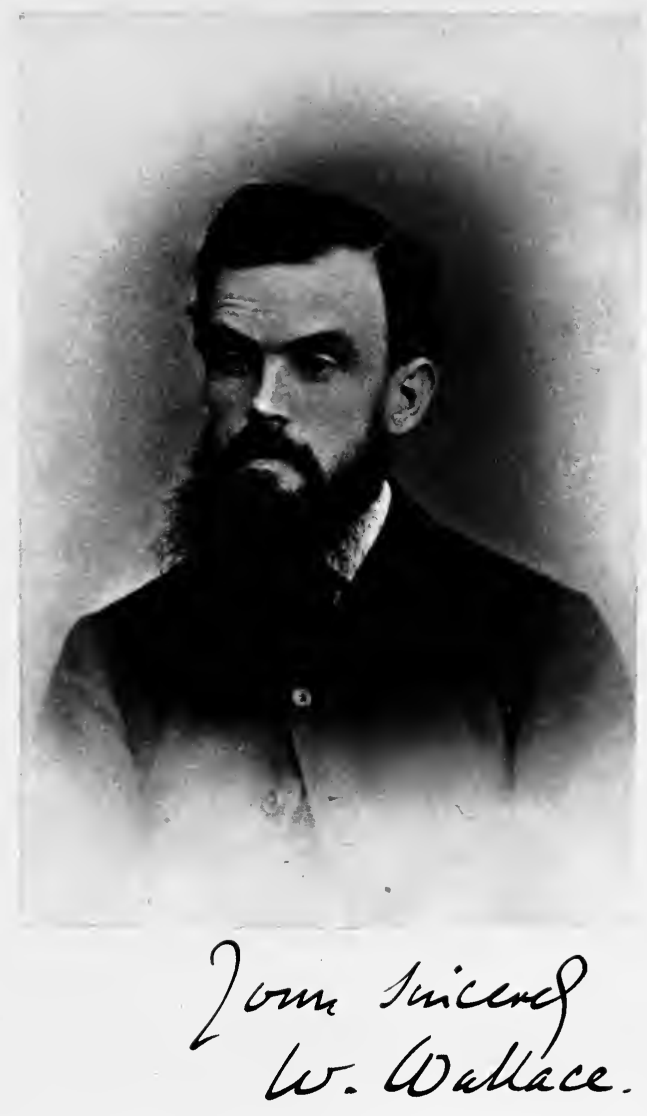




\section{Lectures and Essays}

on

\section{Natural Theology and Ethics}

BY

\section{WILLIAM WALLACE}

LATE FELLOW OF MERTON COLLEGE AND WHYTE'S PROFESSOR OF MORAL PHILOSOPHY IN THE UNIVERSITY OF OXFORD

EDITED, WITH A BIOGRAPHICAL INTRODUCTION

BY

\section{EDWARD CAIRD}

MASTER OF BALLIOL COLLEGE, OXFORD

WITH A PORTRAIT

\section{Oxford}

AT THE CLARENDON PRESS 


\title{
CONTENTS
}

\begin{abstract}
$\longrightarrow$
PAGL:

BIOGRAPHICAL INTRODUCTION . . . . . vii-xl
\end{abstract}

I. GIFFORD LECTURES ON NATURAL THEOLOGY AND THE RELATION OF RELIGION TO MORALITY.

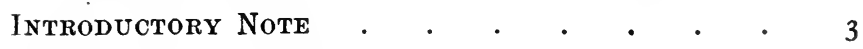

I. The Scope of Natural Theology $\downarrow$ • • $\cdot 4$

II. The Greek Origins of Theology . . . . . 24

iII. The Natural Theology of Christ . . • . 42

iv. Religion and Morality-The Definition of ReLIGION • • • • • • • • • • • 52

v. The Ethical Movement in Religion . . . 60

vi. Mr. Balfour's 'Foundations of Belief' • • 73

vil. Naturalism and Rationalism - The Scientific

and the Philosophical Point of View-The Main Conditions of the Evolution of Reason • 93

viir. Socral and Individual Conditions of Ethics • 113

ix. Man's Relation to Nature-Materialistic and IDEALISTIC VIEWS OF IT . • • • • • • I30

x. Morality as Crvilization-The Material Basis of THE Moral Life . . . . . . . 147 
xi. On some Relations of Morals, Science, and ReLIGION • • • • • • • • • • • 168

xir. The Essential Nature of Religion and its Relation to Morality-The Belief in Immortality

II. ESSAYS IN MORAL PHILOSOPHY.

i. Our Natural Rights . • • • • • • 213

ir. Person and Personality .

iII. ResponsibILITY • • • • • • • • • • zOI

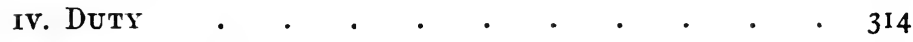

v. Hedonism

vi. Utilitarianism

vir. The Ethics of Socialism • • • • • • . 399

viri. The Relations of Fichte and Hegel to Socialism 427

ix. The Legal, Social, and Religious Sanctions of

Morality . . . . . . . . . 448

III. CRITICAL ESSAYS.

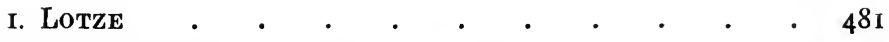

ir. Nietzsche's Criticism of Morality . • • • 5 II

iII. Nietzsche's 'Thus Spake Zarathustra'. • . 530

iv. Studies in the Hegelian Dialectic, by John

M. E. MCTAGGART • • • • . . $\quad$ • 542 


\section{BIOGRAPHICAL INTRODUCTION}

I HAVE undertaken to write a short account of the life and work of the late Professor Wallace as an introduction to this volume of selections from his manuscripts. The existence of a College Tutor and University Professor is so quiet and uneventful, and Wallace confined himself so closely to his academic duties, that an elaborate biography of him would be out of place. At the same time, his influence over his pupils was so great, and his work both as a writer and lecturer was so unique in kind, that it has seemed desirable to put on record the main events of his life, and to attempt, so far as is possible, to estimate the main features of his character and the general purport of his philosophical teaching.

William Wallace was born on May II, I843, at Cupar, the county town of Fifeshire. His father, James Wallace, began life as a mason, and got on so well as to become a successful masterbuilder. $\mathrm{He}$ and his wife, Jean Kellock, were a quiet, industrious pair, who mixed little with their 
neighbours, and devoted themselves mainly to the bringing up of their family, of whom there were five, four sons and one daughter. William was the eldest of the family, and the third son was Edwin Wallace, afterwards Fellow of Worcester College and author of an edition of Aristotle's De Anima, a man of fine intelligence and generous character, who died of consumption at a comparatively early age. The parents were simple and truthful people, the mother especially being a woman of considerable energy and originality, and their example had no little influence in developing in their son that quiet independence and uncompromising devotion to ideal aims, which were leading notes of his character. His ability and steadfastness of purpose showed themselves very early. Both at the Madras Academy, Cupar, and subsequently at the University of St. Andrews, he easily took the first place in all the studies to which he gave his mind. His main interest at first was in Classics, in which he had the advantage of the teaching of Professor Sellar and Professor (afterwards Principal) Shairp, but in the last years of his course he came under the influence of Professor Ferrier, to whose lectures he traced his first intellectual awakening and his initiation in philosophical study. He did not take to golf as an amusement like most St. Andrews students, nor indeed did he ever care much for athletics in any form; but he early developed a taste for natural beauty, which he indulged in long country walks. At St. Andrews he was specially impressed by his first view of the 
sea, and used to spend much time in watching the waves breaking on the rocks or rolling up the long slope of the sands.

For such a studious youth in Scotland, the Church seemed the natural profession; and his parents sent him to the University with that object. But after spending four years in the Arts course at St. Andrews, and especially after his philosophical studies had awakened him to independent thinking, Wallace came to feel himself not specially fitted for that profession, and somewhat doubtful whether he could comply with its requirements. On this subject an interesting anecdote is told by a member of his family. It had been arranged, in conformity with the wish of his mother, that he should go to the Divinity Hall in Edinburgh after having completed his curriculum at St. Andrews. But at last, when the day came that he should start, he said to her, 'Do you really wish me to go? If you say the word, I will go.' His mother, seeing that his heart was not in it, turned away in silence; she was much disappointed, but was too wise to press him further in such a matter.

Having thus changed his plans, he was recommended by his professors in I864 to try for an Exhibition in Balliol College, which he succeeded in getting. At Oxford he showed the same easy mastery of the work he had to do, taking a First Class in Moderations I866, and a First in Literae Humaniores in the following year, gaining also the Gaisford Prize for Greek Prose, and, not long after, 
a Craven Scholarship. I remember making his acquaintance when he first came into residence in Oxford, and the impression of youthful staidness and self-command which he made upon me. In Balliol, owing to his retiring disposition, his comparative maturity of mind, and his disinclination to athletics, he was not well known to many of the undergraduates, and a certain bluntness of manner, partly the result of shyness, gained him the nickname of 'The Dorian.' But he was greatly respected and admired, and his genuine kindness of heart and rectitude of purpose made itself felt by all who came into near relation with him. Jowett and Green both had a high estimate of his character and powers, and he was strongly influenced by both in his mental development. From Green he received a further stimulus towards the study of philosophy, and especially of the philosophy of Germany; and long afterwards he spoke of what he owed 'to that example of high-souled devotion to truth, and of earnest and intrepid thinking on the deep things of eternity.' On the other hand, the intellectual influence of Jowett was more in the direction of Classical scholarship and of literary style, and of general balance of mind. In the preface to the last edition of Wallace's Prolegomena to the Hegelian Logic, which was written under the influence of Jowett's recent death, he says a few words about his 'old Oxford Tutor and friend,' touched no doubt with the idealization of memory and regret, but characterizing the nature of Jowett's influence as 
truly as anything that has been written of him. 'The late Master of Balliol,' he says, 'was more than a mere scholar, a mere philosopher. $\mathrm{He}$ seemed so idealist, yet so practical; so realist, and yet so full of large ideals; so delicately kind, and yet so severely reasonable. You felt that he saw life more steadily, and saw it more whole than others; as one reality in which religion and philosophy, art and business, the sciences and theology, were severally but elements and aspects. To the amateurs of novelty, to the slaves of specialization, to the devotees of any narrow way, such largeness might, with the impatience natural to limited minds, have seemed indifference. So must appear those who on higher planes hear all parts of the harmony of humanity, and with the justice of a wise love, maintain an intellectual Sophrosyne. On his pupils, this secret power of an other-world serenity laid an irresistible spell, and bore in upon them the conviction that beyond scholarship and logic there was the fuller truth of life, and the all-embracing duty of doing their best to fulfil the amplest requirements of their place.'

In I 867, just after taking his Degree, Wallace became a Fellow of Merton College, and was shortly after appointed to a Tutorship, the duties of which he continued to discharge till his death, in addition to those of Whyte's Professorship of Moral Philosophy, to which he was elected I882, as the successor of T. H. Green. In I 872 he had married Miss Janet Barclay, daughter of the Sheriff Clerk of 
Fife, who, with a daughter and two sons, survives him.

The main after-events of his life were connected with the publication of his books. In 1874 he published his translation of the Logic of Hegel (from the Encyclopaedie), with Prolegomena, in which he dealt with the main preliminary difficulties of the study of Hegel. His Epicurean Philosophy appeared in 1880 (in the S.P.C.K. Series of Ancient Philosophies). It contains a delicately appreciative account of a philosophy to which we should hardly have expected Wallace to feel any special attraction. It traces the origin of the school, and dwells with much sympathy upon the beautiful harmony and ideal simplicity of the society of friends which Epicurus created. In this work Wallace first showed that desire to realize in all their details the circumstances of the life of the thinkers in whom he was interested, which was a marked characteristic of his writing. It was not that he exaggerated the importance of such secondary elements in biography; he even apologizes for paying so much regard to them; but he took very great pleasure in collecting even the least important facts about the philosophers or poets whom he was studying, and in visiting the scenes associated with their lives. Generally he directed his summer tours to such places, and in different years sought to familiarize himself with the environment of Hegel, Kant, Schopenhauer, Nietzsche, and finally, of Wordsworth and Coleridge. Thus, while writing his book on Kant, published in 1882, for 
Blackwood's Philosophical Series, he paid a visit to Königsberg. The result is shown in the very interesting and humorous biography in which he pictures to us in a very lifelike way the surroundings of the great critical philosopher and his faithful servant Lampe. The part of the book relating to the philosophy of Kant is an excellent résumé, but suffers from the fact that he had to cut it down so much in order to reduce it to the required size.

His next book, the Life of Schopenhauer, published in I890, was written in a similar way. It is perhaps the best of his smaller books, and contains a very vivid account of that curmudgeon of genius-if we may be allowed the expression-in which the defects of his character and philosophy are indicated, but at the same time full credit is given to him for that deeper idealistic impulse that runs through his works, and the wonderful gleams of poetic or philosophic insight which he exhibits from time to time. In this volume Wallace displays a very rare biographical gift. I do not know any biography which makes us to see more clearly that the character and thought of its subject are different aspects of the same thing. We are made to realize how Schopenhauer's violent recoil against materialism and empiricism, and the impatient and intolerant idealism which was his mental characteristic, almost inevitably resulted in his negative Pantheistic theory of the world; and how, at the same time, he was enabled by a logical tour de force to give to that negative view something of the value of 
a positive, and to maintain that the ultimate unity has a sporadic manifestation in art and life, which it is the open secret of genius to detect. Thus we are enabled to understand the strange alternations of depth and shallowness, of penetrative insight and savage prejudice, of egoistic passion and selfabnegation, which showed themselves in his life and found expression in his philosophy-a philosophy whose influence upon some readers has been so great, partly because it was such an immediate reflex of the character of the author. Take one passage :-

'One may say,' says Wallace, ' that there are two Schopenhauers in the field. Even the meanest of God's creatures, says the poet,

"Boasts two soul sides, one to face the world with, One to show a woman when he loves her."

Schopenhauer's beloved was no mortal maiden, but an angel vision-or was it a reality? -of truth. There is the Schopenhauer of the outward biography, an irritable, petulant, paradoxical creature, plagued by a most unconquerable vanity; whose acts accuse him of being selfish, harsh-mannered, and sordid, with a history full of trivial incidents and vulgar quarrels; self-engrossed, dead to the sweet ties of domesticity, and deaf to the call of public and national interests; sinking as the years passed by into a solitary cave, whence, like the giant in Bunyan's Allegory, he raged impotently at the heterodox wayfarer. Unfortunately in some of his books, especially in the later, this unpleasant self 
is rampant. But these same books, at their best, give the picture of another soul, which, freed from the bond of temporal quarrels and the world's litigiousness, draws closer to the great heart of life, and tries to see clearly what man's existence and hopes and destiny really are; which recognizes the peaceful creations of art as the most adequate representations the sense-world can give of the true inward being of all things; and which holds the best life to be that of one who has pierced through the illusions dividing one conscious individuality from another, into that heart of divine rest where we are each members one of another, essentially united in the great ocean of Being, in which and by which we alone live '.' The chapter that follows this gives not so much an analysis of Schopenhauer's work, as rather a sympathetic rendering of its inner spirit; and the whole biography is a great illustration of the principle that the most powerful criticism of an author lies in a thorough appreciation of the best that is in him.

In I 892 Wallace brought out the second edition of his translation of Hegel's Logic, carefully revised, and enriched with many notes ; and in the following year he republished his Prolegomena, so much modified and enlarged as really to constitute a new work. Finally, in I 894, he published a translation of the last part of Hegel's Encyclopaedie, The Philosophy of Mind, with five Essays, in which he reviews the subjects of the volume, dealing especially with

${ }^{1}$ Life of Schopenhauer, ch. iv. 
the question of the method of psychology, and its relation to ethics and theology.

In 1892 he was appointed Gifford Lecturer in the University of Glasgow, and in the two following years delivered two courses of lectures there on the history of Natural Theology, and on the relation of Morality and Religion. What of these lectures has been preserved is printed in this volume. Wallace had contemplated a complete rewriting of these courses, and also the preparation of a volume on the ethical ideas in the poets of the nineteenth century. But the execution of these and other projects was postponed till he should be released from the lectures of the Merton Tutorship. In I 898 he would have earned a pension for thirty years' service in that College, and have had much more leisure for literary work. But in February, 1897, in riding down a hill about eight miles from Oxford, he appears to have lost control over his bicycle, and was dashed against the parapet of a bridge at the bottom. He survived until the following morning, but never recovered consciousness.

Wallace's life was purely the life of a teacher; he never took any prominent part even in University politics, though he frequently served on the Board of Faculties and other committees for University administration, and, both in these and in the meetings of his College, his words had great influence. He formed his opinions with much independence, and his forceful, and often pointed and luminous expression of them, was such as to lend them full 
weight and effect. $\mathrm{He}$ had not a little practical insight, and much of what one might call mental detachment and impartiality, and even those who could not agree with him often felt that his words cast a fresh light upon the subject. 'He was a quicktempered man,' writes a member of his College, who had good opportunities of judging, 'but never bore malice, was always inclined to think matters over, and, if necessary, to express a change of opinion. He had the strong and vigorous sense which enabled him to strike at the root of practical questions.' And the Warden of Merton speaks of 'the incisive brevity, weight, and pertinency of his remarks at College meetings,' and says that, in discussions on discipline or examinations, his 'desire to be just was evident, and he was not afraid to stand alone in his judgement.'

While, however, Wallace did not decline such University business as fell to his share, his main interest lay in his work as a College Tutor, as Lecturer on Philosophy, and as a writer on philosophical subjects. As a College Tutor, he gained the respect of many generations of Merton men; and after he became a University Professor his influence was greatly extended. He was not indeed naturally fitted to be a teacher of Passmen, and in later years he did not take any share in that work. But as a teacher of philosophy to men reading for the Honour School of Literae Humaniores, he has had few rivals in the history of the University. "Of this, indeed,' as Principal Fairbairn has said, 'only 
those who passed through his hands are qualified to speak, and the most qualified have spoken in terms of unstinted praise. It might be hard to some, though to none so hard as to himself, to break through his habitual and constitutional reserve; but he was so true a man, so good a scholar, so high and pure a thinker, and 'so conscientious a teacher, that association with him could not but be to the capable an education in itself.' To exercise his full educative power, he required to be known, and he could hardly be well known except to those who had some depth of character and real interest in philosophy; but upon those whom he influenced at all, he had an almost transforming power. His sincerity and simplicity of manner, his absorbing interest in the real purport of philosophy, and disregard of what was merely formal and technical, his dislike of sham and pretence, and his sympathy and power of entering into the difficulties of a student, even his intolerance of idleness, and the severity of the demands he made upon his pupils, awakened in them an admiration and enthusiasm seldom felt for any teacher.

I have before me many letters from former pupils, who are well qualified to estimate the value of the instructions they received, in which he is spoken of in language that might seem extravagant, if it were not so obviously sincere. One old pupil writes: 'I should think that no one who was taught by him could fall into carelessness or insincerity of thought without feeling rebuked. It was teaching that could not pass away, because it gave one new powers and 
a higher life.' Another says: 'When I was in Oxford, I was simply saturated with his sayings, and was always quoting him and writing about him to my friends. I remember writing that he was a Carlyle, but a Carlyle with eyes fixed on thought rather than on practice.' Another says: 'All his pupils must feel that he was their intellectual father -a sternish father at times. He provoked us to thought, and his words stuck in one's memory like burrs. I was warmly attached to him, and felt this more strongly every time I saw him.' A Fellow of Merton, who was quite recently a pupil under Wallace's tuition, writes: 'It is extremely difficult for so young a man as myself to attempt adequately to appreciate the greatness of our late Professor; but an intercourse of two years, and the intimacy into which that intercourse brought me, inspired in me-and here I am speaking for all his pupils, not for myself alone-an admiration, I might say a reverence, which was never felt toward any other teacher. From the first we could not but feel the utter earnestness of the man, the intense seriousness with which he approached the great subjects of which he was trying to give us some faint conception. His method was severely Socratic ; for the first year of work with him he struck us sometimes as stern and hard, as demanding too much; but we soon came to see that if he asked much from us in the way of devotedness, enthusiasm, labour, and self-denial, he asked much more from himself. To have known him as I did for two years in almost 
daily contact, was a high and generous inspiration. $\mathrm{He}$ had more of the prophet about him than any man I have known, and he was regarded by those of his pupils who could at all appreciate him, with a whole-hearted devotion such as few others ever inspired. His memory is the most precious possession of my University life.'

Wallace's lectures were in many ways unlike the usual University type; they had an individual flavour which it is not easy to characterize. They were not systematic expositions of the subject, as already formed and settled in the speaker's mind, but rather like attempts to realize its significance afresh, by approaching it now from one point of view and now from another. He seldom read from a manuscript, and when he did so, the constraint of reading seemed to deprive him of the freedom necessary to effective speaking. His custom was rather before lecturing to fill his mind with his subject, making many notes, and often writing out even many pages of extracts from the authors criticized. Generally, however, especially in later years, he made no attempt to write out even a sketch of what he had to say, but trusted for the expression to the impulse of the moment and of the audience. Speaking thus ex tempore, he never seemed to have any difficulty in finding words for his ideas, and his sentences flowed on without hesitation ; though he was somewhat dependent for his effectiveness upon the mood and temper of the moment, and, we may add, upon the state of his health. But by this method he 
seemed to gain unusual power of putting himself en rapport with his audience, and of communicating to them, by a kind of infection, his own vivid perception of his subject, as it rose before his mind in the moment of delivery. His hearers seemed to be receiving thought in the making, and not as the cutand-dried product of the study. The play of his mind upon the questions discussed, the strange touches of humour with which his discourse was lighted up, the subtle beauty and conclusiveness of expression which he often attained, and, through it all, the gravity and earnestness of his manner, produced an impression which was unique of its kind. $\mathrm{He}$ did not aim at giving to those whom he addressed the kind of things which might be useful in the Schools, but rather at showing them how to think and feel. His thought seemed never the working of an abstract intellect, but rather an attempt to deepen life by making it self-conscious and communicating it to others. 'He is never other than stimulating and suggestive, and, in a sense, he was always preaching,' said an appreciative listener ; and it is not impossible that the fact that he had looked forward to the Church as his profession, as well as the strongly ethical cast of his own mind, tended to give a practical turn to his teaching. He might indeed be fairly said to be a preacher of ideal truth, and his lectures seemed to be to him an opportunity in which he could free himself from the circum praecordia frigus, which made it so difficult for a man constitutionally reserved, and further trained 
to reticence by academic habits, to utter himself freely on the highest subjects.

'To those who live in London,' writes Professor Muirhead, 'his figure has not been unfamiliar for some years past, when he has come to lecture at Toynbee Hall, or the London Ethical Society-the tall and somewhat gaunt outline, the earnest and thought-worn expression, the perfect mastery of material and language, which enabled him to speak for generally over an hour, without note or reference, yet without a slip; the graphic and humorous illustrations must have stamped themselves on the memory of many. His habit was to choose for his subject some individual thinker (Rousseau, Epicurus, Nietzsche, Wordsworth, were the titles of some of his lectures) ; or if he chose some more abstract topic, such as "Duty," he was careful to attach what he said to some concrete instance; the lecture last referred to taking the unexpected turn of a vivid characterization of Frederick the Great as a type of devotion to duties of one's station. Ideas were to him living forces, and unless he could show them in actual operation in concrete instances, he had little hope of making their scope and meaning clear '.'

In the published works of Wallace, what first strikes the reader is their literary quality, which is unusual in philosophical writing. His style, with more continuity of thought, has much of the subtlety and refinement which characterize the writings of Jowett. One cannot read many pages without

1 Fortnightly Review, May, 1897. 
coming upon one of those 'Olympian sentences,' as one of his pupils called them, those "̈ $\pi \epsilon a \pi \tau \epsilon \rho$ ó $\epsilon \tau \tau$, winged at once with thought and imagination, which seem once for all to fix and define for us some aspect of things. And on a closer view, one finds that this power of speech is not a mere literary gift, but due to the fact that he thinks (Platonically) not with his intellect only, but with his whole soul, using his imagination and his sympathies to aid him in identifying himself with the object, and explaining it from within outwards. It is due also to what, for want of a better word, we must call the intuitive character of his mind, which led him rather to see the whole in every part, and therefore to attempt to realize it as something with independent life, than to trace out its connexions and relations with the other parts. For, though his main work was devoted to the exposition of Hegel, the great modern systematizer of Idealism, and though he had, as we shall see, a subtle appreciation of the dialectical method of Hegel's thought, it cannot be said that his own tendency was to system, or to the close tracing of the filiation of thought upon thought. His effort was rather to realize by subtle criticism and sympathetic insight the different aspects of the matter with which he was dealing; and then to gather up the general result in some luminous imaginative expression. His way was to ruminate upon a subject till 'the fire burned,' and clearness of vision led to vivid and characteristic utterance. Or we might say that reflexion was to him rather a means to an 
end, a way of securing more perfect vision, and that he hardly cared to analyze or methodize it for itself. $\mathrm{He}$ once spoke to me of the 'wretchedly episodic character of his mind,' which seemed to be a strange complaint from one who was always looking at his subject, whatever it might be, in the light of the unity of the whole. But what he meant is, I think, illustrated by many places in his writings, in which he seems to suggest point after point, to view the subject in aspect after aspect, and then to call upon the reader to make the synthesis for himself, with the aid of some striking metaphor, or else, as Professor Muirhead indicates, of a sketch of the life and character of some individual, in whom the idea he is discussing was embodied. It is in harmony with this that he quite as often seeks to illustrate his thoughts from the poets as from the philosophers. He was a constant and unwearied reader of all the great ancient and modern classics, and he often made a special study of any new appearance in literature. And both in literature and philosophy what he sought was not thought or system for itself, but rather as the concentrated expression of life, the quintessence of human experience. The Hegelian philosophy had its strong hold upon his mind mainly because he seemed to find in Hegel one who united idealism with a more than positivist insistence upon the emptiness of abstract ideas, and whose thinking was a continual effort after the comprehension of the actual in its concreteness and complexity.

It is an indication of the same longing to get 
close to reality that so much of Wallace's interest was by preference drawn to writers whose tendencies were just the reverse of his own. $\mathrm{He}$ seemed to feel that philosophy was only to be trusted if it could verify itself in the most unfavourable of instances. He was fearful lest his idealism should become empty, if he did not continually bring it into contact with the crudest empiricism; that his optimism might get shallow if he did not continually drag it up de profundis from the deepest divisions and contradictions of thought and life. I have already spoken of the great pains he took to realize to himself, not only the intellectual atmosphere in which the philosophers and poets about whom he wrote were living, but also all the details of their outward life.

Wallace's criticism is almost always appreciative, and we might say, at times appreciative to a fault. $\mathrm{He}$ was, indeed, not without some of the logical pugnacity attributed to his countrymen, and which made a friend of mine say that when a Scotsman agrees with you on ninety-nine points, and differs on one, he always chooses that one point to speak about. He could occasionally fulminate with much vigour against views and tendencies of which he disapproved. But on the whole he disliked and avoided the atmosphere of controversy, and generally when he thought an author worthy of study, he took infinite pains to enter into his point of view, and even to suggest reasons to justify what seemed paradoxical and extravagant. This may be noticed 
in his treatment of not only Kant and Hegel, but of Epicurus, Hobbes, Schopenhauer, Nietzsche, and others. Certainly the fault, if it is a fault, is more than compensated by the subtle insight which is the natural reward of this kind of criticism, and which enables him to see the affirmation that is working behind the negations of the authors he is examining, and to find out all the grains of gold which are hidden in their dross.

Wallace's most important work, of course, lay in his exposition of the Hegelian system. In the Prolegomena to Hegel's Logic, even in its first form, he did much to remove the preliminary difficulties that embarrass the student; and in the enlarged edition, he discussed very fully all the main aspects of the Hegelian philosophy, giving also a sketch of the whole movement of the Logic, and showing its relation to the other parts of the system. The main defect of the Prolegomena is one which I have already indicated, viz. that while the topic of each chapter is treated in a very suggestive and penetrative way, the links of connexion between the different chapters are not always fully indicated; and in consequence the whole has the aspect of being a series of essays, rather than of a connected treatise. This, however, is more in appearance than reality, and to any one who carefully studies the volume as a whole, it will become evident that there are few real difficulties in the subject, which have not been thoroughly dealt with. The points upon which Wallace dwells most fully are, first of all, 
Hegel's view of the relation of the point of view of philosophy to that of the ordinary consciousness on the one hand, and that of the sciences on the other. In connexion with this, he takes up and discusses very fully the various misunderstandings of what is meant by Idealism, such as the supposition that it is the reduction of the objective world to an appearance in the consciousness of the subject, or that it involves the reference of the phenomenal world to a transcendental world of ideas. Such misconceptions he tries to meet by an historical survey of the transition through Kant and Fichte to Schelling and Hegel; and again by showing that the fundamental truth upon which Idealism exists, is the relativity of all distinctions. In particular, he seeks to prove that it does not set the object and the subject against each other, or deny the reality of the former any more than of the other, but that it insists primarily on that ultimate unity of all things which Plato adumbrated in the Idea of Good.

'The central or cardinal point of view of Idealism ${ }^{1}$ is,' he declares, 'its refusal to be kept standing at a fixed disruption between subject and object, between spirit and nature. Its idea is the identity or unity (not without the difference) of both. In its purely logical or epistemological aspect, one can easily see that, as Schopenhauer was so fond of repeating, there is no object without a subject, and no subject without an object. The difficulty arises 
in remembering these excellent truisms when one of the correlatives is out of sight, and the other seems to be independent, and to come before us with a title to recognition apparently all its own. . . The basis of all consciousness and mental activity is an original division, a "judgement" or dijudication of self from self. But once the dijudication made for such ends, it is a mistake to forget its initiation, and lose sight entirely of the fact that the observing mind is also the active, and that the object-self is not merely in relation to the subject-self, but in a higher unity is identifiable therewith. ... What Hegel, after Schelling, teaches, on the other side, is that the process of sense impression and the manipulations to which it is subjected by intellect presuppose, for their existence and their objective truth, a Reason which is the unity of subject and object, an original identity uniting knowledge to being.'

If, therefore, we attempt to separate spirit from nature, we end in depriving of all meaning the element which we try to treat as an independent substance. As Schelling puts it ${ }^{1}$ :- ' Opposing and separating the world of intelligence from the world of nature, men have learned to see nature outside God, and God outside nature, and withdrawing nature from the holy necessity, have subordinated it to the unholy which they name mechanical, while by the same act they have made the ideal world the scene of a lawless liberty. At the same time

${ }^{1}$ Proleg., p. 165 ; Schelling, iv. 306. 
as they defined nature as a merely passive entity, they supposed they had gained the right of defining God, whom they elevated above nature, as pure activity, utter "actuosity," as if one of these concepts did not stand and fall with the other.' On the other hand, we must not conceive the unity so asserted as a transcendent Being, in which the difference of things is simply lost, but simply as the unity of experience fully thought out. 'This transcendental, absolutist, a priori philosophy, which stands so strange and menacing on the threshold of the nineteenth century, is after all only, as Kant sometimes called it, an essay to comprehend and see the true nearness and dimensions of the much-quoted experience. All knowledge exists in (not on) the unity of experience. All the several experiences rest in the totality of one experience,-ultimate, all embracing, absolute, unconditioned, universal and yet individual, necessary and yet free,-eternal, yet filling all the works of time-ideal, and yet the mother of all reality,- unextended, and yet spread through the space of the universe. Call it, if you like, the experience of the race, but remember that that apparently more realistic and scientific process connotes neither more nor less (if rightly understood) than normal, ideal, universal, infinite, absolute experience. This is the Unconditioned, which is the basis and the builder of all conditions ; the Absolute, which is the home and parent of all relations. Experience is no doubt yours and mine, but it is much more than yours and mine. He who builds 
on his experience, builds on and in the Absolute, in the system, a system which is not merely his. In his every utterance he claims to speak as the mouthpiece of the Absolute, the Unconditioned; his words expect and require assent, belief, acceptance ; they are candidates (not necessarily or always successful) for the rank of universal and necessary truth; they are dogmatic assertions, and, even in their humblest tones, none the less infected with the fervour of certainty. For, indeed, otherwise it would be a shame and an insult to let them cross the lips '.'

Again, if this be so, we can understand that the task of philosophy is not merely to sum up the results of the sciences, or to show the harmony of their first principles, but it is to transform our ordinary view of the world as a collection of independent things, or even of things acting and reacting on each other, by thoroughly working out the idea of their unity. In opposition at once to the mystic view that would lose all things in God, and the empirical view that would rest in their apparent independence as phenomena conditioned by time and space, a true philosophy must be guided by the idea of systema system which does justice to all the divisions of reality, yet attempts to show the organic or superorganic unity of the whole. Philosophy cannot stop short of this; and if it be said that such system is unattainable, the answer is, that the thing is done by us all, and has to be done 2. "If not as men

1 Proleg., p. 169.

${ }^{2}$ Philosophy of Mind, Essay i, p. I 8. 
of science, yet as men, as human beings, we have to put things together, and form some total estimate of the drift of development, of the unity of nature. To get a notion, not merely of the general methods and principles of the sciences, but of their results and teachings, and to get this, not as a mere lot of fragments but with a systematic unity, is indispensable in some degree for all rational life. The life not founded on science is not the life of man. But he will not find what he wants in the textbooks of the specialist, who is obliged to treat his subject, as Plato says, "under the pressure of necessity," and who dare not look on it in its quality, "to draw the soul towards truth, and to form the philosophic intellect so as to uplift what we now mainly keep down" (Plato, Rep. 527). If the philosopher in this province does his work badly, he may plead the novelty of his task, to which he comes as a pioneer, or even as an architect. $\mathrm{He}$ finds little that he can directly utilize. The materials have been gathered and prepared for very special aims; and the great aim of science-that human life may be made a higher, an ampler and happier thing-has hardly been kept in view at all, except in its more materialistic aspects. To the philosopher the supreme interest of the physical sciences is that man also belongs to the physical universe, or that Mind and Matter are (to use Mr. Spencer's language) "at once antithetic and inseparable." He wants to find the place of Man,-but of Man as Mind-in Nature.' 
This view leads to a new conception of logical method, in which the old difficulty of Plato, whether inference proceeds from the known to the known, or from the known to the unknown, receives its solution. We cannot base knowledge on principles which we know independently of the results based on them, or on so-called 'facts' which remain to the end what they were for us at the beginning. For any such principle or fact, as thus isolated, must be imperfectly conceived, and can be rightly conceived only when we discern in it the relations and connexions which at first we overlook; nor can we stop short in the process of regress and reconstruction, of corrective interpretation and reinterpretation, till we find the whole in, or behind, our first starting-point. 'Begin where you like, the reason of things, if you allow it to work, carries you round till you see identity where you saw only difference, or effects where you only looked for causes. You begin, as the inductive logician, with the belief that the process is from the known to the unknown. You start with your basis of fact, as you called it. The nemesis of things forces you to admit that your facts are partly fictions, which waited for the unknown to give them a truer and fuller reality. You talk at first of induction, as if it were a single and simple process, which out of facts builds up generalities and uniformities. You learn as you go on that the only induction which operates, except in cases which have been artificially simplified by supposing half the task done before you apply your 
experimental methods, is an induction of which the major part is deductive, and where your conclusion will be recurrently made your premiss. Your induction only works on the basis of an hypothesis, and must be itself linked in the "concatenation of truths," a concatenation which is itself a criticism and a correction 1.'

From this it follows that the mechanical method of construing the whole as the aggregate of the parts, and also, what may be called the chemical method, in which the unity of the parts appears as a new partial existence with qualities that have no apparent essential connexion with those of the elements out of which they come, must be regarded as abstract methods, which, though they work well within a certain region, yet rest on a limited and hypothetical construction of things. And they must both ultimately yield to the 'method of development which is the method that is applicable to the full concrete reality, not like the others to parts abstracted from and insulated in reality ${ }^{2}$,' a method which ' has to blend induction with reduction, and to start from both ends in the series of causation at once,' and which goes upon the supposition that the determinations of each part can be truly known only when we regard it as resting upon and returning to the unity of the whole. This method 'recognizes in the object it examines a certain independence or originality, yet also the pressure of an immanent law, which does not wait

${ }^{1}$ Proleg., p. 188.

2 Id., p. 2 I4. 
for the outsider to put it together, but constructs itself as it were after a plan of its own '.' It sees in it the 'same subjective principle, both analytic and synthetic, as we own in thought.' The object is for it, ' neither a mere thing to be explained and construed $a b$ extra, nor a mystery of sudden transformation to be passively accepted; but a growth to be sympathetically watched and understoodunderstood, because it follows the same order as the movement of our own thought in the process of knowledge. Similia similibus cognoscuntur.'

As an actual specimen of this method of treating an object, and working towards the comprehension of it by following its own dialectic, we may refer to the eighteenth chapter of the Prolegomena, where Wallace attempts to deal with the idea of Personality, and to show how the different views of it may be regarded as steps in self-explication; or to the remarks in the next chapter on Genesis in mental life. The concluding chapters of the Prolegomena give an account of Hegel's application of this method to Logic itself, showing especially in what sense the whole system is developed out of the idea of Being with which it began, and in which sense the beginning really presupposes the system.

In the Essays prefixed to Hegel's Philosophy of Mind, Wallace's last published work, there is an attempt in the same spirit to discuss the value of the different methods in their application to

1 Proleg., p. 221. 
psychology, and to maintain the ultimate superiority of the method of development. The following passage may be sufficient to indicate the general point of view. 'The vulgar apprehension of these things seems to assume that we have by nature or are born with a general faculty or set of faculties, which we subsequently fill up and embody by the aid of experience. We possess-they seem to imply - so many "forms" or "categories" latent in our minds ready to hold and combine the new materials supplied from without. According to this view, we have all a will and an intelligence; the difference is only that some put more into them, and some put less. But such a separation of the general form from its contents is a piece of pure mythology. It is perhaps true and safe to say that the human being is of such a character that will and intelligence are in the ordinary course inevitably produced. But the forms which grow up are the more and more definite and systematic organization of a graded experience, of series of ideas, working themselves up again and again in representative and re-representative degree, till they constitute a mental or inner world of their own. The will is thus the title appropriate to the final stage of a process, by which sensation and impulse have polished and perfected themselves, by union and opposition, by differentiation and accompanying redintegration, till they assume characters quite unsurmised in their earliest aspects, and yet only the consolidation or self-realization of implications. 
Thus the mental faculties are essentially acquired powers, acquired not from without, but by action which generates the faculties it seems to imply. The process of mind is a process which creates individual centres, raises them to completer independence; - which produces an inner life more and more self-centred, and also more and more equal to the universe which it has embodied. And will and intelligence are an important stage of that process.' In what follows, Wallace gives a very suggestive commentary on the way in which Hegel follows out this idea, not only in psychology, but also in ethics and the philosophy of religion.

As may be partly seen from the account just given, Wallace was at once one of the most faithful of the followers of Hegel, and at the same time the most free from any clinging to mere verbal fidelity. He does not deal much in Hegelian formulae, even when he is explaining Hegel; rather he is very impatient of such literalness, and never rests in the Hegelian thought till he has reproduced it in a new form, or in many new forms. His allegiance means that he seemed to himself to find in Hegel just what he wanted for the development of his own tendencies of mind. On the other hand, just for that reason, I think his expositions of Hegelianism extremely faithful, and little influenced by any preconceptions. They seem to me to be explanations from within outwards, and less embarrassed by subordinate technicalities than almost any other treatment of the subject I have met with. If there is a bias 
in them at all, it is, as I have already indicated, that he emphasizes more the aspect of Hegel in which he agreed with Schelling, and therefore lays more stress upon the presence of the whole in each part, than upon the negative dialectical movement from one stage to another. But this is rather a question of comparative emphasis than of any essential difference of view.

In his general attitude to philosophy, Wallace combined a strong, almost unswerving confidence in the general idealistic point of view, with an extreme distrust of his own power of stating it adequately. This arose partly from a consciousness of the complexity of things which made him continually ready to look at them in new aspects, and to reconsider views of them which he had neglected, or to which he felt he had not done sufficient justice. It arose also partly from his high literary ideal, which made him keenly alive to any defect of exactness or refinement of expression. As I have said, he took endless pains in gaining an intimate knowledge of any subject or author whom he was studying, even down to the most external and insignificant details of biography; and when preparing any work for publication he wrote and rewrote what he had to say, till he was even in danger of losing the spontaneity of his original draft. I hardly think I have known any one who was so much oppressed with the vision of perfection, or rather with the combined and almost irreconcilable ideals of literary and philosophical excellence. This is partly the 
reason why he did not produce more, though it was also due to the fact that his circumstances, and the various claims upon him, rendered it necessary for him to combine the work of a Tutorship with that of his Chair, and also to undertake other work which left him comparatively little time for writing.

It is harder to speak of Wallace's personal character, and of what he was to those who knew him intimately. The somewhat abrupt speech and manner, which might repel strangers, and made the process of becoming intimate with him slow and difficult, did not conceal from those who came nearer to him the deep sincerity and reality of the man, and the tenderness and strength of his affections. And those who knew his private life know what sacrifices of any kind he was capable of making for those in whom he was interested. He was one who hid his good deeds almost as if they were crimes. Generally his innate reserve made it difficult for him to show what he was, out of his own household, and a comparatively narrow circle of friends. During the work of the Term, he often seemed rather oppressed than satisfied with what he could do. But he had correspondingly keen enjoyment in the times when the pressure was relaxed, especially in the numerous tours which he made with his family to places interesting from literary or philosophical associations. He was a 'lover of the meadows, and the woods, and mountains,' who had the deepest enjoyment in natural beauty, and who would go miles to see the first spring flowers and bring 
them back to his family. He loved the simple and the natural, and he was intensely averse to any kind of show or display. But one could not be long in his company without feeling the influence of his strong rectitude of nature, and of his latent and never directly expressed enthusiasm for that ideal view of life which he regarded as the truth.

In regard to the contents of the following volume, only a few words need be said. Wallace was not in the habit of writing out his lectures, and hence some of his best work in later years exists only in the form of notes, which are too disconnected and unfinished for publication. But there remains a considerable amount of writing, mainly on ethical or theological subjects, from which I have selected the parts that seemed most likely to interest the public. With the exception of two reviews, none of the papers included had been prepared for publication by the author, and consequently some of them are lacking in completeness and consecutiveness of treatment, and others want that finish of literary expression which his writings generally show. At the same time, I think there is some gain on the other side, especially for those who desire to search into the actual working of a philosopher's mind. There is in them often a certain spontaneity and freshness, a directness and force, which more than compensate for any defect of form. The Gifford Lectures, in spite of their fragmentary condition, contain a fairly adequate expression of his view of the relation of philosophy to 
theology, and of religion to morality. And some of the papers, especially the Essays on Moral Philosophy, have a tentative and heuristic character, as of a mind testing different ways of thought and seeking an outlet in one direction after another, which will be specially attractive to those who like to see thought, not ready made, but in the process of development. On the whole, they do not seem to me to fall below the usual high standard of the author's philosophical writings, and they show more completely than any of them his mind upon the highest questions of Religion and Morality.

I have to offer my best thanks to Mr. Bernard Bosanquet, to Professor Jones of the University of Glasgow, and to Mr. J. A. Smith of Balliol College, for assistance in selecting, from Wallace's manuscripts the papers that were most suitable for publication.

Edward CaIrd.

Balliol College,

oct. Iо, I 898 . 


\section{E C T URES}

ON

\section{NATURAL RELIGION AND THE}

\section{RELATION OF RELIGION TO MORALITY}

[BEING THE GIFFORD LECTURES DELIVERED IN THE UNIVERSITY OF GLASGOW IN I 894 AND I 895$]$ 



\section{INTRODUCTORY NOTE \\ TO THE GIFFORD LECTURES}

Professor Wallace delivered two courses of Gifford Lectures in the University of Glasgow. In the first course, delivered in 1894 , he discussed the subject of Natural Theology historically, giving a sketch of the views of Greek philosophers, and showing their influence on the development of Christian doctrine. The first three of the following lectures belong to this course; the other lectures of this course exist only in the form of newspaper reports, which are too imperfect and fragmentary to be reprinted. The first two, dealing with the scope of Natural Theology and the Greek Origins of Theology, do not correspond with the newspaper reports, and seem to have been written after the course was delivered, when Mr. Wallace was thinking of preparing his lectures for publication. The third, on the Natural Theology of Christ, was actually delivered.

The second course, delivered in 1895 , dealt with the subject of the relations of Morality and Religion. Of this course, nine lectures have been preserved. The first five lectures were occupied with a review of the various 
influences, ethical, literary, and scientific, which are affecting the religious thought of the present time, and changing the old dogmatic conceptions with which religion was formerly associated. Of this part of the course only two lectures are preserved (the fourth and fifth of the lectures following). The MS. breaks off abruptly at the end of the second of these two lectures, at the point where Mr. Wallace entered upon an examination of the influence of modern scientific conceptions upon the religious idea. The rest of the lectures of this course, from the sixth to the twelfth lecture, are preserved. They begin with an account and criticism of Mr. Balfour's Foundations of Belief, and then proceed to discuss the general subject of the relations of morality and religion. These lectures, though they have not been in any way revised or corrected since they were first written, seem to me to contain some of the most original and suggestive pages which Professor Wallace has produced. 


\section{LECTURES}

oN

\section{NATURAL RELIGION AND THE RELATION OF RELIGION TO MORALITY

THE SCOPE OF NATURAL THEOLOGY

At the present time, Natural Theology is apt to seem a belated stranger, if not even an impertinent intruder, in the circle of the sciences. The very term, the combination of noun and adjective, suggests an ill-assorted pair, or perhaps a contradiction in the conception. Theology, firmly established on its rock of Scripture, looks down almost contemptuously on the feeble efforts of unassisted reason to feel after God, if haply it may find Him. An impassable gulf is declared to separate the range of nature, which is the field of science, from the higher sphere of religion and of divine things. In the latter, it is urged, mere human reason is incompetent, or, where it is not altogether incompetent, it is altogether subordinate. For theology the necessary stimulus and starting-point must come from above, and has in fact come in the shape of a supernatural revelation. The mere natural man by merely natural means can know nothing of God, and, if he is to know anything of Him, must be directly or indirectly enlightened about God by God Himself. 
Questions like these may be said no doubt to go to the root of the matter. But it will perhaps also be admitted that, before proceeding to these extremities, there are problems of some importance connected with the scope of the terms employed. To mark the problems which are under examination, the contrasts of natural and supernatural have to be dealt with. The history of theological conceptions has to be traced.

And, in the first place, we must try to rise out of and beyond the conception of Natural Theology which is most familiar to the English mind, the conception which was adopted by Paley and the Bridgewater treatises of the present century. Natural Theology is thus restricted to the study of the evidences of design in nature, to an examination of the mutual adaptations in the physical universe which seemed to indicate as their origin an intelligence ordering all things for a purpose, that purpose being on the whole understood to be the welfare of man. So many and so striking are, from this point of view, the appearances of wise arrangement, moulding everything into materials for the use of humanity, that it is impossible to suppose them to be the result of chance, to be the undesigned consilience of independent agents.

This kind of Natural Theology, though with Paley (1802) and Chalmers it lasts on into the nineteenth century, is really a survival of a mode of thought more appropriate to the seventeenth and eighteenth centuries. By Francis Bacon (1605) Naiural Theology, with an alternative title of Divine Plilosopliy, is described as that 'knowledge or rudiment of knowledge concerning God which may be obtained by contemplation of His creatures.' 'It suffices,' he adds, ' to confute atheism, but not to inform religion.' Even at that date the subject was a popular one: on this topic, remarks the author of the Advancement of Learning, ' I am so far from noting any deficiency as I rather note an excess.' Bacon, in fact, seems 
thoroughly aware of the limited scope and negative character of the remarks and observations included under the title of Natural 'Theology, as indeed might have been expected from one who has complained elsewhere of the unhappy results of mixing up theology with science.

The authority of Sir Isaac Newton contributed, in England at least, to subordinate science to certain presuppositions from theology. In the Scholion Generale which concludes the third book of his Principia (1687) Newton almost steps out of his way to affirm, as against Cartesianism, his acceptance of the creationist theory. Hypotheses like that of Descartes may profess to explain the stability and symmetry of the planetary world by a purely naturalistic or mechanical evolution of an aggregate of material particles according to the laws of movement. Newton, on the contrary, distinctly states his conviction that 'All these regular movements do not have their source in mechanical causes'; and in the (posthumously published) letters to Bentley plainly says, 'the diurnal rotations of the planets could not be derived from gravity, but required a divine arm to impress them.' This argument is indeed of little value: for it only means that the man of science is unable to construct a scheme of evolution without lacunae from the assumed primordial state of matter down to the ordered system of the present epoch. Yet if we translate the figuratively materialistic language of Newton into more abstract terms, we may say that, however far back we retrace the origin of the present scheme of things, we cannot really escape the hypothesis of a system which even in its molecules was instinct with the presence of law and order.

The whole tenor of Natural Theology betrays its connexion with an age of practical and utilitarian science, which, however, had not cast off its religious faiths, and was solicitous to keep the two sides of its life in some sort of correlation. Works like that of John Ray, The Wislom of Gorl manifested in the Works of Creation (169I) popularized, and we may even 
say vulgarized, the idea of making 'the book of nature a commentary on the book of revelation.' The example apparently 'caught on' and satisfied a need of the times. The Boyle lectures, instituted for what is sometimes called the proof of fundamental Christian doctrine against all outsiders, of other religion or of none, offered a vehicle for such reflections. The new natural knowledge, which had hitherto struggled onward on its own resources, winning favour by its intrinsic attractions, received a status of respectability in the social hierarchy. Even as the older Church had given an ex post facto consecration to movements and organizations that had first started beyond its pale, so Protestantism allied to itself the rising spirit of research, and sought to make the sciences pay tribute to the religious and theological interests of the age and country.

Among the early Boyle lectures were those of W. Derham, in I 7II-12, published under the title of Physico-theology. This is the name which in the more careful use of words is specially appropriated to the branch of Natural Theology now under discussion, the argument from the contrivance and adaptation supposed to be detected in nature to the existence of a designer and contriver of more than human wisdom and power. In I 7 I 4 Derham followed with an Astro-theology, specially illustrating the way in which the heavens declare the glory of God. These essays found imitators in England, and still more in Germany, to which at that epoch England stood more in the position of an ensample than she can be at present said to do. It may be that by such observations the pious Christian mind was enabled to strike up a relation between religion and the other aspects of life and reality. Derham's two works were translated into German by the notable scholar and compiler John Albert Fabricius in 1728 and 1730 , who also contributed to the literature of the subject by a Hydro-theology in 1730 , and the outlines of a Pyro-theology in 1732. The philosopher Christian Wolff dealt with the whole subject in his Theologia 
Naturalis (1736), of which the first volume treated especially of the a posteriori evidences, whilst the second gave the a priori or metaphysical argument. One writer (F.C. Lesser) added three special departments for pious reflection: viz. on stones, insects and shell-fish, endeavouring (in the words of one of his own titles) to show how, under the authority of Scripture and reason, 'by attentive study of otherwise neglected natural facts one may rise to a lively perception and admiration of the omnipotence, wisdom, goodness, and justice of the great God.' Other writers in the half-century preceding Kant's first Kritik dealt with the religious lessons which may be derived from the phenomena of snow, plants, birds, thunder, locusts, fishes, bees, earthquakes. These treatises, long since consigned to oblivion, were not without their particular occasions and appropriateness: e.g. they preserve the memory of the great snowfalls of 1726 and 1729 , the plague of locusts in central Europe between 1747 and I749, and the earthquake at Lisbon in 1755 .

Of this mode of bridging over the interval between science and religion Paley's Natural Theology in $\mathrm{I}^{802}$ is a belated survival, a character still more attachable to the Bridgewater treatises published more than thirty years later. But as it reappeared, it had lost in naturalness what it professed to gain in logical plausibility; for with the larger apparatus of scientific method the line of evidence grows artificial, and rather reflects the acumen of the demonstrator than the skill apparent in the works of nature. Meanwhile the conceptions of matter and of nature had been passing beyond the phases at which the argument for final causes took them. The relationship of a creator to the creatures as that of an architect or manager to his works was no longer deemed adequate, nor did it seem the highest praise which could fall to him that he had made the best of somewhat recalcitrant materials. The great mechanician is only a mode, and an insufficient mode, of conceiving God's supremacy; and even 
if it be specially suitable to the genius of a utilitarian age, it cannot rank as more than an analogy under which we form a partial conception of the divine mode of action. The problems of the cosmos presuppose for their solution a greater power of adapting matter than human agency as yet possesses: so that, if God works after our methods, He must exhibit our powers in a transcendent degree:- such is all that the argument carries.

Religion had little to gain by these demonstrations: at least any religion which had real vitality and was not a form of words parasitically seeking to gain support from alien growths. There is, indeed, a natural piety which sees God in everything, and translates every word of nature into a whisper of God. When the devoted Jesuits, who in the early part of the seventeenth century carried the Gospel to 'New France,' write back to their French superiors, 'To live in New France is in sooth to live in the bosom of God and to breathe only the air of His divine guidance'; when they say, 'How good it feels in the sacred horrors of these forests, and how much of heaven's light is found in the dense darkness of this barbarian land,' we recognize the presence of that faith which removes mountains, where the vision of dominant conviction transfigures wilds and Indians into a rift through which shine the glory and love of the Eternal. It is the same when we find Jonathan Edwards describing his feelings, when sometime between his seventeenth and twentieth years his mind had first been visited with some insight into the deeper realities of life, and he had retired to what he calls a solitary place in his father's pasture. 'As I was walking there and looking upon the sky and clouds, there came into my mind so sweet a sense of the glorious majesty and grace of God that I know not how to express. . . The appearance of everything was altered: there seemed to be a calm sweet cast or appearance of divine glory in almost everything. God's excellency, His wisdom, His purity and love seemed to 
appear in everything: in the sun, moon, and stars: in the clouds and blue sky: in the grass, flowers, and trees: in the water and all nature: which used greatly to fix my mind.' Even the more terrible phenomena of nature participated in this new spirit. 'Scarcely anything among all the works of nature was so sweet to me as thunder and lightning. . . I felt God, so to speak, at the first appearance of a thunderstorm.' Even in such immature sentimentalism we can see that it is only the sun-possessed eye that can behold the sun itself. It is the pure in heart that see God: and Pectus facit theologum. The dominant principle, idea, love, passion determines the interpretation of facts. So while Charles Kingsley finds it a nobler thought to hold that 'Deity created primal forms capable of self-development into all forms needful pro tempore and pro loco,' than to follow the old view of a creation once and for ever established in its species, Mill is more inclined to see in the evolutionist hypothesis the supplanting of the old creator by what Darwin called 'my deity, natural selection.'

To minds susceptible mainly to practical and material considerations this form of Natural Theology, the physicotheological argument from design, has seemed a sounder basis than the ontological method which appeared to juggle with ideas. In Mill's judgement it satisfied the requirements of inductive inference so far at least as to suggest a considerable probability in favour of an intelligent and powerful being as the guide of the cosmic movements, but to be less cogent now that it had been, if, as the Darwinian hypothesis suggested, the same facts could also be explained as the cumulative effect of accidental variations, and of the mutual actions and reactions of all existences. Yet on a closer inspection perhaps it may be said that the real effect of design arguments is only seen when they are pushed back to their ultimate presupposition in the radical unity and interdependence of all things that are. Things are not external to each other and 
independent: they are not merely brought into affinity and correlation by an outside impulse and guidance; but are essentially and primordially in organic interconnexion, sympathetic, interconscious, in a many-sided reciprocal attraction. Its weakness is the tendency to regard humanity as the centre or pivot on which the whole effort of creation converges: whereas the human interest is only a relative and partial centre, not to be elevated into absolute authority to the exclusion and depreciation of others.

Besides this use of the term Natural Theology, restricting it to the physico-theological argument from design, there is a wider use of it to mean what is also called rational or philosophical theology. Here we come in touch with what has been called Natural or Rational Religion, and with the naturalistic and rationalistic movements which mark the course of the seventeenth and eighteenth centuries. It is not unfrequently said, and with some surface plausibility, that Lord Herbert of Cherbury (De Veritate, 1624) gave in modern times the impulse to this free-thinking movement. The thinkers of the Renaissance and Reformation had been occasionally touched by the larger spirit of religious faith. Thus Erasmus in his Encheiridion could say 'Christum vero esse puta non vocem inanem, sed nihil aliud quam charitatem, simplicitatem, patientiam, puritatem, breviter quidquid ille docuit.' To him it seemed that inspiration was not limited to the Jews: the ethical scriptures of Cicero, Seneca, and above all Plato, formed a catena of truths not unworthy to be linked along with the theism of the Old and New Testament. It is this 'natural religion' which is an inspiring principle to writers so different as Sir Thomas More, Rabelais, and Montaigne. It finds voice in the syncretism of Mutianus Rufus: 'Quum Jovem nomino, Christum intelligo et verum Deum.' Sebastian Frank (I495-1543) identifies the lumen naturale with the 'word' or invisible Christ: he sees in the historical fact of Adam and Christ only a symbol of the eternal relation 
of man and God: 'Omnis homo,' he says, 'unus homo: vita una et eadem omnibus.' The older Realism revives, and sets the eternal Spirit against the changing history of the letter.

But the oldest example of the phase of Natural Theology belonging to this pre-Reformation period is the Theologia Naturalis of Raymond de Sabunde, published in 1438 . It is probably best known by Montaigne's Apology. Montaigne knew little more of the author than that he was said to be a Spaniard, and he is described on the title-page as doctor in arts and medicine, and professor in theology. Montaigne, who tells us he made a translation of the work (published apparently in 1.569), speaks mysteriously of the original as 'basty d'un espaignol, baragouiné en terminaisons latines,' which seems an exaggeration of the character of the text as we have it. The obnoxious matter is contained in the prologue, which has been omitted in all subsequent editions, as condemned before 1500 by the Index ${ }^{1}$. The prologue in a few pages states the scope of the book. There are two books given by God to man. That originally given was the book of nature, or of the Universitas creaturarum. But by reason of his blindness man was unable to read it; and another had therefore to be given, the book of Holy Scripture. Unfortunately the key which Scripture affords is itself a dubious and puzzling gift. Its obscurity requires in the interpreter a special training, that of the scholar and priest: its authenticity needs to be corroborated by research and argument. Philology, grammar, logic, and rhetoric are indispensable, if we are to make a proper use of the supernatural key to the meaning of the world and life.

The case with the book of nature is very different. It is a connatural part of the regular order of life, and can be studied by the unassisted intelligence sine magistro. There

1 The full title of the book is Theologia naturalis, sive liber creaturarum, specialiter de homine et de natura ejus in quantum homo, et de his quae sunt ei necessaria ad cogncscendum seipsum et omne debitum ad quod nomo tenetur et obligatur tam deo quam proximo. 
is no possibility of misunderstanding it, and no risk from forgeries. It is an infallible science which any one can acquire 'in a month and without labour, and it requires no effort of memory.' This is the 'light of all the sciences,' without which they are but vanities. It contains that rule of nature by which a man learns all his duty. And now in the end of the world it is necessary to every Christian that he may be established in the Catholic faith. It argues, infallibly, 'from those things which are most certain to every man by experience, or from the nature of all the creatures and of man himself, from those things which man most surely knows of himself by experience, and especially by inward experience; and therefore it is a knowledge which does not require any witness but man himself.' But before dealing with man it considers the various orders of created things. For 'the universe of things and beings is set as it were a natural ladder having firm and immovable steps by which a man may ascend into himself.' To grasp these stages in their unity is to learn the meaning of the book of the universe, in which the several creatures and their groups form the letters and syllables. Man learns to see his own purpose, his own dignity and duty, by seeing himself as the convergent unity of lower orders of being, the culmination of a process from mere existence to life, from life to sentiency, and from sentiency to intelligence and will in a free personality. But man himself points upwards to an absolute unity and realization of all being, a being who is the principle of love, the root of all good, and of an all-inspiring delight.

The interest of such a book is to be sought in its historical surroundings and antecedents. Towards the past it gives an echo of that liberal and mystical theology which stretches across the Middle Ages, with here and there a half-heretical thinker taking up the philosophical standpoint of the Alexandrines and of the Gnostics and Neoplatonists. It belongs to a movement which, so to speak, goes on behind 
the Lutheran reformation, drawing its impetus from a more literary, scientific, and rationalist current of ideas; its basis is not the reference from a corrupt tradition to an incorrupt book of authoritative doctrine, but from all written texts whatever to the everlasting and unfailing gospel of nature and reason. It rises, however it may or may not admit this to itself, above the ecclesiastical traditionalism which had been the best-preserved part of the Church's inheritance from Augustine, above the dependence on literal revelation, and while adopting the basis of inner experience, it thinks more of the systematized experience of natural life than of the bare inwardness of mystical theology. If mediaeval theology was determined to understand what it believed, this postulate implied in the last resort the conviction of the reasonableness of the faith, i.e. of its correspondence with the entire system of reality as it had been otherwise ascertained. This conviction is at the bottom of de Sabunde's book. It is partly distorted by a certain boastfulness, marking the intoxication of a discoverer who has learned that a truth hitherto accepted on authority is intrinsically credible, and concordant with fact. But, along with this, there goes a tendency to see in religion an ally of ethics, and to find its essence rather in the scope it assigns to our duty than in the knowledge it gives of God as an abstractly independent being.

Perhaps the earliest occurrence of the title Natural Theology in Western thought belongs, however, to the system of Stoicism. St. Augustine (De Civ. Dei, vi. 5-12) states, on the anthority of Varro, who probably but epitomizes the reflection of Stoic teachers, that there are three species of theology, the poetic or mythological, the civil or political, and the physical or natural. The first is the scheme of divine acts and beings which is suitable to the theatre, the world of literature and art, and its hierophants are the poets. The second is the mode under which a political community acknowledges its 
dependence upon higher powers, and is under the charge of sacerdotal officials. But the third is the way in which the thinker and the man of science sees the great power of things. His eye is not restricted to the narrow scope of the city, nor is it content with the reflection of reality in myth and legend of demi-gods and gods. He looks at the whole of things, at the great system of nature, above the range of art and of popular religion; he finds the truest approach to divinity in a philosophy that seeks the deeper reality, the universal truth, which underlies the visions of poets and the conventional or historical distinctions which national peculiarities have introduced into divinity. To Varro, and to the philosophers for whom he speaks, the two other species of theology were at bottom erroneous, and were only suitable for such as by nature and temperament, or by circumstances and authority, were incapable of attaining the true vision of the essence of things. Yet at the same time it is apparent that he can speak of philosophy as a theology only in so far as he allows the two other interpretations, the political and the artistic, to give colour and form to the somewhat vague and unsubstantial phases of the world-order. It is this confusion between philosophy and practical needs which marks the Stoical system, and which is the inevitable consequent of its professing to give the world a guide through life and its duties. The old antagonism between the philosopher and theologian is smoothed down into that between an esoteric and an exoteric doctrine, or between the inner truth and the accommodation of it to vulgar necessities, and popular incapacity for the higher teaching.

We may thus learn that, under all its phases in history, natural theology is the attempt at a synthesis of two factors in human life, which at their first appearance and always present to each other a certain incompatibility, or it may be hostility. It is the application of science to religion, the interpretation of faith and worship by the intellectual 
principle, and in accordance with the results of ascertained knowledge. It may err by being premature and hasty: it may err by an inadequate perception of the fact to be explained. The science which is dominant at a particular age may be one-sided and imperfect as judged by a later and more enlarged standpoint; and the result of its verdict on religious facts cannot in such a case be unprejudiced. It may turn itself too exclusively to one aspect of reality, too much to the world of physical fact and too little to the realm of psychical life; and it may on that account fail to give a due place to certain aspects of religious phenomena which are alien to its prepossessions. But in some degree the rationalization of belief, the naturalization of religion, is an inevitable problem. There are differences in the extent to which reason carries this determination, but it is only a question of degree. Even the primaeval 'theologian,' whom the philosopher seeks to dispossess, is a philosopher too in his infinitesimal degree. He may be dubbed irrational, but that only means that his reasoning stops short at an earlier stage than we think proper. His development in the line of intelligence has suffered arrest.

Yet nothing is more certain than that a widespread jealousy meets the attempt to rationalize the faith. Not merely natural theology, but theology altogether has seemed to be an intruder on the religious field. The creation of dogma is an injury to the spirit of faith : under pretence of strengthening the living organism, it turns it into a lifeless petrifaction. Nor is this merely a shrinking from intellectual effort, which springs partly from an ignoble preference for the animal luxury of dull feeling and stolid enjoyment, partly from the effects of reaction against the illusions and disappointments that have befallen others. The same tendency is fostered by the preference for action, the sense that theological speculation is an unnecessary, and perhaps a shameful luxury, when so much of the world is lying in sin 
and misery. There is also the delicacy of feeling which shrinks from theological dogma as a kind of profanation, or as at best but 'sound and smoke clouding over the glow of heaven.' The deeper moments of religious experience, where the soul is alone with God, shrink from the cold clear light of analysis and reflection. The heart claims for its object of devotion a unique and incomparable quality, which would be destroyed when such object was classified and reduced to the level of its kindred.

Yet when we come to think of it, we can see that this protest of life against being reduced to mere logic is exaggerated. What it really implies is a feeling that reason is not omnipotent, a feeling that all our knowledge rests on, and arises by contrast with, an unknown; that consciousness must be in perpetual antithesis, but also in perpetual correlation with an unconscious. We may, no doubt, amuse ourselves with the fancy of absolute beginnings and absolute ends. But in sober fact it has to be admitted that all our knowledge rests upon ignorance, that it always has a presupposition, which it as continually displaces. We may speak of an $\dot{a} \rho \chi \grave{\eta}$

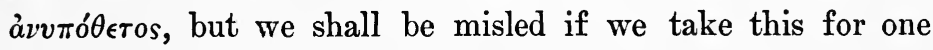
single truth out of which others can be deduced by proper analysis, and upon which others can be built. The true method of science is neither a mere analysis (as the one phrase suggests), nor a mere synthesis (as is implied by the second). Analysis and synthesis are continually alternating and complementary: in other words, analysis is only valuable as a step to synthesis, and synthesis involves a preliminary distinction of elements.

If it be said that it is the object of philosophy to construe religion, that does not mean, as sometimes seems to be supposed, that it has to construct it. To construe a thing is to set it in its relation to other things, to give it its place in a system, to deprive it of its mere individuality, and to understand its place and value. As has been said, some such appreciation 
or estimate is always made: but it may be made stealthily, blindly, and without due sense of proportions. The whole claim made by philosophy is that such evaluation of the factors of life shall be made consciously and with due care, and not at haphazard. It may be maintained, indeed, that, as a matter of fact, the most prominent and widespread forms of religion have grown up in a soil thoroughly saturated by philosophic influences. This is certainly true of Christianity and Buddhism. But, apart from this, we must distinguish between philosophy as a life, and philosophy as logic. In reference to life, philosophy is only instrumental and subordinate. It is the extension and deepening of intelligence; the translation, it may be said, of the is into the is known; the organization of the fragments of life-so at first they appear-into the complete structure which they really presuppose. Philosophy in this case means the development of intelligence into a united view of all the factors of reality and life in their mutual relationships; the correlation of all departments of human activity with each other, in the light of their being but severally parts and members in working out the ideal of humanity. Philosophy is thus the surveillance of the whole over the members, or rather the spirit of the whole, awakening in each of these members, and making them aware of their mutual dependence. It is the idea of perfection realizing itself in each imperfect medium, seeking to reduce the divergent factors of civilization to accord in the idea of life, full and perfect. To perform such a task a certain aloofness is required. But that is what always happens in any department. To philosophize is to stand apart from the bustle of life: yet the philosopher is after all a man, and his philosophy is only a part of his life, for him perhaps the most important, yet in the great system of human collective life reduced to a factor and a share.

When philosophy arises, it comes because of felt contradictions. It is stimulated by the presence of difficulties and 
incongruities, not to say inconsistencies, in the religious scheme, It is all very well to say with Vincent of Lerinum (Common. II. 3) that 'quod ubique, quod semper, quod ab omnibus, creditum est, hoc est vere proprieque catholicum.' But to discover what possesses the marks of ' universitas, antiquitas, consensio' is a task that soon appears to be hopeless, unless we call in the aid of reasoning and reflection. A mere statistical enumeration and summation is in such a problem impracticable. The marks, literally taken, are inapplicable: the universal and eternal is not found in the range of sense-phenomena. To find it, we must gradually educe from the facts some idea in which they find their unity, and which again in its turn serves as a standard of criticism. Not that such an idea is found once and for all. It is itself but an ideal capable of indefinite approximation, the organized product of a vast number of less adequate steps towards it.

It is not therefore in a wilful aggression on a peaceful field that we are to seek the origin of rationalizing in religion. Such effort at rationalizing in religion is only the reaction from the effects of hesitancy and dispute. The variety of contemporary belief, the changes in the successive phases of faith and doctrine, are sufficient to account for the attempt to give a reasonable character to a faith. But this is not the whole of the problem. There are other departments of human life, and these in course of time develop with unequal speed and to disproportionate extents. Contradictions thus emerge between church and state, between art and religion, and between science and theology, in the restricted senses in which these terms are ordinarily used. It is partly in consequence of such divergences that Natural Theology has found itself in competition with theology in its narrower sphere.

It is, and should be, the business of philosophy to release the human problem from this departmental division-so far at least as each of these elements of life tends to isolate itself in one-sided supremacy. The antitheses between art 
and morality and religion, not to mention many others, have their relative justification; but they do harm when treated as independent forces. For a large and philosophic view, morality is a part and step in the great process of man's self-development, a part which, if on one side it is in unbroken continuity with the fulfilment of the elements of psychical life to a free and full personality or true self, is on the other hand building a framework of social relationships, without which religion would hardly deserve that august name, and would certainly not rank as the great humanizing energy it is supposed to be. Such a philosophical view, again, will free religion from the taint of an evil 'other-worldliness,' which often befalls it, and give it its right place in the scenes of daily life and the sympathies of common intercourse. Released from its isolation and specious sacro-sanctity, religion will appear as the crown and consecration of an actuality which often in its details seems trivial and frivolous. Art, again, as it releases the tension of desire, and reveals the repose and self-completeness of existence, will keep religion from falling away from the temporal scene, and protest against the absoluteness of scientific analysis. And science, in the narrower sense, will recognize its limitations, and above all the hypothetical character of its constructions, which are after all approximations to the infinitely complex structure of the real, made practicable only through the self-restraint of an abstraction.

Such a Natural Theology grows up inevitably as man emerges from the cave of tradition and custom, and realizes that in him, as an intelligent and rational being, there is something superior to the mere individuality which sets him as only one among the many things of the world, and that he is (in the phrase of Protagoras), in some sense, the measure of all things. Nay, more, it may be asserted that man has never been wholly without this faculty of raising himself so as in some measure to survey and control his environment, 
instead of being wholly immersed in it, and forming a mere part to be moulded and altered by agencies outside and above him, of which he has no control. The degrees in which this power has been exercised may range within an immense space; but the germ of such detachment, of such individualization, which lifts the individual above a mere passive participation in the whole to which he belongs, seems to be indispensable to characterize humanity.

The note of naturalness in theology, therefore, lies in its superiority to restrictions due to special historic conditions. The antithesis of natural is not to revealed: but to one type of revealed, exalted as the alone revealed, to the exclusion of all others. When it uses the term natural, it does not, except in the restricted sense of physico-theology, mean to exclude from its survey the field of history and of human life. It rejects, indeed, the notion of special revelation, if that be understood to imply the communication of full-made truths by a miraculous importation of them into the human faculties. But, on the other hand, it does not, by calling itself natural or rational, imply that it turns its back upon history and experience. It may be that at certain epochs, in a fit of disgust at vulgar credulity and in hatred of superstition, it imagined that unassisted reason could of itself construct a creed. But in so far as it did so, it was labouring under an illusion. There is no absolutely unassisted reason. Reason, on the contrary, only lives by a perpetual antithesis to sense: it only emerges from the soil of reality and life, from the fact of experience: it is experience made more and more harmonious, complete and self-explanatory. Its only conflict with revelation arises because revelation is said to introduce - into the sphere of human knowledge and experience a fact absolutely unique and incommensurable. Unique and incommensurable, in a way, every reality is: but not in the sense that it forms no part in the compass of reality, giving to and taking from its environment. Natural theology, the theology 
of reason, claims the prerogative of man to examine all things, and is but an attempt in a special range of questions to carry out that purpose fully, without bar or check from any specially privileged province.

Christian theology is a different thing. That is no inquiry into truth, no free scientific pursuit, no mere theory. It is the redaction into a system of the non-historic and essential constitution of the Church: the reflex of its life-spirit, its needs and relationships, in a shape determined no doubt by individual instrumentality, but by instruments pervaded by a common faith, a historical experience, a sense of eternal community,-eternal with an eternity such as no nation can boast, because the church, each and every visible church, believes itself, through and above its earthly manifestation, to be a city divinely founded and maintained. 


\section{II \\ THE GREEK ORIGINS OF THEOLOGY}

Natural Theology as already described in last lecture has been almost identified with what in the present.century would be usually called the philosophy of religion. Either term may be taken to denote a reflective study of the facts or phenomena of religion, when that study is methodically or systematically pursued. Such reflection can hardly be turned upon religion, until religious facts or phenomena have grown into the rank of obviously objective material for observation. There must be a tolerably well-defined group of performances, rites, ceremonials, sacrifices, prayers, \&c., upon which the vision can be turned. Till that epoch has offered such material, religious life, in feeling and act, may have been intense and vigorous, and may have undergone various transformations; but so long as these phenomena have not been set in special relief, and brought into a certain anomalous position in life, they will be passed over with the indifference which awaits all that is familiar and awakes no sense of curiosity. It needs the stimulus of a trouble and a want to prompt laggard curiosity. Religion must have come to be in some measure detached from the observed : it must no longer form an organic part of his life and being. With the process of social differentiation the several aspects of life come to be more or less strangers to many of those who share in the social unity. Religion will thus have become the special care of a certain order, and present more and more a mystery to those outside the sacred 
circle. Diversity of interests, and even of religious interests, is a condition for the study of religious phenomena. Here as elsewhere, it is when the first fervour of life and zeal is past that reflection begins. Theology, therefore, as an attempt to note and correlate the phenomena of the religious life, will have a certain antipathy to the first age of devotion. Religion at such an epoch has become, instead of a common all-embracing influence penetrating life, one interest among many; a memory and a hope, rather than a present faith. And such interest may come either from those professionally interested in it, or from the outsider and the critic. To the former the main work of theology is the codification of faith in a creed. To the latter it may either be a subject of disinterested study, or an interest which he would fain rescue from the hands of the mere specialist, and base upon a wider foundation than the mere authority of a text. In the latter case we have what is called natural theology. The natural theologian aims at widening the basis of faith by an appeal to a wider range of corroborative fact, but he seldom studies religious phenomena in a spirit of philosophic impartiality. He has a special view of what constitutes the essentials of religion as opposed to its accidents : a view which in the main represents the average standpoint of his time and not a result of critical inquiry. The natural theologian of this type has a practical interest: he is anxious to purify religion from what he regards as the extravagances of superstition and to rest it upon a surer evidence than that of a supposed supernatural authority. To such an one the nucleus of true religion lies in its ethical context, or rather in its supposed guarantee of three ethical needs: a God, to make the world of nature co-operative to the success of duty; Freedom, to raise man above the necessitation of purely physical influences; and Immortality, to make man's capacities a match for duty's infinite requirements. ' What Christ did,' said Leibniz in the preface to the Théodicée, 'was to translate natural religion 
into a law, and to give it the authority of a public dogma.' Natural religion so understood is the warranty by metaphysical fact to the absolute claim of duty. Morality is possible, because nature is not omnipotent over man by its impulses, nor victorious over him by the dissolution of his body, and because God who holds the keys of nature is the warder of morality. The emancipation of man from the tyranny of nature is the essence of morals, and the purpose of religion is to furnish a creed in which that liberation is guaranteed by a metaphysical or supernatural theory of life and the world.

The philosophy of religion cannot have the directly practical aims of this so-called natural theology : its standpoint is purely that of the critical observer who seeks to understand. But the term theology has a further disadvantage as applied to denote the science of religion. In a strict etymological use, the term may seem either defective or redundant. It is defective, because it sets in peculiar relief and isolates from its context one important term of the religious life. It separates the object or outward projection of religious faith from the faith and life to which it stands in essential relation. It leaves God, so to speak, bare and abstract, withdrawn from the witness of the spirit, and left cold and dead on the analytical board. So left, the object of theology loses its life and significance, and the theological demonstrator is therefore obliged to begin his work of .exposition by a task not known in the same way to the other branches of science: he has to establish the reality of his object, which has become only a name, and to prove, as it is called, the existence of God.

Yet, on the other hand, the name theology may seem redundant as a title for the phenomena of religion. It is possible that the object of religious life, the objective focus of faith, may scarcely rise to the definiteness, individuality, and stability which would fairly entitle it to the name of 
God. Life may be controlled by the unseen, and what is sometimes called the supernatural : faith and hope may turn from the world to something hardly unified and permanent enough to be called a divinity. And so, without clear idea of God, there may be that presence of the other world in this, that dependence on something supernal or infernal, which seems the central power of religion. It is evident, therefore, that if theology is to be regarded as equivalent to the theory of religion in general, it must not be confined to one precise shape in which objectivity and quasi-sensible form is given to the powers and influences on which human life is assumed to depend.

Theology, as we know it, is a product of Greek civilization. It is a trite confession to admit the debt we owe to Greece. But perhaps it may be thought that it is not in the religious sphere that that influence most obviously prevails. And no doubt it is true that the germinal principle of the religious life established amongst us comes from the Hebrews, and especially from a movement arising in the later Judaism. Yet, for all that, it was through Greek words and Greek literature that the oracles of the new faith, the letters of its first evangelists, were proclaimed and written; it was through the systems of ethics, and the schemes of virtues and vices, worked out by Greek moralists, that it had to define its relations to social life: and it was through the attempts of Greek thinkers to determine the conditions of truth, and the value of the various factors in reality, that the Christian community had to justify its conception of life, and correlate its view of the first and last things with the conventions of civilization. Even before Christianity emerged upon the scene, Greek influences had come to pervade Western Asia. Not, of course, that the peasantry of Palestine, or the commonalty of Syria were familiar with Hellenic ideas, and instructed in Greek philosophy. That, if ever possible, could only have been accomplished in many ages. But, at the 
centres of light and leading through the East, it was Greek thought and Greek culture that gave the tone to literature and religion. Even in the stronghold of Judaism the influence of Hellenism was felt at every corner, and it determined, by its opposition, the movements that rose up to repel it. Greek was the vehicle of intercommunication between races of alien manners and speech. And thus even on the religious field ' captured Greece took captive her barbarian conqueror.' Even when St. Paul carried Christianity to Corinth and the West, he carried it as one who had been born at Tarsus and had gained some familiarity with that Greek culture, which influenced even the teachers of the Law, as it had influenced the later writers of the Apocrypha literature.

Greece, in fact, furnished the mould for the science of religion, just as she supplied the grammatical categories in which the study of language has been carried on. Practical needs led ingenious instructors of Greek to formulate a scheme for describing and defining the facts of language : to create a system of rules for guiding the speaker and writer in acquiring the phrase held to be alone correct in the rnultiplicity of practice. Thus grew up a grammar, meant originally for Greek, which came to serve a like purpose for other tongues. So long as the new languages were of a kindred structure with Greek, all might go well: but when in course of time the forms and rubrics so obtained had to be applied to languages of quite other structure, like the Semitic, or the languages of Africa and the New World, the old scheme was found to fail. Gradually this incongruity led to the perception of the need for a new method of the study of languages: a method which should not force the more primitive stages into forms and moulds suitable only for an advanced stage of linguistic development. The analysis of language had to be carried further and with a wider reference in order to fulfil its purpose. It had to find a new alphabet and syntax of more comprehensive scope. 
So in some measure it has been with the philosophy of religion. It is futile no doubt to ask how that philosophy would have fared if speculation on religious phenomena had by some freak of fate begun elsewhere and not in Greece. And if it be an ignoble indolence which proclaims that whatever is is right, it is a still more mischievous conceit which grumbles that whatever is is wrong. Yet it may not be without its uses to reflect that theology would hardly have taken the shape it has done had it grown up under other influences. There is an unparalleled clearness and visual objectivity about the Greek gods; an individual independence, and a systematic unity in their differences, which sets them in a unique position in the world's pantheon. They need only be compared with the strange impersonality of Chinese religion, whether we regard the supreme imperial heaven or the ill-defined but pervasive multitude of lesser spirits; with the mystic haze through which the Vedic gods emerge under the magic efficacy of ritual and sacrifice; or with the abstract imps of momentary act and quality, which were so often all that stood for deities at Rome-to let us see how different is the atmosphere in which the Greek gods live and move. In other races the religious process had stopped short at an emotional or devotional stage. But with the Greeks the divine power stands out in individualized shapes with clearness of outline and definite personality, probably unparalleled in religious development. The conditions of cultus or worship, the prayer, sacrifice and ritual, fall into the background, and allow the object of worship and of sacrifice to emerge in brilliant and conspicuous form, standing out independent of the religious process in which they had their birth. Theology thus becomes a mythology, or, a history and a description of certain divine persons, a collection of legends and sacred tales about gods, who, separated from the religious interest and motive in which they had their source, move about and act with interests of their own, denizens, almost, of the real 
world. The first $\theta$ eodó yol are narrators who tell the history of beings, no doubt related to man, but somehow raised to an independent and collateral existence.

At least the religion of Greece upon its higher levels dealt mostly in this region. It is a strange feature of Greek life that a poem so secular as the work of Homer should be said to give us the theology of the Greeks. We must always remember that the poet-and this is true even of Vedic hymns-gives a picture from a special point of view and from a special level of culture. The works of Greek literature and art reveal Greek life to us, in the first instance, as it appeared on the heights to those emancipated from the baser influences of ignorance and superstition. It is true there are traces everywhere of the lower strata, the basis of common life. They come out in isolated moments, and show the abyss which always rolled under the sunlit tablelands of art. The criticisms of Epicurus and Lucretius on the religion of the masses, though possibly affected by fanaticism, may serve to counterbalance the more aesthetically refined but perhaps irreligiously trivial ideas of popular art. And thus, though the Greek philosophers are not out of touch with the vulgar needs of religion, they chiefly deal with it as it appears on the literary level. The $\Delta \epsilon \iota \sigma \iota \delta a \iota \mu \nu i ́ a$ which comes to the front in Nicias and Xenophon, the foul rites which flourish in the obscurity of antique custom or of modern licence, the freaks of witcheraft and magic, are only seen at faint instants. Greek religion, like everything Greek, was, until comparatively modern times when closer research and the influence of wider anthropological study had taught a different lesson, regarded under an idealized and poetical halo, which separated it from grosser reality.

When philosophy came upon the scene, it found the phenomena of religion arranged under two heads. On one hand, they had been to some extent regulated, licensed, and reduced to a fixed type for the community. They had 
adapted themselves to the ruling influence of the social organization, stamped with an appointed ritual and an order of worship and service. In Greece, as well as in Rome, religion was an integral part of the social system, indistinguishable in practice from other performances needful to the stability of the political edifice. Religion, in this point of view, had hardly separated itself from the general political problem: the gods were part of the state, of the system of custom and law. But there was also a poetical theology, in which the gods had come to form a group of realities, with a history of their own, independent and collateral. Towards this mythology philosophy, following even the more reflective poetry, began at an early period to take up a critical attitude. Xenophanes had boldly accused men of having formed the conceptions of these gods too much in their own image, and of having attributed to the heavenly ones all that was disgraceful among men. Philosophy thus ignored the origin of these tales in the conditions of more primitive life, and treated them simply as regards their effects on the morals of the contemporary community. From that point of view Plato laid down two canons or 'types' to control the eccentricities of popular mythology : the first, that evildoing must never be attributed to a divine agent; the second, that a divine being should be represented as always true and unchangeable in his revelations of himself to man.

In Plato there is no discussion of the problem of religion as a whole, in its psychological premisses and its metaphysical presuppositions. There is indeed no one term in Greek which can cover the whole field. Piety $(\epsilon \dot{v} \sigma \epsilon \in \epsilon \iota a)$ is at one time counted as one of the more important characteristics of the good man: but in the scheme of the Republic e.g. it finds no distinct recognition. The service of religious observance is relegated to the special eare of priestly rules, and forms no part of general humanity. But of the political value of religion Plato is deeply convinced, especially, as it seems, 
in his later years. The gods of the commonwealth are for him the sign and bond of its social unity, of its vigour as a living and thriving organism. The essence of their being and nature, therefore, lies not so much in what they abstractly are, as in their significance for the ethical life. So far as Plato can be said to define God at all, it is as the form of Good, something higher than being and than knowledge, something neither to be treated as a mere objective nor as a mere subjective, but as transcending that opposition. If, therefore, we ask, as polemics has often asked, whether Plato inclines to pantheism, or to a personal God, it is impossible to give a simple answer. Unquestionably he is not all things, either as aggregate or unity; for he is distinctly declared to be above the contrasts of good and evil in this world. Here, in this world, there must be always evil: always, that is, truth can only be reality as presupposing error, and goodness cannot free itself from the presence and opposition of vice. For man there is left the effort to become like unto God, in whom is no evil at all. There thus seems to be two extreme or absolute poles, one all goodness, another all evil, between which actual existence is a struggle: and these poles seem to be real. To the modern relativist this supposition of Plato seems a mistake. He recognizes the opposition of good and evil, but he does not believe that that means the struggle of two self-subsistent forces, which come into external collision. He believes no more in an absolute good and absolute evil, than in an absolute cold and hot. Only that can be good, in the real sense of that word, which is not wholly good: $i$. e. which has in it further possibilities of goodness. A thing is evil which has fallen short of its goodness, yet is not bereft of its goodness altogether.

But if we say that God is good, it must be in another sense of the word. Thus the 'form of good' is a directing principle which draws mankind ever higher and higher on the path toward perfection. It is, we may almost say, the 
form which Godhead presents to us, the shape in which His presence and power appear; and yet it would be rash to identify it with Him. The essence of religion, it may be added, is in what it is for us. The gods or God are made no better by worship which men offer them. But man by such service wins his reward in an ennobled character. $\mathrm{He}$ attaches his existence to the eternal tendency upward and onward. Beyond all struggle, his attainment. Only if we call this perfection of attainment goodness, we do not mean that it is good merely, free from all taint of evil. At the moment when evil ceases to trouble, then the word good loses its old meaning. So much agnosticism at least seems necessary to retain. Existence involves antithesis.

On another point Plato touches upon religion, and that is the relation of God as maker and creator of the world. Here too he tends to remove the creation from the direct contact with the creator. The thesis in which he is interested is the rationality of existence, i.e. its unity of meaning and purpose. Here again the essential point is not the act of God as creator, but the wisdom of order in nature which permits man to work towards ends. There is intelligence in things, an intelligence which however can only show itself operative on a black gulf of unintelligence. Only, here too, we must not follow Plato or his modern analogues, if he puts a blind matter here, and a wise arranger there supervening. We must not break up the two parts of the antithesis from their inseparable solidarity. Matter is only for an intelligence which manipulates: and an intelligence is a mere word unless in relation to a matter which it penetrates. Or, as intellect presupposes sense, and sense implies intellect, so mind implies matter, and matter is only so by antithesis to mind.

In Aristotle we can distinguish two levels of theology. There is, first of all, the general assumption of teleology in a united universe. There is nothing in vain, nothing random. 
There are no inexplicable episodes in the world due to violent. and chance interposition. God does not interfere from without. But, on the other hand, there is nothing chaotic. The world is all an ordered and co-operant unity. God is in a way to be identified with nature: a self-centred, self-moving system of things. There is an art in things: but it is unlike human art, because it is immanent in the things themselves, and not directing from without. God is not banished from His universe. In all nature there is a source of growth and movement, which in the last resort can only be explained by an attraction-a strong love by which Aristotle in metaphorical language represents all things as drawn towards the prime aim of desire and principle of thought. In the very heart of all existence there is a craving for perfect existence, for the fulness of being. Man, like other things, has his place in this order, and a high place: but the higher the seat, the harder the duty, the closer the obligation. The son in the family is less left to the licence of his own devices than the bondman.

Thus in the Aristotelian realm of nature there lives and moves a principle which is quasi-intelligent and quasivolitional. It acts, if not with a purpose, yet never in vain. All things natural have in them something divine. Nature is alive, in eager and incessant motion, struggling onwards towards greater perfection, wrestling with an obstacle which is always present to it. Even without explicit consciousness it is straining uniformly and regularly after the best. The world of nature has thus an indwelling divinity, but a divinity concordant and unanimous with being, and not anarchic, unexpected, or irregular. This view is in sharplyconceived opposition to the atoms of Democritus. Meng agitat molem. Movement is not mere locomotion, but is the path of self-realization, of the increase of being.

But at other times when Aristotle is engaged with the transition from metaphysics to physics there is a tendency 
to a kind of materialism. On the outskirts of the material or visible universe is the home of the divine. Far away at the limit of the world of time and place and movement, there is a world of unmoved unvarying being, source of eternal energy, where there is no void, but fulness of reality: another world which, not by the force of mechanical impact but by the strength of love-yearning, draws to its fruition of perfect life all that in the sensible world is but in the promise and potency of being. Materialistically understood, at some far-distant verge of things the supreme reality, God, comes into quasi-sensible contact with the great circle of the cosmos, and causes to be initiated in it a movement which thence descends through sphere after sphere, till it reaches even this sublunary world and vivifies the things of earth. In the heavens divinity is near: in the stellar and planetary spheres it is powerfully present, but on earth it is marred by disturbing influences. How much in this conception, which has been familiarized by Dante, should be assigned to the twilight of imagination, and how much is to be translated into rational terms, is a point on which there might be long discussion. Discount the metaphor: and to define God as extramundane may mean that $\mathrm{He}$ is the key to the multiplicity of existence, the enveloping unity which gives coherence and meaning to all its parts. Regard the figurative language as the essence of the matter : and it means that, far away beyond the range of experience, there is another range of existence of finer texture: an order of superior beings, yet somehow things of like kind after all.

The source of these difficulties and contradictions in the theology of Aristotle is, partly at least, to be sought in his failure to get at the root of religion, and in his accepting up to a certain point, and admitting to a certain authority, the results of the process of religion, the theogonic process. $\mathrm{He}$ is anxious apparently to show that popular theology and the worship of celestial bodies has a philosophic value. To do 
that, he takes them as objects given, and for which an. appropriate interpretation has to be sought. But he is premature in the identification of deity with the unity and rationality of existence. The epistemologist, who examines the history of our ordinary physical knowledge, shows how the things we seem to see as many independent objects, each out in a world of their own, unaffected by our being so or otherwise, are really dependent for their separate existences on a system of relations without which they would not be what they are. It is not otherwise with the gods. The aspects of deity are the result of a historical development: they are for men, not indeed nothing in themselves, but only symbolic of something more : they live in a covenant between God and man. And the conception of God is more akin to ethical problems than to the inquiries of physies. To understand the gods or God, we must get to see the place and scope of religion as a whole.

Now it may be said that such an inquiry hardly falls within the scope of ancient philosophy. The idea of $\phi \dot{v} \sigma \iota s$ which holds so governing a position in the Greek systemsthe conception of true reality as opposed to appearance and accident, and the conception of philosophy as knowledge of supreme quality-do not fit into the view of things which commends itself to the religious mind. But above all, ancient philosophy was unaccustomed to the psychological and epistemological standpoint. It had not learned to ask for the origin in mental development of the realities which in various grades composed the fabric of the world. It did not, to use the Kantian phrase, think of 'deducing' the deity, or in a commoner phrase, of 'proving' God's existence. To 'deduce' God is to exhibit the grounds on which a certain conception claims to hold a place in reality, by showing that without it reality will no longer be what it professes to be. To 'prove' God is similarly to show that there are tendencies and purposes in things, which point beyond themselves, and 
require a synthesis in absolute unity and power. It seems strange at first sight to talk of proving the reality of your object. But the reason may partially at least be made evident. When Socrates, according to Aristotle, insisted on the duty of definition as the guarantee of real knowledge, it is obvious that he did not apply his method to all things indiscriminately. What he defines are ethical and political terms. He takes these vague words, and by an application of real concrete instances, he reinstates them into their full being and truth: shows them to be constituent elements of the world of human life and fact. So we 'deduce' or 'prove' the existence of what has become doubtful, what has lost its place in the universe of things, and rolls about, disinherited and expropriated, a nullity and a question. To deduce it, is to show the inadequacy of the otherwise accepted reality, if it be deprived of the element or principle in question : to show that, in what we accept, there are other things involved, other considerations potent, which we neglect, but which must be there, otherwise what we suppose we have would fade away into nothingness and collapse for want of due coherency. And this deduction is necessary, because in practical life first or ultimate principles tend to be forgotten, while the mind is engrossed with the particulars which imply them.

The whole tendency of Greek philosophy was to conceive of God as the great principle of the natural order, as the supreme reality, as the object of all objects. He is the order, or He is the source and author of the order, of the physical universe. He is the supreme condition, on which for the philosopher depends the intelligibility of nature, the final source of all its movement, the goal of all its becoming. But for the individual who has to live and not merely to speculate, God must be something more and different. Science, great as it is, is not supreme: it is only an instrument of life, a part of the machinery of intelligent existence. 
It was Kant who gave these questions their prominence in modern philosophy. He dealt with science, with morality; in a less degree, with art and religion. Gradually as he proceeded his problem was extended : it began with 'What can I know?' or 'What are the conditions which make knowledge possible, and which therefore draw certain limits to its range?' Scientific reality and truth, the truth and reality which are implied in our ordinary way of knowing things, may not be co-extensive with the whole field of reality: it may indeed involve something over and beyond itself, on the existence of which it tacitly counts. Now the conditions which Kant signalized as necessary to knowledge were that a sensation should be given, and that such sensation should be placed in an order of time and place, and referred to objectivity by means of certain concepts which he called categories. That the reality should be given, not made,-a sensation, not a thought, is not a new principle: but when it comes to saying what is meant by 'given,' and what precisely is the feature of 'sensation,' the answer of Kant does not carry us far. Phrases like 'affect the sensibility' are after all only phrases. Kant distinguishes between the 'receptivity' and the 'spontaneity': and while he identifies the former with the senses, gives the latter characteristic to the intelligence. But, in the first place, it is clear that to separate the receptive from the spontaneous in this matter-of-fact way is impossible. There is no receptivity without spontaneity, and a pure spontaneity does not exist: both imply action, and that in reality is always re-action. And, secondly, to identify sense with receptivity is only possible on the assumption that we have already defined and perhaps enlarged the scope of sensibility itself. Defined it: in such measure as we have accentuated the aspect of 'affection' by something 'given.' Enlarged it : in so far as there is no longer any restriction to the special senses, or organs of sensibility.

But what Kant laid even more stress upon is that all 
science, and therefore all we know as reality in the stricter sense, lies within certain totalities. These are time, space, and experience. None of these are given us as totals : yet on the relations of elements within them as such totalities all reality rests. That is real which has temporal and spatial relations ; that is real which is an integral part of experience: but experience, time, and space, are only ideal totals. There is only one time, one space, one experience; but such a unity is not a fact: it is an ideal always approximated to, and governing every increase in knowledge, but never realized. Reality thus is always fragmentary, a part in relation to other parts, an item in a system: it always presupposes something beyond itself, and is only determinable by relations in a totality; which, however, recedes perpetually, and never comes within the range of knowledge strictly so called.

Science is thus hemmed in by certain limits, or rests upon our respecting certain conditions. It can only succeed by not attempting too much: by attaching itself to a given point, and by connecting this with something else, defining it in one direction. If it attempts to grasp a totality, it must inevitably fail. And yet its whole success is gained by the conviction that each thing is in and of a totality, and has infinite relations, which can be explored so as to determine it. Thus it can only reach the totality by a succession of partial efforts, each correcting and completing the other. Kant hardly would say with Spinoza that God, the absolute unity of being, is the presupposition of all knowledge: for his favourite way of stating his view is that the original unity of self-consciousness is the source from which all determination flows. But when he comes to consider more clearly what this consciousness is, he seems to admit that it is not an individual mind (if such a thing there be), but consciousness in general. And what is consciousness in general? A consciousness not limited to a localized person, not equivalent to a single soul, 
but something in which all single psychical function lives: a synthesis embracing the several minds.

What Kant seeks to bring out is really that God cannot be regarded as an olject of knowledge, or at least not merely as that. He cannot be reduced to one object in the multitude of things. Yet to treat Him as such an object seems inevitable to human nature. Everywhere, after a step gained in advance, it tends to throw itself upon some centralized conception, as if that contained the key of the future, and formed a standpoint on which one could rest. Again and again it is obliged to cast away its idols, or at least to allow fresh objects of worship to set themselves up at its side. But still the old fallacy afflicts it: it translates the part into an image of the totality, and reduces the godhead to the limits of one of its parts.

What Kant is driving at is that there are different grades in the hierarchy of reality, that the order of physical things or of nature is, as it is ordinarily described,-i.e. as a mechanical system of cause and effect-rests upon presuppositions which it is itself incompetent to explain. Science in that sense, as a knowledge of causes and effects, cannot include God: for He can only come under it as a 'first cause' or a 'final end'-two conceptions which equally contradict the very implication of the term cause. You may style God a causa sui; but such a term really means that He is more than a mere cause: or it means that in the full concept of 'cause' there is an originality involved which can never belong to a single thing, but always implies a synthesis, or, as it is called, a 'sum of conditions,' co-operating with the single prominent antecedent.

Kant thus, on the one hand, declares that God cannot be described by the categories, because these all presuppose a variety of things in correlation; and yet that a quasiapplication of the categories to Him is inevitable, because $\mathrm{He}$ is active under these restrictions. But over and above 
his negative results, he has insisted that God, with the cognate positions of freedom and immortality, is required by what he calls the moral law. Perhaps, for the present, we may generalize Kant's teaching to the effect that, if God is not an object of science in the narrow sense of that conception, it is because $\mathrm{He}$ is above it and gives the very presupposition of it. Even so Plato has described his 'idea' of Good, as standing to all reality in the same relation as the sun does to visible objects. As the sunlight is, in different aspects, the cause of growth, and again, of the visibility of sensible things, so the 'idea of good' is the force which makes reality active and operant, and enables the knower to understand it. Nor is this agnosticism. Agnosticism holds that, behind all single objects we know, there may be a total object which we do not know. But, according to the present account, God is not something behind or beyond other objects. Each of them is, indeed, less than Him ; but all in their various degree express them and involve Him. In none of them can we say finally, 'Here $\mathrm{He}$ is': yet we may not say either, 'Beyond all of them $\mathrm{He}$ is to be sought and possibly found.' $\mathrm{He}$ is personal: yet, but at the same time, supra-personal : moral, but at the same time more than moral.

The Greek philosophers, more perhaps even than Hebrew prophets, emphasize the unity of God. The prophets, by the intensification of their conception of Jahve, gradually made him the God of all the earth : but in so doing they unawares altered the conception, and repelled deity, as it were, into greater depths of distance. The Greek philosophers saw in him the unity of nature, the source of life and motion, but Himself something above nature, and removed from the sphere of change. They were not interested in the religious acts and feelings in which He was efficient: they sought in the conception of Him rather a counterpart to their doctrine of the unity of all being. 


\section{III}

\section{THE NATURAL THEOLOGY OF CHRIST}

The value of Christianity in the historical development of natural theology does not in the first place lie in any addition it makes to the conception of God, but rather in the experiential demonstration it may give of the factual reality or truth of that idea. In that sense it claims to be the revelation of God, whereby, instead of being an objective aim of worship, or an idea underlying all intelligence, $\mathrm{He}$ is realized and present as the light and life and love in all that lives and is. It thus verifies or evidences the conclusions of reflection and criticism; but in so doing sets them in a new light. The transcendent God and heaven are seen as present and within us, as in the world and in the soul, though they knew it not, and had sought the missing principle even on the further side of being. Christianity may thus be styled emphatically natural religion, in so far as it professes to realize the implications latent in all historical forms of faith, but freed from the restrictions to which they were therein subject. It claims to satisfy the realism of spontaneous devotion and the idealism of the philosophical consciousness: to be all that religion ever meant to be, and to bring forth certainty unto truth.

It is difficult, however, if not impossible, to select any special article of religious faith which is, in its general aspect, a doctrine peculiar to Christianity. Its uniqueness lies rather in what some would call the personality of the founder. So 
far as one may venture to specialize the expression of that uniqueness, we may say it consisted in his absolute and plenipotentiary freedom, and in his utter realization of the immanence of God in this present life. In this conviction of the power of endless life and the presence of reconciling love, theology lost its former aloofness and abstraction. It might be paradoxically put that Christianity is atheism: meaning thereby that God, for it, ceases to be a mere object, controlling life and reality and becomes identical with the reality of reality, the life of life. Prayer, for it, becomes not a request for blessings from a separate being, but a communion in which the soul essentially realizes its unity in all things with God. Sacrifice there can henceforth be none; for man in turning upward from nature is not rejecting the source of his being, but fundamentally working with God. Yet, on the other hand, there is an initial and absolute sacrifice: it is the 'baptism into death,' the 'taking up the cross,' the 'imitatio Christi,' becoming, as St. Paul puts it, a slave of Jesus. But this, again, is only another aspect of, and is dependent on, the sonship of God: the consciousness of the grace of the Father, of universal mercy and love, or, briefly, the eternal life. Thus of this death, it is true, mors ianua vitae, and it had been so described by Plato. What Christ affirms more distinctly than Plato, is that man has not in this to struggle alone, but has on his side the porver and the goodness which is the life of all things, or, in the familiar words, a Father in heaven.

Christianity thus sets in the forefront the omnipotence of God and the liberty of man. But that omnipotence is directed against all other authorities and constraints, against everything in nature that might be supposed to control human destinies. The Greeks and Romans made much of the worship of Fortune, and, indeed, the whole conception of popular religion is saturated with it, with ideas of chance, luck and destiny. Ethics has always tended to teach that 
man is the architect of his own fortune, and that happiness rests with our own activity. Religion, as expressed in Christianity, not merely connects all fortune and event with God, but insists that man has God upon his side, and by faith can rise superior to his enemies in fate and circumstance. On the other side, the liberty of man essentially consists in his sonship to God, in the realization by feeling and thought and act, that his real life is not in the temporal and transitory; it consists in a predominant sense that in and over all partial act and feeling, and deeper than all separate objects of desire, there is an absolute unity and rest. Thus the theology, strictly so called, of Christianity is combined with what was in early days called an 'economy': in other words the doctrine of God is essentially a doctrine of the relation of man to God, and of God to man, and indeed of the actual (even if not the abstractly essential) interdependence of the two.

The 'economy' of Christianity, however, takes a step further, and that of vast historical importance. The realization of this sonship, thus visibly and tangibly, is, in the first instance at least, the work of one man, who brought life and immortality to light, and who might thus be described as the mediator between God and man. It is through his vision that those first drawn around him see. He, therefore, occupies an unique position: he is the bearer of tidings from an only dimly apprehended land, and it is faith in him that gives the message its reality. On the other hand, there is struggling through this belief at second hand a faith in the unseen reality itself through the witness of the spirit. The first witness is only an elder brother who has been the first to pass beyond the veil, the leader and vanguard of many brothers. But on this point there gradually emerges a profound difference in the religious world. For the majority, faith comes to mean belief in a message authenticated, not by its own merits, but by the special authority of the mes- 
senger, that authority in the end being due to his essential participation in another world and of a more than human nature, i. e. more, in the sense of non-human and divine. This view, in some degree and with many variations present from the first, becomes the orthodox creed of the Church in the fourth century. The other view, which again was always represented and in not fewer variations, even while assigning an unparalleled position to the founder, does not regard him as a supernatural being, in any sense in which that term implies a break of a new force into the realm of natural powers. The supernatural, as a further province occasionally trenching on the ordinary world of experience, it cannot accept, believing the supernatural to be but the natural, seen by faith as the garment of divine goodness.

The conceptions involved in the new idea of the relations of God and man necessarily took time to clear themselves of accidental accretions and stand out in all their significance. And that the more, in proportion to their novelty, and the distance at which they stood from the dominant habits of contemporary thought. The seed, however good, gathered, as it grew up and flowered and fruited, the consequences of its soil and circumstances. No doubt the impression which was forced upon those who saw and companied with the living ensample and realization of the life of man in God, and which spread with enthusiasm from disciple to disciple, and from place to place, caused a profound change in the aims and hopes which regulate conduct. But the so-called 'new man,' though a new structure, built upon a new plan and with 'new hopes aggrandizing the rags and tatters,' is after all not divided by any abrupt breach of continuity from his old past. Centred in the one thing new and needful, he may no doubt for the moment exclusively note the gulf that parts him off from his former self. But the novelty lies only in the controlling or animating faith and idea: and when that fails to hold its sovereignty over his will, when it sinks 
into the calm and cool of reflection, and becomes one among. many impulses of the man, the old propensities and acquired habits resume their independence, and reassert themselves in such force that they convert the new life they but now owned as supreme into a vehicle and a minister of their glory.

New ideas-which always and necessarily underlie and vivify a new scheme of life and conduct-cannot be received with pure passivity. Often, it is true, something very like passivity marks those who accept them. A wave of enthusiasm, an epidemic of imitation, sweeps like a natural and irresistible force over all who come in its way. Hearts burn, new powers awake, gifts almost miraculous display the presence of sympathetic and generous excitement, in the gathering where soul knits itself with soul, and each has the strength of ten, or even of ten thousand, because the boundaries of individuality are broken down, and the spirit works mightily in each and all to comfort and convince with irresistible inspiration of the universal in man. So it was in the early days of Christianity, as in other like times : an unloosing of curbed in energies, of hopes and fears, of ideals and passions, of antipathies and regrets, all stimulated by the new idea, on which in their turn they again reacted. A period of fermentation, irregularities, impossibilities, signs of a new and vigorous life, but signs also of old and vigorous passions working together; a harvest of wheat and tares mingled, needing time and patience to disentangle them, and defying the best efforts of those who, like the apostle Paul, tried occasionally to regulate the course of growth and check the riot which ever and anon tended to cause social, political, and domestic anarchy. Even from the first, though not with the distinct classification a later and more reflective age was able to import into it, there were great differences dividing into sections and strata the Christian religiosity, and the relation of man's spirit to things divine. The truth of the unity and identity of man as man, of the incalculable individuality 
which makes each as it were equally valuable in the sight of God, is no doubt a never to be forgotten principle. But equally memorable is the diversity and inequality of human gift. And it shows itself everywhere, not least in the act of faith. To some faith is an act of personal trust, a dependence on another's word and an abandonment of the personal claim or right to see and appreciate for one's self. In itself this confidence in humanity, in the common feeling and bond of life, is an indispensable principle of conduct. Without the sense of solidarity, of community, of fellowship, the fortune of man in this world would be but low and brute-like. Members, one of another, and of the Church invisible, the individuals of this community share in each other's advance or backsliding. But that each should lean on the other, it is necessary that each should also stand by and for himself. Or, if there be one to lean on, that rock must be not temporal but eternal, not man but God : or, in another way of putting it, the stay is to be found finally not in the Church visible, but in the Church eternal which is in the heavens.

Such faith as rests upon the immediate incident of personal influence and sympathy is an implicit faith. Due in the main to custom and circumstance, content to go with the majority, organized or unorganized, it simplifies the burden of life by allowing others to bear it. It finds its typical expression in the words of Augustine, that, were it not for the authority of the ecclesiastical organization, the Christian faith would be for him incredible and absurd. Yet these words, exaggerated as they seem, probably contain a glimpse of truth which it is easier to let slip than to formulate in proper proportion. They mean that the religious idea is essentially not an individualist perception, not a single fact which stands separate and palpable, but an organic and organizing principle, which binds man to man, and of which the Church is the embodiment and evidence. 'How can a man love God,' it is said, 'if he love not his brother also?' 
How, it may be added, can one see and realize God, unless he, see and realize the community and solidarity of man? On the coherence and coincidence of these two aspects all religion depends : it is this which, when it is alive, makes it always propagandist; for you feel that it cannot be really true for you unless it is true for others also. The Church, says the allegorist, is the bride appointed and preparing for Christ. She is, in other words, the visible and material organization in which a great truth is maturing: and the wedlock of the fact with the idea is again the full realization of the Unity, when God shall be all in all.

In the kingdom of God are many mansions: and while some are content, as it were, to live on tradition and authority, to believe on trust, to repose on the common strength, it is necessary that there should also be from time to time a few, a select number, who resolve, or rather are compelled by a necessity naturally laid upon them, to see for themselves. Theirs also is faith: but it is the faith of insight and of knowledge, the faith which is Gnosis. Hard things have been said of Gnosis, and harder things of Gnosticism : but it cannot be too clearly seen that Gnosis is the very life of the Church, the blood of religion. It is the faith which is not merely hearsay and dependence, but which really envisages the unseen for itself. It does not believe on a person: it believes in and into Him: it becomes, by an act at once voluntary and impelled from without (as all human action that is really entitled to that name), participant with Him and through Him of a force of life and conduct.

Gnosis undoubtedly has its dangers, but so also has Praxis: and after all the dangers of the one lie very much in the same line as those of the other. And that is the line of individualism and separatism. The truth lies in the subordination of all action and all knowledge to the common good, i.e. to the ideal ends of the community which has realized its unity in God, love, life. But as God and man are allowed to 
fall apart, God there and man here: as speculation devotes its energies to the former, and moral conduct is mainly concerned with the latter, the speculation tends to become frivolous and abstruse, the moralism to become cold and superficial. If the latter tend to isolate good deeds, by which name it complacently denotes almsgiving, \&c., the former becomes a love of transcendent inquiry into powers and beings which live and move in us, as we live and move in them, but of which, taken abstractly, we can say nothing wisely.

From age to age the genuine Gnosis has been the life-blood of religion in the world : we may almost say it is the arduous guest by which from time to time a new Prometheus brings fire from heaven to relight the smouldering and all but extinct altars of faith : or rather it is the channel whereby the winds and waters of the spiritual life refresh the decaying garden of God. Such Gnosis, which is firstborn and genuine faith, was that of Paul, of Augustine, of Luther, and of many thousands, named and unnameable, who have, in that daring of soul which is the good providence of the world, sought not an implicit but an explicit faith. That they, any or all of them, should have seen the full reality is impossible: yet amid the errors which must arise in the attempt to express incomprehensible eternal things, they have,--even when, as always happened, their own vision faltered and their message was but half followed or mainly ignored by contemporaries and successors,- - still served to keep alive a light of that higher world which otherwise fades from human sight. They retrace by what is called experience, i.e. by the energetic but necessitated reliving of our former life with full consciousness, that perennial way of religion which has become a tradition and a name.

The great deed that seems to emerge as the life of Christ is the bringing into one of God and man : the discovery that the supernatural is in the natural, the spiritual in the 
physical : the eternal life as the truth and basis of this: God manifest in the flesh : removal of the partition wall between God and man: the immanence of the divine, not as a new and imported element in human life, a special bit of man peculiarly holy, but as the truth and life in life. And the practical corollary is twofold: first, it is absolute peace in believing, the assurance of reunion, the good conscience which is free from the bondage of the ' weak and beggarly elements ',' the pure heart which rejoices in the Lord: the removal of fear and doubt: the 'strength which is as the strength of ten.' The veil is rent away which in the days of ignorance hid God and made him an unknown God: clad him in thick darkness and terrors of the mount, saw him invisible in excess of light, heard him whispering indistinctly in the separate events of natural and human historya factor incalculable, mysterious, awful. Thus the heart is made strong and cheerful: it has no hanging remorse, no repentance in the sense of doubts and remorse; for the true repentance is a conversion of the whole soul to newness of life, the appropriation of a new will. But there is another side : the absolute freedom of the Christian man is absolute allegiance to God : his independence rests in utter dependence. His freedom is from the tyranny of partial claims, individual desires and objects, from the halfnesses and weaknesses of our nature: and it is won by identification with the universal. It is, in short, here that there comes in what is called humility. To define it exactly is difficult, if not impossible : for, like all goodness, it has the defect of its quality, and to be precious it must never part company with its correlative, independence. Humility is the sense of solidarity and community: the controlling and regulating power of the consciousness that we are not our own, that we are God's and our neighbour's ${ }^{2}$. Humility is the attitude of an individual who recognizes his individuality, his partiality, his dependence,

1 Gal. iv. 9.

${ }^{2}$ And for our neighbour see the parable. 
his immanence in the whole, and his conformity with all the parts, and yet of an individual who knows himself his own, and not another's, a free man of God, a son and heir. To be genuine, it must go hand in hand with the good conscience and the faith unfeigned.

Finally, the most practical corollary is Love, 'A $y a ́ \pi \eta$. There are, said the Jew, two great commandments on which hinge all the law and prophets. The first bids love God with all strength and soul and intellect; the second, love the neighbour as self. If we separate them and minutely try to balance the several claims, it will lead to unpleasant and profitless casuistry. But they are not separate, and they cannot be balanced against each other. God, self, and neighbour,-they form an indissoluble trinity. Yet if the central dogma of Christianity be the community of God and man, the kingdom of the heavens, it is easily mistaken and misconceived. It is not to be confused with mysticism. Mysticism is the potent sense of the unseen, the vision of the higher truth which sweeps the lower away. In it the soul swoons away into the unseen: it passes by a bold act of anticipation beyond the divisions of earth, and rests in utter identification with the great source of life. The end of religion is thus a certain deification: the finite and temporal sinks absorbed in the great sea of being. God here tends to become all in all: the individual and personal is utterly swamped, and the great peace of the universe reigns unchecked.

Such mysticism can only be a mood-a mood that needs its corrective and antithesis. It is the reaction from battle and struggle-the lapse into the great bosom of nature, into the identity of existence. To it the other world comes to be a world to which we can only come by leaving this behind. The mind that lingers on it may be more logically or more aesthetically inspired: but in either case he will be apt to lose religion in Theology, whether it be a mystical or a scholastic theology. 


\section{IV}

\section{RELIGION AND MORALITY.-THE DEFINITION OF RELIGION}

In this second course of lectures it is my intention to deal with the question of the inner relations of morality and religion. There is what may be called a departmental view of human life which sets religion here and science there, which separates art from morality and morality from religion. It is a view which is useful in its place, but we should not allow it to influence us too far. I shall not deny that there is an ethics which, to all appearance, is independent of religion; but I think it may be safely said that at the present day a mere ethics and a mere religion are equally impracticable and undesirable. Neither without the other can fulfil what it promises. I do not mean that religion is always necessary as a schoolmaster to enforce morality, but I mean that, if we look to the origin and foundation of morality, in other words, if we ask what is the function and the place of morality in life and the universe, whether it is an accident or the essence of things, whether it is something that may or may not be, or something that must be, if anything be: if we ask such questions, we are driven to recognize that religion is the complement and the implication of the moral life. At any rate it will be my object in the following lectures to try to show that it is so: or at least to point out some directions in which ethics seems to imply or postulate ideas, which lie at the very root of those religions 
which have played the most important part in the history of the world.

The phrase 'Religion of Morality' has to the ears of the purist a sound ominous of a confusion of kinds, a mixture of heterogeneous natures. Religion, it is thought, is one thing, and morality another and altogether different. From the one side the scorn falls on what is called mere morality, from the other there is equal suspicion of mere religion. The fanatic will keep sedulously apart the human and the divine, the service of this world's humanity and the devotion to the other world of eternal life. The confusion, it may be urged, is like that of one who speaks of architecture as 'frozen music,' who breaks down the barrier lines between epic and drama, who mixes poetry and prose, or blends sculpture with painting.

Yet, it may be replied, is it not precisely the characteristic glory of the highest art that, even in its definite department, it speaks a language which awakes life and emotion in fields seemingly far disparate? Like the outpouring of the prophetic spirit on the first Christian Whitsuntide, it is understood in many alien tongues. The great poet, the great composer, the great painter, are endowed with an inspiration wider than the so-called legitimate scope of their art. They do not indeed mingle or confuse kinds, do not bring in poetry to help where painting fails, or try to turn prose into poetry by any accidental efflorescence. But in the real artistic life, the life in the soul and spirit, which is all form and harmony and grace, each art, divided in mediocre artists from its sisterhood, again draws in the strength of its undivided source, the comprehensive spirit of art itself. In its spirit and truth every separate art ceases to be so separate; it speaks with an utterance which knows no limitation of departments, which spurns, because it overcomes, the barriers fixed by grammar and abstraction. The consummate artist concentrates in his special gift the whole range of art-power; the highest art 
special to an age is in a way the epitome and quintessence of all other arts as well.

Adam, says the old legend, gave names to all cattle and to the fowl of the air and to every beast of the field: ' whatsoever the man called every living creature that was the name thereof.' But ere Adam called them they were there, called into being by forces greater than a man-imposed name, knit together by the development of a history, a genesis, which his glance could not in an instant surmise. Their true name, may we say, only their maker could know; and that name, if it were true to their reality, would be perhaps a myriad-syllabled vocable. The stranger, confronted with the problem, gave them names: he is seldom at a loss for that, this nomenclator man : but in the long lapse of years since Eden he has gradually gained a glimpse of the vast discrepance between what he, simply, naïvely, fancifully or practically named them, and the true names which they bore, or will one day bear, in the muster-roll of God. All science, says one, is but a ' language well made,' a language which shall not miss true affinities and underlying connexions; which shall trace, say, in evolutional fashion, the inner genealogy of Nature.

It is the stranger and the outsider who gives the name, the outward observer. The bosom friend, the member of an organic unity, hardly needs a name. Our name, for each of us, is for others to use, for others' convenience. A tribe does not give itself a name; at least in the primitive course of things its name is given perhaps mostly by its enemies, by aliens. And it is oftenest a sort of nickname, the freak of what we call chance, which settles on some conspicuous feature that appeals to the imagination.

Not otherwise is it with names like religion, or morals. When we have recourse in such cases to etymology, we should be on our guard against a misconception of its evidence. The history of the elements of the word will not tell us what 
religion was to those who had it and lived in it: but it may throw some light on what observers saw as they looked upon it. It will tell us something of its outward phases and effects, of the conduct and ceremony to which it gave rise. We cannot tell what the Roman religion really and inwardly was; but whether we follow one etymology or another (re-ligere, after Cicero, or re-ligare after Lactantius), the prominent feature brought before the mind is (as in Lact. iv. 28, ' vinculo pietatis obstricti Dei et religati') a strictness and conscientiousness, a scrupulosity and care in behaviour, a diligent observance of ceremony and form of worship (' religiosi $=$ qui omnia quae ad cultum deorum pertinent diligenter retractant,' De Nat. Deor. ii. 28), a watchful anxiety in presence of some superior influence ('superioris cujusdam naturae ... curam ceremoniamque affert,' De Inv. ii. 53).

It is this idea of strict obligatory control over human action which is prominent in the word as it meets us in its older French and English uses, prior to the seventeenth century. If Luther e.g. speaks of the 'old religion,' it is of its objective ceremonial or ritual side that he is thinking. And so Calvin (Instit. 66) says: ' j'estime que ce mot est opposé à la trop grande licence et excessive que la plupart de monde s'est permise. . . Religion donc comporte autant comme une retraite et discretion mûre et bien fondée.' It is the same disciplinary consciousness of being ever in the great taskmaster's eye that made Frenchmen speak of the Huguenots as messieurs de la religion. And if we open the pages of Chaucer or his contemporaries, we find perhaps a more restricted conception of religion. Religion to him is special consecration of place and conduct to direct special divine service. A place of religion is e. g. a monastery : a man of religion is one in holy orders.

Religion thus holds a separate and definite sphere in life, confined as it seems to selected spots, and peculiar modes of action. It surrenders as it were its claim to rule whatever we 
do, and to be wherever we are, if only we give it and secure it a special realm.

But whatever be the range of its sway, the obligatory nature, the awe-inspiring and legal character attaches to it. Religion is, in fact, divine law. Under that name it appears in mediaeval language as Lex nostra, Lex Judaica. The conception, of course, is, in part, that of the older Judaic, but in a deeper sense it is a common, almost universal, attitude to God. Religion is the sense of a covenant obligation, a binding tie. It need not surprise us, therefore, that in Parsifal and the Nibelungen Lied the word for religion and its sanctity is $E^{\prime}$ (the modern Ehe, now used only of marriage): e.g. in Kristenlicher $\hat{E}$, or den touf, und Kristen $\hat{E}$. And so in Shakespeare the commonest sense involves this emphasis on conscientious obligation, strict fidelity, loyal obedience; e.g. 'Keep your promise with no less religion' (As You Like It, iv. I. 201); 'When the devout religion of mine eye' (Rom. i. 2. 97); 'How many a holy and obsequious tear Hath dear religious love stolen from mine eye' (Son. $3^{1}$ ).

The decisive novelty of the Lutheran reform was in the direction of a subversion of this apparent predominance of objective religion. For the outward ordinance, the minute and accurate performance of measured duties, it substituted the inward feeling, the subjective attitude of faith. The word for true religion in the Lutheran language is Glaube: and the essence of Glaube is füllen. 'Du musst bei dir selbst im Gewissen fühlen Christum selbst, und unbeweglich empfinden dass es Gottes Wort sei.'

Yet it would be a mistake to speak of the movement as a change of the emphasis merely from the objective to the subjective side. To some extent the Catholic mysticism of the later mediaeval times had done that before. The other and perhaps more important step was that the Lutheran reform sought to put an end to the restriction of religion to a specially religious sphere, a higher and peculiar range of 
sanctity. Not that Catholicism had failed to recognize the presence of the divine law in all secular life. Marriage it had declared a sacrament; in other words, it had set the human ethical relationship as part of the direct ordinance of God, as a service of the kingdom of heaven; not as a convenient arrangement for social well-being, but as a method of salvation, and only to be engaged in as a way and means to the attainment of eternal life. If the older Catholicism failed, it was because its social or political organization created and enforced grades of goodness, which were not in accordance with its own essential doctrines.

Lutheranism could not long remain true to its own fundamental intuition. In the stress of conflict between reformation and counter-reformation, reality and belief had to give way to formulae or creeds. The term 'faith' or 'belief' as a volitional act, an effort of the whole man, a lively personal apprehension, was, by the force of objectivity and of words, turned into a set of beliefs, a creed. The only apparent result was, it might seem, that a new narrowness was substituted for the old. Once it had been a special region of act, ceremony, observance: now it was a special form and phrase of definition of doctrine. Religion, in Protestantism, thus gains a dominantly intellectual, a sort of literary, character. According to Calovius (p. 282) it 'comprehends all things which are comprehended in theology, whether they are things to be done, or things to be believed.' But to speak of a 'thing to be believed' is already to use language in which the great vision of Luther runs a risk of being lost. Theology and religion are in danger of coinciding-to the injury of both. Nor need we lay much stress on the fact that the two sides of religion (theoretical and practical) are set side by side, unconnected. It is only a further gliding on the same slope when it is declared that faith proper (fiducia) is preceded by bare knowledge (notitia) of the facts.

Religion had been transferred to the field of science : it had 
been, that is, appropriated by the rising tide of the modern world and of scientific civilization, of literature and popular opinion. It comes forward, or rather is brought forward, into discussion, by those who looked at it from the outside, and tried to correlate it with the other aspects of life. It sought to legitimate itself in the court of science, and became the so-called science of theology, or, on the other hand, it was decried and scorned by those who judged it by the canons of physical science. With the Reformation rationalism, the unchecked lust of reasoning and explaining, had been let loose, and alike in orthodoxy and heterodoxy it ruled.

Yet, that the real sphere of religion was elsewhere, was never utterly forgotten. It hardly needed Schleiermacher to repeat that the essence of religious life is the sense of utter and all-round dependency. When Kant had described the essence of religion as the recognition of all our duties as commands of God, he had said the same thing in balder language, in language less mystically attractive than the vaguer and suggestive words of Schleiermacher, and open to obvious misinterpretation by those who would press the meaning of terms like 'command,' or like 'recognition,' where the old error of intellectualism might seem to lurk.

And, if we take a contemporary of Schleiermacher, let us hear Schelling, who reiterates the essentiality of duty, but of a duty inspired by something higher than subjection, a something which he calls at once heroism, faith, fidelity to yourself and to God ${ }^{1}$.

'By religiosity, the inner power and spirit of religion, I understand,' says Schelling ${ }^{1}$, ' not an instinct groping towards the divine, and not mere emotional devoutness: for God, if $\mathrm{He}$ be God, must be the very heart of life of all thinking and all action, and not a mere object of devout passion or of belief. That is no real knowledge of God, where $\mathrm{He}$ is merely object: either God is not known at all,

${ }^{1}$ Schelling, Werke, Erste Abtheilung, Band vi, p. 558-9. 
or $\mathrm{He}$ is at once subject and object of knowledge. He must be at once our very self, our heart of hearts, and yet comprehending all hearts far beyond us. Religion is higher than dim outstretching hope and feeling for God. The first meaning of the much misused word is conscientiousness; it expresses the law that knowledge and action are at one so supremely, that action must inevitably follow knowledge. $\mathrm{He}$ is not conscientious who in a given case must first set before himself the command of duty, in order to decide himself to act rightly through respect for its mandate. Religion means that action is bound, obliged, that there is no choice between opposites, but supreme decidedness for the right, without option.'

Conscientiousness, it is true, does not always appear as enthusiasm, or heroism; it may consist in strict fulfilment of duty, and, as in the case of Cato, show a certain hardness and harshness in its features. But such strictness and scrupulosity is, like the strictness of life. in the physical world, the germ from which will yet issue true grace and real divinity. When the divine principle at its root has sprung into life through its strictness of sentiment, then virtue presents itself as enthusiasm, as 'heroism, i. e. action which does not spring from the finite nature of man, but is the free and beautiful courage of a man to act as God instructs him, and not to fall short in action from what he has seen to be true'; or if we call such religion faith, the word is not to be taken to mean assent to a proposition which is partly doubtful, and where assent therefore is regarded as meritorious, but ' in its original sense of a trust and confidence in the divine which excludes or abolishes all choice... This faith and this fidelity to yourselves and the divine,' adds Schelling in his lecture, 'I wish you to take with you into life as the sole true fruit of philosophy.' 


\section{V \\ THE ETHICAL MOVEMENT IN RELIGION}

ONE of the most important facts or problems in the life of the present day is that which is best described as the ethical movement in religion. That movement, as it obviously presents itself, has two very distinct phases. It is a movement inside the Churches (both the Christian Churches and also Churches that are not exactly Christian); and it is a movement outside the Churches, though not always or necessarily hostile to them. It shows itself e.g. in the rise of what are called Ethical Societies in America, in France, and in this country-societies which are, indeed, not very important, if judged by outward bulk. A few human beings linked in action for the purpose of bettering the general standard of ethical feeling, may seem rather a subject for jest. But they are one indication of a widely prevailing want of satisfaction with the results both of religious and of scientific teaching: and the initiation of an effort after something better, which the historian of the future will not count unworthy of regard.

The present state of opinion upon ethics and religion may remind the student of history of what happened at Athens more than 2,000 years ago. Then also the old landmarks of local religion and patriotism seemed to disappear. A little town, by a series of achievements and struggles about which the world has not yet grown tired of hearing, found itself suddenly planted on a new scale of existence, with new duties and outlooks, calling for new preparations. It entered upon 
a larger life, the life of a cosmopolitan centre-cosmopolitan, at least, so long as the world was a Mediterranean world. There was a call for more virtue. But what, it may be asked, was virtue? It is a question which in the modern world has had to be asked: for words, li 9 other things, grow stale and unprofitable, mere shadows of themselves. Again and again in the course of history virtue has been taken in a purely neutral sense; or rather we should say, it has been taken in a quite negative sense. It has come to mean, neither doing something, nor the ability to do something, but the not doing something, the power of abstinence. Instead of the idea of force or manly energy, it has been used to express the negation of force, or at best the power of self-control ; nay, it has sunk lower still. So too with propriety: in its first power the word meant being all that one should be, realizing one's own, self-realization, being true to one's own self and working out one's own law. Even in Adam Smith the word still meant the sense of proportion in things. But it too sank till it expressed no more than negative merit, till it stood in a line with mediocrity and meant or suggested something straitlaced, cold, and formal.

Now virtue of the real stamp is positive ability, the power to act, to act well and vigorously. And when we say ability to act, let us add, that ability, if it be real, is itself action. It is the initiative of act, inchoate action, tendency passing forward into energy. It is not mere not doing something which is to be condemned; it is doing, or readiness to do, something which is required by law, by ideal, by social demand, by the needs of life.

As new circumstances involve new work, the call of virtue assumes a new phase. In a stagnant or decaying civilization, such, for instance, as we meet in the later days of GrecoRoman fame, when life and progress had died out, to all appearance virtue came to be endurance, self-denial, restraint: it acquired a passive tincture. At such times the world gets 
to move in a quasi-mechanical routine, and the great requirement is to step accurately in the line, and show no sign of originality or independence. But at other seasons virtue must be positive. It can no longer be a cold morality, a formal compliance; it must be warm, active, and onward-going. It is fully all that it is, only when it is so active. Yet, perhaps we do well to remember that resistance also is action; that much effort may sometimes be demanded merely to produce equilibrium: that energy is not always best exhibited by 'agitation,' and that there may be a strenuous inertia, a service of those 'who only stand and wait.'

To meet the demand in Athens arose a class of teachers who professed to communicate the requisite ability, who taught the virtue which fitted for the discharge of social and public functions. It was urged against them by some observers that in these departments teaching, specific training, culture was unnecessary. Everybody, it was said, can speak Greek, and he learns it naturally by the practice of life. Yet it was found that speaking Greek required in certain cases more than mother-wit and family example could supply. So, too, whatever differences may be between men, they may be all said to be pretty equally endowed as regards a moral sense, shame of wrong-doing, and sense of justice. Yet here too the new complexities of social existence created cases where the old average hardly met the needs of the situation. It is no doubt true in a way that he who can rule his own soul can rule a kingdom, yet perhaps a few considerations as to the aims, methods, and machinery of political life may not be amiss.

The same questions arise for the modern world, and we may say, if we like, that in both cases they are due to the advent of what is called Democracy. What is Democracy? To the observation of Plato, as of many observers since, Democracy has seemed another name for Anarchy. Its very name sounds amiss : it is mass-force, the violent power of the great multitude, of the whole people. It is Kratos-force 
(remember Koátos кaì Bía in the Prometheus). Monarchy and oligarchy are rule and direction of one or few, but democracy, it is said, suggests only absence of all direction, all principle, all originative rule-anarchy.

But Plato, if he is occasionally unjust, and gives scope to sarcasm, is equally aware that democracy may be something better than anarchy. There is a democracy which is according to law, a democracy in which there is no absence of a $\rho \chi \eta^{\prime}$, but where every citizen from the highest to the lowest, from the least to the most capable, is in his measure and degree an arche, archon, though, as we may add from Aristotle, none is ă $\rho \chi \omega \nu$ who is not also à $\rho \chi o ́ \mu \epsilon \nu o s$, i. e. who is not in his own person at once sovereign and subject, at once lawgiver and law-bound, king and commoner. This then is the true or ideal democracy, the organization of the total power of a group of human beings, in which none is merely a mean or instrument of service, but each also enjoys the end of his own and others' action; in which there is fraternity, but not necessarily equality or even vulgar liberty; or where the equality lies in common duty of service, and the liberty in the removal of all mere passivity.

On its negative side, then, democracy is the power and force of the whole body, as against the decided dominance of one or of several classes in the body politic. As so negative, it has an appearance of no direction, of anarchy. But the positive side must not be ignored. And that, in one word, is autonomy, self-direction, self-organization. It is not the negation of direction or government, but its completion and universalization. To realize that positive side is the work of education: and, it is in the recognition of that problem that the promoters of an ethical movement have their place and function in the present as in the past. They are the witness of a feeling that something is amiss; that the order of the world is passing through a change, and that a new effort is needed to set it right, to prevent stagnation 
and corruption. It is not quite so clear that they have discovered the root of the evil, or that they are on the likely way to a solution of the question.

More than this. If we are guided by the analogy of the old world, we may well doubt whether the issue is at all simple and near. Even where only material interests are concerned, it is often long ere the great masses can be got to discern the nature of the needs they labour under. It requires the guidance of genius to show the place of the evil. It is not for everyone to say where the shoe pinches. The sense of the masses is a vague feeling of malaise, a vague disgust, spite, indignation, against something wrong; but to discern what the wrong precisely is or in what it exactly consists, that is just what the masses are unable to compass, and what their leaders, good or false, try or pretend to make possible for them. So it is alike in material and spiritual evil. The remedy comes only by diagnosis, by the ascertainment of the definite nature, the characteristic feature, of the ailment.

So in the ancient Greek world, it was not a simple matter to say what was the evil eating at the root of life. It was easy of course to note symptoms : for a little natural interpretation in a predisposed mind can turn any fact into a symptom, and a spontaneous imagination may easily add to their number. But the diagnosis of the disease of Greece which Plato offered, and the ideal of the good and happy life which he faintly indicated, were too alien to the ordinary mind of his countrymen to find immediate response. Yet the Greek philosophers by direct and indirect energies laboured a soil of which other people reaped the fruits. It is by no means fanciful to say that the organization of the mediaeval Church was the realization of Plato's ideal, though a realization of it which was deeply pervaded by a spirit of alien tone. The early Christian writers themselves in their saner moods spoke of Greek philosophy as the preparation of 
Gospel, though sometimes in their blind zeal they styled it devilish.

To us looking at the facts in the light of history, it is hardly possible to say otherwise than that though it was well done, it was far from being thoroughly well done, or so done that it can be considered satisfactorily done for ever. But we need cherish no illusions as to what we can learn from the past. The cry is again and again raised. Back toit may only be to Kant: it may be to Greece, it may be to mediaeval Christendom, it may be to primitive Christianity, or, as with Rousseau, it may be back to Nature. But in what sense back? What has been done, even the gods themselves (says the adage) cannot make undone. All that historical reversions can do is to suggest that in the onward movement something precious had been left behind, which it were well to recover before going further. But the Nature, the Greece, the Christianity we go back to is not in the past; it is, seen through the arch of experience, the gleam of that untrodden world to which we move. To seek them in the past is to seek the living among the dead. The gates of one Paradise are closed, the Paradise of infancy, of simple hours, of naïve faith. The gates of Paradise are eternally open.

The ethical movement, as it has been called, is the result of various influences, and is an attempt to satisfy various needs. It grows out of felt wants, and gropes about to find a remedy. It is no solution, but a step towards a solution. Its most obvious source perhaps is found in what some people would rashly call the decline and fall of religious belief. But what is thus called by the comprehensive title of religious belief is only one part of the existing religious spirit and institution, and perhaps not its most central or religious part. What has fallen or is falling is not that central spirit of religion which we found described as conscientiousness, devotion, reverence, loyalty, fidelity, enthusiasm, and heroism. 
What has fallen is not that trust in the world order, that faithfulness unto death, that joy in well-doing, that cheerfulness of good conscience, which made obedience no burden, and service a delight. These things, it may be said, are now seldom seen : but so, it may be answered, was it always. It may be added perhaps that they are oftener to be seen for those who have the eye to detect them than our cheap cynicism admits.

What has changed lies in another part of the religious system. What has fallen, or rather what has become uncertain and suspect, is the historical and metaphysical dogmas, the cosmic theory, which have been knit up with religion. In the history of the Christian Church-in a way which I endeavoured in my last year's course of lectures to tracethere grew up slowly and naturally a creed, a body or group of articles, partly historical, partly philosophical, in which an effort was made to express the fundamental Christian conception of what man was, is, and would be; what God is, how the world is related to God and to man; in other words, to furnish a scheme of beliefs about life and death, duty and reward, which should answer all demands that legitimate curiosity on man's part could make. By those who formulated this body of doctrine, these articles of faith, it was believed that their labours and decisions only codified and defined what originally, in some exceptionally favoured epoch of history and in some peculiarly holy land, had been given forth with an authority more than human, and from a source veritably divine. In some way-though precisely how it happened, an unanalytical age barely presumed to inquire-God had communicated directly with men and given them a message, in which the true purpose of existence was revealed, and the means indicated by which the full fruition of existence for man might be realized. That message was, as it were, a bequest consigned to a trust, left in charge of a community who, walking by the light of the revelation, 
maintained it intact in their treasury-archives as a fundamental document, a title deed to the inheritance. That document is of course the sacred Scripture. But while maintaining the deed intact and secing to the training of a select body, the so-called clergy, which should be able to read and interpret it, the main function which the Church claimed as her abiding work was to celebrate, i. e. to repeat and realize, in symbolic ceremony, the perpetual meaning of the said message. A system of rites, a series of sacramental observances, carried out in all departments of life the purport of the fundamental conception of life and duty. The aim of the Church was to make each individual feel and perceive for himself that here and now the meaning of the everlasting Gospel was enacted and realized. A symbolic ceremony was by active participation of the celebrant the sign of an inward process. Day by day, year by year, in appointed cycle, the Church re-enacted the deed once done, the life once lived and the death once died, not in vain repetition or impious travesty of the accomplished fact, but in order to enforce by sensible image the eternal and universal virtue of the truth, of the law of life, the way to life which is true life, or, as the phrase is, life eternal. If it be said that this is but opus operatum operari, it might be replied : Even so, always, what God may be said to do once for all, man, the child of time, can only equal by eternal repetition.

But with the Reformation, which was also and most obviously a Revolt, a new view of the Church's duty emerged. It was supposed, not without reason, that the Church undertook to do by her own authority what had been done once and for all in a remote past. Not content to occupy till He came who should restore all things, the Church, it was said, had usurped the absent ruler's place, and claimed to rule by right of her own, as if her dominion were irresponsible and not merely vicarious. She was accordingly thrust aside as illegitimately intervening between the soul and its God. 
The whole ritual was pronounced to be a work of idolatry. And it was reasserted that not the ceremonial was the essential, but the inward spiritual change which the ceremonial typified. And if, indeed, the Church had so stepped in between, if she had assumed a mediatorial function between man and God, so far the change made was to be justified. If, on the other hand, the Church had only acted in its organic capacity as a whole, to guide and help the faint efforts of its weaker members, the change was less excusable. If the Church had meant to teach that not the temporary event but its real significance was the essence of true religion, if her symbolism was merely the means of making the dogma approach the apprehension of ignorant minds, then who shall say the Church was wholly wrong?

Such in barest outline is the quarrel between Catholicism and Protestantism. It is time perhaps to realize that, like all violent changes, the Reformation only helped progress by accentuating the fundamental issues involved in religious life, as a life in the world. It did not answer the questions it raised, and it imported a new bitterness into all attempts to answer them. At any rate, what happened was that the documentary evidence of Scripture came to be looked upon as all important. The historical record took the place of the Church. The title deed became more important than the estate. Nominally at least, the individual was encouraged to regard the document as a private promissory note, which he could use by the light of his own soul, or by a light privately vouchsafed, without regard to the community. It was not long indeed before the right of private interpretation was claimed. Protestantism gradually and perhaps inevitably came to assert that the whole truth, the whole message of God to man, was contained in the 'Testament.' There each, even the cottager at her own door, could read clear her title to a mansion in the skies. But the fact, which remained unchanged by any formal declaration of indepen- 
dence, was that the interpretation, which fifteen centuries had helped to consolidate, remained in its main features dominant over those who renounced allegiance to the Pope at Rome. The quarrel had in the first instance touched only on the machinery. Like all quarrels, indeed, it induced a spirit of suspicion which surmised evil everywhere. But, in the deeper regions of belief, the old scheme still remained in essentials unaltered as the theory of true life.

And, practically, in all the gamut of Protestantism down to Congregationalism, and if there be ranges beyond it, the individual never came merely and simply in contact with the revelation. He might see with 'old lights' or with 'new lights,' but always he saw the truth revealed in Scripture through some common light, a light burning in a community, however narrow might be the limits he assigned it. When he sought toleration, it was often because he wanted to tyrannize in a body after his own mind. With an excusable inconsistency Protestantism accepted in the main, though with slight reservation and corrections, the doctrinal system which the efforts of theologians in council had wrought out of the data of the original documents.

Now in the course of last year's lectures I attempted to show that it is a delusion to suppose that these doctrinal systems are merely the pure colourless statement in logical form of God-given truth. In all cases they are a synthesis, a compound product, due to a reflection on the data of Christianity, which was guided in the main by ideas derived from Greek philosophy. They are a mixture of good metal and other less worthy elements. And when I thus express it, I do not mean that the dividing line between these elements lies at the boards of the Bible. The line of distinction is harder to draw than that. The tares lie mixed with the wheat even within the sacred precincts; and the separation of false from true is not to be made by simply returning to a given tradition of the past, but in working 
and waiting for what is called the 'end of the world,' the ' revelation of the sons of God. These theological structures were the result of attempts to rationalize the faith and the articles of belief it embraces, and out of them to form a system of doctrine. But such a system could not be final; the doctrine must grow, i. e. it must be altered and enlarged.

Since the Reformation dogmatic theology in the older sense could make no advances. And why? It was then asserted that the real theology lay in the limited words and scope of the Scriptures, and that the creative process of religion had been restricted to the space of a few years. Hence the naïve process by which the early Church built up theology, seeking to give to religion and science, to faith and art, a unity of scheme and idea, was henceforth condemned as unscriptural and illegitimate. All that could be done was to set the same old material in a slightly different light: but to add to it was impossible. You see the results in the endless series of German Dogmatics. A narrower view of the position was to reject all theology or interpretation and cling to the Scriptures alone. Hold to them, and you will be safe.

But this standpoint is untenable. (1) The private interpretation of the individual no less than that of the Church involves the application of ideas of human and social origin. Private theology is liable to all the additional recklessness of individual judgement. For individual judgement is - what? The judgement of one biassed by an opinion due to surroundings, to instruction, habit, and all the various mixture of ignorance and knowledge. Always it is the product of class influences; its roots lie outside its apparent source, it is the work of many causes, necessitated on all hands; and yet it comes forward with the claim of freedom and independence. Wir freie Geister, says Nietzsche. But who gave us Geist and Freiheit? (2) The title-deeds themselves are subjected to criticism. This applies to Catholic as well as Protestant 
theology, so far as it is founded upon Scripture. Yet Catholicism has still the living and actual faith and practice of an abiding body to fall back upon. It has never completely pinned its faith to history and a limited tradition. It has built on the universal tradition of all ages, i.e. really on the essential humanity or rationality of its doctrines.

What was the crowning merit of Catholicism? The very thing which many a modern, accustomed to identify it with the Inquisition and the Society of Jesus, or perhaps with a caricature even of these, would probably deny to it. That is, that in a rough and imperfect way the Church regarded itself as a central and guiding principle of life, to which indeed all other things were but ancillary; but, just for that reason, conceived it as a duty to give to each of them a place and a function within itself. Hence science, art, social life, political union, grew up as integral parts of its structure. The unity, perhaps, was somewhat roughly compacted: and it only held out against criticism so long as progress was slow or imperceptible. But still, as Dante shows us, the synthesis of life was there. Already, however, in the Cinquecento the Renaissance indicates that disease has set in for the organism; that disease which consists in the too unequal growth of the several members. And soon the Reformation comes to make a deep rent in the one body of spiritual life. It breaks up the unity of art, science, morality, and religion. And it does so, though with characteristic variations in either case, both for the Reformed Church and for the Church of the Council of Trent.

But, on the other hand, science in the mean time has been setting itself up side by side with religion, taking religion in the narrow sense. That is, a view of the world's meaning and drift has been slowly growing up, parallel with and partly antagonistic to the strictly religious view. The latter has no doubt the advantage of being a more closely wrought, complete coat of mail. But it is antiquated. The 
new view is growing, fragmentary, progressive, and therefore incomplete. It is forming from different sources, by slow processes of natural growth, here a little and there a little, though it still remains the property of a few and are by them known only in parts. It is chaotic, assertive, and self-contradictory ${ }^{1}$.

1 At this point the manuscript abruptly stops. In the three following lectures Professor Wallace examined the influence of modern science and litcrature in changing our ideas of religion. The manuscript begins again in the sixth lecture with an examination of Mr. Balfour's Foundations of Belief, and is continuous to the end of the course. 


\section{VI}

\section{MR. BALFOUR'S 'FOUNDATIONS OF BELIEF'}

The title of Mr. Balfour's book promises to lay bare the 'Foundations of Belief,' and 'to delineate, and if possible to recommend' a particular way of looking at the worldproblems' - a way which may be briefly styled the theological, perhaps even the Christian. The theme of the book is less purely theoretic, and more polemical than its title suggests. It is in the main an examination and an indictment of a modern creed, to which the critic has given the name of Naturalism, and which is, by definition, the negation of all theology. The book falls into four parts. In the first part there is an exposition of some 'consequences,' which in Mr. Balfour's judgement follow from the naturalistic creed, certain changes, which its uncompromising acceptance would involve, in our estimate of the principles we call ethical, aesthetical, and logical or intellectual : in other words, this part seeks to show that the naturalistic standpoint, if thoroughly adopted, would in the long run dry up and cause to wither away every belief in the paramountcy of righteousness and beauty and reason ${ }^{1}$.

Naturalism, it is therefore concluded, is practically insufficient. The second part, under the title of Some Reasons for

1 The book, perhaps by an oversight, describes this part as 'Some Consequences of Belief'; it really treats of 'Presumable Consequences of the Naturalistic Creed.' 
Belief, carries us to a point of outlook from which we can, at a proper distance, survey the philosophers, the men of sound common sense, and the professional theologians, at their work of providing a rationale for $a$, or their, or the creed. First of all-and that from respect to their 'formidable following'come the Naturalistic Empiricists. By that name is meant those who, in the first place, attempt to provide a theory which may show on what the certainty and stability of the sciences rest, a task in which they have failed ('such,' remarks Mr. Balfour, 'is after all the common lot of philosophies'); and who, in the second place, disguising or ignoring their failure, have, under cover of the successes of the sciences which they profess to explain, contrived to foist upon the blatant part of the world a theory of life and of all reality, which is no necessary concomitant or part of genuine science, and which at once fails to satisfy the conscience, and violates the coherence of reason. In a second rank, as befits their scanty numbers, and their foreign origin (for their utterances, made English out of German, are such no 'ordinary Englishman will consent to assimilate'), come the Idealists. 'Very remote, indeed, from ordinary modes of expression,' the doctrines of these 'Idealists,' or, as they are often doubly dubbed in the text, 'Transcendental Idealists,' are for the general reader's sake veiled in a chapter in smaller type, which he is recommended to omit. For the present it need only be said that under this head are weighed and found wanting certain views, more or less attachable to Kant and T. H. Green; the net result of the criticism being that these views have their natural outcome in Solipsism, the theory that ' in the infinite variety of the universe there is room for but one knowing subject, and that for each one of us severally this subject is "himself." Such a conclusion, so obviously inconsistent with science, morality, and common sense, seems indeed to justify the place given to 'transcendental idealism' on Mr. Balfour's index expurgatorius. Behind these Metaphysicians who are 
poets of the abstract and supersensible, but to be sure, poets with a difference (for it cannot often be said that the product of their labours is a 'thing of beauty'), come as third line of array, the troop of Rationalists. These, otherwise known as champions of common sense or enlightenment, are not, as such, philosophers: they, indeed, ignore, if they do not despise, metaphysics. They judge as men of the world, and test every belief by one touchstone: they ask, of every article of any creed, does it 'square with the view of the universe based exclusively upon the prevalent mode of interpreting sense-perception'? Rationalism, in short, is the method which, in an age where the physical sciences have a preponderating éclat, inevitably leads to Naturalism. It is 'Naturalism in embryo.' And its right to the name Rationalism is based on its carrying out at least that principal function of reason, which is to smooth away contradiction, to remove inconsistencies. Lastly, as a fourth group, with its own attitude to the problem of belief, comes the band labelled 'Rationalist Orthodoxy.' Here muster the Natural Theologians, who make theology 'a mere annex or appendix to science, a mere footnote to history'; or who, in other words, profess, by an extension of physical methods and the evidence of historical fact, to read God's word in the rocks, in the struggles of animated life, and in the course of civilization. The doom of Natural Theology is written: it has appealed to natural science, but it is not by the method of science that it can 'break out of the naturalistic prison-house.'

The third part propounds 'Some Causes of Belief.' It supposes us to take the position of an observer from another planet ' who, in a spirit of detached euriosity,' surveys beliefs from the outside, so as to find out the place they occupy in the natural history of the earth and its inhabitants. The task of this observer is, it may be suggested, by no means easy, not to say impossible: but let that pass. With a penetrative power such as archangel cannot match, he sees 
where it exists (in certain vital forms) the correspondence of neural change and psychic event: he sees the beliefs of external things with their order in time and place forming in the individual mind. But he soon discovers that other influences than those of the physiological structure of the individual man are at work in forming the individual's creed. Man's beliefs are not all on one level: they rise in a kind of hierarchy. And to explain such of them as are connected with the higher scientific, social and spiritual life of the race, there is needed something more than physiological structure: an appropriate environment is required. In that environment one group of causes influencing these higher beliefs is specially selected for notice. This group is named briefly Authority. To fix its place and function, according to Mr. Balfour's estimate of it, we need only note that it is styled the 'rival and opponent' of reason. It 'stands for that group of non-rational causes, moral, social, and educational, which produces its results by psychic processes other than reasoning.' To Authority we owe the order and stability of the moral world: by it the efforts of reason to rationalize are 'coerced to a fore-ordained issue' : throughout the whole course of history its part in producing belief is immense, inevitable, and, on the whole, beneficent: it is through it that are generated 'psychological climates,' i.e. general and irresistible habits of belief of which reason is but the dupe or the captive. Even 'rationalism' itself rules those whom it rules, not by its reasonableness, but as a mood and a fashion of the set, the age, or the place. Political 'loyalty' is one of the most valuable products of authority. The believer, it is true, will often attempt by reason to justify his faith; and in the causes which, as a matter of fact, have generated it, he will profess to discover reasons which legitimate it. But in so doing, he is the victim of an illusion which he would be the first to condemn in others. 'It is from Authority that Reason itself draws its most important premises.' 'It is Authority rather than Reason to 
which in the main we owe not religion only, but ethics and politics'; and not these only, but the essential elements of the premises of science, and the foundations and the superstructure of social life. And, on the other side, we are reminded, that ' reasoning is a force most apt to divide and disintegrate.'

The fourth part offers 'Suggestions towards a Provisional Philosophy,' i. e. towards the ' unification of all belief into an ordered whole, compacted into one coherent structure under the stress of reason.' Of these various and heterogeneous beliefs, certain, viz. those about the world of phenomena, the so-called material world, possess a peculiar prominence; for they seem inevitable and universal to a degree to which no others can lay claim. But from the view of reflective reason this pre-eminence is 'irrelevant.' The omnipresence of the material world in our habitual moods is the product of an irrational coercion; it is forced upon us by the elementary necessities of life, bred from infancy into our very flesh and bone. The universality and necessity of our beliefs in the reality of the material world cannot, therefore, confer on these beliefs superiority of rank or dignity. The needs which a scheme of belief must reasonably satisfy are not merely those which we 'share with our brute progenitors.' It is on this gradation of beliefs that the whole question hinges. The postulate underlying all beliefs about 'phenomena,' as well as about things other than what are ordinarily called phenomena, is a 'harmony between our inner selves and the universe of which we form a part'; a correspondence not partial, but complete, between our essential selves and the eternal reality of things. It is the assumption that the human consciousness in its fundamental character, its essential requirements, strikes a note which is answered in complex harmony by the deepest heart in the ordered frame of the universe.

At this point Mr. Balfour interpolates some remarks on the 
relation between beliefs and formulas especially in theology. There, as he puts it, ' the explanation and the thing explained are mutually dependent.' The abandonment of a theory which formulates a religious experience often carries with it, to popular apprehension, the negation of the fact on which it is based. It is as if gravitation would cease to act, should the gravitation theory be shaken. But there is another point which gives a special character to the theological formula. That formula is not merely a statement of theoretical agreement: it is the index and the support of the unity of an associated organization. Hence an alteration in the creed tends to draw with it a revolution in the corporate life. And even while the formula remains to outward appearance the same, its inner meaning is almost certainly undergoing a continuous and hardly perceptible change. The words of it no longer are answered in those who repeat it by the thoughts which they once awakened. And in any case the thoughts themselves are, at the best, but inadequate representations and expressions of the one all-embracing reality, be that reality in the last resort what it may. "What kind of a universe,' cries Mr. Balfour, 'would that be which we could understand ?' It may be exaggeration to say that the very absurdity and impossibility of a dogma are the best witness to its truth; but at any rate an excess of simplicity in a theory is always a good ground for preliminary suspicion.

These distinctions-the distinction between the two functions of formulas as expositions of doctrine and as a basis for common action, and again the distinction between the formal precision of formulas as modes of expression, and the material reality of the belief they shadow forth-may serve to moderate our demands upon formulas and our criticism on their imperfections. They suggest how difficult it is to determine that element in doctrine or dogma or belief which may be truly styled immutable, which amid all variations of formula and 
explanation may be regarded as the ark of truth, the veritas vere catholica enshrined and hidden in formulas. What these 'immutable doctrines' are, Mr. Balfour does not take upon himself to say. But that there are such propositions, charged no doubt in course of time and progress of knowledge with richer and richer content, 'propositions about the real world capable of ministering unchanged for indefinite periods to the

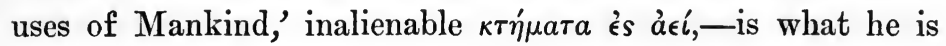
concerned to asseverate.

The fourth chapter of this part is of the nature of an argumentum ad hominem. It is addressed to those who, while ready enough to admit or insist upon the radical inadequacy of all theological formulae, are under the fixed impression that scientific statements bring us face to face with supreme reality and touch the very foundation of things. By a few pertinent questions, e.g. as to what is a 'thing,' and by some decper probing of Mr. Spencer's admissions as to 'ultimate scientific ideas,' Mr. Balfour urges the inference that, if we cannot clearly make out even what is a 'thing,' it is not wonderful that we should come short in our knowledge of God; and that, if the basis of physical uniformity is admitted to be a puzzle, some obscurity is not a wholly intolerable offence in theories about the basis of moral law.

Science cannot solve all riddles. It cannot, as represented by its theoretical exponents, even justify its own premises. But it has its place. It is not, indeed, as Naturalism supposes, the possessor and standard of all truth and reality, but it is a province and an important one, co-operating with others in the revelation of the one reality. These provinces, physical science, ethics, aesthetics and theology, are (each in its measure and kind) ' the expression of a reality beyond our reach, the half-seen vision of transcendent truth'; and the problem of philosophy is (with all its powers, be they what they may) 'to harmonize the detached hints and isolated fragments in which alone Reality comes into relation to us.' 
We have, however, not done with ' Naturalism.' It has to sustain another and a closer assault. The early chapters showed how utterly insufficient was its explanation of morality and beauty to justify the place these hitherto have held in the scheme of life. But, at the present stage, the point is, that 'Naturalism' is inconsistent with the very implication or presupposition of knowledge itself. If Naturalism is to be our ultimate creed, science or knowledge is a mere accident in the course of evolution, a chance product in the development of matter, with no claim, or at least no right, to be judged as true or false. No doubt, if the ordinary assumptions of Evolutionism are correct, 'knowledge,' since it actually exists, (only how can it be entitled to the implications of the term knowledge?) must have been advantageous to its possessors, a useful weapon in the war of world-evolution. But the rank of a critic of life or a theorist of ultimate truth it must surrender: for these, by its naturalistic genesis, it possesses no competence.

Only on one hypothesis can we emerge from these abysses. And that hypothesis is that, above and embracing us and the world, there is Being, Reality, through whom it is intelligible and we are intelligent. And if it be said that we cannot form any conception of how this one reality, this transcendently true, stands to us and the world-how it, so to say, interferes in things-the retort is easy. No more can we tell how soul acts on matter or matter on soul. Every self is in its turn a creator in the world, endowed with a creative faculty which, from the purely naturalistic point of view, is inexplicable. Nor merely from the naturalistic point of view. Mr. Balfour equally on his own part acquiesces in 'the existence of an unsolved difficulty.' The problem how man can be an agent, in tautological phrase, a free agent, is a real difficulty in psychology : but it is certainly not less intractable there than it is in theology.

Science then cannot maintain its claim to be true, to be 
knowledge of reality, without postulating the idea of something not less real, which is the harmony of mind and the world; or, if we may borrow the language of another philosophy, the identity (or unity) of subject and object. It does not of course follow that this quasi-scientific Deity is the God of religion. Yet compatible or connected the idea in both departments must be, if the problem of philosophy is to be solved, if science and religion are to be coordinated.

The incompatibility between the two departments is supposed to show itself most acutely in regard to the question of Miracles. These are understood to be at variance with the scientific principle of the Uniformity of Nature. Here Mr. Balfour, retracing the ground of his former book, urges that the uniformity of Nature is a fine-sounding but somewhat nebulous phrase, and that laws are not more than abstractions formed for scientific purposes. He urges, what is more obvious, that the modern definition of a miracle, if definition that may be called which practically negatives the existence of the definiendum, is entirely foreign to the epoch of organic religious life, and implies a division between the natural and something else, perhaps spiritual, which is no less strange to the religious consciousness. Nor is it possible to lay down canons generally acceptable as to what constitutes a wonder: for these can only be based on a prior determination of the whole meaning and scope of things, and that ex lypothesi is not in existence.

If again a miracle be said to imply the 'special action of God,' a special providence, or, in general, a 'preferential exercise of divine power,' it may be noted that such 'preferential action' seems an almost invariable presupposition of religion, and not a mode confined to special times or places. If so, at what point can we draw the limit to the range of its operation? And, on the other side, with what right dare we represent the universal God as entering into more intimate 
relation with one part of creation than another? We seem shut up in an antinomy between God as alike near to all, and as specially close to each. Nor is this a matter for religion alone. Ethics also seems to lose grip, if God is regarded as indifferent, or, still worse, as malevolent. An immoral or an indifferent God must in the long run render ethics impossible.

It would seem then that, if we assume that God is, ethics and religion require us to believe or postulate that he enters into special relations with individuals and nations; and evolution, as sometimes interpreted, suggests that the frame of things is an 'economy,' a work carrying out step by step a purpose, a striving towards something yet to be.

In short, whereas, according to a naturalistic creed, scientific, ethical, and aesthetic beliefs are simply the products of phenomenal causes or sources, non-rational, non-ethical, nonaesthetic; the truth rather is that we can only restore the balance between cause and effect, can only get a real reason for the alleged result, by postulating behind these non-rational and non-moral forces a rational and moral God. Nor is the beautiful in a position different from that of truth and morals. Beauty may be no 'objective' fact, as the phrase has it: still, here too, we may and must believe that ' in the thrill of some deep emotion we have for an instant caught a far-off reflection of divine beauty.' Religion too ceases, on the same postulate, to be a mere psychological phenomenon of the naturalistically conceived individual. 'Mankind have almost always claimed for their beliefs about God that they were due to God': or, the cause of religion must be something adequate to the given effect. And, if that be so, the distinction between the sphere of the natural and the sphere of the supernatural must be broken down. The effort, by which the human soul rises and grows in wisdom, goodness, and truth, is unintelligible without a counter-process, the process by which God continually communicates himself to man. 'Unassisted reason is a fiction.' 
All progress is the product of two factors, a divine influence and a human effort. In other words, 'Inspiration' (if the divine co-operation with humanity is to be so called) ' is limited to no age, to no country, to no people.' 'Let us not,' says Mr. Balfour, 'give colour to the opinion that God's assistance to mankind has been narrowed down to the sources, however unique, from which we immediately and consciously draw our own spiritual nourishment.'

Can we then judge between the conflicting-for conflicting in many, though not all or perhaps even most, ways they are - can we judge between the conflicting claims of various religions to authority over the lives and consciences of men? Or, putting the practical and immediate question which comes first to the occidental, by what criteria shall we determine the claim of Christianity to take precedence of a general Theism, which speaks of God only as the one supreme Reality or Transcendent Truth? The criterion, says Mr. Balfour, is found in the degree in which a religion ' ministers to our' ethical needs.' What are these ethical needs? 'They are the aspirations and ideals which inspire conduct; they include, above all, harmony between the interests of the individual and those of the community.' And that harmony, urges Mr. Balfour, can be perfectly secured only by the complete correspondence between virtue and felicity in a future life. Above all, the fundamental ethical need is to keep entire the dignity of human nature, of man's essential self, as against the mere immensity of the material universe. In these latter times 'we search out God with eyes grown old in studying. Nature, with minds fatigued by centuries of metaphysies, and imaginations glutted with material infinities.' Whether this be so, whether the causes of the practical atheism of the world are not to be rather sought in its petty cares and the deceitfulness of riches, we need not discuss. At any rate, even if speculation by itself may discover that moral excellence is for ever incommensurable with material bigness (Mr. Balfour says 
' grandeur,' but the word is out of place ; 'grandeur' is always moral), ordinary mankind can only get an ' imaginative grasp' of this truth by a history and a doctrine such as that of the 'Incarnation.' Physical science, again, as she more and more reveals the immensity of the physical universe, makes us realize more and more the dependence of mind on physical organization and environment. And if speculative philosophy here too shows the account given by materialism to be at bottom inconsistent and meaningless, it needs a visible demonstration, an intuition of the faith-inspired imagination, such as the same doctrine of Christianity presents, to transform that speculative glimpse for the mass of mankind into a lifecontrolling and life-exalting dynamic. And, last but perhaps not least, if the problem of suffering calls for all the power of philosophy to explain its function in the great whole, Christianity, in its picture of a suffering God, ' ministers to one of our deepest ethical needs.'

And, now, passing from the analysis of Mr. Balfour's contribution to philosophy, let us try to ascertain its value. Is it new, and is it true? And first, let us welcome his discovery of the function of philosophy. That function is to put together 'under the stress of reason,' 'into one coherent structure,' the contributions which art and morality, science and religion, severally bring to the expression of the One Reality. It is to systematize and harmonize the various provinces and different aspects under which the Being of Being is known, felt, perceived, and surmised by us. In the long run, a double, divided truth, a truth in theology which is indifferent to a truth in science, is intolerable to humanity. The monistic, if that means the unificatory, instinct is irresistible. To some, no doubt, the transcendent truth, the supreme reality, the infinite Personality, may have a more pleasing sound than has that pedantic term, the Absolute. If so, let them remember that the obnoxious term means neither more nor less than the others, so long as the others are kept at the 
height of their meaning, and not used as a vehicle under which casual associations may be insinuated.

Philosophy offers the great Eirenikon: a method of peace and reconciliation. If it is to be monistic, its monism must be one which leaves abundant room for difference, for dualism, for further even than dual opposition. Unity requires at least two, probably more, members of truth. It cannot sacrifice religion to science, or science to religion: nor, in its completeness, can it neglect even the rights of art. It is true that many will probably join Mr. Balfour in his view that it is forced and arbitrary to treat the ' artistic fancies of an insignificant fraction of the human race during a very brief period of its history' as important elements in building up' humanity and the spiritual world. They may, like him, think ' most schemes of metaphysical aesthetics very absurd,' and hold that there is ' no natural punishment attached to bad taste.' Yet something may be said on the other hand for those who hold that the beliefs of the cultivated races as regards the place of art in life are only the more developed manifestations of a faith, efficient and living, as early as any traces of human life can be found: that the aesthetic theories of metaphysicians are after all only the systematized efforts to trace out and analyse that charm, which lights up the dull levels of life, and of which most of us, if human, have at times felt the power; and that bad taste carries with it inevitably a lowering of tone, a confusion of judgement, a perversion of aim, than which there can be no punishment more exemplary. But, whatever may be our estimate of the function of art in life-and art, remember, is all that gives life its grace, its dignity, its form, and not a thing to be locked up and sometimes looked at in museums and galleriesit is at any rate true that, to the English public, the contrasting views of life are those derived from religion, which in some dim way includes moral doctrine, and from physical science. That there are other sciences which deal with the 
inner life, i. e. the completer reality ; that political effort and ideal is the obverse and test of morality; and that national righteousness is that without which individual righteousness is a puny and diseased thing-these are points which a few realize, and which many painfully surmise. For the most, however, the antithesis is set, simply and solely, between religion (or theology) and science. And because it is so set, without due regard to the environment or context, it is set falsely and foolishly. There have indeed been times when the conduct of the so-called theologian, in adjusting religion to scientific advances, has reminded one of Miss Matilda Jenkyns and her friend in protecting the colour of the new drawing-room carpet. The sun in its course blazed through and down on a strip of the Brussels, and the ladies spread newspapers to shelter it from the withering ray. But as the sun gradually moved on and on, the newspapers had to be again and again taken up and placed on a fresh patch of light. It is certainly not so that Mr. Balfour understands the reconciliation. Each has its place. Science, such is his plea, ' can only do what it claims to do,' i. e. ' reveal reality in its special way, if it presupposes a theory of existence, very like that which in its ultimate premises constitutes the base of theology. But reconciliation thus acquired, through identity in fundamental principle, is far from interfering with a wholesome growth of either separately. As someone has said of its relations to theology, 'non adjutrix nisi libera, non libera nisi adjutrix philosophia.' 'In its labour,' says M. Sabatier, 'the human race builds an eternal cathedral of which the two main columns (colonnes maîtresses) are science and the holy life (la vie sainte). They spring slowly from the soil, and rise parallel in the air. Amongst the workmen who labour at this divine work, some are discouraged and fear the two columns may never meet and form the vaulted arch they dream of. Others, impatient, inflect the severe rectitude of the lines of the construction, but the 
false and apocryphal work they thus make, is self-ruined and self-demolished, because it violates the rigour of the mysterious plan of the invisible architect. The religious worker is humble: he guards himself against the impatience which makes us faithless, and the discouragement which makes us cowardly. He lives by faith, not by sight: he raises the two pillars of his inner life in obedience to the prescribed rules, knowing that his duty is not to make them arbitrarily converge and join before the time, but to build them stone by stone, higher, straighter, more solid. Science is only positively served by those who with all strictness apply the laws of scientific research. Similarly, we advance in the moral life by an undeviating obedience to the ideal law of conscience '.'

Mr. Balfour therefore has risen to that idea of philosophy to which Schelling and Hegel, following out the suggestions of Kant, have given its characteristic modern form, but which has really been the underlying aim of all the higher modern, as it was in a great measure, of ancient speculation. We can hardly indeed apply to Mr. Balfour what the aged German poet, Fr. Rückert, has dared to forebode (1864)-

\footnotetext{
- Was Kant hat angebahnet, Was Schelling vorgeahnet, Was Hegel ausgeschliffen $\mathrm{Zu}$ glänzenden Begriffen, Bis es ward ausgepfiffen, Es wird aus der Veraltung Gewinnen Neugestaltung In höherer Entfaltung.'
}

That prophecy still awaits its fulfilment, when it shall come : yet before it comes, it is necessary that the doctrine shall sink as a simple rudimentary form into the common stock of culture. As such, its appearance in a work like Mr. Balfour's is a welcome symptom, that the general standpoint of

${ }^{1}$ A. Sabatier: Esquisse d'une philosophie de la religion. 
philosophy is finding its way to the heart of the nation, despite the uncouth tongue in which its oracles are written. But, before this very general idea can be the principle or the foundation of beliefs, it must explicate itself into something less indefinite and scanty. It is not enough to say that four, or it may be more, provinces must combine, that their several glimpses of reality must be reconciled. A good deal remains to be done before the terms of union are to be defined. Are the provinces or faculties co-ordinate? Are they mutually corrective and complementary? What are their several tasks? To answer these questions is to indicate the foundation of belief: and in common phraseology it is to write a philosophy. A provisional philosophy will not answer the purpose. Provisional, of course, every philosophy is, in a sense : each exists only until there come a better to supersede it. But it must not build, on that account, a mere shell, perfunctorily: it must do its work with all its heart, and soul, and strength, as if it built its house for eternity.

Of all this positive work, to which contributions have been made by many, here and elsewhere, after Kant had mainly concerned himself with the critical and negative task, Mr. Balfour does next to none. He simply does for the English public what Kant had already done, but, according to him, had not by his interpreters and commentators succeeded in teaching to the average insular mind. Whether there are not more who have ceased to bow the knee to the Baalim of Naturalism than Mr. Balfour suspects, is a question we need not discuss. Yet to have impressed upon the public that philosophy is the way to a complete theology-not, we need hardly say, to religion-is a service which the religious bigot, if such there be, may rate less than lightly, but which most other people can only welcome. Our thanks would have been less mixed, if Mr. Balfour had not, to generalize his own confession, 'found it easier to satisfy himself of the insufficiency ... than of the absolute sufficiency, or any of 
the schemes by which it has been sought to complete or modify Naturalism.' That is the weakness of a man who possesses considerable faculty of dialectic and enjoys the zest of debate, and whose instinct is to look for weak points, pulling a complex theory to pieces by piece-meal attack. It is no doubt the accredited method of parliamentary warfare, but even there its results are hardly so pleasing or useful as to lead us to desire its extension to the more serious problem of philosophy.

When Mr. Balfour again urges that ethics, aesthetic and science, are only retainable in their truth, beauty and righteousness, on the hypothesis that behind the phenomenal process of sensation and movement there is an encompassing ' reality,' if that is to be the word for the presence and power of the Idea, we can only say that we are glad to see that the fundamental dogma of Platonism still serves to the rest-andshelter-seeking soul as the shadow of a great rock in a weary land. Plato too had to fight with the champions of what Mr. Balfour has called 'Naturalism.' To them the whole fabric of moral, aesthetic, and spiritual ideas was a matter of physical history : thought was a fact of brain-movement, and beauty a growth of associations, generated out of what was utterly without aesthetic quality. The naturalistic theory of life was as complete, if not as detailed, in Athens in 400 B. c. as it is to-day. And against that theory Plato lays down his axiom that ! it is by the beautiful that things beautiful become beautiful,' and that knowledge would not have been at all, had not things and perceiver been at one in

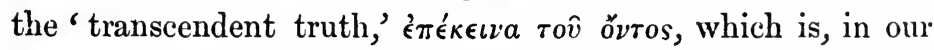
modern phrase, at once real and ideal, and so above either alone. In other words, you cannot completely explain the higher form by the lower elements; a true synthetic unity is not a mere product or sum of its elements: it is unique; and they are, at best, its condition, or in an older phraseology, its material, but not its final or formal, cause. To use words 
like sum or product, is simply to ignore a principle of organization, a law of crystallization, which rules and manipulates its constituents. You trace, scientifically, the gradual evolution of form from form: but, behind the facts and results, is the agent and the life, the idea in its efficiency, the substance of Spinoza, the Absolute of Mr. Bradley, the Reality of Mr. Balfour, infinite, ever-new, ever-creative; never a mere putter together of the old, but with the old materials, by a cosmic and divine phantasy, creating the new. Its syntheses are more than syntheses: they are at each stage a new birth : a fresh revelation of the infinite spirit of life, the life of life, the cause of causes. Yes, here too, we miss a deeper view. The religious mind, as well as the scientific and the aesthetic and the moral mind, each are jealous of their own : the reality behind science stands awful and grim in presence of the ideal of art, the God of religion : and this introduction to theology does little to bring them together. When Mr. Balfour points out that, behind all the variety of formula, and all the imperfection of dogma, there are ' immutable doctrines,' nourished on which men have lived and died in hope, faith, and love, the philosophy which I have learned from is agreed. But it would hardly be satisfied with the mere confession-of an unknown God. That is a hopeless search for God and reality, which is seeking him in an ever receding reality behind and beyond phenomena. Phenomena too are of God, nay, in their place and function, they are the visible and sensible body of God. Sensible matter too is part of the immutable doctrines. It is not, as Mr. Balfour seemed to say, a mere 'irrelevancy that the material body, the material world, stands with a pre-eminent reality.' Far from it. The whole spiritual, the aesthetic, moral, religious life, needs the body; and with a bodiless, a disembodied spirit, it ceases to have meaning, reality, and power. You have heard what Mr. Balfour has to say of the power of Christian dogma of Incarnation to fulfil our moral 
needs. To my mind the central value of the doctrine of the Incarnation is to teach that all men, as they live and are, are sons of God; sons, some of them prodigal, and some conceitedly goody: but all, if they would but know it, and' knowing, realize it, sons of God; with the Godhead in spirit within them, suffering, enjoying with them, their bodies temples of the holy one who inhabiteth Eternity. The eternal reality is in it all : God is in it all : not, as Mr. Balfour seems to think, alone by himself, enjoying an unchanging beauty of which we can only catch glimpses, but with us and in us, suffering in us and with us, the eaptain of our salvation, the firstfruits of many brothers. We,-if I, a mere disciple, may speak for the great masters of those who know,take the Incarnation as no mere temporary fact, but as the eternal truth of human life and history. We can rise to the poet's words: 'Lady, I fain would tell how evermore thy soul I know not from thy body, nor thee from myself, neither our love from God.'

Not less is Philosophy in general agreed, that the true test of the truth of a religion is its capacity to satisfy our ethical or moral needs. It would, perhaps, hardly be content with a mere phrase, which is left open for interpretation by each private sentiment. Still less, perhaps, would it, like Mr. Kidd and Mr. Balfour, regard the consilience of individual and social interest as the only nameable moral need, or treat a future life, a vague word, as clenching the need. It would probably take a different view about the place of punishment, and it would certainly note that moral conceptions of the future life were the fruit of moral life. But it would in the main agree to accept Mr. Balfour's thesis. Only I think it would put it in a less restricted phrase. It would hold that we are primarily and essential beings who have to act, to be agents. We are, as it were, endowed with a problem, enriched with a task-the task to live. It is only by slow degrees that we gather all that it means, that we see what 
we really and truly will. All experience, all science, all association, all suffering and joy, show it more and more fully. But always it stands behind and before, above and within, a light to our feet. Plato called it the idea of good; the Gospel of St. John calls it ' the light which lighteth every man that cometh into the world.' 


\section{VII}

NATURALISM AND RATIONALISM. - THE SCIENTIFIC

AND THE PHILOSOPHICAL POINT OF VIEW.THE MAIN CONDITION OF THE EVOLUTION OF REASON

As interesting range of questions is opened out by what is said in Mr. Balfour's Founlations of Belief as to the nature and function of theological formulas, as to the respective place of Reason and Authority in forming beliefs, and indeed as to the general scope of the two cognate habits of mind or attitudes of thought which have been styled Naturalism and Rationalism.

Perhaps there are few things more noteworthy, and yet few things more neglected, in the study of the history of human thought, than the tendency to accentuate the points of partial difference and to ignore, as if taken for granted, the deep and broad bases of fundamental agreement. Each great philosopher-an Aristotle, say, succeeding a Platobuilds in his turn upon the uncontested and accepted body of doctrine and belief which is common to him with his predecessors. For that very reason he says little about it. What he lays stress upon and, to the careless reader, seems alone to think essential, are certain favourite ideas of his own, certain peculiarities of definition and detail, which are his peculiar work, and which pass into history as the essentials of Aristotelianism. So things seem from the outside. To 
a profounder study Aristotle is himself a Platonist, sharing the deepest convictions of Plato, but, like a true and perfect man who is never a mere imitator, carrying the germ out into the fulness and integrity of an individual system, without which discipleship is a sham and a snare. It is not so merely in philosophy. It is a general law that what counts at first sight is difference. When we measure our income and our resources, it is not wholly what we are and have that gives the habitual tone to our mind. What we see as ourselves in our mental vision, what we think others will estimate us at, is the differential amount between our estate, our endowments, and theirs. The nearer the fundamental equation of what we are and have with what others are and have, the more keenly do we set store by our petty prerogative, in that imagination of compared dignity which haunts us like a demon. It is not always his poverty that makes the poor man's hardship : it is as often the sense that he is poorer than others : poorer, above all, than others he would otherwise have matched.

We may apply these principles to the judgements which we have heard passed on Naturalism and Rationalism. An '-ism' is by its inmost being always in opposition. It marks a protest against a feature which is believed to be erroneous and injurious. As it thus emerges, it is no complete theory of the subject with which it is chiefly concerned. On the contrary it subsists only because it has tacitly taken over into itself, and accepted without question, the great bulk of the general creed or system against which it raised a partial objection. Utilitarianism e.g. protesting against what it considered an irrational, ascetic, or sentimental vice in the dominant formulation of ethical doctrine, still, in the first instance, accepted the general lines of moral order and progress. Socialism, again, as it first appeared, was no comprehensive theory of the ideals and methods of collective life, but chiefly a criticism of the chief evils of a disintegrating 
individualism and a suggestion of remedies. But it is easy to see that things cannot so remain.

In the first place, a struggle inevitably arises between the old and the new. From some points of view the new is obviously at disadvantage. It is the theory of a partial point of view, and as it steps beyond its original limits, it is almost sure to fall into inconsistencies, and make mistakes in extending its principles. On the other hand, it is generally backed by an enthusiasm and eagerness, which is only intensified by anything that suggests the superiority of strength that lies at the command of its opponent, the established authority. It is inclined to credit itself with all or most of the truth, and leave only force to its opponent. The older and larger body of doctrine, again, is apt to attach too much importance to formal and logical inconsistencies, and to forget that there may be much in the new formularies which those who hold them read, so to speak, between the lines, but do not think it needful to express. But in the struggle it is almost certain that each party will exaggerate its differences. Forgetting altogether the many points where it might well admit ' he that is not against us is on our side,' each concentrates its view on those apparently cardinal issues, in which it can raise its battle-cry, 'he that is not with us is against us.'

Now the Rationalism, which we heard described as an embryo Naturalism, is under that historic title mainly a product of the eighteenth century. In its origin it was the continuation of that protest against the men and works of darkness, which Ulrich von Hutten waged by the side of Luther, the war against superstition, idolatry, obscurantism. But as a great authority reminds us, it is hard to pluck up the tares without destroying some good wheat. You cannot, i.e. the race of man cannot, draw a hard and fast line where the true worship of God gives place to superstitious idolworship. It is not merely that good and evil grow so closely 
side by side : that were a minor difficulty: but in most of human life it is hard to say where good does not grow out of evil, and evil out of good. It is only the sword of God, which pierces to the dividing asunder the bone and the marrow, that can discern the secrets of life. A too ardent assault upon superstition may itself become a superstition, and a baleful one, for its champions.

But for that fault it was not the Rationalist who was mainly or solely responsible. The least concession was refused to his claim for more light. He was commanded to bow reverently to the ever-revealing Church, or to the revealed Scripture. In the presence of these oracles reason must be dumb. There is a vulgar proverb to the effect that, if you ask for a silk gown, you may get a sleeve. As the Rationalist was given little, he naturally came to demand more. When it came to the time of Voltaire, the cry Ecrasez l'Infame, which originally only meant a demand to clear the temple of thieves and money changers, came to be the ominous threat of a clean sweep of all that Christianity held and holds most precious. Nor that alone. There were heard mutterings: Ni Dieu ni maître: down with all absolute irrational authority, be it in realms secular or in realms sacred. And all this, just because the cry for light was gagged, because the stream of reason was stopped by a great dam piled ever higher, until the stream, gathering into itself the myriad impulses of human nature, high and low, became a wild flood that for a while swept all institutions into ruin.

So it is with Naturalism. It in its origin was the protest, not against the supernatural in itself, but against a supernatural conceived as arbitrary, incoherent and chaotic : it was the protest against the idle profanity which thinks it has explained an event, when it has said, with pious gesture, that it is the work of God,-as if aught were not the work of God. Naturalism is not the antithesis of theology, as Mr. Balfour has assumed, though a vindictive theology has 
often pushed it into such an attitude : nor is it the assumption that the beggarly elements of sense-perception are enough to frame for us the picture of the world, though, a foolish Spiritualism has often driven it into the arms of Materialism. Naturalism and Rationalism must not be judged solely by what they are at the worst, in the hands of sciolists and polemics; they must be judged altogether, in their worst and their best, in the principles which at first gave them direction not less than in the course which through the intermixture of effects they have occasionally taken. It is an easy-going Rationalism, unworthy of the name, which thinks its only function is to knock off corners, and smooth inequalities. 'What,' cries Mr. Balfour, 'would be a world which we should understand:' or, as I suppose, which we had thoroughly understood? A world, clearly, without interest; the den of listlessness and dumb despair: or rather the iceage of humanity, when to be and not to be would for once be absolutely alike. But, on the other hand, what were a world which we did not understand, had not in any measure understood? A world full of fears rather than hopes: a perpetual uncertainty, a grisly mystery, which made darkness cover the earth, and gross darkness its peoples. The world which reason claims is one where she may go for ever on and never die : a world where nothing can be called utterly unknowable, though much may remain for ever unknown: a world where, as humanity accumulates more and more its intellectual and spiritual capital, we shall move about more and more freely, i. e. more and more wisely, as becomes those who are called to inherit the kingdom. The world which the genuine Naturalist desires is not different. It is a world of law : but in the ideal sense law in Nature is even as law in the social sphere. To the beginner in sociological study, laws are an aggregate of commands of a general character, set by somebody who can command to others, who will by some means and to some extent be constrained to obey. To the idealist-you will find 
him in antiquity amongst the great Stoics of the middle period (as may be read in Cicero) - to the idealist, law is one system, one economy carried out in different grades, all mutually interdependent, whereby the right working of each member of the community may be attained, whereby each may not only do his duty as past ordinances have appointed, but may find an outlook and a stimulus to conceive and execute ever fresh, ever higher codes of duty.

So it is also with the world of scientific law. The older scientists looked upon laws as so many ascertained uniformities of sequences, regularities in the succession of cause and effect, which, as they grew more numerous, admitted of codification, and some degree of system. The net result of them was a hint to man in his practical endeavours, that certain things can be done, certain others cannot be done. The reign of law was thus a disguised reign of force : it seemed to consist of a network of checks spread over the whole structure of the universe, as so many barriers within which God, it might perhaps be said, had tied his own hands, as well as limited the possibilities of man. On the other hand, the idealist viewwhich has always lurked at the heart of religious faith, though often strangely marred by foreign concretions-looked at the future rather than the past, at what was to be, rather than what was. Put religiously, it subordinated the creational (taking that term in its narrower sense) idea of God to the providential. It looked at Nature as, not merely what was and is, but also as what will be. It regarded the universe (as Goethe has pictured it in that series of aphorisms which he drew up under the stimulus of Frau von Stein's charm) as at once Natura naturans and Natura Naturata, as an organic community, an ideal, or as St. Paul might call it, a spiritual body, working by myriad ways to an end which only gradually reveals itself, and using methods or modes of operation, which in parts we can discern, and when discerned we call laws. The reign of law has here become, if not the 
reign of grace, at least the kingdom of the spirit. All its special laws are but fragments, from time to time abstracted and isolated, which enter into the one unity of organization. Nor dare we set limits to the possibilities of that organization. If we exclude the old conception of miracle, we exclude equally the conception of inflexible rules to which God must bow. And if we could rise to the height of beatific vision, which is difficult, not to say impossible, we might, turning round Browning's words, say, 'All 's law, but all's love.'

This is a long way from Mr. Balfour's Naturalism. But it has an equal right, nay, a far better right, to the name. It is the Naturalism that full-grown science seems more and more brought to adumbrate. Mr. Balfour, 'for reasons with which it is not necessary,' he says, ' to trouble the reader,' has selected the name Naturalism for what might equally have been styled Agnosticism, Positivism, or Empiricism. When reasons are concealed, it is improper perhaps to surmise them. And yet it hardly seems going beyond a legitimate inference to suggest that the name was chosen as a way to deal a more crushing blow. To assault Naturalism and Rationalism is to strike Nature and Reason : it is to support Supernaturalism, and the Materialism of authority. It looks a little like seeking to wound an opponent by an insult to his beloved.

But, as old Socrates pulls himself up, and admits that when he saw his love Philosophy lightly dealt with, he spoke somewhat vehemently; so here we may admit that after all Mr. Balfour does not mean it: it is only an incident in the polemical debate.

To the superficial glance, the history of philosophy seems to be a mere succession of opinions, contradicting or controverting opinions that have gone before, and to be in turn contradicted by opinions yet to come. On a deeper view this contradiction is a phenomenon like the supersession of the flower by the fruit. For the plant's life under all apparent incoherence is one process, continuous, incessant, in which 
one plant soul creates for itself a body which is ever chang-. ing, yet which in some sense ever remains identical with itself. So, reasoning by analogy, the annals of philosophic failure need not unduly depress us. It is, says Mr. Balfour, the common lot of philosophies to fail. Even so to the rash judgement is every human life - and the greater its scope and task, the more decidedly - a failure. It comes with promise of peace and good will, and when it is over, it seems to have left a sword that pierces ever deeper and deeper into the heart of humanity. It bourgeons out with the fairest flowers of art and letters; and yet, as the times roll on, these flowers seem to corrupt, till the air is too heavy and poisonous for men to breathe it and live. It founds a great and glorious empire in which social energies should find all room for their ameliorating play, conquering and to conquer; and the political grandeur is there only as it were to intensify and accelerate the ravages of the cancerous growths under the sleek and prosperous surface. It spreads the light of science; and the chief use of the new weapons science prepares is to rend asunder the fabric of social well-being.

And yet it would be rashness, on the strength of these appearances, to pronounce a verdict on human life, on the efforts of science, art, religion, and law, which would echo the merely pessimistic cry as if failure were all. 'Thou fool,' says the strong-hearted apostle, ' that which thou thyself sowest is not quickened except it die, and that which thou sowest, thou sowest not the body which shall be, but a bare grain ; and God giveth it a body even as it pleased Him, and to each seed a body of its own.' Take this phenomenon of life by death and death to life, as it shows in our own inner and individual life. The resolution which (we often can hardly tell how) emerges into the light of rational volition, must, before it issues in outward act, plunge, first, into the warring mass of other impulses, which, awhile silent, as if they had yielded up the ground, only its existence 
stimulated into activity; and then, as it reappears, altered and complicated from the struggle, it must again plunge into the seething mass of outside efforts, the surge and swell of the adjacent world, to re-issue with the body which the providence of nature and history has been pleased, we cooperating, to give it. To us, the spectators of our own selves and of outward event, this drama, this Divina Commerlia of human life, presents itself so. We have hardly formed our resolve, when we regret it: the voices of our other selves, of that manifold pack of half-formed personalities within us, none of which we dare honestly disown, are raised in protest against the usurping monarchy of our overt resolve. The democracy, or shall we call it the ochlocracy, of passion and appetite has to be heard and reckoned with; and a struggle arises, of which the issue is a modification and enlargement, for better or for worse, of the original purpose. It is the same with the outward act. It never is exactly what we meant it, and as we meant it. We are disappointed and discouraged by the event: and often it seems as if, the higher and purer our aim had been, the greater had been the discomfiture in our achievement. What do these things teach us? First, perhaps, that we must not judge what manner of men we are by the thoughts and resolves that come to the surface in our hours of clearest vision : that we are not the simple and straightforward units we fancy ourselves to be, but rather an undulating and varying unity of impulses and powers, growing slowly by effort and discipline into the unity of the perfect man. And secondly, that we, however original, personal, individual, or monadic we may be, are still units circling in, penetrated by, and fulfilled with, a larger social life, a common, it may be, national spirit, which is at once outside us and within us, at once containing us and contained by us, on which we depend, and through which we gain such independence as can ever be ours.

It is a mistake, therefore, and a fateful one, to isolate the 
phenomena of life from their context. Falsus in uno, says a vulgar adage, falsus in omnilus. One error entails another, one lie involves a second, to try to cover it. So undoubtedly it in part is : and so it would for ever be, if life and humanity were what some people call logical, if pedantic consistency were the rule. But the world is not in that sense of the term logical or reasonable: though in a larger sense, and with a more generous scope, it may still be called logical and reasonable. To be reasonable is, in the full sense of the term, to be human : it is to cling to and follow after unity, but not always to ensure mere consistency. The function of reason is to seek totality, to be comprehensive. It is more than abstract intelligence; it is the faculty of ideals, the faculty that dreams of and tries,--of course never quite successfully, and let us add, never without some success,- to give completeness, system, rounded perfection to our lives. It soars beyond science, because it springs from an impulse larger than that which brings science to birth. It has been said to be the purpose of science to find a theory of nature. That is a scope which can only be claimed by science, if we give to science a very wide meaning. Science, as such, in its actual performance, has a humbler scope, a more practical and more practicable aim. And this aim is,within certain ranges approximately and roughly marked off, under certain conventions, and with certain hypotheses which work, i.e. admit of experimental treatment and confirmation-to constitute a system of coherent relations, of unvariable sequences and unconditional causality. For science, properly speaking, there is no Nature: Nature is to science a poetic, artistic, or metaphysical word. A science deals with a group of phenomena, roughly demarcated by common sense, and seeks to organize it into a system of coherent relations; which, it may be added-in case some one may dream that you can have relations by themselves-include things related. Such, at least, is the scope of all the positive sciences. 
The scope of ideal science or philosophy is quite other. In common talk, indeed, it is often implied that the science of the ideal is only a generalization or an extension of the positive sciences into a region where they grow large, but at the same time vague and fantastic. But in truth, philosophy is no mere sum or generalization of the positive sciences. It is a view, or attempt at a view of Nature, i. e. the whole sum of facts, lived, experienced, and believed in their unity: it is the fulfilment of the task which, according to Bacon, is appointed to man, to be the minister et interpres Naturae. That is more than the special sciences do or profess to do: it is the work of a science, which is ideal no less than positive; a science which includes art, religion, and morality as its handmaids, but handmaids who are maids of honour and not mere helps in the kitchen of humanity.

Thus reason is the principle of unity: but of a unity which works through, and in, diversity. The dispute between reason and authority as to priority and posteriority is one which may be paralleled with another more notorious controversy. Did the hen come first or the egg? To answer it, let us ask how reason arose, and what it works : let us ask what authority means, and not content ourselves with vague nominal oppositions. Just because reason is so often opposed to authority, they must have something in common, were it only some common subject to dispute. And, indeed, a quarrel unites as surely, and the cynic may say, more closely and permanently, than a friendship. Indifference, presumably, is not union. A certain propinquity of interests, a community of purpose, is needed for a vigorous opposition. Nay, may we not further say, that in many a case we quarrel more fiercely with others, just because they say out aloud something which we would fain keep silent in ourselves; and that the rage against the enemy outside is only the evidence of an inward struggle in our own breast, which we have failed to quench? 
Now what is the fundamental feature of all reason, of all ideal forms? Surely this, that they rise from us, seem to be our offspring, nay, perhaps, our product, and yet, without any warning, turn round and lord it over us. Take conscience : it is, says Butler, a principle of reflection, it is our act of judgement: and yet it claims (and we cannot help in a sneaking way admitting the claim) to be the voice of God. Take fashion: it is a whim to which we seem to give currency by our own act, and yet it plays the inflexible despot. We calmly speak as if we made the laws, and talk of ourselves as law-givers and law-makers; and yet the law rules in its own right. We love, and it seems the expression of our freest personality; and lo, we have forged a chain which, whether agreeable or not, binds us for perhaps a life. We act purposely; and it seemed free for us to do or to abstain : yet the deed is an irrevocable master; the gods themselves, says the Greek proverb, cannot undo what is done. Even the light word, to which we unthinkingly give voice, may one day chastise us with scorpions.

How can these things be? Are we really so little lords of ourselves as they seem to show? Can we only assert our freedom in order to throw ourselves into a more effective bondage? Whence came this reason? Reason, we have lately heard from Mr. Kidd, is individualistic in the uttermost, the weapon of disintegration. When we say, 'Come, let us reason together,' it appears that we mean (not, as the men of old time thought, 'Let us try to agree, and remove the stumbling-blocks that cause jars between us ;' but, in the modern language), ' Let us dispute and divide.' Now it is simply impossible to allow any one thus to play the fool with language. No doubt, if the thing had been done long enough ago, the rose might still smell as sweet had it had another name. But as things are, names have been preoccupied, and to play false with them is neither more nor less than stealing. And stealing a good name, as Falstaff 
tells us, is a more serious crime than stealing the trash that is in our purse. It is a kind of treason to humanity : Nomina numina.

Is reason then a private property of the individual? Is conscience, is soul, is love? In one thing Mr. Balfour is quite right: the higher spiritual life with its beliefs is not explicable from the physiological or biological individual. In that biological framework and function, as every one is perhaps aware, we are of elose kindred with the animal world, and, eomparatively speaking, of very close kindred with certain members of it. We know that every human being, as an embryo in his mother's womb, runs in a few months through, we may almost say, the whole scale of animal life. An ancient Greek sage, of supposed mystic tendeneies and oracular utterance, told in some verses the story of his life, as he passed, still one soul, through various animal forms, in sea, in air, and on land; and people thought him moonstruck. It is now received as the soberest scientific truth that each of us-and in the lapse of no long time, as measured by the horologe of our daylight world-has rum through a eareer more romantic and strange than old Empedocles or Agrigentum probably ever dreamed of. We are-and the less we forget it the better, the higher we may learn to become-we are, in the substantial framework and function of our being, animals, comrades of the dog, the hare, the ape, and the tiger. They seem sometimes far apart from us, brutes at the worst, poor relations at the best. Now that-I do not say, wisely or unwisely-we have concluded that we are made lut a little lower than the Elohim, and no longer see angels as an aristocracy of ereation above us, but fancy ourselves as its foremost rank, we are apt to forget that the difference between us and the nearest mammals sinks to at least apparent insignificance in comparison with the gulf between them and the amoeba, an apparently amorphous, structureless mass, or rather molecule. 
The evolution of reason, of authority, of morals, of art and religion, that is the problem. I spoke the other day of the birth of a soul. I may come later to speak of the birth of conscience. What is it that we can expect to find in this mode of enquiry, in this path of evolution? There was a time when the word for the new birth was creation. But the word was a little too abstruse for many who employed it, and it led to strange fancies of a superhuman man mocilding creatures out of nothing. With all this confusion of vulgar imagination, the philosophical conception of creation had nothing to do. Something of the same confusion has infected the modern term Evolution. Evolution has been taken to mean a process of continuous change by which, if you only give it time enough, an A will some day turn into a $\mathrm{B}$, an oak become a beech. So once on a time the chemists-but at that time they were called alchemists-had the fancy that, by some method of manipulation yet to be discovered, iron or one of the baser metals would be transmuted into gold. The alchemist saw transmutations of a kind going on everywhere in nature, and with a judgement perverted by the lust of wealth, he came to look upon all the mineral kingdom as a range of steps which, if we could only get the secret of transmutation, would bring us nearer and nearer to its final head and supreme development, the royal Gold.

A similar frenzy seized some biologists at hearing the idea of transformation of living beings. The whole kingdom of animals presented itself to their minds as one continuous development from some primary organism which, allowing sufficient variation in circumstances and sufficient length of time, might become, to put it briefly, anything in the possible range of animality. Now that this is possible or impossible, I am not concerned to say. The very word impossible, indeed, is not one in favour with sensible men, and is one that science will rarely use. Perhaps, like Napoleon, the 
sciences may call it 'a blockhead of a word.' Science, i. e. human knowledge of facts and laws of fact, can ascertain to a certain extent that something has or has not been done. But to pronounce that it cannot be done, is what it will only do with the qualification: 'so far as we at present know.'

This holds in the region of biology as it holds elsewhere. Transformation of animal form and function within certain limits has long been a fact of common experience. It is hard or, as things stand, impracticable, to lay down definitely where these limits lie: they are often very elastic; how elastic, we dare not forecast: but all experience tends in the direction that there are limits, and even impassable limits. It is easy, but it is frivolous, to say that we can place no limits to the power of adaptation which we actually observe. Such a style of argument is after the fashion of the man who, finding his horse did not perish under a gradual reduction of his corn, proceeded with a so-called logical mind-it is the logic of the fixed idea, and common amongst the insane-to maintain him on no corn at all. We cannot place the limits, perhaps, but the limits may be there. All observed variation in present nature, or in the historical process which palaeontology partly reveals, takes place within limits : and if the limits in the data afforded for long past ages by palaeontology seem wider than those exemplified in the present day, perhaps we may be permitted to suggest that the evidence of the geological strata is a matter which has not yet received its final interpretation, and should not be put too much in the first brunt of battle. Evolution, in short, is at present a working hypothesis. If any one asks what that means, it need only be said that, by the assumption that all living things may be conceived as forming links in a continuous chain of life,-instead of being taken, as the casual observer might suppose them, to be merely diverse and apparently unconnected,--we get a point of view for biological 
study which both suggests wise and far-reaching questions, and makes it more easy to find answers. More than this the Darwinian theory need never become: but this is quite sufficient for scientific work; though perhaps not enough to gratify an ignorant and aimless curiosity, which would get behind the beginnings of things, and, so to speak, see them as they were before they were made.

The fact, then, which biology would seem to start from, is the probability that man was once, when no one knows, a creature in all appearance and in all structure very like an ape, a creature closely allied to certain species of our existing quadrumana, but yet somehow sui generis: a unique ape, an ape which really was not an ape as we know apes, but which had in him the promise and potency of humanity; just as the human embryo of to-day, though in its earliest stages it reminds the observer of certain animals, has in it, whether the anatomist can detect it or not, a je ne sais quoi which determines it to be man, and nothing but man. The startingpoint is, you observe, not entirely a fact : but it may fairly be called, from the biological standpoint, a plausible and workable hypothesis. There was then a time within the present century, when each of us, man or woman, so far as all the experimental tests could tell us, was the very negation of all we as adults claim to be: a time when for us speech and thought, reason and morality, all the distinctive peculiarities of human shape and structure, were not. As in the old story of the creation of the terrestrial globe, so there was a time when we were 'without form and void': an amorphous, inorganized mass. And yet shape and organization were there, though our organs and even our instruments failed to detect them.

It is in that sense and with these limitations that I speak of the evolution of reason or of morality. I can attach no meaning to the statement that reason or morality was made out of something utterly other than itself. Non-reason does 
never beget reason, nor does non-moral beget moral. We may possibly lay down the conditions, the circumstances, the occasions, which facilitated the event, its sine qua non. But the secret of the first birth, the secret of life's emergence at conception, the mystery of origins, is well kept. Still, now as of old, each birth is a creation. We have learned-thanks to Darwin, and, as I am more especially bound to add, to others before Darwin - that creation is a process law-governed, a work of reasonable not arbitrary deity; that the whole organic kingdom is a systematic unity, the unveiling in time and place of one grand plan. We can guess with much probability the scheme of architecture, but we have not forced the hand of the architect, and stolen the secret of his work. We are, to him, in a position not unlike that of the grammarian and the critics to a great original genius in poetry or painting; we can catch, or deem we catch, some of his tricks or his mode of composition. But Raphael and Dante are always on another plane than their imitators, and He that sits in heaven may perhaps smile at those who so boldly identify the way they construe his plan with that plan itself; or who fail even to surmise-and this is the important thing-that $\mathrm{He}$ is an architect who draws no plan and directs no workers, but is himself the life that inspires the worker and the source that supplies the work.

It is the evolution of the human mind we study, with reason as its governing function, with morality, art, and religion as its characteristic products. And that means, when, and under what conditions, can mind be seen emerging? In what atmosphere did it draw its breath, from what parentage did it spring? The psychologist who analyzes mental phenomena assumes mind as a given fact; or rather for him the soul is a geographical term, used to denote the range within which certain phenomena which he describes are to be found, and sometimes equated with the sum or aggregate of their phenomena. The comparative psychologist will show 
us-by a process of guess-work and more or less plausible analogical interpretation of stories of animal life, of movements executed by animals-how in the animal world with varying degrees there are indications of the presence of several of the faculties found in man. And these comparisons are very interesting, if always a little liable to the defect of alternative interpretation. But we must go a little further than either of these, and ask: When or under what conditions do we first observe the human, the rational soul?

The answer briefly is-and the same answer will apply to morality, art, and religion-that reason is a social product: it appears and lives in human association. Just as cohesion, or electricity, or any other material property only exhibits itself in a correlation of elements, which are at once antithetic and interdependent: so the human soul is a phenomenon which appears and lives in the sociality of human beings. There is doubtless a sentiency which is part of animal nature in general: but even it, we may note, only exists in a great community of physical life. The specially human soul is a social fact, the resultant and index of a social effort. Society, the reciprocity of man with man, is the atmosphere in which it breathes, the soil in which it grows. Man, the individual physiological being, exhibits in association with his fellows the products we call rational, moral, aesthetic, and religious. And it is only man, not all animals, that does so: a statement which need not be pressed to exclude all approaches to reason in the socalled lower animals. Hence we conclude that in him there is a something which in the appropriate environment will so develop. The soul is his potentially, let us say: and yet it would never be actual-any more than hydrogen and oxygen, of their separate initiative, form water, without some constraining agent-unless another soul were to be made at the same stroke.

To some it may sound a paradox to say that reason is not of the individual, as such, but only of the socialized or 
civilized individual. It is not so long ago that indignation was lavished on the anthropologist, who dared to hint that primaeval man in his birth-time had been speechless. And yet the obnoxious fact reveals itself afresh in every human infant. The doctrine that reason is the concomitant of sociality is a common one to philosophy. Hear Hobbes: 'Reason' (which he defines in his rough way as conceiving a sum-total from the addition of parcels, as in short 'reckoning') ' is not, like sense and memory, born with us, nor gotten by experience only' (by experience Hobbes means 'the tear and wear of life '), 'as prudence is, but attained by industry.' Hear Fichte: 'Man would not be rational or human, were he purely isolated and unsocial.'

Let us not, however, misunderstand. Juxtaposition, association, in and by itself, could yield nothing. But where there is a something-which however we do not know in itself, and can only discern in its effects-this association leads to a new development: it is the meeting of energies which causes birth. The human being, to put it in materialistic figures, is charged with force, energy, faculty: but energy requires solicitation from without, to bring it into exercise and actuality. The human individual, as such, is to all appearance simply an animal: primus inter pares, perhaps, yet still only amongst his peers. But under that appearance there are in him possibilities of unique energies. There are tendencies and potencies craving to meet each other, and to link hand in hand, heart in heart. All the various ranges of Nature live, if we speak the religious language, under some special dispensation of God: in scientific phrase, they have each their own law of development. The specific law of human existence is sociality. It is that which makes us human beings. The absolutely solitary, said Aristotle, is either a brute beast or a god. This is a truth of which all exceptions prove the rule. St. Simeon Stylites is as much dependent on a social environment for such life as he leads, as the most sociable and business- 
like citizen of Antioch. Even the Cyclops of the Odyssey, who is said to live reckless of all neighbours, finds that they will not stand his midnight howls.

But if sociality be the root, the medium, the atmosphere of all that is distinctly human, there is one peculiarity about it which cannot be passed by. To the rest of the natural world their peculiar law, the guiding principle of their being, seems (I will not at present go beyond 'seems') to be given to be their own inalienable property ; a natural endowment, a fixed law, which they have without effort, and which they cannot or will not transgress. Man, doubtless, like the rest of Nature, has his so-called inherent properties, his instincts and qualities. But all that he can call specially his own is an effort, an acquisition. As I put it before, he inherits a task, he is endowed with a problem: his riches are all to be earned.

This sociality is not a quality but a tendency, craving for fulfilment, tasking the energies. Man has been defined in many ways. Let us for the present say that he is par excellence the being who works, labours: that he is so in tendency, in progress. Man the worker-' that which he hath done but earnest of the thing which he shall do.' 'Tis true that barbarian man, and still more savage man, is idle: and that their survivals in modern days - whether at one end or other of the social scale-still carry out the old animal ideal. But with these exceptions which only prove the rulefor savage man can only idle while his women and other slaves toil, and later barbarians nourish their idleness largely by some sort of force and fraud-the rule for man is not to merely accept the given, but to mould and fashion it for himself. In him nothing merely is : it is to be: it has taken on it a new law, the law of becoming, as the law which governs him and the things he deals with. With his emergence on the scene, the world has, as it were, got a new relative centre: all things have become, or rather are more and more becoming, anthropocentric. 


\section{VIII}

SOCIAL AND INDIVIDUAL CONDITIONS OF THE

\section{DEVELOPMENT OF ETHICS}

THE point at which we had arrived in the last lecture was a consideration of that sum or group of conditions under which the characteristic features of humanity make their appearance. In a broad general way we gave it the name of sociality : meaning thereby to indicate the fact that reason and morality, art and industry, science and philosophy and religion, only present themselves in associated bodies of human beings. It is perhaps in one way trivial, yet is it in another way important to add, that association is not here treated as a cause or a reason. If we say that morality or religion or language is a social product, we must not deceive ourselves. Mere association can do of itself nothing. Association is, so to say, the outward visible sign of an invisible inward grace : and the first thing to realize clearly is, that you cannot have the one without the other. The mere fact of there being two or three or more people together would not make anything grow or become, which had not its root in some way in the single individuals. So, too, the conclusion of a syllogism dare not, in one way of looking at the matter, add anything new to the premises: whatever goes beyond the premises is of evil, and erroneous. And yet, this material identity does not prevent the conclusion being a real addition to our sum of knowledge. You put, as the phrase is, two and two together : and the result-well, it is not quite 
two and two, but two and two put together. No doubt, if you insist on overlooking the 'put together,' or treating it as if it were nothing-what anybody can do, and so a negligeable quantity-you may say we are exactly where we were. Yet, when we are ourselves, and not playing the verbal quibbler, we know that to put two and two together is to create something new, something irreducible to, and incomparable with its factors or elements. All the data of Hamlet were already somewhere, before Shakespeare touched them; and yet, except as implicit in the predeterminate laws of life natural and social, or if you prefer it, in the determinate will of God, Shakespeare's Hamlet, the Hamlet of the modern world, was not. Or, again, the musical notes are, in a way, all there; and yet each musical genius that comes upon the scene is a creator of new constellations of harmony.

So here, the mother, already enriched with reason and love, bending over her infant, does not by her glance, her smile, her touch, give it a soul, a spirit, a reason : and yet in that glance, that smile; that touch, soul, spirit, reason, are as surely born as the physiological life of the same child is born, and so far as we know is only born, in the congress of male and female. As in that case the elements of the living being, the constituents which build up structure, are older, far older than the two parents, who to popular apprehension are the authors of the being of their progeny ; so in the spiritual world, the child and its mother severally bring to their union of soul a store of powers and faculties prepared by, it may be, centuries of inherited tradition. Yet it is in the main true, that it is the mother's and father's look and touch, charged with the fruits of life, of life both theirs and that of myriad others which have gone to make up theirs, which kindles into flame the dull materials of humanity, and begins that second birth, that spiritual parentship which, at least not less than the first, should be the peculiar glory of human father and motherhood. And, to prevent mis- 
conception, the gift of soul and spirit, if gift it be, is not on one side only. If the parent, in a way, makes the child, it is not less true that the child makes the parent. He kindles new lights, and pierces out new depths, in the parent soul; builds his world anew, with other features and fabric than of old : brings him nearer heaven or nearer hell; but at any rate, if the parent ever really sees his child eye to eye and approaches him touch to touch-and unfortunately we dare not assume that this always happens, so many parents and children have never seen each other's soul-face-he is not as he was before.

We are here concerned with facts, and with the fundamental condition of our human reality. With facts. It might have been that each of us should have been sent into the world, a fixed and complete quantity of energy charged with a certain rôle; a germ, containing a certain bundle of possibilities, and capable of developing all that was prefigured without help or hindrance from other things. It might have been that each of us should have existed as an independent individual, burdened indeed internally with a certain drag or limitation or inertia of resistance,--so that the infinity, implicit in each of us, never became at any moment wholly actual, wholly equal to the absolute and perfect Being,--but yet not hampered by anything without; and thus the outward happening, though it was to all appearance perpetually about to interfere with what we did, would yet never really come into contact with us, but would be kept off, as by some plate-glass surface, or by some impermeable yet transparent adamant encircling our sphere of being. So, it appears, thought the great Leibnitz. Each real being-he called it a Unit or Monad-he thought to be, as it were, a god, a potential never quite perfect god, but filled with an instinct towards greater and ever greater completeness : a being, always fragmentary, in that there were numberless other beings outside it, utterly independent of 
it, yet all somehow, more or less faintly, within its ken, ideally present to it; it and all the rest again having the full, real, true God above and over all as a sovereign, the real bond which was represented in this ideal harmony. It is; you say, an inconsistent conception. But the inconsistency is partly, I may suggest, in the fact that it is the phraseology of a compromise. Its voice is the voice of eighteenthcentury Deism, which was the final deposit of a century of Lutheran orthodoxy: but its hands are the hands of something very much liker Spinozism than his contemporaries fancied.

At any rate, without committing ourselves to any denial that in a higher interpretation the idealism of Leibnitz may hold its ground, for the present we must insist on the reality of the fact of inter-action. The individual, so far as phenomenal facts go, is what he is, through and in his surroundings. But to call them surroundings or environment is to mislead. The surroundings of the individual are, however paradoxical the phrase may sound, not merely around, but in him. They are part and parcel of him : he is part and parcel of them. The old idealists, such as the later Stoics, were fond of insisting that things are what we make them, or take them to be. Everything, say Epictetus and Marcus Aurelius, is $i \pi o \lambda \hat{\eta} \psi \iota s$; imagination, fashion, opinion, rules the world. But if this is true, there is necessity for reaffirming a corresponding and counter-truth: 'Things are what they make us become.' Neither side, taken by itself, has a monopoly of productiveness or creativeness. Things are not, as an idealist like Fichte might be supposed to say, mere stuff for us to cut and carve for our own sakes, and as we please. They are-and this is what Fichte, who was not a mere idealist, did say-the stuff by our manipulation of which we become better or worse. In other words, they subdue us to them, just as much as we subdue them to us. And if that be so, it would seem to follow that what we call 
our acting upon them, is, in equal degree, their acting upon us. Action and re-action are always equal : because, as a philosopher might say, they are the same thing, seen from two ends.

External things are the tests of our reality. The so-called Berkeleian idealist was supposed to hold that, in the case of sensible things, their esse was their percipi: to say that they existed, was only another phrase for saying that we perceived them. And some scoffers jeered at the lunatic philosopher who reduced all reality to a spectral phantasmagoria in his, i. e. the philosopher's, mind; or, as the cruder critic said, in his brain. But these species of philosophical propositions are only fully understood, when they are seen to be reversible. It is equally true that the percipient gets his being from the perceived. Not to know them, it is said of some great ones, argues yourself unknown. Do not be too rash, therefore-I may perhaps say to the very young metaphysician,-do not be in a hurry to throw overboard the sensible world. It is true that a metaphysician of fame has declared that you cannot hope to be a genuine philosopher, if you have not had at some time a serious doubt as to the so-called reality of the material world. There is something in this, I admit: but it reminds me of the encouragement given to a beginner at the game, when he is told that he will never turn out a crack golfer, unless he first breaks a club or two: or of the general warrant sometimes thrown out to the young that, if later years are to bring forth a crop of good and valiant deeds, it is necessary to begin with sowing some wild oats. In these cases I suspect there is a little of the confusion which in the logic books is said to take post. hoc as if it were propter hoc. In other words: it may be a grand and generous soul will, just because of his nobler mettle, commit faults and break hearts, ere he, so to speak, gain the full mastery of his machine, and learns to elicit the high music that is in him; and a player of the grand style may 
break an instrument or two, before he learns that even golfsticks are to be handled delicately and with respect, as becomes what are no mere rigid things but organs of the spirit. But it would be a perilous thing for the clown to draw encouragement from the necessary mishaps of genius, and suppose that he can only trundle his wheelbarrow with its load, if he imitates the prancings and caprioles of some high-bred steed. So it is with the way to philosophy. Every one must take his own path, his own royal road. There is no regulation pattern, no scheme of philosophical salvation, which each must undeviatingly follow. It is not necessary, in order to be a philosopher, to doubt the reality of the external world; but it is necessary to abandon two beliefs before, philosophically, you can be saved. The first is that the external world is the reality, and that our mind, our ego, is a mere echo, a reflection, or epiphenomenon of it. The second is that we are the reality-we, the scheme of ideas-and that the external world is a mere dream, the passing phenomenon of our minds. The former error is Materialism, and some people call it Realism : the latter is Spiritualism, and some people call it Idealism. Salvation, philosophic or otherwise, can come only to one who has disowned both errors, and who has learnt that the truth lies in the utter qualification of one half-truth by the other. The way to philosophy can only pass through a point where we see that neither subject or object alone primarily is : where we learn that things are, because we by reason understand how things are what they are, and, not less, because the sense passively receives the impress of their action. Inner and outer must ntterly coincide to give reality.

These epistemological considerations are not alien to our present problem. For they tend to show that the bond of reality, as Leibnitz hinted, is in something which comprehends us and things : that reality is not in things of any grade whatever, but that things are in reality: or that reality 
resides in the manifold system of relations, the complex, which binds them together. None of the rings which form the chain of reality is itself strong enough to hang the others thereon; yet, on the other hand, each of the rings is charged by implication with the whole. Each is, has being in itself, but when we look earefully, it is in itself only through the being of others. Each, as you view it from the standpoint of the other, is only a phenomenon: and yet each must be real, or it could not even be a phenomenon. Everywhere subjective initiative is inseparable from passivity, as of an object, to something else.

This reciprocal interdependence of aspects holds good, as perhaps few can care to deny, in the relationship between man and things. And to us, looking at the problem from our present standpoint, here might seem to be the commencement. We go forward to meet the world, to learn from it, to struggle with it; if possible (and it is not fully possible) to overcome it. But it is we who go forward: we, the collective, the race of man. Even when an individual David goes forth to meet Goliath, he is a champion of an associated host, the bearer of an ancestral and national interest, the worshipper of his country's god, the wielder of the weapon which centuries of customary skill have fashioned, strong in the sympathies of his compatriots, and strengthened by burning hatred against the uncircumcised Philistine. The individual in the search for science is no less sustained, fortified, inspired, by a long past, by many ages of struggling humanity. The scholar, even the most rudimentary, does what he does only in the strength of what his forefathers and their comrades have done and suffered. By all means let him be proud of his intelligence, his wit, his genius, his science, his freedom of mind. But let him remember that if he is free born, some one has had to pay for him the price of his emancipation. When Renan at twenty-five years old entered on his brilliant course of philological and historical achievement, he started 
from a great capital of tradition, which he entered upon partly by labour but largely by inheritance. He received, in the dispensation of Nature, all that acquired power of patient work, of sympathetic insight, of natural piety and human tenderness, which his Breton peasant forefathers had laboured for; he entered upon all the august memories, the organized strength, the systematized logic and learning, the grand theistic conception of the Catholic Church: he gathered the fruits of a scientific struggle, prolonged through centuries of experimental research, of theoretical construction, and of attempts to find a law in human life and human history. Wir freie Geister, we emancipated intelligences, is the favourite cry of a modern German thinker, as he thinks of himself and a band of advanced thinkers. It is a cry that calls for humility at least as much as pride. One has read of armies in retreat before some terrible destroyer, brought face to face suddenly with a deep and precipitous ravine, and compelled by the mere pressure of horror from behind to march on and on, till the gap was filled with prostrate human forms, and the survivors reached the other bank safely by the involuntary self-sacrifice of their front ranks. Something like this is always happening in the annals of each life. That each of us can individually seek to develop our individual minds, prosecute our separate studies, reach intellectual, artistic, or social eminence, is possible only because we are raised on the joined hands of many unknown to fame, who have formed by stern resolve and hard clench a solid roof over that abyss of mere animality into which we should otherwise fall. Science, art, and religion, all that makes life glorious, all that constitutes the special glory of individuals, grows out of the root of sociality. They rest and grow, says Hegel, in the State. But what, according to Hegel, is the State? Not something, assuredly, which lives in London, and has its holy of holies in the offices of the Treasury: not something which lives for the time being in the Cabinet, and in the upper and influential 
circle of the bureaucracy. The State, as Hegel conceives it, is the completed organization, the self-contained social form, in which human life can develop its ideal activities : it is an organization in which the family forms the perennial, and so to speak the natural basis, the ever fresh, ever creative spring of moral, intelligent, and artistic life: in which the interdependence of industrial effort, commerce, social and commercial demand and supply, constitutes the ever-widening stream: while the more purely political organization itself blends all these divergent interests and natural ties into one single and comprehensive nationality or people, wherein the members can both play their own part well, and contribute their quota in orderly way to the total work of humanity.

Before the individual could deal successfully, reasonably, well with the natural world around him, he had to deal with his own kind, and, combined in action with them, to gain the weapons and the machinery for carrying out his ends. Before he could cultivate science and art, he had to live, and to live he must live in a community. It is no doubt a temptation to separate one part of this from another, to suppose that outward activity created inward faculty, or that inward faculty gradually evolved outward instruments. But the whole point we here have to insist upon is, not the separateness of these two, but their necessary interdependence. Man was not an intelligent creature, who gradually devised newer and abler tools; nor was he an unintelligent creature, who became intelligent by the reflex action of the machinery he had devised. The old question at issue between Anaxagoras and Aristotle, 'Is man the cleverest animal because he has hands? or has he hands because he is the cleverest of animals?' can never be answered as it stands. The two developments go on pari passu, parallel to each other, each always cause and always effect of the other. As Spinoza puts it, there is no body without a soul, no soul except it be the idea, the life and consciousness, of a body. The aptitudes of action belonging 
to the body are exactly equivalent to the intelligence and rationality of its soul. Soul is not something given a body to direct; body not something handed over to a soul's direction. The union of reasonable soul and animal body is a deeper thing than either spiritualism or materialism. Reality has, according to Spinoza, a double aspect: seen this way, it is soul; seen that way, it is body: this way, you attribute to it modes of thought; that way, you attribute to it modes of extension. It is true, you may say, that this is to exceed the facts; for you only see in yourselves, and infer in those like you, that there are two aspects. But, answers Spinoza, you cannot have this doubleness of being even in these cases, you cannot carry your reasoning a step, unless you admit that, beyond and behind these two aspects in you, there is an identity, i.e. a self-reaffirming coincidence of these two aspects.

That intelligence and reason, conscience and language, emerge only through social, collective, or combined action is the point. Sociality is not mere juxtaposition, mere aggregation; if it be ever describable as a quality or property of the human animal, it is only so in the sense that in man there is, in a degree and way unknown to the other animals, an impulse which drives him to combined action. There are, of course, what are called animal societies, of which certain species of bees or ants form the typical instances; though there are others perhaps which in some respects come closer to their human analogues. Between the almost stereotyped caste scheme of the former, and the looser and more flexible gregariousness of the latter, man steers a sort of mean. It is not that we can say he is, in any line of distinction, absolutely and utterly unique. To establish such an impassable gulf of division between himself and the whole animal world, has no doubt been a dominant interest in human curiosity on these matters. But it is hardly describable as a noble, still less as a disinterested curiosity. It savours of 
meanness to think our titles to grandeur will bè securer, if we can exclude the claims of the animal creation. Nobler, I think, is the attitude of St. Francis, when he speaks of his 'brothers' throughout creation, and, with the Hebrew psalmist, calls all things from sun and moon to young men and maidens, old men and children, to praise the name of the Lord. One thing I know, that neither science nor philosophy are interested in the question of excluding dogs from heaven, on the ground, apparently, that the spaces of paradise would become inconveniently crowded. Perhaps the day may come when the gospel can be preached for what some people complacently call the 'beasts that perish.' So long as the device is 'Let right prevail,' we may be confident no legitimate right will come short.

But we are concerned with man : and with man sociality is an effort. The physiological individual, the pure animal, if we have a right to such an abstraction, tends to slip away into isolation. At the best, he eats and drinks side by side with his fellows; but, unless provender is plentiful and space is wide, he tends to quarrel with his neighbours, with those who wander beside him. Even the attraction of sex is a fickle and feeble bond. I do not know whether Professor Drummond is right in saying that through the animal world ' the apathy and estrangement between husband and wife is radical and universal.' Too general utterances in these matters are undesirable, and the cynic may point out, with too much apparent justice, that this apathy and estrangement are not confined to what is ordinarily called the animal world. But at any rate it seems tolerably true that, in most cases, the connexion not merely between animal husband and wife, but generally between animals, is fairly described as indifference tempered by occasional caresses and quarrels: while, in the cases where a closer and more lasting union prevails, as in the social animals, it has a stereotyped and mechanical character, as if the several creatures were automata moved by 
some necessitation behind them. The human association is co-operation, society in work, or action. At first perhaps it is an association of labourers cemented by their common subserviency to some end; afterwards the association of labourers who interest and attract each other, not merely through their final end but also in themselves; not merely for the temporary or lasting pleasure their deeds confer, but also for their own sakes, as independent centres of action, who can be for us all that they may be, only when they are never mere instruments but always also sources of original activity.

This is, in a nutshell, the evolution of ethics. It begins when co-operative action first appears upon the scene, and it marks the fact (first) that the single self has made a step forward, has broken the mechanism of nature, and assumed a direction, set forth an end; and (second) that it did so in a strength not entirely its own, through a will not completely self-centred ; that it depended on help, on co-operation, and thus submitted itself to a bond. At first, indeed, it lays the stress, so far as it can, exclusively on one side. It treats the contribution of others as a mere subserviency to its own initiative. It is selfish, and makes its own utility the centre of all judgement. It forms relations of inequality, of which the type is that of master and slave. The human being is, at this stage, only one among the instruments of production and conquest, distinguished from the rest only by his flexibility, his plasticity to the master's hand. Even this, however, is an advance on a more primitive condition. For the merit of the relation is that it has introduced order and stability, which is the first and indispensable condition of all progress. The worse preliminary stage was an age of chaotic, inconsistent, erratic conjunctions, when each to other was as a comet coming occasionally and at barely predictable intervals over the other's path. Such would be the ideal state of savagery, a state, it need hardly be said, which has left no traces and 
which, indeed, in its utterness, is inconceivable. For by savage we mean simply a degree of civilization far removed from our own, in which all the more characteristic products of advanced civilization are conspicuous by their absence.

The evolution of ethics, i. e. the process whereby these faint traces of ethicality have been actualized more and more, is the process in which the two elements in all ethics have acquired increased light, and by which their solidarity has become more and more real. These elements or factors, to repeat, are the principle of direction of will-movement on the one hand, and that of co-operation and co-ordination on the other. The essence of all ethies is shut up in the word 'Autonomy'; but shut up, perhaps, so as hardly to be perceptible. Its first part is the idea of originality of action, of initiation, of movement to end: its second part is the idea of law, solidarity, community. Emphasize the first, and ethics seems to be purely idealist, a chase for unattainable perfections, for self-satisfaction, it may be, even, for pleasure. But, as our most thoughtful novelist says: 'The cry of the young for pleasure is actually-I have studied their language - a cry for burdens.' It may be that a theoretical hedonist may say of Lais, 'I have and hold her, not she me': yet if Lais does not hold him, it can only be because some petty care, some mean tie, binds him with a more constraining force, and makes him lose even the best of Lais. At any rate, it is true that the ery for pleasures is the cry for life, for struggle, for tasks : and, inevitably, as life rolls on, it turns round into another and an opposite ethics, the ethics of realism, and of passivity. Thus ethics becomes compliance with a code, obedience to a rule, the thraldom of law and custom; it becomes the negative sense of duty, and then, as the same novelist adds, 'the old ones cry for having too many burdens on their shoulders.' In this second stage ethics leaves half its meaning behind: it grows negative, and ascetic, the bondage of Sinai, a schoolmaster to be listened 
to, a school to be submitted to. The very word 'school' is a standing commemoration of this change. In its Greek original, $\sigma_{\chi} \circ \lambda \dot{\eta}$ is release from the distraction of petty tasks, from the bondage of custom, the fragmentariness of practice, and the ascent into a freedom where we see things whole and true, where we are our own full selves, enjoying the full sense of accomplished and yet progressive being. Thus school meant the leisure of free development and full selfrealization, the sense and enjoyment of life unimpaired, one and complete, reserved for those who, having passed through the trials of experience, the ups and downs of a much-divided world, might now on the Delectable Mountains behold the turrets of the celestial city rising out of its earthly preparation stage; reserved also for those who have yet the world before them, and can rest awhile, under the Interpreter's care and in the House Beautiful, beholding all the wonder of the world that might be. So are the glories of school fallen.

Of these two elements, let us look at each in succession. The first is effort, direction, onward movement, the discharge of energy in pursuit of end ; an end which, however, only comes clearly into view as it is realized. Its full name is work, labour. The human animal, indeed, is not the only worker. Some of the animal world have their work more completely organized, as the phrase is, than man's has yet been. It goes on almost with mechanical regularity. And ancient aphorisms, as well as modern socialisms, sometimes seem as if they deemed that man would be more perfect, if he more nearly approached the painful regularity of the ant. A world from which imprudence, folly, intoxication, heroism, wantonness were utterly banished seems a promising ideal: the ideal of life, not exactly as an eternal petrifaction, but as one uniformly self-repeating round of tasks, discharged with punctual regularity, in a prison-house from which there should be no escape, no release. To organize life, or, more correctly 
perhaps, to mechanize all its movements; to reach a stationary state where all would do well, or at least none could do ill; to remove all volition and substitute an unfailing determinism; such might be the vision that the sight of the ant should produce, not merely on the sluggard. But, alas! man is not the industrious bee, the ever-virtuous and much-to-be-imitated ant. These things are perfect in their way, precisely because of their inferior nature. The anthropoid, as our scientific friends prefer to call primitive man, had from the point of view of the rest of Nature what is vulgarly called a 'bee in his bonnet'; or, to take another phrase, he was at the beginning an 'ugly duckling.' He was an outcast amongst the innumerable races of the animal world. If I may use for the moment the language of a foul-speaking book, lately done into English, he was from the very first a case of 'degeneration.' He broke, this diseased, strange creature, through the calm stupidity of the animal world. He ate at an immemorial date from the tree of the knowledge of good and evil; and he fell, or, in modern slang, degenerated. Even so is the wheat, which is our staff of life, a degeneration from some unknown and probably little worth, but correct grass, which suffered little from blights, and grew admirably even amongst thorns and in stony places.

Let us not insist on both having our cake and eating it. It may be that the ant is happier, better, more virtuous than man. I know no way of determining it. Or rather it may be, as I surmise, that these words used of ants are meaningless. At any rate, let us pluck up heart of grace and not merely confess, but with all humility boast: Errare humanum est. Let us feel quite clear on this point, that to abolish error in this world is to make truth impossible. There may beand we hope it at the consummation of all things-a time when the wheat and the tares will be eternally separated. But, for this present temporal scene, let us maintain the solidarity of opposites. You must pay for your white, if you 
will have it, at the cost of black; if not, you will get, if you get anything, a dull monotonous grey. The virtues ean only grow on a soil which as necessarily will bear vices. The word purity has no meaning save as against evil desires repressed, against incipient impurity. Let the virtuous woman reflect that her coronal only shines so bright because of what otherwise had grown into her fallen sister. There is none good, it was said, but God; 'why callest thou me good?' And I reply, with respectful decision, one may well call thee good, in so far as thou fightest the fight of faith, not as if thou hadst already attained, or wert already perfect. And we dare not say, 'God is good,' because so to call him seems to bring him down to the level of such an one as mortals are, and to offer a cheap commendation of him whose ways are not as our ways, nor his thoughts as our thoughts.

Man is not the industrious bee, or the ever-virtuous ant. He is not that kind of pattern. Rather is he, equally at the root of him, idle. His industry is an effort: his work is only partly a pleasure: he constantly relapses from the strain. Oftentimes, indeed, he looks round among the animal world and would fain shake off in fancy the awful yoke that lifts not night or day, the call of work to be done, aliquid facien$1 \mathrm{um}$. In a grand passage of the Metaphysics Aristotle has remarked that in the economy of the universe, as of a human household, it is not the highest in rank on whom life sits easiest. The slave, as he is called, has his hours of rest, his rude amusements: the laugh in the kitchen sounds often louder and looser than in the drawing-room. The weight of responsibility is removed: whereas in the ruling members, noblesse oblige presses with perpetual weight. The roving Bushman, with little to bless himself with in material wealth, sings all day and far into the night for very lightness of heart: while the latest products of civilization-with some exceptions, thank heaven !-go to their daily tasks with tense and apathetic faces, as if they were prisoners. 
There are, in short, two spirits in man, and both seem equally natural, equally essential in making him what he is. He looks before and after, says the poet. The animals are engrossed, it seems, with the present. But be this as it may, man, visited by the glimpse of possibilities which arise for him through social activity, has thus opened up for him a vision of the recurring contradiction of what he is to be with what he has been. $\mathrm{He}$ is an animal, and sometimes would be glad to be nothing more. But there has been realized within him, by social action and co-operation, the sense of something better. He has risen above himself, yet without leaving himself. He has gained a human soul, a social spirit, that puts him into sympathy with a portion of his fellow creatures, and has in it an expansion to which no limits can be set. But it is a spirit which is only to be maintained in struggle against his old animal self. It is the spirit of a wider nature, born out of other elements besides those of his own origination. Thus, though it grows out of him, it has its source in a wider, a larger world. It is reason in him, and not entirely his ; except in so far as his continual effort is to be not only himself but more than himself. It is conscience, the eternal witness to the 'ought' against the 'is': and yet a witness also that the 'ought to be,' in a higher sense always 'is.' 


\section{IX}

MAN'S RELATION TO NATURE. - MATERIALISTIC AND

\section{IDEALISTIC VIEWS OF IT}

THE relation in which Man stands to Nature makes it to him at once antithetical and inseparable. Nature, if we look at it in a large way, is that which, whether we will or no, goes on according to a law of its own, working out of itself all the potentialities it contains. In simple dignity, unhasting, unlingering, sometimes as it were with simplicity of a child, and sometimes with the inflexibility of a formed manhood, it marches on, governed no doubt, as we are gradually brought to surmise, by laws, but not troubled by any of that consciousness of possible opposition between the law and the fact, which is so frequent and so bitter an element in our human experience. We may have by science convinced ourselves that its course is hemmed in at every point by uniform laws, but nature itself is to the mere obvious perception free, determined by no alien force, itself supplying the very means by which it is made better. And as against such nature uniform, complete, all-encompassing, man seems the child of caprice, irregularity, and self-contradiction; his business, we should, if we spoke hastily, say was to thwart and pervert, to defy and constrain the great power of things: only that if he for a little slacken his efforts, and cease from troubling, the other elemental forces resume their sway, and in a few years or centuries leave no obvious traces of his works. He builds his bridges, he forms his conventional 
barriers and settlements over and across nature's surface : but they are founded on the moving sand of his conceits, and are in no long time swept away to the bourne from which there is no return. Impotent and vain, brooding over ideals which the natural conditions forbid him ever to realize, man seems to the mere realist (who in this matter takes a pessimist tone), to be an inexplicable and absurd freak of naturea child born of nature in some foul hour of mysterious incest, doomed from his birth to struggle, but to struggle for ever in vain, against his mother and her ordinances, vexing her soul with his vanity, his insanity, his despairs, by his ideals moral and immoral; but doomed also, at some distant date perchance, to fade away into nothingness, and leave the weary world at peace from the perverse iniquity of her Caliban, her youngest and most froward child. To the mere idealist perhaps, on the other hand, the antagonism takes a more optimistic issue. He sees in man a being who already was, in some higher sphere before nature came to be, and who still will be after all the works of nature are shrivelled into nebula. Or rather, perhaps, the idealist sees in him a being who in his inmost essence has no past and no hereafter. His life, as we, speaking the language of one short-lived race, call life, is but the misconceived or half-understood representation of something deeper, higher than it appears to be. The true life, the 'life that knows no ending,' and perhaps knows no beginning, is the invisible but real pre-supposition of the struggle to be which we call life. Charged for a while with the task of guiding some little portion of material nature, the soul, as the old idealism named this imperishable germ of being, has a watch to keep, a service to render; it is, by some dark law of universal order, submitted for a time and times to a probation; to, it may be, an exile in an alien world, with an ever-present yearning for its true country, which is the heavenly, and an occasional reminiscence of its spotless beauty: and at length, after the campaign is over, the soldier 
spirit, according to its constancy or its cowardice, is given back to the real, i.e. the invisible world, with due meed of joy, of penal but purifying torments, or of unending pain.

Such are the schemes of conceiving the relation of Man to Nature which have had an historical fame. The first, that of the materialistic and pessimistic observer, sees in man a revolter against nature, an unintelligible accident, the sudden emergence of an unearthly, unnatural ideal, as of some portentous star in a grey moonlight sky. It foresees, with no shadow of a doubt, that the rebellion of man is foredoomed to inevitable failure: that the meteoric light which he flashed -must and will be extinguished, and leave behind only a dead meteoric stone more in the cosmos. And yet, while his scientific senses force him so to judge, there is something else in him which, with at least not less authority, obliges him to declare that, notwithstanding the inevitable collapse which sooner or later will come, he for one will fight, and ever fight, whatever the issue. He hears the loud yelp of the Fenris wolf coming ever nearer, more heart-crushing; he sees the powers of ancient darkness, the giants, gathering round stonily imminent as the light grows dim, and on the face of Loki the smile of assured triumph settling grislier and grimmer; the jaws of the world-serpent open for their prey; he feels the eternal frost creeping to the vitals of the earth, he declares that he cherishes no hope of an ultimate reversal of the doom impending: and yet, undaunted as a bridegroom to meet his bride, he goes forth, mightier in his mood than the elements which seek to engulf him, and bury him and his revolt out of sight. It is unintelligible and absurd, you say : but it is magnificent. But is it so unintelligible after all? Is it not rather the reason of life suppressing the reason of logic, and of what the short-sighted call science? 'All men are mortal,' says the logic-book, ' and Peter is a man; therefore Peter is mortal.' So far so good : but every man, every woman, eternally supersedes that conclusion as a half-truth 
for him and herself, and says by act, which is more rational than the formal syllogism,-Non omnis moriar; whereby they, by deeds done in love, survive.

The second scheme may on the whole be styled the Platonic, or, in special form, the idealist and spiritualist. In the development of the Christian church, and partly even in the very origins of Christianity, it has entered into the body of Christian doctrine in a measure which has made it practically impossible to separate the two elements. Perhaps most people hardly realize, or even are aware, how thoroughly their conception of life and immortality, of the here and the hereafter, which they regard as essentially Christian, are in their origin and form Platonic: though, be it added, of a Platonism which has undergone much vulgarization in the process of incorporation, and even before it. But the fact is, the modern reader of the sacred books can only with great difficulty, much selfrestraint, much purgation of mind, get into even tolerably direct contact with them. In some works of religious art, when symbolism took other forms than it does now, the artist gave to his saintly figures a nimbus or aureola round their head. What is that nimbus? It is the 'cloud of witness,' the work of witnessing spirits, who, as the generations rolled past, have brought out in quasi-sensible shape the significance of the bare fact or of the barely visible personage, and stamped it, in always altering and increasing complexity, on the face of the saint; even as, in a different way, a painter by his finer symbolism may depict in a face a depth of character which no casual observer had been able to see. Even such a nimbus gathers round the plain words of an ancient text. Such a text also lives and grows fuller of complex life. It gathers up and bears around it a charmed halo, of which in the end it seems almost sacrilege to try to strip it. And to pause a moment in an inviting side-issue, let me ask and try to answer the question: Is it well to strip it off? Yes, I reply, for certain purposes well: but not in all respects 
well. To illustrate by an analogous case, 'Let us,' says a French writer ', 'see in woman nothing to trouble us, nothing mysterious : let us strip her of all this romance : (dépouillonsla de tout ce lyrisme) which we throw, as it were long veils, upon our troubles : let her for us be truly nature (qu'elle soit pour nous vraiment nature).' We know what to say to this proposal of $M$. Barrès; or if any one will not say it, he can hear it from Wordsworth. It is well for certain purposes that we should, as he puts it, know the very pulse of the woman's machine: should, i. e. know that like all humanity she is animal, weak, capricious, fearful: should remember that, as Schopenhauer was fond of putting it, 'under, or, if you prefer it, over the lady, there is always the woman.' But it is, on the other hand, emphatically not well that, as the same Schopenhauer was inclined to do, the man should so far strip himself of humanity as to wrench with brutal hand from her all that developed and ordered grace and spirit of womanliness which, through the age-long operation of association in the family bond with all its varying types, in social organization, in natural union, have made her, though not less 'truly nature,' still also and thereby,

'A spirit still, and bright

With something of an angel light.'

And now for the application of the analogy. It is well that the scholar and the critic should try to penetrate beneath the accumulation of rags and patchwork which, they say, have gathered about the ipsissima verba of a sacred book. The present generation fancies, and in some respects no doubt rightly fancies, that it has at length learned the right art of interpreting the texts; that by scholarship and history it enters more sympathetically into their innermost central meaning. On the whole I agree: I do not like to quarrel with the Zeitgeist. Yet, at the risk of being more than usually frivolous, I must just suggest a doubt as to our

1 M. Barrès, Un Homme Libre, p. 44. 
all-sufficiency. We all sometimes in a vacant hour turn to old numbers of Punch. If we go back thirty years, we come in its pages upon bonnets, dresses, shawls, which, in proportion to our degrees of youth, we pronounce hideous, tasteless, unnatural, or at best quaint, such a contrast do they present to the naturalness of the present style. Yet some of us can remember a time when, for reasons I stay not to inquire into, these same pieces of garb seemed to earn quite other epithets. So in other more scientific fields perhaps -I will not go further towards prophecy-it may happen that a later time surveying the labours of the nineteenth century may pronounce our most impartial criticism pretentious and absurd; or, without going so far, may venture to say that our critics were under the influence of their time, and saw its ideas and beliefs reflected in the works, which they professed with due impartiality to do no more than expound.

But, however this may be, one thing needs remembering; and that is that all the books on which humanity has fed, humanity has in its turn made to develop new growths. And the same is true of its songs and its pictures. Have you realized that those books we turn to, not often perhaps if compared with our vulgar readings, but again and again when we would, as it were, bathe ourselves (se retremper) in the fresh bracing pools of some mill stream: that these books have much written, so to say, in sympathetic ink between the lines; or, changing the metaphor, that the letters in them quiver and glow in the throb of historical emotion? A recent Hebrew scholar e.g. gives us a book on the origin of the Psalms, and their religious significance. In some respects it probably matters little, and for the sake of truth and accuracy it may be even a great gain, to ascertain that these lyrics are not the effusions of that somewhat excessively amorous and cruel adventurer king, David ben-Isai, but the outpourings of a later, more cultured, and more devout, and even a more 
patriotic age. But the main thing after all for humanity at large, even for the scholar in his ex-scholar moments, is the mental, moral, religious sustainment or inspiration these hymns afford to universal human life in its struggle onwards and upwards. It is the temptation of the scholar, especially of the critical scholar, to isolate the text from its comment. For purely historical purposes that is entirely right, and we are not likely to have too much of it. But all the same, none of us can afford to be pure or mere historians. The danger therefore is that we go back to the 'beggarly elements,' under the impression that we are thus getting nearer the real truth. It is vain to talk of reading these books without note or comment. The comment also has in course of time become part of the text. Every reader is trained in a traditional interpretation which, with what ability he may have, he helps to develop and hand on. There is no private right of interpretation, if that means privilege : private right is based on common law.

And now to return. The Platonist idealism, which has largely entered into the formation of the Christian idea, and has again issued from it to form quasi-independent schemes of idealism and spiritualism, has generally been disposed to regard nature as an enemy, but also as an illusory enemy, already in essence vanquished. Whereas, on the materialistic theory, the sudden rise of the intellectual and moral warrior, who defied the hosts of nature, is utterly surprising and unexplained; here, on the idealist hypothesis, the spirit is distinctly declared to have descended from above and from outside. 'Intelligence,' repeats Aristotle, following an older theory, 'comes in from the door' $(\theta \dot{v} \rho a \theta \epsilon \nu)$. The soul has come from heaven, i.e. from the supernal abodes of the highest mind, to enter into and dwell with man. Itself a divine germ, it has assumed the human form; or, in metaphor, it has entered a tabernacle of earth. In that post, however, it has its task before it. It, a pure intelli- 
gence, must co-operate with creatures of lower breed: as Plato in his figurative language puts it, the soul is a charioteer who can only drive through life with the help of two unequally yoked horses, one gallant and violent, the other sluggish and cowardly: or, as he varies his metaphor, the man we seem at first sight alone to see, has, lurking under that fair exterior, a being half-lion, half-serpent, and another many-headed creature, more complex and grotesque than poet's fancy has feigned. Thus, at least, in moods which the dominant current of the later Platonism loved to retrace-though I think they are after all a by-path, and not the royal highway which the great Athenian himself chiefly loved-thus did Plato present man in antagonism with what some will now call his nature. In Plato's speech, nature is the eternal order of righteousness, the law that works through reason into good. A later age, indeed, came to speak of body, or, as it is otherwise called, 'the flesh,' under the name of nature. This, however, is not Plato's phraseology : nor is it the phraseology of St. Paul. St. Paul's Greek and his philosophy may not be always unexceptionable, but in his letter to the converts at Rome, he is perfectly unmistakeable in the distinction between nature (which is the great common law for all mankind, of which Judaic law is only as it were an appendix or special edition, issued for the use of a stiff-necked race) and those evil lusts which are against uature; even as by the law of the flesh he means the principle of an imperfect life, which narrows its aim, and perverts its proportions to partial, one-sided, fragmentary issues. It was a degradation of language, in which Christian theologians have perhaps helped, to speak of nature as the adversary of spirit.

Of the two views that wrestle in Plato's mind, the one sees Nature as the starting-point of Spirit, as a germ which by physical discipline and the moralizing stimulus of society (as expressed e.g. in art and letters) may become more adequate as a vehicle of the highest life. This tone of thought is 
shown in the contempt he pours on those who spoke as if virtue was against the grain, was an unnatural thing. On the contrary, he says, virtue is the very path of nature. And to the last his theme is that the righteous are by nature happy, and the happy must be righteous. Still, in his later writings, a change has come over his spirit. He sees the world lying largely in wickedness. Natural influences seem banded against the life of the highest soul : and an ethics of asceticism ever and anon crosses the older creed of free self-development. The good recedes into the innermost soul and the uttermost sphere of reality. Man's true life is elsewhere, and not here.

Of these two views let me add only one word more before I pass on. I have sympathies with both. The realistic or materialistic interpretation of nature and man may be imperfect and may be inconsistent: yet it has at least, I think, the merit of seeking to found itself on facts, not on illusions. Its facts may be narrowly apprehended, crudely interpreted : yet there is such a thing as a sturdy independence, which refuses to borrow a crust or a coal which it deems not honourably earned, and will rather fight the world starving than beg or steal ideal hopes and transcendental beliefs. Of the idealistic hypothesis, on the other hand, I will only say that it may be true : in some essential points, perhaps, it must be true. But, as it is ordinarily stated, it soars too daringly into the realm of the unknown; it draws too large cheques on the bank of our 'ethical needs'; and above all, it introduces too vast and arbitrary a gulf in the order of development of reality. If animal life, though a new thing not reducible to its antecedents, yet comes in the order of nature as their due sequel; in like manner we must postulate that the spiritual life, the life of righteousness, beauty, and goodness, shall be a continuation of the same natural, which is thus in its essence also a supernatural, order.

The soul, mind, or spirit, then, with all its objective, or 
more than barely objective, creations in morals, science, art, religion, is born, generated, produced in the social medium, through the effort long prolonged, intermittently pursued, and often misdirected, an effort of social co-operation. There is, of course, in man, as in all animals 'that nourish a blind life within the brain,' an animal sensibility, an animal prudence, which we call instinct. There is in them, just as with due degrees of variation in all living things, a sensitive soul : it may be, if we follow the hypothesis of Fechner, that such a soul is to be found even in stars, as in planets; for they also in their way exhibit what we call vital phenomena, the appearances or exercises of living. And this soul, if we for the present restrict our consideration to the animal world, comes into existence under conditions of which biology can give an approximately correct ascount. What is more, this 'vital principle,' the principle of animal life, is not, as the so-called 'vitalists' are alleged to hold, a locally separate being or presiding genius who sets in motion, guides, and controls the whole stream and circulation of the vital phenomena. That old idea-so far as it was ever distinctly held by any thinker, and not merely an attempt to express in abstract generality the supposed kernel of popular opinion on the subject-was no doubt an analogue of other oldfashioned ideas, not even now extinct in the sphere of government and politics. In the pre-scientific mind, in the imaginative popular way of looking at fact, in the Vorstellung, as Hegel would say, rather than the Begriff', the initiative of social effort was believed to lie with a governing power, and to proceed thence to all the periphery of the body politic. So in the world-government, God, to Leibnitz for example, was the sovereign being, or the architectonic mind. And in the microcosm, in the human mind itself, the will and the intellect, the superior or aristocratic faculties, were understood to rule the inner world, and to give the starting-point for action and reflection. 
In the modern time, which we sometimes call the scientific, and sometimes (with the qualification I before indicated) the democratic time, we neither think so, nor, whatever our politics be, can we think so. In this one point the modern advanced liberal touches the conservative, and makes one of those recurring conjunctions of extremes which puzzle the adherent of the old party lines of distinction. The new idea, indeed, is difficult to express, for its very nature is to be a vague strong feeling and therefore inexpressible: once you try to define it, either side will protest that was not their meaning. It is, if I may again quote $M$. Barrès ' ' the feeling that the masses alone make us touch the foundation of humanity: the people have revealed to us the human substance, the sap of the world: or 'In coming near. the simple, I have seen how under each of my acts there co-operates with conscious activity an activity which is unconscious, an activity like that which is seen in the animals and the plants: I have simply added to it reflection.' Or again: 'Yes, this force which agitates in our veins, this absolute "me" which tends to sourdre in the deplorable "me" that I am, this perpetual restlessness, which is the condition of our perpetual coming to be, they know it as we do, those humble companions, the goat and the ass, which Berenice takes out to walk on the common. In each is a superior being who would fain realize itself.' Or again: 'It is instinct much more than analysis which makes the future. It is instinct alone which dominates the unexplored parts of my being, it alone which enables me to substitute for the "me" I appear the "me" towards which I march with eyes bandaged.' In one word, it is the idea of the social solidarity as controlling and enabling individual performance, of the whole psychic organism as a higher thing than a mere system or hierarchy of powers, of the world itself as immanent in God and God immanent in the world, which rules our psychology, sociology and theology.

${ }^{1}$ Le Jardin de Bérénice, pp. I 75-183. 
I shall not for one moment seek to ignore the fact that the new phraseology has its dangers like the old. We fight for a conception, we get it : and yet we are not happy. Even the successful suitor who has just got his mistress's yea-word, is said to have a momentary shiver of self-searching. None of these things, taken by themselves, can satisfy the soul's infinite thirst for truth, beauty, good. Yet may one more than another be, for the individual and the age, the appointed means whereby he may not merely discern the relations of things, but-which is the unum necessarium-may, to the measure of his ability, set his life on everlasting foundations.

But those who have accepted the conclusions of biology, are less consenting when they are asked to follow the march onward into sociology. They admit that science is within her rights, when she declares that life, animal and vegetable, is a phenomenon equally open to study with the phenomena of light and heat ; equally inexplicable, if we insist on going back to an 'original' or 'ultimate' force ; equally intelligible, if we have regard to the laws and conditions of its existence and development. They admit that the power of the organism cannot be assigned, either in perpetuity or in trust, to any archaeus or single agent located in itself. They are content to define life as the consensus of vital function, without feeling much put about by the remark of that scare-crow, the formal logician, who tells them that their definition involves tautology. As if, forsooth, every definition that is worth its salt did not, overtly or covertly, contain a circulus in definiendo, or, in other words, return into itself.

But when they come to the intellectual Pryche, what the Aristotelians and their successors down to Kant's time called the superior faculties, i. e. the intellect, reason, will, conscience, aesthetic sense, they cry out against Materialism, Naturalism, Empiricism and so on. They cry out: "These things are from above: they have a higher origin than the merely sensitive and appetitive quasi-animal faculties.' And they do 
well to cry out: these things are from above: these things have a higher origin. Their mistake is to introduce the divine stage-manager through a trap-door, or to lower him in a swing; to add, suddenly and at one stroke of magic, something which the original structure of the play we call the universe, a play into which he has certainly put himself, would not naturally evolve by itself. One of the most significant utterances of Him who loved to call himself Man (for that I need perhaps hardly remind you is the plain English for the Semitic idiom 'Son of Man') is, 'My Father goes on working, up to this moment, and I work too.' Creation is incessant and per-. petual: the world is ever in the making: we do not know what we are, because we know not yet what we shall be. God, said the old legend, rested on the seventh day: but the newer legend says with one voice, that God rests never, neither slumbers nor sleeps; and with another voice that His Sabbath remaineth for ever and ever. For if it be true even of the human artist, that into his work he puts something of himself, and that that something-like the trees the 'laird' planted or bade his son plant-will go on growing when he lies sleeping; it is more emphatically true of the Divine Artist or Artificer: for, with him, fine art and common craftsmanship are indistinguishably one. The world is not merely his work: it is, as Plato dared to say long ago in bold metaphor, his own only offspring, his only-begotten, the gradually realizing and realized image of himself, the apparency (or, as it has been rendered, the glory, $\delta o^{\prime} \xi a$ ) of the Father.

What we have said, then, was that the emergence of these superior faculties in history-by which I mean, not human record but the process of becoming, or, as it is called, of evolution-is conditioned by the social effort of man; of man, i. e. originally to all appearance very like other animals, but containing germs and tendencies unobserved, because unsolicited, which would one day set him perspicuously dis- 
tinct from those who yet are of his kind, the kindred of an older lineage than stops at the days when Adam delved and Eve span. Those things, powers and faculties, we have called them, grow in him as a social being : a being, i. e. who is born male and female, and so never quite without some relations to pairing, to parentship, and blood-kindred; who, even apart from sexual ties, is forced, if he will live, to join hand in hand, to lend a hand and an eye, to work for a common aim ; who cannot be altogether alone at any moment of life, and who, though common phrases seem to assert the contrary, knows the pang of death through his ineradicable sociality.

' Unassisted reason,' we heard the other day, 'is a fiction'; that means that reason is the very breath of sociality. It is not the work of the individual. What he 'is pleased to call his mind' is the evidence of something in him greater than his narrower self. All that he is as a spiritual creature, he is in the give and take of society. His own, as Shakespeare has told us in Troilus and Cressida, is not his own till it comes back to him from the life, eye, hand, of another ${ }^{1}$. Our intellectual world, our morality, art and religion, are built up,- - built up to some extent in each of us individually, -but always by an act which is collective and social. So far this, perhaps, will be accepted. But I must press it farther home. True, some will say, that the evidence forces us to the conclusion that these objective and universal creations just mentioned are the result of a national or tribal co-operation. But surely you must admit on the other hand that the human mind, and its superior faculties of will, intellect, conscience, sense of beauty, religious sense, are innate and original, the very substance and essence of man. Well, without taking refuge in some obvious lurking places suggested by the concluding terms, I will directly reply with some hope of future counter-admission, that I cannot

\footnotetext{
1 Troil. and Cress. iii. 3. 96-123.
} 
admit this proposition. I know nothing of faculties and I doubt if you know much more, i. e. of faculties apart from and utterly previous to their exercise. You would not probably be in the way of saying that a man runs because he has a faculty of running, any more than you would repeat the old joke, that opium causes sleep because it has a 'dormitive' faculty. The appeal to faculties is very much like a justification of one 'I think so' by another 'because I think so.' Faculties are, firstly, only an inference, though I should like to add a necessary inference, from the fact of their exercise. If I did it, you say, I must have been able to do it, I must have had a faculty for doing it. If you did it! but are you quite sure that you did it, you and you alone? Or, is your phrase an elliptical one? Are you not, so to speak, sitting in the chair of Nebuchadnezzar? That king (in a pretty legend which the somewhat apocryphal book of Daniel has preserved) was walking on the royal palace of Babylon, and as he looked on his city for which he had done so much, he could not refrain from saying were it but to himself: 'Is not this great Babylon which I have built by the might of my power?' And, straightway, a voice fell from heaven : the kingdom departed from him, he was driven out from men and made his dwelling with the beasts of the field. The punishment, you observe, is no arbitrary imposition: it is only the acted, outwardized thought. For all that glory of civilization, these fanes, academies, storehouses and all they symbolize, were the combined work of uncounted workers in many generations; and he was but the foremost minister of his kingdom, and, if you prefer it, the servus servorum Dei. And as he said, so it was: he had dreamed himself all alone, and alone he was, - as one of the beasts of the field.

True, where there is exercise, there must be faculty. If it is done, it could (as least then) be done. But this somewhat trite or, as some call it, insignificant proposition hardly 
warrants the assertion that each of us have the faccilties in question. You can, of course, carry on the war longer, if you like; you can say, we must have had the faculty to have the faculty - we the individuals - to become we the social. But here I cease to pursue; if you adopt Scythian tactics and retire into the wastes, $I$ can do nothing: and at present $I$ am not prepared to follow the plan suggested to Darius, and attack the sepulchres of your fathers. Let me rather say, that, for all purposes of common intelligence, real faculty is only where there is actuality: and that is only in the reciprocal action and reaction of at least two agents, or, if you prefer it, an agent and a patient, who are for ever changing places.

But there is another thing to be said about the faculties, which we thus severally tend to appropriate. When we have them all before us, it gets a difficult matter to adjust their mutual relationships. How far is conscience e.g. different from will, or will different from intellect? How do they severally stand to $u s$, to our self or ego? The phrenologist, or, as we now know him, the brain physiologist, will perhaps reply: 'Oh! but we have localized the faculties in the brain.' I understand they have localized, to a not very great extent, and with some dispute, something in the brain : but I doubt whether it is the faculties. I doubt whether you can, if words are to be used plainly, speak of localizing faculties. Perhaps, first, you will have to settle whether mind itself is localized in the brain. That, some may answer, is a 'foregone conclusion': to which, if I may give full meaning to the words, I assent. 'If not there, then, where is it? it must be somewhere.' Well, these are questions I cannot answer, or you insist on asking. Similarly, I cannot tell you where God is : not that I do not draw a difference between God and mind. God, it may be said, is everywhere: and my mind,-well, is not everywhere. One thing I will say : as I do not know whether God is to be said to be within 
or without the world, so I cannot tell whether the mind or soul is within or without the body. To fix your faith on such words, is to play at metaphors with the Devil in a game where he is almost sure to win. You do not, I presume, identify your heart, when you give it away, with the central machinery of the blood-pump, nor is a broken heart necessarily a rupture in the cardiac muscles. But you reply, mind is a function of the brain, is it not? Happy, or shall I say, unhappy man, to whom that ill-savoured word 'function' gives repose. But, if I must use it, I will say: Yes, mind is a function of brain, acting in conjunction with the whole graduated universe of things.

At any rate, when we come to conscience, will, aesthetic sense, we may cease to talk of brain localization. Of course, these, like all mental exercise, involve action of brain cells : they go, so to say, through certain tracts, and adopt certain paths fitted for them. So some spiritual action uses the hand, some the teeth, some the lungs. But it seems to me as quaint to call this localization as it would be to say, digestion resides in the stomach. These phrases, doubtless, have some meaning, but it seems confusedly involved. No: it is in the sphere of their action that we get the difference of will and intellect, conscience and reason, intellect and aesthetic sense. You gain nothing, and perhaps lose much, by hypostatising a faculty of will, beside intellect. You will and understand, you reason and have conscience: but if you do, it is in the co-ordinated and combined work of society, not by special drawers in your particular mind. Your reason and conscience, your intelligent will, and your sense of God, come to you in the course of an associate life, towards which you co-operate: if they are in you, they are there as social energies, for human service, and thereby for higher and wider aims. 


\section{$\mathrm{X}$}

MORALITY AS CIVILIZATION. - THE MATERIAL BASIS OF THE MORAL LIFE

THE question 'What is Civilization?' can, like many others, be answered in two or three very different ways. We may, for instance, looking round on the more striking but familial features of our own national life and contrasting them with others more remote or opposite in character, select certain of these as marking out the boundaries of the word's denotation. We know, of course,-it is, indeed a commonplace and an axiom,- - that we are a civilized people. And on these premises it is concluded that civilization means railways, lighting of streets by night, a certain legalized and moralized form of marriage, the institution of property, churches, and so on, in a list which may be as long, and consist of such items, as the knowledge or aim of the observer suggests. Any group or community of men which is without these features, or has others opposite to them, is accordingly styled uncivilized. We no longer for instance, at least in an offensively frank way, buy our women to wife. That practice therefore stamps a people as uncivilized. We no longer openly eat our fellowhumans, though it is still a legitimate test of skill to be able to prey upon our neighbours, and as an elegant phrase puts it, suck their brains. The cannibal, therefore, is uncivilized. We dress, or rather in ceremonious manner, we doubly dress, when we dine: and the absence of clothes at the festive board is a mark of uncivilizedness. 
So speaking, we take what we conceive as the essence of our civilization to be an absolute standard, to be the civilization of civilization; and every feature of it, except such as those which we may, for some reason, think trivial or casual, is regarded as an item in making up the total idea. A little extension or experience, a little travel through history, helps to dispel this illusion, or at least to modify it. Gradually, as we escape from our ingrown prepossessions, and can look out from a disinterested observer's standpoint, we come to speak of a Greek, of an Egyptian, of a Chinese civilization, and the rest. Of each of these foreign, and it may be vanished civilizations, we can, through the help of books and other monuments, construct a picture, approximately correct: not, of course, quite so complete or so well-compacted as we can form of our own state; more confined to externals, and penetrating less to what is within, but still in essence a picture of the same style as that which we delineate of our home product. Each such delineation is what we term a'description': and description, though the logicians seem very unwilling to admit and register this plain fact, is, always of an individual instance, always a constructed percept, never a concept or general idea. And, so long as we keep to this field of individuals, and do not dig deeper down to their basis, that is, to the universal or general (which again, as the logician knows, is always the sphere of definition as opposed to description), there is really no good reason for drawing the line anywhere, and saying that here civilization stops. Once you cease to regard your own peculiar property, your private and particular civilization, as the one and sole type of real eivilization, you are set moving on an inclined plane; and, as historians of civilization, you will have to speak of a Hottentot or an Eskimo civilization. But having gone so far, can you stop even there, and if so, why? Just as religion means, first, and vulgarly, your religion : the dominant or predominant religion of your nation and time: then, secondly, a set of 
phenomena, found in different and perhaps in all races, occupying a similar or analogous place in their national life to what ours does for us: so with civilization. Our own civilization we know in a way, however imperfectly, both from without and within, subjectively and objectively : the civilization of others mainly from without, objectively. But neither of these methods of knowledge is finally satisfactory.

The historical outlook inevitably leads to comparisons : and comparisons lead to criticism, to selection, to judgements of good or bad, and to the formation of a scale or order of merit. Our 'boasted civilization' is weighed in the balance against others, known or imagined: and sometimes, and at some points, it is pronounced wanting. With an imperfect consciousness of what and why, there grows up in the mind thus reflecting a sense of a direction or purpose, of a main end or principle in the complex structure of civilization, by which its parts and members can be judged as well or ill developed, as degenerations or steps of progress, as survivals that have lost meaning, or as rudiments which apparently have not yet wholly found it. It may, as just hinted, be sometimes difficult to say in clear words what this central idea is : for, at first, it is only a felt and experienced influence, it acts instinctively, and, if you like, blindly as a clairvoyante, before it comes to seize itself in the light of clear self-apprehension. We come thus to a third stage in our way to the meaning of civilization, in which we seek to get at the unity, which underlies and holds together the various phenomena of our own civilization, and which also is the organizing tie in all. And, as a first step in that direction, we must look for what Goethe used to call the Urphänomen, the typical and, as it were, aboriginal phenomenon: the single example which projects the completest image of the fact in all its essential elements: the body, as it were, which lets the soul most translucently show through it.

In one way, the way, we may call it, of Nominalism, it is 
easy enough to see that civilization is citizenship. The fact that it points to, or means, is a 'city.' And when we say a city, we mean, if we but think of it, any gathering or association of human beings which, within limits larger or smaller and with more or less permanence, has a kind of independent completeness; which in a visible way shows a co-ordination and subordination of individual actions towards some common end that belongs to all, and can be enjoyed by each. A eity, in this sense, is equally to be seen in the group of tents which shelters an Australian tribe, in the commonwealth of ancient Greece, in the kingdom of Israel, in the Chinese empire, in the United States. The name, however, belongs originally, properly, and grammatically, to only one period of these historical formations. The city, as such, appears for the first time in Greece; and later, by imitation, in Rome, in the Hellenized east, in mediaeval Europe : and thence, by an extension backwards and forwards, the name gets applied to all organized communities of men. But why, one may ask, first in Greece? Because-so at least we can partially answer the question-in Greece, and especially at one period of Greek history, the inner thought or idea took perceptible shape, visible form. A city, according to Aristotle, the ancient theorist who has tried to tell us what the Greeks meant by what they named a módıs, is of such a size that you can easily survey it in a single view, of such population that every citizen may know in a rough way every other, and where all may be able to meet in such a place that one speaker's voice can reach them all. This, you observe, is unity to sight as well as unity to thought: it is idea wedding fact in a very palpable, tangible way. But, we may, I think, go beyond these Aristotelian notes of what makes the city a perceived or seen unity. In various other directions, it had no less visible and sensible symbols of spiritual oneness. It had one central fortress, perhaps, where in extremity it might concentrate its militant life; it had one temple, or it might 
be, a conjunct group of such; it had one market-place, where the citizens saw their industrial and commercial unity realized, and where, as the hours went round, the business of chaffering about the merchandise of each gave place to the business of the common good; it had one, or an ordered series of great common festivals, half-religious, half-social (if we use our analytic terms to describe them), into which the whole community threw itself with zest and zeal; it had, perhaps, one common, and perhaps open-air, exhibition of art and literature, which was a gathering-place of the community in which it specially felt itself one; it had its meeting-place for the fathers of the city, its public hearth with the ever-burning hearth-fire of the land, and its public table where those worthy of general honour found a home; it had its own comparatively comprehensive yet simple code of laws; and its one great burial-place, where the living could linger and dream with their departed.

Contrast all this with, say, Glasgow. There may be physical obstructions other than size which here make a synoptic view of the whole city impossible: but, even apart from fog and smoke, it is plain that Aristotle's conditions would not be realizable, even in a single one of its parliamentary divisions. But it is when we come to the signs and symbols of mental and moral unity that the contrast of the modern city stands most obvious. There are some attempts, costly and even grandiose, to give expression to municipal unity, - and what a fragment of unity that is, after all! - but the most ardent admirer of Glasgow will scarcely assert that they are adequate, whether one looks solely to the place they take in the mere field of observation, or considers rather how far they possess that vigour, that dynamic activity, that hold on the lives and sentiments of men, which was exercised by the monuments of Greece, and by many imitators of Greece in later times. But, while one says this, one should add that other things are to be taken into account. The modern city 
has an immense scheme of adjustments and arrangements, a mechanism which works to keep it together, which is very efficient, and yet not very conspicuous to the outward eye. It is a rational or intellectual rather than a visible or audible machinery. This rational machinery makes little show and has but slender bulk. It does by a touch, a pen-stroke, what in more sensuous ages required a vast display of force. What in the sensible sphere rings loud and shows clear, that, when translated into intellectual methods, grows a thin but efficient breath. And yet, while we admit all this, the want is not thereby made up. Still, as Coleridge says, the heart doth need a language. Man does not live by forms or words : he needs also the actual bread of deeds. The word by itself, the bare general, unimpassioned, mechanical, reasoning method, will never be enough without the bread of visible ceremony. No doubt, if we may take an illustration, the civil marriage by the formless formality of registration is the main thing ; and it might be the sole thing, if we were only reasoning machines. But as yet we are not citizens of Laputa, we are still human, i.e. weak and reasonable. There is, as Plato says, a child in each human being, a child that walks by sight and touch, not by faith; there is, not merely in women but also in men, not merely in plain men but even in business men and rationalists, a child-like being which craves for its due, the meed of sensibility, the intuitive symbol. And what is true of marriage, is true in a different way of all the organs and systems in social life. Concept without percept, says Kant, is empty. The truth has not merely to be said, and posted up in formula, it must be done and made visible hour by hour, day by day. The very word for the Greek city will help to illustrate. We translate it, awkwardly enough, by the phrase 'city-state.' That is as if we were to say of a human being (and it is what perhaps we dare say of the fewest), that he or she was body-soul: the body the transparent and perfect temple of the spirit: a dress, as it were, so 
absolutely well-fitting, as to reveal while it veiled. And as it is only a perfectly shaped person who can afford to wear a perfectly fitting dress, so only a perfect state, which is the spirit, can be embodied in a clear-formed city.

Civilization, then, was embodied, or seemed or be embodied, at one period or rather instant of history, in a city. But before it reached that point of development, before the spirit had visibly come to dwell in mortal body, it had run through a whole series of less adequate forms: and again, after it reached that form, it has had to recommence the same problem but with larger data, less easily manageable conditions. Greece, as it were, created one visible form of union, as an earlier world had created the family: and again and again its example has been imitated, no doubt with much divergence and defect, as e.g. by the Italian communes of the middle ages, and similar institutions. But, partly through the ever-increasing size of cities themselves, partly through the further need for enabling several cities to form a lasting and stable union, the social evolution of the modern world has been towards an organization of a machinery which should render immensely larger associations possible. The main interest of this movement in its recent phases has, however, lain in the discovery of the mechanical conditions of organization, i. e. the means by which space and time can be practically obliterated, and rational or intelligible methods of combination made to operate, where the old sensible methods had become impossible. This kind of progress is one that is ever going on, even within the range of our organic senses. Thus the mere primitive senses themselves,--touch, with its specifications and developments in taste and smell,--have been in the higher animals supplemented and in part superseded by eye and ear; each, in its own peculiar way, a vastly more rational sense than that which it supplanted, bringing us by the mechanism of light and sound waves into contact with regions to which the primal touch seemed utterly inadequate to reach. And 
yet the rational beauties of a sight and sound world fail ultimately to satisfy us. They are only surrogates at the best. In the stress of strong emotion, in the keen instants of life and of death, we seek to go back to the weak and beggarly rudiments, the animal elements of mere touch. Even touch, it may be said, does not bring spirit close to spirit. Yet the hand grasp, if real, and not a mere play of callisthenics, is our nearest approach in the sense world to the soul to soul of the spirit. But in the human world, the chain of means and methods between us as the agent or source, and us as the recipient or end of action, is mainly a system of external material things. The age of machinery is upon us, as, in one way, it always has been; but the chain of means by which we come in touch with ourselves grows longer, the network of mechanism grows denser and less penetrable. The vast range of instruments, set in order and system, rises in pseudoindependence, a self-subsistent thing, a real world, almost like a second and more soulless nature, standing imperious between our needs and their satisfaction. The prophetically speculative chemist enthusiastically tells us that ere long we shall cease to go to the animal or vegetable kingdom for our foods, and that he will feed us by new methods from his laboratory. Animals and plants will be allowed or encouraged by destructive agencies to disappear, and man alone, by a series of mechanical creatures of his own devising, will gradually convert the realm of nature into his pabulum and his dress.

These things may be only in their extravagance a dream, and, as many may think, a hideous dream. But that they express a direction, and a prominent direction, in modern civilization is undoubted. Poets, said old Homer, are strong in fiction, and the modern scientific inventor occasionally runs them hard in his promises. We have fallen on what Hesiod might have called an iron age: in which the machinery of means makes us almost lose sight of ends. Civilization has come to 
stand for the means of civilization. But, after all, the life is more than the food, whether that life and that food be bodily or spiritual : and what we shall put on, is not as important as what, within our clothes, we are. Like Martha, we are careful and troubled about many things; but many things are not needed. The necessaries of life, as Jesus taught her, are but few, perhaps but one; but beyond the necessaries, which are but means, come the real goods and true ends, the things which, if chosen, are a good part that can never be taken away.

'The world,' says Wordsworth, as said the apostles before him, 'is too much with us.' What is this world, against which the religious man and the poet raise their voice? It is the skeleton, the carcase, the dry bones of life: it is the machinery of living, left apart from the ultimate ends which it subserves. The fool in the parable built larger barns and increased his stores. He had multiplied machinery and thought he had perfected organization. But organization in its truth is machinery plus a soul, a heart, a life. These alone are spiritual stores such as thieves cannot steal. 'To love the world' in this technical sense is to be devoted to the things which are the means of true and good life, as if they were ends in themselves. Property, wealth, health, honour, and all institutions are goods; but they are good for certain ends more ultimate, or, if you like it, more fundamental. If you seek them for themselves, and not for the service, the action, they render possible, you become an idolater, a worldworshipper. You are, in New Testament phrase, godless (or without God) in the world. Without God, in one sense, no one can be. But each man can, if he will, ignore him without whom he cannot be. The old monastic ethics of the mediaeval church said, in its bald and drastic way, that the flesh was foul and devilish. Wherein lay the foulness and the possession by the devil, thus attributed to the flesh and the world? The flesh that is so stigmatized is the body of one who has 
forgotten that the body is what it is by a great co-operation; that it has been wrought by kindred, parents, and society; that it is not its own, but bought by a great price, the burdens carried by fatherhood and motherhood, by the whole society in which it has been reared. Every body is a product of the social capital, an investment of social energy and care. It has a debt upon it from which it can never be emancipated. That body which is stigmatized as the flesh, is a body of one who holds it as his absolute own, an estate without debt or mortgage, to dispose of as his separate soul may direct. Always, though not solely a means, it has been made merely an end.

Not different is it with the world. The world, the materials or mechanism of civilization, is also a social product. The world is the realm of outward things, into which man has put his activity, and through which he has sought his satisfaction. It came into existence, and can only be maintained in existence, by constant effort and exercise, and by conjunct effort and exercise. Every item is the fruit of consideration and service from countless sources. Our comfort, our very existence, in even the smallest matters depends upon the co-operation of a complex of causes and energies, which no mathematician could estimate. In our superficial moods, when we skim the newspaper, we are sometimes ready to cry out at the iniquity, the malice, the selfishness of men. But we may rest assured that in the main it is far otherwise. The psalmist who said : 'All men are liars,' was guilty in his haste of a double exaggeration. All men certainly are not. But not even any man is wholly a liar : he has his exceptions, and, if we knew him better, we should find they were many. It is even doubtful whether we can safely say of any one: He lies. Politeness after all is nearer, as usual, to the truth, when it forbids such language. For to lie, when we come to think of it, implies, to make it complete, a diabolic malice which it is hard to attribute to any one bearing the human form. Our coarse, hasty judgement lumps all the qualities of a human being 
under one head which he casually presents to us. $\mathrm{He}$ is a thief, an adulterer, a liar, a murderer, and therefore bad irretrievably and utterly bad. Can any good thing come out of that ruffianly and barbarous land of Nazareth? And it is true that one fault by the logic of fact tends to entail another. Yet it is also true that utter badness is, so far as we follow the indications of experience, impossible. Even the vilest helps in many, almost infinite ways, to keep together the political frame. $\mathrm{He}$ is a thief, we say: but there is honour, and a fortiori honesty even among thieves. Vice is possible, only because its opposite, common, unrecognized virtue is so superlatively dominant. The weakest,-equally, we may say, with the strongest, when either contribution is alike necessary,help to create the materials of civilization; the directing head must be supported by the labouring hand; and unless the labouring hand gives free co-operation, born of a partly free initiative, all the wisdom of social architects will be ineffective. The leader, the director, can only lead and direct by the selfleading and self-direction of those he yet is well said to lead and direct. 'What,' asks one, 'moves the bell-wether?' Who leads the leader? Who sets the fashion? Who forms public opinion? And the answer is, that in all these questions, by the very way of asking, the answer is made impossible. There is no independent starting-point of motion : no merely passive units waiting to be led. The waiting units are silently but surely giving their own direction: and he is the wise leader in politics, or elsewhere, who, as it were, can hear the grass growing, can by anticipation catch the first faint breath of the coming storm. The dumb cattle need the herdsman, yet the herdsman, to be worth much, must have some insight of sympathy with the dumb herd he seems to guide.

But here, as in the case of the corporeal organism, so when he looks upon the part of social product, the world next to himself, the individual may easily forget the social origin and 
therefore the social debt. He may look upon the means of civilization as his own to be done with as he pleases. Or, forgetting the end for which they exist, he may treat them as ends in themselves. The world is at first the name for the mass, ultimately the whole mass, of material things, considered as means or machinery by which we may be, each of us, all that we would be; i.e. means of self-realization. But when we say self-realization, let us guard against a mistake. There is a self which realizes and a self which is realized. They are, and they are not, the same. The one is the germ, the beginning; the other the end, the full-grown organism; between them lies a world, an economy of means and ends, a passage from all emptiness to all fulness. Yet in the emptiness there was more than seemed present. For in that germ, in that human thing, there dwelt all the fulness of godhead, and the end was what it was, because omnipotence lay in the cradle at the beginning.

We are perhaps now in a position to answer the question what is civilization? We may (I) identify it with certain objects, a collection or aggregate of things, a stock of objective goods or materials, a machinery of useful and pleasant things, of which we can draw up a list more or less complete. W.e sometimes call it material civilization, and include in it clothes, railways, \&c., and in so styling it, we may perhaps tend to despise it. Thus we are sometimes said to civilize a country, when we get its inhabitants into clothes and facilitate their means of communication. (2) In a natural revulsion from all this we may declare that civilization is an inner subjective thing, a state of mind and character. There has been created a common medium, a social atmosphere, in which the strangeness, uncouthness, roughness of individualities ceases to trouble. This is formal, just as the other was material civilization. Irregularities have been polished off, or, at least, a world of common social forms has been createdsociety in the narrower sense-a world of culture, of education, 
regarded as the means for making us all citizens in this world, ' the world' as it is called. In this connexion we may almost say that civilitas, which means something more comprehensive, has been well rendered as urbanity, civility, politeness. It is an admirable and a necessary quality, at the very root of much that is good. But it is obviously an inward which is very much of an outward. At the best, it is only a manner, a hypocrisy, which well imitates the deeper sense of solidarity. The real unity of society may have gone while the appearance of it still remains ; there is a sort of equality, but there is no fraternity. (3) Civilization in the fuller sense is the union, or, to say it better, the identity, i. e. the being-inoneness, of outer and inner, of subjective and objective. But when we say, union or identity, we must note that this is not iuxtaposition or addition. It is not enough merely to add to the abundance of material civilization a sufficient extension of literary culture, of manners, of common sociality. The two elements must become in a deeper way one. The material must embody the formal; the intellectual life grow out of the corporeal. Poetry, art, literature, must begin from home, not take their inspiration from an alien world. And material civilization must become the visibility of the spirit. Instead then of the verbal admission of civility that we are all in a way fellow-workers and have in some sort a common right, what is wanted is the practical carrying out of that idea in every detail of reality. A community is civilized in which the solidarity of human effort is the first and foremost principle, in which citizenship is realized as the governing idea of all life. But realized and real it must be, and not merely acknowledged as a mental principle or in words and forms. A community is not civilized in which the subordination of all the materials of civilization to the commonweal does not receive palpable expression. That is the point for which the Socialists fight, however much they may sometimes lose sight of it in side issues. It is an aim not, indeed, 
probably to be reached by what in their sense is called the 'Socialization' of the means of production.

If, however, it be important to note that civilization is at its height morality; that, in other words, the matter and the form of civilization both receive their justification and sanctification from the life of the spirit which they further and realize; it is not less important, on the other hand, to note that for morality the material conditions are all-essential, and, indeed, are more than mere conditions : or, to put it otherwise, they are not purely 'material' conditions, as that word is usually understood, but themselves products and parts of the spiritual life. It is true that the ordinary observer of modern times has been apt to draw distinction between the moral life and the economic or industrio-commercial life very much to the glorification of the former. Yet, as against this, it must be said that industry and trade are intrinsically parts of the moral life, and that, in so far as they fail to be so, they at the very same moment cease to fulfil their own proper function. Economics is itself a part of moral science; it is a study of certain abstracted parts of moral life with a view to determining their intrinsic relations and laws, ultimately with an eye to the welfare of the body social. So, again, the modern reader draws a distinction between the various elements of the Judaic law : one part of it is moral, another ceremonial ${ }^{1}$; one is made up of precepts of universal significance, and the other of rules of temporary authority, now supposed to be in the main abrogated. But all this is a mistake, and a mistake which is fraught with misleading consequences. Ethics is not

1 According to Wellhausen, Exod. xxxiv. I4 seq. is the original decalogue of Jahve worship in old Israel. (Thou shalt worship no strange god: thou shalt make thee no molten gods: the feast of unleavened bread shalt thou keep : all that openeth the womb is mine: thou shalt observe the feast of weeks, and the feast of ingathering: thou shalt not offer the blood of my sacrifice with leavened bread : neither shall the sacrifice of the feast of the passover be left unto the morning : the first of the firstfruits of thy ground thou shall bring to the house of Jahve thy God: thou shalt not seethe a kid in its mother's milk.) 
solely concerned with general precepts; the point of its remarks lies in their application. Dolus latet in generalibus. Nor again are the special and detailed precepts of a purely ceremonial nature : they are commanded, it is not our business here to ask how far rightly or wrongly, as conditions and indeed parts of universal and individual welfare for Israel; they are therefore entirely ethical. But equally, of course, Dolus latet in particularibus. Each particular rule tends to be set up as an independent aim, as a thing worthy and precious in itself, apart from its relations and functions.

The prophets of old Israel-and prophets, I hope I need remind no one, are not predictors of events to come, but those who speak to men what they believe to be the truth or message of God-probably, indeed certainly, made no utterly new discovery when they declared that Jahve cared less for sacrifice and burnt-offerings than for righteousness and truth and mercy. Always the human heart has felt that; though always it has to be reminded of it, so apt is it to rest content with what is behind, instead of pressing on to those things which are before. And what the earlier prophets said, the last of them, Jesus of Nazareth, seemed to corroborate. The firstfruits of prophecy, in the movement which began with Ezra and culminated in the age of the Maccabees, had been an intensification of legal particularism. The nominal bond of Judaism covered both those who called themselves the righteous, and those who were called the 'sinners.' In its nobler phases-and no reader of the psalms and the later literature can doubt of the existence of such noble phasesthese antithetic names had their ground in the resolute courage which realizes the ideal of God's kingdom, as contrasted with the weakness which eares for no such thing. But, in certain conspicuous and dominant instances, as we learn from the New Testament, it was far otherwise. The ' righteous' was the Pharisee, the punctual observer of detailed rules, and the regular attendant on temple service, while the 
' sinner' was any one without this circle; what, in these parts, we might call 'belonging to no denomination,' 'a joined member of no religious body.' In the face of these facts there is much in the language of the Prophet of Nazareth which, to the careless hearer, might sound contemptuous of special observance and detailed ordinance. What he really warred against was the superstition which thought to supplement moral defects by care in special observances; the idolatry which held particular ceremonies as absolute as the ethical needs of man. But the language had its effect, as had that of the prophets, when read casually and out of its context. It was supposed by a section of those who called themselves his followers, that ethics and religion henceforth were to deal with the higher spiritual life, and that the common round of duties was comparatively unimportant. The error was taken up by an unintelligent Spiritualism, and ethics, like religion, was treated as almost too good for human nature's daily food.

It is against misconceptions like this that the older Hebrew Scriptures, which Christianity presupposes and out of which it grows, are of permanent value. It may be true, as says John C. Calhoun, that 'they didn't know everything down in Judea'; but they knew some things which it would have been well if the later ages had not lost sight of. They knew that, even if religion is not a matter of meats and drinks, meat and drink are no trifles which religion may ignore. They knew that religion is intimately wrapped up with the tillage of the field, the pasture of the flocks, the rules and modes of wedlock, the custom of the market, with sanitary rules, with the treatment of disease. They may have been mistaken in some of their views, but they were certainly right in their main thesis; and the whole bent of modern progress is towards doing what they did in a completer way. To them religion and ethics left no sphere of life untouched. Every theological doctrine had for its converse a practical 
command, or rather everything they believed about God was ipso facto a law of life. No otiose theology this ; on the contrary, one submitting itself to experiential verification, and glorying therein. It is no mere assertion that 'God is good': it is 'Taste and see that God is good.' Jahve is the God of his people: all their interests are his, and he deputes none of them, and thinks none of them unimportant.

The modern world thinks too gingerly of God. 'Thou thoughtest that I was even such an one as thyself;' one, that is, who does not care to dirty his hands with manual labour, who dwells only in the high places of wisdom and policy, who leaves to lower arts and vulgar attention the lesser matters of the animal life. What is perhaps worse, some have thought that they could tell what God is by the way of scientific generalization. But God does not so reveal himself. He comes and comes alone to him who does well, i.e. faithfully and heartily, the work which in the ordinances of nature lies next to him to do. If he come at all, he comes altogether, in the lowest as in the highest, sooner perhaps to the day-labourer than to the speculative thinker, because the latter perchance thinks he can find out God by patience and resolution, while the former in honest effort, seeking no great things, is perhaps readier to hear the voice: 'Friend, come up higher.' The modern world can only gain religion, and have such vision of God as man can have, when it realizes to the intensest that the wise and foolish equally enjoy his sunlight, that to him nothing is common or unclean. The old churches at least saw this ; and if they did amiss in trying literally to reproduce a code, that may have suited the later Israel, for the use of Geneva or of Scotland, yet their principle was right, absolutely right, the principle that religion is no separate element, no function of a separate organ, but a power governing all life and consecrating democracy into theocracy. 
It is nearly half a century since a German scientist of a school which we for brevity's sake call Materialistic, scandalized many good people by the remark that Der Mensch ist, was er isst; an untranslatable pun. 'Man is what he eats.' Nowadays we have grown accustomed to the scandal. It is perhaps unnecessary at this date to note that ' eat' must here be taken to imply 'digestion,' to include drinking and breathing, and perhaps other less definable modes of receptivity. Even with these qualifications many people will shrink from admitting it in its absolute plainness: they will insist that there is something in the original structure, and that there is more in any of us that can be, straight off, equalled to any aggregate or mixture of carbon, nitrogen, phosphorus, and the rest. With these good people I will not attempt to argue. I will not even go into the problem whether, when the 'heart' of l'ani Fritz was captured by a dish of apple fritters, there was not something of human nature in it; nor will I appeal to any housewife's experience of the ratio between dinner and a husband's mind and temper. I will rather say, Friends, are you not, to put it mildly, a little wanting in apprehension? The man who thought it worth while to say: 'Man is what he eats,' must have suffered much from a generation who said that it mattered nothing, and that he, his morality, his intelligence, his religion were things of a source far transcending what he fed on. He spoke in some weariness, and uttered the other half of the truth. No man, no, nor angel from heaven, if he speaks human speech, can put a concrete truth, a truth, i.e. of life-reality, into a simple proposition.

But what I touched upon this old phrase for, was not to rake up the special controversy it awaked. It is to recall the truth that morals, intellect, art, and religion, are all, profoundly and in their very inwards, affected by the economic condition of a people. Given a certain arrangement of the means of production, and you can only have a certain kind 
of morals, art, and religion. You may encourage schools of art, apply the persuasions of punishment and training to make people moral, and build churches till they fill every corner of your streets, but it will not answer. The foundations of things lie in the commonwealth, and these foundations are its economic arrangements. You fancy, no doubt, that fine art has nothing to do with vulgar craftsmanship or honest labour, but it is far otherwise. You think religion will cure the wretched homes of horrid poverty and insolent wealth : but it will not; for religion will not and cannot live where there are such abominations. You fancy morality sits high and safe on the eternal rocks of reason: but, probably, if you got nearer, you would find that the venerable queen of life has long since been petrified in these altitudes.

The foundations, perhaps even the ground-plan of the moral, religious, artistic life, are laid and fixed in the form, which at any given epoch is dominant, of providing and distributing the means of subsistence. What was the beginning of it all? Of course, we cannot tell : we know nothing of primitive man ; most likely we shall in the literal sense never know primitive man. But we can go so far as the most primitive races that are upon the earth at present. Yet, if we speak of races, let no stress be laid upon that word, and the differences it may involve. The vanities of breed count for little here in comparison with the greater uniformities of art, morality, and religion, which are found wherever in the surface of the globe there is approximately the same form of production of the means of subsistence.

The lowest rank is taken by tribes, found in widely different localities, mainly supporting life by means of hunting and fishing. Such tribes as the native Australians, some Brazilian groups, the Eskimos, the Andamans, the Bushmen in South Africa, and the Terra del Fuegians. The terms hunter and fisher have first to be realized, before their 
force appears. To the modern citizen, hunting and fishing are to some extent a by-play, a sport : in which the object, in the majority of cases, is placed at a hopeless disadvantage. We shall understand it better when, with Lady Nairne's song, we remember that the herring which some call 'vulgar faring' are to fisher wives symbolic of 'lives of men.' But, even in the fishers' case, the primitive people have a sterner war to wage : a war, in almost sober truth, between combatants not equally matched, when man had yet to mould his weapons, and learn the secret of mastery: when, as tell the Indian hunter's' legends, he began to steal from the various creatures their distinctive weapons, and made himself the sole proprietor of all nature's wiliness. It was a struggle too in which for long the victory was, to say the least, uncertain; in which there were many disappointments, long periods of trying hunger, other times of rude gorging; a wandering life running round the cycle of the year, as game drew it here and there; with domestic life, fitful and but forced, with all the illnesses and weaknesses which fasting and feasting alternately followed can produce; leisure for art of a kind; a passionate love of excitement in moments of full meat; a dark, mysterious godhead, dimly connected with woods and streams, with storm and cloud, with unknown perils, with the beasts. Marriage and property, as we know them, were not, save in their rudiments. Yet laws or customs, rigid and numerous, complicated and terrible, grow up. Nor is hunting all. Almost everywhere in these hunter days, the woman has a province of her own. It may be, as in Brazil, that she begins a rude cultivation of the soil; and while her mankind prowl in woods for a while and then sleep or loll till hunger next appeals, she by feebler, but more unremitting energy, gathers a stock of vegetables and fruits. So long as life is so harassed, half the virtues we respect, half the attributes we attribute to deity, half the developments of art, cannot arise. 
It would be out of place here to try to follow out the steps by which the pastoral stage emerged; how the agricultural followed: and how, industry always increasing, complexity supervened. But if the survey could be made, it would show, first, that art, religion and morality, and, we need hardly add, science, grow up and take form in society, and that the essence or ground-plan of society lies in its economical arrangements. The lawgivers of old Israel saw clearly that in them is the root of the matter for morals and religion. The modern spiritualist laughs at the ancient believer, whose god gave him corn and wine, and sat him down under his own vine and fig-tree. But we may spiritualize our God overmuch. God is not merely the guardian or the rewarder of the narrowly moral law. The real moral law of God is the law of all life : and such a God is a living God, the strength of all who believe in him, the shelter in the storm and the heat. God, we may be sure, is not indifferent to morals and still less is he immoral: but perhaps he may be less like a moralist or a judge, a lawgiver or a king, than we are sometimes taught to conceive. Perhaps, as many count morality, he may be more than moral. 


\section{XI}

ON SOME RELATIONS OF MORALS, SCIENCE, AND

\section{RELIGION}

IT is not easy to describe the plain fact of morality; for if it be a fact, it is not as others with which we are more familiar. It is not subject to what are ordinarily called the scientific tests. It cannot be measured or weighed. You can no more detect its presence by experiment strictly so called than you can that of mind or will. You cannot prove that an act of pure virtue was ever done. God is not the only object, if object one may for the moment call Him, that neither microscope nor telescope can discover. Scientific instruments and methods, in the technical sense of their terms, are as little able to detect the presence of intelligence, of purpose, of goodness, of beauty. Psychology, as a strict science in the older sense, must confine itself to the physiological laboratory.

Kant himself has not ventured to assert, that in the world accessible to the scientific, i.e. the sense-bound intellect, there is such a thing as freedom, as morality, as God. All he ean say is, in the first place, that if morality be unreal, or rather if it be not the central reality, the keynote of all thought and life, then you have not merely lost the spring from out your year, but you have ruined the fabric of reality. At least something like this is implied in the course of his argument. It is true that the world known by science seems to remain as an assured and independent result, whether 
there be a moral reality or no. Given a set of sensations, and certain formal tricks of arrangement in them; given an intelligence which gives to these sensations some unity and consistency; and the phenomena, the casual appearances which, as the phrase is, impress themselves upon us, seem to form groups and systems of sufficient stability and solidity to deserve the name of empirical reality. And 'empirical reality' is all Kant claims for so-called things or objects. But a philosopher can hardly rest content with a phrase like 'empirical reality.' Even to say, in words more intelligible to the plain man, that the sense-world of science is a real world, because we feel it inevitably, and because we can calculate and predict its phenomena with a high degree of security, is to say what is true, but what does not go far enough. What is this feeling, this impression we speak of as a self-evident datum, and of which we say that it is inevitable? Let us answer: this feeling is always the reverse side of activity; we are 'impressed,' because we are active, and go forth to meet the world. Were we not active, we could not be thus passive or receptive. The physiologist knows that efferent and afferent nerve-conduction are ultimately inseparable: the stimulus received from without is only possible because of coincident stimulus from within. The eye must strike the sun, in order that the sun may dazzle the eye. So in the mental world, perception were not, if volition were not. Only a being that wills (I use the word in its widest sense) can perceive, as on the other hand only a being that perceives can will. So it is with the synthetic intelligence, with the scientific mind that builds up the data of sensation into groups, types, classes, uniformities, relations of cause and effect, and so on. To say that all this is so, because of the original synthetic unity, or of 'the transcendental unity of self-consciousness,' is no doubt true also, but it does not go to the root of the matter. Self-consciousness, what and why is it? Self-consciousness 
does not-I fear I must apologize to the philosophically trained hearer for making this remark-does not in logic mean the state of mind when a shy person imagines that it is not what he or she does, but that it is he or she who does it, which is the fact of supreme interest to all observers. Self-consciousness to the philosopher means the emergence of intelligence, from its mere awareness of outward fact in a sort of mirror-like reproduction thereof, to an apprehension of itself as co-agent, i.e. as in action and reaction with an outward world, and yet at the same time, as, in some mysterious way, supreme in surveying the play of its own actions and reactions; itself the scene, the play, and an observer, who, in some strange league with author and manager, is more than mere observer. Understanding, said Kant, makes the world, makes nature. Whereat the wiseacres who love to criticize where it is hard to understand, spoke certain witty-sounding words about Solipsism, or the strange fancy of some mad philosopher that his mind made all things; and also certain words intended to be witty, which rested on the assumption that when Kant said 'nature' or 'world,' he meant the whole lump of earth, and other lumps of other earths, called suns and planets, with all the countless fragments into which we are accustomed to divide the large earthly lump, e.g. into coals, carts, \&c. But intelligence, as we have, I hope, already seen, is not a thing which can be the sole property of any one being, or be supposed to be included in one single brain: it is, as old Thomas Hobbes said, the same in every man, a common atmosphere or spirit in which they live and act, and which finds its visible embodiment and guarantee in what for shortness we call the 'City' or State. The understanding which makes nature and the world is in no risk of falling into Solipsism: that is the one thing it cannot do: sooner than do that, it must perish. It cannot be self-confined, in the narrow sense; its self is the universe, potential, if not actual. 
But it is hardly less important to realize that the so-called world or nature is not a mere aggregate of things. Nature is an elliptical phrase for the order, the indwelling order, the self-unfolding order, the progressive uniformity, of what you loosely call 'the natural world' without much thinking what you mean. Each separate thing is, no doubt, also and rightly, called nature: but it is so, because in each there is the presence and power which animates the whole: a complex of relations which we can never hope to completely unveil, and which would, if we could but know it, bind it in some way with every other item in the universe of things. And so it is with what we call the World, with, however, this difference. When we speak of the totality of things as nature, we think mainly of that totality as a selfdirecting, self-systematizing being, rolling on the cycle of its changes, our vicissitudes even included, by laws of its own. But when we talk of the world, we are in the first instance more impressed by the practical aspect of reality. We see in it, not so much a mere theoretical problem to be unravelled, as a field of action in which order has been established, and will yet more and more be established, in subservience to human needs; needs of all kinds and all grades, some of them what we call material, some what we call spiritual. Even the world, as we saw the other day, tends to slip from us into independence: yet always we feel it is the field of action, a unity to which we (we and not I, or if $I$, then the absolute ' $I$ ' of Fichte, which is equal to the collective infinity of 'we's) have given as it were the bond: we, as humanity, as what we are and are not, but will be, when we are all that we may be. To the view of the sum of things as nature, which is the theoretical view, the outlook of the contemplative spirit, man seems but a little thing: a part in a great system, not merely bowed down before the physical immensity of the spectacle, but even more abased before the transcendent Power which seems to mould its destinies and 
therefore his. The other view of it as the world-the Kosmos, mundus-is taken from a different standpoint, that of action rather than theory. It sees in the system of things an order and an economy, of which man-humanity is the central point, on which all things hinge. It implies that in him lies the key to the mystery: a key, however, which has yet many doors to open : or rather-for metaphor must break down here-a key which has magic history and fairy powers, which is not yet what it shall be. It is humanity, social humanity, forming itself by slow steps : slow, though sometimes, when we are immersed in some petty advance, we think with pardonable, yet foolish pride that we have made immense strides : forming itself by industry and commerce, by art and science, by philosophy and religion, to decipher the mystery in which it was born, and thus better and better understand itself. For this is perhaps the main thing. Man, to use an old phrase, is the microcosm, the little world. He becomes more and more himself in proportion as, by work and thought, by art and science, he more and more makes the larger world his own.

And this brings us round to the purport of an inevitable digression. The 'Nature' which the philosophic theorist, the metaphysician poet, sees as the background of unity in which lie all the several materials, of which the several sciences make their most by observation and experiment and calculus : that nature, as Kant points out, is not itself a fact of science, of sense, or of intellect, as he defines them. It is the reflex of a mental unity, of a mysterious unifying power we sometimes call imagination or the faculty of ideal construction, and at other times call the 'original unity of apperception.' 'Nature' in this sense goes for its roots deeper than perception or apperception (which means the organizing or assimilating of perceptions into a concrete percept). It goes back to the practical side, the active part, the will, the effort to do and live, the effort to be more and more of what we are 
as yet less, that nisus of self-conservation which can only succeed in being that by being more than that, by being a nisus or effort to become more than it was, to be all that it had not been. Intelligence reads off one world of uniform law, because will demands one world for life to be realized in : reason theoretic gives a unity to nature, because reason practical, starting from a ' me' or ' ego' which is weak, incoherent, unrealized, is ever seeking to elevate it to be a ' $m e$ ' or ' ego' which is one, comprehensive, and complete. If you speak of nature as a unity governed by unfaltering law, it is because human reason in its action, industrial, moral, artistic, postulates the subservience of all events to one common end. And that end, what is it?

An old answer, most of us here are familiar with, tells us that 'man's chief end,' at least, 'is to glorify God, and to enjoy him for ever.' It may be,-I do not know,--that those who framed these words thought, as think some of those who read them to-day, that the two parts of the answer represent two stages, one here, another hereafter; and that they regarded the latter as a reward attached by grace to the earlier. Yet perhaps too they may have entertained an idea of a more intimate connexion between the two aspects, both in time and in essence. To us at the present day, the words, if we try to get their meaning and do not merely repeat them, sound unfamiliar, echoes of a time when other fashions ruled the social and intellectual world. To glorify God, ad maiorem Dei gloriam, are phrases which the sciolist, sometimes in places where one would expect better things, finds an easy subject of scorn; and I am not concerned to deny that there have been curious misapplications of them. But are our own phrases so impeccable? If, in a bald literal way, it be impossible to glorify the Supreme, as it is impracticable to gild refined gold, is it any more possible to organize God, him, the supreme organizer and organization? But neither the Presbyterian divines nor Renan altogether wasted words. If 
it be a truth that God created man in his own image, it is no less a truth that every man recreates God in his image. It is the Word, the only-begotten Son, who for ever reveals, or, as I should translate it, describes and interprets the Father. But to do that, man, so to speak, must be fully himself: he must become not a separate sphere in creation, but the organizing principle of all. He must more and more realize the infinite possibilities that are in him, by realizing more and more the unity of creation. Herein lies for him a difficulty and a danger. He fancies in his impotence that the less others can be, the more he makes them cease, the more will he himself be. His grand impulse, his glory perhaps - and he sometimes thinks it for God's glory alsois to kill. He crushes down his fellows. He ruthlessly sweeps away the lower races whica check the free swing of his interests. The beasts of the field and the fowls of the air fall a victim often to the mere lust of killing; and the choicest trees and shrubs have been irrecoverably cut down by the maddened colonist and trader who knows no god but Plutus. The terrestrial fauna and flora are fast losing their variety. The earth's surface has been ravaged and rent into unrecognizableness. He has captured and tamed some of the beasts. His own species he has sought to enslave, i.e. to destroy their separate personality, and make them mere tools of his hand. And, almost universally, he has sought to make his vassal or bondwoman out of the woman of his own kind; her, who, just because she is nearer to him and in all senses dearer to him than aught else, has always been the most unenslavable of all things and the most untameable of all his captives. And yet he wonders that he is without peace, security, and happiness: he wonders that his heart is empty. But if there is one truth more certain than another, it is that for every thing destroyed in its own nature and independence, there is a corresponding lack created in the destroyer. We can only be what we are meant to be, in 
proportion as we can establish such a relation between us and other things that they may realize their full being. It is not merely human persons that are ends in themselves: though their essential worth it may be especially our interest to maintain. But in a way all things are such ends. And they are so for us because, unless they attain their full development, we fall short of ours. The enslaving man is a man enslaved, in a worse sense, by his slave. There is nothing single nor solitary, said the Stoic, in the city of God we call the world. No doubt, we may shut our eyes to the essential sociality of man : we may act as if it were not. But in that case we pay the penalty, not in a punishment deferred, and to be paid by some mysterious machinery, as the Christian theologian, misconceiving Plato's metaphors, has sometimes seemed to suppose; but in a lowered vitality, an empty heart, the sting of not, it may be, remorse, but of realized failure. It is the eternal law of righteousness, that the soul which falls short of the law of universal respect, and treats one of the least of things as if it too were not God's creature, that soul is struck with a withering of which the natural issue is death.

For our own sakes, for our own interest, we must be tender, respectful of all things. I know there are some to whom all this will sound absurd, quixotic, fantastic, if not worse. To such I would say, like Cromwell: 'I beseech you, brethren, think it possible that ye may be mistaken.' It is possible, I dare say, that a single soul may find salvation for itself: but it may be doubted if such a salvation is greatly worth the trouble. A great Christian has left on record the word that he would almost be accursed himself rather than see his kinsfolk left to perdition. As Plato has it, a single traveller may perhaps find shelter from the dust-storm that ever blows across the way by retiring into the shelter of some wall : but the only true hope of betterment is to save himself by forming a company, and ultimately it must be a large company, of his 
kindred. They are poor creatures who press into the warm hall, whilst any of their near and dear ones are still shivering in the cold.

But more than that is here at stake. Freedom, says the old Scotch poet, is a noble thing. But they are of the fewest who know what freedom really is. Its essence is, in each, respect for the individuality of others. We sometimes hear it said that the age of reverence is past, gone with the age of chivalry. But if these good things have gone, it may be that they were not wholly good; and that in these 'good customs' God did not fulfil himself so fully as to justify - their eternal endurance. What ended the age of chivalry was that it was not chivalrous enough. It is easy to be chivalrous, if only the lady be but young and fair, if only your enemy be nobly born and nobly bred, and when love and honour follow on service rendered. But when chivalry passed beyond these charmed bounds, its lance lay useless, and its knight errantry grew cold. So, it may be, there was something false in the ring of an old-time reverence. It was, perhaps, too one-sided, too partial in its scope. Juvenal somewhere speaks of the ' reverence due to boyhood.' What he says in one special sense has a wider meaning. There is room for Vice Versa between fathers and sons, between husband and wife, between many other relationships. Our reverences all round have perhaps been but measured on one little patch of life, and left all the rest desert. We wish, no doubt, to have others in agreement with us, but agreement is worth little unless it is genuine and spontaneous. Ibsen, in one of his plays, has depicted a husband and wife who, after years of juxtaposition are still strangers, so that the relation between them is one of fear and distrust, tempered by something that might grow to love. An occasion arises when an old tie tends to reassert itself over the wife. The husband's natural impulse is to assert and make good on the other side the legal, i.e. the force-sanctioned, bond which marriage law gives him. But 
a more reasonable impulse prevails ; and, by effacing his own brute authority, he restores his wife to her self-command, and the temptation is at an end. I do not inquire how far such conduct might be in each case possible or advisable. But I think I may say that half the embroglios of this world arise from the substitution of mechanical for moral suasion. And by moral suasion is meant, not counselling, or advising, or recommending, or persuading, in so far as these imply a foregone conclusion; but an effort on our part to exclude the influence of all other than purely rational, i.e. common or social motives, to efface all the brute force of personality, and to trust only to that higher personality which may well be called impersonal. The triumph of morality is attained when, with all the earnestness of conviction, we can resist the impulse to tyrannize over a wife, or a husband, or a child, or any one whose legal relations to us puts them, as it is facetiously called, at our mercy. If sons and daughters revolt, if a whole sex is shaken by incipient mutiny, it is time, not perhaps to tear up the institutions which are concerned, but certainly to consider, and consider with practical effect, whether there be not something rotten in the state of Denmark, to account for such fretfulness and protest. And these remarks do not, I hardly need add, cut only one way. So long as mere force is in any way directly influential in human life, so long we are not civilized or moral. In an imperfect world force is necessary, but only to protect rights : and rights are, in their own nature and function, the modes of realizing freedom.

Now the very conception of nature and a natural world, with which the philosophy of science makes us acquainted, has its justification in this prime moral need. As a world, the material objects fronting us, whether persons or thingsfor materiality is a common attribute of them all-are a means for our self-realization. By it and them we become what we are, and the larger and more organically one they become, the 
better developed are we. They are necessary to our fulfilment: in and through them we are made perfect. But not merely do they constitute our environment, as a kind of spring-board by which we may rise to higher things; they are also a natural world, a world of nature. As such, they one and all, each through all, and all through each, follow a law of their own. That is the great lesson which philosophy, as it follows the lead of the natural sciences, continually impresses upon us. Each part of nature, if you like to put it religiously, is alike near and dear to God: alike, i.e. in so far as its nature is in its measure his care, as peculiarly as if there were none to compete with it. This was the truth which Spinoza expressed when he identified God and nature, and refused to concede to man a place utterly outside the natural range. It may be that the phraseology of Spinoza was hardly adequate. But at least, it taught to those who would listen, that the lordship of man over nature is essentially a ministry and a stewardship.

If Kant, therefore, insists that Freedom is the essential of humanity, it is clear that this freedom cannot overthrow the necessity, such as it is, of nature. Rather freedom has meaning only in correlation to such necessity. It lies-and Spinoza saw this as well as Kant-in acting, and not in mere being. Nobody is free. All action is freedom. The world which is and has been, and which must be because it has been, cannot be the only world, or cannot be the full world, real with the highest reality. The ordered cycle of changes and uniformities must be the expression of an intelligent will, and $I$, the agent, must participate in the direction; I must be not merely a part of things, controlled and necessitated by other things, but also and essentially one with the whole, an individual, so far independent and co-operative, in a greater and complete individuality. And lastly, Kant assumes, as has been even now implied, that, if morality is to be the centre of reality, there must be God. So far Kant sees clearly: but when he comes to ask more definitely what it is 
that God does, his vision seems to grow unsteady. Christianity, in Kant's day, had brought the world to a Deism, which had ousted God from the present life of reality, and relegated him to a Far beyond and Hereafter. From that Far away he still came, supervising, rectifying, and punishing. And so Kant was understood to speak of him as if it were his task to adjust the failing proportion between virtue and happiness, to compensate the good for their sufferings, and to make evil in the end unprofitable. Yet, if Kant said so, we may be sure that was not the true meaning at which he aimed. Even God, we may assert, cannot undo what has been done. God does not, as Plato supposed in his myth, let go the helm of the world for a time, and again and again return to save the vessel. He is not the synthesis or adjustment of nature and moral order: rather in him they are one. We may not see the convergency-point: but action and theory presuppose its necessity. Kant, we may maintain even against appearances, did not commit what Schelling calls the 'abomination' of 'seeking to deduce God from the requirements of morality.' And if we may even less care to adopt Schelling's phrase, ' It is a duty to be convinced that all immorality is in its essence and root unintelligent and irrational,' we may at least agree with him in holding that ' to the wrong-doer, it is just the diminished reality which gets expression by him that is his punishment.'

But what is morality? To this question Kant himself has returned an answer which is historic. For Kant the fact of morality is, as all the world knows, the sense of duty. Kant's King Frederick II may be cited in support of this view. Thus in I760 (in the midst of the Seven Years' War) he writes to D'Argens : 'You must know it is not necessary that I should live, but very necessary I should do my duty. We are in this world to work. To do good ... is a duty which every man ought to fulfil according to his means.' Or again, 'Both my body and my mind must bend to their 
duty.' Or, in a letter to the Electress of Saxony (1766), 'Do to others only what you wish they should do to you : this principle includes all virtue and the duties of man towards the society in which he is placed.' Duty, no doubt, often coincides with inclination; obligation is often dissolved, as it were, in pleasure. But if we wish to see it as it truly is, we must, in Kant's view, look at it when it stands alone : we must see it, as Plato hinted long before Kant, as it behaves when unsupported by liking, opposed by desire. When so seen in its purity, it comes upon man with a downright command, 'a categorical imperative.' The latter phrase is Kant's: but because the phrase is his, no one need suppose the fact which it names was any discovery or novelty of his. The categorical imperative is as old as humanity, as old as reason, as old as love, as old as the faith in God, as old as the first efforts of art to eternalize the passing show. It is a command without a reason: because it is the supreme command of reason itself; but for the present, we need not meddle with that, and simply note the fact alleged by Kant that its authority is unconditional.

All this, be it said, was not new. But, as German biography in the end of last century can show, it had a deep and stimulating effect on the conscience. It disengaged a great fact out of a mass of irrelevant details : and even if it a little exaggerated it in so disengaging it, that is a fault which may well be borne with. Even Goethe, who did not himself see the moral life chiefly as duty, felt so far inspired as to make it a theme of some stories. It needed some genius thus to set duty in its high seat, to realize what Kant calls the 'grandeur and sublimity of its name.' Grammatically, all that Kant did was only to set the singular for the plural, and that you may say is a small thing. Perhaps, and yet, if I may borrow an example to make the difference clear, whatever tone men may adopt when they speak about women, it is generally a higher note they feel themselves obliged to strike 
when they think upon woman. Duties, in the plural-and they go endlessly into the plural, into the detail of lifeseem sometimes trivial, tiresome marks of bondage and hampering conditions to free development. So even thought a French moralist, Malebranche, rather more than a century before Kant: les devoirs to him savoured of the lesson to be learned, the exercise to be done, in consequence of command issued yesterday, and to avoid a punishment expectable otherwise to-morrow. And so Malebranche, turning half-contemptuously from mere duties, bade the seeker for true and noble morality keep his eye ever bright with the love of order.

And there have been many ready to outdo Malebranche in depreciating the yoke of duty. It is, they say, the mere weight of tradition, the mere incidence of authority. To them, the phrase about doing duty in that place and station to which God has appointed us, has an air of feudal hierarchism, of unchangeable caste, of a system which hangs blindly to the past, and forgets the whole onward tendency to the future. It seems to bar all progress, all reform. It may do for common folk, 'for country folk who live beneath the shadow of the steeple, the parson and the parson's wife, and mostly married people.' But something better is needed for young men and maidens, for all who would (if not leave the world better than they found it, which they may think either a vain task or a work of supererogation) yet raise themselves higher in the scale of being. Why should they be bound by what was done ages before them, by the remnants of custom and observance handed down from an ignorant and half-barbarous time? Duties : why, the word is a bugbear to check progress ; it is a catchword of the friends of order, of the party of stagnation and perhaps of reaction. Or, again, they cry: Duty is one of the 'fads' of Christianity: and Kant himself in his ethical system was only putting in philosophical formulae the memories of his youth, when under pious parents he learnt the decalogue and the later commandments. 
So Schopenhauer has said and many have re-echoed since. I will take the liberty of saying that it is a poor argument against any part of a philosophic creed, to say that it has been smuggled into it from Christian sources. We may all have our own views about the personality of him who gave his popular and prophetic name (Christ or Messiah) to the Christian life: but there can be little dispute about the fact that the ideas, the principles at the root of Christianity, are in no sense peculiar to it, in no sense its special property. I say with Schelling, the Schelling of his later time, Christianity is as old as the world : its ideas, its hopes, its faith, its love, are those on which the nobler sons and daughters of humanity have in all ages and in all lands nourished in some measure their inner life, gone forth to meet the world and death. It also, like Kant, proclaimed no new truth, no truth which had never been there before; but, as its adherents believed, in their Master they saw one who gave to words and ideas the power of a life, one who helped them to see the invisible world as they had never seen it before, and with a strength of faithful vision which shot past even the gates of death into the land of eternal life. But the ideas of Christianity, its legitimate ideas, are consonant with all reason, and kindred with all true thought which has tried to fathom the mystery of life. And it would be a poor system of ethics which, forsooth, because it was proud to be called human or humane, should consider itself either entitled or obliged to shut itself out from the New Testament and the Hebrew Scriptures, on the ground that these were 'revealed.' If ethics is not to annex any of the doctrines which in different ages and countries are believed to have been revealed, ethics will have a rather narrow survey. But it has annexed them, and will do so more and more.

And undoubtedly this conception of ethics, as, on the one hand, a system of laws, and as, on the other, a duty to fulfil or obey them, is one which stands out conspicuously in what Hebrew philology has taught us to regard as the great products 
of the so-called prophetic reform. A people of shepherds, cradled in the desert, and there taught by some providential method to realize the unity of their life in a God, who goes forth with them to battle, rejoices with them in their joys and has compassion on their sorrows, is through some course of events led to occupy a territory half-agricultural, and to exchange its nomadic habits for the ways and manners of the townsman and the cultivator. As years roll on, its old organization shows itself unequal to cope with the altered circumstances. Internal dissensions, external violence, wreck its prosperity and partially destroy it. A fresh effort of concentration is needed : a reform, which is at the same time a going back upon the old spirit of unity and obedience to the one living and guiding principle of collective action. Then arose a series of men,-we know them as the prophets of Israel,-who, strong in the sense of their solidarity with the one spirit which guided Israel in the distant and legendary past, and will, as they believe, guide him in the years to come, declare themselves the messengers of Jahve. Rebuking, consoling, reminding, encouraging, they emphasize one central truth that the whole people, and man by man, is the servant of Jahve, charged with a work to be done, laden with a burden never to be thrown off, but always sustained by the sympathy, the help, if need be, the merciful punishment of the Lord of Hosts. At first, the work which they conceive as thus imposed is a particularist work for Israel's interest, and Jahve is the God of Israel: but as prophet succeeds prophet, the servant of Jahve, i. e. Israel, collectively and individually, becomes, so to speak, an apostle for the human race, and Jahve himself is seen to be the God of the whole earth, whom heaven and the heaven of heavens cannot contain. And God himself comes to be, as it were, embodied, though never quite lost, in the conception of a Law, of a great order which he reveals as determining the aim and methods of life, for the nation and the individual. All life is part of a great duty, 
to reveal the glory, the wisdom and mercy of Jahve, and to work out the spirit of righteousness. Yet is the Lawgiver the friend, the lover of his people: if they have been as the unfaithful wife, he is as the loving husband, who judges righteous judgement, i. e. forgives, because he knows what humanity is. The dominant note, therefore, is a harmony of two elements : it is the sense of utter and everlasting dependence, the fear of Jahve : but it is, in its highest moments, joy in the Lord : if he is with us, who can be against us? and though we faint and fail, God is our strength and our everlasting own.

It is a mere injustice to Judaism to say that it had not a spring of life and strength within it, a well of ethical water springing up to everlasting life. What the last prophet came to fulfil, that the earlier law and the prophets had taught. This we may be sure of, that Judaism would not have lasted through the fearful ordeal of Mediaevalism, had it not been something nobler than a mere system of rules, codified into endless multiplicity of detail. Do not let us abuse the Law because of the lawyers (some of whom must be bad); or charge the righteous with the petty conceits of Pharisaism. The I Law only came to be a grinding burden, an unfulfillable task, when he that was Lord of the Law seemed to men to withdraw into himself, to show himself no more to Israel, and to leave as his witness and testimony a cast-iron code, or a code which, if flexible, was flexible only that it might catch more than it could ever do by its rigidity. The Law became an evil to be cast forth, an idol to be burned, at such time as it came to shut out God, the living God, from his people, and left the Moloch of legalism in its place. But not so had the prophets or the author of Deuteronomy understood the relation of Law to God: not so the preponderating voice of the Hebrew psalmists. Yet it is true that, in the struggle which the Jewish race had to wage on its own soil for six centuries till Titus scattered it to the winds, stress came to be laid on the elements of exclusiveness; that the fear of the Lord 
tended to suppress hope and joy in believing; and that the Law degenerated to all appearance into a burden of precept and deduction from precept, too grievous to be borne.

Yet if the central idea of Semitic religion took its place in European culture, it was not without a profound alteration in its structure and its relations to the other elements of national life. A Semitic scholar has tried to make out that the great contribution to religious thought by the Semitic race was the idea of monotheism. It is perhaps a little difficult to say what the monotheistic idea veritably is. But, in any case, it may be asserted without unnecessary paradox that the strength of the Semitic contribution to humanity does not lie, strietly speaking, in ideas. The people of 'ideas,' of thoughts, in the ordinary sense, are the Indo-European races. The Semiteand by Semite I mean in the main Hebrew and Arab-is a man of vision, a seer, one who envisages truth in its individual concreteness. His genius is lyrical and historical, not dramatic or philosophical. What he sees, he utters; what he feels, he can reveal; but it is a monologue, and no reflection. And, secondly, he is a man of action, rather than thought; his beliefs are not articles of a creed, but postulates of action. For him God speaks to man directly, face to face ; speaks in the spirit of the moment, and for the thing to be done. His great function is the imperative, the word of action; not, 'so am I to be rightly thought of,' but 'so must it be done.' Creation itself is a mandate, not a making : its word is fiat.

Even the later appearance of Semitic religion is like the earlier. Mohammed, too, is a man of simple sensuous vision; he sees his Lord as a beardless youth with locks of curly hair, and on his feet golden sandals. God comes nigh. He descends till he is only two bows' length from the prophet and nearer: Mohammed sees Paradise, with its dark-eyed maidens and the green-robed faithful at their side. But observe it is all fresh and vigorous, with the hues of young belief, and not a mere lingering image in some after-time. 
And it goes from the sensuous to the spiritual at one step. 'Every night' (or every Friday night according to another form of the tradition) 'God comes down to the firmament of the earth and says: Wherever there is a sinner who repents, I will turn myself unto him, and him that begs for forgiveness will I forgive.' But the thing ever present, occasionally relieved by the idea of the compassionate and all-merciful, is the sense of life's emptiness without God, and of God being all in all. Once the prophet stood before a heap of dung and said: 'So, such is the world,' and then he took rotten rags and mouldering bones, and cried: 'That is the world.' And the prophet said again: 'If ye knew what I know, ye would laugh little and weep much. I see what ye see not, and hear what ye hear not: the earth groans, and well may it groan. There is not one span-breadth whereon an angel does not press his brow into the dust. By Allah, if ye knew what I know, ye wóld laugh little and weep much. Ye would cease dallying wantonly with your women and go forth into the street and humiliate you before God.' When God's omnipresence is so felt, one does not wonder to hear that a certain verse of the Koran made Omar faint : or that one day he took in his hand a corn-straw and said: Oh, that I were this straw! Oh, that I were forgotten and for ever forgotten! Oh, that my mother had never borne me' :- or that Abubekr cried: 'Oh, that I had been created as a bird and not as a man!'

The strength of Semitic faith, the religious gold it brings, is not the discovery that God is, or that he is one, but that he is alive, active, ruling the generations of men' that he is the law and the spirit of life. Its God is not a 'being,' an 'is,' but an 'ought' : not a God of the past but of the future: not of the dead but of the living. He is not the great worldsource, the great object of all objects : if he is cause, he is essentially active cause; if he is substance, he is also acting 'subject.' To his people he is as a father, a husband, a leader, 
a fellow-warrior; at once above them and among them, their own better half, their truer self, their conscience, their spring of action. The shades in Islam are darker than the earlier Judaism and the later Israelitism: God is perhaps too terrible. But the faith in the power that makes for righteousness is strong: the obedience to duty is enthusiasm, and if the visions of Paradise shine too sensuously bright, who are we that we should find fault?

When Semitic faith reaches the lands of Aryan races, its form and character change. The Greek spirit, the IndoEuropean spirit, seizes upon it, and makes out of religion a theology. It was so with Islam, when it penetrated into regions under Persian and Greek influence. God came to be an object for theoretic contemplation, for description and analysis. The creed became a series of propositions, stating scientific or quasi-scientific truth. God, if still defined as the sum or supreme of reality, had only a logical thing-like reality, not the reality of life and action. He had to pass into transcendence; for how could a being so surpassingly great co-exist with a world of beings so small? Be content to say merely that God is, and you are very near practically affirming that he is not. You then become alarmed; for old memories cling to the name, and you begin to look about for proofs of his existence. And when reality is lost, it is not easy to find it by arguments. You may prove by a thousand reasons that your friend must be faithful; but if your faith in her is gone, what are they worth? That verb 'is' is always elliptical. It calls for a completion of its predication. Give it no complement, and you may as well almost let it slip altogether. And the complement of the predication in God's case is : God is all in all, is ever-acting, is mine. Stop short of these completing words, and your phrase misses fire, does not eatch, hangs inert.

But if this change, which in the Aryan mind so often came over the religious life, was inimical to religion, it had also evil 
consequences for morals. It took the life out of it, and left it a law, a form, a 'cold morality.' If life, therefore, was to be given, it had to be galvanized into the moral order from without. That might be done by a supra-mundane God, who by fiat corrects the defective correspondence between the sense of duty and the sense of life. Perhaps, on the other hand, like young Fichte, you may assert in words that we need no god other than the moral order. But if you use such words, you will probably be obliged to own, as Fichte afterwards did, that a moral order so understood is very different from what the phrase ordinarily means; that it is not an order but an ordering life; that it is not moral but something to which morality, strictly so called, is a means.

Christendom, as I showed more at length last year, drank deeply, through St. Paul, and later through the Roman legalism, of the Judaic spirit. Duty, the sense of everpressing law, grew to be misconstrued as a regard for already promulgated laws, a service to ordinances, a machinery of order. But duty is more than order or obedience; and that is what it was Kant's especial business to teach; not to emphasize-though that also is good-that man lives under a categorical imperative. The ethical doctrine of Kant is chiefly concerned with an argument to show that the moral law is freedom; that its order is also progress: and that the categorical imperative is only fully phrased by autonomy. The moral law, if it be a command, is not a command from without; if it comes from above and with authority, that authority is not (in the ordinary sense) supernatural, and that 'above' is to be taken not of locality, but of grade of function. Every ethical precept must be judged by one test: is it a co-operant part of the great ethical ideal of growing perfection for the individual and for the collectivity? Can it, in the fullest light, and with all clearness, be said to be an integral part of that good will, that will to good, which is the essential prerogative of man, however much in moments 
he fails short of it, or in ignorance works against it? This will to good, which has no limits or dividing lines, which is not will for the good of self, or of society, or of humanity, but for all good and good in all, is another name for reason, and another name for love. It is the spirit in man which is his higher nature, ever enacting rules of good, ever setting up new methods of reaching the ideal; but always conscious that they are, though good, not the good, and therefore, though to be obeyed, not to be blindly obeyed. They are to be obeyed, one might say, not as we would obey God, but as we might bow before one of his angels. Progress through order, and order for the sake of progress: yet, alwaysthough it is a dangerous truth, as some may think-the order is progressive, duty is moving. Even so it is with religion. Man, it has been said, never is, but always to be, blest. So says one, "the true God of Israel is not the god who comes naturally (i.e. as result of previous process) to the Israelitic consciousness : he must be apprehended by an express act of the intelligence. All the patriarchs look forward to a salvation to come: and God himself is only to be understood as a God who becomes and lives, who for us is not what he will yet be.' So duty is not adherence to a fixed post : the soldier of duty has no doubt an obligation : but he will discharge it ill, if he think it is all predetermined and within the bond.

When in presence of Lear, her sisters and the court, her father asked Cordelia his question, her reply was :

' I love your majesty

According to my bond, nor more nor less.'

And again :

'You have begot me, bred me, loved me: I

Return those duties back as are right fit, Obey you, love you, and most honour you.'

Cordelia defended herself against the charge of untenderness by the claim to be at least true: and excused apparent coldness 
by the defence, 'I cannot heave my heart into my mouth.' Her situation was, indeed, excusable; she was tempted. A foolish father, hypocritical sisters, and a gaping crowd, might well have been too much for her; and like a second Vashti, she refused at the monarch's beck ' to show the princes and the people her beauty.' But natheless, even though her tempter took the guise of an angel of light, the love of truth, she fell, a not wholly innocent victim. For duty is not perfectly rendered, when it is rendered as duty and no more: it can never be merely debt paid, but always must have added grace : it must not be paid, but as if freely given. It is sad when the hypocrisy of over-statement drives one into matter-of-factness : for matter-of-factness just wants a gracious touch to light it up into truth. Cordelia, for a moment, but a moment of great issues, was prim and proper; and considerations, quite irrelevantly personal, closed the issues from the heart to the lips. An evil spirit, the evil spirit of sisterhood, subjugated nature and daughterhood, and the jealousy her words let loose went on to work out all its tempestuous mischief. 


\section{XII}

THE ESSENTIAL NATURE OF RELIGION AND ITS RELATION TO MORALITY. - THE BELIEF IN IMMORTALITY

WE have seen more than once that it is hard to lay down a line to distinguish religion from morality. In a phrase quoted from Schelling, we found the religious spirit described as conscientiousness, only however in order that such conscientiousness itself might be identified with heroism and enthusiasm. But in each of the terms themselves there is a corresponding antinomy. In religion, e.g. at whatever stage we regard it, there is a strange antithesis between the power attributed to the god or gods, and the implication that the faithful worshipper has all this divine power as it were at his command. Even in the lower forms of savage religion the worshipper believes that, if only the right methods are employed, the powers that rule in the various parts of the natural sphere are at his disposal. The believer, however, ascribing superhuman powers to his god, still, by an apparently contradictory attitude, hopes confidently to find these powers subservient to himself. There is thus, on the one hand, fear, subjection, dependence: but there is equally on the other, hope, confidence, and appropriation. There is an underlying sense of essential kindred between man and God, but between the two parties there is at the same time a division or apparent hostility: a hostility which, however, may be said to be implicitly overcome, because it can be over- 
come by means and methods at man's disposal. The face of God may be often veiled and apparently averted, but, though the friendship may be concealed, it is there, and by applying the right means can be re-awakened. God and man are, as it were, old friends, as Pindar said, from the same stock; but (shall we say, in the process of civilization?) they have drifted apart; a variance has arisen, and requires to be removed by communication, according to a certain set of observances. These friendly observances, however, God himself has, it is understood, revealed at some auspicious moment. He may be jealous, he may be mischievous, he may be uncertain; so it has seemed at times to many of his worshippers; but underlying it all there is a certainty in the worshipper that, if he follows the appointed methods of approaching his God, he can by them secure for his interest the great powers of the world. Thus understood, religion means a sense, on man's side, of a Power superior, indefinitely superior to himself, controlling him and things with absolute authority: yet graciously permitting him, by an appointed or revealed series of observances, to exercise control in his turn. Man, in his weakness, has ultimately on his side God in his strength: if, that is, a certain barrier between them be first removed, a mode of doing which has in some way been disclosed to man by the deity. Thus in the very forefront of religion stands the postulated fact of revelation. Man, away from God and having lost sight of him, is as constantly persuaded that he is opening a way back to himself, as it were, giving signals and beckoning from the darkness in which he dwells.

It is usual in these days to regard everything under the conditions of the struggle for existence, and as a weapon for use therein. Of material weapons man has invented or appropriated many. He has wrested from the creatures their own claws, tusks, bones, and used them to subdue others; he has chipped and shaped stones, and finally hammered and fused metals into his tools. But all these implements are 
slight in importance if compared with the metaphysical ally, the supernatural aid, which he has secured in his contest. All the ranges of nature, animate and inanimate, may resist as they like his efforts to subdue them: but man has a weapon in his possession stronger than anything they can possibly bring against him. By an instinct earlier than any history can trace, he sets the power in and behind phenomena on his side. He is naturally a theogonic being : he has at the very root of all his action an instinct, the instinct of reason, which grows and becomes more determinate, that he is, as it were, backed by great powers to the extent of which he can and will fix no limits. He projects his own self to be into the nature he seeks to conquer. Like an assailant who should succeed in throwing his standard into the strong central keep of the enemy's fortress, and fight his way thereto with assured victory in his eyes of hope, so man, with the vision of the soul, prognosticates his final triumph. He sees, often faltering, the writing on the wall, which announces for those who can read it the foe's defeat. Thus behaves, thus exults, that reason in him, stronger and faster than reasoning, which already reaching beyond his mere physical individuality, knows ' no limits to its sway; its flag, the sceptre all who meet obey.' It, the god-discovering, godbegetting instinct, is, as it were, the long-neglected foundling of some great hero by a lowly mother, who goes forth, a Theseus, in search of home and adventures, working his way slowly into recognition, the hidden father ever and anon vouchsafing tokens of encouraging manifestations, till in the fullness of all times the hour of unification and final restitution shall come.

Such a power reveals itself especially, as it were palpably, in particular incidents and events of his history. It takes shape here and there, in the course of experience. It is, if you like so to put it, the sense of the infinite; but that only means the feeling, and occasionally the vivid realization, that 
behind the definite and the accomplished there is ever more and more yet to be attained. For at first the conception of the object of each feeling is very inadequate. Its infinity only appears in an endless emergence of new and ever new gods. We speak of the concluding result of such a theogonic movement of the human spirit as polytheism. But polytheism is only the summing up by reflection of a process which comes upon God here, there, and anywhere, and which, now that it has found so many instances of godhead, stops, and gathering them together forms them into a system. Thus the mere assemblage, the mere pantheon, of a polytheism is not the primal religious fact, but a subsequent product of theological study, seeking to arrange, codify, and co-ordinate the forms of divinity, which have successively arisen in the course of natural development. Each of its successive, or even simultaneous, deities was a god, or, indeed, was God; each a specimen, as seen under the perspective of a special time and place, of the great power of things: and it was only when classification supervening found a multitude of such beings awaiting its decision, and all claiming to be genuinely accredited, that the question arose as to their mutual relation. Each, as it first appeared in the form of deity, was God: each even afterwards, when the religious worshipper took it seriously as a divine power, was still God: but when the deifying instinct had ceased, and there were only its results to compile and compare, the products left for the artist and the historian in the course of the theogonic process had to be adjusted to each other. Theological ingenuity, taking each of these products as an independent and individually real entity, and asking how the multiplicity can be grouped, creates a mythological pantheon or system of gods. If, on the contrary, we remember that each god was only a fragmentary step in the evolution of God, we shall refuse to recognize any of them in separateness as fully God; though each was for the time and place a symbol of true divinity. 
We shall treat the variety, not as exclusive individuals to be grouped in a collective body, but as fragments or faces or aspects of one supreme reality, one Godhead successively surmised by man, and successively self-revealed in the course of history.

A real polytheism, if it were possible, would violate the very postulate of religion. If the gods are many, they cease to be God, the object of worship and power, and become mere objects suitable for treatment in art and literature. So it was in Greece, in India, in Germany, and indeed almost everywhere: so it might have been in Israel. Always a polytheism is rather an artistic than a religious phenomenon, a category of theological reflection, not a directly religious birth. In the truly religious field the God is one and complete, at each time one and all. It may be that the worshipper, who now paid his reverence to Aphrodite, at another time to Demeter, could hardly tell what was the relation of the powers he successively adored. But, on the other hand, these were not problems that troubled him : they are problems that concern the theologian. To the faithful heart, seeking help and hearing, each at the moment is God, each omnipotent; with, no doubt, the qualification added as reflection steps in-in his. sphere. But, at each moment in the stress and strain of real life, the many practically converge into one. Here; as in so many other instances, religion and theology separate. But theology belongs to literature or to art: it deals not with the living gods in their life and activity, but with their names and historical place; with the statical aspect of the pantheon, not with its dynamic life; and its difficulties of mutual arrangement little perplex the real and earnest worshipper. These matters are of externals, and do not touch the central meaning of religion. They arise after you have left the shrine and the presence of God. In brief, the multiplicity of gods is but the reflex cast upon Olympus by an ill-organized community, which has put its parts together by mechanical 
juxtaposition : it is the field for sacerdotal learning rather than an interest of genuine faith. And when it seriously exists, it is a sign that religious development has been arrested for purposes other than religious: that political or artistic interests have carried the day. To religion, therefore, the glorious Greek literature and art gave no helping hand. Just as in mediaeval Europe Greek science was spun out into multiplicity of detail, but lost touch with the root of science in reality; so Greek mythology was a gorgeous parasite that left its parent to grow blanched and unnatural under its shade.

The main difference in religions is due to the advance of man in other fields, to the growth of man's knowledge of the world, to the general result of his civilization : in other words, it is determined by the advance of his knowledge of nature and by the growth of his own sociality. By the former, it is corrected and co-ordinated on its objective side : by the latter, on its subjective. If it be asked which of these is most important, perhaps, from the religious standpoint, we shall not err in emphasizing the subjective. The theory of objective godhead is essential : but its revelation in and to man is the natural prius. It was e. g. in the former direction that unity was given by philosophic reflection to the theology of Greece, in the latter direction that unity was given by prophetic effort to the religion of Israel. To the man of scientific reflection, God was the central being, the supreme cause and source of movement in the physical or objective world: he was the reality of all reality, the object in all objectivity. To the religious man, who did not analyze his religion, God was the central source and rule of action, the standard to live after, and the life to live by, of the moral community. Thus the poetic remoulding of Greek mythology was in the first instance mainly a matter of theology : it did not directly touch the heart, and had little or no effect on the popular religion. Of that religion, 
at least of its inner life of faith, prayer, praise, we indeed know but little : literature and art can tell us comparatively little about it. It is the picturesque, the artistic, and finally the historical and philosophical sides of the products of religious genius that we see: of the devotional side we can gather but little directly from the works of the sculptor and the poet. But we are hardly, therefore, entitled to suppose it non-existent. To the cultured classic writers, to whom we owe the main part of our knowledge of Greek civilization, religion was evidently a matter which lay in the main outside their range of interests. And from several indications we are almost entitled to assume that, even as art was defective and almost prohibited in the more religious phases of Semitic civilization, so religion, strictly so called, was a defective and undeveloped element in Greece. Non omnia possumus omnes. Religion in Greece always tended to become identified with a sort of theology and theosophy. It was a kind of $\theta \epsilon \omega \rho i a$. Even the monastic Christianity of the Greeks tended to be what the occidental worker calls idle contemplation, that looked away and away into the easy calm of nature and the peace of God; a leisure of vision in which the distraction of life and business were left behind, in which even the strain of duty ceased, and the soul was at peace with the universe, untempted, unattracted, unoccupied. The Greek Church has still a Christianity of its own, and under Christian names it reproduces much of the spirit that created the drama and the theoretic life.

If religion be what we have described, it would seem in its first essence to have little or nothing to do with the community and with morality. It is so to speak on a deeper level, a more fundamental stratum than morality. Morality seems to be but a means to better and higher life, while religion claims to be or contain the fundamental postulate in the struggle for life itself, the postulate or belief that the inmost and supreme forces of the world are on man's side. Only in the earliest 
historical forms of religion this postulate is underlying and implicit, hardly daring to own its presumption, and does not with full self-confidence come to the front. It is rather a hope, mixed with fears: a wish that has yet to be actualized and fulfilled by strange and unintelligible methods. There is no security in it : no faith that can cast out fear. It is a groping upwards of feeble hands; and though it never utterly fails-that were the death of deaths-it recurrently droops and hesitates. Man is not at inward ease, not at unity with himself, he has not risen to possess his own soul ; and hence he finds no unity, no stability, no rest in the powers which he postulates in the world around him. Just because he is not fully and reasonably man, but presents from time to time different and disconnected parts of man, so is the God he finds ready in nature to support him a self-divided, many-formed, unrestful being. Whether, therefore, we assert with the German theologian Kaftan, that the object sought in all religions is life and not perfect life, that religion is based on the merely natural desire for good, and not on any ethical obligation to realize an ideal; or maintain with others, that it is only through religion that man can uphold his inner independence against the obstacles which nature throws in his way; we must still say that life and good are words that have no proper meaning for a being who is entirely without ethical quality. To talk of ethical ideals, unless these terms are carefully defined, is beside the question. A desire for good is not a mere desire for pleasant feeling, but a desire for self-satisfaction, for a better, truer, more real self; and thus in every way it implies an ideal. Life is not a purely physical or animal state, but the self-centred realization of an intelligent soul.

Morality, then, far from being a mere means to more perfect life-which implies that life would still be life apart from it -is essentially a part, or rather, as we have already ventured to conclude, the centre and life of life in all human existence. Or, in other words, it was through the social bond and social 
effort that man became a true and living soul. That made him in the human sense one life, one being, and differentiated him from the mere animal. For his unity as man lies not in the physiological organism, but in the enveloping idea of common sociality. It is precisely his quality, his privilege, to have ideals, because in him always, to make him man, there is the contrast between what he is and will be, between matter and spirit; there is the faculty of error, which is the faculty of truth. He is always in division and tension between what he is and what he would or ought to be. He is not a life self-complete, to which a further grace of perfection may be from time to time added as an ornament, but which can go on in its normal course as mere life. To live is, for man, to form ideals and to fall short of them: they may be very lowly ones, not what popularly would be called ideals at all; but at any rate, from the day that the social sting entered into him and made him a competitor, from the day that social sympathy inspired him and made him a co-operator, there has always been a contrast, however slight, between his $I_{s}$ and his Ought to be, between the given and the postulated. What may have been the case in that pre-social life which, according to Hobbes, was, if it ever was anything, 'nasty and brutish 1,' we need not greatly eare; at any rate, for human life in general, we may say that always it is governed and constituted by reason, which bids a man not to be what he is, but to be such as the dictates of a larger and a society-postulating consciousness requires.

Morality is not something without which man would still be man, and his life still be life; not a counsel of perfection, but an unconditional universal imperative. No doubt, by careless abstraction, we may speak of such a soulless life as man's life, and imagine man as still man with all social relations and all their hopes and fears and demands obliterated. But these are plays of that old fallacy, called by logicians 
Acervus, which supposes that, because you can diminish a quality till it becomes next to nothing, you can therefore leave it out altogether. If we reject such false abstraction, we may go back and assert that in the very beginnings of religion there was morality. Non-moral, i. e. non-social and non-civilized man, we know not. Morality, sociality, civility is his proprium. His morality, indeed, may be quaint and untasteful as judged by later specimens more familiar to us ; yet that is a judgement which the lowest savage, as we complacently call the savages of another type than ours, can easily retort. But the rudest savage has a life only because he lives in others, for others, by others; because his life is determined and formed by rules, customs, observances, painfully numerous and apparently onerous. It is from this superinduced backbone of his, this political framework and spirit, which is his only because he is son, father, tribesman and what not, that he derives the moral support that enables him to claim the strength of nature, or of nature's inner self on his side. The claim for life, the Anspruch auf Leben, of which Kaftan speaks, is a cheque which he feels entitled to draw, because nature has already singled him out for a special prerogative, charged him, as it were, to be her interpreter or steward. His citizenship, his appropriation of the materials of the natural order for purposes of his life, seems to justify his presumption that he has unlimited right to claim the backing of the universe, or of Him who ultimately is the reality of the Universe, when in any special instance he seems baffled by obstacles in his path.

Indeed, were it not for the sociality in which he lives it would be hard to see how man, in his individual weakness, could claim the supports of the force or will that lies behind the visible oppositions of things. It is in the conjunct action of himself and his group that he feels himself able to hold up his feeble self in the face of things. He belongs to a royal race, a people chosen by the powers. It is in proportion as 
by social union he makes life more of a certainty and less of a weary struggle, that he rises to conceive himself as no mere accident or epiphenomenon in things, but as their leading purpose and chief interest. If he thinks that he is only a little lower than the Elolim, it is because he has formed a metaphysical reality which is his, and yet something greater than his mere natural individuality can hold. If he feels himself a match for the powers of the physical world, it is by the strength of his community concentrated in consciousness; and if he dares to believe that the influences of the world are anywhere on his side, it is again because he is one of a group which has entered into specially close relationship with a certain physical region, has become, as it were, co-heir with the powers that rule therein, and formed a sort of covenant of alliance offensive and defensive with them, or with the main Baal and lord of the land. The original gods are local gods, of power and influence narrowly defined by the sphere of the social power to which they are attached, but in that sphere they are supreme. Outside their ordered circle there are other natural powers, vague, treacherous, not yet as it were reduced to the social order of human companionship, but even they too are not wholly unreconcilable enemies. When we speak, therefore, of nature-religions and ethical religions by way of contrast, we use terms rather loosely, and a potiori. The German anthropologist speaks of nature-peoples. But there are no nature-peoples, Natur-Völker, but only peoples which to outside judgement leave much to be desired in the character of their civilization; so much as hardly to deserve the name civilized at all : yet are they still in some degree civilized, never mere children of unadulterated and non-rational nature, and their very abominations are the proof of their humanity. So in the other case. A nature-religion is only an ethical religion of a rather less organized ethicality than is presupposed in other religions. There is no non-ethical man, though the ethics of certain times may be very unlike those most 
familiar to us. But, as we have already seen, ethics, religion, art and science are dependent for their development on the degree in which the community has solved the problem of sustaining life by the production and distribution of material goods, so here it may be noted that in the early stages of civilization the incident obligations of ethics are perpetually dodged by the ever-pressing pangs of hunger.

And just as man believes that the life and emotion of the Power in nature beats somehow in deep sympathy with his own, and that a force greater than his own is on his side, whatever obstacles may temporarily deflect his course, so he believes that the visible life he and others lead here is not altogether extinguished by death. If it be an indestructible tendency of social man, i.e. of man as man, to claim the support of the general principle at the heart of things, and to have by appointed modes metaphysical aid always at his beck, it is no less his tendency to assume his existence prolonged into a world beyond death. Even to the savage, and most of all perhaps to the savage, the idea of the termination of all his existence by death seems absurd and unintelligible. But in this case, as in the others, it is in the strength of the social tie that he is able to prolong the vision of life in a perspective to which only the incompetence of his imagination sets a limit. The tombs of his fathers, these are his holy of holies: there is set up in visible shape the enduring memorial of his conviction, that death cannot break the invisible continuity of his real life.

In a passage of great power at the close of Fifine at the Fair, Browning has given a sort of survey of human civilization. Beginning with a vision of a great crowd in the Square of St. Mark's at Venice, he proceeds to use it as an emblem of that strange masquerade of change in permanence and permanence in change, which the movements of art, science, morality and religion present. At length he sums up all the work of human culture, in all its branches 
and all its variety, in one single picture, reduced as it were to its lowest denominator, its grayest and most unadorned shape. And that epitome of all man's monumental labours is one of those dolmen-tombs, the long, low, narrow avenue ending in the funereal chamber with its great broad lid and its foreignly curious stones, supporting as at Maezhow a great memorial mound. That is the net result, the epitome of civilization-a tomb! For in that grim structure, so toilsomely reared as if for ever, man has boldly claimed to be heir of the ages, he has extended his hopes into the illimitable future, and with superb self-confidence deelared that he does not all die. Such a tomb is a temple, the witness to a faith in life eternal; for even the gods in older legend had their sepulchre: was it not in Crete that men showed the grave of Zeus? But the tombs of the saints still work wonders; and the graves of the fathers are the pledge to the sons of the times that are yet to be, as well as the record of immemorial beginnings.

Let us not however misunderstand the evolution-formula. There have perhaps been some who have regarded the protective defences, by which some persecuted race has survived and escaped its assailants, as a happy trick by which it suddenly endowed itself with new properties. So some seem to think, man, like to be worsted in the struggle for life, said to himself: Let there be gods, beings of my kindred, but far more potent, on my side: Let there be a life hereafter, so that I may not be haunted by the weakening thought that all is vanity. If man so said to himself, it was, we may be assured, by no idle fiat, but because in him spoke something other, and yet not wholly: other, than himself. Scientific writers sometimes remind us that the whole beauty of sight and sound in the world is a sensuous illusion: really, they tell us, there is no colour, save in the eye, no music but in the ear. It is kind of them to stop where they do ; for why there should be even weight, or foree, or direction, if 
the human senses are gone, some of us may be excused for doubting. Certainly if 'ifs' and 'ans' are to be used so boldly as good ware, we may expect crashes. It is a poor jest to argue that, if something which is were not, something else would be something still more else. It is not for us to pick and choose the bits of reality we are to accept as genuine. It hangs all together; and if you give up any of it, its most sensuous or materialist part, you cannot be sure of retaining even the spirit. And, equally, if you give up the more spiritual, you endanger the more material. No doubt the reasoning and rational being, generally young, imagines he could pick and choose, so as to leave out certain disagreeables. But experience (and experience is only matured reason) shows that good cannot be got without evil: or rather that those distinctions, though practically useful, are, as Spinoza saw, not easily attributable to the supreme substance, the Deus, which is another word for Natura.

It is not man's single intellect that makes the gods, any more than it is man's single intelligence that in Kant's phrase makes nature. The intelligence in either case is more than the physical individuality can contain, and the 'making' is in this case 'presupposing'; which means realizing that there is something efficient in nature, which does not appear on the surface. It is the discovery that the process of civilization, which in its appearance and obvious tendency is a turning away from nature, a departure by human inventions from the rectitude of primaeval arrangements, is not so uniform as it looks. It seems as if man were encroaching on the divine, and stealing its prerogatives; as if he were preparing for himself the fate of Prometheus, to expiate his rebellion against the universal law. But Prometheus has within him a secret that keeps him confident even under the tortures inflicted by an angry Zeus. He knows that Zeus, who thus tyrannizes over earth and heaven, the blindly natural god, is not to reign for ever: he knows that a saviour will come, 
that in the struggle of man with the first nature-a struggle which, like all such, is not without the evils and violence of wild war-there is preparing a new heaven and a new earth, wherein dwells righteousness. He knows that he has on his side a better and a greater Zeus, a God who far from being jealous or hostile to man, will yet reign through man, and raise the son of man, in the consummation of all things, to sit upon the throne of his kingdom.

There are two weapons, if we again turn to the evolutionist formula, which man has used against the waste and wear of time and chance. In the strength of a living and active sociality, man has defied the brute powers of nature; and he has appealed with faith to their inner spirit and purpose : or rather he has taken the permanence of sociality as the pledge and foretaste of an extension of his being, to which time and space can set no limits. He has claimed God for his everlasting ally, and been content with nothing less than immortality. But if we say 'immortality' we must guard against any special limitation of its meaning, any special theories as to what and when and where man is immortal. Our ideas on that subject-and I suspect, as I hinted the other day, on many kindred topics-are largely dependent on popular and exoteric interpretations of Platonism : and, even if Plato's ideas on this topic were much clearer or more undisputed than they are, and personal immortality were a less ambiguous phrase than it can honestly be said to be, we need not here bring them into account. As I use the term, I take it, in its very widest sense, to mean that our inner true being is not a visible and a sensible thing, that it is that in us which is unextinguished by death. 'Sentimus experimurque,' says Spinoza, 'nos aeternos esse': a personal experience tells us we are above and beyond time. That is all. And if you say, it is not much; if you speak confidently of life and immortality elsewhere brought to light, if you refer to the speculation of St. Paul which we hear so often by the opened 
grave; I will only say that, though as a human being I would fain like others be able to say more, and be glad, like the children in the carol, to bring tidings strange yet true from the land of the leal, I can see in both of these only the reaffirmation of one doctrine, that man lives and fights the world in the faith of a persistence, whose possibility he can by science neither affirm nor deny, neither prove nor disprove, but which in some shape and some grade seems as essential an element of humanity, whether externally formulated or not, as the belief in God. Both are still of faith as of old ; if they were otherwise than of faith, they would not move men as they have done. If they seem less obviously prominent in the world than they once were, may it not be that they have sunk as perpetual stimuli even into the hearts of those who, when they consciously reflect, seem halfinclined to reject them from their creed? For as not every one who says, 'Lord, Lord!' shall be admitted to the kingdom, so, says one, 'loving hearts have thought they saw in atheism a form, to their mind the most respectful, of modest and profound piety ;' and many, who in words have rejected immortality, have done so because of their ideal faith that ' flesh and blood cannot inherit the kingdom of God.' These things, like others, are justified by their fruits. That is a poor faith in immortality, which would seek in it another chance to make up for neglected opportunities here, or to replenish in after-time the now-kept-empty vessel of love: as it is a poor faith in God, which is content with the belief that, however slackly things go now, he will one day come to be our judge.

But, as of the belief in gods, so of that in immortality, it is true that, in a loose use of words, we may say that it is at first without ethical significance. What does 'ethical' mean in this connexion? Probably to most people of an unregenerate mind, it means that which is or ought to be visited with rewards or punishment; and to the most unregenerate 
mind, especially the latter. Ethical, to this type of moralist -and he has long been a common one-always connotes, in the first instance, approval or disapproval, and, in the second, a wish to see an example made and a whipping inflicted. Such moralists take a fine personal interest in the moral law, but perhaps scarcely an ethical interest. There is undoubtedly a time in the history of civilization when punishment occupies a foremost place amongst its machinery. There was a time when, wild in woods, the noble savage-and especially the noble savage's children-ran, little troubled with the fear of discipline, and with no obvious penalty from political sanctions. There was, no doubt, a sort of tit for tat: but it had something of a sportive character about it: as when the Australian savage, having injured a man, has to stand as a goal for the missiles of his adversary or adversary's relative. But as things went further, and civilization advanced too fast for the natural pace of some who had to follow, it was found necessary to apply sharper goads to the slow and refractory so as to quicken their pace. And so it continued, till punishment almost came to be looked upon as the end for which civilization had been wrought, and jails and scaffolds as its obvious symbols. At present we begin to have some doubts as to the right to punish. Just as we now recognize, if we but think, that physical sicknesses are very largely due to our own misconduct, and therefore, in a schoolmastering world, fit objects for penal treatment; so we recognize, on the other hand, that crimes have some of the nature of disease, and are in many cases their own punishment. And we have on the whole admitted, not that criminals are faultless, but that casting stones at them is not the best way of putting matters right, and has an unpleasant tendency to generate fresh offences. At any rate, punishment has ceased to be quite the noble function it was half a century ago.

Now, when people spoke of the ethical transformation of 
the religious idea and that of immortality, they were thinking of the spirit of a time when, in the course of social and political development, the important uses of punishment had first dawned upon men. In Homer, e. g. where penal codes are still defective, there is on the whole little use of the afterlife for penalty, except in the case apparently of some extremely profane persons. In Pindar, again, the after-life is partly conceived as a field for further development of things set going here. But in Plato the penal machinery of the other world is in full operation, and for the punishment craze, i. e. the extravagant enthronement of it, he is considerably to blame. Curious results, indeed, come about by the change of view : and Zeus might have to punish in his modern capacity what he (according to earlier creeds) might also be said to have inspired. But that, perhaps, is an inconsistency not confined to the Hellenic world.

And what Plato did in a mild way, the extravagances of vulgar, and especially vulgarly theological, imagination carried to terrible lengths in Christendom. Both perhaps got the framework of their ideas from Egypt, where, as the Greeks thought, the immortality of the soul was discovered. And certainly, if not discovered, it was there applied as a great disciplinary agent in accordance with the exemplarily bureaucratic spirit of the Egyptian régime. The world of the dead was a great law-court sitting in permanence, and making an exhaustive scrutiny of the deeds done in the body.

The important point for us is not to rest satisfied with the restriction of ethical conceptions to a stage when they are dominated by the rule of laws. Of laws, I say, not of Law: for while laws are commands with penal sanctions attached, Law is the voice of God, or the sweet reasonableness of harmonious and self-completing life. The law, said one,meaning the code of laws, - was a schoolmaster to bring us to the heirship of the promises. There is a period of discipline, but it is subordinate, and a means of self-development; its 
justification is to anticipate the end, and so give direction to effort, that would otherwise hurt itself and others, and waste precious time. But it has its limits in its end : it must never extirpate, though it may accelerate and facilitate, self-education and freedom. And of God, therefore, we need not think too much as an authority to coerce an erring world. True morality is not a thing of rules and observances. Far, indeed, should any man be from speaking scornfully of forms, traditions, and the bonds of social authority. Without them we should be poor and miserable creatures; through them is all progress. But they are not everything. When Michael Angelo's great vision of the last judgement was set open to view, a certain high official at the Papal court complained that its nudities were indecencies, worthy of places unnameable rather than of the buildings in charge of the Vicar of Christ. Michael Angelo's first notice of the criticism, says the legend, was to give his critic a place amongst the evil shameless ones. But he had at length to reckon with the Pope, who echoed the complaint. 'That,' replied the artist, 'is a fault easy to set right: there are harder things to amend than that.' And the order was forthwith given to Daniele da Volterra, to be known hereafter in art history as Il Braghettone, the breeches-maker, to veil the offending members. Now breeches-making in this sense is a comparatively easy matter; and a great many people are of opinion that it is the most important of all matters. And its necessity to some extent is undoubted. Only the tailors must not be too proud. It is a nobler task to mould fine limbs, strong, graceful and active; and for that end tailoring, otherwise commendable, sometimes stands in the way. It is excellent again to clean the outside of the cup and the platter : but there is still the business of the inside.

And so, let us not forget-we all do forget-that the art of morality is not, how not to do it. Its function is not merely to keep us from falling, nor is it to help us to become proper. It is to teach us to love God with all our hearts and strength 
and mind, and our neighbours as ourselves. The old Stoics used to say, 'Follow Nature': and Bishop Butler has remarked that this is but a loose way of talking. The Stoic perhaps might have retorted that it was a lax way of talking to say, 'Obey conscience.' For all formulas in nutshell fashion are lax.

The Stoic and Butler also said, 'Follow God.' In each case you must realize that, whichever you do, you take your life in your hands; you enter on a grand enterprise, a search for the holy Grail, which will bring you to strange lands and perilous seas. For you cannot say, interpreting, "Thus far and no further, merely according to the bond and the duty.' In following God, you follow by what has been, what is ruled and accomplished, but you follow after what is not yet. 'It may be that the gulfs will wash us down'; it may be that the gods of the past will rain upon us brimstone and horrible tempest. But he that is with us is more than all that are against us. Whoever keeps his ear ever open to duty, always forward, never attained, is not far from the kingdom. The gods may be against him, the demi-gods may depart, but he, as said Plotinus, 'if alone, is with the Alone.' 
ESSAYS IN MORAL PHILOSOPHY 



\section{OUR NATURAL RIGHTS}

'THE phrase 'natural rights' is, we are sometimes told, a survival from the obsolete language of a controversy long since forgotten. The very words that make up the phrase are ambiguous. Each has in turn been the confusing battlecry in a combat where the fighters knew not what they fought for. And yet, if we look into it, the question underlying the phrase is not of a merely antiquarian interest. It touches on problems which never cease to excite curiosity-which each age has to face and to seek to solve for itself.

The history of the idea we need not here attempt to draw out in full. Perhaps germs of the claim to natural justice have never been altogether absent from the world, even in primitive conditions of society, but it may fairly be said that such demands hardly rise into the clear light of reflection till the last days of the ancient world, and the time when modern Europe slowly emerged from the disintegrating structure of the Roman Empire. The idea of natural rights inherent in man as man seems to indicate its source in a period when the atoms that had been solidly built up into ancient society began, as dissolution of that society set in, to feel themselves entrusted with their own fortunes, masters of their scanty savings from the ruin of the old world. That old régime of Greek and Roman times at least had taught the few who were favoured by social status to be free and 
equal : and had inspired thinkers to suggest that, apart from the ordinances of statecraft, such liberty and equality were the birthright of each member of the human race. The history of the early centuries of modern Europe, the so-called Dark and Middle Ages, is the record of an attempt, prolonged through centuries, to create a tolerable order of human life out of the dislocated and scattered elements which were left by the changes during the first centuries of that period. The old order did not entirely lapse into nothingness; it survived, however, not as a visible empire, but as an idea of order and unity, an idea animating the efforts of many individuals, governing the actions of more, and rising in a few to the height of a bright and passionate devotion. This idea of human unity, which was the legacy of the decaying system of antiquity, was brought into contact with another idea, the idea of voluntary attachment, of fidelity to comrades, of loyalty to a self-imposed leadership, the idea of community based not, as the old world had been, on local ties, or on family necessities, but on free and independent combination to attain some common end. The typical associations of the mediaeval world, the orders of chivalry, the monastic brotherhoods, the industrial guilds, found their unifying principle in participation in a work for some general good, in giving themselves up to the realization of some object freely chosen, but, when once accepted, claiming the sacrifice of the whole breadth and depth of life. The Church itself both directly and indirectly fostered this sense of individual independence. Over against the visible local kingdom and its claims upon the subject, Religion set up the idea of a higher and universal kingdom, which was above and beyond the secular authority. If it often sank into only another and a subtler tyranny, still in theory the Church was to the members of the petty principalities of Europe ruled by their local despots one of the safeguards of personal liberty. It cannot be too clearly stated that in the darker periods of mediaeval history 
there were learned and wise priests who upheld the reign of impersonal law, of justice and mercy, amid the struggles and brutal violence of selfish chiefs.

Thus the very methods, through which order emerged as a self-won product from the chaos of the transition period between the old world and the new, made it only too likely that a sentiment of individual autonomy, of free and independent contribution to the result, should remain as a settled conviction in the mind. The services rendered in this process by the idea of citizenship, as a natural law in which lived transfigured the political results of the old world, were hardly remembered. It is not therefore to be wondered at, if, as soon as political speculation began to awake, as soon as attention was turned on the nature of sovereignty, the view gained expression that kingdoms and commonwealths were the work of the voluntary efforts of individuals. Such speculation, first started into keen activity when the controversy between Pope and Emperor reached a climax, was invested with new and more general interest by the wars of religion in the sixteenth century. We there find Jesuit and Protestant alike (with different motives) proclaiming the theory of the divine right of the peoples to choose their own form of government. A fresh stage of the controversy was due to the fifty years' struggle between the Stuart kings and the leaders of Parliamentary government. 'The advocate of the Puritan revolution, John Milton, lays it down that 'all men were naturally born free, . . . born to command, and not to obey': that the 'authority and power of self-defence and self-preservation' is a 'natural birthright,' whereas the 'power of kings and magistrates' is 'only derivative, transferred and committed to them in trust from the people.' So too John Locke, the advocate of the 'glorious revolution' of I688, taught that men, being by nature 'free equal and independent,' surrendered their 'natural power' and freely consented to abide by the decisions of the majority so long as 
they were thus the better enabled 'to preserve themselves, their liberty and property.'

When we come to the middle of the eighteenth century, we find Blackstone, in his Commentaries on the Laws of England (1765), expounding the lessons of Locke as a fundamental doctrine. 'The principal aim of society,' he explains, ' is to protect individuals in the enjoyment of those absolute rights which were vested in them by the immutable laws of nature.' These 'absolute rights of man,' summed up in the general name of the 'natural liberty of mankind,' which means 'a power of acting as one thinks fit without any restraint unless by the law of nature,' have in most other countries been restricted or altogether destroyed, but in England they are coeval with our form of government. Thus though founded upon nature and reason, or even on the will of God, they have in this country, according to Blackstone, the peculiar advantage of being defined by different laws in a number of private immunities. They include three principal or primary articles, the right of personal security, the right of personal liberty, and the right of personal property. These broad terms, however, are whittled away by definition. Personal liberty, e.g. is explained to consist in the absence of slavery, and the freedom from arbitrary or illegal arrest.

Ten years afterwards the question of natural rights was transferred from the region of academical discussion to the arena of public meetings. The ideas of the revolutionary party in Europe were carried to America by Thomas Paine, the author of Sound Common Sense (1776) and The Crisis. As early as 1773 a meeting at Mendon in Massachusetts had adopted resolutions 'that all men have an equal right to life, liberty and property,' and 'that a right to liberty and property (which are natural means of self-preservation) is absolutely inalienable and can never lawfully be given up by ourselves or taken from us by others.' The 'principle of self-preservation,' which holds the central place in this 
document, is pronounced necessary alike to the well-being of individuals and to the order of the universe. In the American declaration of Independence of July 4, 1776, the same views are reproduced: 'We hold these truths to be self-evident, that all men are created equal, that they are endowed by their Creator with certain unalienable rights, that among these are life, liberty, and the pursuit of happiness : that to secure these rights governments are instituted among men, deriving their just powers from the consent of the governed, and that whenever any form of government becomes destructive of these ends, it is the right of the people to alter and to abolish it, and to institute a new government, laying its foundation on such principles and organizing its powers in such form as to them shall seem most likely to effect their safety and happiness.'

The attitude of Burke on the subject of natural rights is worth noting. In his Thoughts on the Cause of the Present Discontents (1770) he maintains in a most outspoken manner the origin of all government in the popular will. 'The King,' he says, 'is the representative of the people: so are the Lords : so are the Judges. They are all trustees for the people, as well as the Commons : because no power is given for the sole sake of the holder: and although government certainly is an institution of Divine Authority, yet its forms and the persons who administer it, all originate from the people.' But on the whole he declines to enter upon ultimate questions of principle. His consideration, he says, in his Speech on Conciliation with America (I775), is 'limited to the policy of the question.' 'I do not examine whether the giving away a man's money be a power excepted and reserved out of the general trust of government: and how far all mankind, in all forms of Polity, are entitled to an exercise of that right by the Charter of Nature.' 'The question with me,' he adds, 'is not whether you have a right to render your people miserable: but whether it is not your interest 
to make them happy. It is not what a lawyer tells me I may do, but what humanity, reason and justice tell me I ought to do.' He contrasts titles and compacts with what 'the reason of the thing' requires.

In his Reflexions on the Revolution in France he contrasts the historical and legal character of the English Revolution with the abstract theories of the French. 'No experience,' he says, 'has taught us that in any other course or method than that of an hereditary crown, our liberties can be regularly perpetuated and preserved sacred as our hereditary right.' When our liberties are thus considered 'in the light of an inheritance, . . . our liberty becomes a noble freedom. It carries an imposing and majestic aspect. It has a pedigree and illustrating ancestors. . . . We procure reverence to our civil institutions . . . on account of their age and on account of those from whom they are descended.' The French declined to follow this path and give to their recovered freedom a correspondent dignity-by recalling the privileges that had been discontinued. "They have "the rights of men." Against these there can be no prescription : against these no agreement is binding, these admit no temperament and no compromise.' For Burke these rights are a piece of 'political metaphysics,' dangerous only because they afford a ground of quarrel with all government, on 'a question of competency and a question of title.' Not that he denies what he calls the 'real rights of men.' 'Civil Society is an institution of beneficence : and law itself is only beneficence acting by a rule. Men have a right to justice : they have a right to the fruits of their industry, and to the means of making their industry fruitful. They have a right to the acquisitions of their parents : to the nourishment and improvement of their offspring : to instruction in life and consolation in death. Whatever each man can separately do, without trespassing upon others, he has a right to do for himself; and he has a right to a fair portion of all which society, with all its combinations of skill and force, can do in 
his favour. In this partnership all men have equal rights, but not to equal things.'

But man, in the convention by which society is formed, ' has divested himself of the first fundamental right of uncovenanted man, that is, to judge for himself and to assert his own cause.' 'That he may secure some liberty, he makes a surrender in trust of the whole of it.' 'Government,' however, 'is not made in virtue of natural rights.' It ' is a contrivance of human wisdom to provide for human wants.' And if 'men have a right, that these wants should be provided for by this wisdom,' then,-as amongst these wants is 'the want, out of civil society, of a sufficient restraint upon their passions,'-it follows that 'the restraints on men, as well as their liberties, are to be reckoned among their rights.' And 'the moment you abate any thing from the full rights of men each to govern himself,' 'from that moment the whole organization of government becomes a consideration of convenience.' Thus the science of constructing a commonwealth is not to be taught a priori. It presupposes a long experience. 'Political reason is a computing principle. It calculates morally and not mathematically.' Whereas the pretended rights of men are 'all extremes,' 'morally and politically false in proportion as they are metaphysically true,' the rights of men in government are their advantages :-consisting often in balances and compromises. 'By the theorists of the revolution the right of the people is almost always sophistically confounded with their power.' But ' till power and right are the same, the whoie body of the people has no right inconsistent with virtue.' 'Men have no right to what is not reasonable and to what is not for their benefit.'

Burke notes the influence which the legal profession exercised on the course of the American as of the French Revolution. 'I have been told,' he says, (Conciliation with America) 'by an eminent bookseller that in no branch of his business, after tracts of popular devotion, were so many 
books as those on the law exported to the plantations. . . . I hear that they have sold nearly as many of Blackstone's Commentaries in America as in England.'

The language of the American declaration of independence is vague and rhetorical; it reduces the language of popular philosophy to the form of doubtful maxims. It proclaims in its fantastic simplicity not merely the right, but the duty of insurrection against an unfaithful government, and suggests in the ' unalienable right to the pursuit of happiness' a justification of any acts of a human being whatsoever. What may not a man dare to do in such a quest? Similar assertions of 'inherent rights,' 'unalienable and indefeasible,' occur in the special declarations of principles or bills of rights drawn up by the single states. But side by side with these appeals to abstract rights, to general principles, borrowed from the dominant philosophy, there is, as we noticed in Blackstone's remarks, an appeal to historic precedents. The Congress of New York in $x_{76} 6$ claims 'all the inherent rights and liberties of the king's natural-born subjects within the kingdom of Great Britain.' They are entitled to 'the undoubted rights of Englishmen, and appeal to the principle and spirit of the British Constitution.' The people of Connecticut takes its stand on the liberties, rights, and privileges which it has received from its forefathers. And the declaration of rights drawn up by the Congress of Philadelphia in October, 1775 , bases the American claims on the old rights which were brought from the mother country, on the English Constitution and inherited privileges founded on the acknowledged acts and practices of the British Empire. The two grounds of argument are directed to different classes. The reference to historic facts is intended for the diplomatic world, for those accustomed to the language of statesmanship, who count a single precedent worth a hundred principles. The appeal to natural justice-to 'imprescriptible' rights-is for the popular heart, for the crowd which rolls like a sweet morsel 
under its tongue the large sounding phrases of vague and flexible ideals.

The success of the Americans in their insurrection had been largely due to the help of the French fleets and armies. Among the French officers, the most distinguished was the noble and brave, but vain and imprudent, Marquis de La Fayette. When the news of the uprising in America reached France, La Fayette, then nineteen, and a captain of dragoons, enthusiastically resolved to espouse the cause of liberty, and braving all opposition of friends and the dangers of arrest by his own Government, hurried across the seas to take part in the struggle for independence. After the war had ended in success, La Fayette returned to France, and in 1787 , at the still juvenile age of thirty, was elected as one of the Notables whom the king had summoned to advise him on the measures to be taken for the redress of grievances throughout the country. In the Constituent Assembly which succeeded, we find La Fayette on July I I, I789, presenting the proposal for a declaration of rights modelled on that which Jefferson had framed for the Americans.

The sound of 'rights' was far from unfamiliar to the French ear, but hitherto it had been associated with a very different set of ideas. The rights that most promptly occurred to a French lawyer were the feudal rights, governing the tenure of property and regulating the lives of almost all dwellers in the country. It was not that these rights were peculiar to France: they were found, and sometimes in a stricter form, in almost every country. But in France the peculiarity in the position of the privileged classes, the nobles and the clergy, was that for more than half a century before the Revolution they had ceased to occupy any direct place in the political administration of the country. When the long struggle between the monarchy and the feudal lords was ended, and in 1756 the last of the feudal brigands was taken and beheaded, the king Louis XV was left in a position where 
he could fairly say, as he did ten years later say, ' It is to me alone that the legislative power belongs, independently and without participation. The whole of public order emanates from me.' When that result had been reached by the efforts of Richelieu and Louis XIV, the justification of the feudal system had ceased. The great nobles had practically abandoned their place in the country in order to dance attendance at court, and the smaller nobility who still resided on their lands were often poor and had no real participation in the management of local affairs. The same was true of the clergy: neither they nor the nobility performed any public service, or had a sense of public and national duty. An administrative centralization had been established long before the Revolution; France was governed by central bureaux; the king felt the sovereignty as his heritage and managed the public revenues by his own 'intendants' in each province.

But though the territorial lords had been deprived of their supremacy, many of them had still many 'fine rights' (de beaux droits) attached to them. Though he neither discharged a useful function as local magistrate and administrator, or as representative at the seat of central authority, the seigneur had a number of privileges which were felt as all the more burdensome by his peasant neighbours just because they were no longer in any legal political dependence upon him. His seigneurial jurisdiction-one of the prime consequents of feudal superiority (for la justice suit le fief), was still left to him, and he had those rights d'aubaine, d'épaves, \&c., which followed from the feudal sovereignty of the landholder, besides the so-called banalités (the obligation of the tenant to use the superior's mill, \&c.) and the corvées (or obligation to perform so many days' work for the superior). Besides these the noble class enjoyed in many cases either a total or partial exemption from taxation, and public places were often in their hands: they had the exclusive right of 
sport, and the game-laws were a constant offence to the cultivators. The nobility and clergy, in short, had sunk into the position of privileged classes, who no longer justified their position by exceptional services. They were the inheritors of imposts and dues felt as oppressive by those who saw no reason for them, and as insulting by those who had come to feel themselves comparative freemen. Feudalism, as De Tocqueville remarks, ceasing to be a political institution, still remained the greatest of all the civil institutions of France. 'The seigneur had ceased to govern: but his presence in the parish and his privileges effectually prevented any good government from being established in the parish in place of his own.' To such a position had sunk those knights who, says a Spanish chronicle in the tenth century, kept their horses in the hall where they slept with their wives, to be ready at any moment to repress disorder in the land.

From the earlier part of the century onwards a pervasive influence had been making itself supreme in France. The practice of social intercourse among all who belonged to the privileged classes, or could for temporary reasons be reckoned amongst them, became the main problem of life : encroaching on and gradually suppressing the intimacies of conjugal life and of parental affection. A uniform code of manners, la bienséance, imposed upon the select multitude a characteristic form which was so finely balanced, so soon impressed, and so universally spread that it seemed hardly to be felt as a gêne, and became to a large class a sort of second nature. It taught the art of sympathy, the form of friendship; it gave the skill of concealing pain and weakness, of checking unseasonable individuality, of putting on a smiling and serene face in trouble, and of not offending others by the assertion of personal prejudices. The great vice to such a period lay in being une espèce, an original. But even this wide empire of the salon had its limits. The distinction between the gentilhomme and the roturier remained uneffaced and apparently 
uneffaceable. The nobility and the 'third estate' grew more and more hostile to each other: and France offered the spectacle of a country broken up by class distinctions, into groups almost caste-like in their nature.

But beyond all these divisions there lay a common meetingground in literature. And the literature of that period is a literature which is dominated by philosophy, by speculation, by the search for and the worship of abstract and absolute ideas. Political theory which had been fostered in the seventeenth century in England found during the middle part of the eighteenth century its home in France. In a social state, founded on inequalities and permeated by conventions, inquiry dealt by preference with the theory of natural justice and the nature of political power. The list of writers who lay the foundations of social and political science is headed by the name of Montesquieu. The Spirit of Laws (1748) did not do all that its admirers have sometimes said : it did not discover and restore to humanity its long lost titles. But it did, on the basis of the vague definition of law as a ' necessary relation derived from the nature of things,' partly show that laws are in the last resort facts beyond the arbitrary interference of governments, dependent on circumstances of nature and history, and governed by scientific principles no less inflexible than those of the physical universe. Before such a theory, arbitrary powers and incoherent privileges must necessarily hide themselves. Other theorists, dazzled, as even Montesquieu himself at times is, by the splendours of Greek and Roman history, and misled by the legendary glories of early Sparta, preached doctrines more tempting to the dissatisfied and unsuccessful. The Abbe Morelly in his Code de la Nature (I755) laid down three fundamental laws: the nonexistence of private property: the character of public functionary attached to every citizen : and the duty of every citizen to contribute to the public welfare. The fountain of Socialism flows in his postulate that 'every citizen is 
to be supported, maintained, and employed at the public expense.'

One of the most instructive of these writers, especially as dealing with the question of natural rights, is Mercier de la Rivière, in his book De l'orlle naturel et essentiel des sociétés politiques ( 1767 ). The first of all rights according to him is that of individual liberty, or 'personal property' : from which as a necessary consequence flows first that of property in movables (mobilière) and secondly in land (foncière), the latter to be justified by noting the necessity of continued possession for making proper use of the soil. These three fundamental species of property are linked together and justified by the maxim : that duties are the justification of rights, and rights give the means of exercising duties: 'Point de droits sans devoirs, point de devoirs sans droits.' But if the right of property thus understood is a necessary consequence of human duty, it is no less evident that it further involves liberty and security: and that all institutions which are indispensable to maintain these three ends are parts of the ' essential order' of political societies. So far Mercier follows the common track of the liberal theorists of his day. But in what succeeds he makes a new departure, and follows a line, afterwards adopted by Fichte, in opposition to the maxims of Montesquieu as to the separation of the 'three powers' of government. His view is briefly stated in the words: "la puissance exécutrice est toujours et nécessairement puissance législative;' and his reason is that the distinction if made cannot be maintained : either will inevitably usurp the functions of the other. But the real justification of this view is to be found in his distrust of the sway of personal opinions and arbitrary pretensions among the various claimants of supreme power. The ideal institution of government is, he maintains, to be sought in the direction which will leave least room to the rivalry of individual interests, to the varying chances of a majority. The best government is therefore a hereditary 
monarchy-a despotism, but one founded not on ignorance, but on a knowledge of the true laws of the social order. It is in short the ideal of paternal government, of a 'legal despotism,' of the authority of one man who is supreme and sole, but who has no other interests than those of the community, and whose knowledge is adequate to his function.

What Mercier de la Rivière thus lays down is the view of the great economists of the century. Political liberty, as the active participation in legislation by each member of the community, is what they hardly consider worth striving for. These writers are the panegyrists of the State. The main security for Liberty which they thought necessary was a wide-spread system of popular education. According to Quesnay, 'public, general, and continual instruction in the principles of essential justice and natural order' are the means to render despotism impossible. And he has nothing but contempt for representative assemblies and all the machinery of popular checks to the preponderance of the central power.

What the economists desired was a social and administrative reform: the removal of abuses, the destruction of unnecessary restrictions to free intercourse and commerce; they wanted to simplify government and give administration uniformity. Turgot, Vincent de Gournay, and François Quesnay are the chief names amongst these writers who, as the advocates of the emancipation of agriculture, industry, and trade were originally known as 'Économistes,' but since the time of Dupont de Nemours have been commonly styled 'Physiocrates.' The title 'Physiocrat' gives expression to one of the two principles which Gournay is said by Turgot to have discovered: that the industrial and commercial life of nations is governed by laws as unbending as those of physical nature. The other principle is the practical application of these laws to explain by their habitual violation the misery of the poor and the straits of the government in France. For in France there 
prevailed a complex system of regulations interfering at every stage with the freedom of trade, a system on which province was set against province, town against town, on which free initiative was impossible, and invention had to contend against established prescriptions. The programme of Gournay was Laissez faire, laissez passer. It was the protest against the exaggerations by which the royal intendants in the provinces fixed the length to which a piece of cloth should be woven, the pattern to be selected, the number of threads of which it was to be composed. Such was the founder of the doctrine that Turgot (1727-8I) sought to make his countrymen understand. Quesnay (1694-1774), the physician of Louis XV, is the author of the Maximes Générales du gouvernement économique d'un royaume agricole (I768). He believed that agrieulture had been depressed by an undue pursuit of the manufacture of articles of luxury, and directed his attention towards methods for inereasing the production of grain and wine, in which he believed lay the national wealth and strength. What he demanded was the liberation of the farmer from those burdens which pressed so heavily-abolition of forced labour, reduction of the taille, and complete liberation of the trade in corn both within and without the kingdom. Thus Quesnay claimed for agriculture and original production, what Gournay asked in the interest of manufactures-the removal of useless and harmful restrictions. After all they only repeated and repeated almost in vain the advice that Boisguillebert, that 'insensé pour l'amour du public' (1697, Le détail de la France), and Marshal Vauban (1707, Projet d'une dîme royale) had given long before. Vauban pointed out that le menu peuple was the part of the nation which bears all charges, which has suffered and does suffer most, and which yet by its labours and its taxes enriches both the king and the kingdom. To remedy that state of affairs Vauban suggested the abolition of all existing taxes and replacing them by an ineome tax of a tenth on all.

Q 2 
is instituted to guarantee to man the enjoyment of his natural and impreseriptible rights. 2. These rights are equality, liberty, security, property. 3. All men are equal by nature and before the law. 6. Liberty ... has for its principle nature, for rule justice, for safeguard the law : its moral limit is in the maxim: Do not do to another what you do not wish should be done to you. 8. Security consists in the protection accorded by society to each of its members for the conservation of his person, of his rights, and of his properties. I6. The right of property is that which belongs to every citizen of enjoying, and of disposing at his will of, his goods, his income, the fruit of his labour and of his industry. 21 . Public reliefs are a sacred debt. Society owes subsistence to unfortunate citizens, whether in procuring them work or in assuring the means of subsistence to those who are incapable of working. 22. Instruction is the need of all. Society ought to favour with all its power the progress of the public reason, and put instruction within the reach of all the citizens. 33. Resistance to oppression is the consequence of the other rights of man.

The Constitution of I795 (August 22), drawn up after the fall of Robespierre, departs somewhat both in form and matter from the two earlier statements. Among the list of rights, it preserves silence on the right of insurrection, either as primary or derivative right: and it observes the same discretion as to the claims of the unfortunate poor. With regard to equality it lays down (Art. 4) that it 'admits of no distinction of birth, no hereditary transmission of powers': a phrase which for vagueness probably gains the prize amid the whole collection. The main novelty, however, of this paper is its title: it is a Declaration of the Rights and Duties of the Man and the Citizen. Under the head of the Duties of man we find, Art. 2. All the duties of man and citizen follow from these two principles, graven by nature on all hearts: Do not do to others what you would not wish any one 
to do to you: Do constantly to others the good you would like to receive from them. 4. None is a good citizen who is not a good son, a good father, good brother, good friend, good husband. 5. No one is a good man who is not sincerely and religiously observant of the laws. 8. On the maintenance of property depends the cultivation of the field, all production, every means of work, and the whole social order.

Whatever may be the faults of these documents, it is elear that they do not sin by their revolutionary eharacter. Their tendency is eminently sober and conservative. No thorough equality, no licentious liberty is promised or praised: but moderation in all things, and a mild sort of fraternity, involving no very severe services to humanity. The liberty sought is absence of illegal and arbitrary interference by individuals: the equality is only an equality in rights or before the law. Property is expressly and evidently placed as the keystone of the social fabric, and the control of his goods entrusted to the proprietor is ample. We know indeed that on this last point there were debates: and at one time Robespierre thought it well to argue against Condorcet and the Girondists, who held that ' man is master of disposing at his will of his goods, his capital, his income, and his industry,' and to insist that the right of property was borné comme les autres. But this acknowledgement of the right of the community was not seriously proclaimed, especially after Babeuf had in his newspaper insisted that each eitizen should have secured to him la suffisance, mais rien que la suffisance, and had added that, as the soil of a state ought to secure the existence of all its members, the population should, if need be, suffer diminution to the requisite extent. And the condemnation to death of Babeuf and Darthe was the answer of the majority of the revolutionary authorities to the demand of Sylvain Maréchal, another of this band, for égalité du fait, real equality, and la Communauté des biens. The revolutionary 
is instituted to guarantee to man the enjoyment of his natural and imprescriptible rights. 2. 'These rights are equality, liberty, security, property. 3. All men are equal by nature and before the law. 6. Liberty ... has for its principle nature, for rule justice, for safeguard the law: its moral limit is in the maxim: Do not do to another what you do not wish should be done to you. 8. Security consists in the protection accorded by society to each of its members for the conservation of his person, of his rights, and of his properties. I6. The right of property is that which belongs to every citizen of enjoying, and of disposing at his will of, his goods, his income, the fruit of his labour and of his industry. 21 . Public reliefs are a sacred debt. Society owes subsistence to unfortunate citizens, whether in procuring them work or in assuring the means of subsistence to those who are incapable of working. 22. Instruction is the need of all. Socicty ought to favour with all its power the progress of the public reason, and put instruction within the reach of all the citizens. 33. Resistance to oppression is the consequence of the other rights of man.

The Constitution of I795 (August 22), drawn up after the fall of Robespierre, departs somewhat both in form and matter from the two earlier statements. Among the list of rights, it preserves silence on the right of insurrection, either as primary or derivative right: and it observes the same discretion as to the claims of the unfortunate poor. With regard to equality it lays down (Art. 4) that it 'admits of no distinction of birth, no hereditary transmission of powers ': a phrase which for vagueness probably gains the prize amid the whole collection. The main novelty, however, of this paper is its title: it is a Declaration of the Rights and Duties of the Man and the Citizen. Under the head of the Duties of man we find, Art. 2. All the duties of man and citizen follow from these two principles, graven by nature on all hearts : Do not do to others what you would not wish any one 
to do to you: Do constantly to others the good you would like to receive from them. 4. None is a good eitizen who is not a good son, a good father, good brother, good friend, good husband. 5. No one is a good man who is not sincerely and religiously observant of the laws. 8. On the maintenance of property depends the cultivation of the field, all production, every means of work, and the whole social order.

Whatever may be the faults of these documents, it is clear that they do not $\sin$ by their revolutionary character. 'Their' tendency is eminently sober and conservative. No thorough equality, no licentious liberty is promised or praised: but moderation in all things, and a mild sort of fraternity, involving no very severe services to humanity. The liberty sought is absence of illegal and arbitrary interference by individuals: the equality is only an equality in rights or before the law. Property is expressly and evidently placed as the keystone of the social fabric, and the control of his goods entrusted to the proprietor is ample. We know indeed that on this last point there were debates: and at one time Robespierre thought it well to argue against Condorcet and the Girondists, who held that ' man is master of disposing at his will of his goods, his capital, his income, and his industry,' and to insist that the right of property was borné comme les autres. But this acknowledgement of the right of the community was not seriously proclaimed, especially after Babeuf had in his newspaper insisted that each citizen should have secured to him la suffisance, mais rien que la suffisance, and had added that, as the soil of a state ought to secure the existence of all its members, the population should, if need be, suffer diminution to the requisite extent. And the condemnation to death of Babeuf and Darthe was the answer of the majority of the revolutionary authorities to the demand of Sylvain Maréehal, another of this band, for égalité du fait, real equality, and la Communauté des biens. The revolutionary 
movement was in its accredited utterances far from being socialistic, or antagonistic to the rights of private property. Indeed, the charge most readily brought against it would be that it appealed to the baser prejudices of the bourgeoisie, and was too much a mere middle-class movement, which ended in elevating the third estate to a level with the two older privileged classes.

It has often been remarked in similar cases that the general phraseology of a document must receive its interpretation from the special circumstance to which it applies. People talk large and wide: but they have definite facts in view. Partly from incapacity to formulate in definite and precise terms, partly from the weakness of rhetoricians, men are in the habit of clothing their meaning in preposterously ample vestments. At the time this difference between the sign and the thing signified is not so striking for those whose situation helps them to interpret the language, but as distance of place and time intervenes the gap between word and meaning grows more conspicuous. The accent, the tone, the sentiment, which qualified the sense and pointed the hearer to the fact, are now absent: and one has to wonder, and wonder in vain what the orator had precisely in view. Now in the case of these declarations it is evident that they are drawn up by journalists, half trained in philosophic thought, and hurried by the appetites of their clientele; anxious to formulate in a few brief propositions and catching phrases of apparent simplicity the cardinal principles on which society ought to be reformed, which were also in their opinion the principles always underlying social life, though now and for a long time past ignored and despised. It is undoubtedly true that the course of the revolution is marked both in the very beginning and during the reign of the Terror by wild excesses, lawless orgies of passion-driven and base-hearted individuals and multitudes; that a system of terroristic administration prevailed during considerable 
periods; and that low selfishness and degraded hatreds sought their gratification under the guise of a demand for legal fairness and punishment of accumulated misdeeds. But in its general and legitimate current and tendency, to which these documents are an attempt to give a logical expression, the revolution was only a levelling up of the tiew état to the condition of the two others, and a removal of the disabilities which checked the free growth of arts and industry. The revolution of 1789 in fact was the victory of the tiers état. When the abbe Sièyes at the beginning of the struggle asked his famous question, 'What is the third estate?' the only reply he gave was 'Nothing': it had by the revolution, as he predicted, become 'Everything.' It had swallowed up the privileged classes. It had succeded in quashing the old feudal entanglements, which still were potent enough to make life for the peasant and the townsman full of real or supposed indignities. No doubt in course of that process the poorest class had gained ineidental relief. Dependenee, like that deseribed by Voltaire as prevailing in the vicinity of his own country seat, was no longer possible. The serfs or dependent bondsmen (mainmorlables) of the great monasteries had been emancipated. But what was chiefly attained was a common law, without privileged exeeptions (aucun privilége ni exception au droit commun de tous les Français), and a removal of the old guild restrictions (il n'y a plus ni jurandes ni corporations de professions, arts et métiers). There were to be no more lettres de cacht, or arbitrary arrests of supposed dangerous characters. And as to that fraternity which is so often coupled with liberty and equality, perhaps the only mention of the thing is when it is spoken of as an object to be secured by the institution of feltes nationales. For the spirit of fraternity we must go elsewhere: go for example to the Seoteh poet, Burns, who welcomed the New Year of 1795 with the spirit-stirring ode which concludes with the lines 
'Then let us pray that come it may

(As come it will for a' that),

'That sense and worth o'er a' the earth

Shall bear the gree an' a' that.

For a' that, an' a' that,

It's comin' yet for a' that,

The man to man the world o'er

Shall brothers be for a' that.'

But in Burns the ery is not in the first instance for either liberty or equality; but for something very different, independence. 'The man o' independent mind,' ' the honest man, tho' e'er so poor, is king o' men for a' that.'

The declarations state the rights of the man and the citizen. The second epithet qualifies and limits the first. They say nothing of the woman and the child. The very document which lays down the principles of liberty and equality, proceeded to exclude from their operation a large portion of the population of France, or at least to draw a far-reaching division between two classes of citizens. Section II of the constitution of I79I marks off from the rest what it calls the active (as opposed to the passive) citizen. An active citizen must be a man and a French man, not less than twentyfive years of age, paying rates equivalent to three days' work, not engaged in menial service, not under accusation of crime, nor under decree of bankruptcy. By the constitution of 1793 the age of active citizenship was reduced to twenty-one years, and no other debarring conditions were allowed, except condemnation to peines infamantes ou afflictives: but the constitution of 1795 again refuses citizenship to the bankrupt debtor and to the menial servant.

These facts are enough to show that the large professions of the creed must be cautiously interpreted. The same point is involved in some of the arguments by which Bentham, in his chapter on 'Anarchical Fallacies,' has criticized the declarations of I79r. Is the relation of husband and wife, of master and apprentice, of hired servant, consistent with the assertion of such rights of equality? Are not the 
prineiples of equality and liberty in their literal statement sufficient grounds for destroying all social order whatever? The so-called right of resistance to oppression says in effect: 'Submit not to any decree or other act of power, of the justice of which you are not yourself perfectly convinced:' and the practical result of the formula is 'to excite insurrection at all times against every government whatsoever.' Bentham starts from the principle that 'natural rights is simple nonsense : natural and imprescriptible rights, rhetorical nonsense-nonsense upon stilts.' 'A reason for wishing that a certain right were established is not that right.' 'Right, the substantive right, is the child of law: from real laws come real rights, but from imaginary laws, from laws of nature, come imaginary rights, a bastard brood of monsters.'

Bentham further attacks the contract theory of government on which the doctrine of the superiority of natural rights to law is based. The theory, he says, ' is a pure fiction, or in other words, a falsehood.' 'All governments that we have any account of have been gradually established by habit, after having been formed by force.' And, as he adds, 'What signifies it how governments are formed? Is it the less proper that the happiness of society should be the one end kept in view by the members of government in all their measures?' The protest of Bentham is mainly directed against the vague and impractical nature of the resolutions, and the danger which such indefinite formulations carry for: the uneducated who are unable to supply the necessary correctives. Once assert that 'the laws have no right to forbid certain actions,' or 'that whatever is not forbidden by law cannot be hindered,' and you destroy all habits of obedience to government, and 'annihilate for the time being and for ever all powers of command; all power the exercise of which consists in the issuing and enforcing obedience to particular and occasional commands: domestic power, power of the police, judicial power, military power, power of superior 
officers, in the line of civil administration over their subordinates.' There is one thing and one thing only superior to the laws, superior i.e. to this or that particular law; but that is not a natural right, it is the law of the constitution, the fundamental prineiples, which particular laws are so many attempts to express in detail. Of the conformity of these laws with this general spirit of union no single man is the judge, although each is entitled to his opinion: he is free to think as he pleases, and we may add that he has a right to express his opinion.

The declarations themselves are shallow and uncertain, whenever they are pressed to disclose a consistent meaning. They fail either to present in clear conception, or to define in a satisfactory mode, the comparative claims of natural rights and the common happiness. They make no attempt to define that law before which all are equal, which determines the limits of liberty of speech and of the right of property, as of liberty in general. They hint, but dare not say, that liberty is only realized by law, and that all law is in its very essence coercion. For in short they are trammelled by the situation. It was, on the one hand, necessary to throw a decent covering over the accomplished insurrection, over the revolt made against constituted authority: and this is done by affirming a right of resistance to oppression and by a protest against hereditary privileges. But it was, on the other hand, no less ineumbent on the framers of these documents to make order possible for the future: and to this end they insist upon the limits of the natural rights and on the majesty of Law. Thus double-faced is the catalogue. As for the reference to public relief of the poor, and a general system of education, they were for the time 'sacred duties,' i. e. pious wishes.

These rights of man, like much else in the Revolution, drew some of their inspiration from Rousseau. But Rousseau was a deeper philosopher and a less narrow mind than the leaders 
in the political strife, and had a wide human seope which was foreign to their whole attitude. The social problem had exercised him deeply in its various aspects. In the year 1732 , he tells us, as he was making his way on foot through France, he had allowed himself to be drawn from the road by the interests of the landscape, and had wandered so long in his entrancement that he entirely lost his way. Weary and faint, he at length gained a peasant's hut, at which he made bold, after the manner of his native mountains, to ask for refreshments, for which he was willing to pay. The peasant gave him-and it was all that he had, according to his own account-a dish of skim-milk and a piece of coarse bread. As the young man greedily swallowed his repast, his entertainer, concluding from his appearanee that he was a bona fide traveller, proceeded to open a trap-door by which he descended to a cellar, soon to reappear with a good white loaf, an appetizing ham, and a bottle of wine. But when, after this more generous meal, his guest offered payment, the peasant's suspicions revived that his visitor was a spy of the taxcollector ; for as it appeared, unless every sign of a prosperous homestead were obliterated and abject poverty stamped on whatever met the eye, ruin from exactions was inevitable. Rousseau left the spot, he says, with the germ of that inexhaustible hatred he ever afterwards felt against institutions which enabled the oppressor to wrench from the toilers those gains which nature had in her bounty destined for them.

Some people tell us that in every man there are two natures, two selves: but it is seldom that the two beings within a man are so at variance as in Jean Jacques Rousseau. The very name is a symbol of antagonism. On the one side, the commonplace and ordinary John James, doubly common, by its two common names : on the other, the distinctive character of Rousseau. A union of aristocrat and democrat: of man and woman : of child and sage : of sinner and saint. His life 
up nearly to his fortieth year was passed in a silence and seereey, which we should be mable to get over, were it not for his own revelations in his later years. Left without a mother at his birth, his earliest years were spent in unequal companionship with a father, not much more settled in manhood than himself ; and the two would sit for hours entranced over the fortunes of some hero of romance, or the searcely less fantastic story of some of the great men of classie biography. At the age of ten he was deprived of this snateh of home life. His father, involved in the consequences of a brawl, sought relief in flight from Geneva, and abandoned his son, who was taken under the protection of an unele, and brought up for a few years in a way that failed to supply the discipline he had hitherto laeked. The youth grew up with no real world of duty and drudgery to limit his straggling impulses, but rather in a fantastic world filled with the ideals of sensuous and sentimental gratifications; ready always, like a Don Quixote, to deck out the real with visions of fair and pure femineity and grace, but also inclined, more like Sancho Panza, to sink these high ideals in the realities of vulgar or worse than vulgar prose. His first contact with the requirements of steady work was a failure. He seemed incapable of becoming a clerk, and he found his apprenticeship at the engraver's intolerable: and so in his sixteenth year he absconded from Geneva and began that life of wanderings and vicissitudes which lasted for more than twenty years. He became to appearance an adventurer and a vagabond: a stranger to his country, and a recreant to the religion of his native town : a hanger-on now on one patron or patroness, now on another : obliged to descend to the position of a menial and a lackey, in order to earn a livelihood: gaining strange experiences of woman in a love that was an inextrieable labyrinth of passion and calculation, of delicacy and coarseness : sinking into depths of pruriency and meanness, and vulgarity that one is hardly obliged to believe literally even on his own showing. And yet in that 
strange nature-with its keen and erratic sensibility and its defiance and distrust of convention and decorum - in that incessant eontradiction between ideal independence and real subjection to the implied or expressed wishes of some noble protector, there was something pure and noble, which was dimmed but not extinguished by the vulgarity and rudeness which clung to many of his outward acts. It has been said by an ancient thinker that the true physician should be one who has himself run through an experience of the ills that flesh is heir to, who has learnt by suffering what maladies really are. Perhaps it may be sometimes so in moral malady and weakness also. If we believe, as we may, that he who sins does not wholly sin, but still preserves a principle of moral health which, though driven back into the central citadels, still does not altogether yield the fortress, then we may think that Rousseau had emerged from the night of spiritual sickness and uncertainty with a tenderer perception of the inroads of evil, a more clairvoyant sympathy with the temptations of weakness and doubt, than he could have had if he had himself been whole and sound. The inconsistency in Rousseau's behaviour is not so inexplicable as it seems. To the majority of the world the intercourse of life takes place by forms and symbols, by external ordinances, which are as it were the organs and feelers connecting soul with soul. In Rousseau's case these intermediate helps which divide while they connect were dispensed with. He lived in direct and immediate rapport with his environment. As on summer afternoons he rambled alone with his dog through the woods of Montmoreney his spirit was wrapt up into sympathy with the nature around him; he abandoned himself to a stupor of eestasy and could only utter the words $\hat{O}$ Grand Etre! $\hat{O}$ Grand Etre! For such a spirit passing in immediate spirituality from itself to the life and heart in all around, it must have been hard to keep pace with those who only moved and felt by means of the material organs, the garb and fashion in which they had moulded 
themselves. And such disengagement from human ordinances, from form and symbol, is impossible without loss. If it is the spirit alone which can truly inspire communion, and convert mechanism into life, it is no less true that without a definite mechanism, without external signs and objective manifestations of the imner will there is no real communication, but only an intention of it, an unreality which is blown about by every wind of fancy and feeling. It is impossible really to live the solitary life in which the society of the hermit is created for him by the vigorous intuitions of imagination. So when Rousseau tells us that he began to live on April 9, I $75^{6}$ (the day he settled at the Hermitage), because he left behind him the intrigues and frivolities of Paris; when he speaks of himself as surrounding himself in these solitudes with an ideal society worthy of their beauty, we must remember that though he holds the peasants of Montmorency to be more useful members of society than the well-fed idlers of erudite Paris, still the society of his Thérèse, of his wellbeloved dog, and his old cat, have their corresponding defects and mar the perfect development and freedom of his spirit. Disdaining the graces of civilization because of its hollowness, he finds relief in a vulgar liaison which has its own deceptions : and when he asserts the independence of the sage, he sometimes falls into the rudeness of the egoist. When he made the great discovery which so many Stoic souls have made before and since, that the source of men's misery and wickedness lies in their false opinions, he forgot that it is impossible even for the solitary to avoid and leave behind him the dangers of mistaken estimates of the goods of life. He was engaged in an impossible struggle, and in a world where forms must exist, his every act solicited that inevitable contradiction which keeps asunder the ideal and the real. It is hardly to be wondered at if his overstrung brain, assailed by real persecutions and pestered by designing friends, at length gave way to the strong and often baseless delusions that embittered his 
later ycar's. We must take him for what he is, and not refuse to accept the prophecy and the poetry, because the poetic harmonies gave but a shrill sound and his visions of the perfect had but a shabby translation in his actual life. 'An indolent soul seared at every care, an ardent, bilious, and too susceptible temperament? (it is so he analyzes himself) are bad endowments for an honest and honourable life: but they could not destroy the sympathy which went forth for all beings, which grasped humanity in its folds, and entered even into the unconscious life of the nature around.

The first lesson which Rousseau had to teach his generation was, like almost all his writings, a paradox to his age. All truth at its first announcement must be a paradox : a shock to existing opinion: 'to scholars a stumbling-block and to the world foolishness.' 'The current belief of the literary circles of his time-its belief ever since the time when Bacon and Descartes had pleaded for freedom of thought, for more light, for the increase of knowledge-was that in widening our acquaintance with the laws of nature lay the panacea for the evils of the world. Multiply science and art, and you accelerate the millennium. To that opinion Rousseau in his first work threw down his gage, and he continued to the end to maintain the thesis then set up. That thesis is not that science and philosophy are pernicious, that civilization in the sense of increasing culture is a mistake, but that they are not all in all, that they are instruments and not ends; that life is more than art or science. Mere knowledge is but a poor thing. What Burns puts in his simple words :

\footnotetext{
'It 's no in books, it's no in lear,

To make us truly blest,

If happiness has not her seat

And centre in the breast;
}

or what is implied in Bishop Butler's words, 'the science of improving the temper and making the heart better'is the theme of Rousseau's first essay. This was what 
Kant meant when he said that Rousseau first taught him that the supreme work and glory of arts and scienees lay in the service of humanity, not in the mere scholar's joy in discovery and creation.

The second step taken by Rousseau is in form a discourse ' on the origin of inequality amongst men.' That inequality it deduces as the inevitable consequence of the development of the human faculties, due to the freedom by which man commands nature and seeks to rise to greater and greater perfection. But when the moral authority conferred by law is out of all proportion to the physical inequalities, it is contrary to natural right. Sueh eontrast to natural right is seen 'when a child commands a gray-beard, when an imbecile conducts a wise man, and when a handful of people is ready to burst with superfluities, while the starved multitude is in want of necessities.' The original man, the uncivilized child of nature, is indolent and easy, he lives in himself, ' il ne veut que vivre et rester oisif.' But the civilized man is never at rest, he seeks for power and reputation, he works himself to death in order to gain the means of living; because it is from the opinion of others and in their judgement alone that he gets the feeling of his own existence. The civilized man thus lives only in appearances, he sees himself through the opinion of others, and hence an universal dissimulation, 'de l'honneur sans vertu, de la raison sans sagesse, et du plaisir sans bonheur.' This is the true theme of the essay. It is the demonstration that man in soeiety has lost the mastery of himself, that he has handed himself over to an authority which deprives him of all real initiative, all spontaneous action, all sincerity.

The same theme appears in the Emile and in the Nouvelle Héloïse. The Nouvelle Hélö̈se is a dissertation, presented under the form of a romance, upon love, marriage, and family life. Few subjects connected with these interesting questions, whether sentimental, moral, practical, educational, economical, are not to some degree touched upon or even examined at con- 
siderable length. The Emile is a treatise on education. It is an education not for a special end: ' vivre est le métier que je lui veux apprendre'; and its hope is to produce a man who in one and the same course shall be prepared to transcend that contradiction in life as it is, which makes nature drag a man one way, and men drag him another; that contradiction between the moral and the physical which afflicts humanity. Civilized man is born, lives, and dies in slavery : his first ideas are those of empire and servitude. The method of Rousseau, which he holds is the method of nature, is to treat the child for many years as a purely physical being, to let him feel in good time the heavy yoke of necessity, la nécessité des choses, but to give no place in his dictionary to the words 'obey and command,' and still more those of duty and obligation. The child is not a reasonable being, and ought not to be treated as such : but just for that reason he must not be made to feel himself the puppet of human will. His rights as an individual in the natural world ought to be respected: he also must learn 'l'habitude de s'asservir sans peine à la nécessité des choses.' It is absurd to speak to children of their duties before you speak of their rights: the first sense of justice is not from what we owe, but from what is due to us.

The fundamental idea is the slavery in which society holds us. But it would be unjust to Rousseau to suppose that he wishes us to return to the state of the unspoiled savage who is sufficient for himself and lives a real totality, not a mere fragment of the social body. Rather the aim of education is to secure for man his independence as a member of society. The ancient philosophers sometimes discussed the problem if the best man was also the best citizen: and they answered it by saying that the two ideals would coincide only in the perfect commonwealth. Rousseau, as it were, answers from the other side. When man is so educated as nature prescribes, he will, when the age of reason comes, be able to take his place in the true commonwealth. - But the moral 
and political life must not be permitted to thwart and pervert the natural.

If Rousseau has given in his view of education a new conception of the rights of the child not to be a plaything of men, but to be subject only to the laws of nature, until he becomes of an age to understand reason; he has in the same treatise, in the book entitled Soplie ou la Femme, based the education of women upon the indications of nature.

The treatise on the social contract is an attempt to give new force to the old doctrine of the sovereignty of the people. But who are the people who are thus declared sovereign? Not the multitude, or any portion of the multitude, which has been separated and distinguished from the governing body. The people which is sovereign is the organized people, actually assembled in its completeness ; if it is sovereign at other times, what it has is a passive sovereignty, a background of authority, vast, indivisible, inalienable, which rounds off and underlies the several exereises of authority in the existing government. The people is sovereign, but the sovereign does not govern; he does not exercise executive functions, he does not put his own hands to work: like the immortal gods, the mortal god called the state only works by his delegates.

The people is sovereign : what it wills is the law, the principles which guide the exercise of the magistrates. But how is this will to be ascertained? The people is a multitude, it consists of individuals, one of whom may wish this, and another wish that. Can we find out what they will by counting votes, and conclude that what all have willed is the will we are seeking for? No, replies Rousseau, the general will is not the will of all. Each is guided, naturally or directly guided, by his own interest: and only if we suppose the more and less to eancel each other, would we get the general will. The people, if left to itself, always wishes or wills the good; but of itself it does not always see it. The judgement which guides the general will is not always 
enlightened. What the general will requires, then, is not identical with the decisions of a majority or even of a unanimous vote: for if the voters are blind, their decision does not truly represent their will. The people thus is represented as a blind but good-natured giant, who needs to be enlightened as to what he really wants: to be taught the 'conditions of civil association' which we call laws.

'T'o teach it that, to let the people see what it really wishes, is the function of the legislator. Thus, strange anomaly, the people must get some one to teach it what is its real will. Such a teacher must be a superior intelligence, sympathetic with human passion, and yet himself passionless: independent of our happiness, and yet ready to charge himself with its eare : in one word, a God. The legislator is not a magistrate, nor is he sovereign. Ilaving no authority, he yet has before him the enterprise of transforming human nature. Unable to employ either force or reasoning, he must have recourse to an authority, the intervention of heaven, which can constrain without violence and persuade without convincing. The fundamental laws of a nation, its action of supreme power, come as it were from something in man which is higher than man: they reveal themselves to him as the central tendency and drift of his being. The general will, in short, transcends the individual and can never be confused with the tyranny of democracy.

A somewhat curious instance of the effect of the ideas of Rousseau and the Revolution upon a mind of ordinary qualities, though in extraordinary mass and mixture, is seen in a youthful composition of Buonaparte. The following are extracted from an unfinished essay he wrote in December, I 790 (he was then twenty-one), in competition for a prize offered by the Academy of Lyons for an answer to the question 'Quelles vérités et quels sentiments importe-t-il le plus d'inculquer aux hommes pour leur bonheur?' (Buonaparte, it may be noted, was then at Ajaccio full of plans for the emancipation 
of Corsica.) He begins by defining man's happiness as 'la jouissance de la vie la plus conforme à son organisation.' That organization is partly physical and partly moral. With regard to 'notre organisation animale,' it has as its indispensable wants food, sleep, and sexual pleasure (manger, dormir, engendrer ${ }^{1}$ ). It is only emphasizing the last point when he remarks that 'Sans femme il n'est ni santé ni bonheur.' But man is more than animal: 'notre organisation intellectuelle a des appétits non moins impérieux : sentir et raisonner.' And man must learn 'que sa vraie gloire est de vivre en homme.' And happiness lies especially in the feelings (not in the reason). Le sentiment is the bond (lien) of life, of society: it is by it that we enjoy ourselves, nature, our country, and the human beings who surround us. Such enjoyment does not require great wealth as its means. In fact the rich live to their hurt under 'l'empire de l'imagination déréglée.' Still all men have a claim to be listened to for so much as is. necessary to enable them to carry out the life required by their organization. Hence not merely a wife, but a certain amount of terrestrial property is a sine qua non. ' L'homme en naissant porte avec lui les droits sur la portion des fruits de la terre nécessaires à son existence :' and it follows that the legislator (the organ of society) must resolve the political problem 'de manière que le moindre ait quelque chose.'

One may compare with this what George Sand (Histoire de $m a$ Vie, i. 50) says of her grandmother Madame Dupui de Francueil. Among other papers the latter left behind an essay 'Du Bonheur,' which began 'Tous les hommes ont un droit égal au plaisir.' The word plaisir, aceording to George Sand, means 'un bonheur matérial, jouissance de la vie, bien-être, répartition des biens.'

The demand for the maintenance of natural rights was almost a new feature of political life in the eighteenth

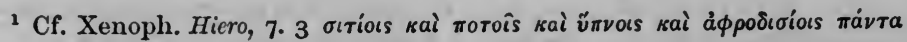

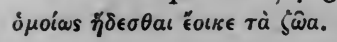


century. In the Petition of Rights exhibited by Lords and Commons to Charles I, in 1628 , the claim is made to a 'freedom inherited by the laws and statutes of the realm'; the rights and liberties prayed for are those according to the laws and franchise of the land, 'the laws established in the realm, either by the customs of the realm or by acts of parliament.' And in the Bill of Rights of 1689 'the rights and liberties asserted and claimed are the true ancient and indubitable rights and liberties of the people of this kingdom,' and the acts complained of are distinctly stigmatized as illegal usurpations of power. Everything asked for is a corollary of the same liberties, rights, and grants, which in Magna Carta secured the supremacy of the law of the land and justice over arbitrary power of the king or the king's officials. The tendency prevalent throughout is what may be called Legitimism, the doctrine of historic rights, of hereditary privilege. The claim of the present is founded on a possession of the past; it is the consequence of a precedent. Liberty and right rest upon a charter, a special historical fact. The rights and liberties have the same justification in a line of long descent, as the nobility and the monarchy have put forward for themselves against the parvenu and the radical. Unable or unwilling to raise the difficult questions of right and wrong, the advocates of national freedom and of justice contented themselves with the appeal to a distinct past-a past which was never present, a supposed and believed primeval use and wont. It is the same appeal to the custom of our forefathers which leads Antigone in the Greek play to appeal against the commands of the king to the unwritten and sure statutes of heaven whose origin is in immemorial antiquity. What the race holds dear it credits with birth in the beginnings of the ages ${ }^{1}$.

1 Heine, Englische Fragmente, xiii : ' Die früheren Bestrebungen, die wir in der Geschichte der Lombardischen und Toskanischen Republiken, ... verdienen nicht die Ehre eine Volkserhebung genannt zu werden : es war kein Streben nach Freiheit, sondern nach Freiheiten, kein Kampf für 
The eighteenth century was not satisficd with the results of this doctrine of historic rights and of legitimism. It despised the weakness which, rather than confront the real issue of right and wrong, took refuge in an alleged creation of the right by primitive custom and statute. It would have no more of those liberties (franchises) which are the creations of charters and royal grants. It eame to the conclusion that rights were something which monarchs and governments could not bestow, that liberty was 'above their sceptred sway'; that rights and liberties had a basis in the nature of things, independent of rulers who might acknowledge and declare, but could never make them. The mission of government, one of the philosophers of the time had said, is not to make laws, but to promulgate those laws which are necessary and natural, which are relations inherent in the nature of things. To ascertain these rights therefore is according to the philosophers the province of reason: and what is from one point of view called natural right may from another be called rational rights.

A right, it is said, is always the creature of law. But law is itself an ambiguous term, or rather there are laws and laws; and it is and has been a problem to say what are the differences and what the analogies which subsist between moral and positive law, between law political and law physical,

Rechte, sondern für Gerechtsame : Korporationen stritten um Privilegien. ... Erst zur Zeit der Reformation wurde der Kampf von allgemeiner und geistiger Art, und die Freiheit wurde verlangt, nicht als ein hergebrachtes, sondern als ein ursprüngliches, nicht als ein erworbenes, sondern als ein angebornes Recht. Da wurden nicht mehr alte Pergamente, sondern Principien vorgebracht.' See also Goethe, Faust, p. 72, ed. 1858, Mephistophiles to the student :-

'Es erben sich Gesetz' und Rechte

Wie eine ew'ge Krankheit fort:

Sie schleppen von Geschlecht sich zum Geschlechte

Und rücken sacht von Ort zu Ort.

Vernunft wird Unsinn, Wohlthat Plage,

Weh dir, dass du ein Enkel bist!

Vom Rechte das mit uns geboren ist,

Von dem ist, leider ! nie die Frage.' 
laws of nature and laws of society: or generally between what is called the law of man and the law of God. And the usage of language can here be no certain guide. It is easy of course to begin by propounding the view that every law is a command, issued by a well-marked superior to those in habit of submission within a political community knowing no master outside, and a command moreover which says not merely 'Do this thing,' but 'Do this sort of thing.' For the rough and ready practice of jurists such a definition may be sufficient: and it is then natural to add that laws of nature and moral laws are comparatively improper generalizations in the usage of the term. But it has to be pointed out that for the most part laws, even political and civil, are not so mueh commands to do a sort of thing, as statements that, if something is done or left undone, certain painful consequences are intended to fall upon the doer or the negligent person. Each so-called law has its place in a system of law, and has its meaning governed and determined by that system: it is subject to the canon of consistency. The laws of a country are thus the successive and continuous explieation of the conditions of social welfare, inherent in the general characteristics of human nature and in the special situation and qualities of the special community. A semblance of consistency at least is therefore indispensable, if they are to be laws. But if this be so, the laws of a country are only in a very secondary sense the commands of an assignable authority. The popular consciousness has always seen in the laws something above the control of individual will, of dictation or caprice. Actual law, it is true, has not unfrequently seemed due to the individual will: but this was and is possible because of the ignorance in which the community lives as to its true will, because, at the time when the law was enacted, the discrepancy between the decision of one and the demand of the universal was not apparent.

The dispute which, as it was formulated during the Middle 
Ages, raged round the origin of law from will or from reason was, as is usual with such disputes, partly a question of names. When Grotius held that natural right is so immutable that it cannot be changed even by God; or when Gabriel Biel proclaimed with the true scholastic piling up of impossibility to a climax : 'If, which is impossible, there were no God, who is divine reason, or if that divine reason were in error, still if any one were to act against the right reason of angels or men, or any other there may be, he would do wrong : and if no right reason at all existed, still if any one were to act against what right reason would dictate if there were any, he would do wrong,' they certainly seem to run counter to the view attributed to Occam that law originates solely from the divine will, and binds only in virtue of his command. Yet it is only the old question of Christian philosophy puzzling over the distinction of faculties of intellect and will. The eternal and necessary conditions of existence and of welfare rule us whether we will or no: and a mere perception of their existence elevates them into the position of laws. But in the case of human welfare there are peculiarities. Human life is governed by the conception of ends, by ideals. Its characteristic feature consists in the formation of common aims, of ideals in which a community or society are interested. The human being is essentially a social animal: a creature which enters into confederaey with others, which forms groups or unities. Or rather, to speak more truly, the human being is from the beginning, so far as we can see, differentiated from all animals by a something in him, which makes him not merely a creature of momentary impulse but a unity of self through diverse times: which makes him at one with others so far at least that, in order to realize his own existence, he must conceive and set it forward as bound up with others in a unity - a unity of greater or less compass, according to the circumstances and the time. There thus is ever present within him, but in greater or less degrees of force and range, the sense 
of community, of a common basis or unity, a common life in which he and others share. This sense is what in some respects we call the work of reason, in others of sympathy. In other words, what forms the unity is partly an unconscious principle, natural fellow feeling founded on sensuous and visible ties: partly it is a reflective and reasoning principle, which carries him from more obvious and more sensibly palpable ties to the more universal, generic, and intellectually realizable.

Now this community only exists by means of the minds of those who constitute it. These partial unities which are formed, no doubt make use of natural facts and rest upon physical boundaries: but, strictly speaking, there are no boundaries in nature. One part passes on into another and the world is a single totality. A river, a sea, or a mountain only becomes a boundary in virtue of the action of those who live beside them. Energy and enterprise can practically annihilate the barriers which nature interposes: whether a particular natural feature shall be a barrier or a link of connexion, depends on the human beings who have to deal with it. Thus the principles of union in the actual community rest upon the will and intellect of those who make it up. It is not a natural fact; but is made what it is by the conception and loyalty of its members.

This is the place at which arise the two opposite conceptions of a political unity as, on one view, a work of human wills, of deliberate and intentional compact, of action originating in individuals; and as, on the other view, a natural structure, a necessity of human nature, a fundamental fact which must be accepted but cannot be explained. The theorists of the eighteenth century, as has been already pointed out, were led to regard as most prominent the part of individual enterprise in forming the social body: it seemed, in short, as if they regarded the state as depending for its existence on the goodwill, the caprice even of the individuals, who with a view to 
further their private ends entered into a eompact of confederacy. Now as against this view it was perfectly fair for writers like Paley to urge that all government, having begun either from the power of a parent over his family, or of a commander over his fellow-warriors, had from these natural beginnings been maintained by the three motives of prejudice, reason, and self-interest on the part of the governed. But it was wrong in them not to recognize more explicitly than they did that the authority alike of the patriarch and of the leader in war rested upon reason and sympathy from its very commencement, was at least dimly felt to be the vehicle for attaining a common utility, and presupposed the indistinct conception of a unity and system of things. Even from the first we may make bold to say the human unity, however constituted, was not founded on mere naked force, but owed a certain homage to will and reason. The despot who wilfully applies the resources of a family or a community solely and singly for his individual good is a rare phenomenon: he generally is himself persuaded and manages to some extent to persuade others that he is subserving permanent and general interests. For, as Paley remarks, the physical strength almost in all cases resides in the governed, not in the government.

It would seem to follow then that the authority of a government rests upon the idea of a common good, upon a general will, which it is supposed to interpret and promulgate and enforce upon recalcitrant members. For indeed the very existence of government implies first, ignorant, and secondly, malignant members: i.e. people who do not know the general good which embraces their own, and people who prefer their own interests instead of the universal. As against the first class, government can avail itself of the instrument of education, of instruction in the rights and duties of human life: and for those who believe that a knowledge of the right is a certain method of realizing it, the 
second object would in this way also gradually be attained by removing the main cause of their recalcitrancy to authority. Such obviously are the two chief functions of government: and if the duty of punishment is the more directly incumbent, the duty of educating, i. e. of giving them all necessary and desirable means to enable them to perform their civic functions, is even more fundamental.

The ideal perfection of a state then would apparently involve its own suppression. But practically such a result does not come within the bounds of possibilities. For the conception of the duties of the commonwealth is not a fixed and settled quantum : it grows from age to age: and henee the necessity of edueation and of restriction is always incumbent. For as the existence of the state lies in the active conscience of its members, every new aperçu of its duty and function arises in a single mind, and has to work its way by the growing association of several, until it becomes the dominant belief of the majority. Thus the practicable ideal of a state is that its constitution shall be in accordance with the wishes and intelligenee of the largest possible numbers, shall rest upon the widest possible basis of popular agreement. But this necessity of the nearest possible approximation to unanimity, as a practical condition of a working polity, must never put out of sight another side of this question; and that is, that the material points in which the popular majority agree, shall be the true and abiding interest of the whole community and so of each member. A mob and a multitude in agreement is no guarantee of the right of truth of its conclusions. 'Private judgement and public deliberation,' said William Godwin, ' are not the standard of right and wrong: they are only the means of discovering them.' 'The functions of society extend not to the making, but only to the interpreting of laws: it caunot decree, it can only declare that which the nature of things has already decreed.' In other words, while it is the aim of the prudent politician to take measures such that 
the vast majority of a country shall be on the side of truth and justice, and so to secure what is called political liberty, or the participation of each in the making of the law, it is equally the duty of the wise statesman to take means for making the majority realize the true issues and complete bearings of the measures which may be set before them. He must, in short, get them to see that they are on the side of reason and nature, that their resolutions are not creating a right, but recognizing the conclusion forced on them by the events of history and the circumstances of nature. The human mind must be disabused of the delusion that it makes laws, must discover that there are conditions governing the common life of human beings whether they will or not, and that it will never be well with it till these are recognized.

Does what has thus been said leave room for the distinction between absolute and relative rights, as they are severally called by Blackstone, between natural and adventitious rights, as they are called by Paley? It is evident, and hardly need be said, that the term natural need not be taken to imply a state of nature previous to that of civilization. The natural is neither equivalent to the savage, nor to the paradisaic stage of the world's life. Savagery and civilization are alike within the realm of nature, and alike show departures from the natural. It is no doubt the case that longing eyes are sometimes cast from the confines of advanced civilization towards the apparently unfettered ranges of savage life. But experience soon shows that the bonds of convention are not solely to be found in the higher levels of society; that the rule of custom and usage rules with iron rigidity the primitive barbarian. It has often indeed been supposed that innocence and natural grace have taken up their abode in the country with the peasant, in the borders of civilized lands, in the primitive barbarism of the tropical islands. But the truth in this only is that the savage and the civilized man have got different vices and virtues. Nature can govern life in all 
levels of civilization, and unnatural life is enforced to no grade or landseape.

Natural rights then are consequences of the fundamental laws of social existence, of those laws which make life-incommunion possible in all countries and all times. Now though it is true that we can to a certain extent choose our company, the extent to which we can do so is limited. We can to some measure change the incidence of social pressure: but get rid of it altogether we cannot. In certain states of society it is reduced we may say to a minimum. But it is the very condition of human life that we cannot get rid of it altogether. We may therefore dismiss the hypothesis of a meeting of individuals previously isolated and independent with the view of constituting an association. Individuals thus absolutely individualized would never have come together at all. Sometimes indeed speculative theorists, in order to put in an emphatic light the necessity of a recognition by each of something higher than these petty selves, have put forward the picture of the brutishly chaotic state of affairs which would be inevitable, if each were in his acts to behave as if he were alone in the universe, if each in short were resolutely to pretend to be what he knew he is not. But the picture of such a social state is only the reductio ad absurdum of pure egoism, a demonstration that pure egoism vigorously carried out is self-destructive. And pure egoism can only be carried out, if it is ever carried out, because so many other principles of salvation for society are in operation, that its effects for evil are swallowed up in the general tide of good.

The question therefore is-society being the condition of human life-will we adapt ourselves to its indispensable terms or not? Now it is evident that those terms will vary to some extent from place to place and from age to age. The conditions on which society is possible for a group of hunters will be very different from those incumbent on a society partly agricultural and partly manufacturing: the conditions for 
a country village will be different from those of the closely packed inhabitants of a large town: those of a set of peasantfarmers will be other than those for a body of ecclesiasties. And yet it is scarcely less evident that amid all these diversities there will be certain analogies, certain principles common to all forms of association. Not of eourse that we can find these general principles as so many separate conditions on which the peculiar and local principles supervene. The world is not made in that way. Rather it is that we, coming later and reflecting comparingly on what we see, can detect in the characteristic constitution of each certain features which ean be stated approximately in general terms. These general features of life, never presented abstractly by themselves, but always realized in a special type, are what give rise to what have been called the absolute or natural rights of man.

There is another sense in which we may speak of natural rights. By what is natural, we mean the opposite of artificial and affected or forced. A thing is natural when it flows from one principle in all its details, when it is not in one part out of accordance with itself in another, but exhibits a solidarity and unity of all its members and functions. The natural is marked by unsought harmony, by consilience, as if each element by some magic power in itself sprang up to meet and join hands with every other. In the course of history a society like a clock gets out of order. The one spirit which ought to pervade it, the one law which ought to govern it, is replaced by a number of petty principles. Under a superficial bond of unity, for example, under a strong centralized financial administration, there may yet be no real unity of life throughout the kingdom. Such, for example, was the condition of France before the Revolution. Such more or less tends to be every great social union. There arises a state of affairs which may be illustrated by comparison with the conditions of the physical body in disease and in dissolution. In disease what happens is a disruption of the 
social continuity: some of the organs and tissues acquire a partial independence, and work by other principles than the general consensus of the bodily organs.

After dissolution a similar process is repeated with intensification. New organisms arise and take the place of the former vital structure. Something similar to this oceurs in a state of society. Parts of it get ossified : one part has gone on, while others have got left behind: some have developed abnormally and, as privileged bodies, attracted more than their fair share of the supplies of vitalizing matter. In such a state of affairs the cry for natural rights is a demand for justice, equity, equality, for the removal of narrow restrictions, for the destruction of complexities that have ceased to be useful or intelligible, and for greater simplicity and uniformity in the administration of business, especially in application to law and business.

Thus in these ways we may agree both with the school which speaks highly of natural rights, and with the school which disparages them as misleading and unmeaning verbiage. Where they are dangerous is when they are supposed to be something which the individual carries about with him from his birth onwards, something so peculiarly his own that he can at pleasure retain them or surrender them to others. To this theory no mercy can or should be shown. All that is a man's own is what he can do: what belongs to the physical individual is mere power or force. Even the word 'can' is ambiguous : it sometimes means what one 'may' do-and in that case is not applicable to the mere individual, considered out of relation with others. But a man's rights are not mere powers; they are powers sanctioned or recognized by something transcending the mere individual. They are claims which he has on the behaviour of others, grounds for interference, justifications for action in certain contingencies. Such grounds for claiming from another some specified behaviour presuppose a common standpoint, a public ground 
on which persons meet; or, in other words, righto belong only to persons, and a person is an individual who subordinates limself to some comprehensive or uniting principle, something which puts them in relation to each other. The right implies a controlling authority on which these persons can fall back, something (at least logically) antecedent to and inclusive of the individual, which makes him more than an individual, by giving him the entry to a sphere in which other individuals also enter. The mere individual has no rights as such; he has rights only as a person, i. e. as member of a society, as embodying in himself, at least partially, the larger aggregate of which he is a unit. The person has rights, because though an individual he is also implicitly the species: in him we find exemplified and realized the law of the class to which he belongs. A person in short is an individual who has what we may call a public character, a social function to perform. $\mathrm{He}$ is raised above himself by his conscious adoption of the class to which he belongs, by his sense of being constituted and governed by the general system or idea which is exemplified in him. A person is an individual realizing the universal. He is not merely one amongst many, not merely a single being in the multitude whom we note as we pass over them in review, not merely a being with peculiarities or idiosyncrasies of his own, out of which we can by an effort of abstraction disentangle the general properties. As a person he is conceived of as having respects and relations to the whole of which he is a part, and to the individuals who are his fellow-members. Thus the person is the individual which has lost its unrelatedness, which is a member of a groupa conscious and co-operating unit of a society.

There are legal and moral persons just as there are legal and moral rights. The term moral is ambiguous. At times it merely denotes the opposite of the physical : as when we distinguish a man's physique from his morale, or physical from moral sciences : a sense in which the words mean pretty 
much the same as the antithesis between material and immaterial. The moral in this general sense is what cannot be brought to book in definite objective fact, what eludes the test of experience and observation. Something of that wider meaning always attaches to the term moral: the moral is intangible; it eannot be weighed, eounted, and measured. As such it is especially opposed to the legal, as the outer and obvious shell is opposed to the inner kernel, as the potential to the actual ; as the great ' may be' to the definite and ascertained 'is.' But the antithesis must not be pressed too far, or' treated as absolute. They are two partial aspects of a single fact, that fact being the fact of human society: of which they respectively present the statieal and the dynamical element, the element of order and the element of progress. The legal is the moral cooled and stationary: the moral shows us the same element still fluid and energetic, shapeless and indefinite, but alive. The total fact is the social life of the world, where the prineiple of progress is in a healthy state always in union with the principle of order, the dynamical always keeping up the statical. Law is but the deposit, the fixed result, of the operation of that instinct, which while still heaving shapelessly is called morality. In the actual world they are never wholly separate: one without the other is dangerous to the community.

The merely moral is the purely internal : the merely legal the purely external. And just as it is true that 'summum jus summa injuria,' so it is occasionally found that nothing is so immoral as the conscience which refuses to be enlightened by objective order. Law, moreover, in constituting obligations and rights, does not constrain the holder of the right to make use of it. Morality, on the contrary, issues in the inexorable imperative of duty. Rights permit: duty constrains and obliges. Or, perhaps, while rights control another, duty controls one's self. And carrying this a little further we may see that rights are strictly speaking concerned, not with 
the inner relations of a man to himself, but with his relations to others. A man's rights refer to his external aspects, to those points on which he eomes into contact with others, to his objective manifestations. So long as he remains purely inward, rights have no application to him. Thus if we say a man has a right to his opinions, we must mean, if we speak correctly, to refer to the expression or utterance of his opinions, so long as they remain merely opinions, and do not affect the existence of others injuriously. So again the right to freedom of conscience would have no meaning, unless it included the outward expression - to what extent of course is a problem-of the beliefs and ideas which conscience cherishes. And as conscience is primarily negative in function, it at least will cover the right of not taking part in any performance to which conseience objects.

It is for the same reason that the person means in the first instance the physical body; for that is obviously for external purposes the primary objectification of the self. In the body the will and intelligence is present or presumed to be present for the outsider: and any injury done to the body is an injury distinctively done to the person. No doubt we can speak of the moral person; and the person as moral is independent of the body, is purely inward and spiritual. And such a power of abstraction has sometimes been claimed by those who maintained that the beauty of the soul remained untarnished by whatever was done in the body-who supposed in short that the sanctified spirit could lead a life of its own in lordly indifference to the claims of the grosser nature. Such is the tendency of some forms of mysticism. But a humbler philosophy, which follows the track of experience and confines itself to the fortunes of the embodied spirit, holds that in the main the soul is sympathetic with, suffers and acts in and along with the body. It refuses to admit, except for moments of difficult and dangerous abstraction, the separation of the inward and the outward of human nature; and 
while it maintains and allows the distinction of inward and outward, it denies their separate and independent existence as a fact coming within the purview of science.

Rights then are conditioned by law, and law only exists where there are external relations forming a system, constituting a social group. Rights mark ont the place which belongs to each in that system, and are only valid where such a system, economy, or constitution prevails. Outside it and apart from it, an individual has no claim to be called a person, and to be charged or invested with rights. Belonging to different societies, more or less co-ordinated with each other, an individual sustains several persons and thus possesses a variety of different rights. The basis of his rights then lies in the system to which he belongs; and to belong to a system is to perform the functions which are required of him in that system, not merely to be a passive and idle member of it, fruges consumere natus. A right is thus, as it is said, correlative with a duty. My rights, or the sphere of my rightful existence, are the consequence of my performance of certain external acts, of my making my existence felt by my prescribed conduct.

At this point comes in the right of coercion. So long as my entry into a society is an entirely voluntary act, so long the right of coercion in that society can only exist in a very moderate degree. I enter it upon a definite understanding, and can only be responsible to the extent of the bargain. Even here the society naturally expect me to make good any loss which my conduct may have caused it to sustain. The way in which it accomplishes that result is as follows. Strictly speaking all men form in the last resort one vast society. But for practical purposes that comes to mean that all civilized men form one society. The extent of that confederacy has varied from time to time. In the ancient world it was an oasis on the shores of the Mediterranean: indeed it was so much as this, only in the concluding days 
of the Rcman Republic. In modern times it comprehends a large minority of the world. Slowly through the agres progress is made towards realizing actually the implicit community pointed to by the Stoic saying: homo sum, nithil humani alienum: changing the moral into a legal community, and creating a real jus gentium, a true international law, not in the sense of a public law governing various nations as nations, but in the sense a common law dealing in a uniform way with the acts of individuals in society. So-called international law, as a collection of diplomatic usages, conventions and courtesyrules of intercourse especially in war, is of course no law at all, but a set of inferences from the common practice of belligerent states, supplemented by an indefinite number of pious wishes.

In reality the summit of real unity is reached in the independent political state, which so far acknowledges its solidarity with other civilized states as to assist them by the extradition of criminals against the common law. The state then, for all practical purposes, may be taken for the supreme society: and up to it all subordinated societies ultimately refer; or it finally takes cognizance of all inferior societies, as if they were its delegates and instruments. The state then is the ultimate creator, guardian and guarantee of all right in this world. It exists by the combined action of its members, and exists more or less clearly in the consciousness of each. It is important that this consciousness of the whole in each should receive an objective manifestation in a special body, told off for the purpose-a universal estate, separated as far as possible from individual interests and entrusted with the guardianship of the common weal. This estate is what we call the government, the executive and judicial body, the permanent administration. It is charged with the duty of seeing that the conditions of public order and progress laid down, or to be laid down, in the laws are complied with. In order to carry out that mandate 
it has the right to punish. That right to punish does not belong to the government in virtue of any compact, by which the members of the state bound themselves on entering it to submit themselves to chastisement, if they violated the term of their engagement. As we have seen already, the state as society is the condition of human life; and although at first a community may feel itself as merely a little usurpation amidst the general chaos, and so allow its defaulters to escape if they can beyond its limits, it gradually comes to see that the earth is one, and that it is bound to pursue the eriminal from land to land through the world. The state, in short, must realize that it is the mortal God, and that in this world it should be ubiquitous and omnipotent.

Its duty as a government is then to see that the laws or conditions of social (i. e. human) order and progress shall be obeyed and realized in the conduct of individuals; in other words, that the rights of each, both his general rights and those special rights he possesses as member of special associations guaranteed by the general order of the state, shall be respected and maintained. To this end punishments are available. What is a punishment? A punishment in the first instance is an act of restitution, if possible: a reinvestment of the injured party into rights of which he was deprived, and a denudation of the violator from the rights which he had misappropriated. But this is only sufficient in certain cases: those cases, viz. where examination shows that a right has been interfered with; where loss has been sustained, but where no malice or intentional hurt can be shown to exist, where there was good faith on one side as on the other. There all that government has to do is to see that the goods removed are replaced by an equivalent, as nearly as may be to the loss sustained. But in such eases it is not enough to show that no malice was intended; it may also be required that no criminal neglect of ordinary 
precaution be proved. It is an assumption based on the very nature of society that certain obvious and fundamental relations shall be continually present to the mind and govern the conduct.

But punishment proper only steps in where the injury is designed, or where the carelessness is of the degree styled culpable, i.e. is such as to show a dereliction from the ground of the first principles of social life. If it be asked, does the law then take cognizance of the motive and of the character, the answer must be both yes and no. Of the motives affecting the agent law has no regard, except so far as they modify the action; but in so far as they give the action a new character and constitute it what it is, law must take regard of the motive. If the action is conformable to law, is overtly in accordance with social terms, the state by its authorities is satisfied: if it is not in conformity, the state may have a very considerable interest in the reasons of that non-conformity. For though law deals only with actions (which are all outward) it cannot lose sight of the fact that an action is made such by a purpose, an act of will, and that an act of will is due to the adoption by the whole acting man of some desire or appetite which arises within him. It has therefore to consider the demerit of that appetite as a principle of action and overt consequence. Accordingly the punishment will be heavier or lighter not in proportion to the character of the individual, but in proportion to the more dangerous character of the dispositions which evidence their existence in his actions. If drunkenness, for example, is the immediate motive of the action, then the action will be more severely punished by those who hold that the temptation to indulgence in liquor is supremely pernicious to the interests of the community. 
A person is commonly defined as the 'subject of rights': it is sometimes added, 'and of duties.' The two ideas of 'rights' and 'persons' are thus closely connected and perhaps interdependent.

Persons are distinguished as 'natural' or fictitious: as 'physical' or 'moral': as simple or compound. In other words, they are either (I) individual human beings, or (2) corporate groups invested with powers of individual action, such as the state, a municipality, \&c.

Some confusion may arise by applying the word 'moral' to corporate personalities, as when Rousseau (and others) call the state a personne morale : artificial associations, corporations, colleges, \&c., coming under this head, and denoting aggregates which are formed of units already existing in the shape of individual human beings. But these human beings, as members of the corporation, seem in part to surrender their original personality. They are called 'moral' in distinction from the individual persons, human beings who seem to derive their personality from nature.

But, strietly speaking, we may hold that all true personality is moral. Pufendorf seems right in holding that personality is always 'moral,' always, i. e. due to a relation of thought, and to be carefully distinguished from mere natural individuality. A person is, according to him, an ens morale; it is originally (he speaks the language of the contemporary logic) 
a modus (not a substantia), though it is constantly in danger of being ('ad normam entium physicarum') treated as itself a substantia, i.e. hypostatized in an individual reality. Personality, in short, is a quality of the human being that expresses his moral nature. And the moral nature of man lies in his being subordinate to a general law, or being a member of a community, in which he forms an integral part and performs a function. Or, personality, like morality, only belongs to man in so far as, though a physical individual, he is implicitly universal.

The community to which man belongs is in its idea absolutely universal: i.e. if expressed in terms of space and time, it is a community of all times and places; eternal and omnipresent. In fact, it is only of limited range, or of restricted universality: a community consisting of a special group of human beings in a special country and age. The physical individual, as member of this absolutely ideal kingdom (of humanity and of God), is a moral person : as a member of a particular and definite kingdom, he is or has a legal person. In practice, the moral personality is not always widely separated from the legal. The moral is just a step or two ahead in extent: we do not rise at once from the special to the absolute universal, but rather in certain directions seek to diminish the narrowness of the actual scope of life and advance a little way towards that infinite which we can never attain in actual accomplishment.

In the other or common sense of the phrase 'moral person,' however, nothing of this sort is implied. It only means a 'person' made up by the aggregation and organization of individuals into a unity, which acts and suffers in common, and has recognized organs for the expression and enforcing of its will. And, strictly speaking, it would seem that such an aggregate only receives the title of a person, in the legal sense, when it is itself treated as a unit by a larger unity in which it inheres. Thus the corporation in a political 
community is invested with its personality by charter or similar authorization from the supreme sovereign. On the other hand, an independent state is only a person, in so far as the consciousness of the state at any moment is governed by the idea of its ultimate end or function, of its place in the system of humanity: it is a person in so far as it has what we may eall an eternal and infinite consciousness, or as it recognizes above it the authority of conseience and of God. And in practice it is a person in so far as it regards other states and other states regard it, not merely as so much power, but as power controlled by moral ends, regulated by reason, freely setting before it good aims-i.e. aims conformable and contributory to the general good.

It may be of some use to note historically the usages of the word 'person.' 'Persona' in Latin means a 'mask' - an 'assumed or fictitious countenance' in contradistinction to the natural face ('facies sua,' Sen. Ep. 24. I3). Secondly, it means the part or character played by an actor: his assumed part: and thus by degrees the individual himself considered as having a certain outward presentment. Thus even a thing may be said to have a 'persona,' when it is conceived of as presenting a eertain aspect or front, an appearance as distinct from its reality. In this sense 'personatus ' means 'assumed,' 'counterfeit,' 'unreal.' The general meaning of the word, however, does not include this suggestion of deception: it merely connotes the particular aspect and character in which a man appears to the world: and from this it is easy to see that a human being may sustain several persons, or play more than one part in the complex organization of any existing society.

In law the contrast is put between person and thing, between 'persona' and 'res.' A persona is thus a human being, but considered as invested with a certain function and social character; not a mere abstract human being, but one having a special place in the body politic, one who counts as 
something in the world. Hence in a state of society which legitimates slavery, the slave is in legal language said to have no persona or public character. His social existence is, so far as the law goes, entirely absorbed in that of his proprictor:

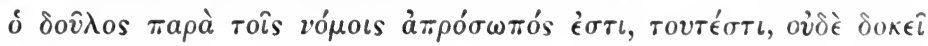
$\zeta \hat{\eta} v$ oủồ à $\pi \epsilon \hat{\imath} v a \iota^{1}$. His presence or absence makes no difference in the social sum : he counts only as a chattel. It is tolerably evident that such personality is a quality inhering in the individual through his place in a system : or that to transform the merely living human being into a legal person there is required recognition on the part of the state.

In mediaeval Latin the word persona is found in several shades of meaning. 'To lose one's persona is to become a slave. But more commonly it denotes a dignity or faculty, and secondarily the person charged with such dignity, function, or right and obligation. Thus we hear of a 'persona et potestas emendi et vendendi': and Boniface speaks of 'Laicus quidem magnae personae ad nos veniens.' It is especially used, however, of the holder of a clerical dignity: hence the modern English parson, which in Chaucer is still 'persoun.' A persona is in John of Salisbury a beneficed clerk (as opposed to a curate). Personatus is the dignity of a persona. A piece of Old French of the twelfth century speaks of a meeting where 'erent del pais li barun assemblé, deien, arcediachre, persones (= curés) et abé ${ }^{2}$ ' A 'personnat' is a sort of benefice in a cathedral church. It is evident, in short, that the dignity and office par excellence of the mediaeval period has usurped to itself the title persona: the 'parson' is the clerical functionary, the most distinct representative of a public character.

As we come down we find the word 'person' extended like other dignities to a larger and larger sphere. Even in Madame de Sévigné it has still a certain distinction attached to it: speaking of a lady, she says 'elle lit, elle travaille, 1 Theodor. Herm. vii. 6.

2 See Littré and Du Cange. 
'nfin c'est une personne': she is in short 'somebody '? But at last it seems in a phrase like 'itre content de sa personne' $=$ to be satistied with one's self, one had got to the bottom. Even here perhaps a careful observer might allege that there was a distinction between the judging self and the apparent, presented self, which appears to others. In Einglish a person is abont the least one can say of one: when one spealis of a 'young person' one has come close to a state where the human being has coised to be even a woman and become a mere link in the chain of society.

There is another use still however. A law treatise on the Liberty of the Subject speaks of laws relating "to the body or person,' and of 'the seeurity of the person or body.' And it is from the same reason that we speak of a woman's person, meaning thereby her physical appearance. 'My face is my fortune, sir, she said:' it may be that in the ease of a woman there is an especial ground of regarding her physique as specially constituting the character or part she has to play in the world.

'The theological application of the term 'person' need not detain us. It is now well known that the so-called Athmasian creed, in which the doctrine of the three persons of the 'Trinity is so conspicuously presented, is a document eompounded about the time of Charlemagne in the Latin language, and only assigned to the authorship of Athanasius in order to give it venerable authority. The Greek term corresponding to persona is $\pi \rho \sigma \sigma \omega \pi \nu v$ : but the Greek word on which turned the

1 Cf. Keller, Leuto von Seldhyler, x. 31 : 'Sie machte gănzlich den Eindruck von etwas Einzigem und Personlichem: es war, kurz gesagt, eine Person.' Schillor, 10. 308 : 'Die Abstraction unterscheidet in dem Menschen etwos das bleibt und etwas das sich unaufhorlich verandert: das bleibende nennt sie seine Person, das wechselnde seinen Zustand: See Zietelmann, Begriff und Wesen der juristischen Person (Ioipzig, 1873'. Cf. Luther, Wider Hans Worst: 'Dio Person wird euch niehts helfen, wenn euch das Recht veriampt.' Goethe, 43. 5 : 'Der Schauspieler muss soine Persönlichkeit verlliugnen ;' 25. 364: 'Der Monsch wirkt alles wus or vermag auf den Menschen dureh seine Personnlichkeit.' 
disputes of the Arian controversy in the fourth century was

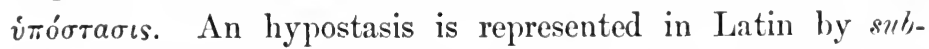
stantia, and the question of hypostasis is closely allied to the question of essence or nature. In the 'condemning clauses' of the original form of the Nicene creed rebuke is addressed

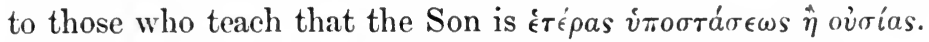
Gregory of Nyssa is the Eastern advocate of the Trinity in Unity: according to him, Scripture is found $\phi v \lambda a ́ r \tau o v \sigma a$

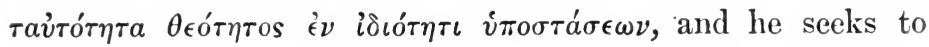
reconcile to the mind the antithesis between the $\dot{\eta} \tau \hat{\eta} s \phi \dot{v} \sigma \epsilon \omega s$

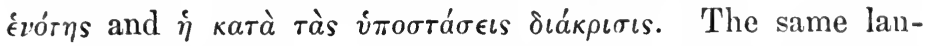
guage appears in Augustine ${ }^{1}$, who declares that the same whole is a Trinity 'propter proprietatem personarum,' and one God 'propter inseparabilem divinitatem'; but he differs from the Greek Fathers in holding that in each Person the Godhead is fully realized, not, as they maintained, merely the particular aspect of universal deity.

If we next ask what attempts philosophers have made to examine the ultimate principles involved in a term which jurisprudence is content to handle without too minute analysis, we may first turn to Locke. Dealing in Book II, chap. xxvii. of the Essay on Human Understanding with the question of personal identity, he is careful to maintain that it cannot be based on, or consist in some mysterious identical substance, a solid substratum of hard matter at the centre and kernel of life. It lies and can only lie in an active consciousness, a 'thinking thing,' which attributes actions to itself. Personal identity lies in consciousness; it is the sameness of a rational being and consists in the act of intelligence, in the consciousness which, while distinguishing itself from itself, still refers the passing, variable mood to the permanent self; shows the variations of consciousness as phenomena of one consciousness, and realizes the one consciousness (out of time) in the succession of con- 
scious states in time. $\Lambda$ person, says Locke, is a 'thinking intelligent being that has reason and reflection, and can consider itself as itself (the same thinking being) in different times and places.' $\Lambda$ little further on he tells us that 'Person is a forensic term, appropriating actions and their merit, and so belongs only to intelligent beings, capable of a law and happiness and misery.' He means that, when we punish, we presuppose that we are dealing with a person, and by that we mean an agent whose acts are recognized as part and portion of himself, as proceeding from himself and all connected together in one sequence or consistence, forming parts of a single unity. But he also means that in merely intelligent beings, without feeling of pain or pleasure, this idea of a self, a responsible self, would never arise. In us, however, the 'concern for happiness' is 'an unavoidable concomitant of consciousness.'

The last point may be compared with some remarks of Lotze. It is impossible, he says ${ }^{1}$, to define the meaning of 'mine' by a logical combination of concepts. It is a primary experience, by which the difference of the mine and not-mine is first felt and realized. This form of experience consists in the feeling of interest, of pleasure or pain. What pains or gladdens me is absolutely distinet from what I represent either as indifferent, as painful, or as pleasant, without feeling the supposed weal or woe. And so in his Prycho$\operatorname{logy}(\S 5 \mathrm{I})$ he maintains that a mere act of knowledge cannot be the motive of this distinction (between me and not me). 'Mine' comes before ' $I$ ' or 'me' : and we must distinguish, he adds, between feeling our self as a self, and knowing our own being: between the sense of self and self-knowledge. The latter is the subsequent interpretation of what came earlier as an experience of feeling. Thus the consciousness expressed in ' $I$ ' does not belong to a merely intelligent being. We must accordingly distinguish between the spiritual nature common

Ieligionsphil. \& 33 . 
to all, the general essence of soul or universal appearing in all individuals: and the nature of the ego by which each soul distinguishes itself from all others ${ }^{1}$. Each is not a mere specimen of a class, a mere particular case: he is also and more essentially a being-for-himself, a self-centred being, referring all that he is to himself. This is the secret of life, which is inapprehensive to logie: of personality, which refuses to be dissolved in the universality of philosophy.

As yet we have only seen that personality was based on reason and intelligence, on the power of self-disruption and of self-reunion, but, further, on a reason which is not mere intellect but is an intelligent life, feeling and realizing its concepts, and realizing them indeed before it can properly be said to know them. It was natural for Butler, commenting upon Locke, to raise a question as to what Locke meant by the 'substance' he perhorresces, and how it differs from 'being': and to declare that, though consciousness may ascertain for us our personal identity, it can hardly be maintained to constitute it. The discussion touches on a radical problem of philosophy-what existence applied to spiritual being or to 'ideal reality' can properly be held to meanwhich hardly came forward for clear examination till Kant and Fichte.

Mansel ${ }^{2}$ can hardly be said to throw much light on the question. Distinguishing between the 'accidents of consciousness and its essential constituents' he points out that, though 'the matter of consciousness is continually changing, the form abides permanent and immutable.' No great gain perhaps follows from applying to the question this Kantian distinction of form and matter. It however emphasizes itself in a phrase like this: ' $I$ exist as a person only as I am conscious of myself, and I am conscious of myself only as I exist.' Our being is a conscious being: a phrase which is too bald not to stand much in need of 
exposition. Mansel adds that there are two conditions indispensable to personal existence, time and free agency: there must be a succession in time (of modifications in a persisting subject), and also a power of attention or volition. 'The last seems to mean that a person must not be a mere drift. of events upon a stage, but must also possess a power of surveying and so far controlling the stream, a power of comparison, unification, and initiative. We come bark very much in this to the phrase of Ieibniz: 'Persona est cuius aliqua voluntas est, seu cuius datur cogitatio, affectus, voluptas, dolor.' Clearly in other words a person is not a thing.

It is only very incidentally that Kant has given any exposition of the idea of a person ${ }^{1}$. We call a rational being a person, he says, because his nature points lim out as something which can never be a mere means, but must always be treated as at the same time an end in itself. As persons, rational beings are possessed of a certain worth or dignity, in that they obey no law but a self-imposed one. A person thus has the special prerogative of guiding his course by principles derived at once from his own point of view and from that of every other, as a legislative being. Our person is distinguished from our state (Zustand): our personal value from the pleasant or painful condition in which we are. And thus finally our personality reposes upon the power we have of regarding ourselves from an ideal or intelligible point of view, as purely free, originative beings. And so Kant comes to a conclusion like that of Ahrens, that human personality lies in the union of the contingent and finite element of individual life with the absolute and divine reason: and implies a power of the mind to detach itself from the given fact by an act of utter spontaneity. A person is one who has been able consciously to grasp and make his own all the varied qualities of mind and

$$
1 \text { P. i. } 1 \text { ro. }
$$


soul which belong to him as an individual. This power of reducing to unity and stamping as his own every mental element and faculty is what belongs to every person as such: and it constitutes the common generic aspect of human personality. Hence, says J. H. Fichte, 'the normal man is one who has raised his individuality in all its parts to personality, who has brought all mere instincts, \&c., to the full property of intelligence ${ }^{1}$ ' Yet in all men this personality is imperfect. There always remains an insoluble residue in the background, from the depth of which continually rises the unexpected and the undesirable.

The movement towards personality is thus a realization and concentration of the characteristics of the individual. These, scattered and isolated, are appropriated and unified by the act of the genius or inner self: they are no longer mere fragments of being, but fused into an instrument and symbol of the self. But in this act each sets himself in antagonism to others: he becomes a person by asserting and determining himself against others: he marks off his own sphere of personality; and in constituting himself a person shuts himself off from others, who yet are recognized as independent of him in that very act of renunciation. Thus the person is essentially an individual, one among many. But the formation of personality is a process which goes on in each by reflection on others, whom he at once acknowledges and excludes : the creation of this reduplicated individuality thus implies a movement pari passu towards community, or the recognition of another self-another yet the same-in others. The subject thus measures the value of his personality by the reflection of it he imagines he can trace in the judgement of others. The individual or free subject thus attains to personality only in company and competition with others; and from this social relation flow both his rights and his duties, as he alternately seems to exclude others and to include them

\footnotetext{
1 Anthropol. 25I.
} 
with him in the same community. Those rights which follow from the mere fundamental conditions of community, before any definite and special free relations have been formed, are the original and inalienable rights of men, the rights in which all men, as members of any community whatever, are equal to each other. It is in these everlasting rights that personality as such consists: the abstract right of free self-development and self-determination - the equal right to exist and live his nature out.

But as J. H. Fichte has hinted, and as Lotze has enforced at some length, the finite being finds himself on all hands confronted by forces with which he did not invest himself, and by laws which he has to accept, as well as by wills different from his own: nay, even in the recesses of his own being he seems to meet with a dark strange substance which is in him, but is not he; and to which as a vehicle his whole personal development is attached. We have grown up as it were by piecemeal, and are never wholly ourselves; we identify ourselves with the particular point of view at which we stand in a particular stage of our development. The complete sanity of self-control, of self-mastery, and absolute possession and appropriation of all our souls is what we never fully attain. 'It is only to a limited degree,' concludes Lotze 1, 'that we can say that it is .we who act: for the most part action is carried on in us by the several groups of ideas or feelings to which our mental machinery at each instant has given predominance. Still less are we in time quite all our own. Much vanishes from memory : most of all does it gradually lose hold of the individual moods of feeling. Many grooves of ideas, in which when young we were at home, come before us in later years as foreign phenomena: we can hardly find our way back to feelings in which we once indulged with enthusiasm; the power they once wielded over us has left scarcely a trace behind. In the walks into which later life brings us we

1 Microc. iii. 574 . 
come to regard as unintelligible aberrations those aspirations which we onee held to be inalienable members of our inmost self: we cannot understand how we could ever have felt such impulses. In truth, therefore, we have little ground for speaking of the personality of finite beings: personality is an ideal, which like all ideals is proper only to the Infinite in its unconditioned nature, but to us is, like every other good thing, only vouchsafed under eonditions and therefore imperfectly.' Thus, he sums up, 'a full personality is possible for the Infinite alone: the peculiarities of the finite are only hindranees to its development.'

It is necessary, however, to examine briefly this attribution of personality to the Infinite or Absolute. The point on which Lotze seems to lay special weight is the imperfect character of such personality as is exemplified by human nature. The same thing may be said also of morality, and even perhaps of religion. Each of these has a something in it which presses onwards to a perfection, the attainment of which would be its own annihilation. The religious man aims at a growing and increasing divinity or likeness to God: if this likeness reach its ideal limit in identity with the divine nature, then it is no longer strictly entitled to be called religion. It has passed beyond itself into the reality which it aimed at, and in the continual but unending approximation to which its very life and existence consists. But the state thus imagined is one which it is impossible to realize in clear thought. The truth rather seems to be that religion, like everything else in humanity, only exists in what we may call a radical antithesis, a synthesis of two aspects, neither of which can be severed from the other. It is, on the one hand, a sense of the dependence on the divine, of the infinite littleness of human nature, and on the other a sense that God is with man and that even now, in this world, God and man are reconciled in one.

And so it is also with morality. The law of duty is a 
standard which, as it is approached, ceases to bear the old aspect of obligation, and passes into the guise of autonomy. A perfect morality would be a state of soul in which the struggle between conscience and appetite has been completely transcended in a willing union, where the appetites become the rady messengers, or organs instinct with good doing their master's will as their own. Morality, as Kant says, arises because man regards himself as a citizen of a higher world, a spiritual kingdom; regards himself as a legislative and spontaneously legislative member of that kingdom, embodying a law universal in his every single resolve and action. But man, though obliged by something within him to put himself in that position, to assume that high place and rank, finds himself as matter of fact a citizen of the sense world, the world of nature, a mere link or rather an aggregate of mere pieces in a physical system, which governs his movements. He is moral only by an effective act to make himself; to realize his vocation, and affirm the initiative and independence of physical law which he claims. He finds himself a fragment; he believes himself to be a whole. His life is a struggle between his realization of this faith and his acceptance of the position of fragmentary fact. Neither aspect can be ignored, and so long as that is so, man cannot be perfectly moral, just beeause he is a sensible creature. Morality thus is founded upon an idea-the idea of a spiritual nature, the faith in an 'intelligible world'-an idea which can never in this world be realized. Perfect morality and perfect religion earry us beyond themselves to an absolute in which we may suppose them to be satisfied: satisfied, however, by being carried out to that consummation which destroys what is their very essence.

It is the same with personality. The ideal of personality is the complete penetration of all that comes within the compass of the person : it is the animation of all the parts of the human mind and body, and all that subserves these, with 
one mind and spirit: the thorough appropriation of every particle that is mine with the full reality of me, so that I may be complete and at home in every part. But such an appropriation rests upon a distinction of mine and thine which is fundamental and immediate: it involves an individuality, feeling and asserting its own distinct existence amongst other individualities. The personality therefore is only a position assumed to mark out and define individual existence. If it could be what it would fain be, it would be universal, all-embracing: for at no point can I stop and say: Thus far do I go, and what is beyond is to me indifferent. Any limit which is to be drawn must be imposed by the existence of other personalities equally self-assertive in the region to part of which $I$ am obliged in this way to confine my claim. Just as religion only exists because man is always differenced from God, and morality because the appetites are not absorbed and annulled by the reasonable will, so personality only exists beeause we are not pure spirits and mere ideal beings, but have a visible and sensible basis to our existence, in passions, limbs, and material conditions. We are persons because we have an excluding individuality, 'ein bestimmtes materiales Ich'; though that personality is only inherent in the definite materiality by virtue of an implicit universality of appropriative and unifying thought. It is only because they act in a sense world that rational beings come into connexion with each other, and, while excluding one another, yet somehow keep up their unity with that which they have excluded. Hence personality can only belong to a member of a world, to one who is not everything, but stands in contact and relation with others outside himself. Such a position cannot belong to the Absolute or Infinite. We cannot indeed say that the absolute is impersonal, but we may at least say he is something more than a person.

Personality then is an idea which, as we know it, is realized 
in the case of a person, or of persons. As in other cases, we must distinguish between the singular form of the universal idea, and the singular or plural of its several manifestations. 'Thus truth is an idea; its real aspect is seen in particular truths, none of which are ever adequate to the absolute idea. Nor can we deduce from the idea of truth any particular truth whatever, or find in any higher conception a criterion or standard by which all subordinate truths may be recognized. We can only say that all truths must be consistent with each other; that a truth which is inconsistent with another truth shows itself or the other to be no truth; that wherever there is a want of clearness and distinctness-or of coherency with the whole system-there there is error or falsehood. When we refer our pereeptions to experience, we do not merely mean that one perception is coherent with perceptions of the past, we mean that they both form members of that united world in which all experience is embraced.

Similarly we distinguish duty from duties: and we dare not try to deduce the latter from the former. We ean only say here again that duty is (not indeed an abstract, merely identical unity, but) a system of unity in which perfect harmony prevails; or that, in the language of Kant, the only criterion of moral law lies in its absolute compatibility in every part-its adaptation to hold good in action under every circumstance. 'Les devoirs,' as Malebranche said ', are infinitely various-they are only the external fact, the 'devoirs extérieurs': but true virtue is only one-the 'amour de l'ordre.' 'Il ne faut pas confondre les devoirs avec la vertu.' What Malebranche called 'la vertu,' Kant called 'die Pflicht.' It is this inner spirit which is his 'great, sublime name' : an inward or ideal, which can never be proved by experiment to have an outward existence, or ever to be a fact. The duties are given us by the conditions of human life in society, and we cannot

\footnotetext{
1 Traits de Morale, c. 2.
} 
deduce them from any idea of duty, any more than we can deduce a given animal from the general idea or law of life.

So too, according to Plato, we rise from the diversity and aceidentality of outer conduct, of justice as the world knows it,


the justice in the soul, the systematic disposition of faculty in the system of human nature. The just act as such may flow from various characters : it may be the product of prudence, of calculation, of caprice, of impulse, of hatred or of love. But it has only one true and genuine cause, the proper balance and co-operation of the several principles which constitute human nature: the proper subordination of the impulses which crave for enjoyment, for pleasure, under the conception of the true reality and good of life, and their supplementation by a due development of that spirit of independence and activity, which in its excess delights in war and struggle, and of the intelleetual energy which by itself might be lost in mere contemplation of speculative conceits. The man in whom sueh a balance of forces was established, would be in himself a principle of justice. And being such a principle, he would, if he could exist, have no need of external arrangements and systems of polity: he would be a law to himself. Unfortunately such a unified being is only an ideal, a standard man, with whom we compare the man developing each of these interests to a more than due extent. And in the city which Plato constructs we have a machinery by which the ideal, not realizable perhaps in the individual, may be attained by the influence which in the fabric of the state each part exerts on the other.

So personality is only known as a person among persons, as a visible and sensible one among others, maintaining his ground amongst others, keeping up a unity and consistency of his being in all its details. But each of these details, and they are infinite in number and minute complexity, is part of other connexions; each enters into a variety of relationships, and has so to speak interests and laws of its own. The person 
therefore is a fictitious unity, an artificial product, so long as he has not completely identified himself with all his parts, and them with himself. But such complete identification is for a finite being impossible. Each part of him carries him out beyond his actual self into another world, a world in which he is not supreme, and where other persons hold sway. Hence the person soon begins to compare the implicit or potential universality that he felt himself striving to be, with his own partial attainment of it, and with the like attainments and elaims of others. The result is a mixture of oppositions. On one hand he seeks to carry the claims of personality farther and farther, to extend his being in range, even if he cannot master its ground in intensity of penetration. Such is the instinct of power. On the other hand, he seeks to get the most out of his actual possession, to identify himself completely with what he does appropriate, and to gratify the instinct of pleasure. Or again he may seek more and more to realize for himself that his personality is something transcending all that is visible and sensible, that he is other than the things he sees, feels, and conquers; and this in its excess is the instinct of the mystic and the quietist. For him the external world is annibilated: his personality is wholly inward and invisible: and his only actions are done in his soul. Instead of using the invisible self as a stepping-stone or point of view, he essays to dwell in this upper world. The conflicts which arise in the visible world deter him from venturing into it. $\mathrm{He}$ surrenders the corporeal embodiment of self, and withdraws himself into his purely spiritual being. He concerns himself solely with the internal unity, and resigns to alien control that outer world where supremacy is always imperfect and can only be kept up by constant effort and is constantly liable to interferences which no skill or prudence can wholly provide against.

Real human personality must be something different from this. It uses the world as not abusing it : or, in every tie 
which it forms with external things, it remembers that the conjunction is a temporal one. Or, feeling itself in essence eternal, it does not on that account make light of its existence in time, from moment to moment and in local and limited spheres. Human personality is essentially a unity of oppositions. And we may even go so far as to say that its special appearance is in the visible and outward sphere. As a person, we are primarily what we are to our neighbours: we occupy a certain place and discharge a certain function in the visible world. Hence a man's personality is not his mere intellect, but his whole being: it is more than his books, more than any definite work he may have accomplished. A great. personality is a sum of influences, each of which may so far be exercised apart, but which produce their chief effect in virtue of some individual bond which holds them altogether and makes us feel more than we can consciously explain on analysis. Thus the personality is not the body merely, but the body and matter as informed, controlled, organized by mind and soul.

But the essence of personality is undoubtedly shown in the distinction of I and Thou. To be a person is thus not merely to be an individual, but an individual which recognizes another individual as possessed of the same essential characteristics. The person, while marking off self from others and claiming a certain sphere as his own, does at the same time admit the existence and rights of the other. Each has as it were a double order of organs. His grosser organs are exposed to the influence of the external world, whether he will or not. He cannot choose but hear, when mighty noises convulse his ear. But so long as a certain point is not passed, he is independent, and ean only hear by an inward sympathy or participation. He hears only when he imitates by an inner and more delicate organ the tones which are echoed in his outer organs. He must help if the effect is produced. This is the right of personality : and it is violated when another 
individual by physical violence forcibly induces a change in the organism of the first to which he does not respond.

When so looked at, personality or personal identity (on which, as Locke says, ' is founded all the right and justice of reward and punishment') is made an ideal of complete unification and self-control of all the parts and aspects of a man's nature. We begin with what may be termed 'psychological personality': the 'I' which 'is not a conception, but a mere consciousness that aceompanies all conceptions.' Thus the 'I think' is a conception (or judgement) which is the vehicle of all concepts whatever ${ }^{1}$. Or, as it is put in the Proleg. $\S 46$, note, "the " $I$ " is no conception, but only a designation of the object of the inner sense, so far as we do not apprehend it under any specific character : it is nothing but a "sense of existing" (Gefill eines Daseyns) without the least conception, and only represents to us something to which all thinking stands in relation.' Kant's point, it must be observed, is that the ' $\mathrm{I}$ ' is not a thing or object among other things : we cannot put it before us as an object: if we could do so, the ' I' would cease to be an 'I,' and become a Not-I. Or, as he otherwise puts it, the ' $I$ ' is not something of which we have a 'standing and abiding impression,' a steady clear image. It is always a subject, always active, and never to be conceived as a passive object, or permanent substance. Thus Kant maintains against metaphysical (rational) psychology that the Ego is a bare apperception, which underlies and makes possible all our forms of conception : but we can never so far objectify it, and put it in the order of objects, as to treat it as a substance, the simple persistent something which underlies all mental change. Thus he calls it a mere 'feeling of existing,' as distinguished from the intellectual ideas of relations. 'Subject' can never become 'object,' or it ceases to be 'subject.' 'There is a profound and indelible distinction between the idea of a thing (which is a formula expressing

${ }^{1}$ Kritik der R. V., Dialektik, bk. ii. ch. I, Paralog. 3. 
the relations between the parts constituting it, and between it and other things which are connected with it) and the existence of that thing, its real being, life and actuality. As Kant remarked, in dealing with the scholastic arguments for the divine being, existence is not an attribute of a thing, not a mere part and portion of the idea: but something unique and sui generis. The reality, as distinct from the idea, is something active, something which appropriates and holds the idea, and feels resistance or contradiction of the idea as a disturbance of its own being; something which exerts an effort and sustains opposition. Existence then in its last resort is not something which can be touched and measured, but something which is felt, felt above all in the immediate self-experience of mental life. Existence therefore is properly spoken of only where there is susceptibility to influence, capacity of action and reaction.

Hence, as was already hinted, no being can be called a person who is not capable of feeling and action, as well as a mere idea of the intellect, a mere object of apprehensive judgement. Personal action is distinguished from the operation of necessary laws, or from the authority of mere ideas, which are true, but do not exist. Mere ideas, mere concepts, have no power in themselves: they are made alive and real only in a living consciousness. The idea has to be incarnated in flesh and blood. Hence the influence and place of great men in history, the force of a real personality. The theorem may be there: the facts may arrange themselves in the very act of expressing a law : but unless the living heart and voice take up the burden of the idea it is ineffectual. The mere words even may be present; but they are only

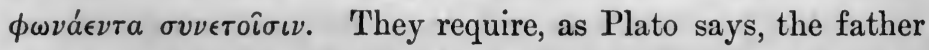
of the word to cherish and defend the children of his thought, and strengthen their ghostlike forms with his own life and blood. The soul or central self is more than the mere intellectual concept: than a type, plan, or idea on paper or in 
mere words: it is the actual concentration of all the system of relations in one source of power, making the words breathe and the thoughts burn. It is only as a state of the soul that the concept enters as a force into the real world and changes the material. 'That the idea may live, it must be embodied in a person or an institution: and an institution is after all only a moral person-a complex person.

Kant then seeks to show that the Ego eannot be treated on the same level as the mental or physical phenomena which it observes: it cannot be well or adequately described by such terms as 'substance,' 'thinking thing,' and the like. It is the perpetual concomitant of all mental acts, but not the single object of any: if it be made an object, it is of a peculiar sort-a subject-object. We may to some extent consider it in abstraction from its special phases or attachments, but we ought not to speak of it as existing apart from them. We cannot take the ' $I$ ' out of ourselves and put it 'there' before us. It is true the conscionsness ' $I$ think' is a simple and unanalyzable consciousness; whenever we go into further detail, we leave the simplicity of the condition of consciousness and descend into the detail of actual consciousness of this or that object. But a simple consciousness does not entitle us to speak of the simple nature of the subject of consciousness: consciousness cannot get behind itself and consider its own cause or principle. The Ego is only the 'form of apperception attached to every experience': an epithet noting the subject condition on which all knowledge depends. All the categories on which knowledge depends are only special and detailed forms of this ultimate power and principle of synthesis. Being itself the ultimate condition of all knowledge, we cannot get behind it to see its conditions. It is an irreducible and ultimate sentiment of reality, a feeling of being.

So much for psychological personality, the condition of moral action, or the prius of morality. It consists in the 
presence of a central unity of apperception, a feeling that ue exist in our several modifications, that the various feelings, desires, emotions are ours, belong to us, have a common ground and a mutual interdependence, thus constituting a system with necessary relations. Personality, moral personality, has a double aspect: it is the relation and inter-connexion of elements claiming some measure of independence. Within us personality presupposes a nature which is one and yet many : which has from the beginning a potency of unification of instincts and principles, and which can occasionally at least raise that potency to an actual symmetry and solidarity. It presupposes various ápXaí, which ultimately fall under the guidance or control of one $\dot{a} \rho \chi \dot{\eta}$ : and in that relation, implicit or actual, of the central monad to the others in our being, personality as an inner quality consists. But there is also an outer personality : a personality for the eyes of others and in an external community. In this aspect personality depends upon a system of society, in which each has his place appointed, and therefore occupies a special restricted position. But still in fulfilling that place his inner and moral personality must remain intact. He is no doubt a mere unit: but a unit which can embrace and reproduce in himself the whole society of which he forms a part.

It is for this reason that Kant calls personality 'eine Achtung erweckende Idee.' Moral personality is nothing but the freedom of a rational being under moral laws (whereas psychological personality is merely the power of being conscious of one's self in the various states of one's identical existence): from which it follows that a person is subjected to no other laws than those which it imposes on itself (either alone, or at least at the same time with others). 'A Person,' in short, ' is that subject (agent) whose actions are capable of imputation : whilst " a thing" is capable of no imputation".' In virtue of being an end in himself man possesses a dignity

\footnotetext{
1 Rechtslehre, Einl. p. 24.
} 
$(W u ̈ r l e)^{1}$. Personality ${ }^{2}$, as 'freedom and independence from the mechanism of the whole of nature,' elevates him as a moral being above his sensible nature, which attaches him to the order of things. Personality belongs to a being endowed with inward freelom-with the power of absolute initiative.

Thus, as Hegel remarks, 'to be a person is the grandest thing a man can be: and yet the bare abstraction-a person -is somewhat contemptible in the very expression.' It is different from the subject or psychical person, the mere possibility of personality which is found wherever we find a living human being. As an individual, I am a being defined in various ways, of such and such an age, so tall, in this or that space, with such and such a temper, eharacter, and modes of thought. But all the while as a person I can set aside all this particular aspect of myself and reeognize it as something separable from me: can look at myself as a pure personality, in which all speciality and limitation of $\mathrm{my}$ nature is cancelled and lost to view. So viewing myself I see myself as absolutely unconstrained and unlimited, as infinite, universal, and free. Thus if I ean be said to see myself here as an object, it is an object absolutely simple, general, and selfidentical. It is not till an individual and a nation have reached the point at which they can dismiss as irrelevant to themselves any special phase of being to which they are accustomed, that they ean be said to attain personality. Thus in personality we have the contrast between the limited actuality and the unlimited possibility, between the phenomenal aspect and the essential being, between the particular definiteness and the latent universal. Personality is the power of realizing and keeping in view the universal, free, and unlimited being, amid the particular and definite or isolated forms which threaten to overwhelm it. It is as tending to sink the particular in a mere general relation- 
ship that the term person seems occasionally a term of reproach.

Thus a person is, on the one hand, an individual or individualized being, one among many -in ordinary cases, a single living human body-which, on the other hand, has the capacity of regarding itself as a universal, not bound by limits of actual achievement, but as infinite and free. This is the so-called mystery, grandeur, or contradiction of personality. In the little physical individuality which is alivein the single subject or living soul which is a mere point excluding all others and excluded by them - there is a potential universality, a claim to absolutely unconstrained existence, to complete independence of action, utter spontaneity. Unchecked this may degenerate into disease; the individual may see himself in his petty individuality as all-embracing and deserving universal empire.

But on two sides this danger is guarded against. In the individual consciousness there is the sense of the moral law, which gives moral personality: i.e. the individual sees himself subject to a law which categorically regulates his actions and appoints his sphere. And around him he, as a living individuality, is confronted by others, who implicitly claim the same universality as he does: and with whom therefore, if he is to live, some modus vivendi must be established, on the ground that each of them is equally a person, and that whatever be their implicit universality, in the bounds of their external manifestation, their personal existence, they must mutually recognize each other.

'Thus personality has a double aspect: neither part of which can be absent, though the one is mainly emphasized as moral, the other as legal personality. The legal personality is always found in a thing, a material body, or something which can represent or stand for a material thing. Even the human body comes under this head. It is more closely connected with the person than other things: but of it too 
it can be said that the person can divest himself of parts of it and yet retain a visible personality. But also of things external to the body it may be said that I cannot be altogether without them: I must have something mine in the external world, or my personality will cease to exist. 'Thus my organic body is the first and most rudimentary realization of my personality, but of it, as of other things, I must take possession by an act of will, forming and appropriating my body as an organ of myself. My body and my property are means of objectifying, realizing and maintaining my freedom, my universality, my independence. In them I am present, and by them I carry out that absolute claim to all things, to self-mastery and complete sovereignty, which is inherent in personality. The human will goes forth with the conviction that things are lordless, appliable by the first comer, waiting for a meaning and soul to be given them.

The legal personality is under the rule of right or law. Its principle lies in the restraint imposed upon the freedom of each by the reegnition of the (in principle) equal freedom of all. The rule of right is, 'Be a person and respect the personality of others ${ }^{1}$ ' As the will of a person towards things, as the instinct of realizing personality in a material world, the range of personality is unbounded. The mere thing is impersonal, and has no rights. Hence man, individual man, has towards things an unlimited right of appropriation ${ }^{2}$ : he treats the purely natural world as possessed of no substantial existence, as a mere vehicle for his manifestation. But the position is altogether altered by the existence of other persons: and now there arise two conditions of existence. On the one hand, each recognizes the existence and right of the other: or perhaps it is now first of all that we can properly speak of rights, meaning that each recognizes a certain sphere of action as belonging to the other, and gets a certain sphere recognized as his own.

1 Hegel, Rechtsphil. $\S 36$.

${ }^{2}$ Ib. $\S 44$. 
But on the other hand, each may persist in the original instinct and ignore the other: we have then the rule of might, where they take who have the power, and they keep who ean. When this rule of might is regarded as an outrage on the natural law of right or mutual recognition, it is describable as the dominion of wrong and transgression.

The moral personality is not under an external, but an internal law : it is a member of a spiritual and invisible, not of a visible and material kingdom. The moral law commands: the law of right only forbids and restrains. The sphere of law is the range of what is permitted, or of what is forbidden: it does not say, Do this or that, but rather, Do not do this or that. The sphere of moral law is the sphere of obligation and duty. The latter commands eategorically: the former only permits. Thus while legal personality concerns in the first place my relation to other beings, moral personality deals with my relation to myself, or with the relation of my sensible to my spiritual nature. Legal personality therefore depends upon the institution of a common law, of a sovereign judge, of a commonwealth organized and united. Moral personality is independent of all outward law: and if all beings were perfectly moral, i.e. subject to the inward law, there would be no need of a law of rights. But man is very far from being so constituted: he can only make himself moral (which he is not through nature) by means of the labour and discipline of edueation. The law of right is part of such education. It attains its object indirectly.

Logically it may be said that law comes before rights, and that rights are the creations of law : they exist only because they receive the public sanction. But historically the process often seems to present the opposite aspect. Law is only the gradual accumulation of a number of jura, or rights, independently asserted and determined by special acts. Law at first only exists in petto, in the conseiousness of the people, and is elicited by its chosen interpreters. The judge in Homer has 


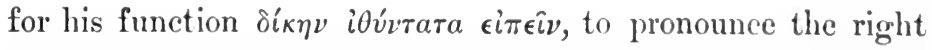

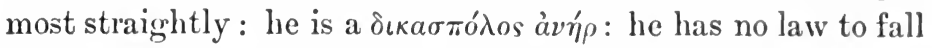
back upon as a written and systematized body of laws. Law at first only exists as a fundamental and underlying principle

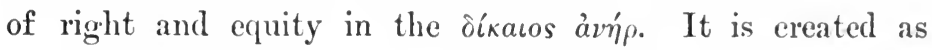
a system in accidental or oceasional decisions, which affirm the special right in an individual case. Gradually such isolated jura, or asserted and accepted rights, grow in number, come more and more into relation with each other, and require consolidation and harmonizing. For as they grow up singly, and, though resting on a common consciousness, have to be got at by a special fact and through the judgement of a single human being, they may possibly conflict with each other. Again, considering the strength of the tendency to imitation, there is a chance of precedents gaining ground in cases which are hardly in pari materia. Still in some ways it may be that, while law thus remains in the common consciousness, it is less likely to get stercotyped than when it is reduced to a written code. But on the other hand, the legal administration passes from the people to the judgement of a special class or person, who in German is said to shape the verdict or doom. When that happens, formality, pedantry and ossification are apt to set in.

Still we may say that law makes its first appearance in the shape of so many rights or decisions actually given. These rights present themselves as belonging to the individual, and it is in battle for such rights that revolutions take place. And while law seems to come from above and be imposed on the unwilling, rights spring from beneath and only require to be affirmed and accepted. Jus is right: jus civile is the right attaching to the citizen (of Rome). The struggle for legal right takes the form of an effort on the part of individuals and classes to claim something, which they believe to belong to them and to be unjustly withheld. Thus legal rights arise as the claims of personality, of individual human beings, 
as the claim of the individual to a recognition from others. It is only gradually that the idea of rights sink into the idea of a common law.

Rights then are the claims of individuals upon others, and they are only affirmed as rights by the recognition and acceptance of them on the part of these others. It is moreover as against others, against individuals, that the individual has rights : not as against the state or organized community as such. They are the boundaries between individuals, denoting the range of power and influence which the community has recognized as belonging to its several members. Such rights therefore need not be equal : they are simply the powers belonging to the individual, which are licensed, accepted, or recognized by the state. The principle of right is reciprocity: what you would not wish done to yourself, you are not to do to another. This is the respect of personality, the negative condition of virtue. Right assigns to each his place and prevents one from encroaching upon another. Its real origin is a moral one, the claim of personality to be master of its own development, to be subject to no law but that which it imposes upon itself. But to attain that end, it must recognize in others the same claims as it makes itself, and so restrict its own plenitude. No one can claim a privilege strictly so called, that is, a right which departs from the general equity and balance of the system.

Thus the right of personality is the right never to be treated as a thing. No person, however, can claim that right unless he himself admits and practises it. 'Persons,' says Fichte ${ }^{1}$, 'treat each other mutually as persons, only so far as each acts only on the higher sense of the other, and therefore leaves it to his free will to accept the action, leaving his lower organs wholly unassailed and unchecked.'

In practice this view is confronted by the difficulty of determining whether the conditions of personality have been

\footnotetext{
1 Naturrecht, p. 87.
} 
complied with. But here it is probably best to err on the side of presuming personality to exist, and therefore requiring to be respected. As we have seen, personality in its full phase is an unrealized ideal. It is therefore difficult to discover any inferior limit where it may be presumed absent. At what time, for example, is personality to be recognized as present in ehildren? It is true that the law fixes with some show of agreement a time when the infant acquires the full rank of person, when he emerges from minority and is invested with the charge of himself. But the period of majority is fixed in view of certain domestic and social interests, and cannot be regarded as an answer to the scientific question. Nor can we altogether aceept the poetic dietum that

'The baby, new to earth and sky,

What time his tender palm is prest

Against the circle of the breast,

Has never thought that this is I :

But as he grows, he gathers much,

And learns the use of I and me',

as meaning more than that the feeling of 'defined isolation' is not yet clearly conceived and set before him. Personality may exist in very real germ long before the use of the personal pronouns has been mastered. And even the baby has something more than the thing, as also in another measure has the animal : they each appear in some degree to be conscious of an inherent principle, a right to their own unimpeded development.

This right of personality then is never to be treated as a mere means, but always as having its end and principle in itself. Thus the body in which the personality is primarily objectified must always be treated as the cause of its own movements, and still more the mind. A person e.g. is not treated as a person, if external action upon him is so vehement and violent that it moves and affects him without his own consent. Any loud speaking, e.g. which bursts through the 
barriers of his organs, is thus disrespectful and obtrusive. Any rough handling or fondling, which in the least forces his organs to comply with those of another, is an outrage on personality, which is not penal, only because it is commonly vulgar. Where personality is presumed to be fully developed, we must always ask the other to co-operate with us, to respond, to do himself what we wish or teach him to do. Only partial imbecility can justify any intrusion. But on the other hand, if non-intrusion be a right, affability and readiness to meet another is equally a duty.

Still the person must be allowed, so to speak, to choose his own company, ideas, movements, \&c. All that he can be fairly expected to do is not to shut himself up to the suggestions of others, and not without special reason to close the organs of sense to the communication of others. The very essence of personality is equality, liberty, and fraternity. Liberty is a peculiarly negative word: it means that the individual as a person is not to be made to do anything against his own will: it means freedom from assault, intrusion, and outrage : but it does not always mean liberty to do everything which he might like to do. It is guarded by equality and fraternity. But equality in this phrase does not mean equality of powers, natural or acquired: such an equality is partly impossible, partly undesirable to secure. It is sometimes said that the equality meant is equality in rights or equality before the law: i. e. that in all affairs of public interest there shall be no privileged treatment of individuals or classes: it means, in short, a claim to equity and impartiality. But it also is a postulate that beneath social differences and natural distinctions there is a common meeting-ground, an average standard to be presumed, a dignity of man and of woman, as such, which puts them on a level. And this equality therefore is bound up with fraternity: the equality is that of brothers and sisters, of children of the same father; members of a community. Liberty is checked by equality, and the excess 
of equality prevented by liberty: and both are humanized by fraternity - by the identity of a common humanity.

How far the conditions of personality are satisfied in an individual is not easy to say. It requires possession of mental and bodily health. But what, it may be asked, is health? The answer is supplied by Plato. The body, like the soul, is an organism: a system of parts mutually adapted, each possessing a certain independence and proper function: which however in a healthy state never actually rises to utter severance from the general. The whole adjustment in its details in the body is governed by the laws of mechanism : at no point can we say that a special prineiple of life, a vital principle, steps in and directs the interaction. The principle is one with its parts, it is in each part and in the whole: it is the supposed explanation of the fact that there is this solidarity, this unity which transcends and interpenetrates the separation of parts, tissues, and organs : it is the principle of equality and fraternity in the body: and also the principle of liberty. No part can eneroach on another, no part can be held less essential, no part be treated as separable from the others, without in each case inducing a perturbation of the general fabric. Each has its own province, its own right or duty: but none can permanently act in independence of the others; and all must practically experience that the general law of life, of self-maintenance of the total organism, is a principle overriding particular rights.

It is equally so in the soul, in the psychical range, only that here something further seems to supervene on the mere organism. The vital prineiple is always engrossed in its part, and can never be regarded as an independent agent. The unity of the body is a unity of co-operation, the result of factors which work in obedience to a common law. But that common law is out of sight. In the soul, on the contrary, the very essence of the whole movement is that it rises in some degree into the light of consciousness. And the peculi- 
arity of consciousness is that it is a whole conception or form which gradually fills itself in detail with the fullness of its partial shapes. The unity, however implicit and potential, underlies and realizes itself in each step towards particular manifestation. The unity is primary: and it is only because duration as a whole of time lies as an undeveloped basis that we come to make distinetions of the duration of special states. We count these, not by the summation of their separate periods, but by the means of a common basis of consciousness which, while parting itself out, does not lose hold of the whole.

This unity of consciousness reacts, if we may say so, upon the body. The body has other than the merely organic movements, which follow according to impenetrable laws of instinctive nature. The purely animal movements are governed by an idea; and the body itself is by mind transformed ( 1 ) into a sense, (2) into an instrument. It is in this double capacity that the body is strictly ours, the organ of our mind, of our intelligence and our will. The word 'organ,' indeed, covers both meanings. As such the body is organized or articulated by the mind: i. e. its parts are differentiated in use and function, made to some extent independent of each other and under the direct control of each other, and capable at the same time of co-operation in executing a complex movement.

Now bodily health consists in this completeness of organization and articulation of the body as an organ or instrument of the soul, no less than in the mere regular movement of the purely organic life. The difference however between the normal soul and the normal body is considerable. Of the proper proportion of parts and distribution of functions in the normal body, it is easy to get a tolerable definite conception. But as Lotze remarks ${ }^{1}$, we have no type of the definitive shape which ought normally and necessarily to be taken by the several psychical powers. In order to estimate how far a soul 
is or is not in a healthy state, we have recourse to two methods. On the one hand, we gradually form some ideal picture of the state which the soul in its collective capacity ought to reach. On the other, we consider how far the various means at our control for that purpose may enable the soul, not alone, but when aided by the average amount of favourable conditions presented by life, to attain this normal end. 'That is, we first have a rough idea of what mental sanity ought to be, and then we ask how far the given facts in ordinary conditions are likely to realize it.

Now as regards the first, we see that mental health and wealth do not depend on a mere accumulation of single facts, but on solid ideas of what life is and ought to be, and what the world around us really means: it does not lie in confinement to a fragmentary life, limited in its range of view, and moving for ever in the same monotonous routine, but in a large and free scope of experience: nor does it lie in the degree of variety and intensity to which we can bring our sensations and aspirations, but in aequiring the proper estimate of values, in calming the turmoil of temper and gaining at once 'sweetness and light,' that gentle reasonableness which, though not less free to receive impressions than in the beginnings of life, is at the same time matured by experience to a wiser judgement of their comparative worth. The true ideal of a fully developed personality does not consist merely in a keen intellectual acumen, nor in an intense but inactive susceptibility to the moods of happy feeling, nor in a perpetual unresting activity; it involves a balance of all these elements. But few, if any, reach this; and if this be perfect health, 'wir sind,' as Lotze says, 'fast alle krank.'

Yet we are not in the habit of applying this rigid standard. We are indeed ready to admit that we are far from having made the best of our possibilities. We see, as we look back on ourselves and others, that many faculties which had the 
germ of almost endless expansion and usefulness, have turned out mere single accomplishments, petty facilities of produetion in one department, whilst others have taken lines of growth of which we thoroughly disapprove. Hours of selfexamination come, when we are ill at ease in reviewing the result to which time has brought abilities that promised so fair. And yet in spite of this self-condemnation, we still do not hesitate to pronounce ourselves spiritually sound. To explain this contradiction, we must take note of the second point of view, our judgement on the possibility of reaching the ideal by the help of normal and average conditions.

We admit that our course of mental growth has taken false directions: but we do not believe that the psychical formations are equally irrevocable with the corporeal. We separate the permanent reality from what we suppose the mere appearance. We fancy ourselves, even after all these mental misgrowths, to be still fundamentally unaltered in our general capacities as when we began our career. And when the failures of development have been cast away, as the withered leaves are stripped from the trunk of the tree, we expect that the indestructible root of life and character within us will throw out fresh shoots, perhaps more vigorous and better than those which went before. So long as the derangement has not penetrated to the very root and centre of our life, we conceive it possible that alongside the actual depravity and failure there still survives a better spiritual principle, an unextinguishable source of fresh spiritual health. It is only when we find that movements originating within us, or obstacles which we can trace to some bodily infirmity, hinder us either for a time or for ever from giving birth to new and fresh life from the old source of life, that we recognize the commencement of spiritual disease. And it follows from this way of thinking that we are indulgent in our judgements : we do not regard as intolerable departures, either eccentricities of feeling and sentiment, or disagreeable specimens of intel- 
lectualism cultivated in one line solely, or excess of unreasoning passions. It is only when, on actually experimenting, we find that there is no longer the capacity of applying the general potentiality of mind to even simple objeets, that we admit the existence of mental derangement.

But this hypothesis, which would so much simplify the problems of mental diagnosis, cannot be aceepted. We eannot always distinguish the permanent health of the faculties from the perversity of their actual applications. There are no ready-made faculties of permanent quality and power, which can be manipulated without alteration of their strueture and nature. As Plato said, the food of the mind eannot be eonveyed in vehieles alien to itself, but only in the mind itself which is modified according to its content ${ }^{1}$. The soul cannot be conceived of as exerting side by side a variety of utteranees, good or bad, aceording as outward eircumstances suggest, while the root and stem remain sound and unaltered: every application of the general faculties of mind is at the same time a modification of the instrument we use. Nor ean it be denied that the employment of the faculties, as it varies, leads to ehanges in our powers of judging things ; the eye is perverted when the heart is turned on base material. There is danger in the tendeney to treat these prejudices, peculiarities and whims of character, as mere superficial inequalities not affecting the sound heart and judgement at the bottom. The outside angularities, irregularities, and so-called originalities of mind which are thus engendered, are symptoms of a state verging towards mental insanity. Still there is some excuse for the distinction between the faculties themselves and their applications. In derangement proper there is a thorough-going unrest, a want of proportion between the inner faculties. But in the product resulting from cramped and perverted development, the mental forces have got some sort of equilibrium. The weak, ill-grown mind of 


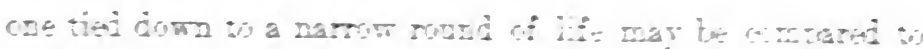

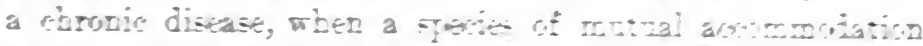

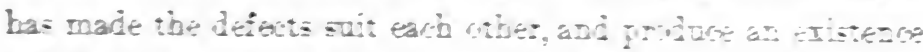

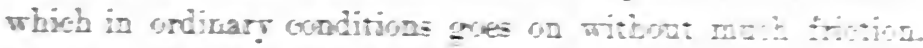

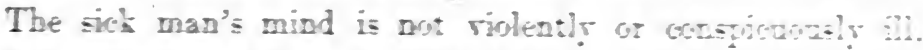
exhibits no great lesions. Bat it is all on a falor vels. His want of sanity has grown into a bearable srstem, but still it is remorid from true health of sorl.

Mental deragrement then, as ondinani! understrod, dus not merely mean the state in which, from whaterer canses, the estimates of things and the sense of their importance are perverted, or in which the riems formed about circumstancs; in tbemselves distant and indifferent, siom a want of intellectual talance, an inequality of judgement: it means that, whether from these condition or otbers, the onilinary facts of everyday life, open to what may be called coular demonstration, are falsely apprehended or are misinterpreted.

But when the law treats a person as a responsible agent, this is the ultimate limit which it lays down. A responsible agent mast not be suffering from mental derangement: he must be in possession of sound senses and sound mind; and by this the minimum meant is that he is capable of ordinary penception of single facts and has ondinary capacity of interpreting or inferring from these facts. Witbout this a being is said to be utterly irresponsible. He is not strietly speaking a person, is not possessed of the common foundation of rationality. Yet it may be doubted whetber it is possible to lay down definitely the conditions required to prove responsibility. Jurisprodence certainly has not done so. In the nature of the case it is obrious that no absolute rules can fix how much power of judgement and perception is sufficient to constitute rationality and responsibility; and in any given case it can handly be possible to prove that these conditions have not at all been satisfied. Thus we are foroed, like Aristotle, to be content with general and rague considerations. 


\section{III}

RESPONSIBILITY

There are two points of view from which responsibility like personality may be regarded. We may deal with it, looking at the individual or at the community. In either aspect we get a part of what is meant by responsibility.

The word is partly synonymous with terms like accountability, imputability, and is closely connected with punishment. 'The term responsibility,' says Bain, ' is a figurative expression. Seeing that in every country where forms of justice have been established, a criminal is allowed to answer the charge made against him before he is punished, this circumstance has been taken up and used to designate punishment. We shall find it conduce to clearness to put aside the figure and employ the literal term. Instead therefore of responsibility, I will substitute punishability.' To the same effect J. S. Mill trenchantly says: 'Responsibility means punishment.'

On this, however, two remarks suggest themselves. The first is that, when punishment is made the practical index or proof of responsibility, 'the real question,' as Mill himself says, 'is one of justice-the legitimacy of retribution or punishment': not punishment merely, but the conditions in the individual which make it right to punish him. And secondly, though responsibility is a condition of punishment, it is not limited to acts which deserve punishment. It is a feature of the world, which might perhaps be explained, 
that the good that is done is accepted much more passively than the evil :

'Men's evil manners live in brass: their virtues We write in water $^{1}$;'

and

'The evil that men do, lives after them:

The good is oft interred with their bones ${ }^{2}$ '

People are responsible for the good they do no less than for the evil: but no one is curious about the authors of our blessings. The public treats all its servants as bound to the full discharge of all the benefits their faculty affords, and only attends to their special performance when it falls short of the normal average.

The terms 'accountability' and 'responsibility' undoubtedly seem to refer to a 'serutiny' or examination, to which the deeds of a person are liable in consequence of his occupying a public function. Such is the $i \pi \epsilon \dot{\theta} \theta v v o s$ ápXí which has to give an account of his administration-who, unlike the rovvapxia ${ }^{3}$ or autoeracy, is subject to law. The idea is one of dependence-subjection to a higher will. A $\epsilon \tilde{v} \theta v v a$ or aecount has to be rendered: the person so rendering an account being evidently treated as a deputy or servant charged with a funetion, and not as a wholly independent (irresponsible) or self-centred agent. But while the term $i \pi \epsilon \hat{\theta} \theta v v o s$ is in Greek specially applied to public functionaries

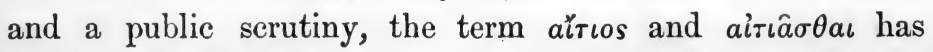
a wider range. The term aiııâ $\sigma \theta a \iota$ means, to bring a charge against, to accuse; but it has also the more general meaning, to allege as the cause: and similarly while aitía generally means an accusation or change of crime, a crimen, it is some-

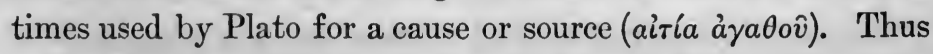

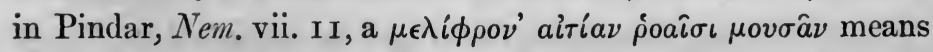
'a pleasing subject (motif) for the flow of song': and alтเos,

$1 K$. Hen. VIII, Act iv, sc. 2. 2 Jul. Caesar, Act iii, sc. 2.

3 Her. iii. 8 o. 
though usually 'the culprit' or 'accused,' is also the author

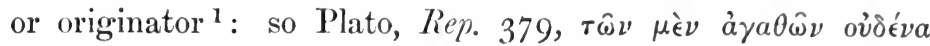

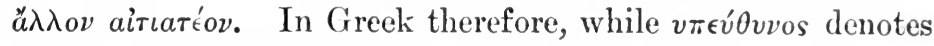
especially the liability to a public account and examination, the idea in altios is that of authorship or causality, of source or origination.

In Latin again the term reus is usually applied to the accused person, eulprit, both before and after trial; but it is also used to mean 'one under obligation to get or supply, e. g. reus dotis, or voti reus, i.e. bound by a vow': the reus, in short, is the party who has made a covenant: and a res is a ground of action, a reason, or plea. A causa similarly is an interest or reason for acting: like res, it seems originally a forensic term which has eome into wider use. Res means the object of a right: a reus is a human being who is the object (not subject) of a right.

Responsibility, it thus appears, has something to do with causality. The term 'imputation' means the same as attribution: imputare often means 'to make a merit of,' 'to take credit for,' or ' to give credit for.' Thus Tacitus, Germ. 2 I : 'gaudent muneribus, sed nee data imputant, nec acceptis obligantur'-i.e. they take no credit for giving, and count it no obligation to receive. So ascribere is literally to place a thing to a person's credit, to count it among his debts : i. e. to treat it as part of his property and dependent upon his will.

The notion of desert (merit), good or ill-desert, falls in the same group. 'The idea of ill-desert,' says Butler, 'does not merely mean that it is for the good of society that the agent should suffer: it follows (as a perception) on finding that an action is unsuitable, or out of proportion to the capacities of the agent.' In other words, an action has good desert, not because of the rewards which law or custom may attach to it, but intrinsically by its natural and inherent adaptation to the

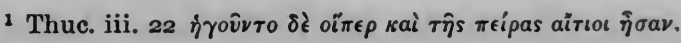


constitution and cireumstances of human nature. In Latin bene mereri is to earn a place on the credit side (de republica, on the books of the commonwealth): to pay a debt or perform a duty is mereri: whilst the epithets bene or male comnote that the obligation has been more than or less than equally discharged. Thus the idea of ill-desert is to have fallen short in duty, to have failed in extinguishing the debt. Meritum means debt or due; or, otherwise, the same thing is on one hand a debt, on the other a eredit: hence the word has both the meaning of 'benefit' and 'fault.' So the debts belonging to a person may mean his rights of action against others, i. e. what is to his eredit in their books, no less than what it is his duty to pay.

Through the whole phraseology there shows the close parallelism between the moral and the economical use of the terms, between the moral and the legal. Nor need this cause surprise. The moral, though it form the basis of both legal and economical, is later in coming to distinct expression. The juridical moreover includes the economieal. And all of the terms imply a system of things, an established order: they connect with ideas of order and authority. Responsibility implies an ordered world, in which all things (act) have their place and are related to one another, have mutual connexions. The fixing of responsibility is like the search for causes: a responsible agent is a cause in the moral world. And just as each cause is also an effect, so each responsible being is also, from certain aspects, only a link in the change of causality. He is not airios, but only ovvairios. Just as we may say that the cause of an event is the sum of the whole antecedents or conditions, and yet can select as the cause one circumstance, which directly produces the effect that up to the moment of its appearance had not seemed to begin, so the responsible agent is the last or decisive moment in leading desire into action. In ordinary life we are under the belief that a healthy 
mental organization is responsible for the direction of the will. No question is here raised as to free will as a metaphysical problem. It may be maintained by the metaphysician that the will is always governed by the law of sequence of effect upon cause. The question now before us regards a difference between individual wills. Are there any wills which are under the sway of a malformed mind so completely that responsibility is to be denied them? It is grenerally admitted that there is a class of human beings thus incapacitated. 'To say preeisely who are insane is not an easy task for medical or juridical psychology. Such definitions as that 'it is a chronic disease of the brain inducing ehronic disordered mental symptoms' are little more than verbal, with the addition that 'mental aberration' is a predominant symptom of brain disease. But how much of this 'physiological' disease is necessary to constitute the irresponsibility of the insane, is a question to which probably no general answer is possible. We must content ourselves with saying that there are mental states (dependent apparently most directly on nervous conditions) which, in eertain cases and under certain respects, deprive a man of those faculties on which mental responsibility is based.

Such conditions required for a rational direction of will are (1) a correct apprehension of the external world, and of the precise point in it towards which action is directed; (2) sufficient collectedness to see the present aim of action in its general bearings on our life and circumstanees; and (3) a healthy sense of reality, which makes this estimate of consequences no mere dreamy conception but a vital active apprehension. Where we are under a delusion as to outward facts, and especially of the physical laws governing the matter we propose to manipulate; where we are infatuated by a present passion to such an extent as to lose all sense of proportion and to be unable to keep our permanent wellbeing in view, and where we see the world and ourselves, 
but see them like phantoms in a world which we have no connexion with-there responsibility in the fullest measure is absent. But there are shades of difference in this general sphere. Sometimes, as in the ease of a passionate outburst, or of acts done under unreasoning panic, or under the effect of stimulants, the responsibility for the single act is in abeyance; but it is replaced by a general responsibility for the habitual character which facilitated their perturbations. Many of our actions originate in a very fragmentary selfconsciousness. But, merely on that account, we should not lose responsibility: imputation ceases only when there are causes working not merely in the moment of action, but persistently-causes, not susceptible of our modification, which make the average amplitude of elear and realized perception and conception impossible.

For law fixes, or at least assumes, an average standard of sanity, an average duty of self-possession and attention. It calculates on every man in a way doing his duty. This is the basis of responsibility as of obligation. Nor, when we say that the individual is responsible to society, do we mean only legal responsibility. Legal responsibility as a rule looks only to the past: for the aim of law is to maintain or preserve the established and attained order of things. For law is mainly the instrument and guarantee of order and security : it is little concerned with progress, and has its interest in the conservation of the past. Law does not anticipate and lay down lines for future development, but rather fortifies what has been achieved against the risks of innovation. But moral responsibility looks upon the order of things not merely as fixed but as progressive; it treats man as a member of a progressive system, and as having duties other than the mere maintenance of the past.

It is thus assumed that every man has a sort of public interest-a conception of a good common to him with a social body: that he regards his action as entering into and forming 
part of a system or realm of conduet, and as not remaining isolated and ineffectual amid a foreign mass of other actions. In consequence of such a postulate, a man is bound to know the law-so far as the law is an expression, made public, of those conditions and relations under which his acts must adapt themselves to the general body of action. There are cases where ignorance of the law does exeuse; but in general it is assumed that a man, as a $\zeta \omega 0$ " self as a perfeet self only in his relations with his community, and is aware of the recognized and published conditions of his partnership. Similarly, a man is presumed cognizant of the general notions of morality current in his place and time. In all of these points it is taken for granted that the individual lives consciously the common life, participates in the common ideas, and knows what is definitely and generally expected of him. These common obligations or expectations he is bound to fulfil, answer to, and satisfy.

He is also expected to have a tolerable idea of a common system of things into which his action enters: a capacity of knowing the nature and consequences of acts, the general rules and probabilities of sequence in events. It is from this point of view that a man is held responsible for the consequences of his acts, and that these consequences enter into our estimate of his moral character. But the consequences which are thus taken into account are the normal, natural, and necessary consequences-the outward utterance of the inward intention. But a man is not responsible merely for the consequences of his acts which he intended: he is responsible no less for those which with ordinary foresight he could have known to follow inevitably from them. This extension of responsibility will be variously measured in different cases. But undoubtedly there is a culpable negligence, and a minimum of attention to facts and conditions is presumed from every citizen.

Similarly a man is presumed to be capable of some amount 
of self-control. He is credited with the power of attending to general principles of conduet and to distant motives, and of comparing them calmly with immediate incitements. A man must be able to control himself, just as he must know the nature of his own acts. He must not lose sight of general duties and considerations in the moment and under the pressure of the momentary sentiment. His power of selfcontrol may be limited in two ways. He may be subjected to compulsion by means of threats, or perhaps of bribes. But compulsion of this sort does not remove responsibility: it forms no excuse for crime, though it may be admissible as a ground for mitigating the punishment. The only compulsion in question is that which destroys freedom and responsibility. Such compulsion is physical constraint, which properly speaking leaves the doer no longer an agent, but only an instrument in the hands of brute force. But in ordinary practice, compulsion is allowed to embrace motives which are exceeding terrible and powerful-such as, in the words of Aristotle, no man could withstand, or which exceed the measure of human nature. There is a gradation, not fixed on any principles, but introduced on particular occasions, between such constraints from external suasion as average self-mastery is considered equal to resist, and those which tax to the uttermost the most heroic virtue. Here, as in the question of knowledge of act and circumstances, jurisprudence follows on each occasion a vague tact, or popular sense of discrimination - a common al $\sigma \theta \eta \sigma \iota s$ rather than any definite rule or logical principle.

But as there is a violence, an encroachment on the will from without, which may culminate in actual violence, or physical constraint by the force of others, so there is an internal violence, which may culminate in a state of pure passivity to the solicitations of any whim or fancy, without power or wish to resist it. Such a state of insanity-of idiocy, when the judgement is absent and reason or knowledge 
is impaired, or of mania or melancholy, when passion b linds the will and prevents the employment of reason-is recognized as destroying responsibility no less than external violence, or frand or deception. The case is not so simple with the lesser degrees, in which impulses cognate with insanity are prevalent. Here it is obvious that, just as we do not regard any threat as proof of practical compulsion because it was successful, so we cannot hold every insane impulse to be irresistible, merely because it is not resisted. And just as with compulsion, persuasion, instigation, \&c., we hold that a man for practical purposes is not so free and responsible as without them, but yet that he might resist them if he would; so, in regard to the stimulation of appetites and instincts which tend to carry towards unlawful action, we do not consider the difficulty of overcoming them a reason for holding it not possible to overcome them.

Rather the current view is loath to regard any one as not in some measure a free agent. Practical law insists no doubt that one must draw a line somewhere; it cuts the Gordian knot which it cannot untie. Law has to do with averages, and makes rough assumptions, subject always to a certain amount of modification and correction in applying them to any case. But for all except those who are proved to belong to another category, the law assumes their sanity and responsibility. And in so doing it does them honour : it credits them with the possession of the common attributes of social humanity. It assumes, that is, that they are not 'dumb driven eattle,' but can always - it rests with them-become 'heroes in the strife.' It treats them as men-free and responsible, self-controlled, self-legislative, persons-who are their own masters, who have redueed their own impulses to unity and subjection, and who have raised themselves to the common or universal standard of their age and country. It does not degrade them to the position of automata or machines moved by forces of which they have no mastery, 
which they are barely conscious, and even if conscious, are powerless to alter.

But if the popular sentiment shrinks from degrading any human being to the level of irresponsibility, it is otherwise with the scientific inquirers of modern times. On the one side, emphasis is laid on the preponderant influence exercised by heredity. Each at his birth receives by descent from his nearer or more remote parents a physiological endowment with a corresponding temperament, proclivities, instincts, which so far predetermine his conduct for him, and render his responsibility for his actions a rapidly vanishing quantity. On the other hand, it is alleged that the statistics of crime prove, by their comparative uniformity through periods of years, that criminality depends more upon the constitution of the social environment in manners, morals, ideals, than on that of the individual personality: who is thus freed from a responsibility which is transferred to the shoulders of the community.

According to a recent development of these theories, connected with the names of Cesare Lombroso ${ }^{1}$ and Enrico Ferri in Italy, and of Prof. Benedict of Vienna, and which are fanatically adopted by some Russian writers, the criminal is a distinct and hitherto unrecognized species of human being, marked off by definite peculiarities both from the sane and from the insane. According to Benedict, human beings fall into four groups, which comprise, besides the mentally sane and insane, the two classes of the degenerate and those who are congenitally deficient in psychical calibre (neur-asthenics). There are thus found amongst us, partly from inherited qualities and partly through the acquired effects of certain modes of life, a large class of individuals who are beneath the normal definition of human beings, whether that definition be purely physiological, or moral, or aesthetic, or intellectual. To beings so constituted the ordinary stimuli appeal with

\section{' L' Uomo delinquente.}


little or no force. If their physiological force is under par, they become skulkers from work, fond of vagabondage and indolence. If their debility is moral and aesthetic, they are unsusceptible to the voice of sympathy and beauty, of art and nature, of duty and social ties. Intellectual feebleness is shown in the inability to follow the links of a continued argument beyond the first and simplest steps ${ }^{1}$.

Aceording to these writers crime is due to four main eauses or conditions. These are social eircumstanees, pathological states of the agent, degeneration, and atavism. 'T'he first of these may be afterwards considered. The others may now be examined. No one is prepared to deny the influence of heredity. It is an undoubted fact that peeuliarities of parents are reproduced in their children : that not merely are their general eharacters physical and moral often repeated, but that even apparently incidental and temporary conditions of the progenitor are exhibited in effects on the progeny. Every one can quote examples of famous parents with famous children: of personal peculiarities which mark families through several generations, of the frequent occurrence of physical resemblances. And, in the next place, there is a general agreement upon the interdependence of physical and psychical characters. No one seriously believes nowadays, if they ever did, that in the phenomenal world, the only world of which there is science, the spiritual is not inseparably conjoined with the corporeal. It is further admitted that nowhere do we find the normal man or woman-the abstract generic type without any specific modifications. If we define man as the rational animal, we do not mean that he is never unreasonable: and if we call him a social animal, we are aware of a rooted instinct of independence and isolation in him.

If heredity is a fact, so likewise is variation. If on the one hand the progeny resemble the parents, on the other they tend

1 Cf. Rev. des Deux Mondes, April, 1887; Unsere Zeit, Feb. 1888. 
to vary from them. Natural and artificial selection, the action of circumstances and the operations of human purpose, tend to alter the hereditary nature into new forms. And these forms in certain cases tend again to reproduce themselves, and again to be subjected to the modifying agency of man and nature. In some cases the acquired characters remain a permanent part of the stock; in others they last only for a few generations, and then revert to the original stock; in others they do not descend by inheritance at all, but each individual has to acquire them afresh.

These facts would seem enough to show that, though heredity is a fact, it is premature to speak of a law or laws of heredity. M. Ribot in his work on L'hérédité psychologique admits that it is indeed impossible to determine 'scientific laws' of heredity, but proceeds to lay down four 'empirical laws,' as a convenient classification founded on experience. These are as follows: (1) tendency of parents to bequeath psychical characteristics; (2) preponderance tendeney towards inheritance from one parent; (3) tendency to resort to remote ancestral type, atavism; (4) heredity exhibited at corresponding periods of life.

It is hardly necessary to say that such vague tendencies can scarcely be called laws. There are laws in the same inexact sense in which we speak of the 'laws of association of ideas.' For a law in a proper sense, more is needed than a mere discovery that one fact is sometimes, or generally, or often, connected with another. We want to know the precise conditions in the one which are influential upon the otherthe numerical evaluation of the amounts, ratios, \&c.

Heredity has been-admitted as a fact. Strictly speaking it might be urged that it is only a theory or interpretation of a fact. This fact is the occurrence in progeny of qualities and characteristics similar to or identical with those exhibited by their parents or ancestors, near or more remote. To say that these qualities are inherited is to use metaphorical language 
borrowed from the sphere of law. But in the case of inheritance strictly so called, what is inherited is an existing right, which has a continuous existence and can be passed on from one person to another. In the case of heredity strictly so called, there is no such persisting right, property or thing. It is easy to say that the characteristies inherited are, while nonapparent, in a state of latency, dormancy, or abeyance. But these terms are only covers of ignorance, and eonvey no real or positive meaning. A latent or dormant object is existent, but inactive, concealed and asleep. But to say that the characters in question are in any true sense existent, is to talk the language of figure.

It is much the same here as in the case of memory and recollection. The ordinary language of heredity is parallel to the crude conception of ideas or images stored up in the mind or brain and recalled from their latency into active consciousness. A little reflection shows that we can only in a metaphorical way talk of the furniture of the mind, and regard the mind as possessed of store-rooms and presence chambers. And if we adopt the language of some scientifie speculators, and speak of hereditary qualities as organic memory, this transference is more interesting than really edifying. We may, if we please, indulge in a supposition that the elements of our original constitution are a limited number of elements, which, like the coloured pieces of glass in a kaleidoscope, present a succession of different forms as they revolve, but occasionally in consequence of their small number recur at intervals in the same form, or if they once assume a peculiarly stable grouping, may for some time recur in almost identical shape. At any rate, if the number of original elements in each stock is limited, clearly the number of permutations is also limited, and it may even be that one combination will, while certain influences predominate, recur very frequently. 


\section{IV}

\section{DUTY}

There are two judgements which according to our changing moods we are inclined to make about our species. At one time we are especially struck by the diversities which part man from man and race from race. At another we are apt to feel the influence of that touch of nature which makes the whole world kin. Perhaps the abstract philosopher is too ready to assume the permanent identity of human nature everywhere, and the mere historian and naturalist too likely to take every variety as a unique specimen. If this be generally the case, it is also specially applicable to man as a moral being.

First of all, it is clear that, in every period of history and every sphere of life, man has a life to lead under circumstances and conditions which are the same to all. Rich and poor, learned and unlearned, have alike to traverse the path from birth to the grave, alike to learn the terms of life, alike to struggle with enemies and with circumstances, alike to win friends and love, alike to learn some measure of wisdom and character. Up to certain limits nature allows no exceptions to her law: omnes eodem cogimur. It can hardly be said too emphatically that in the deeper realities and the fundamental problems of life, savage and civilized, king and peasant, have nothing to envy each other. But on the other hand, if the fundamental notes and harmonies of the tune are the same, there is immense variation possible in the minor details, 
details too so numerous that in their suceession and multiplicity we often lose sight of the main movement, and imagine we hear an unique performance. There are the general differences of rich and poor, strong and weak, wise and foolish, which entail corresponding intervals between lives, as they show more rapid movement, more elaborate detail, and more precise systematization, or the reverse. Even length of years may seem to involve such additional wealth, though in most cases it hardly affects the substantial value of the life. Specific differences again of different posts and offices in life, entail a variety in the qualities required to make them exhibit in their special range a reflection of all that life ought to be.

But there are other differences between human beings. Hitherto they have been considered as single beings, in essentials the same, though differing in natural endowments, and in the accumulated powers which these natural endowments have permitted them to acquire. But human beings are not known to exist in this unqualified individuality. Historically and really every human being is a member of a group. That group may be a nation, a tribe, a family; it may also be an association with which the ties of kinship have very little or nothing to do. But always-anomalies like Robinson Crusoe on his desert island do not make an exception-men and women are members of such a group. And what is implied in being a member of such a group? Very much ; and that mainly because such membership is not a mere matter of arbitrary choice, and is not a mere juxtaposition of individuals, each of which remains as independent and self-centred as before. What brings people together into such groups is not their will, but their need ; 'their poverty, and not their will consents.' The cause which combines people in a society is not a matter of their choice; it is an idea which confronts them more or less consciously as essential to their welfare, as expressing their need and 
demanding their service. People realize, not always equally clearly, that there is a work waiting to be done, a work which they have to do, and which ean only be done by conjoined effort. The world without them, the national world, for example, of field and wood and river, is not eut up into parts distinctly separated from one another: rather each part is dovetailed into another, and all form a unity. There is no absolute boundary line anywhere, if we inspect closely and minutely: to a microseopic glance there are connectinglinks and transition lines to be detected everywhere: but it is otherwise to a rough practical survey. For practical purposes there are many demarcations apparent between parts of nature--some of them no doubt arbitrary and artificial, others however decidedly more natural and scientific. As an instance take national boundaries. An absolute dividing line might be said perhaps to exist in an impassable range of mountains, in an innavigable water, in a trackless desert, or a malarious swamp. But there are no such mountains, waters, deserts, or swamps. Yet for practical purposes there are many changes of geological formation which interpose sufficient barriers. And a thousand other circumstances, some physical, others dependent on history and tradition, combine to magnify the obstructions of these geographical circumstances, and to form national and political groups, in their totality quite distinet from their neighbours. So it is in other divisions. Each trading and industrial group tends at its extreme to pass over into some other: every rank or order in society fades away into others adjacent: every association of believers in any creed tends to lose itself at its margin in a class, who are hardly distinguishable from those who hold the opposite creed. But for practical purposes the distinctions hold good: the world is an aggregate of parties and societies, in which individuals have their place and subsistence. In the long run the whole inhabitants of the world form a unity of will and purpose, just as the earth is one whole and its 
differences sink into unimportance when we note how they all pass at their limiting verge into each other.

Such a vision of unity in the world - in the world visible and material, and in the world human and moral-was not, and could hardly be. clear in the early days of history. More limited horizons, both material and spiritual, spanned the survey of early humanity. Yet whatever was its range, the collective world gave to the view of the single members within it a power and a system which they could not otherwise lay claim to. Built up into the compact unity, they shared in the power, the interests, the joys, the sorrows of all the rest. Their little souls - with tiny range and scanty powers, it may be-were expanded and elevated by the partnership of others in the group of higher genius and character: and these last gained a fulcrum for their energies in the sense of solidarity, the willing hearts and hands around them. So there grew up, and always in some measure grows up, a common, a social, a collective life; a spirit only realized by the energies of individuals, and yet living on above and beyond them, taken singly. It is in the light of that common life that we look at and judge our own special lives. In the background of our consciousness, dominating it though never coming much into view, stands a collective life, a common enterprise, a general achievement, in which our contribution and effort takes its place and does its part. On such a support and such an embracing unity we all singly fall back, and in the light of it we form our plans, and carry them out.

Such grouping also gives an ideal extension to our life. Before we came into the world and after we leave it, that world has no direct bearing upon us. But by means of those who associate with us, and with whose lives our own is bound up, we find ourselves living in idea both in the past and the future. The members of the family e.g. thus get a conception of life and work, which invests them with the burdens 
and the pleasures of a vast brotherhood-a kindred which ramifies out in many directions, both towards the generations that have passed away and those which are to follow. And to this ideal extension of the scope given to the individual there are barely any limits assignable--except the limits which practically arise because, as successive circles of influence carry us further from the self, the vision grows fainter and at length sinks exhausted. Still far beyond the range of actual touch, historical sympathy sets the individual amid a kindred of great names. Even in the barbarian tribe the individual has set in his soul, embalmed in sweet memories of old achievement, the heroes of his race, whose acts he almost feels to be re-enacted in himself again. In their strength his strength is as the strength of ten, because his heart is the great heart of his race. And even in our associations of to-day, half the secret of our life is hidden in the social groups, to which we belong and from which we draw our influences.

It is because and in so far as we live thus not for ourselves but in the common life, the general work, of some portion of the world, that we are moral beings. To be moral is to be raised out of our selfish isolation. Purely and wholly isolated indeed we cannot be. We are parts of the world and have a share in the common activity, whether we will or not. But it makes a great deal of difference how we enter upon our inheritance and take our part in the community of toil and pleasure. And it makes a great deal of difference what community our lot and circumstances have cast us into. In the ideal, as we have seen, each community, each group, dovetails into another, and by degrees a federation of communities would bind the inhabitants of the world into one great consentient realm of humanity. The real aspect is very different from this: there is no such hierarchy or gradation, or harmony of the different associations. They grow up at haphazard, here and there, without plan, and without adaptation to each 
other : they necessarily fight against each other, as each sticks persistently to its own aim, and ignores or thwarts the others.

Yet in each community there is some good; each of them is relatively and comparatively a moral influence. Even the band of robbers and thieves nourishes within it some virtues. Seen from the outside indeed, all seems dark and terrible. But we must never judge by the outside alone. It would be diffieult to find any community in which all the influences were hopelessly and utterly bad. And as Bret Harte is fond of illustrating in his stories, not merely is there honour among thieves, but there is love and self-sacrifice amongst the degraded. As we penetrate into the heart of a society, we find it different from its mere superficial character.

We have then no actual community which is all-embracing either in place and time. Even our oldest societies, even our national existence, or our ecelesiastical institutions, carry us after all but a little way back into the history of the past. We trace our national history back for a thousand years, but long before we reach even the Conquest it has lost all close connexion and touch with us. And so it is in the divergence of assoeiations throughout the world. Nowhere is there more than a side of humanity represented. Nationality rises up against nationality. And it hardly seems possible to hope that it will ever be otherwise : nor if it were possible, does it seem desirable. At times it seems as if national differences were fading away: but probably the change, when it oceurs, is only a passing phase, a transient step on the way to the formation of new groups. So long as the natural diversities of soil, climate, and production exist, so long probably there will be partitions of grouping amongst the inhabitants; and so long as human nature varies in individuals, so long they will league themselves together in a variety of disparate groups. But in and through each aspect and branch of life there shines the faint light of an idea greater than itself: each nation in its own conception has ennobled, 
perfected, and rounded off the circle of its life: and through its limited actuality it has given expression to an idea nuch grander (because really infinite and eternal in its aspiration) than its framework would let us suppose.

We turn to some of the great historical societies of the world to illustrate how their moral idea is rooted in their principle of community and takes a special form according to circumstances. Let us begin with the people of Israel. There are two things about that people which at once strike the stranger: its Law and its God. In history there have been codes and laws, ancient and modern : nowhere perhaps has a nation been so wedded to its law, and that law so grand, as among the Hebrews. The very life of the later Judaism is based upon its law: a law not in the modern sense only, but a complete guide of life, moral as well as political. And that law the law of God-the God of the nation. Then, as never elsewhere, a community felt itself the especial favourite, and therefore the more than ordinarily obliged subject of the Lord of universal life. And that Lord was finally regarded as commanding 'to do justly and to love mercy'; 'to let judgement roll down as waters, and righteousness as a mighty stream'; 'to set right the oppressor, judge the fatherless, plead for the widow.' The good Jew therefore had his undoubted temptations to national pride, because he was of the chosen people, and to attachment of excessive importance to the letter of the law; and by these temptations he fell. But in his idea he was greater than in his performance. He and his nation was the 'servant of Jehovah,' the servant i.e. of him whose revelation lay in the law of mercy, righteousness, and truth. That is the truth which Judaism reached at its point of highest development, and which it has handed down for all like-minded in after ages. We have sneaking proverbs amongst us, to the effect that Honesty is the best policy, and that God helps those who help themselves. How much grander the confidence of the Jew when he says, "Thou hast 
loved righteousness and hated wickedness: therefore God, thy God, hath anointed thee with the oil of gladness above thy fellows.' For all humanity the Jew has expressed the faith that the path of the just, the wise, the merciful, is the path that shineth more and more unto the perfect day: that it is the path traced by the stars in their eourses, the law of the world. Some say the moral law is only a human eoncern, perhaps even a human and temporary convention. The Jews had seen it in another light. There were lays in their history when they had thought their God concerned mainly with incense and with offerings. They learned otherwise, as one of their later teachers says: Thus saith the Lord of Hosts, the God of Israel, I spake not unto your fathers coneerning burnt offerings and sacrifices: but this thing I commandeth them, saying, Hearken unto my voice, and I will be your God. . . Trust ye not in lying words, saying, 'The temple of the Lord, the temple of the Lord are these: but if ye throughly amend your ways and your doings; if ye throughly execute judgement between a man and his neighbour, if ye oppress not the stranger, the fatherless and the widow, ... then will I cause you to dwell in this place ${ }^{1}$.

Let us next turn to the Greeks. Here the circumstances are altogether different. In Palestine, an isolated people, hardly holding its own between the great powers of the Euphrates and the Nile, a little enelave in the desert of Syria, clings firmly to its national unity and its national God, and sees itself a royal nation, with a sacred law : and when it sinks from its height, still clings to its legal obedience, still maintains its isolated place. In Greece, a people open to influences from all hands, and spreading in all directions into the adjacent lands: a catholic and versatile race, but a race which had broken up into scattered communities, and which had advanced beyond the patriarchal into the industrial and civic age. Here the characteristic form of society is based on

1 Jer. vii. 4-6, 22. 
the existence of an aristocratic order, a class of organizers and rulers, removed from the necessity of daily toil in all its severity, and yet not far enough removed to be made idle and luxurious. They are just so far above want as to be released from its terrors, and their minds are still free and vigorous, open to all the curiosity of the child, eager to understand and ready to enjoy. In the age of Greek history which gave rise to this ideal the Athenian could boast: ф८лока$\lambda o \hat{v} \mu \epsilon \nu \mu \epsilon \tau^{\prime} \in \dot{v} \tau \in \lambda \in i a s$. To us at the present day art is a costly thing. We pay our best painters paltry sums: and when they are gone, we lavish thousands on the picture-dealers, professional and amateur, who have speculated on their works. The great artist of Greek antiquity found his eustomer in the community: but it was a customer who worked with him, and with whom he was in sympathy.

What governed the member of such an aristocratic elass in his conduct? The idea of his class, no doubt, its opinions, and judgements. But who were that aristocraey? Not, as in modern times, a select few, far beyond the common level, nor a erowd of rich, possessed of something far exceeding the eommon means. They were a great body of eitizens, of various grades, but not separated by the great gulfs of modern society, members of some town, small as judged by modern standards. Theirs was a select opinion, unquestionably, but not so select as to be strikingly narrow. It was freed from a depressing utilitarianism, one which is careful about immediate and vulgar utilities: and could give itself up to those higher and wider utilities, which are not of the moment, but for ever. Hence the standard was the beautiful. The ' beautiful' means to the Greek a great deal more than it does to us : more of an ideal and less of a mere sensuous quality. Of all the powers which can act upon a people to inspire morality perhaps the yoke of this is the lightest. And yet even here the standard is not purely subjective. The idea of beauty grows up in the consciousness of the community 
and under the stimulus of an environment. But it is as it were in a region above the law, not something required, but something freely given for the sake of the thing's own grace. And so, in the days of Athenian greatness, the spirit which animated men to do great deeds was not sense of gratitude to the state, so much as a desire to keep up the consciousness of high and noble achievement. The word was virtue rather than duty. People did not realize that to do all they could do was after all only what was required : they aimed at distinguishing themselves by adding some new glory to their common mother, by raising higher the name of the commonwealth. They fancied themselves glorified in and through their country, which did not stand as a sovereign over them, but as the expression of their best activity and to be carried further by fresh energy. 'Their loyalty is evvola: not devotion, but good will: and their ideal of a community is one where all are free and equal, and where to rule and to be ruled are always alternating.

Turn to another epoch of the world, the Middle Ages, when out of a general disturbance of relations order is slowly establishing itself in the world. Countries that had gained some measure of industrial and intellectual civilization, but had failed to organize themselves otherwise than for purposes of taxation, are overrun, and, as the phrase is, conquered by tribes of semi-barbarians headed by some chief. The chief, who merely owes his authority to his warlike supremacy and his control over those who have banded under him so as to win power and substance, is gradually turned into a monarch, and his chieftains or eaptains into so many rulers of provinces. It takes a long time before the mere warrior learns that he has other duties than those of plundering strangers and enriching himself. What violence has gained can only be maintained by further violence. Hence the old feudal barons and their men in the tenth and eleventh century are brutal and barbarous: they live in a world full of strife, treachery, 


\section{4}

cruelty, and they flourish by their fitness in these arts. But it was only an uncomfortable sort of survival after all: the conqueror was miserable in his conquest. And alongside of him there was an order protesting against murder, against bloodshed-at first even against soldiering in every shape. But the ehureh, gradually departing from this strictness, which Augustine had maintained, had come to express a toleration of war, if war was just. Partly through Christian teaching, partly through the common protest for merey and gentleness, which cannot long be altogether absent where human hearts beat, a change had come over the view of the soldier's work. Chivalry appeared as the fair flower and spirit of feudalism. The latter had been hereditary: linighthood could only be acquired by steps of probation and showing one's self worthy of the post. How it first grew up one cannot tell. 'Elle naquit d'elle-même,' says one author. Or like the Romance order of architecture, 'elle est née partout à la fois, et a été en même temps l'effet naturel des mêmes aspirations et des mêmes besoins.' It was founded on the German usage of pledged allegiance to a leader, but it substituted allegiance to a moral ideal. And it appears as a fullgrown institution in the Chanson de Roland (1066-1095?), i.e. it is always more of an ideal than an institution properly so called. It was the sacrament, baptism, consecration of the warrior. He was still a soldier, but his 'sauvagerie' had become 'prouesse' ('nul chevalier sans prouesse'), and he had added 'courtoisie.' The knight of the crusading epoch was no doubt bound, first of all, to fulfil the divine law ('essamplir la loi Dieu'): he was presumed to be loyal to the Christian faith and to the Church: and in his special duty of courage, he was expected to let the unbelieving Saracen feel the weight of his arm.

One of the greatest defects noticeable in certain philosophers' books on Morals is that they confound the duties (devoirs) with the virtues, or that they give names of virtues 
to simple duties: so that though, properly speaking, there is only one virtue, the love of order, they produce an infinity of them. This puts confusion everywhere, and so embarrasses the science of ethies that it is hard enough to see clearly what one ought to do to be a grood man (homme lle lien).

It is evident that virtue ought to render its possessor virtuous: and yet a man may lischarge his duties, may do with ease acts of humility, of generosity, of liberality, without having any of the virtues. The disposition to discharge this or that duty is not properly speaking virtue without the love of order. When a person discharges his duties, he is virtuous in men's eyes. But a man is not always such as he appears: and he who never fails in the outward duties of friendship, except when the order, which alone is our inviolable law, prevents him, though he may sometimes appear a faithless friend, is truer and more faithful, or at least more virtuous and more amiable, than those excited friends who sacrifice to their friend's passions their relatives, their life, and their everlasting salvation.

Virtue then ought not to be confounded with duties, on aceount of the conformity of names. That deceives men. Some of them imagine they follow virtue, though they only follow the natural inclination (penchant) they have to perform certain duties: and as it is by no means reason which guides them, they are actually vicious to excess, when they suppose themselves heroes in virtue.

Malebranche, when he thus writes in his Traité de Morale (I684), is instructive both by his approach to Kant in doctrine and his divergence in terminology. Though he is barely consistent in his use of terms, and sometimes himself interchanges the duties and the virtues, his main contention is that duty is the mere act-what falls in the eyes of men-the visible conformity to requirement, which may be done for any motive, and is mostly done in response to our inclinations, our humours, our imagination. It is only when these 
outward acts are done through the promptings of the "love of order,' of that 'immutable order,' the 'inviolable law of all intelligenees and of God himself,' a willing subjection to the universal system of reasonable truth. (For to be animated by the love of order is to be guided by reason.) But as it needs a 'very grievous sort of labour' to be guided hy reason, men renounce its direction, and abandon themselves to the easier direction of imagination, to vague and confused ideas, rather than make the effort to get elear and distinct ones.

Examples of duty and of dutiful conduct may be found in every sphere of life. But for some purposes one may see what duty involves, what the sense of duty can prompt and how it may mislead, if one takes a case conspicuously set forth before all men. A convenient hypothesis reigns among many of us who are not kings that they are given or have been given to take duty lightly: that their life is one of pleasure and pleasure only. A common ignorance and a commoner envy lead us to look at the high and mighty ones of the earth with unfair eyes. We try them by a sterner standard than common men. Our feeble imagination enters but slightly into their difficulties and dangers. We expect them to be made of harder stuff than ordinary, and we allow nothing for extraordinary temptations. In modern times when so many direct rivals of kings exist in the shape of the vast army of the uncrowned kings of journalism, monarchy fares but badly in the balance of public opinion. This selfcomplaceney by which we thank our stars that we are not even as these princes is a little Pharisaical. Let us see how once on a time a king found his inspiring principle in the sense of duty.

If we were to call Frederick the Great, king of Prussia, a hero, some people might object against his right to the name. To hear them, the term is only applicable to an ideal, a blameless king. Not so was the word used : not so ought it to be used. A hero is far from being a perfect man. 
He is a man who in some one or more aspects of conduct rises above the average level, and resists fears or temptations which ordinarily are victorious. A single gallant act may justify the name, even though other weakness come to east a shade over the glory. So we may speak of Frederick as a hero, and not the least of them, if also not rising to the utmost heights of heroism. He had fallen, we may say, on an unpicturesque age, a humdrum and commonplace time. Yet for that reason he may the better serve as a model for common imitation. He represents upon the throne the general tendency of the eighteenth century: the mixture of seience with utility, the reduction of science to human enlightenment for bettering and beautifying life. It is the spirit of Lord Bacon's philosophy: that knowledge and art should justify themselves by ameliorating the estate of man. With Frederick that philosophy ascended the throne.

In 1739, the year before he became king, he had finished his Anti-Macchiarel (which appeared in 1740 anonymously). It professes to be a eriticism of the Prince of Macchiavelli. The great Italian who wrote it spoke the language of an age when treachery was universal and tyranny and falsehood had eorrupted all. But he spoke it with the view that, in the aim of reuniting Italy into one state, and casting forth the strangers who preyed upon it, no terms should be used and no quarter should be given. It was the desperate device of a patriot who, when his country's interest seems to demand it, calls out that no compact, no right, no duty, shall stand in the way of realizing his aspirations for independenee. The cry is a mistaken one, but one can at least sympathize with the end, and pity those whose desperation seems to justify to them such means. But Macchiavellism came to mean something else. It came to mean that a government, in order to preserve itself against internal and external enemies, need be held back by no claims of right or prineiples of duty. In the holy duty of asserting legitimate authority of sovereigns 
the subjects were to be treated by the reason of state, i.e. cajoled, deceived, and if need be imprisoned. Macchiavellism was another name for political jesuitry.

Frederick had grown up under two influences, which combined to mould him into a man unlike the average sovereign of his time. On the one hand he had been a scholar of the philosophy and literature of his age: he had learned to admire Wolff, and was devoted to Voltaire. From the former he learned the principles of liberal and reasonable morals and polities: from the latter a wide humanitarian culture. Wolff taught him to reason the principles of conduct: Voltaire taught him to rise superior to the narrownesses of superstitious religion. He gathered, in short, the ideas of the reforming and liberal thinkers of his time, both in their constructive moderation and in their critical flippancy. And for a while it seemed as if he were going to lose himself in the life of a dilettante and amateur in literature. But he had grown up under another rule which, though he spurned it at the time, left profound traces. His father was intellectually of little breadth of view, liable to fall into pedantry and bigotry; but under these excesses there were concealed the sterling qualities of punctuality, dutifulness, willing service to the country he ruled. And one is glad to know that Frederick Wilhelm before he died was known by his son to be a true-hearted father to his people, doing his duty to the full measure of his knowledge, even if that knowledge itself was small.

Frederick, so influenced, was not likely to accept the ordinary Macchiavellism. He was indeed no believer in the virtue of either kings or common men. 'Le gros de notre espèce est sot et méchant. Tout homme a une bête féroce en soi.' The human species when it is left to itself is brutal, ferocious, and barbarous. And what men in general are, sovereign princes exhibit in a more conspicuous way. Between man and man, in short, there are no hereditary distinctions. 
'Everything,' he says, 'would be lost in a state, if birth were to carry the day over merit.' 'Le prince doit ître sans cesse attentif ì ne distinguer que le mérite personnel, et ì ne témoigner que du mépris pour l'opulence sans mours et sans vertus.' 'Birth is only a chimera, if it is not sustained by merit.' 'Les hommes, ce me semble, sont tous d'une race également aneienne.' He protests therefore against the view common amongst his contemporaries, that a 'king's subjects are only meant to be the ministers and instruments of his ill-regulated passions.'

A prince, on the contrary, should realize that 'ce rang dont ils sont si jaloux (leur élévation) n'est que l'ouvrage des peuples.' Hence the sovereign is strietly the representative of the state: he and his peoples form only a single body. Far from being the absolute master of the peoples under his dominion, he is only 'le premier domestique.' A sovereign prince 'est le premier serviteur et le premier magistrat de l'état' - obliged to act with probity, with wisdom, and with entire disinterestedness, as if at each moment he ought to give account of his administration.' 'Thus the true glory of the rulers consists ' $\grave{a}$ remplir les devoirs de leurs charges, et à répondre en tout à l'intention de ceux qui les ont revêtu de leur pouvoir, et de qui ils tiennent la grandeur suprême?'.

The general maxim of government is this: 'La base de ces systèmes (de lois, politique, \&c.) doit toujours être relative au plus grand bien de la société.' The sovereign thus becomes a far-seeing and kindly householder. He must direct his conduct by a prudent estimate of the common need. "Tout souverain attaché au bien public est obligé de se pourvoir de magasins abondamment pourvus, pour suppléer à la mauvaise récolte et pour prévenir la famine.' He will have specially to realize to himself the needs and difficulties of the poor. 'Le souverain doit se souvenir de l'état du pauvre peuple,' 'se mettre à la place d'un paysan et d'un manufacturier, et se

1 Consider. s. le corps polit. de l'Eunope. 
dire alors, si j’étais né daus la classe dont les bras font le capital, que désirerais-je du souverain?'

In his own view he was 'born for the arts', and it was, as he once puts it, chance which decreed that a philosopher should sway the sceptre. From the battlefield he yearns for the time when he can reason with his friends 'sur le vide et sur la nullité de toutes les choses de cette vie.' But in the true spirit of the Stoic, he corrects himself: 'Il faut prendre l'esprit de son état.' For, as the Stoics had long ago recogrnized, it was not every day, if it was anywhere short of the ideal world, that the sage could perform a като́ $\rho \omega \mu a$, a thoroughly right and successful action, a deed of perfect virtue. More essential was it that he should know how to

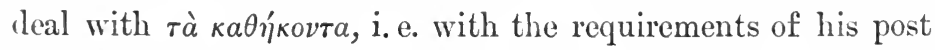
and situation, as they severally came upon him in life and demanded his energy. And Frederick feels that he is born a prince, and is only anxious to realize all the requirements of the post. Thus though he confesses to the Electress of Saxony that, if the choice had been his, he would have preferred the quietude of private rank, the remark is only one of those imaginations of the great may-be. His real convietion is that 'l'homme n'est pas fait pour être oisif : il faut qu'il s'occupe à quelque chose, et qu'il ait toujours pour but le bien de la société.' A good citizen is a man who makes it his inviolable law to be as useful as is in his power to the society of which he is a member: and as a type of the citizen who does his duty in the narrow eircumstances of an artisan, the king depicts his shoemaker Reinhart.

On what principles does the king found this morality? Not on what is ordinarily called religion. 'L'amour de nousmêmes, l'humanité, la nature enfin, nous retient et nous retiendra plus que la religion.' Of religion his view is that it consists of two parts, a superstitious and fabulous element, and, on the other hand, a moral creed necessary for the maintenance of society. Of the former he is contemptuous, 
he sees in it little better than falsehood and deceit; but he is hardly prepared to admit that all orders of society can dispense with the necessity of such an admixture. It is otherwise with himself and the selecter souls who have got enlightenment. For, according to Frederick, the interests of morality ean be benefited only by the spread of sound knowledge. 'Le même esprit qui dome le goût des seiences porte ceux qui l'ont à remplir exactement le devoir.'

The first principle of all action, he says after the Stoics, is self-interest. But it is the special province of education to give a true and enlightened view of self-interest. Always ' la plus grande et essentielle partie de l'édueation est celle des mœurs.' But whereas to the great mass this teaching is by precept or catechism, by example, and above all by the intermingling sanctions of religion, in the enlightened mind the teaching must be a fuller revelation of the intimate ties which bind things together. How individual and general interest combine Frederick does not clearly explain. They act reciprocally: 'Ia société doit faire notre bien, et nous devons travailler réciproquement à son avantage.' In his letters against the political indifference of the Epicurean he lays it down that to the country which has done for him everything he owes a thorough and absolute gratitude. Salus publica is his suprema lex. Whatever his country needs he will cheerfully yield : if its interest bid him renounce a treaty with another nation, then that renunciation will be made. His principle of duty he professes is much the same as that of the gospels. 'Ne faites aux autres,' he says in 1776 in a letter to the Electress of Saxony, 'que ce que vous voulez qu'ils vous fassent: ce principe renferme toute la vertu et les devoirs de l'homme envers la société où il est placé.' It is in short the principle of reciprocity, and, as it stands, it is in need of some support from the idea of the unity through which the reciprocity is made possible.

For him then self-interest is identified with labour for the 
benefit of the community. 'I have a people that I love,' he says. 'I must bear the burden which lies npon me. I must remain at my post.' We see that Frederick envisages his ideal under the form of attachment to the State, as the highest earthly realization of his conception. He has a religion; it is a pure theism: not very dogmatic or firm, any more than are his views on the immortality of the soul, or on the freedom of the will. On all of these points, which in earlier years he had been so ready to discuss, his attitude is rather that of an aspirant hope and craving for the ideal's realization than that of a firm belief. He falls back therefore on reasoning to justify his faith in virtue: but after all that faith itself is its own best justification. The utility of virtue is such a noble utility as does not admit of a single and ocular demonstration: and only appeals to those who, as it is said, 'aiment la vertu pour l'amour d'elle-même.' Hence in his epistle to Keith (175I) he represents himself and his friend as one of those who eherish a disinterested love of virtue :

\footnotetext{
'Le bien du genre humain, la vertu, nous anime; L'amour du devoir seul nous a fait fuir le crime: Oui, finissons sans trouble et mourons sans regrets, En laissant l'univers comblé de nos bienfaits.'
}

This sense of duty is his constant consolation. It is the gift, he says, of philosophy which, as he put it (1760), was the staff on which he stayed himself, his support in adversities. In calmer times he aimed at combining the inclination to be happy with the claims of duty. He would be at once Stoic and Epicurean. 'Pour moi,' he writes to his sister (Oct. 7, I 747), 'je suis heureusement désabusé de cette passion (ambition); j’ai cuvé le filtre qu'elle m'avoit donné, et je ne songe qu'à écouler d'une façon tranquille les jours que le ciel me départ, de profiter du plaisir sans en abuser, de faire tout le bien que je puis, et d'abandonner l'erreur, l'astuce, et la vanité à ceux qui en veulent être les dupes.' But in the darker days of the Seven Years' War he falls back on the faith 
in duty. Thus he writes to Voltaire (July, 17.59), 'J'aime ì être heureux autant que qui que ce soit. . . Quoique je désire tous ces biens, je ne veux cependant pas les acheter par les bassesses et les infamies. La philosophie nous apprend ì faire notre devoir, à servir fidèlement notre patrie, à lui sacrifier tout notre itre.' As he had said on his accession, 'J'ai cru que depuis la perte de mon père je me devais entièrement à la patrie,' so he writes to d'Argens ( 1760 ), 'vous devriez savoir' qu'il n'est pas néeessaire que je vive, mais bien que je fasse mon devoir.' And again (1768), 'il faut que mon corps et mon esprit se plient à leur devoir. Faire le bienc'est un devoir que tout homme doit remplir selon ses moyens.' So (in 1759), 'je vais mon chemin: je ne fais rien contre la voix intérieure de ma conscience.' It is not necessary that I live: but quite necessary that I do my duty.

Thus in January, 1757 , he left instructions that, if he was captured by the enemy, not the least account was to be taken of his person, or any attention be paid to what he might write under imprisonment. So in the Raisons de ma Conluite Militaire, 'I have held it my duty to render aceount to the state and posterity of my position and the grounds which determined me.... When the question is about love to country, I challenge the whole world for rival, and to these sentiments I will stand fast to the last breath of my life.' Our life, said his testament (written 1769), is a long passage from birth to death: during this span of life it is man's chief end to work for the weal of the community he belongs to.

The cardinal or ' essential trait of the moral consciousness is the control of some feeling or feelings by some other feeling or feelings,' says Mr. Spencer ${ }^{1}$, such subordination being of course conscious, i.e. being what is called self-restraint. But if it be a conscious relinquishment of personal for general good, such moral self-control presents features which may be produced by several external motives, by fear, $(a)$ of a visible ruler;

1 Data of Ethics, 113. 
(b) of the general opinion of society; $(c)$ of an invisible or supernatural ruler. All of these sanctions of duty, the political, soeial, and religious, as they are usually called, bring about results which are apparently identical with those of the properly moral self-control, of the self-control fully and strictly so called. According to Spencer, they are at first co-extensive with and indistinguishable from moral self-eontrol: i.e. it is impossible for us to penetrate into the inside of an action, and say definitely what principle prompted it. Further, he adds, the socio-political and religious or sacerdotal controls are preparatory to the moral, which evolves under their shadow or protection, and only finally emerges, after a course of social evolution, as an independent principle. These non-moral controls of action, again, are essentially coercive, i.e. they have joined with them the thought of external coereion, and are based upon or refer to certain extrinsic, incidental, or factitious consequences, generally evil consequences. The dictates of moral self-restraint, on the contrary, have a 'perceived rectitude,' or an 'essential propriety'; they refer to the intrinsic effects of the acts in question.

Thus in the conception of duty or obligation the sense of restraint or control has a double source. The one is a certain coereiveness or compulsory quality, due to the extrinsic effeets of the socio-political and the sacerdoto-religious sanctions. This element is obviously, thinks Mr. Spencer, of only temporary value-a feeling due to transitory circumstances, which will fade away, when these other restraints have done their schoolmaster work, when the Law has prepared the ground for the Gospel. The other element in self-control is the superior authoritativeness of the representative or more complex feelings, of the 'ideal' feelings, as compared with the simple sensations and appetites. Those feelings which are representative or ideal, which are coneerned with indirect rather than immediate effects, and with effects general rather than with effects special, have on the whole, by their own 
(haracter, and still more by the influence of tradition, education and experience, a preponderant authority over mere present impulses or sensations referring to immediate gratifieation. But here too, as moralization increases, the sense of anthority diminishes: whereas originally we feel in our immediate propensions constrainel, as $i \pi i j \kappa o o$ or subjects of the ruling $\left(u_{f} \chi_{\left(\omega L^{\prime}\right.}\right)$ reason or general feeling; as we grow more morally self-restrained, the sense of restrinint disappears in a $\sigma \tau \mu \phi \omega v i a$ or iporota between the two orders of feeling, so that they fall naturally and normally into one harmonious tone or utterance. In that ideal state of consummated morality, the essential trait of the moral consciousness will itself disappear : there will be no conscious control or subordination of feeling to feeling - or, in commoner language, of passion to reason-but the very possibility of discord will have been removed. Thus, as we may conclude, the end or consummation of morality is to be absorbed, to render itself unnecessary: at its moment of perfection the antithesis in which it lived will disappear and be merged in a complete unity.

The first point which calls for examination in this sketch of moral progress is the commencement. The moral idea appears (according to Spencer's account) at first in a sort of disguise, so mixed up with the company of the socio-political and religioso-sacerdotal controls, that it is indistinguishable from, and co-extensive with, them. Gradually it emerges from this subjection into the place of an independent principle, only however in the close to disappear and fade a way in the effulgence of the blessed life of the ideal or absolute social state: a state 'so constituted that man's spontaneous activities are congruous with the conditions imposed by the social environment' (p. 275). and that the remote pleasures have been made in all their force immediate. Now that moral self-control has in all ages been mixed up with external controls, is a fact so palpable that perhaps none will dispute it. But when we ask the relation between these various controls, and the 
explanation of their authority, some divergence of opinion may appear probable. Or, in more general language still, we may ask, what is authority and how does it stand related to coercion? The answer to these questions is that authority in its proper and original sense does not imply compulsion and enstraint, but rather a priority of origination and superiority of idea. Authority originally belongs to those whose voice was foremost, whose thought was rapidest, whose energy was most effective. The socio-political sanction is in its origin the influence of the pioneer, the leader, the carlier and abler. So only without factitious aids could it have established itself. In other words, it rested originally on identity, on solidarity of view and interest between the ruler and the ruled. 'A $\rho \chi \eta$ ' is essentially authority of the pioneer or commencer. But no less unquestionably and inevitably this rightful sovereignty, this natural and normal àрเбтократía, takes on less pleasing characters: and it does so by the operation of the family principle. The leader hands down to his sons the superiority which he owed to nature and reason, as a gift passing by inheritance. Then the mischief begins, when the natural basis of authority is gradually replaced by mere imposition and force of inertia. When authority rests upon tradition-upon what was, but is not, or even when a judgement is accepted a second time merely because its author had found acceptance before-then it rapidly passes into the false position of an extrinsic director, an arbitrary and coercive influence. That all authority degenerates into such a eompulsory force, may with a certain propriety be admitted : but no less it should be maintained that before it could become degenerate, and as a necessary backbone even to support its occasional and frequent acts of degenerate character, it must possess a general acceptability of leadership, a strength derived from its being the interpreter and spokesman of a public sentiment. Before the king could impose a violent restraint in arbitrary ways, he must have acquired the intelli- 
gent confidence of the majority; and before the priestly power could wield the superstitious instincts of a people in crafty ways, it must have gained what authority it has by the work of the natural instincts of the people themselves.

When Othello is charged by Brabantio with stealing his daughter's affections by drugs, and charms, and conjurationsfor how else could

' A maiden never bold, Of spirit so still and quiet that her motion Blushed at herself ${ }^{\circ-}$

how could such a maid 'fall in love with what she feared to look on'?- the accused succeeded in convincing his judges that the only witcheraft he had used had owed all its efficacy to the fact that that sceming-quiet maiden had subdued her heart and consecrated her soul and fortunes to her lord the Moor. So it is with the control of the visible ruler, the invisible ruler, and the general social pressure: they are not originally superimposed upon an unwilling people, but are the objectifieation of tendencies and ideas inherent in that people. It is the natural result of the way in which the mind regards phenomena and interprets the sequence of cause and effect, in other words, of the ruling ideas that it imports into its conception of natural processes - that a religious authority arises in this world to represent the dicta of the invisible world. The king and ruler is made such ultimately by the willing suffrage of those who obey him, and ceremonies often keep up a memory of the original process long after it has ceased to be a reality.

Such is not Mr. Spencer's view of the philosophy of history or of the law of sociological development. That process he reads apparently as consisting in the preliminary existence of a military to be followed by the dominance of an industrial age. This view, which seems to repose largely on the superficial aspect of the change from mediaeval to modern Europe, can hardly stand a close inspection. It is a strange delusion, 
fostered in part by the different form in which modern war presents itself, and partly due to hasty inferences from the exceptional cireumstance of Great Britain. Industrialism and military life are not separated in this gross fashion, any more than egoistic and altruistic impulses. Far from being separated, they are constantly united in their development. The industrial type of each is reflected in its military type, and the latter reacts upon the former. The organization of industry reappears in the organization for war, and the fact that one is industrially engaged is no reason why one should not also perform military functions. In a primitive community all have certain industrial functions, even the women and children : and similarly all are obliged to perform their part in war. As civilization advances, some are excluded from direct participation in industry, and the same applies to the service of war. In the modern world both industry and war are practised on more scientific principles: i.e. they are more socialized, carried on by great companies, systematically organized and not liable to the casual and intermittent phases they severally used to display.

It is possible no doubt to imagine that the modern world should surrender its local patriotisms, its national prepossessions. Instead of the inhabitants of a certain coast or valley seeking to get the best market for their peculiar produce and trying every means to oust their rivals from the supply of that produce throughout the world, we may fancy to ourselves a general federation of states, which should organize the trade of the world in such a way that every district would have its speciality of produce, and would receive in return for its contribution a proper and proportionate share in the other articles making up the total production of the world. Thus internationally the principle that each shall produce by labour according to his faculties and shall receive for consumption according to his wants, would be established, say, at first for Furope. But such a consummation, not to mention that it 
would only make the situation worse for externals, is something toward which we see no tendency; to which, indeed, the fierce recrudescence of nationalism within the last halfcentury runs entirely counter. When every country of Europe is waging an internecine industrial war through the savage continents and the islands of the Pacific, it is a curious thing to commend the age for the growing superiority of the industrial over the military spirit. The modern form of industry and trade gives a wider range to the weapons of war. What we see, and are likely to see in the future, is a keener phase of the struggle for existence between nations. No doubt by the constitution of modern states, which has afforded a certain sphere of comparative security, a rapid extension of industry has been made possible: and the few states, or the one which was able to take advantage of the situation thus produced, have had a fine time of it for a little while. But as the numbers of competitors have increased, the profit has rapidly waned. Each nation is forced to discover rude and unknown markets, where it may for a while extract an extravagant rate of profit. Its whole aim is to make immediate gain, and in doing that it cares not one whit what may come next after it has left the scene. The European commercial world is doing on a grand scale what the Arab ivory and slavetrader does in a more forcible way in Africa. He looks only to immediate returns, and in an attempt to secure them he wastes recklessly the materials of wealth. Every European country is tending more to depend for the substantial necessaries of life on the barbarous parts of the globe: and retains its supremacy only by a certain control of the mechanical arts and practical technology. But these are easily transferable in this age of mechanism, and when that transformation is accomplished, the countries of modern Lurope will find themselves face to face with a difficulty which they have not previously encountered.

'To return then to the views of Mr. Spencer with regard to 
the evanescence of duty, an idea which is due to the coercion of political and religious authorities, and which tends to disappear with the advance of civilization, we may say that, as he himself admits, it is not of the essence of morality, which means free self-restraint or self-control. The mere coercion of external order does not generate a moral act, but only an act which in its outward aspects can hardly be distinguished from it. The laws, as Aristotle said long ago, speak about everything : they bid us do all the acts which are the characteristic performances of the good man in each department of life. The visible, the invisible, and the indefinite (or mob) ruler extend their voice and decree over all that a human being can do. And the majority of the world, as we found Malebranche saying, are apt to confine their view to these requirements. Nor, if we look facts fairly in the face, have we any reason to suppose that this coercion is becoming less and that the individual is gradually accommodating himself to the environment. It is true that in some places phenomena point in that direction : but they are hardly such as make one long for the ideal of society when the sense of legal and social compulsion has ceased. Mr. Bryce has described what he calls the 'fatalism of the multitude': meaning thereby 'the loss of resisting power, the diminished sense of personal responsibility and of the duty to battle for one's opinions, which disposes a minority and an individual to submit without the need of a command, to spontaneously renounce its own view, and to fall in with the view which the majority has expressed '? That, however, is not what Mr. Spencer means. For beyond this mere mechanical moulding of the individual as an unresisting unit or member in the social mechanism, he directs his view toward an ideal society, where each has become his own government and supplies his own ruler. In such a case obviously coercion is needless; each naturally and normally does what is right and finds pleasure in it. But hardly any-

\footnotetext{
1 American Commonucealth, iii. 127.
} 
where are there obvious tendencies to realize this complete independence of the righteous individual. Rather everywhere the yoke of social and political and religious coercion seems to continue, though it may occasionally change its aspect. Till the possibility of crime has been eradicated from human nature, we may spare our attention to the details of this evolutionist utopia.

There is somewhat more to be said on the second point in his doctrine of the evanescence of the sense of duty or obligation, namely, his view as to authority of conscience, the moral imperative of duty. Authority and obligation, as Butler long ago maintained, naturally belong to the principle of reflection or conscience ${ }^{1}$. Judgement, direction, superintendency is a constituent part of the idea of conscience 2 . As a principle of reflection, it is manifestly superior to a mere propension. So, according to Spencer, the representative, complex, and general feelings possess a superior authoritativeness, as compared with simple sensations and appetites. How they get this is not very clearly explained, but he seems partly to claim acceptance for it as a selfevident truth. Partly also he would accept Darwin's view, that the sense of duty is caused by the felt contrast between a higher social instinct or acquired character and a mere natural and original instinct. But this is again to revert to the explanation of authoritativeness from coercion or external pressure. And in that direction there seems to be no hint of any explanation of the word 'higher,' if that be taken as something different from mightier: or of the idea of authority as distinct from coercion-which after all means only an application of strength or power. And, as Butler remarks, there is an essential difference between mere power or strength and authority: between superiority de jure and de facto.

Now Spencer does appear to acknowledge an inherent or 1 Preface.

Ser. ii. 
intrinsic superiority as an element in moral self-control, which fact self-control he regards as the basis and essential trait of morality. But he has a strangely hesitating way of approaching the fact. 'The feelings have authorities,' he says, 'proportionate to the degree in which they are removed by their complexity and ideality from simple sensations and appetites.' 


\section{V \\ HEDONISM}

T're hedonist school lays down that the end of all aetion is to attain pleasure, and, indeed, to get the maximum of pleasure or of enjoyment. We profess, no doubt, it is said, to seek now for this, and now for that object: for health, wealth, power, knowledge, of ourselves and of others; but in reality the secret aim, at the root of all this variety of professed goods, is pleasure. For surely, it is urged, it is obvious that whatever we do, we do because we believe it will afford us satisfaction: and satisfaction is only another name for pleasure. Or, to follow the language of James Mill: Desire is only another name for 'idea of a pleasurable sensation.' It is this idea of pleasure and nothing else which originally and really sets the will in motion. By degrees, it must be owned, we get into the habit of speaking as if we desired not pleasure, but the things which bring the pleasure. But this is only a figure of speech, which has grown upon us by association, but need not deceive us.

Now in this there seems to be a nest of eonfusions. One of them, which is comparatively simple and not equally obvious in all languages, is the identification of will and pleasure. Tel est notre plaisir : the Latin placet and lene placilum are similar instances. With it may be compared the use of the Greek

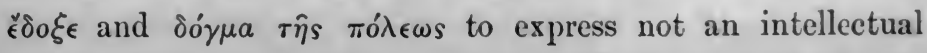
opinion, but an imperative resolution. The lesson to be drawn from all such language is, that in real life the psyehological 
abstractions of quasi-independent faculties are not treated with much respect. We may for our own purposes distinguish between the intellectual, the emotional, and the volitional; but none of these exists really without some tincture of the other. The human intellect is not a dry light, but suffused with a strain of passion. The will has no real existence, except as containing an intellectual conception. We have allowed ourselves to be over-influenced by the ideal separation of different faculties. Above all, the intellectual classes -and they naturally are chiefly engaged with the present problems-are apt to forget that books are not life and reality, but only the reservoirs in which the materials of life have been stored up, dried food, so to speak, or goods in tins. They confound a vast and always increasing stock of words and formulae with an actually realized enjoyment and possession of ideas. A great deal of our scientific stores is, like the works of art in our museum and galleries, in the shadowy state of the ghosts in Hades which need to drink living blood before they can communicate their message. The average intellectual, i. e. bookish, life breeds in those who come under it a habit of treating words as we do the coinage ; never realizing that in every coin are represented and embodied the labours and the means of enjoyment of real human beings, that

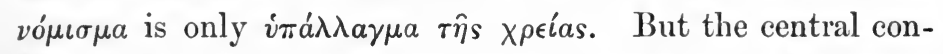
fusion in the whole statement is the hypostatizing of pleasure. And that in two stages: first it is treated as $\chi \omega \rho \iota \sigma \tau o ́ v ~ \tau \iota$, as a something independent, existing per $s e$ : this is the fallacy of the transcendentalist, who invests the forms of our thought and sensibility with an existence as things. Secondly, it is treated as a series of sensible objects- $\tau \grave{a} \pi 0 \lambda \lambda \grave{a} \eta_{\delta} \delta \epsilon^{\prime} a$ : pleasures are spoken of as so many kinds or individuals: this is the fallacy of the vulgar, who tend to identify a quality or characteristic with the particular things which ordinarily or habitually manifest that characteristic. The victims of the first fallacy treat of Pleasure, with 
a capital P; and if they do not, as they are very liable to do, take the further step of personifying their pleasure, they at any rate fail to realize the essential relativity of the notion. $B y$ that relativity is meant that pleasure is simply the sense of a correspondence between the agent and his surroundings, or the sense that a movement initiated by the organism has not gone off at random, but has, as it were, returned and converged in the organism as its end. Pleasure is not another thing beside life, but it is the sense of life, and in particular, of life as a process of outgoing or differentiation, immediately transforming itself into the obverse process of in-going or redintegration. In health and vigour these two processes are almost synchronous, and certainly inseparable: the activity which is put forth is not spent on some ulterior end, but immediately reverts into self, is at once apperceived and realized in the self. At other times there is a long interval possibly between the forth-putting and the ingathering.

The distinction between the two cases is rendered by Aristotle as that between év'́ $\rho \gamma \epsilon \iota a$ and $\gamma^{\epsilon} v^{\prime} \epsilon \sigma \iota s$. The latter is activity of which the end or fruition is outside itself : it is work done under direction, and having its issue or result in the

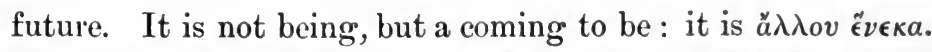
Such is the life of business in its áoxodía, plagued as it is with the hope of an end or consummation yet to be reached.

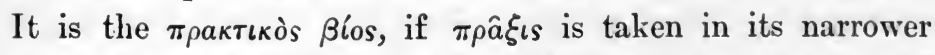
sense as negotium, the antithesis of $\sigma \chi 0 \lambda \dot{\eta}$, as the action of one who has set his aim, his goal, in the future. But in the wider sense of $\pi \rho \hat{a} \xi \iota s$, in which it is equivalent to $\hat{v} v \in \rho \rho \epsilon \iota a$, the activity is self-realization, fruition as well as action, not merely $\pi \rho \hat{a} \xi \iota s$ in the limited acceptation, but also $\theta \epsilon \omega \rho i a$. It was indeed a tendency of the Greeks, fostered by their political and social condition, to find such èvépyєıа more especially in $\sigma \chi \circ \lambda \eta^{\prime}$, and to identify it with $\delta \iota a \gamma \omega \gamma \eta^{\prime}$, that activity which is so little of an effort that it is little beyond the tranquil easy consciousness of life passing on, like the ceaseless rippling, 
glittering, and whispering of a brook over its pebbly bed, or

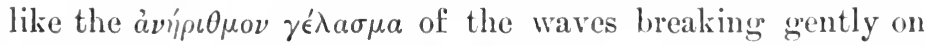

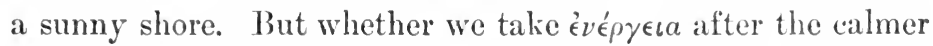
mood of the Greek, or the more energetic of the modern, it is essentially not action which is, so to speak, commanded by a power outside it, and directed to a foreign end, but action self-initiated and self-enjoyed. If we may believe the writer of the seventh book of the Nicomachean Ethics, the Platonic school attempted to get from $\gamma^{\prime} \dot{v} \epsilon \sigma \iota s$ to évé $\rho \gamma \epsilon \iota a$ by describing

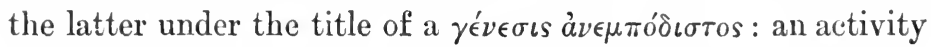
which was free and self-contained, released from subjection, and attaining its natural end. They added, however, that

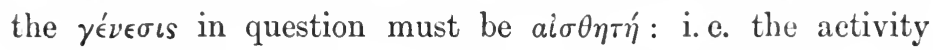
must be a felt activity, must be consciously apprehended as free or self-realizing energy. This is a point to which Aristotle himself returns in the tenth book. There we get a sort of supplement and correction to the view of $\epsilon \dot{v} \delta a c \mu o v i a$ given in the first book. Happiness had been there defined as

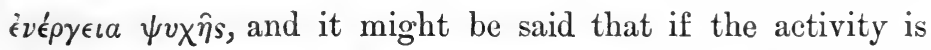
psychic, it must be self-conscious activity. But this is hardly correct for the standpoint of Aristotle whose whole tendency (in accordance with what we may call the prevailingly objective character of Greek philosophy) is not to regard happiness as consciousness, but rather as a function of the self, a form of the mental life, a realization rather than a possession, but without any special emphasis on the purely subjective side. This subjective element, however, comes out, though still very imperfectly, in the statement

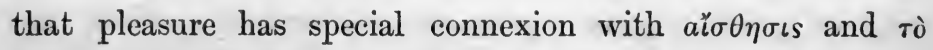

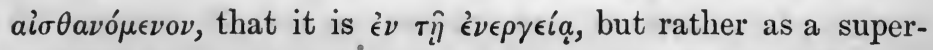

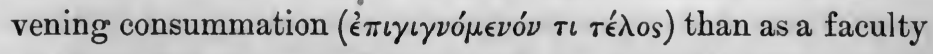
which can consummate: i. e. rather as a natural resultant which action puts on to crown itself, than as a special power which itself yields that consummation. It is the unbought and unbuyable grace of life: the electric spark, as it were, 
which flashes out at the point where the outgoing line of action returns upon itself and is just completing its redintegration with self: it is the consciousness that the object, which is presented by natural causes, or which we have ourselves prodnced by an act of will, is in harmony and cooperation with the subjective conditions and forces of life, which reveal themselves in our voluntary agency.

It follows from this examination that pleasure is no substantial or independent entity, no object per se: but, as the Stoies ealled it, an $\dot{\epsilon} \pi \gamma^{\prime} \epsilon^{\prime} v \eta \mu a$, a sort of surplusage, like the striking of the clock, which may keep equally good time whether it strikes or not. Of course this does not mean that pleasure is not a real or important element of consciousness. As Aristotle long ago remarked, pleasure is the sign or symptom of self-realization: the witness that an action is not done for external motives, but that it is the exhibition of a $\epsilon^{\prime} \xi$ เs, i. e. of a faculty which has been made part of the original self, has been in short acquired or made our own second nature, if it was not our first. Pleasure, or as we may now call it, satisfaction, means that we have attained our end : it is not itself the end. The idea of pleasure, which Mill speaks of-let alone the doubtful use of the word idea-means the idea of ourselves pleased, i. e. of ourselves attaining the object of our effort, the idea of ourselves satisfied, of ourselves self-realized. Such an idea is not an invariable presence in consciousness. In cases where the self-realization has its outgoing and its incoming moment in immediate juxtaposition, where indeed the one is at every instant becoming the other, where action is pleasure, there is no previous idea of pleasure, no anticipation of it in faint consciousness to compensate us for the reality which is as yet absent. The statement, indeed, that the idea of pleasure stimulates to action, is on a par with its converse doctrine that it is present uneasiness of desire which determines to voluntary action.

Deeper than pleasure and pain are the stimuli themselves, 
the impulses, appetites, or natural propensities of human nature. These are the various aspects in which the great fact or process of life is partially and in detail represented. That great fact or process may be described as a process of metabolé, with its two sides of anabolé or katabolé: or in plainer language, life is the continuous ridge or acme of a double process, which consists, on the one hand, in the assimilation of material or in the acquisition of matter to realize its formative powers, and, on the other, in the rejection and disintegration of the formed material as soon as the process of formation is completed. Life, in short-and this seems the essential thing to remember-is the process, and not the product. It is not, as has sometimes been said, the correspondence of inward changes to outward changes, or the correspondence of a moving equilibrium within to another without. It is the inferior half of a truth to say that life is adaptation to the environment: rather where life is, the environment is adapted and assimilated, employed in the service and for the realization of formative energy, or, in other words, to body forth that molecular movement up and down in which life as a physical fact or process consists.

But life, more and more conspicuously in proportion to the visible complexity of the organism which it inhabits, is parted up into a number of partial processes of self-realization. These initial movements, which we call impulses and appetites, are the primary details, the several exemplifications of the great movement of life. With regard to the large number of them, impulse and actualization go hand in hand, with little gap or interval. The impulses which find vent in exercise of most of the organs, such as those of sense, are to some extent of this character. It is different with the appetites strictly so called: and it is in problems connected with them that ethics is strictly concerned. There the forthputting of energy has to be undertaken for a remote end. Work, labour, in short becomes necessary to procure the 
means of satisfaction, to complete the circuit. And so we are again confronted with the distinetion between work and play: the latter being activity which is immediately felt and found to be at harmony with the self, and thus directly pleasant, whereas the former does not immediately carry its own fruition with it, and is therefore either neutral, or, if contrasted with some possible direct pleasure, may become decidedly painful.

As so regarded, the impulses fall into two classes; one, in which the pleasure is normally immediate, the other, in which the pleasure is only to be found at a greater or less distance. On the one hand are the impulses craving immediate exereise, on the other the appetites of hunger and thirst, which demand not so much exercise as satisfaction or repletion. The former are tendencies to expend or explode what has been acquired; they are processes of katabolism. aceompanier with liberation of energy. The latter are tendencies to aequire and assimilate, to concentrate and unify; they are processes of anabolism, gathering up energy and embodying it in strueture. The two must go on simultaneously, and the ideal of human life at this stage would seem to be reached if the expenditure of energy from muscle and nerve could be so arranged, that the individual was able to appropriate the amount of material goods requisite for the maintenance of his own being and wellbeing. It would be a legitimate development of this idea if we were further to suppose that a social group might be constituted, of such a magnitude and such elements, that the parts of the total product, needed for the maintenance of the whole group, should so be distributed amongst the members as to make the work of each at once soeially useful and individually pleasant to the agent. Such was the ideal of society formed by Fourier. But it is tolerably evident that, although by wise arrangements something might be secured much better than our existing society, 
the realization of the conversion of all work into play can only be treated as an ideal-the greatest possible approximation to which, however, remains the duty of the social reformer. No organization will ever make labour cease to be trouble: but probably a great deal more might be done by organization to make it a labour in which delight is taken. It is no great curse to be obliged to gain one's bread by the sweat of the flesh, or the toil of the brain: but it is a curse when the sweat and the toil do not bring the bread, or even when they bring it, not as a direct fruit or remote result of the toil, but as a supervening something, attached to it by a social mechanism of which the recipient understands little, and for which he entertains little faith. And to reverse this state of affairs is a problem which cannot be solved by any reduction of hours of labour, but which will require a training in the mechanism of the social organism such as few have yet dreamt of.

But to return. Before pleasure emerged, impulses and appetites had sought their way to actualization. They had found it by natural ehannels, by the outlet of energy, i.e. in those ways which opposed least resistance to its expenditure. Similarly the appetites had learned the matter required for stilling their demands, learned it, no doubt, by a course of irregular experiments. In the next stage, however, we see the clearer emergence of the idea of pleasure as an element in the business. Man thus passes from the stage of instinct to the dominion of intelligence. He came into the world with tendencies and impulses for which he is not responsible, with a complicated living organism, which is ultimately a system of oppai appearing one by one, and appearing first of all by the action which they spontaneously initiate. That action reveals to him his own nature, at least in its elements, in partial or fragmentary aspects, as they occasionally occur. And so he has offered to him at least a pathway of escape from the immediate and utter subjection of action to impulse. 
So long as impulse, fortuitously appearing, spontaneously works its way to realization, one is no more in control of it than the savage is of the flood and the hurricane. But once consciousness represents to reflection the whole range of the spontaneous movement from the first dim uneasiness of impulse to the final stage of satisfaction, and does this for impulse after impulse and satisfaction after satisfaction, two or three consequences are entailed. In the first place, the idea of a satisfaction of impulse and appetite takes its place as an initiative of movement. It is a misinterpretation of this when James Mill defines desire as an 'idea of a pleasurable sensation.' 'The misinterpretation consists in treating a 'pleasurable sensation' as an independent object. Of a pleasurable sensation as such, there can be and is no idea. What there is and ean be an idea of, is a definite kind of action, an individual phenomenon, which will give, as it is believed on experience to have given, satisfaction. It is the idea of a definite pleasure, meaning by that the idea of a definite event, oceurrence, or thing which was found pleasant. It is not then an abstract pleasure, not even an abstractly pleasurable sensation-i.e. a sensation which is pleasant and nothing more-but an objective and definable fact, which has been found to be a realization, a furthering and perfecting of some one side of what we know as our self. The idea of a pleasure means the idea of a pleased self, and that again means no general or indefinite ego, but the real ego or personality of a particular moment, generalized perhaps, but still perfeetly determinate and precise. Desire then is and is not of pleasure. It is the desire of pleasure, if pleasure be understood to mean not a general something which is pleasure and nothing else, but a specific object which by its correlation with some aspect of the total organic being has acquired the attribute 'pleasant.'

One more remark on the phrase 'idea of a pleasure' as equivalent to a desire. This conception goes along with that manner 
of psychology which was first made familiar by IIume, and has since been reproduced by Mr. Spencer. That is the distinction of mental facts or phenomena into two orders, a fainter and a more vivid, not separated by any hard and fast line, but still sufficiently apart to warrant us in regarding the distinction as important. It is partly like the old Aristotelian distinction

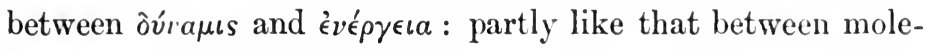
cular and molar movements: between latent process and perceptible change. At a certain stage movement fails to be detected by the unaided senses; at a further stage it escapes the notice of our most accurate instruments of research, while it is still pursuable by our inference and logic to further depths. So, according to the psychologist, our mental states or exhibitions of mental (psychical) action have a variety of grades, from their first grosser reality as actual impressions, vivid sentiencies, to their finer and more imperceptible reality as ideas, the distant echoes or images of these stronger excitations; and finally to the stage of apparent quiescence or latency, the stage of what may be called by the somewhat contradictory name 'unconscious idea,' or idea latent in consciousness. Such ideas, of satisfactions emerging by some accident from their latency, find themselves occasionally reinforced by the circumstances of the moment, when these all point decidedly in one direction : and they are developed to a still greater extent, when through innate want of energy or absence of other external stimuli, the whole soul is allowed to dwell and fasten on that single image. Such overmastering impulses, due not to the idea of a pleasure, but to the idea of an action with which satisfaction is imagined to be intimately involved, are the natural experience of the untrained and undisciplined young, of the barbarian in all societies, and attain their worst exhibitions perhaps in the ill-disciplined and ill-proportioned minds of those who by a sudden revolution have gained imperial position. Of the first Napoleon, says M. Taine: 'Chez lui, aucune idée ne demeure spéculative et 
pure: aucune n'est une simple copie du réel, ou un simple tableau du possible: chacune est une secousse interne qui spontanément et tout de suite tend à se transformer en acte.' And 'Taine explains this absenee of self-control, not merely by the fact that the emperor was tout imagination, but by his early upbringing in an island, where the administration of justice is a farce, and where the public opinion bestows a frank admiration on well-laid ambuscades and successful acts of treachery.

But it is by this same faculty of guiding his course by ideas of pleasures that the voluptuary is generated. The voluptuary seems to be a victim of reason and imagination. The animal is comparatively safe because of his defective range of intelligence. But the human being, at a very early stage of civilization, or rather in very low levels of barbarism, soon learns to misuse the motive power of ideas, and begins to seek for pleasure over and above what comes in the normal and average performance of function. Idleness and want of varied interest are the great parents of intemperance, and the savage is fully qualified in both respects. He knows nothing of the discipline of labour, and nothing of the other ideal discipline which gives a man ideal interests, public aims, social plans to pursue. And what is true of the savage, is repeated in some measure by the gangs of vagrants and tramps in modern times.

A more dangerous development, however, judged by its ultimate effects, is seen in the voluptuary proper. He is generally, like the tramp and the beggar, a product of a highly civilized society; i.e. a society in which the construction of a well-jointed and secure form of social institutions and the establishment of a solid and safe property system have been carried to their height without any corresponding growth of the sense of moral solidarity, of public duty, of general human fraternity. For such an one the regulative influence of normal work has been removed, and has not been replaced by any zeal for ideal ends or common good. He becomes not a seeker for pleasur- 
able sensations in general, but a very close approach to that creation of abstraction. Not pleasure in general, but the greatest possible variety and multiplicity of pleasures is his aim. In the pursuit of art, he is the dilettante who sips only the honey that can be got from the selected flowers. In science, his range is measured by what he finds interesting, what gratifies his taste, or personal whim. But above all his motto is to extract pleasure from as many sources as he may, to turn everything if possible into a cause of pleasure, and, if that be impossible, to surround himself as far as he can with a wellarrayed system of materials, out of each of which as they revolve around him he may get its quota of enjoyment.

That such an art of pleasure is altogether illegitimate it would be wrong to say. Under the common name of voluptuary hasty thought is apt to confound two persons altogether different. Or we may say that there is a true and a false Epicureanism. The false Epicureanism makes the acquisition of versatility of pleasure-taste and the accumulation of a stock of pleasure-means an aim in itself, or for the ultimate enjoyment of the agent. But within proper limitations, Epicureanism may present itself as the effort to make the setting and framework of human life free from unnecessary jar and fret, so as to leave the energies unimpaired for higher and better work. We are told by Mr. Spencer that 'pleasuregiving acts are life-sustaining acts,' and 'every pleasure increases vitality,' and ' raises the tide of life.' Both of these propositions, as Mr. Spencer well knows and subsequently admits, are misleading, because we are not yet in that social millennium, where actions are at once and simultaneously completely right and completely pleasant. In the world as it is, a great deal of readjustment is required before mankind can trust the guidance of their emotions, or of their sensations ${ }^{1}$. And this adjustment is not merely, as the author seems to suppose, between mankind and the social state; it is equally

1 Data of Ethics, p. 99. 
an adjustment needed in the organism of the individual man. Except on the idea that the organism is a perfectly normal one, exactly adjusted in every detail, the pleasure which results from an action is no sure indication of the lifesustaining or vitality-inereasing qualities of the said pleasure. We may almost go so far as to say that there is a pleasure which is a sure symptom of imminent death: the satisfaction which is felt when the morbid structure is so thoroughly pervaded by disease that the sense of struggle and disproportion vanishes in an ease which is the forerunner of collapse. But in general we may say that, in an organism which is liable to partial disruption of continuity of function, and where each part in turn usurps the prerogative of the whole, there may be a great variety of pleasures which, far from attesting the health of the whole, only attest the private convenience of one organ, and which, though they raise the tide of life in a one-sided way, really do so at the cost of other parts, and thus depress the general vitality. Such usurpations of language which applies only to the ideal and normal manin whom every part performs its function in due subjection to the common function, without any tendency to separation or isolation of life-are utterly inappropriate and perilous when applied as a guide to the more or less abnormal creatures which the great mass of humanity are. Let us keep ideals and normals in their place as standards of perfection, and remember that each actual individual has always a problem of his own which cannot be settled by generalities.

We are on safer ground if we adhere to the negative proposition that every pain is evidence of incongruity between the part and the whole organism, and between the whole organism and its circumstances of life. We may even say that pleasure is evidence of a congruity somewhere, but for practical purposes that proposition is of little value. It is a poor consolation for one dying of some organic disease to 
know that at a certain point there will be such harmony established between the diseased centre and its immediate surroundings that he will feel a great ease and calm. Nor, again, when we are told that, if the actions are life-sustaining, the pleasures which they bring with them will be life-sustaining too, do we learn anything of very much value as a guide of life. If you are a normally constituted human being in a normally constituted and thoroughly adapted society, you may be pretty sure that your pleasures are all on the side of normal and ideal existence: but only an irrational optimism will treat that hypothetical idea or principle as a presumption to be taken for granted in actual life.

And yet on the other side it is to be remembered that the influence of pain and pleasure is not a simple or plain matter. Here again facts force us to abandon the general lumping of pleasures under one abstract category. To the popular apprehension at any rate it would seem evident that some pleasures enervate and others stimulate: that some pains benumb and others fire with zeal. Mr. Spencer on one occasion seeks to prove his point by pointing to the effect of what he calls 'good spirits' on work and play. It is but a loose style of argument which can put 'good spirits' as an equivalent for pleasure, or 'low spirits' for pain. A deal of mischief is done by this fancy for levelling away all distinctions, so as to be able to point out pleasure here, pleasure there, pleasure everywhere, and then get a simple, uniform principle. In short, if a general law of duty is complained of as giving but a poor light in difficulties of moral detail, a general law of pleasure can hardly escape a blame for the same fault.

So to return to our Epicurean with the good heart, in bonam partem. $\mathrm{He}$ is one who has learnt that a great deal of vice is due to the pains of misery: who has observed that every irritation and vexation which befalls a human being tends to remain in his inner consciousness ready to burst 
forth on the first available object, however innocent. There are hundreds of troulles which are not of importance enough, or are too mueh part of a portentous system, to be got rid of by a bold act which takes up arms against them and by opposing ends them. Pains that at once awake activity to overeome them are not unmingled evils. The others, which we dare not or cannot treat with these vigorous reprisals, are the bane of life. The sufferer feels as if he harl a greneral grievance against the world and humanity, sometimes even against God: and unable probably to charge the offenee on a specific eause, he discharges his irritation on those who are nearest and ought to be dearest to him. Some such evils come through the organization of society; and the individual, feeling himself for the most part powerless to remedy the mischief by direet action, is content with, as the children say, passing it on, and probably with some interest added to the principal burden. But other such irritations come from causes less amenable to social agency: to the effects of an overheated and ill-ventilated room, of an illcooked and ill-compounded meal, of malarious locality, of tasteless and aggravating furniture, of ill-pitched voices, of misfitted articles of apparel, of discordant colours, and so on. The Epicureanism which for itself and others seeks to abolish the causes of these pains, is a noble Epicureanism. No one need suppose that, when these are removed, the world will be a paradise of lotus-eaters, where it is always afternoon. When these curable evils are removed, there will be plenty of real evils still, and as the eye is no longer pestered by the mists which always accompany a fretful atmosphere, it will see work to be done in directions hitherto unsurmised. Before the brotherhoods who aspired to live a religious life could settle down to their task, it behoved them to clear away the thorns and briars, which less wise asceties might have kept in hand to torture themselves withal.

It follows then that though ethies must be concerned with 
pleasures and pains, the problem for it is, first, to determine what are the right or true pleasures and pains, and secondly, to consider the means by which these may also be the actual pleasures and pains of the individual. Every activity, be it bad or good, may have its pleasures: and according to the general verdict of hedonist writers, the only distinction between them is one of quantity, however variously in detailed methods that quantity may be estimated. Now, of an individual it might be true to say that in a deliberate choice between two or more courses of action his choice is due to a belief that the results, taken altogether, of the action-i.e. the action taken in its full and entire range-will give him more pleasure, or be more in accordance with and afford more satisfaction to his whole nature, than those likely to follow another course. But is this equivalent to the doctrine of a pleasure-tariff or pleasure list? Can a general list of pleasures be drawn up, not confined to the estimates of an individual subject, but dominating the tastes of a large multitude?

That such a list can to some extent be made out would seem to be generally allowed: and if so, what implications seem to be contained in it? To answer this question we may compare an analogous economic question. In the course of trade we find that prices are not fixed by the will of isolated individuals but by the chaffering and higgling of the market, i.e. by a process of offer (hypothesis) corrected by other offers, by tentative steps, which aim at arriving at the general or common estimate put upon articles brought to the mart. The àopá, mart or guildhall, is the place of public and common resort: it is the scene of the respublica, the ground on which the кoเvwvia is actualized. The price is fixed by a social act-an act not carried out artificially at one step, but, after the manner of natural processes, by a series of adjustments and readjustments. In some stages of society, it is true, the price is settled by a direct act of the organs 
appointed by the sovereign people. But any difference in method need not conceal the fundamental fact that the price and the value of commodities is settled by the whole social group, and settled by it not arbitrarily, but after comparison of the place of the given article in the systematic aggregate of social want. Price is fixed not by one man's demand and by one man's supply, but by the total demand and total supply in the social group to which they belong. It varies therefore with the fluctuations in the total social system.

Somewhat similar is the tariff of pleasures. Each individual has no doubt a standard of his own in these matters. Just as he has a stronger demand for certain commodities, so he has a bias towards eertain pleasures. But his enjoyment of the latter, like his appropriation of the former, is not a matter in which he alone is concerned. If we set aside for the moment abnormal cases, we may say that all pleasures have a social element, and that they cease to be real pleasures except in so far as they are correlated to the consciousness of other men. The pleasures of ambition, power, love, sensuality, are complete only when they are responded to by the feelings of others. The pleasure of each therefore depends upon the social consciousness : i. e. upon the conception of life and work held by the common group to which an individual belongs. For that reason the quantity of pleasure in acts is measured in any group by the amount in which the activity, to which they are attached, is felt or believed to contribute towards the production of the common well-being or general comfort. But if we say common well-being, we mean well-being as determined not by a formal or official creed, but by the intrinsic and natural belief in the group and its members. We mean the actual conception of happiness which pervades the group: the governing ideal of $\tau \grave{o} \epsilon \hat{v} \zeta \hat{\eta} v$ : the more or less systematized aggregate of actions and feelings which constitutes the contents of the idea of life for that group. The happiness which is thus put as a governing conception is again not a general or abstract 
conception. It may be vague in parts-not sufficiently detailed -but it is the strictly individualized and determinate eonception held by a particular group, epoch, and people. The conception of Ev̇saunovia implies, when fully wrought out, a hierarchy of activities and enjoyments, a systematic eonception of life.

It is built up, no doubt it may be said, of single pleasures, and these pleasures of the individual. So, it may be said, the total scientific conception of the facts of the world, alike in its more popular and its more elaborate phase, rests upon what are called single experiences, individual observations; on what we may call in the last resort mere passing sensations of the individual. But, as Kant may probably be considered once for all to have demonstrated, human consciousness is not such a mere disjunct sequence in the single mind, nor such a mere otiose co-existence of conceptions in several minds one beside the other. It is true that Kant has mainly insisted on the fact that ours is a systematizing conseiousness : that just as our alimentary system analyzes and builds up the mere aggregate of elements contained in a piece of food into a living organic fabric, so our intellectual and cognitive system, in its two digestive apparatus, called respectively sense and understanding, constructs the material of experience into that formed and systematized experience, which in its most formed and systematized degree we eall knowledge or science. But we may carry Kant's argument a step further. Our consciousness is not merely a systematic organ in itself : but it is an integral part in the constitution of the general or common consciousness of humanity, in each of its various grades of association, up to the very highest and most universal.

What is thus laid down implies that experience is a process of continual self-correction : first (if we may distinguish and treat separately what goes on pari passu), in the individual consciousness, secondly, in the collective or co-operant consciousness, self-correction and self-adjustment. And that, because every patch and item of experience, every so-called single 
observation, and mere sensation is for the human being a self-extending, self-asserting, and thus a self-universaling fact. Every single perception is a possible infinity : not a mere perception, but an apperception of itself, a self-apprehension; and that means, that it always carries us a little way, and sometimes a great way, beyond itself. The rudimentary idea, just because it arises in a self-conscionsness, has in it a little of the prophetic and anticipatory: it travels a little way into the unknown, it is not merely its bare single self, but is symbolic of a wider behind or beyond it. This anticipatory tendency, to round off the part into a postulated totality, to carry on the present moment into the future and thence back to the past, is the rudimentary or essential nature of human reason. It is the tendency to interpret the given, i. e. to see it not merely as it stands, but in its meaning, in its bearings, in its context and implications, in its generality. To interpret nature and thus to anticipate her next word is the fundamental function of man-the ground-function through which both truth and falsehood alike become possible. Error arises when the process of interpretation and anticipation is abruptly or arbitrarily fore-closed at one step, or is carried too far at one step without due caution. Truth, on the contrary, can only be secured through a continual revision and correction of the idea or interpretation in the light of fuller data, which, put face to face with the already made accumulation in idea and interpretation, have to unite in furnishing out a fuller and more authentic symbolism.

Let us apply this to pleasures. There also we begin with single experiences of individual souls, mere transient, isolated, and momentary emergencies of pleasant feeling, i. e. occasional perceptions that some act of our own, some circumstance about us, is in harmony and response to the needs of our organization as a whole. But what is revealed to us of our organization as a whole in consciousness is not much at first. Yet we can certainly say that the mere felt feeling is never 
left wholly uncorrelated with a little range of possible feeling around it: it makes us, as a pleasure, feel ourselves as pleased -it awakes the vacant idea of self and gives it a real content. But the satisfaction which is awaked by an incipient idea of self, or rather which awakes such an incipient idea, is an interpretation: it has symbolized more than it actually is. What we call experience, meaning the succession of circumstances that affect our lives and feelings, comes to test such interpretations, and to be itself tested: for each such experience is itself to us interpreted, and will only be interpreted well, when it is taken in connexion with the whole available context in our mind. Gradually there grows up a conception of happiness which is strong enough to impose itself as a regulative on each aspirant to the title of pleasure.

But that strength especially comes to it because it is not a mere isolated or individual idea, but is backed up by the power of a social consciousness, which has fostered it and brought it to maturity. And had the individual been reared and had his consciousness developed under a simple single and equal social influence, the domination of the social standard over his individual feeling would have been supreme, and monstrous in its autocracy. An illustration of what the dominancy of the social conception of happiness is, is seen in the manners, and-as in this natural stage the distinction of manners and morals is at a minimum-in the morals of savage races. There, we may say, the whole group is a tolerably uniform and homogeneous mass, well isolated from surrounding and disturbing, i. e. variety-introducing influences. Hence the influence of $\nu$ ó $\mu$ os is despotic, and even in the private consciousness there is apparently no sign of any rebellion or assertion of the rights of the individual. And something analogous is seen even at the present time in narrow self-contained groups, little islets of opinion which manage to maintain their isolation in the general movement of currents to and fro. The possibility of individual freedom, i.e. of the divergence 
between manners and morals, comes with the contending claims of several groups, to all of which the individual belongs, though without falling precisely under any: or it comes with the appearance of divergences of sub-groups inside of the general uniformity. Such sub-groups are probably never wholly absent in any group, constituted of individuals so variable as men, and in circumstances so different as the world affords. But in some countries, e. $\mathrm{g}$. in great expansive plains and small secluded valleys, the uniformity often becomes oppressive.

Along with this variety of groups, within the radius of the same general circle to which the individual belongs, there is given room for variety in the social standards from which the individual gets his rule. He is still overpowered by social influences, but in the multiplicity of contending masters there is an opening for freedom. That such freedom should be complete it is necessary (I) that every aspect of human nature should find strength and support in some social institution, and none be left to languish in the merely individual consciousness : (2) that these various institutions should be so co-ordinated and subordinated in an organized system that none can claim more than its due share of the individual life, or attempt to cancel the claims of other aspects. To secure this latter condition is the business of the State, which seeks to organize social institutions in such a way that it may be an exact reproduction of the whole tendencies of the whole man in their normal hierarchy and system. In such a State man is free, really free, i.e. not liberated from the social yoke altogether, but liberated from its one-sided, fractional, and partial tyrannies, which are what make the social yoke intolerable. A false emancipation, on the contrary, is the withdrawal from the yoke of society altogether, or the pretence of withdrawal, which arbitrarily seleets an agreeable environment, and leaves the rest to look after itself.

Such is the perfect idea of human society, as it is secured in what has been called the free and less appropriately the 
democratic state. Man is escentially social: his whole development is accomplished through social influences. But these influences, if they took the form of the simple and uniform pressure of a homogeneous environment on the individual, would generate a heavy and retarding social tyranny. Even when they part into a variety of influences, working through their several institutions and associations on the individual, they tend, whon left to themselves, to affect him unequally and irregularly. What happens is as follows. A variety of different ideals presents itself to the acceptance of the individual. But they present themselves piecemeal and as it were by accident: not co-ordinated with each other on any plan, not referred to any higher principle. Life has become a chaos, amid which the individual, with what resources he may, is obliged to select some portion in which to work out his own function, leaving the rest to their confusions. In such a condition of affairs the political unity may exist in name; but in reality it is only one amongst a number of contending principles of association, side by side with the religious, the economic and the educational principles. The true or reasonable State must be more than this. It must be supreme visible organization of all principles of organization whatever. With the invisible kingdom of art, science, religion, it cannot, even if it would, deal : in the region of temporalities, i.e. of materialized and tangible existence, the State is supreme -not as a supervening domination, but as an indwelling organization. With art, science, religion, as such, as spiritual principles of human energy, the State has nothing directly to do : but wherever they appear as organizations, wherever they rise into materialized actions, there the State is present, not as something alien and antagonistic, but as the whole organization controlling the eccentricity of the parts.

Such a State is an ideal, but it is the supreme ideal of the visible development of humanity. Yet every State, so far as it deserves that name, has the ideal aim. Each State is 
in its measure the idea, or it is nothing: in so far as it seeks to afford to each of its members a common stock of goods, out of which they can individually derive the strength necessary for cach, and yet sceks to present to each what he specially wants, not indiscriminately in a great aggregate of omnigenous goods, but in special organizations and institutions accommodated as far as is possible to all the existing varieties of human temperament and endowments. The State is thus in the best sense a socialistic agency, a system in which each finds his interest satisfied, in which each gains the appropriate scope for his outward development. But it should be added, while we are on this point, that the socialisting organization has been created and must be maintained by the persistent exercise of human function. 'The stock from which each takes what he needs for his private use, he must at the same moment replenish, and replenish with interest as well as principal. It is a wide-spread and constantly recurring fallacy that the State ( $\tau \dot{o}$ кoเróv) has an independent and self-subsistent stock of resources upon which individuals can draw at will. The fallacy was a natural one when the State was not-when, as Plato says, it consisted of two antagonistic states, the rich and the poor, one- of which supposed that it was solely entitled to draw on the civic bank, while the other had the less pleasing duty of keeping it supplied. But such an abnormal condition of affairs, when a community can for ages live by plundering their neighbours and foreign communities, or in which one class of the community makes the honey which the other will consume, cannot be made the basis of political theory, as distinct from the art of polities. In the ideal or theoretical State the common stock only exists in so far as the associated individuals produce year by year and age by age more than they spend. The produce of successful brigandage, whether in open war or in commercial rivalry, cannot be permanently reckoned upon as sufficient to compensate the absence of industrial habits of hand and head. 
Pleasure then is socially determined, just because the self is socially realized, i. e. realized by the help of a more or less complex social organization. Pleasures and pains, so far as ethics is concerned with them, are social pleasures and pains, not the mere natural organic accompaniments of psychical activity or susceptibility. These, of course, we have to begin with: they are the elements, the raw material, out of which the life-product, the finished works of the art of life, are to be made. The successive experiences of pleasures are part of the general experience of life : and as in all experience they partly help to build it up, partly receive correction from it. No single experience is infallible: it has to be confronted with the total idea as its critic, though it serves in turn to suggest a criticism of that idea. What experience thus helps to establish is a bulwark of sound judgement, of laws and general principles, which protect against any casual, desultory, and irregular inroads of experience. So in the case of pleasure, the total and collective experience (i. e. of the individual, as transcending his several moments, and as included in or enlarged by his social medium) corrects the mistaken judgements or interpretations of early sensation. For, as has already been said, we live not as a whole at any instant, but by partial aspects and oceasional flashes of sensation, here a little, and there a little. And each pleasure is the defined and individualized pleasure of a moment-of one aspect or phase of life. It reveals to us our own nature, but in a partial or fragmentary revelation: and it is only through a process of constructive comparison that we come to learn what we in a fuller and fullest sense are. Above all, the evidence of the social pleasures is given towards the doctrine of the social solidarity of human beings.

Thus the general conception of human happiness will determine the character of the particular pleasures. They no doubt have served to constitute that conception, but in constituting it they have themselves been altered and shaped 
in adaptation to the total system. And the conception of happiness is, as Aristotle pointed out, a conception of activity and of activities : of life in short, as actualization, rather than of the pleasant conseiousness which attends the actualization. As such it is objective, rather than subjective: rather something done than something felt, or, perhaps, something not merely felt but also done, realized, objectified. The dominant idea is thus not satisfaction, but self-realization involving satisfaction, and involving always a greater and greater degree of self-realization. The end is happiness: happiness is self-realization, but the self which is realized is not the mere self living a solitary life, but a self which, with varying grades of attraction, draws first family, then city, and lastly the whole human kind into the eircle of its self-interest.

Pleasure thus is useful as an index to the line of life; yet taken singly it is not an infallible index, but one which calls for correction, first by an united and growing experience of the whole individual life, secondly by the coineidence and opposition of other pleasure-experiencers. To this point Plato directs himself in the Philebus. The crude positivist starts with the assumption that every sensation is true and real. A further process of reflection serves to show that to which these epithets are applicable is not the sensation as such, but the interpretation or implication which is given to it. But sensations when thus understood, as they must be in the case of human sensation, are not more true and real than they may be untrue and unreal. Their truth and reality comes to them from their implication and relations, i.e. from their connexion with a context. It is only by an ellipse of language that we speak of a single object as real: it is real only as part of a world in which it acts and suffers. So with pleasures. A pleasure is a species of interpretation-an instantaneous interpretation generally-of something as a constituent part and pareel of our life and activity : a perception or rather a feeling of agreement or harmony, of 
adaptation of environment to self, and of cxpansion of self without loss in the environment. Such perceptions like all others may crr, and may err persistently, as in the case of the stick seen to bend at its point of immersion in the water, or the square tower which at a sufficient distance puts on a round shape. The positive Positivist of course refuses to call this an error of perception: it is, he says, an error of judgement: as if there were any perceptions which did not include an act of judgement and rapid or latent inference, i. e. extension beyond the mere seen to the suspected. And, similarly, he will have it that every pleasure is an ultimate and irreducible real element, an ultimate brick of the set of bricks out of which life is made. There are no such ultimate bricks or atomic (i.e. irreducible and indivisible) pleasures: pleasures like other perceptions are what they seem, i.e. what they are thought to be; and what has been called real from one point of view, is from another made unreal, i.e. is transmuted into another fact. Thus arises in the last resort the final or penultimate conception of life, which has been formed, not out of an addition of pleasures, but out of a testing and mutual correction of pleasures in the medium of experience; where reason, acting on the broad field of time and space, through its synthetic powers builds up a world, a living world, not by putting piece to piece, but by that subtler and higher mode of composition-which we may call metabolism and metaphorically illustrate by fire-where the very molecules and invisible organisms of each constituent are so amalgamated that the result is, as it were, the secretion, the distillation, the organic product of inorganic elements. Such a process of life is the form, idea, or standard by which all future experience of pleasures is dominated: just as the increasing bulk of scientific knowledge and the clearer conception of fundamental laws and principle of physical existence come to dominate experience, and serve as a criterion by which alleged experiences of an abnormal character can be 
tried. It is true that neither in the one case nor in the other ean absolute finality be attained. Not in science, because here the unexplored regions are still vast: new lights may throw into the shade much that is now approved, and the whole system of the physical universe is a moving and advancing equilibrium, of which the sciences have only traced the contemporary form. Still we hold it probable that no new discovery will utterly destroy and annul the old, though it may cause its proud proportions to dwindle and to lose all independent place in the new palace of truth. Nor in conduct: it is perhaps ton early to say that all the possibilities of human nature have been exhausted and realized, and new ranges of human life may be made acceptable by pleasures hitherto unexperienced, so that the very centre of gravity of human existence will be displaced. Yet here too, probably, the lesson of the past is rather in favour of the view that, though there may be considerable alteration in the gencral arrangement, the main constituents of human life will retain a place not very different from what they now possess.

Thus the moral and social control the physical: happiness, as a general idea of well-led life, of activities perfectly realized, lays down the law to pleasure in its individual appearances. The systematized totality, which is not a mere sum of pleasures, but the organic unity in which pleasures tend to become completely harmonious, is the standard and the measure as against the individual and the occasional. Life organized is the judge as against the several unorganized detailperformances of life. Happiness is the summum bonum as against the single or several pleasures. But the judge is after all only

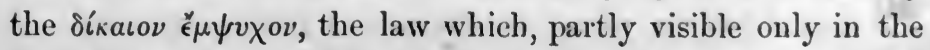
several cases, becomes clear and strong in their organized and systematic grouping. It is not an alien authority, except in so far as the part claims an independence and sets itself out over against the totality and system to which it ought to belong; in which case the law appears as coercion, constraint,

$$
\text { B b }
$$


and compels obedience. And, further, happiness is a law only when and because it has acquired objective and permanent shape, because it is an habitual mode of life, a solidified form of action, an institution. Happiness must no doubt have its seat and centre in the breast: but it will not be happiness if it have not also a permanent visible objectivity. Only as such is it secure and real, protected against the dangers which attend isolated and individual pleasures, against individual recklessness and fluctuations. Thus the demand for happiness, if it is not to degenerate into a mere clutching at a maximum of pleasures, and so eventually to contradict and destroy itself, must be regulated by the organization of human life, by its objective manifestation in institutions and modes of life.

Such a conception of life in its entirety, in its full development, in its objective manifestation, in its organized systematization, is what the Greek philosophers understood by Nature. $\Phi \dot{v} \sigma \iota s$, says Aristotle, is the sum of existence regarded as containing its own rule and origin: it is the constitution of the universe and of each thing in it, when that thing has attained the full completeness of its being: it is the normal and thoroughly adapted existence, that existence, as Plato says, which is not mere ovंría, or reality bare of organization, but the higher reality of the good which rises far beyond its phenomenal existence in power and glory. For Nature, to Aristotle and Plato, is not merely the sum of existence, but the organization and the organizing principle of existence, definable on the one hand as God and the good, doing nothing without purpose; on the other as the multitudinous realm of life and actuality in which all things work together.

When the early philosophers spoke of $\phi \dot{v} \sigma \iota s$, they regarded it, whatever might be their private diversities of interpretation, as a synthetic and organizing matter, principle, lawa universal which transcended all the several particulars, 
though not itself another particular outside of them, but rather the centrality and unity of all principles and particular phases. It is the cardinal doctrine of Greek thought, as it is the inspiring principle of Greek practice that, over and above the superficial differences and divisions which the conditionary forms of time and space force upon our apprehension, there is a unity out of which these differences can be explained, and by the gradual and fragmentary action of which they arise. Philosophy in fact consists in the effort to realize this unity-to transcend these differences of detail, which to the impatient and non-persevering glance seem to be all. A partial philosophy, an imperfect culture, puts its own sense upon the cry, 'Back to nature.' It says, with 'Thrasymachus its mouthpiece, that the institutions of mankind are only the despotic devices of the few to avail themselves of the services of the many, or that moral rules are but arbitrary lines of demarcation breaking up and keeping asunder what nature has meant to be united. It infers that such institutions and such rules will be discarded by the 'advanced thinker' and the 'intelligent members of society.' If it is mildly sentimental in its love of unity and harmony, it may stop short at a half-mystical, half-sensuous absorption in the charm of undifferentiated and Adamic life, discarding the grosser forms of convention and bathing itself in an idyllic complacency of natural sympathy. If it is more turbulently concupiscent, it seeks fiercer pleasures and more tyrannie usurpations of the means of enjoyment.

It may, indeed, be said that the exhortation to follow nature is for a moralist but a loose way of talk. The charge is one which may be equally brought against any of the general or abstract forms in which an ethical principle is couched. None of them in epitome are without similar dangers of misuse. And the abuse made by the Sophists of this phrase is only parallel to that which has been made by other moralists of other phrases. There is no one phrase, no one B b 2 
idea, which is adequate to convey the content of morality, or ethics would have been settled long ago. As Plato remarked, the idea of good is at least composed of three distinct ideas: and Herbart has treated it as only completely constituted by the synthesis of five.

But Plato and Aristotle with their Stoic followers, when they clung to the faith that good conduct consists in the life conformable to nature, explained what they meant by

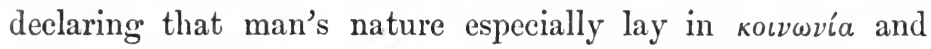

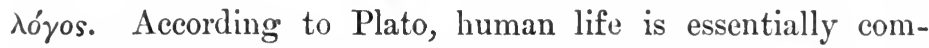
munity, because its economic needs cannot otherwise be satisfied. Without community none is secure of existence: only in a common organization can the individual life be

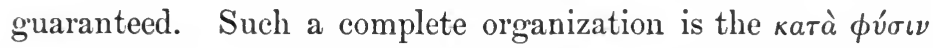

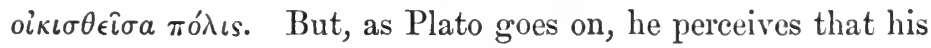
principle changes its aspect, and what he began with as $\phi v \sigma_{\iota s}$

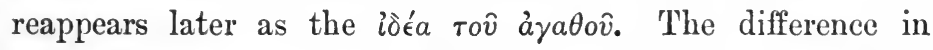
point of view is significant: it marks the stage at which Greek philosophy tends to emancipate itself from the conditions of its time, and enters upon a line of thought where it comes into touch with the higher Christianity. That is, Plato was dissatisfied with the limitations of the conception Nature. Nature, he half feels, is blind, is neither this nor that, is all things at all times, is too much sunk in the immediate and fragmentary, and emerges too little as the ideal or spiritual principle; for this, though it appears in the visible and temporal organization, is yet never quite exhausted by the actual, but looks before and after, and is not merely the movement in time and space, but the eternal identity in which that movement is only a stage or phase. One can hardly say that in Plato this identity is a self-consciousness; rather it is the permanent law or outline of movement which the several phenomena of the world partially reproduce, and which the philosopher after long preparatory study may learn to detect. It is the eternal ordinance and co-adaptation of things, which 
exists for those, says Plato, who can so train their vision that it no longer sees phenomena merely but penetrates to the truth of things, the ultimate and objective synthesis of the universe, the final laws, which determine man's problems in life and death. To us it would perhaps be otherwise conceived. Some would hold it to be but a subjective synthesis, the mere effort made by the individual to put together for his aims and according to his preconceptions the elements of his experience. Others would rather note that the eternal ordinance must be conceived after the analogy of an eternal ordainer: as a self-consciousness which sees its own travail and is satisfied in the work, and which yet is also a mpóvoıa that transeends the actual and is the indwelling spirit of a continuous and intelligent self-adjustment. 


\section{UTILITARIA NISM}

3

ONE great shortcoming of Utilitarianism was that, as K. Marx says ${ }^{1}$, 'it took the modern shopkeeper, especially the English shopkeeper, as the normal man.' But 'he that would criticize all human acts, movements, relations, \&c., by the principle of Utility, must first deal with human nature in general, and then with human nature as modified in each historical epoch.' Bentham belonged to an unhistorical or rational age, it is said. Perhaps it would be truer to say that he represents a relative or comparative truth: the truth that no social institution, law, or ceremony can claim to be received or obeyed except in so far as it contributes to produce social welfare. He is perpetually at hand therefore with his question Cui Boro? On his principles no rule can subsist in authority without being justified by its effects: all rules must be in harmony and co-operation with each and form a system. Hence his proposals for the reform of the law and its codification.

Secondly, Bentham taught that, when we say society or community, we mean only the individuals forming it, the community being otherwise a figment. Here also there was a truth; but error, at the same time, had inserted the thin end of the wedge. The truth is, that the community has no universal or transcendent existence apart from its particulars

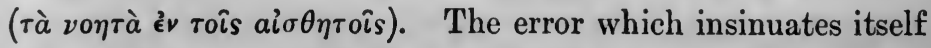
is, that the community owes its existence to the conscious

1 Capital, p. 622, Eng. tr. 
choice or option of these individuals : that they have made it of their own free will, and that at that will they ean unmake it, and resume, if they can indeed ever be said to have surrendered, their independence. This, the common error of the century which culminated in the Revolution, is the error of Bentham, who inveighed against the rights of man. Hence the happiness of the community is only the sum of individual happinesses. And Bentham only avoids seeing the possible opposition between individual happinesses, and hence the impossibility of treating their relations in the state as expressed by a sum of addition, because he holds a naïve faith in the unforced accordance between publie interest and rightly understood private interest. It is only in curious and exceptional cases, eases which wise precautions of legislature would render almost incapable of occurrence, that there will be any serious conflict between the claims of virtue or duty and the impulses craving self-satisfaction.

But further, when Bentham is asked to explain the meaning of Utility, or to what kind of human being certain acts or relations are useful, his answer is, To a being which ean feel pleasure and pain. That is what man has been reduced to. The question which settles whether any thing is or is not a subject of ethics, is not, Has it reason? but Can it suffer? Can it feel pain and pleasure? Thus all the reality of life, all its positive aims and occupations, sink out of sight and leave only the mere creature who can be managed through his two sovereign masters, pain and pleasure. But here Bentham is kept in company by more than one English writer, e. g. by Mr. Spencer. Pleasure is a 'necessary form of moral intuition.' Pleasure somewhere, at some time, to some being or beings, is ' an inexpugnable element' of the 'ultimate moral aim.' Only that the later author is so far more careful, and means only that, had man not been a being subject to pleasurable and painful feelings, morality would have had no meaning. Thus instead of saying like Bentham that pleasure is all, we find 
him treating it as a 'neeessary form' or 'inexpugnable element' of morality: a proposition which no school of moralists is concerned to deny, though there is great diversity of opinion as to the place where it eomes in.

We may perhaps better understand the position of Bentham if we compare him with Hobbes. Hobbes, too, begins with an assumed primitive normal man : but his eye is not so exelusively bent on pleasure as that of Bentham's man. 'The great aim of the Hobbesian crude-man is power, predominancy, self-assertion. He is not content to suffer pleasure or pain: but would fain see the fruit of his soul's three great passions, desire of safety, of gain, and of glory. He is essentially a competitive, quarrelsome, active, and domineering being. Of course Hobbes got his man, as Bentham did, from the society round him: he stereotyped in an absolute and universal form the restless revolutionary man of the English revolution, as Bentham did the placid bourgeois type of the nation of shopkeepers, little anxious for glory, and watching only for comfortable ease. Neither type is fundamental man : and yet as on Bentham's man was built the conception of life which still lingers disconsolate in our Liberalism, so on Hobbes' man was built the theory of sovereignty and authority which has been used at different dates to support the practice of absolute monarehy.

Hobbes saw man in the stage of eriticism, of transition from one system of life to another, in the agonies and struggle of a new birth. The feudal system of personal rule had been gradually centralized: instead of many feudal lordships with separate subordinate jurisdictions there had been substituting itself, by a process which culminated in the Tudor monarchy, a concentration of all jurisdiction and power in one. But that one power had retained, as far as might be, the same characteristics which belonged to its divided and local predecessors. It was essentially a personal monarchy: and the personal monarchy, though with many signs of coming 
disruption which the Queen was shrewd enough to note, culminated in Elizabeth. With her two suceessors the prudent via merlia ceased almost everywhere to commend itself. 'The democracy, which had uplifted its kings to supreme authority over their nobles, became fully conscious of its sovereignty, and proceeded in a wild outburst of zeal to realize its ideas of right and impose them as a sacred duty on the recalcitrant world around. Each not merely did and thought what was right in his own eyes, but was bent on making others do likewise. But the prevailing element was the recrudescence of the religious spirit. During the whole of the Middle Ages the individual sense or spirit of religion had been dead, or had only burst out here and there in isolated and therefore heretical fits of personal devotion. The English nation, like the rest of modern Europe, had been converted to Christianity in the gross-in battalions and counties-according to the influence of the political power. Even when in Henry VIII's time it became Protestant, political initiative had a great deal too much to do with the change. But in the latter part of the sixteenth century the reformation movement assumed a more personal subjective character. For the first time since the early days of Christianity religion becomes a real, living, and governing interest in men. But under the guise of religious, or even of Biblical enthusiasm, which made human ordinances ultimately rest for their sanction on divine models (these divine models being differently perceived by Puritan and Prelatist), there was another principle alive-the principle of private judgement, of individualism, of anarchism. It is disguised, because one party appeals to the written word, the plain witness of honest interpretation, the other to the traditional form, the sanctions of long authority. But both alike, the sacerdotal ritualist and the biblically minded Puritan, were departing from the ria merlia of English tradition, and to each other they seemed respectively to be lapsing into superstition, or to be wandering into religious anarchy. 
It is such an individualistic man, in the stress of contest, casting off allegiance to the old institutions, which yet, even without his will, control his action, that we meet with in the one-eyed and one-sided picture of human nature given by Hobbes. He is far from the primitive or normal man. He is rather a full-grown product of civilization-an old civilization-who, not alone, but simultaneously with multitudes, throws off these integuments, and with full-grown faculties proceeds in a competitive spirit to construct a social habitation de noro. Above all, he is a being in whom self-consciousness, self-assertion is abnormally developed: a being who has realized his independence and is bent on carrying it to the uttermost. Such a man is far removed from the primitive being, whose life is largely under the bondage of environment, tradition, family, and social order. He has an individuality, exaggerated and conscious, which to the more primitive types is unknown.

In some respects the man of the Benthamite age is the very reverse. If in the sixteenth century the effect of renaissance and reformation, of inventions and discoveries, had been to stimulate individuality, to produce a burst of originative and creative genius, the effect of the scientific and philosophical movement from 1680 to 1780 was to generate a common average of convention, culture, and judgement, a well-informed, comfortable, and well-mannered society. The eighteenth century having laid up, as it thought, much eapital for many years, was engaged in an effort to arrange the world, evenly, systematically, and agreeably for its future habitation. It was of opinion, indeed, that kings and priests had too much in their hands, and that they managed the affairs of the world neither wisely nor honestly. But the spread of enlightenment, it thought, would naturally put an end to these pretensions of the secular and the spiritual guides. Only let plenty of light in upon the dark chambers of the law, the civil administration, and the 
churches, and the melancholy spectres which haunted them would flee away, as in Dürer's picture, and leave the world to enjoy itself. What was the mistake that these worthy reformers laboured under? It was what we may call a very inadequate conception of the structure of society. They supposed that society consisted of a number of separate bits : and as some of these were inconveniently placed, and crowded others a little too much, they expected to make themselves easy by casting away the obnoxious and unnecessary appurtenances. This theory was a mistake. As the phrase goes, the social structure is a living organism, not a mechanism : which means that if some of its parts are removed, the others are seriously affected, and the whole organism may possibly perish. They tended to conceive the social organism after the fashion of animals which are acephalous, without thereby ceasing to live: or after the fashion of others, in which, if one member is cut off, the force of the total organism soon succeeds in throwing out a new member to take its place. In this last point, indeed, they were partly right: but it is necessary to add that such powers only appear in the very elementary forms of social union, and that the theory has not much application to the highly developed states of modern Europe, where after the head has once been cut off, it shows a persistent reluctance to bud out again. And there was another fault in their premises. Those theorists, who thought men would be happy if only governments ceased to trouble and priests to confound, had not realized that, invisible or dimly visible to them, there was a large multitude who looked upon themselves, much as they looked upon their stumbling-blocks.

The Benthamite therefore imagined that, if the inconveniences of certain effete institutions were got rid of, man would be left in possession of certain eternal dwellinghouses, where his soul need only consider how for many years it might best eat, drink, and be otherwise merry. He had not realized that the social house in which he fancied himself 
secure for ever, as in a structure of nature, was the work of human minds and hands, that for mankind to live actively and energetically is the business of businesses, without which no pleasure permanently can be secured, and that this business must often be carried on, whether pleasure comes very directly in the work or not. A century of peace-for the colonial conflicts with France and other transient brushes in connexion with German affairs never seriously disturbed the insular tranquillity-had led England to believe that the comfortable abodes, which each man of the dominant middle and upper class had carved for himself in the social system, were founded upon natural rock, and not on something which could only be held up by the same strenuous effort which had been originally necessary to found it.

In short, both Hobbes and Bentham had been strictly bound down in their conclusions by the immediate data of their age. Their desire to be practically and at once effective made them forget to institute a further comparison, and base their conclusions on a wider experience. They have given us philosophies which are in many respects identical, with this important difference, that Hobbes heads a line which leads to collective and despotic socialism, while Bentham gave fresh impetus to a movement which can hardly stop short of anarchic individualism. Hobbes' main idea is security, organization, power : Bentham's is comfort, convenience, pleasure.

As against theories like those of Hobbes and Bentham, the evolutionist and historical view of the ethical problem endeavours ( $I$ ) to get over the confusion of the specimen of one historical period with the normal or natural man, and (2) to lay a deeper foundation for its investigations than they had laid. (I) As specially historical, it brings to our recollection that man and society are in a process of development, which to a large degree takes the shape of continuously growing complication, an increasing multiplicity of elements; and that, as organization grows and extends, there is a strong 
tendency for a large part of it to go out of sight, and leave in public view only certain portions, which portions thus, to careless observers, seem all that needs be noticed. As we compare civilization with civilization, we find certain general regularities or uniformities of succession and connexion in each. Within certain limits, we may say that there is in Greece an age of feudalism and of chivalry; an age which reminds us of the revival of letters; and an age to which we come so near that we should almost call it modern. We see that at analogous stages of development certain doctrines or ways of looking at life and conduct get predominant. Thus we are led to the idea of a law governing not merely the connexion of one stage of development as a whole with its successor, but also determining the various aspects of a state of society which are at a given moment in correlation with each other. We learn to analyze a given social group or organism into the various organisms which exist within it, and that in considerable independence of each other. We are forced to recognize differences of shading, often very deep, between institutions and virtues, which at a superficial examination looked of one homogeneous piece. Further, we find frequently that social structures in course of time tend to amalgamate into one forms which were originally separate: that e.g. when a number of institutions and ideas compete for existence, the victorious result is not without considerable admixture of elements and only gains its survival by conscious or unconscious adaptation or compromise. Thus, as we go back in history, the number of forms of social organism does not perhaps so much diminish, as their complexity gives place to simpler structures. But we shall be disappointed if we suppose that among the primitive forms we can find the special form, historical or prehistoric, which may be regarded as the parent or ancestor of our modern systems of life, and our modern types of character. The biological attempts at reconstructing the genesis of man have 
led to the conclusion that we cannot trace the descent or filiation in any one historic line to definite ancestors. None of the quadrumana exactly fit the requirements for the ancestor of homo sapiens. The fish cannot be treated as the parent-form of the reptile. So, in sociology, the form and institutions of savage life, either as observable to-day, or as inferrible from the records and monuments of the past, cannot be taken as a historic starting-point for explaining our development. There is no such continuity as thus implied. For, if this were accepted, then a social group, especially endowed in nature and circumstances, would have to be conceived as ultimately passing over into another organization which also has started from its peculiar faculty and conditions. We cannot suppose Greek civilization e.g. descended from the character and conditions of a non-Greek type: nor need we imagine how, for example, Japanese nature and conditions will show themselves under the guise of occidental modes and institutions. In such matters the lesson of the historical and evolutionist method is that uniformity and identity of development is a fiction; that each nation has a law and career of its own, similar in what we may call essentials, but unlike also in conspicuous features, to the law and career of other national types; and that any national group, which puts on in a freak of admiring imitation the modes and institutions of another of widely different endowment and resources, is surely and rapidly preparing its own dissolution.

But though our materials are' and must for ever remain inadequate for constructing a genealogical tree of human society, they can serve, if cautiously used, to throw light on the mystery of our own development. We can learn from them what may be termed the laws of the structural growth of society, and of the formation of human faculty and character. Not indeed, as has been already explained, that we can directly transfer the law of one period, the causality of one group and age, to determine the law of another. The 
more we regard the problem of causation, the more we are led to see that the vulgar idea of a knowledge of causes enabling us to predict must be carefully guarded and defined. Popular usage no doubt justifies us in asserting that, once we have aseertained a true sequence of eause and effect, we can transfer our knowledge to any point in the universe we may wish to explain. More reflective habits suggest the practical difficulties in the way of such transference. A cause, instead of being one conspicuous mark or symptom, as it is to the uneultivated, becomes to the scientific or logieal mind, a whole group of constituent conditions; and in like manner the effect, in place of being an obvious incident or change, is analyzed into a complex and fully defined group of modifications in some substance or thing. When this change of view has been made in the estimate of cause and effect, it is an easy step to the perception that two strictly identical cases can hardly or can only rarely occur, and that every inference therefore is more or less a mere analogy, to be earefully verified, like any other hypothesis, when it is made to a new and very different case.

Thus we can learn in some measure the laws of social evolution: i. e. some general features, as illustrated in particular instances of social change and social interdependence. We may get better to understand the growth of society out of its elements, its general aspects of differentiation and integration; in other words, we may discover the way in which it buds forth into a variety of outward organs, and then receiving and internalizing these in the individual consciousness, binds them together into a comparatively homogeneous principle, destined however in its turn to repeat the same process. We may even within limits endeavour to get a general view of the historical process over a considerable period, and so far as we can trace a fundamental identity of structure and ideas we may carry our philosophy of history. But such a philosophy has its obvious limits. There are great natural 
divisions in human history, as there are in natural history. Existing history may draw these lines of division somewhat prematurely, and may fix the boundaries at very ill-chosen epochs. 'The capture of Rome and of Constantinople, the Reformation and the Revolution, may not mark real dividing lines, any more than Salamis and the Catalaunian fields. But as our present knowledge goes-and probably for a long time to come-we must submit to accept the existence of ethnic and historic groups, which stand out in tolerably clear separation from each other, and of which it is at present impossible to detect any connecting or transition points of importance. It may not be exactly true for us still to say that European history began with the siege of I'roy, and goes down from that date in one continuous stream: for (I) research carries us by gradual steps beyond the Trojan hosts to kindred predecessors, and (2) new streams of influence have since then profoundly modified the current of development. But still it remains true that for practical purposes there are streams of history and social life so virtually independent of our European career, that no philosophy of history can at present or for a long time hope to show that one continuous movement has been going on, with fresh tributaries, each bringing its quota, to supply the material of the main stream.

But (2) the study of history as a process of evolution for human faculty, guided, we may almost say, by the presuppositions' that 'all the natural capacities of a creature are destined some time or other to develop themselves completely and appropriately,' and 'that in man all those eapacities which are directed to the use of his reason only develop themselves completely in the species, not in the individual' - gives a new view of the present intellectual and moral structure of man. The infinite complexity and diversity of human faculty presents itself from the point of view of

\footnotetext{
1 Cf. Kant, Ideen zu einer allgemeinen Geschichte.
} 
this theory as acquired and transmitted not by natural generation, but by spiritual parentage, by the means of that social and intellectual and moral capital which is stored up by successive generations, but which, if it is not to become a purely dead thing, has to be revivified, or kept vivified by the vital energy of actual men. Such capital is simply the utterance or forth-putting of human energy and formative skill in material things-appropriating and stamping them with man's mark: it is the extension of human personality, its realization in an outward or natural world, consisting of human bodies, animals, and other material objects. In such action man expands, differentiates, and realizes himself into a material organism, in literary, religious, artistic, economic and other forms. But man also concentrates, reflects, or redintegrates these material and separate elements he has 'acquired,' or in which he has lost himself and put part of his own life and force. The economic stock e.g. he redintegrates, partly by consuming or enjoying it (frui), partly by using (uti), i.e. energizing it. But always the passive expression, the lifeless acquisition, must be enlivened by the breath of life from the vital agent. The very spoken word, which otherwise disappears, has to be taken up, reproduced internally, and understood by the hearer. The written

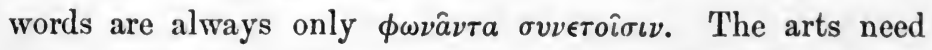
the same spirit which nurtured them originally to keep them away. And the outward ordinances, rites, creeds, holy places, sacred personages of religion need to be assimilated, and made an inner life and feeling by the worshipper, if they are to be more than stocks and stones and vain repetitions.

Thus we come to throw a new light on the problems of psychology. Since the time of Locke it has become a settled maxim that the true method of philosophical study is the psychological. For the study of logic, aestheties, ethies, and whatever else may be held philosophy, it was said that the only safe and sure method was to examine our own 
ideas, and see what was their original or primary stock: and that thus only we might learn what could be built upon them, how far they could be made to go, and what certainty we could have about their objective application. But by psychology we must be careful first of all to explain that we mean something more than the ultimate analysis of the mental structure. $U p$ to a certain part or point, the study of psychology for man is similar or analogous to what it is for the animals. Man, like them, is a being endowed with senses, with faculties of memory, imagination, and something of the nature of intelligence : he has various appetites or attractions towards objects, is sensitive to pleasure and pain, subject to impulse and passion. These faculties are directly connected with his special endowment of a nervous system, with its central organs in the brain. We are not entitled to say that even in these points he is identically constituted with them : he has what Aristotle

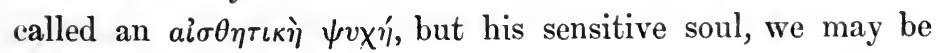
sure, is characteristically his own, though its structure evinces a certain parallelism to that of the nearest animals, just as is the case with his general physical structure. It is further obvious that in this department of psychology, the psychology of the sensible nature in the widest sense, great help is to be had from physiology or that branch of it which is called psychophysics. Indeed it would hardly be going too far to say with Comte-as Aristotle himself had hinted in anticipation of the spirit of the Baconian philosophy-that unless we can reach the physical or physiological realities, i.e. the molecular movements which underlie and constitute the socalled elementary faculties, we shall get very little better than a verbal treatment, $\delta\llcorner a \lambda \epsilon \kappa \tau \iota \kappa \hat{s} s \kappa a i \kappa \epsilon \nu \omega \hat{s}$. In this branch then of psychology we are mainly referred to general biological problems, which here, as elsewhere, are ultimately soluble only by those molecular theories which apply to muscular and nervous movements. 
The psychology which Locke's Essay inaugurated is on a different level. It is more characteristically human. Not, of course, that we need maintain that any brand-new faculties emerge into view when we come to deal with human nature. The difference of grade is not definable in any such simple way as the intervention or aldition of new faculties. It is much more subtle and complex. We may be able plausibly e.g. to show how one after another of the higher human endowments has its close parallel in some animal nature: and yet the total impression and effect may be altogether different. And in this characteristically human field - the field, as

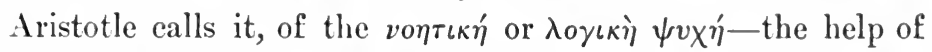
physiology fails us. We are now concerned with phenomena which cannot plausibly be connected with any peculiarities of nervous structure, any characters proper to the physical organism. And yet here as there introspection, which was the method mainly employed by Locke, leads to no valuable results-issues in little better than verbal distinctions and what Bacon calls alstracta. In the literal sense introspection is vain. And this does not simply mean that we cannot observe ourselves, because (I) we cannot both be the agent and patient; and (2) we alter the fact in resolving to observe it. For perhaps it might be said that we can note it the very instant after, and that instantaneous memory is as good as observation. There is of course a large amount of truth in the remark that we cannot easily observe ourselves : but it is a truth which is equally illustrated by the difficulty of taking our own pulse, or observing the phenomena of one's own physical system, and arises from what may be styled the explosive force of ideas, i.e. the involuntary transmission of vivid sensitive ideas into the motor system. The objection goes deeper. The ' $\mathrm{I}$ ' who observes a psychical fact is the same ' $I$ ' that observes a physical fact. As observer it is distinct from what is observed in one case as well as in the other. It only observes well in so far as it is at once disinterested and 
interested: disinterested, because the object is not connected by any material interest; interested, because the object has beeome the centre of interest. That is, the object of observation is the resting-point round which observation circles: the object is not carried round at the pleasure of the observer. Hence the object, even if it originates in the current of our own mental life and interest, must be observed in virtue of an act of detachment or abstraction, which sets it apart from us in the ideal field of observation. But as Aristotle long ago

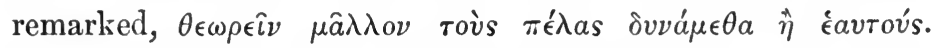
In other words, such self-survey, if it is to come to any good, must be a social survey, i.e. a sympathetic apprehension through our own feelings of other's acts, and of their feelings through our acts. It is in the mutual play of thought and fancy that light reveals the recesses of the

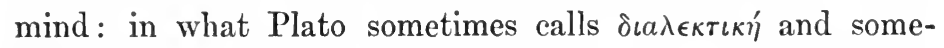
times " $\mathrm{E} \omega \omega$, meaning by the former the more reflective unravelling of the common web of humanity, by the latter the more spontaneous and intimate sympathy which must underlie the intellectual discussion, if it is really to penetrate the barriers of self-coneeit which keep man apart from man, and is to make the two dialectician fellow-devotees of the truth, counting nothing too dear or interesting if so be they may get at the inner vision of reality.

If then by psychology we mean an attempt such as Locke made to get at the source and history of our ideas, we shall not learn much by groping in what we choose to eall ourselves, and still less by consulting the physiologist as to the nature of our museular, assimilative, vascular, or nervous system. These things have their place, but we have passed beyond it when we come to consider the characteristically human aspects, the ideas into which the bare natural endowment has blossomed forth. Physiology e.g. will have a good deal to say on the elements of language, on sounds, letters, syllables: but physiology has no say in the problem of words 
as such, of language. 'The problem of language only begins to trouble when other questions than those of the physical basis of speech emerge for consideration.

And now, as we have said that psychology in its first grade will get her real illumination from physiology or psychophysics, we might say that in this higher grade psychology must seek the help of sociology. But in saying so, we could not fail to note the immense difference of our position in the two cases. Nerve-physiology has not gone very far: but it has a certain amount of consistency, and a certain idea of its method of research. Sociology, on the other hand, is rather a word which denotes a great group of problems waiting for solution than any compact and systematic body of doctrine. Works with the title of Sociology are not unheard of, but they are essays to find the handle of a science, than real exhibitions of its systematic content. What then are the problems which sociology is an attempt to grapple with? Briefly they spring from the growing perception in the present century that all characteristically human phenomenasuch as religion, art, science, property, language-are social and not individual functions, i.e. that they issue through and are the permanent form of the action of individuals, but of individuals co-operating with each other, forming necessary and natural groups, spontaneously as well as reflectively realizing their personality in that of others.

But the peculiar function of sociology in this matter of our ideas may be best illustrated from Plato, who was the first, and for long the only one, distinctly to understand its principle. It is impossible to get a clear idea of what the characteristic forces of human nature are by looking within the breast, by introspection: a mere faculty for that matter can hardly be said to be an object of observation at all. Even if we turn to observe the actions of the individual, we are not much further advanced. By what means shall we discover the lines of demarcation between his actions, and how be led to refer 
these actions to principles or parts supposed to animate him? Evidently our search is completely at sea. We see what human nature is by considering it in its actions (which, as we saw, are only the objectivation of inner motive and character), and considering not the actions of this or that individual, but the actions collectively of the mass of individuals. Such action, recurrent and universal, was, we saw, the real essence of an institution. And in the different social institutions, i. e. the habitual and organized modes of action, we have the revelation of the inner faculty or nature of man, or the realization in visible or perceptible shapes of that imperceptible organization which is the germ of all development, the protoplasm which is differentiated and integrated into organs and system. Thus, according to Plato, we see what reason is by looking at the facts of guidance, government, initiative, legislative, executive, and judicial, in the common or political life. In the governmental organ the common function of intelligence, present in some degree in every human being, has concentrated itself: just as the clothesforming faculty realizes itself first distinctly and obviously in the rise of a tailor class. The institutional form, the social class, is only the outward realization of one aspect, one comparatively independent member of the human organism, when it is, so to speak, written large, magnified, and made uniform, stereotyped. By such objectivation in an organism or institution of its own, the aspect of human nature first realizes its internal unity as also a substantial force. The inward faculty, be it of discernment or of passion, instead of being backed up now and then by some other force, incidentally operative with it, receives back into itself the consciousness of its essential unity with the same faculty in a thousand others.

'In examining the way by which opinion is formed,' says Mr. Bryce ', 'we cannot fail to note how small a part of the

2 Bryce, iii. p. 6. 
view which the average man entertains when he goes to vote is really of his own making. His original impression was faint and perhaps shapeless: its present definiteness and strength are mainly due to what he has heard and read. He has been told what to think, and why to think it. Arguments have been supplied to him from without, and controversy has imbedded them in his mind. Although he supposes his view to be his own, he holds it rather because his acquaintances, his newspapers, his party leader's hold it and his aequaintanees do the like. Each man believes and repeats certain phrases, because he thinks that everybody else on his own side believes them, and of what each believes only a small part is his own original impression, the far larger part being the result of the commingling and mutual action and reaction of the impressions of a multitude of individuals, in which the element of pure personal emotion, based on individual conviction, is but small.'

In this fashion what was originally a mere passing stage in the entire conduct of a human being gradually gains a quasiindependent position. Each nation acquires a psychology of its own: and that psychology locates or sets inwardly in each individual mind a division and hierarchy of faculties, which being at first in each only a mere sketch or potentiality, has come by sympathetic action and reaction to appear in a visible organization, and finally, when consciously reproduced in the individual, to take rank as a substantive agent in his system of mind. The individual has his possibility or germ, an invisible organization, but not yet differentiated into distinct faculty: as he works with others, plays with them, fights along with them, the points in each which are similar to those in others get, as it were, attracted together, associated, and through this associated body or organ which they produce, they are reflected into consciousness, become internalized, and constitute that second or reflective nature and constitution which is found in every social being after he has been 
subjected to social influences. Society cannot, it seems probable, put into the individual anything which was absolutely without germ or foundation in him before: cannot give him in the literal sense a new faculty. But in an intelligible sense of the words, society does and can give new faculties: that is, society ean strengthen what was weak, can lend force from the super-endowed to the sparsely-endowed, can and does create a common capital or stock of language, literature, science, art, method, whereby, as Bacon said, the disparity between natural talents is largely diminished. This is in fact what society means: and a one-sided insistence on this duty or function of society is what is generally understood by Socialism. But society, be it remembered, is only a short name to express the sum of the co-operation and mutual modification of influences issuing from individuals, who amid all diversities in detail are similarly constituted in the main.

The psychology of an individual then is the resultant stage of a process, wherein the native or natural basis of faculty, issuing out and entering into combination with like tendencies or germs in others, is reflected back into the individual consciousness with the distinct and definite quasi-independence which it has received in the associated life of the community. At each period of history, therefore, in each organization, or institution, new faculties are created in individuals. That is, possibilities in them, called forth in new measure, or in new combination, by each variety of circumstances, acquire through reflection and sympathy certain typical and comparatively permanent forms of association, which become so many new species. If it be asked what are the initial or native possibilities out of which all this variety is generated, the only answer is that as yet we cannot completely tell. Human life is self-realization, and its law self-realization through society. Till the end of that process is reached, it would be rash to offer a complete list of the initial faculties, the 
rudimentary basis. Indeed, it would not only be rash, it would be impracticable. We only see these faculties when they have ceased to be natural, spontaneous and rudimentary: when they have become reflective, formed, and magnified into specific organs. 'To use the latter aspect to deseribe the former would only lead to misconeeptions.

On this point the ancient philosophers were probably more cautious than some of the modern. They recognize that the human faculties, moral and intellectual, are so many $\ddot{\epsilon} \xi \epsilon \iota s$, or habits, acquired and formed powers, stereotyped abilities,

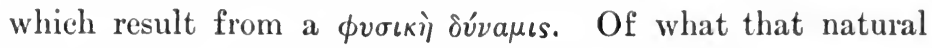
potentiality or germ is in special cases, they do not give any systematic explanation. Of one point they are sure, that the absolute presupposition of all moral and intellectual faculty, the $\dot{a}_{\rho \chi \chi} \hat{\eta}^{\prime}$, is reason or vov̂s: that originative and systematizing faculty which, when it has become differentiated and organized by objective utterance into a reflective shape, is

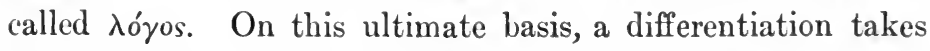
place by the division of two groups of organs-what in modern language we call the sensory and motor nerves, what in Greek psychology are known as al $\sigma \theta \eta \sigma \iota s$ and o $\rho \epsilon \xi$ เs. As to a $\sigma \theta \eta \eta \iota s$, they follow the popular distinction into five organs : as to o $\rho \epsilon \xi \iota s$, they are less clear, till at any rate the Stoies lay down the fundamental ó $\rho \mu \eta^{\prime}$ as the impulse rò ćavrò

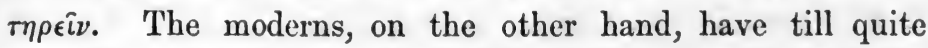
recently contented themselves with classification. But classification is, in its commoner form, only the preliminary of science, and a preliminary which advancing science has to correct and sometimes to discard. The real science of psychology has the further business of explaining the diversity of faculties by showing how it has arisen. In that task it will probably derive some help, as we have seen, from those experimental researches which touch upon nerve physiology. But in distinctively human psychology it will gain much more light from the study of phenomena which are sociological, which 
consist, that is, in the action of human beings on each other in a social body.

In attempting to trace the process of mental evolution, then, care is required to prevent exclusive notice being given to one side or factor in the process. We must get a clear view of social process, social action, social organism. Man forms himself, i. e. his mind, his speech, his manners, his law, his wealth, by his own action; but that action is a social action. Nor again is society an agent supervening upon man, giving him by its organs what he had not before. Society and its organs and institutions are simply human beings in action, uttering their possibilities, but uttering them under the law of intelligence, sentience, or sympathy, which prevents the individual from being a mere individual, and forces him to act, at first with the bare sense or feeling, then with the clearer feeling, then with the more conscious intelligence of intuition, and lastly with the comprehension of the general principle, as consciously objectified rule or law

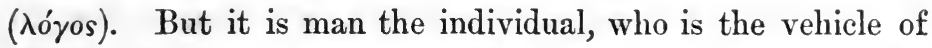
all that social sympathy and solidarity : and while the influence of the circumjacent multitude is continually reducing this to a common rule, a hard and fast law, there is a tendency in the individual to step further, to start on a fresh course.

This view of the relation of man's ideal nature to his real social environment-that environment being itself created under the influence of physical conditions by those who live under it-leads us to say a word on differentiation and integration as factors or rather as stages of development. Differentiation and integration correspond respectively to what in the Hegelian system are called the stages of reality and ideality. Just as a seed may be said to integrate into a simple sum or expression what in the real plant has been differentiated into a multitude of organs and structures, so we may call the seed the vehicle, which contains idealiter 
all that the plant was realiter. But this description applies in a higher sense to social and human evolution. There, as we found, the germ of social life, which is present in all the members of a group just because of their common humanity, appears in the realization as an external structure, falling into parts and organs, liable to assume a certain independence of each other. In the consciousness of the members, at least of some of them, that organization is reflected, but reflected not in parts, but in its totality, or whole function: and thus is invested with a unity it did not to the outward sense so obviously possess. On all its members indeed the institution exereises a silent influence, moulding their thought and temper in definite ways, ereating as it were new faculties, giving powers of apprehension and resolution not originally found by the individual in himself. It is so with language, religion, morality, economie fact. They deposit in the individual mind habitual or eustomary modes of coneeption, forms of feeling, laws of thought, conditions of action, which, though not consciously perceived in their general or ideal form, still mould and constitute the whole scheme of life and conduet.

But in almost every society a further circumstance and source of action has to be taken into account. The even level of the society and the uniform and unanimous course of development is interfered with by two influences. First, by contact with foreign societies. Plato and Aristotle sometimes talk of isolating their ideal community from all external influenees. And this might possibly be a commendable plan, if we could accept the practicability of their hypothesis that an ideal state, perfectly planned and equipped, could be set on foot at once with all that is essential to it. But the evidence of history teaches too clearly that, although there are periods to which the epithet of degeneration and declension can be applied in a relative way, they do not subvert the general law of human history that acquired or permanent faculties are 
evolved out of the yet slumbering potentialities of nature to meet the requirements of a perpetually ehanging environment. Thus the ideal becomes a problem, not a fact: the summary, in a provisional way, of the future convergence and completion of tendencies, of needs and of powers, which are yet in their infancy: a preliminary anticipation of the path and the landscape to some distance beyond the range which is actually visible or has been actually surveyed.

It is then in the contact between group and group that we find the first cause which breaks up the general level and monotony of life, and initiates what we eall progress. The dweller on the borderland, less immersed in his social system as a natural ordinance, sees it more and more as a whole, and in contrast with surrounding ideas. One need only point to the rapid movement of ideas which characterizes colonial life, or to the anti-conservative tendencies of commerce. But also in the group itself there emerge differences. With all the sameness of humanity, whieh leads to identical institutions and manners, as it leads to a common language, there is also a radical individuality in each member of a group, which gives rise in each to a different combination of what we may call the fundamental impulses and powers of human nature. Thus each ultimately may be said to understand and appreciate the social institutions in a way of his own. Thirty millions e.g. are described as speaking the same language. But unless that group form literally as well as figuratively a single family, living together in identical circumstances-a condition which the numbers render impossible and which could only be carried out with a small tribal union-there will be all shades or degrees of difference embraced under that surface agreement. Possibly each individual, and in a clearer degree each family has an individualized language of its own. Every profession has its own technical phraseology. Things hardly change with us so rapidly as they are alleged to do in certain hunting tribes, where a new generation grows up with a language of 
its own. But unquestionably in any larger group, where pronounced habits of life and thought mark off some important section, dialects are formed which insensibly come to effect the main tongue. Where a large portion of society engages habitually in pursuits and is conversant with institutions which belong to the vicious and semi-vicious range, such as the criminal classes, the demi-monde, and the betting and sporting world, we find a large development of slang or argot, and its incursion into literature.

So it is in every social organ and institution. The normal or average level is a conventional estimate which, as Hume remarks, we use for the purposes of social intereourse. When I speak to you, I assume that we use the same language and speak vocables which bear only one sense, else mutual understanding would be impossible. But experience obliges us to admit that our hypothesis is never perfectly realized, and that in many cases the fact very widely departs from the hypothesis. Psychically, no less than physically, each man hears a different language: because to hear it he must reproduce it by his own psychical organs, which are developed in each individual under influences more or less different. Nor is a perfect understanding to be secured by the discovery of what is termed a philosophical language. It is possible no doubt to mend matters. But the root of the evil lies in other causes than the mere words we use. And a nearer approach to a remedy lies for each in the effort to realize and recognize his limitations as well as those of others, and to accustom himself as early and persistently as possible to shun the habit of resting content with words as ultimates.

But it is in the existence of these differences and these nutual disabilities that the hope of progress for finite beings lies. If all merely and entirely agreed in everything, this would not go far to prove that their consensus was right and truth, unless we start with the assumption that their voice was 
the voice of God. The agreement which proves truth and right is not such a mere abstract agreement and nothing more : it is an agreement which admits of differences and even antitheses, but in which these differences tend to find, if they do not actually find, reconciliation. The rox populi, which is the $v o x D e i$, is not the cry of the mob where ten thousand shout as one. It is the voice which, out of difference and disputes, tends more and more to display itself as the one in the many, the ultimate identity which issues out of difference, and which has embraced all that was worth keeping out of these antithetic sides.

Thus progress is achieved through the formation of new and divergent institutions. In the larger group a smaller is inserted and this grows as did the other. A new factor germinates in an individual mind, i. e. through some variation which arises fortuitously or spontaneously (so far as our knowledge goes) in the general endowment of some group of the human species. But such an original, though unique, is not altogether alone. The same ideas which have forced themselves upon him will force themselves by degrees on a smaller or larger number who in the particular point feel and see like him. Feeling and acting with considerable uniformity, they mark themselves out as an association, and create for themselves an institution. But the process does not stop here. If, as it may happen, the ideas and aspirations are local, personal, and of temporary interest, the institution will gradually disappear. But in proportion as they are universal, essential, and permanent, they pass into even wider and wider circles, until finally they become an institution of the whole group, and mould the character of every member in certain forms of thought, feeling, and action. 


\section{VII}

THE ETHICS OF SOCIALISM

Soctalism is one of the 'Isms.' It indicates a tendency and a propaganda in some direction, rather than an accomplished fact or a definite doctrine. Our humanity has been compared to the 'weary Titan.' As he tosses on his uncasy bed or struggles along his toilsome way, one ache or pressure or stumbling-block seems abnormally hard to bear. And as this particular Titan has many heads and many hands, there may be simultaneously more than one misery to shrink from, more than one trial to encounter. But in each age there are some wants that are felt in many breasts at once, and a common cry rises more or less clearly from a multitude of throats. 'The age feels its wants, but it does not always clearly understand what they are, and still less has it clear or distinct ideas of how they are to be relieved.

Socialism is the evidence of such a felt defect-the symptom of an unquestioned evil. But it is far on that account from being a definite conception either of the evil, and of its causes, or of the mode by which these evils may be eradicated. More than that: two further considerations serve to complicate the question. First, it is no easy problem to probe the mysterious paths of social operation, and only too easy or probable that the inquirer, unless endowed with grave judgement and practised skill, may rashly lay hands on agencies that are not to blame. Second, in the concatenation of human life, it is barely ever possible to keep the many strands asunder, which as left to themselves cross and recross 
each other's path and actually unite for considerable lengths into a single thread. We label these strands by various names : religious, political, artistic, economic, legal, industrial, scientific, and whatever others there may be. But, as it has been said, the subtilty of nature is too much for the subtilty of our dialectical distinctions. The real world does not conform to our academic precision.

So it is always with 'Isms.' They are a battle-cry, a watchword, a catchword: but they are not the names of any definite idea. Their force even depends on a certain necessary vagueness, and their ill-defined forms stand out provocative of curiosity and interest as they loom through the mist. They are none the less real or vital on that account. But they are the more dangerous to meddle with, alike for their admiring followers and for their critics and foes. They are never phantoms and fancies, however blurred their outlines may be in the darkness. And they are seldom as fair or as foul as they are dreamed to be. Each of them in its turn gathers under its name hopes and aspirations, hates and horrors, from the other quarters of the souls of those who adopt this battle-cry. The best ideals and the foulest desires may and do come to shelter themselves under the cover of the dominant idol of man's devotion.

It has not been long since the word Socialism with its companion Communism was first heard, just about half a century. In a way the thing, i. e. the feeling or craving which the word implies, is much older. And whence comes that feeling or craving? From the beginnings of recorded time man has been a social being, has lived in and formed what has been called society. He has been linked to his fellow-humanity by sympathy, by language, by reasoning, by common endowments, by natural dependences and artificial ties, by war and by peace, by arts and industries, by religion and by science. This social solidarity remains, as it was, a natural fact, which cannot be altered, though it may be in 
part ignored. But on a grand scale the history of our race, and in miniature the history of each individual, shows another process going on. The child who began as almost a part of the parental group, and in childlike unity with his brothers and sisters, gradually passes out into independent life, and in many cases becomes a stranger to those who were once near and dear to him. In the greater world the cares of daily life and the self-preserving effort which has been painted as a 'struggrle for existence,' make each individual more or less beeme a self-centred and self-seeking unit, who in his habitual mood is apt to forget his common humanity. Each finds his own narrow groove, and inhabits his own peculiar den, whence he eomes forth only as duties and pleasures require his temporary exit. Or, if we modify this too strict picture to commoner fact, the individual is by the effect of circumstance, of momentary passions, of partial interests, bound up with a few others in some local, petty, particular league, serving only immediate, limited, accidental ends. It is still self-seeking which governs him: but it is the selfseeking of a clique, a party, a section.

Against such a fractional existenee, such a surrender of the human birthright whieh in early life seemed so indefeasibly ours, there keeps rising up, from time to time, a protest in every heart that has not altogether lost its humanity. We may sink the man under the office, the title, the shop, the costume, the civic and social badge, but though he is silent and even the eyes bear no sign, it would be rash to infer that nothing has been left but a form of elothes and of eeremonial. And even if there be those whose soul is dead within them, it remains true that there are others in all ages of history and of human life who revolt against the worship of temporary idols and local divinities, and bid man again remember that Allah alone, the living, the self-subsisting, is one God, that he has made of one blood all upon the earth, and that 'a man's a man for a' that.' The sense of human brotherhood revives 
in them: they feel the cords of sympathy drawing hard through all the entanglements of selfishness.

But here a divergenee makes its appearanee between these aspiring souls who seek to rise above divisions and partisan littleness. Some of them, content in a kind of hopelessness or careless because the object of confliet seems so unimportant, would leave the real divisions alone and seek refuge in the life of the spirit, the inward peace, the ideal calm. They see or seem to see through the eontentions, the separations, the hollow relationships of the visible life into the everlasting repose, the beatitude of that indwelling of the spirit with itself, which is at the same time its intimacy with the world of all human souls and with God. And when we say spirit, we mean no more or less than that human, central unity of being which is the deep souree of all noble, simple, honest life, and of all the warmth of real human love and heart. Such is the Mysticism, such the Quietism, in which men of purer natures and more limpid founts of life have dwelt in the company of others like themselves, and, seeing events sub specie aeternitatis, have recreated, were it only in a gorgeous vision of faith, that heaven which is the true home of the soul.

But such men were ever a select few, and the ages grow less and less favourable to their ecstasy. The eye of faith no longer penetrates the distance so boldly to find its home in God. Man has beeome more and more convinced that the divine must dwell among us, that it must be realized on earth as in heaven, and realized not in the heart merely, but in tangible and visible forms. Or, to put it more definitely, the enthusiast, whose glance passes through the dividing shams to the underlying unity, is not content to build that long-lost heritage of humanity in the spirit only; he will not tamely submit to the actual fragmentariness of life, content, if so be he can still enjoy the comforting sense of its ideal wholeness. He protests against the breaking-up 
into fractions of human unity and demands its restitution. He criticizes the casual, unsystematic, inharmonious character of the minor groupings which actually prevail ; he shows how they are not duly dovetailed into cach other, and that they do not, tend to converge and form any collective universe of life : he condemns the inequalities which by slow aceumulations have shut many men out of the common sunlight of humanity, and forced them either to cower despairingly under falling hovels, or to entrench themselves defiantly in palatial prisons. Ile demands that the social basis of human life and action shall be realized, not as a mere general supervision and police of oceasional interference, not as a system of laws which, when definite acts against the common weal have been traced to their author, shall restore the balance and the status quo ante, but realized as a reasonable organization, which watches so carefully, so closely, so wisely, that every part of the social machine shall never fail to keep in mind its social duty, that no part shall be other than an individualized organ or missionary of the whole, that no stagnation, no block, no purely special or local movement shall arise to mar the uniformity of action. Natural laws, he will admit, tend after all to compensate all divergences, to bring all selfishness to become in the end the servant of the common good: a law other than the conscious motive of their actions and business constrains individuals and parties to further the general organism. But the process, he complains, is slow and costly: and meanwhile many a sigh, many a death, many a torture has to be endured, which a reasonable method of organization might have prevented. The world must band itself together to enforce on each by the instrumentality of all that he is nothing, and has nothing, except his moment's life and work : that all else, which through the gift of nature, through the process of history, is gathered and kept around him, is a common stock, which, as the poct says,

'Nulli mancipio datur, omnibus usu.'

v d 2 
Such ideas, like all ideas, are not first heard from those who are deepest in the social slough, who are in the greatest measure disinherited of the common groods of social life. It is from observers, not utterly merged in the social whirl, nor yet quite untouched by its revolutions, that come the first words demanding a renovation of the order of human life. Such voices, indeed, had been heard, ' rari nautes in gurgite vasto,' here and there from age to age. But it is only in the present century that the catena of the witnesses of socialism becomes continuous. First comes IIenri, Comte de Saint Simon, a survival of the old chivalry, but in a new medium of finance, a knight errant of the industrial age. His life-and it is that which fits him to interpret his generation-runs on from the time of Louis XV through the Revolution to the Empire and the Restoration of the Bourbons. The Revolution had hurled the old system from its foundations and broken it to fragments: but it had founded nothing, and left nothing permanent, except a code. But a code is but scanty furnishing for an empty house ${ }^{1}$. And Saint Simon, already past his prime in the days of the Empire, a broken-down but indomitable hearted man, gave utterance to a dream, which drew around his declining years some of the finest youth of intellectual promise in France. And that dream? That the industrial chiefs, the great bankers, financiers, capitalists, who really ruled the world from their quiet bank-parlours, should assume the real duties of their function, should become true captains of industry, leaders of men's movements, because concerned with that aspect of life, the economical, which is the basis of all else. And beside and behind these magnates, whose practical skill and mastery in the art of manipulating men pointed them out

1 The important question, according to St. Simon, is not about remodelling the powers and forms of government, but the law which constitue les proprietés et qui en règle l'exercise. The natural means of reaching liberty is reconstituer la propriété. St. Simon emphasizes bonheur instead of justice et raison. 
as fit to take the place of an effete feudalism, stood the men of science and art, the disciples of Newton and Raphael, throwing rays of sweetness and light into the harder and darker moncy-souls, intermediaries as it were between the practical agent and the celestial source of wisdom and kindness. The disciples who drank up these suggestions, and who remembered their master's dying words, that 'Nothing great is ever done without passion,' rushed with the headstrong and fantastic eagerness of eonverted youth to carry out their mission. Youthful extravagance, and the friction between warring ambitions, soon burnt out their flame, and many of the inspired apostles of the Saint Simonian Chureh cooled down into sober citizens and practical utilitarians. But, even though the propaganda failed in immediate reformation, it left everlasting seeds, and began a permanent ferment. It created the dream of an organization of social life on a single, and that a real basis, not a fiction legitimated only by its antiquity. It maintained for natural capacity the rights of free development, and of just retribution for serviee done. And besides justice, it preached fraternity as its new Christianity - a Christianity of this world, which holds true religion to consist in all work aiming at ameliorating the eondition of human kind.

These were the ideal aims of this Aristocratic Socialism, which creates a new feudalism, an industrial feudalism of light and leading, binding the eapitalist to be the benefactor and the guide of his workman. It was a dream, but a dream of that glorious age of French Romance when Balzac, Victor Hugro, and George Sand saw like high visions of the possibilities for human nature, if only it lived freely and openly by its self-appointed ideals.

The next step in the march of Socialism is on a humbler level. A little younger than Saint Simon, but of far other origin : a petty shopkeeper's son, himself a shopman and commercial traveller, Charles Fourier was especially impressed 
by the unnecessary frictions, the senseless competition, the conmercial struggle for life, which went on around him, and which were due, he thought, entirely to the present absurd arrangements which broke men and women up into separate families, and forced each person throughout life, not merely to retain the partners of their original choice, but to follow one trade and one only from year to year-thus sinking deeper into an isolation from all other human beings, finding life more and more monotonous in his narrow routine, and fretting his soul in a base endeavour to overreach his neighbours. 'The ideal of Fourier is Harmony, in which competition is transformed into emulation, friction into co-operation, and work becomes veritably play. This magic change follows attention to the fundamental laws of human nature-the law of passional attraction. The ordinary life proceeds on the assumption that man is a monotone-a being of a single and consistent wish. In truth, says Fourier, he is a twelvestringed instrument in his normal fullness, and admits of all possible variations in the strength of the various impulses, the combinations or groupings of these impulses, and the dominant moods which regulate their play. Hence to let these aspects of a many-sided human nature have free course and realization, a new social order must appear, in which vice will disappear because only due to natural bent which man's misplacement has turned into a curse. To that end the monogamous family must go, and in its place must arise a social unity of larger numbers, some 2,000 souls, old and young, who shall form a phalanx of the new social army. In each such group where likings, varying from hour to hour, determine each man's work and his companions, and where ingenious arrangements take its sting from the primitive curse of labour, a combined organization, freely built up by natural impulse, aims at the production of some species of product: and as the whole world will one day be covered with similar phalanxes, each engaged with zest and skill on 
a special product, the adjustment of one canton's product to another will flow from spontaneous harmony of passions, and hardly need any interference from the titular omniarch, who sits ruling the nations from Constantinople. When the loss due to war, friction, and irregular production is thus removed, the wealth of the world will fabulously mount. But let us do Fourier the justice to say that, if he had these gallant visions of future weal and wealth, he was consistent enough, at least in his earliest work, to dream that, as a glorious aurora rose triumphant in the northem sky, the harmonious world would find nature's fauna equally ready in the service of peace and increase.

A fantastic dreamer, doubtless. But the fantastic element may in part be easily discounted, and was so by his early followers. What remains? A first systematic attempt to show the mechanism of the appetites and propensions of human nature, and to claim for man's senses their right to a beautiful, fit, and harmonious environment, instead of the present hideousness which stares upon us from a dress, manners, and habitation which have no living relation to the beings they enclose. A protest against the selfishness of life, and a plan, eapable no doubt of much amendment, for making freedom of social intercourse and expression of public spirit a possibility. And thirdly, a plan for giving to talent, to capital, and to labour, a proportionate share in the social product: a plan which puts labour decidedly first, capital seeond, and leaves talent largely to that self-approbation which must always be its main reward.

Out of these two prophets of socialism comes all that is pictorial in its literature, distinct in its conception of the future society, attractive to the needs of the human heart, and inspiring to the souls who here and there aspired to an ampler life, a less selfish companionship. But as yet the mission had only touched these higher souls, in France, in England, in America, and in Germany, who felt dissatisfied 
with the chaos and coldness of life, and with the wayward ignorance and hopelessness of the masses. The next step required therefore was to popularize the ideas, to give them a more artistic grouping, and to bring them into closer contact with the ordinary needs and conceptions of common men. That was done by the social Romance of Cabet. Here a communistic state was portrayed in its supposed actual working in some as yet undiscovered land beyond the Atlantic. It is a nation entirely composed of working men and women, but where the working-day never extends beyond seven hours, where each worke: feels that he or she is a public functionary, no less than if he or she is invested, as may any day happen, with the official titles and duties of authority. It is a land in which all that comfort and care, all that co-operation can accomplish, has been attained. Woman, the ouvrière-and there are no ladies who are not outrieres-is acknowledged in every family to be the social queen: and family life runs on sweet and pleasant throughout, as it does in our present world only in its halcyon days. Strict but gracious decorum prevails in every province of life, maintained by an imperious order, which, like a predestined fate, fears no obstruction and is strong with the strength of the universal will. A wise directory sees that everything is done as reason and justice demand, and as secures the common good. Every step in life from beginning to end is taken under the direction and by the measures of the public authority. The child is, if possible, ushered into the world in a hospital: and early education, uniform for all, and the same for both sexes at first, is traced out by comprehensive orders of council. The choice of professions is conducted under official supervision, and, if need be, determined by examination. Every branch of industry is fixed as regards its extent and conduct by regulation from above, and the whole social capital is the property of the community, which must directly command its administration. The dress, the food, the hours of meals, are 
all the subject of regulation lists, which are the fruit of the best consideration which seience and experience can grive to these problems. Courtship is by no means conducted in a corner, and celibacy is the subject of severe reproach. Art and letters are under a moral and political censorship, which forbids e.g. the exhibition of the nude, and allows only an official press, suppressing the firebrands of journalism. Government is conducted in the fullest light of public criticism, and no exeuse of need of diplomatic secrecy or reasons of state tolerated for an instant. And as for religion, why, though heaven and hell are convenient beliefs for the wretched who look onward to compensation for themselves and their oppressors, they are meaningless in this Icarian community, where religion is replaced by an ethical system, 'sans cérémonie ni pratique qui sente la superstition.' At last comes the end of life, and the deceased Icarian, after finally serving his country by being submitted to dissection and having the report, nameless, entered in the public register, is dissolved by cremation into his elements.

Such was the work which its author, a Frenchman, who had lived some years in England, and read Sir Thomas More, put forward to give the imagination of the masses. And, ever since, the pictures of that romance-in spite, be it added, of the poor little homesteads which were all that came visibly out of the attempts to realize the Icarian community in Illinois and Iowa-these pictures, modified here and there, even illuminated more brightly in parts by later hands, have served as the basis of the portraitures of the Socialist millennium. But if Cabet and his imitators furnish the doctrine of the latter-day things, his apocalypse of the New Jerusalem, we must go elsewhere for the Gospels and the Epistles of Socialism: and pass from the prophets to the evangelists and teachers.

In the latter half of the reign of Louis Philippe, the social restlessness which had brought him to the crown had 
continued to penetrate deeper and deeper, as his own bourgeois selfishness and stolidity, the prudish pedantry of his ministers, and the general stagnation of political life, made the heart sicker and sicker with hopes deferred. The rosewater landseapes of Cabet might please inexperienced milliners or poetical enthusiasts. The real workman in his times of misery, the thinker considering the false and selfish ends of social ambition, and the agitator, anxious to see his ideas of liberty and justice. victorious over the old powers of legitimate monarehy, took a sterner view of the needs of the time-of the Condition-of-Europe question. In England, France, and Germany the irritation is at a height. Theologians, poets, essayists, politicians, all in various tones discuss the evil, and examine or propose remedies. In England perhaps there is least talking, just because there is most acting. In the early years of the post-Napoleonic period Robert Owen had come forward with proposals for moulding men into happy and productive citizens by a more real, practical, and all-embracing education, physical, moral, and intellectual, and by a co-operative system of labour communities. But Owen's work was in the main a personal, practical work, done at New Lanark; done, it may be added, before his theory had been definitely dogmatized. His theoretical contribution is in quality and real content inconsiderable: and that for two reasons. The first is his own organizing personality, which was everything and everywhere: bent, as his phrase was, on forming men's character for them by the circumstances and influences he could bring to bear on them, treating them in short as passively plastic to his wise master-hand. The other reason was his conflict with the instincts and prepossessions nearest to the heart of England: his mechanical system, his calm declaration of favour of a purely reasonable religion, and his proposals towards loosening the traditional securities of the family or domestic relationship. Yet, as has been pointed out more 
than once, while other nations have developed socialistic theory, England during the second quarter of the present century entered by the Factory Laws on that long series of socialist measures, by which the free will or caprice of individual owners to do what they liked with their own, even if that own were but the labour-power which they had to sell, was subjected to regulation, inspection, and positive requirement of beneficial service, in the interest, so far as that interest was understood, of all those immediately concerned, and, in consequence, of the community at large.

Elsewhere the fires, which corn-law abolition and factory inspection had calmed at least for a time in England, burned vigorously enough, if largely in secret. In the manufacturing towns of Western and Northern Switzerland, in the plains of the lower Rhine, and sporadically in other parts, the working classes were being drawn into associations when they learned their strength and began to realize their wants. Many motives worked together in founding these elubs and secret societies. The most prominent and at first probably the most efficient was the spirit of republican freedom, which had been fostered and flattered in the Great War of Liberation, but which, in the twenty years after Waterloo, had been, by exasperation from within and unwise repression from above, gradually turned into a bitter hatred of the Prussian monarchy, and an ardent desire to see the three-and-thirty princedoms of Germany absorbed in one great free Fatherland. Next to this motive was an ideal tendency, to foster a higher public spirit in the federations of the labouring class, to raise their standard of education, and give them a taste for nobler pleasures, social interests of permanent value. And lastly and more potently there was a communistic motive: a desire to level all ranks down to one standard, to eliminate all special authorities and orders from society, and to band the labourers together into the one all-embracing class, which is really no class but the generality. 
The centre of this system of fiery agitation was for a long time Paris. As early as 1836 a Communist League had been founded there by Germans. Four years later it emigrated to London, where it has since remained, connected with the associations of similar aims throughout Europe and America. In 1846 the League offered a place in its councils to one who according to common report had at length succeded in founding socialism on strictly 'scientific' views of the development of the social state. Karl Marx, the most notable and original advocate of these germs of economicosocial theory, was then in his twenty-eighth year. In 1847 he and his friend Engels issued the Manifesto of the Communist Party - an appeal to the 'proletarians' of all nations to combine to overthrow the capitalist party by the attainment of political power. But the cry was heard in a desert: and the sanguine anticipations which Marx and other leaders entertained of a favouring juncture in German policy were signally disappointed. The London Exhibition of 1862 gave an occasion to a renewal of the attempt to federate the revolutionary elements among European workmen: and in I864 the International Working Men's Association was founded with a somewhat similar aim. But this association was a conglomerate of many elements-some, like the followers of Mazzini, being quite opposed to Socialism. But the Socialistic element carried the day, and Marx remained practically supreme in the Association till about 1872, when the growing strength of the Anarchist elements at the Hague Congress led to its lapse and the transference of these elements to America. Since that date the strength of the Socialist party has lain in Germany. When Karl Marx died in 1883 , the socialist parties of Germany who in 1871 had polled only about $I$ in 40 , and in 1877 nearly 1 in 10 votes, succeeded, notwithstanding the Socialist Law of 1878 , in slightly increasing their votes even beyond that proportion.

But, leaving these statistics which are more pretentious 
than edifying, and throw almost no light on the real numbers of believers in Socialism, and still less as to what their belief involves, let us return and try to understand the scientific basis on which Marx based Socialism. Itis chief work, J)as Kapital, of which the first volume was originally published in 1867 , is the sacred book of Socialism. The work is incomplete: but, as it stands, it forms the text to which almost socialistic literature of later times is but the eommentary. In form the work is no treatise on Socialism: it is a criticism of the current political economy and of the capitalist mode of production.

To understand the position of Marx we must remember that he began life in an intellectual atmosphere thoroughly pervaded by the spirit of German philosophy. Fichte had shown his view of public rights by such utterances as that the State is bound to see that every one is able to live by his labour, and that the blameless poor has an absolute compulsory right to support by the State: that mines and forests are properly state property; and that 'the first aim of hunting is the protection of agriculture and by no means the possession of game.' Fichte had even planned an economic state, where everything was organized for the general good, and not by the individual profit. Hegel in his Plilosoplyy of Law had been equally decided. The trader is virtually a public functionary and servant, and the community ought to see that he fulfils his part. Free-trade requires a general supervision to mitigate and shorten the periods of violent convulsion which arise in the course of natural adjustments of supply and demand. Society. has taken the place of the parents and is bound to fulfil their duties to its members, especially the poor, and that not merely by relieving their distress, but by taking steps to save them from the vices which their position, with its sense of wrong, naturally generates. When society is left to its own unregulated activity, the growing interdependence of men upon each 
other leads to the generation, and the more and more rapid generation, of a small class of immensely rich, and a numerous class, depressed in its resources below the normal level of subsistence, lost consequently to all sense of law and honesty and honour - a rabble, or, as it was afterwards called, a Proletariat. In this way it appears that with all its excessive wealth, economic society is not rich enough to suppress such a proletariat. The immediate remedy which Hegel sees is in the revival of the mediaeval guilds and corporations in a form appropriate to modern circumstances. The corporation or guild gives its members a wider family home, a common stock of repute, character, capital, on which he is saved from the oscillations of individual competition, and is trained in a school of at least comparative devotion to a common cause. Isolation of the individual worker leads to a race for riches: and the advantage of belonging to a chartered guild in the light of publicity is to check the tendency to individual prodigality on one hand, or individual lagging behind in the work of industry and commerce on the other. The corporation, limiting what is called the natural right to dispose of his skill as he pleases, really elevates him to be a conscious contributor to a common end. And above the corporation is the State, which keeps the highest common good alive in the several minor or particular associations, where particularities are only too likely to harden and ossify.

It can hardly be wondered at that words like these were as wormwood to the German liberals, as similar doctrines were and are to the extremer free-traders among ourselves. But Karl Marx was not likely to suppose that such functions could be entrusted to the Prussian Government. The real, i. e. the ideal, state, of which Hegel had thus spoken, he saw in quite another direction, and he approached the consideration of it from quite another level. All the socialists from Saint Simon and Fourier downwards had poured out contempt on the moralist, the philosopher, and the metaphysician. 
To them these were the word-mongers of idealism-dealers in some distillation or other from that spiritualist theory which finds its best-known shape in religion. All alike attempted to rule the world by unrealities, by figments. Duties, says Fourier, are only the caprices of philosophers: they are human and variable: but the passions are the voice of nature and fod, and the end of all desire, the fullness of happiness, is that 'graduated opulence which puts one above want,' and, through and in it, the satisfaction of all one's passions. Marx does not deal with the basis of life in this popular and grossly materialist way. And yet his materialisin is in its own way equally decided.

The true basis on which all the phenomena of human life, and therefore of history, find their explanation is the economic. Economic needs and the mode of satisfying them are the ultimate factors which in slightly concealed or completely disguised aspects meet us under the names of polities, morals, and religion. The phenomena may seem to hover about celestial regions, to centre on ideas, and to consist in questions of just or unjust policy. But these are illusions, which have been fostered by certain malformations in the economic structure, and which will disappear when once eeonomic phenomena have returned to their normal limpidity, and permit every one to see clearly that man's activity to supply his needs of life is the only permanent fact behind all the phantasmagoria of metaphysies and theology. The relations of labour and its reward are therefore at the basis of all history-are the only reality in all history. Behind the history of creeds, dogmas, and philosophies, behind the struggles of constitutional and religious history, behind wars and diplomacy, behind the organization of family and state, behind democracy and oligarchy, behind the developments of art and science, there is the great record of the gradual stages in that process whereby labour became divoreed from enjoyment, the means of life from the labourer, and the free 
man in direct appropriation of nature is replaced by a society in which the vast majority are disinherited of the right of direct approach to the means of subsistence, and those who are their reputed possessors are only holders of a bond endorsed by the society of the period.

There was once a time, perhaps, in primitive ages and backward eivilizations, when the members of a little community were all comparatively on a level, and each had his traditional place assigned him in the commonwealth, directly serving it and serving himself, but not dependent on individuals, and so in a modicum of comfort enjoying the sense of independent work. But at the beginning of our European history in the classical period a change had been nearly consummated, which ended in breaking up mankind into two groups, the slave-holding proprietors on one hand, and their slaves on the other. The few independent members of society hardly count when that form of society reached its climax. This is succeeded in due course by the mediaeval society, with its contrasts between feudal lords and their serfs, and the master with his assistants in the trade guilds. The workman in that period has not acquired his general or abstract character of labourer: and the master is not a mere employer for wages. The relation between the two parties is a personal and human one : the serf does a definite and particular labour in kind, and receives a definite and particular protection : the subordinates in the guild-relation are bound to their master by ties almost domestic. The social character of labour is not veiled in its exchangeability for a money price, and the social relation of the producers not disposed of by a commercial transaction. But these relations are inflexible and narrow, and tend to sink into a mere dependence on particular individuals, where the only gain is that one has a definite master, a definite attachment, and is not. a 'misérable' cut off even from the privilege of being ruled.

Where Karl Marx really enters fully and with zeal into 
the history of economic movement, however, is when he traces the stages which have led to the capitalist production of modern times. The rise of the commercial and mercantile elass, the progress of industrial undertakings on a large scale, the character given to manufacture by the introduction of machinery, are all deseribed with force and abundant illustration. We hurry on to the denouement. 'Self-wrought private property, resting so to speak on the coalescence of the isolated and independent individual labourer with the conditions or means of his labour, is displaced by the private property of the capitalist, which rests on the exploitation of the labour of others, yet labour which in form is free.... As soon as this transformation-process has disintegrated the old society deeply and widely enough, i.e. as soon as the labourer is thoroughly divorced from the means of existence, then the further step in socializing labour, and in transforming the earth and other means of production into instruments worked by the organized effort of the community-in short, the next step in expropriating the private proprietors is taken. What is now to disinherit is no longer the labourer working on his own stock of goods, but the capitalist who gets the work out of many labourers. This expropriation is carried out through the law inherent in the very nature of capitalist production, through the concentration of capitals. Every one capitalist is the death of many. Hand in hand with this concentration or the expropriation of many capitalists by a few, the co-operative form of the labour process grows more and more extensive. Then the monopolizing of capital grows a fetter on the mode of production, which has sprung up with it and under it. At last the centralization of the means of production and the associative mode of labour reach a point where they become incompatible with their capitalist integument. The integument is burst up. The hour of capitalist private property has struck. 'The expropriators are expropriated.' 
The main work of Marx may thus be said to fall into two parts, a theoretical and a practical. The general purport of the theory is a refutation of the claims of the current economies to be considered a science of the general group of phenomena with which it deals. In this, he on the whole may be said to join sides with the erities who point out that political economy has not risen to the scientific height of surveying its facts from a universal or comprehensive point of view, but has remained immersed in local and temporary aspects of the phenomena in question, treating the present order of things as an absolute or eternal truth, instead of one stage in a process, the whole laws of which form the only adequate object of economic science. In the practical tendency of his argument, however, Marx stands on a somewhat different ground. The pure and abstract historian, if such a creature there be, is content with pointing out sequences, and is cautious in presuming he can detect causes, still more unwilling to profess to foresee tendencies and immanent laws. The human being, who has not so learned to mutilate his mind, is forced to look at things otherwise. To him the past is big with the future. However uncertain may be his footing, he must use it to jump, or at least to step, into the problems that wait for him. They cannot be put off till uncertainty be annihilated. And so, as we saw, Marx, doing his best to gather the drift or normal tendency of socialeconomic movement, proclaims it as the only light we can have to guide our path and fix in some way the goal. He doubtless erred, as all prophets have inclined to err, in supposing that the end was close at hand, that the process of socializing capital was all but complete. But a little error in calculation does not seriously interfere with the truth of the general principle. And that principle is that the present line of movement is tending in what may briefly be called a socialist direction. To us, imitating him, the true attitude towards this movement is neither to ban nor to 
bless it. If we hesitate, as we should, to term it a natural law, a necessity of social evolution, we eannot deny that it is one, a prominent, perhaps the dominant tendency of our modern civilization. Those who fight against it are by the inner dialectic of antagonism compelled to use its own weapons, and undertake its work. They fight in fact not against it, but against the men who advocate it. Just as the heathen sages and kings sought to stay Christian progress by evineing the inner Christianity of the Pagan theology, just as the conservative defeats the radicals by showing that, on occasion and in his heart of hearts, he is more reforming than they, so Prince Bismarck outbids the socialist by a series of laws enforcing the very duties which the workmen's unions have been aiming at. The good landlord and the bad, almost equally, though by different modes of motion, support the socialist argument. Every syndicate formed to regulate the price of a commodity, in a particular interest, shows the imminence of socialization. The more our individual and our collective welfare hangs upon vast congeries of machinery, partially dependent of each other, and beyond individual supervision and control-except for selfish and, it may be, sinister ends-the more a collective, i.e. a centralized administration, is necessary. Since the first railroads were carried across private property for the eommon good by coercive law, barely half a century has elapsed, and not so much since the factory acts really exercised any considerable influence: yet how much has already been done in the same direction. And if we look nearer home, it is plain that university legislation and university practice have alike tended towards consolidation, subordination to common ends, the socialization of intellectual eapital, and the recognition by the individual labourer of his social or eommunitarian function.

Are we then to conclude that by a quiet and easy transition, society, as it now is, will be so internally transformed by the many molecular changes going on slowly and imperceptibly 
within it, that one fine morning the world will awake and find itself socialist in name, as it has long been tending to become in fact? Or, will the change from the old order to the new be a violent one, the pang of a revolution, abruptly and sharply rending the continuity of life? No man will wisely attempt the task of prophet, save in decorous generalities. Of old time one said, the kingdom of heaven eometh even as a thief in the night; and yet again, Heed not them who say Lo here or Lo there, for the kingdom of heaven is within you. So perhaps will it be with this generation. It must be that stumbling-blocks bar the way, and there will be some rough jolting, perhaps even some deadlier aceidents in the movement. But, on the other hand, the end is not yet. Prophetie socialism lifts up its eyes to the hills; but it hardly realizes how far off they are; how, indeed, to the thinker they are already ascertained to be the hills of heaven, though more eynieal observers might be inelined to call them the fabled mountains of the moon. Philosophy does not much sympathize with the popular coneeptions or miseonceptions of what is meant by progress. To the vulgar rhetorician the word, uttered too often in Pharisaic self-commendation, suggests the image of a long straight road, which, as it goes on, becomes wider and fuller, and filled with a wiser, a merrier, a richer assemblage-a continuous accumulation of good things, with perhaps just a few movements of malaise, an oceasional time of trial, but not more than enough to season and enhance the general sense of getting on. And another view, held by those who fancy they give accuracy to their conceptions by a mixture of exact science, regards progress as taking place along some complicated curve, where, like the traveller through the Saint Gothard following his way gradually through a succession of circles which land him at each outlet on higher and higher planes, we seem alternately to recede from and approach the end in view. Perhaps a sober philosophy, not too contemptuous of the past, nor too sanguine of the future, will 
hesitate to assess the difference of culture-level : and will be inclined to say that it is sufficient faith in God and nature to think that all is for good, without venturing to transcend our data and say it is all either for the better or the best, much less that all is for the worst. To that frame of mind it will be suitable to suppose that each age has its own problem: and that as its day is, so will its strength be. If the problem is more complex, we may fairly hold that the powers of solving the problem are multiplied in proportion, but we shall not therefore conclude that the result is of a higher value. We may shrink from assuming that anything beyond a transference of energy can take place, and hesitate to commit ourselves to theories - and they are those of our current philosophy-that the world goes on accumulating virtue, able at once to eat its cake and store it up.

And what is the bearing of these generalities on human progress on the present question? This: that socialism is no solution of the human problem, but that in its general outline it is rather an indication of its nature, and an attempt to formulate how it has arisen, and in what it consists. That problem is the perennial problem of human association: a problem which at intervals becomes more aggravating and threatening, and therefore calls forth by natural and normal response new efforts to comprehend the difficulty and to find the way out of it. In such an accentuated phase now stands the problem of freeing man's life from its recurrent tendency to become as Hobbes said, 'solitary, poor, nasty, brutish and short.' It is easier in such a case either to minimize or to magnify the evil: but there is safety in saying that socialism, whatever its aberrations, has the credit of keeping people alive to the fact that the social compact is always making and never made, and that it has now become like an ill-fitting dress, which is displacing the assimilative system of society, causing irregular excitation of the heart, and clogging the organs of breathing. 
Not merely does it indicate that there is a problem: it diagnoses fairly well the central seat of the disease, or, perhaps we should say perturbation. The old Saint-Simonian society talked about the rehabilitation of the flesh. 'The word, it is urged, has a dangerous sound. 'Why, that's certain ;' we reply with Hotspur: ''tis dangerous to take a cold, to sleep, to drink! but out of this nettle, danger, we pluck this flower, safety.' Socialism is part of the general protest which has been raised in the realistic interest against a fantastic and unsubstantial idealism, or spiritualism, or intellectualism. When mediaeval Christendom said in its early artists, teste Browning,

'To bring the invisible full into play,

Let the visible go to the dogs, what matters?'

it spoke a very aspiring and, let us retort, a very dangerous dogma. The modern socialist might and perhaps does demand the whole charter of man: but he naturally begins by redemanding what was last taken from him. That the physical life of the body is the basis of everything else, bright with the promise of all life, in art, morals, science and religion, is the one conviction that emerges more and more definitely and palpably in all modern ethics. The soul, indeed, is highest: but we cannot now believe that the soul may be saved without the body, or that physical health and vigour are other than absolutely indispensable to enable the higher life, the real life, to become all that it was meant to be. And this 'rehabilitation of the flesh,' if properly understood, is not contradictory of the precept which bids us deny the flesh. If for one moment I may borrow a Hegelian formula, I should say that our proper attitude in this matter is a negation of a negation. If the denial of the flesh means discipline and culture, means selfcontrol, means the consecration of natural powers to ideal ends, then is such denial praiseworthy. But a mere rejection, ignoring, soaring above the flesh, is vain and false. And the rehabilitation of the flesh means only that the passionate nature, 
at first silenced as an intruder into the life of the spirit, must cease that silence and learn a new language.

The movement is part of that tendency of the modern world to put the state and secular functions supreme. In the Middle Ages the Church stood foremost. Mediaeval life seemed to centre in the Church, as the mediaeval town clustered round the towers and buttresses of its cathedrals. But it needs not much acquaintance with mediaeval life to say that the semblance must not here, more than elsewhere, be taken for the reality. As you examine more carefully, you see that the sacred place is the home of art and science, and that in the carvings on its walls you can trace the evidence of the same jovial and not over sanctimonious mirth which laughs out in the farces and fabliaux of the period. Round the consecrated altar-slab, the nave and aisles of the church, were ground in which plays and marketing were neither vulgar nor unclean : and I need not tell a Cambridge audience that as late as the reign of Elizabeth a play of Plautus was performed in King's College Chapel. There came afterwards a period of differentiation. It was a result, fostered by the Reformation, and still more by the counter-Reformation, to make broad and stern the distinction between the secular and the sacred: and out of this there issued in the sixteenth and seventeenth century the real struggle between the sacerdotal and religious element on the one hand, and the secular and scientific on the other. By the close of the seventeenth century the Church and religion seemed on the whole victorious. But the eighteenth century reversed the process, and by the close of it the triumph of this world and the secular commonwealth seemed secure. Further experience has shown the delusion of those who thought so. The secularistic movement of the present century has had to go deeper and to embrace a wider range. To go deeper: instead of the mere light, intellectual enlightenment, which the eighteenth century held to be the highest gift, it has had to seek for a more 
adequate basis of knowledge, to penetrate beneath the surface of civilization into the workman's lodging, the factory, and the peasant's hut--to realize the existence of what has been called a fourth elass behind the tiers état which emancipated itself a century ago. But at the same time the enlightenment of the nineteenth century, as it has found a profounder basis of fact and knowledge, so it has taken up into itself an ideal spirit, an influence of poetry, art, and religion, which formerly seemed to it absurd and intelligible. The same socicty which bade put on the flesh the new robe of honour, also declared that all its energies were to be enlisted in the service of humanity.

Thus socialism has done well, if it has sueceeded in producing any conviction in the general mind that political party, religious service, and scientific study, all derive their permanent value from the direct service they render in eliminating the eliminable causes of human wretchedness. If it can break in pieces any of our political, religious, or educational fetiches, and bring the priest, the politician and the schoolmaster and bookman to realize that the question of questions ultimately is, Whom have thy labours made better, what hungry and thirsty and stranger and sick hast thou endowed and helped with thy sympathy and aid, socialism will not have been fruitless of good.

Socialism, as was pointed out, is an acute phase of the general social question. It contains in itself, and raised to the highest pitch, the two opposite tendencies which govern the whole process of history. These tendencies appear in socialism in an aggravated, an almost inconceivable antagonism. They are individualism, the proclamation of freedom and equality : and communism, the principle of fraternity or of something to which fraternity is only an approach. On one hand, the demand for absolute independence, for suppression of all authoritative interference from without, for the right to free development from without. On the other, the cry for organization, for socialization, for intensifying the solidarity of all social action and life. 
It is sometimes said, and there is a superficial truth in the saying, that there are two sets of socialists, the collectivists and the anarchists. But it is nearer the fact to say that there are two warring tendencies inherent in socialismwhich, to repeat it again, is only conscious and intensified society--two tendencies, of which one is more prominent in certain minds, or at certain times, and in certain circumstances, or more specially adapted to the conditions of certain classes.

A word on 'Anarchism.' It is an ugly word, and, if associated with bombshells or dynamite, it becomes uglier still. But listen to two of the anarchists who were put to death at Chicago in 1886. 'Anarchism;' says one, 'does not mean bloodshed: does not mean robbery, arson, \&c. Anarchism means the reorganization of society upon scientific principles. Anarchism is a free society without kings or classes, a society of sovereigns in which the liberty and economic equality of all would furnish an unshakable equilibrium as a foundation and condition of social order:' 'Anarchy,' says another, 'is the natural law, instead of the man-made statute. Laws, natural laws, just laws, are not made, they are discovered. Every human ill is produced by the denial of man's natural rights.' It is clear that such anarchism as this is a deduction, an application of a very respectable doctrine, the doctrine to which $\mathrm{J}_{\mathrm{ohn}}$ Milton and John Locke have lent their names. It is also fair to remember that anarchism, as it arose in minds like those of the Russian Bakunin, is the normal reaction from despotism and autocracy, the sovereignty of a despotic church or state. And lastly, when men like Mr. William Morris take an analogous position and cover it with the name of Communism, while expressing their doubts of the permanent value of the socialistically-organized state, it is clear that the doctrine is only an exaggeration of a truth. Anarchism, then, is an unfortunate name, a distorted expression of the view that, the more human action proceeds from internal motives 
and the less it is vitiated by 'all the paraphernalia of official authority, which is after all a burden,' the better will be the results for human welfare and individual development. If thus conceived as an ideal of the state where each is a law to himself, because his basal principle is a faith of solidarity with others, and where free play is given to faculty in all its individuality of growth, because it draws its force from a common soil, anarchy is transformed into an angel of light. And if it adopt the name of Communism, it is a communism which all true theories of the State have maintained, when they conceived it not as a hindrance but as a help to development, as the common foster-mother, out of whom proceed all useful and precious functions, differentiating into endless forms of individual and class performance, but never losing allegiance to the central idea of a common life in which they live, from which they issue, and to enrich and diversify which they contribute. If Mr. Morris thinks that our modern states are too large to give a real home, and that lesser social unities or 'communes' should gather together under the shelter of the State as the mighty mother of 'communes,' that is a form of home rule to which no objection can be taken, provided you can be sure that the members of your petty groups are worthy citizens, who can keep their local patriotism in subordination to, or rather in essential harmony with their general partnership in the community ${ }^{1}$.

1 This lecture seems to have been the introduction to a fuller discussion of the subject, of which there remains only a few notes, and the section which follows dealing with the views of Fichte and Hegel. 


\section{VIII}

IT is urged by writers like Schäfle that Hegelianism is the true parent of Socialism. Hegel, they say, as the anti-reformation said of Erasmus-Hegel laid the egg, if the Socialists hatched it. Yet it used to be maintained by writers of the extreme Liberalist School in Germany that Hegel's work on the Philosoply of Law, published in I 82I, was a philosophy in the interests of Prussian absolutism. The facts of such opposing accusations seem to indicate that that philosophy was, as it claimed to be, superior to the disturbing influences of partisanship or political bias. From the days of Socrates and Plato downwards no eminent philosopher has escaped this assault from partisans, who, finding their theories were not entirely accepted and defended by him, concluded he had gone over to the side of the enemy. The vulgar-and the common politician is always vulgar-parts all mankind by an 'Either, Or,'-' Either he is with us, or he is against us.' His little mind cannot see that a larger intelligence may embrace what he cannot-may put his shibboleth and its antagonist cry alongside of each other, and show they only need a little mutual explanation in order to attain the common aim they pursue by opposing means. Against the impatient cry ' $\mathrm{He}$ that is not with us is against us,' Hegel set the calmer ' $\mathrm{He}$ that is not against us is on our side.'

Fichte, as we have seen, had attempted a sort of a priori construction of the State. In his usual method of step by 
step deduction he had shown that human beings, if they are to live together in the same sphere or range, must inevitably arrange their community of life on general and all-embracing principles. A common and uniformly accepted organization must grow up. For Fichte is not looking at what happens with human beings as they are. As they are, they are, most of them, figuratively half-asleep: they let life drift on, and get into new situations and relations almost at haphazard. One person, and one group of persons organizes life a little here, and another organizes it a little there. But, even in what is called one State, two conterminous often live largely in unconcern of each other. In such a community, visibly and outwardly one, there are a million centres of organization, sometimes indifferent to each other, sometimes crossing and thwarting each other, but never going on in any direction more than a little way. So the world has grown up by patches here and there: each province, it may be each parish, with a way and system of its own, and in none very thoroughly carried out. And individuals do likewise: their minds are like cupboards, each drawer of which has been filled from a separate source: they keep their thoughts in isolated compartments.

Fichte, on the contrary, was the Son of the Revolution, full of its Titanic spirit of radical reconstruction. He sets before his mind the process of a state-formation in which every individual would be wide-awake, would be fully alive to his own interests, would take no step without seriously considering all its bearings, and would stop nowhere short of the ultimate conclusion. He is the prince of doctrinaires, the undaunted and somewhat impatient champion of freedom and of reason. In his constructions we assist at the work of a people of dialecticians who, when they have said $A$, know that they must say $B$, and will not shrink from the resolute development of every element till they have come to their Z. This is what is meant by the State of Reason, 
the Reasonable State. In a sense every state which people live under is a reasonable state: it has its meaning, its justification, its historic value and truth. But reasonable in Fichte's sense it is not. To be literally reasonable in that sense, it must be a transparent system of deductions, one stage emerging from another, one condition implicating another, in the reasoning vision of a single intelligence. Fichte's idealism will be content with nothing short of construeting the state by a logical process from its first wide outlines to its closely compacted organization.

We need only note a few points in which Fichte's rationalizing spirit brings him somewhat on the lines of the Socialists. Not that Fichte was of the general metal of which Socialists are made. But the poor weaver's son of Rammenau in Lusatia had seen the bitterness of the peasant's lot: he had observed the social disorder of his age: and his heart rose against those who seemed to elaim that man was made to obey the laws, whereas laws are only sanctified by their constituting a well-doing community. He had not before him, like the Socialists of 1840 and onwards, the degradation of the industrial population of large towns: but the German peasantry were sufficient instance to give point and meaning to his general principles. And he resolves at one bound as it were to put himself in the heart of the situation. He, Fichte, becomes the multitudinous nation: he in his own reflection relives their gathering into social and national unity : he brings under the focus of his powerful mind all the movements that were really transacted in a million brains, and which for that reason were loosely and incoherently transacted: he, strongly grasping his discordant elements together, constructs the organized State, so that it is a perfect mechanism, with not a joint loose or cranky, and with a thorough system of telegraphy and communication making it all advance and move as one man. It is a splendid machine-a little too perfect perhaps in theory- 
but that will do no great harm in a philosophical speculation, which has a long way before it till it works down into practice.

In such a state there will be no privileged classes-none entitled to an exemption from the common burden. There will of course be distinctions, and each individual will have his special work: but none will be excused work altogether. The State cannot in its issue deny the ends which were foremost in the less compacted aggregate of human lives out of which it arose. And so each must claim his original right to the means of subsistence : in other words, society is condemned, if it has become so organized that any part of the population is against his will prevented from earning his living. This is the assertion of the droit au travail. For had the development of the social order been carried out with clairvoyant eye, men would have protested against the first step which locked up the means of subsistence in private hands, inaccessible to the common administration. Property and its rights, he remarks, are not strictly speaking in the land and its natural powers: these remain common ground : what is property, is the definite use of these materials, the right to transform them or their products into means of human subsistence and enjoyment. Accordingly wherever the proper utilization of natural products does not require their being put for a period into private hands, there it is desirable to retain the control and working directly in the administration of the whole community. Private property in land and natural agents is only valid under these limitations, and only justified by the argument that it is the method of getting the utmost product from nature, and so providing the largest amount for general consumption. But the proprietor's rights do not extend to leaving a natural product unused at his will and pleasure, nor do they include the liberty of destroying the peasant's crops in the pursuit of his lordly sport.

Fichte has thus realized that the anarchy of industry and 
commerce could not possibly be willed, if one intelligent consciousness had continuously guided the evolution of society. The antagonism between the landed or agricultural interest, the manufacturing or craftsman interest, and the commereial or shopkeeper and merchant interest, seemed to him a scandal and an absurdity. Each class, as it appeared to him, and each individual of that class or profession, pursued his business, on that tacit understanding or latent compactwhich Plato called justice-that the other was in his turn performing his part of a great national work, realizing a common national stock or capital, out of which the wants of all its members were to be supplied. Each would have refused to enter upon a specialized work, to tie himself to a limited range of labour, had he seen reason to suppose that he would thereby be putting himself at a permanent disadvantage. Hence, concludes Fichte, the organization of the trades and professions must be the business of the State: the State must see what is the balance of farmer, artisan and merchant, nceded to maintain the whole social fabric in a wholesome condition: and it must so arrange the details that none shall be damnified by having undertaken (on State authority) a labour which does not bring in immediate and material reward. Fichte lived in an age which was eagerly uprooting the old restrictions on industry imposed by the gilds and corporations originating in the Middle Ages. $\mathrm{He}$ saw that the rage for rejecting all organization was overreaching itself : and foreseeing the rapid approach of a day when the corporationless artisans would feel the need of association to help them to attain a worthy life, he declared that the gilds which were abolished nevertheless are bound to exist.

A few passages may illustrate Fichte's view. He supposes a complete free-trade throughout Europe, and this he says is the result 1 : 'In the trading public there arises an endless war of all against all, a war between buyers and sellers : and

'Fichte's Werke, vol. iii. p. 457. 
this war grows more violent, unjust, and dangerous in its consequenees, in proportion as the world grows more populous, as the commercial state grows larger by additional acquisitions, as production and arts rise higher, and as the commodities in circulation thus become more numerous, and the general demand increases and multiplies. What in simple conditions of national life passed off without great injustice and oppression, is transformed after the intensification of demand into the most erying wrong and a source of great misery. The buyer seeks to squeeze out commodities from the seller: and so he calls for free-trade, i. e. liberty for the seller to glut his markets, to find no sale, and from necessity to sell his commodities far below their value. In like manner he ealls for strong eompetition of manufacturers and merchants, in order that-from the difficulties thrown in the way of a sale, beeause ready money is indispensable-they may be compelled to give him the commodities at any price which he in his magnanimity may offer. Should he succeed, the labourer is impoverished, and industrious families sink in want and misery, or emigrate from an unjust nation. Against this oppression the seller defends himself, or assails the stock and supply of goods by the most diverse means, by buying them up, by artificial dearth, \&c. He thus places the buyers in peril of being suddenly cut off from their habitual wants, or of paying unusually dear for them, and having to pinch in some other quarter. Or he reduces the excellence of his goods, after he has been forced to reduce their price. The buyer accordingly does not get what he expected to get : he is cheated : and for the most part there arises with bad, careless work, a further sheer loss in public energy and time and in the products which are so badly manufactured. In short, no man has the slightest guarantee that if he continue to work he will continue to subsist: for men are resolved to be completely free, mutually to bring each other to ruin.' 
'The first and original property, the ground of all property, is an exclusive right to a specifie free activity. 'This free activity may either be named and defined by the object to which it refers, or by its form and manner only; of the first kind is property or possession in a thing, e. $r$. property in the soil, of which however Fichte remarks: "the earth is the Lord's, man has only the power of cultivating and using it for good ends." Of the second kind of property is the right to practise a certain eraft, and to prevent all other men from the exercise of the same art. But in both cases the basis of all right of property is to be placed in the right to exelude others from a certain free activity reserved for us alone, by no means in an exclusive possession of oljects ${ }^{1}$ ' It is clear, therefore, that not merely the agriculturist, but every inhabitant in the State must have an exclusive property of his own, because otherwise he cannot be bound to recognize the agriculturist's right of property, cannot be legitimately prevented from ousting the latter from his field, and robbing him of its fruits. And what would be the exelusive property of the non-agriculturist, the manufacturer, the merchant, in return for which he would have surrendered to the agriculturist the exclusive right of property to the soil? His art and trade-skill he owes to nature and himself, not to the State. In respect of these he is not bound to the State, as the agriculturist to his piece of land. Thrown naked on any shore he can say, 'Omnia mea mecum porto.' What then can the State still give him? Evidently only the guarantee that he shall constantly find work or sale for his commodities, and that for them he shall receive the share that falls to him of the goods of the land. It is through this security that the State attaches him to itself. But this guarantee the State cannot discharge unless it closes the number of those who pursue the same branch of industry, and undertakes to care for the necessary subsistence of all.

$$
\begin{gathered}
\text { 'P. } 444 . \\
\text { F f }
\end{gathered}
$$


It is by this elosing that the branch of work beeomes property of the class which pursues it: it is by this provision for subsistence that it becomes a property from which they can live: and it is only in return for this their property that they can resign their elaims to the property of the agricultural class.

'National wealth,' says Fichte, ' has many meanings. To me the inner essential prosperity consists in being able to procure the most specially human enjoyments with the least labour of a severe and persistent kind. And this must be the prosperity of a nation-not of a few individuals, whose highest prosperity is often the most striking symptom and true ground of the supreme ill-condition of the nation ${ }^{1}$ '. ' It is not a mere pious wish for humanity, but it is the indispensable requirement of its right and of its destiny that it should live so freely, so easily, so eommandingly over nature, so genuinely humanly on the earth, as nature at all permits. Man has to work : but not like a beast of burden that sinks to sleep under its load, and after the minimum refreshment of its exhausted forces is again stirred up to carry the same load. Man ought to labour, without anxious fright, with pleasure and joy, and have time left to raise his mind and eye to heaven, for whose gaze he was formed. He ought not precisely to eat with his beast of burden: his food should be distinguished from its fodder, his dwelling from its stall, just as in his corporeal structure he is different from it. This is his right, just because he is a man ${ }^{2}$ '

' Here we have reached ${ }^{3}$ the source of the greatest part of the still subsisting abuses. In modern Europe there were for a long period no States. At present we are in face of attempts to form some. Further, the task of the State has been hitherto conceived in a partial and half-hearted way, as if it were an institute to maintain by law the citizen in that estate of possession in which he is found. The deeper lying duty of

$$
{ }^{1} \text { P. } 423 . \quad{ }^{2} \text { P. } 422 . \quad{ }^{3} \text { P. } 453 .
$$


the State to invest each with the possession that is his due, has been left out of sight.' 'Conceive a definite sum of possible activity in a certain sphere of action as the one magnitude. The comfort of life which ensues from this activity is the value of this magnitude. Conceive a definite number of individuals as the second magnitude. Divide the value of the first magnitude in equal parts among the individuals, and you find what each should receive under the given conditions. . . The part which each grets is his own by right: he should get it if it is not already promised him. In the State of reason he gets it: in the division which was made by chance and force before the awakening and the rule of reason, each of course did not get it, because some appropriated more than fell to their share. Thus for the actual State which by art approximates to reason the wish must be to help each to his own, in the sense of the word just explained 1'. 'The source of all evil in our make-shift States is solely and singly anarchy, and the impossibility of creating order ${ }^{2}$ '

The method of Hegel has a decidedly more conservative look, but it is not less seathing in its criticisms or less progressive in its results. Fichte resembles an advocate who, by a bold effort of sustained construction, displays step by step the hidden process of some crime, showing how motive arose out of action and consequences trammelled the will until the final issue burst out as it stands before us : and who at the close of his demonstration exclaims, So must it have been. Hegel is rather like the judicious cross-examiner who, by experienced suggestion of topies and by manipulation of data, forces the criminal to tell his own story, to reveal the hidden movements, hopes and fears, weaknesses and troubles of his inner life and intimate circumstances, to be the crowning witness against himself, and the real expounder of those byways and windings of motive which the wiliest outward

$$
{ }^{1} \text { P. } 402 .
$$


interpreter is never quite sure of not missing or mistaking. Observers indeed will be inclined to suggest that the performance is a cleverly laid trick, and that the advocate has suborned his patient to make out his own case as he has prepared it. They may allege, in other words, that II egel has the historical puppets secretly under his control: that he can make the history say what he wants. In reply, it may be said, that no defender of this method will readily pledge himself to maintain that the cross-examiner may not oceasionally be unjust, and may not now and then, by putting things together, cause the professedly independent witness of his victim to bear out the colour of his own presuppositions: but no one who has carefully studied the method will believe that even a master of thought like Hegel could produce marioncttes which looked so surprisingly alive and intelligent, or will allow an occasional arbitrary interference to thwart the general conelusion of a trustworthy and decisive self-revelation.

The Hegelian method professes to show in the real history, prepared, as the experimenters say, by discarding unessentials and trivialities, the very law of growth and construction of our moral, religious, economic, and political world. The world in its history, i.e. in the revelation of its own real time-movement, sits in judgement upon itself, and betrays its own secret. But if it displays how far in each effort or stage it has departed from the normal path, it also shows how in each age and epoch there was a larger principle, a fuller heart at work, and that, though the actual performance was one-sided, it was always accompanied by a compensating and alternative principle which so far mended the mischief the other had caused. Beneath the superficial order of movement-the alternate dominance of one-sided motives, and the appearance of a mere see-saw of principles, a chaos in which brilliant performance is suddenly swallowed up in blank collapse-there is disclosed a real, and much slower, because much more complex and encumbered, process of 
social life. 'This underlying process is the movement of the infinite behind the finite: the march of God in history as opposed to the march of man. Yet they are not two movements, the phenomenal distinct from the noumenal: the former seen in fragments, in seeming regression, in involved curves, and general disorder: the latter a uniform, systematic series-a total and harmonious idea. The appearance is one with the reality for those who ean see it from that commanding position in which its inequalities and discontinuity are redueed to their proper place-where, in short, they cease to disturb the total view.

'The Philosoplyy of Law and Oullines of the State follow this method. They show us first of all that the State has a development from simpler stages, and that in all its stages it is the product of two elements, two principles, law- the prineiple of an objective order, and conscience-the principle of a subjective freedom. In the State we have the meeting, the synthesis, of the legal and the moral : the union of an outward form of order or organization with the inward spirit of self-realization. The republican idea had tended to reduce the State to a purely secular and outward institute for the maintenance of rights, for the security of property, and for fencing round a sphere in which human life might develop individually at its own will and pleasure. On this view the State was but the protecting shell, the restricting framework, of peculiarly human life to be carried on by individual agents within for their several interests. Opposed to this was a conception which ignored the value of such mere organization, and which laid down that the good will is everything, that the conviction and persuasion of being in the right is what defines the moral nature of an action. Here the aspect of selfdetermination becomes supreme. Thus there had grown up an antithesis between order, which is the fruit of law, and liberty or self-initiation which is guaranteed by conscience.

The State is the full and final reconciliation of order and 
liberty, of law and conscience, of manners and morals, but it only appears in its character of reconciler if we look at the two phrases or aspects which constitute it, and each of which has some claim to be identified with the State. The one of these phases is the family, the true 'State of nature' or natural State, if we consider it, not in any peculiar form it has taken or may now take, but in its general features and type in all ages. With this natural aggregation human beings have both liberty and order; but so mixed up and packed together, that neither of these ends is duly secured, till by later expansions (in the developed State) the family, freed from duties and burdens with which it could not well cope, is better able to perform its appropriate functions.

The other phase of the State is what Hegel calls Society -Citizen Society-'bourgeois' or 'tradesmen' society-the society of industry and commerce. This 'bourgeois' society is the 'make-shift state' of Fichte (Nothstaat). It is a system generated in the first instance by the dependence of each for his welfare and subsistence on the welfare and subsistence of all. The narrow range of family life soon proves itself inadequate to the growing multitude of wants and needs which emerge in the course of experience. Human nature soon develops its capacities of multiplying, subdividing, and varying its wants as well as the means for satisfying them. Division and co-operation of the labours needed to produce the means of subsistence and enjoyment know no limit to their extension. This partition of the sum-total of labours required to bring forth the materials of subsistence goes on according to natural accidents, following the lines laid down by the natural endowment of individuals, the advantages of situation, and all the variety of fortuitous circumstance. It is, in short, a process of natural selection which settles what varieties of industry and commerce flourish, and what persons devote themselves to each. The only general laws that can be laid down are the general tendency of the 
systematic groups which deal with the modes of procuring the common subsistence to fall into three main bodies. These are (I) the class which is engaged in appropriating for human use the more immediate products of nature; (2) the class which transmutes these natural products into more and more artificial forms (ineluding the labour of artisan and manufacturer), and which finally secures the entrance of its several products into the general field of consumption (including the work of commerce); (3) the class to which are entrusted the more general interests of the whole society. Such estates and orders of society are the final form which its somewhat imperfect unity can present.

In such a society each has a chance afforded him of securing a certain capital of his own. But not more than a chance : circumstances may be too hard on him. Still the accidental and unequal development by which individuals variously take their place in such and such an estate, such and such a profession or trade, is on the whole a natural and unforced process; and it gives rise in course of time, as it repeats itself again and again, to certain fixities, uniformities, or regularities of social arrangement. Laws to protect such personal property as has grown up in this natural and unequal way are only the expression in verbal formulae of that precipitate, in the mind, of customs-which are the subjective reflex of habitual occurrence. Laws, therefore, are only the consecration of the existent order: they follow the lines laid down by the natural, which is far from being the pre-eminently or strictly just, method of human socialization. But when law is enforced in public courts and by public officials, it means that the community as a whole is resolved to stand by and keep up the status quo, to protect the infringement of those individual appropriations which have grown up by ways and means of which it has no direct cognizance, but to which it gives a right, by its general resolution to hold those in possession as presumably the rightful proprietors. 
But society has other duties than merely to protect rights by punishing those who infringe them. It must further seek to prevent the occurrence of such infringements by maintaining a system of police, which shall maintain individuals in a continuous security, and by anticipating and thwarting crime shall guarantee the welfare of individuals as well as uphold the majesty of the law. And this anticipatory action of the police is soon found to have a wide range.

As the wants of the day are indefinitely multiplied and intertwined, says Hegel 1, there emerge points of view which are equally the interest of all, and where one man's business is also a common concern. Every one relies on there being no obstacles to make it impossible to procure and exchange the means for satisfying these wants: and every one is concerned in shortening, as far as may be, the investigations and transactions called for to that end. Hence also various methods and arrangements come to be employed in the common interest; and these general concerns and arrangements for the common good call for the inspection and supervision of the public authority. Again $(\$ 236)$ the several interests of the producer and the consumer may come into collision with each other. It is true that on the whole the proper equilibrium will be spontaneously established. Still the adjustment requires regulation, and that regulation must be supplied by an intelligent power which stands above both sides. Whence then the right to regulate such details, as e.g. the assizes or fixing the price of the commonest articles of consumption? It arises from the fact that the public show of goods for sale, when these are of quite general and everyday use, is not so much put before the individual as such, as before him in his general capacity, i. e. before the public. If the public then has a right not to be cheated, the inspection of the quality of commodities may, as an affair of common 
concern, be undertaken and eared for by a public authority. But a general supervision and direction is above all things entailed by the dependence of great branches of industry on the state of foreign nations, and on remote combinations, of which the persons specially assigned and attached to these departments are unable to get a complete and comprehensive view.

Free trade and free industry is one extreme in economic life. The opposite extreme is seen when a public organization both supplies the needs of all and fixes their work. 'Thus in the case of the ancient work on the pyramids and other monstrous works of Egypt and Asia, they were produced for public ends, but without the private option or private interest of the individual labourers having any influence on the direetion of his labour. It is this private interest to which free trade appeals against regulation from above. But the fact is that, just beeause such private interest is blindly engrossed on selfish ends, it requires a public supervision, if it is to be made eonformable to the universal good, and if it is desired to mitigate the dangerous convulsions and to cut short the duration of the interval, wherein the collisions would have to adjust themselves by the methods of mechanical necessity. There exists (\$237) indeed for the individual a possibility of taking his part in the common stock, and that possibility is guaranteed by public authority. But it is not only that this guarantee must remain imperfect. It is further, on the side of the individual himself, liable to all sorts of accidents, and the more so the more it presumes him possessed of the pre-conditions of skill, health, capital, \&c. Originally $\left(\$ 23^{8}\right)$ the family was the basis of unity, out of which the individual sprung, and in which he grew. The family had the duty of seeing to this private aspect of the individual: to see that he had the means and the skill so as to acquire a stock of his own out of the social stock, and that he was cared for and supported in case of his 
being rendered incapable. But economic society has torn the single human being out of the family unity: has made the members of the family strangers to each other, and treated them as independent persons. Instead of inorganic nature without and the paternal soil, in which the individual found his subsistence, society has substituted its own soil; and the stability of the whole family thus undermined is made dependent on society and subject to the chapter of accidents. The individual has thus become a son (not of his natural parents, but of) society: society has claims on him, and he has rights against it. Society thus (\$239) becomes the universal family: and in this eapacity it has the duty and the right, as against the wilful and casual behaviour of the parents, to supervise and influence the children's education. It does so, so far as education has bearings on the eapacity of becoming a member of society, especially if that education is to be finished by others than the parents themselves. Further, so far as a eommon mechanism can be provided for that purpose, it has to take the necessary steps. In like manner $(\$ 240)$, where the extravagance of a person renders his own and his family's subsistence insecure, society has the duty and the right to assume the guardianship, and to carry out in their stead the purposes of society and their own. Such a state $(\$ 24 \mathrm{I})$ of dependence, indeed, may not be due to personal wilfulness. Accidental circumstances, depending on nature or on outward conditions of life, may bring individuals down to poverty. And what poverty does is to leave them all the wants of society, while it deprives them more or less of all its advantages, such as the facility of acquiring technical skill and education, even of the protection of law, sanitary precautions, and even the consolations of religion. For society has withdrawn from them the natural means of acquiring wealth (by its recognition of private rights of property), and it destroys the clan or tribe-that form which the expanded family assumes. Thus for the poor, the general 
authority takes on itself the duty of the family, not only in reference to relieving their immediate distress, but also with a view to reforming their disposition to laziness, their malignity, and the other vices which spring from such a situation and the sense of the wrong done them.

But poverty $(\$ 242)$ and all forms of distress to which the individual in his natural sphere of action is exposed, has an inner or subjective aspect as well: and it thus requires a subjective or personal assistance to deal with its special circumstances of every ease, as well as to satisfy the claims of the heart and love. 'This is the point where, whatever general scheme of action be adopted, personal and individual morality will find enough to do. But this assistance is liable to fortuitous influences, both for its own awakening, and in its effects: and society accordingly does all it can towards eliciting the permanent features of the distress and the general principles governing, so as to reduce it to a regular system, and to dispense in some degree with individual assistance.

The fortuitousness of alms-giving, of charitable institutions (and of the burning of lamps at the images of saints, \&c.), is supplemented by public poor-houses, hospitals (public lighting of the streets, \&c.). Private benevolence has still enough left to do, and it is a mistake to claim this relief of distress as solely belonging to the moods of individuals, and the casual character of their temper and knowledge, and to feel injured and annoyed by obligatory general regulations and orders. The state of the public is, on the contrary, to be regarded as more perfect, the less is left for the individual's own personal and particular fancy, in comparison with what is reduced to a general organization.

Where society ( $\$ 243)$ is left to its own unchecked action, its course is marked by a progressive advance in population and industry. As the interdependence of men upon each other through their wants (demands) becomes more and more 
general and comprehensive, and as the modes of preparing and supplying the means of gratifying these wants become also more general, so does the accumulation of wealth increase, just because from this multiplied generality there is drawn the greater profit. But this accumulation of wealth on one side is met on the other by the narrow and highly special character of the special labours, and by the dependence and distress of the classes which are bound down to these labours: a dependence which entails an incapacity to feel and enjoy wider liberties, and in especial the intellectual advantages of society.

A large body of men ( $\$ 244)$ is thus depressed beneath the standard of subsistence, which naturally fixes itself as necessary for the members of any given society. It loses the sense that it is right, and honest, and honourable to support itself by its own activity and labour. 'The result is the production of a rabble $($ Pöbel $=$ proletariate $)$, which in its turn involves an inereased facility of concentrating a disproportionate amount of wealth in a few hands.

Supposing ( $(245)$ the burden of maintaining in a decent state of subsistence this mass which gravitates towards pauperism is imposed upon the wealthier class, or supposing direct means for this purpose are found in other public property (rich hospitals, charitable foundations, monasteries), the result would be to guarantee the subsistence of the needy, without their being obliged to labour for it. Such a result would run counter to the principle of society and to the sense of personal independence and honour. If, on the other hand, the subsistence of the needy is made to depend on labour (by supplying work to do), then the stock of products would be increased. But the evil lies in surplus production, and in the absence of the proportionate number of consumers, who were themselves productive. In both ways then the evil is only magnified. In this way it becomes obvious that with all its excess of wealth, economic 
society is not rich enough, i.e. does not possess in the capital that is peculiar to it enough to keep clear of the excess of poverty and the generation of the proletariate.

These phenomena may be studied on a grand seale in the example of England, as well as the consequences that flow from the poor-rate, boundless charitable foundations, and no less unlimited private beneficence, and above all from the abolition of the eorporations. In that country it has been found (especially in Scotland) that the directest means against pauperism, as well as - and especially-against throwing off all shame and honour, the subjective basis of society, and against the laziness and profligacy, \&c., from which the proletariate issues, is to leave the poor to their fate, and to refer them to publie begging.

In this way, it is shown, eolonization becomes neeessary, and commerce with lands at a more backward stage of civilization.

But when ( $\$ 249)$, instead of realizing the permanent and general elements of society as a mere external order and machinery for the protection of masses of personal aims and interests, the several branches of the social body try to make these permanent elements, implicit in their class interests, the object of their will and activity, society assumes a moral character in itself, and presents itself in corporations. It is in the industrial order, and especially among the artisan class, that the corporation flourishes. Such a corporation takes the place of a second family - a position which general society, in its greater remoteness from individuals and their special distress, could only perform in a vague and general way.

In the corporation ( $\$ 253)$ the family gets a solid basis, a guarantee of subsistence which is conditioned by capacity, a solid basis of capital. But it not merely has such a guarantee : the fact is invested with open recognition, so that the member of a corporation does not require to exhibit any further external certificates to prove that he is something, to evidence his 
qualifications, his competence and ability to make his way in the world. In this way too it is recognized that he belongs to a group, which is in its turn a member of general society, and that he is interested in, and takes trouble for, the more unselfish aim of this group. Thus in his order or estate he has his honour.

The institution of corporations, securing to the individual his craft and skill as capital or source of revenue, corresponds to the introduction of agriculture and private property (in land, \&c.) at another stage. If complaints are made about the luxury and prodigality of the industrial classes, and the consequent production of a proletariate or rabble, we must not forget, over and above the other causes (e.g. the tendency of labour to become more and more mechanical), the moral reason which has just been given. Without becoming a member of an authorized (chartered) corporation-and it is only as authorized that the association is a corporation - the individual has no class honour; by his isolation he is reduced to the selfish side of industry, and his subsistence and enjoyment want stability. In such a case he will seek to get himself acknowledged, by external exhibitions of his proficiency in his trade-exhibitions which are lawless because, as his class or order has no existence (for no association has existence and place in society, except such as are legally constituted and acknowledged), there is no possibility of living according to his class-requirements. Thus he is without any more general mode of life appropriate to him. In the corporation the aid which poverty receives loses its fortuitous character and its unjustly humiliating aspect: wealth again, in its duty towards the fraternity, loses the arrogance which it stimulates in its possessor, and the envy it exeites in others: and honest worth receives its rightful acknowledgement and honour.

The corporation ( $\$ 254)$ involves a certain limitation of what is called the natural right to exercise one's skill, and thus to make what profit can be made. But this limitation 
amounts only to rendering that right reasonable: i.e. it is freed from its self-conceit and fortuitousness, risks to itsclf as well as for others: it is acknowledged, guaranteed, and thus elevated to conscious activity for a common end.

After the family $(\$ 25.5)$ the corporation constitutes the second of the moral roots of the state-a root founded in civil economic society. The family, or first root, holds in undifferentiated unity the two principles of subjective personal life, and objective life for the community. 'These same two principles appear in economic society as the principle of particularization of wants and enjoyment on the one hand, and the principle of abstract legal generality on the other. The corporation, or second root of the state, brings them together in an inward way, and in this combination the welfare of individuals is realized and in a legal institution.

Thus sanctity of marriage, and honour in the corporation, are the two points at which the disorganization of society makes itself felt.

But the corporation $\left(\$ 25^{6}\right)$ is restricted and finite. And thus it, no less than that separation of aspects and their comparative identity which is found in the external order of social regulations, finds its full truth in a purpose which is and is known to be universal, and in the absolute actuality of that purpose. Thus the sphere of civic society passes over into the State.

In the State the inequalities of economic society are corrected. In days of peace, when all the departments of social life go on side by side as if independent, people lose sight of the fact that they and all they possess repose on the State. But in war what Hegel calls the 'ideality' of all private interests is made manifest, and devotion to the State is presented as universal duty and the very basis of all life. 


\section{IX}

THE LEGAL, SOCIAL, AND RELIGIOUS SANCTIONS

OF MORALITY

Ethical writing in England, as befits the supposed character of the nation, has had a predominantly practical aim. The more eminent of the authors who have tonched upon or who have treated the subject have had their eyes mainly turned to the interests of moral training and social discipline. So it was with the great thinker of the Elizabethan age, when he noted with censure the too exclusively speculative and abstract inquiries of the Greek philosophers, and indicated the new needs and purposes of the modern spirit, which from his prophetic soul already received the expression of its under-current tendencies. The moral philosopher of the future, said Francis Bacon, instead of wasting his time and talent in a minute delineation of a-superhumanly grand-ideal or Exemplar of Good, ought rather to lay down the methods and means by which this ideal might be realized, by tracing the roots and fibres of good in the physical order, and showing how natural conditions might be manipulated by superinducing habits and so 'framing and subduing the will of man to become true and conformable' to the pre-established pattern.

In Bacon's footsteps his successors have largely continued to travel. Hobbes is hampered by no suspicions of the quicksands which beset the voyager who would carefully thread the channels of investigation into moral principles. A few simple calculations from maxims that lay claim to an axiomatic self- 
evidency, a few deductions from the great natural law of equality and proportion, which reason, being the same in all men, enunciates and commands, are enough, in his opinion, to construct the outlines of a sufficient moral philosophy, to establish, in other words, a science of 'the means of peaceable, social, and comfortable living.' 'To discover the law of nature and of reason-that moral law, whereof he is as careful as any of his opponents to affirm the eternal and immutable obligation-is a problem which does not require profound meditation, but may be solved with comparative ease. What is to him the problem of problems is to find how this ideal authority, which only obliges in the inner man, may become a power in the actual world, a ruler over the deeds and lives of men. And to get this real power, to secure the practical force of uniformity and order, which is of the very essence of law, no price seems to him too high, no sacrifice too costly.

Even Locke, with all his love of moderation, does not hesitate to state his conviction that, if people were only honest and plain with themselves, morals might with the greatest. ease be reduced to the certainty of a mathematical science. But it is in Bentham that this aversion to speculative theory in ethics reaches its maximum. He tosses aside, with contempt, and perhaps a mutter of impatience, the subtleties of discussion on the origin of moral distinctions, or on the bases of moral obligation. To him such questions so prolonged into unending dialecties seem to betray a stupid and perverse habit of mind, a mind overgrown by prejudices. Any open mind, he asserts, can see at a glance that nothing can claim moral approval except what tends to the greatest happiness of the greatest number, and when you have seen that, you have grasped the one principle necessary. Such a principle is rather more vague than it at first seems, and is not quite free from the double edge of confusion that lies in wait for the believer in platitudes. But Bentham, strong in possessing at least an apparent standard for adjusting measures of 
action, turns his entire energies on the problem of moral education, and, in particular, on the methods of discipline. The principles of social paedagogies, the rationale of rewards and punishments, the modes of adapting his stimuli of pleasure and pain, our two sovereign taskmasters, to the almost endless variety in human natures-these are the points towards which Bentham devotes his powers of analysis, and on which he is anxious to effect a thorough reformation.

The facts as alleged are as follows. First, you have each human being, by an instinctive impulse we may call a law, doing what gives him pleasure and refusing to do whatever causes him pain. Then you have the great fact that there is a moral law, in the sense that each man is expected in case of conflict of pleasures to surrender his particular share, if by so doing the greater pleasure of the majority or entire body is gained or secured. A state of things may perhaps be imagined in which this conflict would be reduced to a minimum. In such a state so clear would be the mutual sympathy, so complete the identity and harmony of aim, so inextricably interwoven the aims and desires of all members, that each would see that his own best interest was secured by serving the community, and that in serving others he was serving himself. But the solidarity and the intelligence involved in such a supposed state, though possibly not so entirely absent as the satirist would insinuate, is not to be assumed without many drawbacks and shorteomings. Passion and prejudice distort or blind the judgement, inferior and partial ties between individuals clash with others equally partial, and with the general aims of the collective community; abnormal temperaments and unusual experiences disturb the harmony of taste and purpose. In the shortness of life it is found impossible to get the long time needed for the generation of that sound knowledge and steadfast conviction, which is the only sure means of maintaining the social harmony and realizing the social end. We must, therefore, fall back upon a lower 
range: we must fight pleasure-seeking by pleasure-seeking, or pain by pain. We cannot wait till the right thing be done in the right way and in the right spirit. It has to be done: that from the outside social point of view is the one thing neelful; and if it only can be got done, we shall not be very curious to ask how.

Such pleasures and such pains, having for their effect (and possibly for their object) to minimzie the conflict so prone to arise in ill-regulated sonls between their immediate impulses, appetites, and instincts which they would fain gratify, and the commandments of social welfare, the felicific order of the moral law, are what have been called the sanctions of morality. The term most properly refers only to punishments, or threats of punishments, to the law-breaker: but it is perhaps no unwarrantable stretch of application to make it cover also rewards for the law-keeper. Sanctions, then, refer to a law: and it must be understood that morality is thus paralleled 10 , what it is so often contrasted with, a law. 'The phrase, 'the Moral Iaw,' is indeed a commonplace. It is perhaps not so much of a commonplace that the name in its origin denoted a portion of the positive code of the Jews, distinguished from other enactments bearing less directly on everyday social welfare: whereas the use of the word, especially since the days of Kant, has carried it into regions where law positive is altogether unmeaning. But, again, if morality be taken as a sort of law, the sanctions which help to enforce it bear reference solely to actual performances. The morality that is secured by sanctions is the morality of outward behaviour: it is what has sometimes been called legality. And to those who speak thus of the sanctions of morality, morality means partly the acts required by the public law or law of the land, but partly, and perhaps even more especially (in virtue of contrast with law positive), it means the acts or forbearances called for, or in various ways enforced, by the customs and fashions of society in its various groups, as well as by the law 
of God or the law sacred, ceremonial and religious. Should morality mean something more than this, or something different from this, something that lies within the heart and will, between the man and himself, between the soul and God, then, it may be asserted, with such a sphere the sanctions cannot directly intermeddle.

Bentham, with his fondness for classifications, has drawn up a brief list of the chief sources whence pains and pleasure may flow to corroborate the general tendency, which we may assume to exist in the human being, to subordinate his wishes to the dominant condition of subserving the common welfare. They fall into two great groups, according as the rewards and penalties are directly or indirectly introduced into the facts by the agency of rational beings, or are spontaneous operations of the natural forces, enforcing the ethical requirements, and tending to show that the moral order is in harmony with the general physical laws. The latter of these is the so-called physical sanction. There are obviously cases in which an act, called forth by an immediate stimulus of pleasure, is followed by a greater balance of pain and loss: and there may even be acts in which the performances required by law and custom are directly pleasant. In such cases an ordinarily intelligent person will by mere prudence be led to conduct in accordance with moral laws. For practical purposes, perhaps, we should limit the applications of the physical sanction to those results or effects which are obvious and undisputed, even, we may say, visible and tangible; to cases where the causality is unmistakeable, or traceable with a kind of arithmetical accuracy. And such experience is perhaps most accessible in the case of many of the virtues and vices which directly regard our own persons, our full selves, corporeal as well as spiritual. And beyond this personal morality with its discipline of the appetites, where prudence manifests itself as temperance and self-control, it is undesirable, at least in 
the first instance, to extend the range of the physical sanction. It is by such considerations of retributory pain following on excess, that the sobriety and moderation which society requires are commended to the reason, which, if at first it seems only the ministering servant of the several appetites, soon becomes, like a wise servant, the mastel who rules them, were it only by playing off one against another.

It is possible indeed to go beyond this narrow limit, and to lay down that the moral law coineides with the law of nature, and that morality and physical well-being tend in the long-run alway's to go together. But if we thus assert that the very stars in their courses fight against evil and make for righteousness, that all things work together for good for those who follow the right in scorn of consequence, we are, in the first place, rumning the risk of destroying the practical efficiency of the sanction, by boldly assuming it to extend to a region where the warrant of verification is hardly possible. And that is not all. Even if the doctrine of the identity of goodness and happiness be true, its truth is reached only by giving to the words an interpretation other than what they usually bear. In that high sphere where moral goodness is its own reward and happiness ultimately implies virtue, it does so because happiness and virtue have alike been raised above their ordinary meaning into something which it has not entered into the ordinary heart of man to conceive. The natural order of which we spoke must be transformed into a nature which would better be styled supernatural. The nature which the moralist assumes as his sanction, that supernatural nature which is the fina! moral order of the world, is a law which he could only read in the apparent chaos of the sense-world, because he had more or less clearly seen it with the inward and intellectual eye in the world of his own spirit. If moral philosophy may, as Bacon said, save itself much futile inquiry by 
earefully gathering up the hints afforded by the unity in difference, by the attractions and proportions, the gradation and centralizing organization of the material universe, it must begin by spiritualizing nature, before it can extract from nature the law of the spiritual world. It is, on the other hand, just beeause the physieal sanction goes but a little way, that its work has to be taken up and continued by sanctions derived from spirit and intelligence.

For man is not merely a part of nature, a sentient organism affected by the material struetures of the universe; he is also a social being, a member of what has been called the social organism. The term serves to emphasize the dependence of individual on individual through the totality of the group to which he by nature or choice belongs. It recognizes the essential teleological relationship of each to all and of all to each : but it falls short of giving expression to the fact that this relationship in ever-increasing measure works through ideas and not by mere mechanieal impacts or material pressure. It forgets that here the unity, which had erewhile been immersed in matter and only manifested in systematic and harmonious movements, has now assumed independence and a being of its own: that it has an existence not merely in, but also above its envelope: that it rises, in short, above itself so as to survey itself, and even to reorganize itself in further forms. It is at once immanent and transcendent: the organizing principle embodied in the mass, and the spirit detaching itself from its absorption, yet not from its connexion, rising into ever more controlling and commanding phases of activity, creating a social organization, a special order of superintendent ageney, a literature and art, a religion and a philosophy.

But for the present we need only consider the agency of this social structure as it surveys itself and guides its organization in the light of its double disciplinary function : first, as an organized total, and, secondly, in its looser and 
more particular groups, as yet but imperfectly cohering with the spirit of the total body. These grive the so-called legal or political sanction, embodied in the laws of the country, and the social or popular sanction, lying in the censures of class opinion, of general opinion, seandal, reputation, fame; in some cases, not groing beyond a mental judgement telling through sympathy in the minds of those who feel it, but in other cases accompanied, in the lesser groups where it prevails, with more or less of material loss and pain in those who are subjected to it. In early times and small undeveloped societies there was no hard and fast line of distinction between these, any more than between law and custom. Yet even there, there are fundamental conditions of soeial life felt to be essential and common, and others on which opinion still fluctuates and varies from person to person and from group to group, which refer more to the sentimental and ideal side of life. 'There are things and acts which by a palpable and visible effect injure the community, at least its members, and there are others which indieate divergencies of taste and aim, differences of judgement, annoyances which can be felt, though it is not so easy to define their precise causes or modes of operation.

To discuss the legal and the social sanction is to ask what is the influence of laws and of social observances upon morals. Or, we may even say, it is to ask a more comprehensive question: what are the actions and reactions on each other of law and custom on one hand, and of morality on the other? Probably a little reflection will show that, although it is for some purposes convenient to oppose law and custom to morality, and even to set law against custom, these distinctions should never make us lose sight of the interdependence of the outward and the inward, of the general and the particular, in one comprehensive idea. In plainer words, it has to be remembered that in the average community the conduct required by the laws and by social 
opinion is what in a way is done or supposed to be done by the predominant majority of the population, and that the conduct to which legal penalty or social stigma is attached is the sort of behaviour only likely to be exhibited by a comparatively insignificant minority. What the society believes itself to do, what each recognizes in the case of every other to be right (however he may in practice exeept himself from the obligation), is what it requires by law and custom. The law states what is done by the vast mass of the community, and not merely what ought to be done: or it presents what is done by the majority as what ought to be done by the small minority.

Law and custom thus represent the result of a process by which, out of the fluctuating mass of what is actually done, there emerges a solid nucleus which serves as a rule or standard, when conscious reflection upon conduct seizes upon the common element, the dense central mean of conduct, around which the divergeneies tone off on either side. Just as, in the individual human being, the experience of life enables him to fix on a more or less definite pivot of belief and thought within him, on which his various opinions and tendencies turn and which he regards as a permanent higher self, so the intelligence of a community gradually detects, and at length fixes in independent outlines the broad middle way on which its movement tends more and more to accumulate itself. In apprehending this, the community, like the individual, has as it were come to itself, has reached the unity and essential principle of its existence, the universal of its particularity.

But with the separation of the common and universal nucleus from its variations and outrunners, there arises an antagonism and a danger. An antagonism: the average presents itself as a normal: what is as what ought to be: what all in a rough sort of way do as what each definitely and precisely has to do. Compulsion and constraint and 
coercion are in the air: the individual sees the law as an external force, an alien control. The law confronts him embodied in a judge, an officer, a government; personalit is set against personality, will against will : organic interdependence is replaced by a more mechanical relationship: the sense of free agency, of autonomy, is replaced by requirement ab extra. The state and the community may in their essence and theory be an organic unity: as they appear in the practice of government, they sink into a machinery, which involves a good deal of friction.

So far as the laws proper are concerned, we have to note a difference in their operation. The older codes of laws content themselves in the main by noting the injuries to the members of the community or to its peace and security in general, which they deem desirable to punish by various inflictions and sufferings. What these are, will of course depend on the social and political system which has become established. But the punishment is in each case directed against an actual violation or outrage on the social order as it exists. In course of time legislation embraces a secondary order of crimes, which are crimes only as it were constructively and ex lypothesi. Penalties are imposed upon acts which lead, or which are for good reasons believed to lead, to results which will be injurious to the common welfare. Here we have the prophylactic action of the state. Trusting to the lessons of experience and the inferences of science, it attempts to eatch an evil before it has assumed actuality, while it is yet in embryo and possibility. In these cases to omit a precaution, which experience has shown to be a valuable safeguard against the emergence of notable calamities, renders the culpable negligence liable to a penalty. Here the State no doubt uses the knowledge gained of the physical sanctions waiting on certain forms of imprudence: but its action is not so much in the interest of the agent, as of the other members of the community, who may probably 
suffer through his neglect. Here, where unassisted nature may be supposed to let the children suffer for the fathers. or the neighbour for the neighbour's sin, the State endeavours to bring home the remote result to the original offender by replacing the ultimate result by an immediate penalty.

Thus, as a rule, while the earlier laws do not require a performance, but only punish the commission an act they forbid, the later punish the omission of a prophylactic act. they require. In this department of law it is evident that we come close to the kind of observances required by society in its non-political and private aspect. It insists upon uniformity: it lays down a particular way of action or behaviour and insists upon conformity. Thus grow up manners and customs, rites and observances, usages and fashions, ritual and ceremonial. While the laws are directed at special performance or non-performance, the social sanction is jealous of any departure from its one course, it craves an unvarying obedience and will hardly permit even a divergence in thought and opinion. This is the vóros $\delta \epsilon \sigma \pi \delta$ í $\eta$ : the custom which pries into and seeks to direct the heart, which persecutes every non-conformant, which would impress on all the stamp of a single model.

But it may be well to point out the source of the tyranny. In its origin custom is wholesome: it is to a large extent the unforced product of common insight and common need in common circumstances. As such, it is no tyrant, but the spontaneous sympathetic action of individuals. Yet as a matter of fact this coincidence is often unreal and superficial. The natural differences of originality and creative or perceptive power, the tendency to imitate in one part of a population which supplements the claim of leadership in the other part, the habit of accepting what is asserted and of imagining that one believes what one has not force enough to discuss--all these proclivities make custom and fashion 
dictatorial and arbitrary, make them represent the verdict of a dominant clique rather than the result of a common effort and a consensus of original opinion. In its ideal the rox populi may be the rox lei: but in its actual appearance it is often the aceidentally predominant opinion of a minority which has put on the semblance of a majority. In such a case, we speak of the tyranny of public opinion, and of the obedience of a multitude to a fancied authority which only a little courage is needed to reject.

'The common law is a realm of liberty compared with the iron bond which these social requirements east around the members of a society. But in either case it has to be remembered that these sanctions operate as moral or quasimoral agents; not as external forces, but as inward constraints. Neither the law nor the custom has its force from its mere mechanieal weight. Its strength resides in the inner confession of the sufferer from its penalties that he deserves his doom. As mere brute force, they are on a level with the forces of nature: they may smite the defaulter down, but when they do so, they rather stimulate and corroborate his will than subdue it. They are felt to be mere accidents from the force of an alien world, a world for which he has no respect, which lies utterly outside him, and outside the world in which he lives. It is otherwise when they are felt as the objectified utterance of his own substance, of his permanent and underlying self, of the world and the life with which his momentary self and life are bound up. To the criminal, in whom the sense of his own partnership in the system to which these laws give expression is utterly absent or dead, the law and its penalty have the same deterrent force as the terror of man's vengeance has on the bloodthirsty or mischievous animal. But wherever the sense of social solidarity still exercises its force, wherever the culprit realizes his own fundamental unity with the authority which made the laws, there the sanction of law and social observance exerts its 
potent psychological force. It is the esprit de corps, the social conscience (and eonscience is essentially social, essentially the voice of a common reason), which makes the mere loss, suffering, and injury a punishment. The sanction after all does not operate from without: but by its ilentification with what is within. It becomes a punishment only when, or in so far as, it is recognized by the sufferer as the necessary sequel of his own act, its inevitable consequence in a world so constituted, and that world as the framework and substantial reality on which his own life is founded. Punishment as an ethical force only emerges when this sense of social solidarity is awake and active: and it was this condition to which Becearia gave such absurd expression when he based the right of the community to punish its members on their actual or implied agreement to accept the penalty of their deeds.

There is, however, a question that falls to be considered here. How far are the aets and observanees demanded by these sanctions moral in their essential quality? How far do law and custom encourage or forbid in accord with the requirements of the moral sense? Of the law it may be said that what it insists upon is rather the sine qua non of morality than morality itself. And of a great deal of social ethics it may be said that they are prophylactic of morality, but not themselves moral. They are the sign and symptom indicating with greater or less accuracy an essential and underlying frame of mind and direction of the will. This, moreover, is not the whole. The social form and legal enactment remains unchanged even when it is no longer in harmony with the inner state of affairs. It comes to possess an authority of its own, independent of what it represents: it asserts itself as a separate structure, with a life and interests of its own. Such an organ of the common life, thus invested with a separate vitality and with a standing of its own, is a morbid growth :- 
'Es erben sich Gesetz' und Rechte

Wie eine ew'ge Krankheit fort:

Sie schleppen von Geschlecht sich zum Geschlechte

Und rücken sacht von Ort zu Ort :

Vernunft wird Unsinn, Wohlthat Plage.'

But this is a disease and a discord not confined to laws. Art and science, literature and religion, also, in the objective institutions and quasi-materialized shapes which they assume, and must assume if they are to be powers in the real world, tend to beeome stereotyped in a traditional form and to be transmitted from age to age, as if they had a value of their own, and were not essentially valuable as factors only and elements in the total life and action of humanity. The inward spirit of morality, in itself inclined to antinomianism and autonomy, inclined, in other words, to claim an abstract and one-sided right of self-determination, is the natural and legitimate enemy of mere conformity, uniformity, and obedience to traditional restraints; but they both are elements in the social life, where moral order unites with moral liberty, and the conservative impulse is in conjunction with the progressive. The moral life, the idea of the social organism, is only maintained in vigorous antagonism, where resolute adhesion to all that is worthy in the past is matehed with resolute endeavour to reach the fruition of a worthier ideal.

It is in the consideration of this antagonism at the root of social life that we find the ground of the tragic character of the ethical process. The human being who is to reach true happiness, who is, in other words, to attain the full fruition of his being, to compass high ends and rejoice in his performance, must, as Plato says, have a suitable and proportionate community; he must, as Aristotle says, have a complete life and fortunate environment. But such duly graduated and harmonious development between man and man, between group and group-not to mention between man and nature-is far from universal, or even very common. 
Wery part, like every man, has the defects of its qualities: it is the nature of finite things that they can only win something by ignoring or letting slip something else. No one party has a monopoly of social virtue. In the tangled skein of luman affairs, to draw out one strand clean and clear requires you to cut or maltreat others. The one view, moreover, in its extremer form inevitably calls forth an opponent with equal one-sidedness but in an opposite direction: yet the two antagonists only come by their antagonism because in their imperfection they yet have a latent sense of their totality and turn angrily against the side which reminds them most keenly of what they have missed. The persecutor when he tortures a dissident belief is angriest because in his heart of hearts he feels that he is fighting against an enemy that is of his own house and has an echo in his own breast; and the sufferer partly undergoes vicarious punishment for this inner foe. Just as, in a very different sphere, one, who has already felt the power of love but unwillingly, struggles hard against its chain, and in blind passion vexes the loved one as the source and objeet of his or her own weakness; so the violence of party strife is often an involuntary and uneonscious recognition of the, at least partial, rightness of the other side. Thus when Saul is loudest in breathing slaughter against those of the Christian way, he is already in the mood that may at any moment break out into conversion to the faith he denounces.

So it is also that the essential sanction or rather impulse given by law and custom is that they embody our own will and mind: the will which, though permanent, we had forgotten. They are the image of our true selves, of sides and depths in our nature which the pressure and distraction of life had obliterated. They speak, as Plato says, with the voice of aged parents and once-esteemed friends whom we would rather not meet, but whose monitions, whether we will or not, haunt us with the power of an insuperable 
necessity. 'They are the face of his country as it presents itself to the deserter and exile.

If it be the failure of the sanction-aspect of political and social laws that they are looked at solely as external forees, and not as deriving their efficacy from their kindred with the forces within the soul, this is still more apparent in the ordinary way of looking at the religious sanctions of which it is now time to speak. In one sense of the term-where however it would be better to speak of the ecclesiastical sanction-it only denotes a peculiar variety of the social sanction in general. 'The church, e.g. as forming a special organization in the State and in society, may exert an influence by separate ecclesiastical penalties on its members, and even create within its bounds a moral standard of its own; or a theocracy, a sacerdotal order, claiming to goveru as the vicegerents of a divine inspiration, may produce a type of conduct and character unlike that of the ordinary community. In a community where the power of the civil state is ill-established and its functions of social regulation illperformed, the ecclesiastical organization-especially when it wields the influence of a more than national union, as it did in the case of the mediaeval church-may assume the post of a judge and regulator, and thus do the work which the secular government is unequal to perform. It is true that, in so far as the religious creed adopts to the secular life an opposition of ideal and aim, such enforcement of morality through the consecrated order may err on the side of asceticism. But these are tendencies not necessarily connected with religious sanctions.

In any case, indeed, the sanctions of religion form part of the established social and political order: sometimes as one of the many social influences, sometimes in close alliance with the secular arm of the state. But ordinarily the sanction of religion means either the occasional direct interference of God in human affairs, punishing acts and omissions 
that escape the meshes of human justice, whether legal or social, or the inevitable final penalty and reward attached to these and other acts in the future world. The former is the belief in a divine power, outside nature, yet supreme over it, which punishes great criminals whom human justice fails to overtake, and secret evil-doers of whose acts the ordinary sanctions have no cognizance. The latter is the belief that all conduct, besides its obvious effects, and its obvious accompaniments in reward and punishment in this world, has future effects and infinite issues: or, in vulgar language, that the good done in this world is rewarded hereafter, and the evil done in this world is hereafter punished. The beliefs, we have said : for here also it is not the outward force of an angry deity, but the faith of the religious mind that creates or contains the sanction. It is the belief in the validity of a sanction which for moral purposes constitutes its force.

It is here that we are often introduced to the 'supernatural.' But this term, with its antithesis the 'natural,' are words to which we should not much pin our faith. What nature is in all the actuality of its detail, is what none of us know. Nature is simply a way we look at the world, a law, condition or conception, under which our mind compels us to look at all facts or supposed facts : it is the statement that whatever exists, exists in complete interdependence; that there is nothing irregular, nothing chaotic, nothing absolutely isolated and unconnected in the natural world. Of this we are absolutely sure: or rather it is the fundamental condition of all certainty and knowledge. But it is a very different thing to assert that the particular uniformities of event which we have ascertained, the particular sequences which have actually been observed, are all the uniformities which exist, and that they exhaust the possibilities of sequence which may be observed. On this sure foundation rests the fabric of our life and knowledge; and therefore if 
we speak of the 'supernatural' we cannot mean another province of our lives and knowledge, which lies in a sort of local juxtaposition, and occasionally, as it were, forms a sort of enclare in the territories of the natural. We can only mean that the forms and terms, under which we ordinarily grasp the unity of nature, are not the only forms in which that unity may reveal itself: we can only mean, in particular, that the forms of time and place are forms beyond which our thought is sometimes compelled to range. If nature be restricted, as it legitimately enough may, to denote a time and space world, a world in which there is always externality, where the unity of the idea is only as it were interpreted into it from some further source; then by the supernatural, we mean the inward and abiding unity which refuses to disappear from the multiplicity, and yet which cannot find adequate expression in the multiplicity: the natura naturans, as opposed to the natura naturata.

If we ask then how far the religious belief that whatever men's sanctions may do or fail to do, and whatever the ordinary course of nature may do, there is still a Providence that controls the operations of nature so as to realize his moral will, and punishes where man and nature fail,-if we ask how far this belief is agreeable with the 'uniformity of nature,' it will be necessary to note the meaning we assign to our statements. And, first, the words may be taken in an obviously pictorial sense. They may mean that occasionally God does directly and personally interfere with the phenomena of the world, that he appears as an agent upon the scene, and takes a place among second causes, instead of remaining as the great first cause, i. e. not, strictly speaking, as a cause at all, but as the life and thought and spirit of all causes. At momentous issues in individual, national, or universal human life, at peculiar places where the world-drama has for the time concentrated its interest for the obscrver, God, as it were, rends asunder the veil which H h 
is ordinarily supposed to cover him, and an almighty right hand is stretched out to make itself felt in human affairs. Such a view is one into which the observer readily falls, who sees events from his limited standpoint and with his limited and particular interests. He views things, as the philosopher would say, from the ground of his senses and his imagination, not from the standpoint of reason. Absorbed in his own, or his nation's aims, he see things from a false point of view, and can only explain the marvellous in his survey by the hypothesis of extraordinary forces. If he is right in his general assumption that no event happens without God, he is wrong by the partial way in which he confines the divine action to a special interference in his affairs. Such a belief may be and often is pictorially effective; and for those to whom pictorial effect is as it were the last word of thought, there is probably some good in even this partial realization of the dependence of all that we are and do on the great source of life.

Yet perhaps the truer meaning of the phrase is that the ways of the world are not all explained and classified in our philosophy or science, and are not all in subordination to the detailed structure of causes and effects we have actually ascertained; that the uniformities we know are only parts, and the order of nature extends far beyond those details of that order of which we are actually aware. It is, however, to the believer in the moral order of the world more than this. It is a far-reaching faith that whatever is, is right. Such a faith does not imply that an adequate and sufficient good has been attained and that we should rest and be thankful. It is rather the full acceptance of the system of nature and of science, as involving that there is reason in the world, and that it is only a partial or defective view that can speak of absolute unreason. This does not mean that every stage in the process of individual or of cosmic life is in its isolation admirable : it means only that what appears dark 
or dismal in the details becomes bright and eheering in the totality. It is the confident antieipation of the ultimate identity of spirit and nature : a monistic faith in the unity of man's permanent purposes with the cosmie order and movement: a doctrine which is perhaps Spinozist in its emphasis on the essential identity of the ordo rerum and the ordo illearum, though hardly Spinozist in its tendeney to regard the latter as the superior phase of the former.

With regard, again, to the belief in future rewards and punishments, here also we have a statement in the pietorial language of imagination, whereby the timeless truth of necessary law is translated into the successive events of a history. What cannot be conveniently discharged at the time, is to be wiped off at some coming day, with a massive weight of penalty and reward which should not fail to impress the observant mind. God, as it were, stands aside, and leaves the human agent free-play for a season: only to step in with awful rigour when the day of reckoning comes round in the end of all things. But what these pictures tear asunder into scenes is the truth that, beyond the utmost consequences of acts as they reveal themselves to us, there are further and further consequences; that, though for us it is forbidden to trace beyond a slight range the effects of acts upon ourselves and our neighbours and the world at large, such effects do not stop where their influence becomes inaccessible to palpable tests. It is a statement that the temporal is only a part of the Eternal, and that, when the thread of life and conduct disappears to the sensuous vision, it has only entered on a new phase, with issues infinite and indestructible.

And if we ask what are the effects of such beliefs on morality, we must reply that the religious sanction operates in one way, when it forms an integral part of the social system, intricately allied with general ideals, observances, and requirements, and when it has a real hold on the life and H $\mathrm{h} 2$ 
thought of the individual soul-in short, when it is in harmony with the whole other aims and beliefs, the environment and organization. And it operates in another way, when it exercises an influence alien to the general tone and temper, when it owes its place to a traditional reverence, and the power of a narrow organization with its imperium in imperio. There is a living religion, and there is a mere skeleton of organization. The religious organism, the objective form in which it is embodied, may like other organizations become self-engrossed, detached from the general life, and drawing into itself, like a morbid structure, the materials which ought to go to maintain the general well-being.

But what is a religion? It has apparently several elements and grows up from several sources. But as we consider them, it behoves us first of all and above all to remember that it grows and lives in the heart and soul of man, and that it exists there in intimate and perpetual interaction with all other human agencies. It varies with the conditions of the individual and of the community. We must think of it as in touch with the other factors and agencies in human life, receiving and transmitting, as well as exerting influences. To treat it as if it existed and acted by itself is to make an abstraction, which for certain purposes may be just or necessary, but which is none the less likely to be misleading and dangerous. To say that it does this or that, is to attribute to one prominent quality of an agent the effect which the whole agent produces. In the first place, it is the religious man, the religious community which is the real agent. And, secondly, in that agent religion never acts alone. Its operation is conditioned, is stimulated and checked by other interests, other pursuits, and ideals. It is in equal correlation too with the manners and customs, the organization or, it may be, the disorganization of the community.

Man, it is sometimes said, is par excellence the religious 
animal. So too man has been defined or specified as a cooking, or as a visible, animal. But this far from implying that man always cooks or laughs: and it need not be inconsistent with the statement that certain savages are unaequainted with the use of fire, and have never been known to relax in a smile. Nor is it inconsistent with the further fact that the style of cookery varies from country to country, and that the taste for the ridiculous is no less uncertain. By the assertion that man has these qualities we mean that the experience of history can only be explained on the assumption of certain uniform tendencies or formprinciples of human intelligence, which lead, when submitted to appropriate stimuli, to certain tolerably uniform developments. A religion then will be the response of certain tendencies in the human organization to certain conditions in the world around. But there may be all sorts of irregularities and what seem anomalies in the general development. The conditions which promote one line of development may be unfavourable to another. It is equally true that a human being is an artistic, or that he is a commercial being: but the mode in which his artistic or commercial activity may issue admits of all shades and degrees. The circumstances which call out one of these activities may dwarf another. Though art e.g. may be justly called the natural and normal result of certain tendencies in mankind, it is quite true that there are many races and many individuals who would be baldly pronounced inartistic. But the term, like so many of the kind, expresses only a comparative defect, not an absolute want. It means that the art is bad, and does not come up to its ideal. So also there are individuals and races in whom the religious instinct appears dormant, if not dead : others in which science and philosophy are practically non-existent: others in which commerce is nearly unknown. And yet as we survey the history of our race we have a conviction that what man has done, man 
may do: and we credit him always with potentialities which are only occasionally realized. This is perhaps a conviction that expresses rather the postulate of a complete and allround development, than a belief which can be actually substantiated by experience. It is the ideal of the perfect man, of a perfect humanity, in which the several exeellencies of individuals form a social nucleus, a spiritual substance, in which each partly acquires a faculty he would never have acquired by himself, and yet each gives to the total a something none could render but himself. It is the normal social man who is essentially religious and artistic, not always in his obvious individuality any single man we meet in the street, though even in his ease we hold the faith that somewhere within him, however hard to get at and however deeply buried, there is an element which, under the proper stimulus of education, will respond to the call from the art and religion without. Sometimes, indeed, it seems so difficult to find the fulcrum on which to rest our motor, that we incline to deny the susceptibility altogether, and are ready to believe that there are human beings bereft by nature of a moral, a religious, or an artistic sense, just as there are some born blind and others deaf. And yet, perhaps, the homonymy of the term 'sense' here misleads us, and makes us forget that, while the senses strictly so-called presuppose a very definite physical organ, the other so-called senses rest upon a much broader basis, and can arise in a great variety of methods, by very various solicitations; and that they represent to a large extent the individualized form of a faculty which is essentially social, and lives in the conjunct organization of the community, largely independent of accidental and particular variations in the single members of such a body.

The essence of religion seems to lie in the sense that this life and this world, this visible and temporal scene, is only a part, or only an appearance, of a greater life, a grander world, which is out of sense and is eternal: a sense that the 
motors of this ehanging scene are in a world beyond and behind them; that the meaning of existence is not contained in the facts and phenomena patent to observation, but postulate for their explanation agencies and forces unaccessible to the mere eyes and ears. But under this common tendency there may be distinguished more than one shade of motive. There is an aesthetie demand for a completeness and symmetry such as the isolated fragments of existence do not always supply: there is a need of explanation, which primitive ignorance and inexperience call for at a very early stage, but which advancing knowledge pushes further and further off: there is a moral need, which would seek some reconciliation of the unfinished and discordant struggles seen in actual life. Yet this sense of dependence of the seen upon the unseen has in all cases been accompanied by the sense that man, who is, on one hand, a part of the visible and temporary, and so subordinate, is, on the other hand, a part of the invisible and the eternal: so that in him there is a meeting place, as at a point, of the finite and the infinite. While, therefore, he feels his kindred with the things that perish and pass away, he feels also his kindred with the abiding and the invariable, with the gods who live for ever.

Thus if, on the one hand, religion is the feeling of allentwining dependence, the utterness of subjection of the part to the total, of the imperfect finite to the complete and limitless, it implies no less, on the other hand, the anthropopathic conviction that the universe is not without a being or beings who throb with sympathy or antipathy to man, who, at any rate, are not indifferent to him, and who, if occasionally they may be his enemies, can by various methods be made friendly and kind. How far in a given case either of these aspects may be prominent will, as already noted, depend upon the grade of development of the other functions of human energy. A rich, full, active life, unchecked in its activity and 
achieving the self-satisfaction of its aims, will feel, no doubt, the grandeur and majesty of the great powers who envelop human existence, but it will not anxiously crave their help or fear their enmity: it will see in their nature and existence

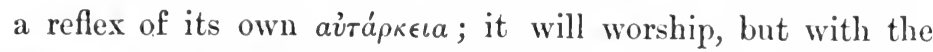
ealm, self-satisfied jubilation of those who glory in their kindred with the immortals, and eheerfully own the vast superiority of those who after all are indissolubly linked with the national life. If, on the contrary, the bond of national life has no outward symbol, if individuals have to find, as best they can, a refuge from the storm of life and a fortress against its perturbations, then the powers of the other world will rise supreme and dominant over the present: they will grow turbid with awful grandeur, and demand the offering of complete surrender. Sueh are the gods of nations rejoicing in their strength and supremacy-projections into the infinite of the national vigour in its finite forms of achievement: and such, on the other hand, are the gods of the needy and down-pressed individuals, seeking in some strange new divinity from lands remote the help that the national gods do not give. Till finally, out of the latter, there emerge religions which tend to supplant the local divinities as well as the gods created to supply a special need, or to be the partial solution of a difficulty-religions which in varying measure are an expression of the need and satisfaction of man as man, in his fullest individuality and in his widest humanity.

Still, not at all times, nor in all circumstances will the religious instinct awake; or if we must say that it is always there, it takes sometimes forms which prevent us recognizing it for religion. It is not for nought that it is sometimes said that to many people wealth is a god, or art, or beauty. All things, said an ancient philosopher, are full of gods. By their actions, at least, such people seem to credit the objects of their devotion with a permanence, a fundamentality, 
a central and all-supporting nature. 'The eye of the devotee, like that of the poet, sees things in their ideal completeness, in a brilliancy and power they never have to ordinary mortals. It gathers round the finite object the wealth of its infinite forebodings, and under the veil of the visible it worships an invisible glory. But for religion in its more specific phase, some greater detachment is necessary: we must rise above practice to contemplation, from engrossment in business to calm abstraction from ourselves and our pursuits. If the world is too much with us, we cannot hope to see God: distracted by its various pursuits, our eye only fixes upon one temporal object after another, and has neither the coneentration nor the power to rise to the totality, or to penetrate to the unity and inner meaning.

We may perhaps note three ways in which this power of the One and All touches. First, there is the sense of loneliness in nature, the feeling of the primitive stranger in a natural environment which in ways many and mysterious comes as a disturbing, or favouring, a controlling influence into his life: a feeling which in the intoxicating attractions of our artificial surroundings is redueed to a minimum, but which may be aroused in one who for longer or shorter time feels himself an outeast and solitary in a great multitude, or who suddenly finds himself in the vast loneliness of naturepossessed by that peculiar sense of the haunting mystery of the outer wilds, so well depicted by the modern French romancer, as speaking to the sailor on dim and distant seas of the misty north, or to the sojourner amid the environing forests of some island in southern seas. But as is the individual, in his feelings and training, so is the articulation of the voice that speaks to him from the circumambient world. Whereas a Wordsworth sees behind the light of setting suns a motion and a spirit that impels all things, the primitive savage finds a deity in more prosaic and proximate objects; yet always perhaps, not so much in them, as behind them, be 
they but stock or stone. It seems somehow as if by many an incident our eyes and hearts, otherwise given away to petty and partial objects and aims, had the veil suddenly taken away from them; as if for a moment they were enabled to see the outlying provinces of life, and to feel the vaster issues of that roar of worlds, which in daily routine we contrive to forget, and which for many purposes we must, if not absolutely forget, at least hear only as a distant and subdued accompaniment to the melody of life.

But if the variety of human fortunes and experiences is felt to be only a department in the great all-embracing universe, if acts and their issues are believed to depend on the unaccountable influences of external forces, or to be a consequence and a detail of the one great cosmic unity; if a dimly seen but intensely felt destiny or overruling influence of fate carries along with it in its train and sweep the lives and works of men, there is also a closer and a kindlier tie which binds the generations each to each, which gives the individual a permanent abiding-place and a substantial immortality. This is the solidarity of human life as first realized in the family and its extensions. But, here too, the full awareness of the bond only comes when the visible unity of the family passes away at death. It is the family deserted of its head which learns to look on that unity as subsisting on and on, yet subsisting in a certain ghostly wise, hardly real, only embalmed in memory; existing in the subjective devotion of those who abide, but supposed to exist quasi-objectively in the ghostly realm of the dead. If the former source of religion consists in the presupposition of a unity in all the incidents of life in the endless range of universal space, the latter welds together present, past, and future in one continuous line of being, and beholds a persistent life running throughout. The infinitesimally short lapse of the momentary and present sojourn of man is felt to be rooted in the past and to have its meaning in onlook to 
the future. It is here that we find what in some ways may be regarded as an equivalent to the modern hypothesis of the continuity of the germ-plasm.

Yet the dead, who have become thus the object of worship, are also changed. If they have lost some of the attributes of humanity, and are thus in worse estate than before their decease, they are also freed from certain of its limitations. They are superior to the ordinary restrictions of time and spaee: they gain an ampler, less defined, more universal being. Still belonging to our general kindred, they have a wider and less determinate range of operation, a subtler power of penetration. Through them the code of family ethics acquires a consistency and authority such as it had not, while they lived: their personality, with all its peculiarities and interfering accidents, disappears, and leaves only the vague, but more emphatic spirit of their general function. Gradually, even, they lose the limits of humanity altogether, and become great spirits of influence: they breathe an ampler ether, a diviner air. They become one with the great forces of nature, with the lordly spirits of the natural world. The father of men becomes also the ruler and principle of the nature.

The fusion is accomplished under the influence of the rise of civilized communities. In such a community man gradually arrives at a new sense of his position in nature and of his relation to his fellows. He ceases to be so directly dependent on the mere grace and bounty of nature : directly, i. e. at the mercy of the accidents of a single place and time. Between the individual and the gratification of his wants is now interposed the whole instrumental machinery of the social union. The concentration and unification of the dependence has in the religious sphere a tendency to substitute monotheism for polytheism, or at least to raise certain deities to a prominence and a permanence unknown before. But the political society is not 
merely an economic organism : it also comes to discharge, and on an ampler scale, the functions of the family and its head. The unity of social life, which under the sway of family ideas was mainly felt as a ghostly influence, inhabiting the realm of the departed, is now realized as a present and active force, distinguishable even from the actual persons in whom it is visibly embodied. Occasionally, indeed, the living monareh, the actual state, may be actually treated as divine, as representing for the time being the eternal majesty of the social force. And in this social force, be it noted, we have a sort of synthesis of man and nature. The culture of the state represents, as Bacon would say, the wedlock of mens with natura: of the human mind with the physical world. Yet even the organized state leads the mind beyond itself: it too is dependent-dependent, so to speak, at its circumference only-but along that circumference the dependence is now seen to be more complete and all-embracing than ever. Yet something further has been gained in the process. The union of man and nature which has been actually accomplished in the arts and sciences of civilization, suggests a farreaching unity in the principles underlying the two sides. God now becomes in a higher degree than before the ultimate purport and therefore the very basis of the social union, of its moral code as well as its material conquests. He has given man the arts of life, has promulgated the law of conduct. That is, here again, the actual sees its warrant and sanction in an exalted ideal, a reasoned-out perfection which is more everlasting and determinate than itself: but that exalted perfection is more than ever in harmony with the actual. Heaven, at this stage, recalls for us the prototypethe moralized and organized world of this earth.

But is heaven only the glorified image, the abiding source and sanction, of the actual moral world, the world of social institutions, the social politico-economical organism? No: religion is more than the sanction of morality; and when 
it is dragged down to this position it is ill both for religion and for morality. The ethical world is but a step, though an all-important step, on the path that leads to God. The social organism, the state, is after all essentially a human and secular mechanism: perhaps, as Hobbes says, the mortal God, but not wholly adequate to the invisible and infinite type. Religion loses its freshness and power when it is treated as no broader and deeper than a moral sanction: and morality is deprived of its human freedom and self-developing growth when it is abruptly described as a eommand from a celestial sovereign possessing unlimited power and wisdom, or even (after the example of Kant) as the law of a realm of intelligent agents, whereof God is the lord. It would be a strange thing, said Aristotle, to consider God as a moral agent. There is a something higher than the life of conduct and practice; and that higher is the life which is essentially self-realization, and not merely a process to something higher than itself. The moral sphere, as we may otherwise put it, has about it a certain unrest; it is an effort to obey an alien law, to work out a problem imposed, to attain an end outside itself. And the problem is by the nature of it insoluble, in the terms in which it is stated. For the very aim of moral action could only be reached by making moral action henceforth impossible. If the world were what it ought to be, what need of further endeavour to make it better. Good itself can only be, on the assumption that evil is there to be overcome: such is the doctrine of many a Theorlicée.

It has been remarked that more than one philosophy has endeavoured to base its moral doctrine on its metaphysical theory, which in the last resort is an article of faith. Thus to one who holds that the end of the cosmic process is the evolution of intellect till it completely subdues will, the ethical rule will take the form of asceticism and quietism. The duty of the microcosm, man, is represented as the normal 
tendency of the macrocosm or universe. So the Stoic taught that the wise man would but cheerfully fall in with a destiny which, even should he refuse, would infallibly carry him with it. It is implied in all this that the moral and social order and progress is from one point of view a part in the great cosmic evolution. In the phases and fortunes of human society there is a great law operative which overrules all individual perturbations and renders impossible all that seems arbitrary or artificial. 
CRITICAL ESSAYS 

HERMANN LOTZE

Neariy four years have elapsed since Hermann Lotze died ${ }^{1}$. His removal from the scene left a sense of real loss, both personal and public, in a large body of friendly readers who hoped that he had yet in store for them a fuller revelation of that subtle spirit of wisdom which had often helped them in the doubts and confusions of modern controversy. It could not be said indeed that one of the great lights of the philosophic sky had gone out; yet at least a bright star had set and left the eye without one of its familiar means of orientation. There was more than the common ground for the trite words uttered over the closing grave that the world was a poorer place since he had gone, and that if he had lived longer, he might have taught us something more. And therefore it hardly needs the appearance of an English translation of his two last volumes, done by a group of Oxford scholars, to suggest a motive for trying to give in English some outline of Lotze's place in the history of philosophy, of his method and his ruling ideas.

For some years back an ill-defined mixture of fascination and repulsion has kept curiosity alive in the neighbourhood of that all but inaccessible peak of adamant, the Hegelian philosophy. Latterly it has been suggested that the sure way to reach its summit, or possibly to attain a more commanding altitude, is to wend along the 'critical' path which Kant made. But that path seems to lead elsewhere: and the wanderers who have gone out by it, are

1 Written in 1885 . 
still struggling through endless hills of difficulty, no nearer the mountain top. It can do little harm to suggrest a study of Lotze as an alternative approach to Hegel. The age in which Lotze first shaped the ideas which characterize him was an age saturated in the conceptions of aim and method of the great German idealists, and yet keenly sensitive to the flaws and failures of their systems. Even if this suggestion turn out abortive and the access to Hegelianism remain doubly barred, the study of Lotze will not have been fruitless. Apart from his dogmatic burthen of ideas and metaphysic, the example of his method-his patient unravelling of tangled arguments, his delieate refusal to precipitate a conclusion till every appeal has been heardwill remain a classic standard for the philosophieal critic. Lotze has besides a special claim on our attention. A student of medicine before he turned to the study of philosophy, he had familiarized his mind with the methodological principles of physical science, and carried into the discussion of metaphysical questions a lively conscience of the requirements of analysis and explanation, which is rare among professional philosophers. Thus if, on the one hand, he may afford a line of regress to idealism, on the other he is not without points of attachment, progressively, to those realistic researches of modern German experimental psychology, which M. Ribot and Mr. Sully have chronicled for their countrymen.

Captious censors may pronounce Lotze to be only 'common sense' in philosophy. Even so, the faculty is not so common that it need be disparaged. Others may allege that he lacks the direct decision of a great teacher, that he guards himself in every dictum by reservations and conditions, and that, though dogmatic in abstract principles, he hesitates and gives forth an uncertain sound when he comes to settle an individual problem or make a concrete application. The latter charge cannot be rebutted. But, it may be added, it is not the highest virtue of a philosopher to solve the Gordian knot by 
a blow of the sword. That is the way of 'practical' men. And 'practical' in that sense Lotze was not. One can understand the worry it must have cost him Saturday after Saturday to sit on the board for testing candidates for the higher educational posts; and undoubtedly it conld only have been the effect of the diminution in the numbers at his lectures during the period he was 'out of the Schools' $(1875-9)$ that he returned to the distasteful task. In his voluminous works there is scarcely a page which touches upon the topies "urrently agitated in the social, political and religious worlds. He does not, it is true, write wholly for the school, but he is academic in tone and theme, and the world for which he thinks is the world of cultivated reflection and scholarly taste. A solitary chapter of his Logie discusses the methods for getting a true vote, when it is needful to pronounce between a number of measures or of men. Yet in a time which swarms with doctrinaires ready for action, it is absurd to give a grudging welcome to the voice of one who neither bans unreservedly nor blesses altogether, but with ealm yet sympathetic judgment weighs good and evil, careful to shun the fallacies of words and the pronounced bias of a transient majority. No doubt to the practical man such a position looks like scepticism. Such a sceptic, too, unsatisfied with the certainty and solidity of much that the specialist looks upon as proved and discovered, Lotze appeared from the first, in his work on the principles of medicine. But when philosophy shall cease to be so sceptical, shall leave the post of criticism to become finally dogmatic, philosophy will be on the eve of euthanasia, with the sciences now made perfect waiting to carry their elder sister to her tomb. It is just because Lotze throughout his teaching never sunk eriticism in mere exposition, but worked up to results by the recurrent correction of successive guesses at truth-in a way that simulates the movement of a living Logos leading him whithersoever it would-that he did knightly service, not 
only as a writer of some repute and popularity, but perhaps even more as a stimulating lecturer for nearly forty years in German universities.

For philosophy in the hands of a professoriate has too often proved unfaithful to her trust. Commissioned by her original charter to keep clean and open the highways of intellectual communication, to light a perpetual lamp in the dark labyrinth of human purposes, and to show through her perspective glass the reality which is hardly visible under the phenomenal aspects of the world, philosophy has sunk once and again into a mere lackey of academic routine and a colporteur of the lore of old tradition. After such a lapse from her high estate, some observer is sure to ask the warrant for her claims, and her title to the rank eonceded her by the arrangements of civilization. Her professors meanwhile either smile like the Roman augur at their own hypocrisy, or complacently take stock of an assured position. They reflect that logic is now more than ever une langue bien faite really to be installed into the memories of pupils; that ethical questions are all practically settled, except for irreconcilables who still rage around freewill, and for revolutionaries who watch for the upheavings of the social storm; and that metaphysics has been finally sent by a sane mental science to rest on the shelf with other historical curiosities, in that vast gallery of the anthropological museum which holds samples of human aberration. In the hardness of human hearts, it is almost inevitable that distribution should thus usurp the place of production; teaching the place of research. The professor of philosophy has been turned into a spoke of the educational wheel, and is no longer, as Plato dreamed, a spectator of all time and all being. The grand instrument of reform, the chief agent in helping men out of the slough of despond, has often sunk into a chief warder of the prison-house of the human mind.

In the history of academic philosophy, that phase of conservative inertia, which has gained the typical name of 
scholasticism, breaks out again and again. In different ages it names its altars after different gods, but they are all honoured only as avatars of the same undying One, the demon of classification. These great names, like Aristotle or Locke, are often much worthier than the mediocrities into which the originals have been fashioned by the hands of faithful but ignorant devotees. Yet the deadly besetting sin of scholasticism is its comfortable persuasion that the sehool was not made for the world, but the world for the sehool. This delusion, that learned institutions were an end in themselves, was notably prevalent in the school which had long time buried in its borders the treasures of ancient ideas. Its dogmatic slumber was broken in the seventeenth century to some extent by that reveillée which was sounded nearly simultaneously in England and France. The very pillars of traditional belief were shaken by the summons of Deseartes to submit every dogma to the test of lucid and complete thinkableness; and for the wantonness of eontroversy Bacon substituted the effort of researeh to establish definite relations between definite elements, with a view to free and strengthen the hands working for human welfare. By this first revolution logie, which had hitherto been used as the handmaid of arbitrary reasoning, received a foundation which one day might serve to support a theory of knowledge and of the method of science.

A second reformation-tardily consequent on the firstundertook for metaphysies what the other did for logic. It is associated with the name of Kant. The new metaphysics sprung from a perception that the older system had started from an unknown God and worked down to familiar man: and it proposed to show that the true synthesis of phenomena could only be reached by a system which began with the analysis of our own endowment of conscious power, and traced out the indications thereon afforded until they offered, if they so should offer, a scheme to explain the secret structure of the 
macrocosm. It first, as managed by Kant himself, the new metaphysics was fearful of its own shadow. It would fain discourage any belief in the higher ideas as more than necessary fictions for ordering and rounding of both knowledge and life. Yet it owned that life would be a bestial chaos, and the theory of organic existence and the sense of beanty an inexplicable deception, unless the symmetry which mind reflected upon the world was a real animating law in the phenomena themselves. As younger heads caught the contagion of the new way of ideas, men plucked from their own consciousness a key to unlock all the doors of the universe. A race of Titans began. Fichte, magnifying the hero for whom eircumstances are only materials for aiding his own development, treated the whole of nature as but a background, delineated as it were gradually into the shape of a world, in order that self-consciousness, in antithesis to a given range of objects, might realize its potentialities in their full form and body. Schelling, a less fiery spirit, vindicated for nature a parallel rank to man, and saw by intellectual intuition their common source in a non-human and non-natural Absolute, -an ultimate assumed sameness from which proceeded two co-ordinate provinces of operation. Hegel, partially learning from both, put mind above nature, and yet made the eternal systematization of thought_the 'idea'-the basis and the result of both. To him the universe was a trinity in perpetual unity. The world of consciousness, while to the cursory observer it seemed a mere incident occasionally varying the even course of physical machinery, was pronounced on closer inspection to be the essential aim and meaning of the operations of nature-the 'idea' or form of law with all its subclauses-which, not being adequately expressed in the physical processes, or even in conseious life (for which, however, it was presupposed), came into manifestation, dimly and sensuously in art and religion, clearly in philosophy :-of which it was thus the mission to reveal God out of nature and man. 
In this new metaphysics the note of distinction lay in the profession to gather from the human reason the organizing principle of the heavens and the carth. The old metaphysics had inherited its dogmas from various sources, Hellenie and Hebrew. What it aceepted it did its best to reduce to logical shape and order, and thence to deduce lower phenomena. 'The new scheme proposed to supply the premises leading up to the original dogmas, to rationalize theology, and to found religion on philosophy. It dared to prove, for those who eould follow its flights, that existence must affirm the reality of those ideas which were postulated by an adequate unfolding of thought as necessary for the maintenanee of the spirit. Yet for those who pondered these promises, it seemed as if the reduction of a dogmatic to a speculative theology led neeessarily to a third revolution. It would then appear that metaphysics is not a mere piece of logic and reasoning, but the work of the concrete human soul, which feels no less than thinks, and is dominated by ethical and aesthetical ideals not less than by logieal rules and forms. It is an ethical reformation which would thus be the necessary elimax of the movement which modified logie and metaphysies.

It was at the very eulmination and erisis in this fever of ideas that Lotze first played a part on the philosophic scene. Of his outward life, apparently, there is not much to tell. An inward balance of powers and tendencies, and probably unrecorded influences of youthful training, issued in one of those symmetrical lives which leave behind but little waste for the chronieler to garner up. Born on May 21, 1817, at Bautzen in the Ober-Lausitz (Upper Lusatia), in the kingdom of Saxony, the son of an army-doctor, who soon after migrated with his corps to Zittau (nearer Bohemia), and who died when his boy was only twelve, Rudolph IIermann Lotze (he dropped the Rudolph ere long) received his schooling at the latter town, after 1828 in its High School or Gymnasium. At the age of seventeen he went up to the University of Leipsic, where four years 
later $\left(\mathrm{I} \delta_{3} 8\right)$ he graduated both in medicine and philosophy (Anglice, Arts). After a little retreat for preparation, and a brief stay in the probationary stage of Privat-rlocent, lotze was in 1842 elevated at Leipsic to the post of professor-extraordinarius, and in 1844 was ealled to Göttingen to fill the philosophy chair left vacant since Herbart's death. At Göttingen he remained for thirty-seven years; and when he left it in 188I to take a chair of philosophy at Berlin, it was only-after a few weeks' lectures-to die on the first of July of that year. Thus, at the age of sixty-four, was closed a blameless, strenuous, and fair-proportioned life, spent in a round of study, writing, teaching, with snatches of rural leisure in vacation, environed with domestic sympathies, and separated by habits and interests from the social restlessness of the time.

The surest waymarks to trace the course of a scholar and thinker are his literary performances: in Lotze's case they are numerous. His first offering to the muses was a little volume of poems in 1840 . After this act of grace, each of the three years following saw a solid work appear under his name: Metaphysics in $184 \mathrm{I}$ : General Pathology and Therapeutics as mechanical sciences in 1842 : and Logic in 1843 . The sterling merits of his medical work indirectly helped him to his Leipsic professorship: and his translation to Göttingen was chiefly promoted by Prof. Rudolph Wagner, to whom he was commended by a similarity of scientific method and attitude in the conflict between faith and science, and for whose Dictionary of Physiology he wrote articles that caused no small stir in the spiritualist dovecots on the subjects: Iife, Soul, Instinct. As early as $184 \mathrm{I}$ he began his contributions to periodical literature by articles in Fichte's Zeitschrift für Philosophie: from $\mathrm{I} 844$ he contributed papers to the Göttinger Studien (notably two on the principles of aesthetics), to the Gelehrte Anzeigen (reviews of books), and other journals ${ }^{1}$.

1 Amongst them, a year before his death, appeared in the Contemporary 
A second period of literary activity began in $185 \mathrm{I}$ with the Cieneral Physioloyy of Borlily life, followed in 1852 by Medical Psychology or Physiology of the soml, and in 1856 by the first volume of the Microrosmus: Ideas on the llistory of Nature and Man, the two remaining volumes of which appeared in $185^{8}$ and 1864 respectively. Connected with this the crowning achievement of his life, in which he has summed up, in a comparatively popular form everything of general interest that he has discussed elsewhere, and added not a few fresh ingredients, was a reply to some strietures of the younger Fichte. This pamphlet (professedly the first of a series of 'Polemies') in 1857 supplies a want of the biographer in dealing with one who seldom or never cares to season with personal talk the dullness of mere abstract diseussions. In the same year he issued a Latin version of the Antigone of Sophocles-no doubt an intellectual holiday excursion, during the strain of composing the Microcosmus, into that Greek world and that 'unique self-enjoyment of existence which' as he elsewhere says, ' everywhere presents its cheering face there.' In 1868 he contributed to the series of histories of the sciences, issued under the direction of the Munich Academy, a History of Aesthetics in Germany: a book which occupies among his writings a position of its own, consisting of a series of thoughtful essays on various aesthetic theories as connected with the general doctrines of their propounders, on the aspects of the aesthetic faculty, and on modern conceptions of Art. His third and last period of literary work was intended to recapitulate the main results of his more purely academic teaching, under what may in his case be called the somewhat conventional name of a 'System of Philosophy.' Of this total only two parts appeared: Logic in $\mathbf{1 8 7 4}$, and Metaphysic in 1879 . The remaining portion, which should have treated of Ethics and Aesthetics-subjects so cardinal in the theory

Review (Jan. I880) the first instalment of a sketch of 'Philosophy in the last forty years.' 
of one who was always repeating that the beginning of metaphysies is in ethies-was never written. Of all these writings only the two last have been translated into English : the metaphysies also into French. The Microcosmus, of which an English translation ${ }^{1}$ has for some time been promised, was long ago translated into Russian. There is a French version (in the Bibliothique de Philosophie Contemporaine) of the first book of the Medical Psychology.

Rarely does a philosophic teacher write, and in such comparative youth, on the fundamental topies of metaphysics and biology, and certainly it is one of the salient features in Lotze's career that at an age, where many men are still fighting for a ereed to live by, his standpoint was already taken and his views on a wide range of questions already formed. Nothing can well offer a greater contrast than his mental history to the frequent change of course which marks the voyage of Kant in seareh of a centre of knowledge, or the slow and secret struggle which keeps many a thinker silent till he has passed middle life, and then leaves him barely time enough to give perspicuous form to the truths he deems himself to have discovered. Temperament and environment had combined to give to Lotze an early, almost premature stability of judgement. The process by which opinions crystallize into a theory had glided on precipitately and yet quietly to a conclusion. There are those who pay for truth by toilsome wanderings on fruitless quests. He came, by the influence of circumstances, into an easy possession of doctrines which, if not absolutely centralizing, are at least amongst the inner range of verities. By the time he was twenty-six Lotze had formulated his views on the weightier matters of philosophy, and on the limits of the principles of science : and by his fortieth year he had published the outlines of his peculiar idealism and discussed the whole compass of subjects on which he allowed himself to dilate.

1 Now published. 
To a person acquainted only with the practice of English universities, the range of subjects embraced by a German professor of philosophy must seem enormous and unmanageable. Logie, psychology, metaphysies, practical philosophy, aestheties, philosophy of religion, philosophy of nature, history of philosophy, - such was Lotze's list of subjects, alternating at intervals during his whole career at Göttingen. For most men such a burden would be unbearable: even for him who can endure it heary costs must be paid out of personal health and opportunity for special development. One is sometimes led to sigh for that division of labour which prevails so generally elsewhere. And undoubtedly there are obvious limits to the extent to which mastery of details can be earried in each of the branches. Yet unless the Positivist contention is to be admitted, and a corresponding branch of physies or physiology to take the place erewhile oceupied by the subdivisions of philosophy (and Lotze in his own youth had maintained the thesis that 'Aesthetics should be treated as a physical science'), the separation of teaching between branches like logie, metaphysics, ethics, cannot be regarded as an unmitigated gain. No doubt matters will be made easier for the teacher who has received a definite subjectmatter, to be dealt with historically and by classifications and analysis, as other sciences are. He will no longer have to complain of being expected to make bricks without straw. But, says the Greek adage: the things that are beautiful are diffieult. In the nature of things, an idea will never be made so tangible as a stone: the ultimate laws of existence must always be perceived by fewer eyes than can recognize the special uniformities. And on two grounds one may plead for some compensation to set against the dispersive tendencies of specialization. In the first place, the doctrines included under philosophy possess a community of purpose, which makes it impossible to sever logic from metaphysics, or either from ethies,-impossible at least, so long as any of them trench on 
first principles, or fail to be content with a mere réchanffée of aneient and vulgar observations. In one branch indeed you may largely observe silence about the other, but only because you have prejudged it and assumed your conclusions. And secondly; when philosophy has come to be broken up into a group of special and detailed inquiries, which differ from other branches of knowledge only because they are less likely to soil the fingers and perhaps to vulgarize the taste of their disciples, it will cease to subserve its main end; which is to keep clear and wholesome the heterogeneous mass of general culture, and to further the universal and liberal interests of man and the commonwealth.

If the traditions of his chair seemed to impose upon Lotze the survey of every province in philosophy, it may be added that the speciality of his own training brought its limitations in the interpretation of that task. Certain aspects of the problems displaced or concealed others. The contact of physics and metaphysies, of body and soul, of nature and history, of mind and matter, of psychology and logic, of the real and the ideal, of God and the world-is under many names perhaps his one favourite theme. Another seareely less frequently recurring tendency is to distinguish adjacent problems, to strip the mask from impossible questions, to expose pretended solutions, to define the limitations of popular maxims and the fallacies in current maxims. But in whatever line, the fruit of his early systematization appeared in the compact and finished formulation of the summaries of doctrine given in his lectures. These dictata, delivered not from manuscript notes but from the memorial stores of a formed judgement to which the way the conclusion was got seemed as essential as the result itself, present in careful miniature a sketch of Lotze's philosophy, which often serves as a key to the larger picture, too luxuriantly labyrinthine, given in his later works. Since his death (1882-4), they have been published from the note-books of his students, 
in eight thin octavos, of less than 100 pages each, dealing with the eight courses, which formed the staple of his teaching.

These lectures given at Göttingen, generally in two courses of four lectures each weekly, both in the summer and winter sessions-delivered, it might be at the hours of $10 \mathrm{a} . \mathrm{m}$. and 4 p.m. respectively-to audiences varying from less than ten in the less popular (e. g. aesthetic) to more than a hundred in the more popular elasses (e.g. psyehology), probably produced on the student youth of Germany a deeper effect than his published writings. Enthusiasm is hardly the word for the feeling of his pupils : but there was a quiet strong attraction in his earnest manner, and the sense that you were listening to one who did not teach like the mere commentator, but spoke with the authority of philosophy itself. His oral teaching had one decided advantage over his written. The reader of the Hicrocosmus and subsequent works often faints bedazzled by the uniform brilliancy of the exposition where no salient abruptness breaks the general polish, and few epigrammatic touches happily print themselves in the memory. Sometimes he loses his reckoning like one who sails along some sinuous channel, where each promontory threatens to close the way and each zigzag of the course discloses a new scene, like, yet strangely unlike the last; and so, growing reckless as to progress, gradually, as he looks on the rhythmic dance of dallying argument, is soothed into somnolent repose. The lingering tendencies of an equitable and reflective mind are combined in Lotze with a too favourable leaning to a quasi-poetical imagery and a falsely rhetorical re-arrangement of words in his sentences. The lesson he had learnt, to look for the deceit lurking both in generals and in particulars, made him interrogate every catchword, and every proffer of narrative in place of explanationof the changeling Mythos put where Logos should have been. These tendencies, which have free play in his later writings, were checked in lecture by the need of being emphatic and 
definite. His earlier writings, though they betray the halting and guarded march of one who knows how narrow is the way of truth, and how many partial truths must be qualified and supplemented if one wants to be honest are still marked by a greater directness of style. The earlier logic and metaphysies-in many ways the most obscure and difficult to understand of his books-are written throughout with a certain youthful rerve and almost impetuous onwardness. And in his pamphlet and reply to Fichte's censures there is much of the same straightforwand rigour.

An author has occasionally been heard to lament that some homonrm among contemporaries confused his account books with fame. Lotze has apparently been the rictim of an opposite mistake. Like an ancient hero, he has been doubled in onder to find a subject proper for the different parts he plays. Tro histories of German literature (those of Kurz and Gottschall) seem to distinguish between a Lotze the poet and Lotze the philosopher. The poet, whom Kurz finds obscure though full of promise, is by Gottschall styled mystical. The poems appeared on the eve of his engagement to his future wife: and doubtless came along with that pure warm blush of imagination which the spring-time of sweet emotions awakes in every nature. But in Lotze the poetry had a deeper source in a perennial power of mind which in the language of an old fantasy nerer allows the discord and dullness of the present to deaden the sense for the harmony and beanty of the cosmic spheres. It might mislead to call Lotze a Mystic: but only because he was much more than that or any similar nickname would imply. Mysticism, it has been said, plays a part in every genuine philosophy. But there is mysticism and mysticism. Sometimes it is taken to mean that at every moment the finite must be dipped into the infinite and thence return saturated with fresh life: that the smallest trifle has to wait for a special intervention of the absolute. One world is in turn immersed in another and released from its influence. 
Lotze, on the contrary, holds that the phenomenal world is also the real: that the infinite is everywhere present in the finite and gives to the finite all its force. But he nevertheless separates the work-lay view of mechanical science from the blissful Sabbath of the spiritual theory. Scientific method must once for all discount the infinite and absolute and prosecute the inquiry into phenomena, mental as well as material, on the hypothesis that definite elements when brought into definite relations with each other exhibit the finite result with invariable regularity. But though it is for scientific calculations needful to imore the infinite, the prineiple cannot be allowed more than an instrumental value. The material is only intelligible as the manifestation of an immaterial: mechanism must presuppose a living mind, and the universal reign of law proceed from the personality of God.

With ideas like these, we are not surprised to learn from himself that it was a lively inclination towards poetry and art which first nuade him philosophize. He came to the study with a head trained in seientific conceptions, and a heart full of the eternal romance of that light which never was on sea and land. His teacher at Leipsic was Christian Weisse. Weisse, originally an admirer of Hegelian method, had gradually diverged from the main current of the system, and, whilst still retaining the form, had sought to find other material, more consonant with established beliefs, which might be systematized by its means. Like the younger Fichte, Weisse tried to put on a better footing those ideas of God, free-will and immortality, which the theory of Hegel had left as exoteric names, not admitting of precise interpretation in the terms of the system. It was with this type of thought, in which the great circle of ideas connected with the names of Fichte, Schelling, and Hegel had come to form ' more a characteristic kind of culture than a rigid system of doctrine,' that Lotze was brought into contact in 'that fair 
time of earlier youth.' In its very vagueness he found the liberty he wished: yet amid the varying matter of private interpretations he gained, he says, a 'nucleus of convictions' which he never surrendered.

The year 1841, in which Lotze's Metaphysirs appeared, marks a crisis in German philosophy. Hegel had died ten years before: Herbart that very year: and Schelling had just gone to Berlin to begin his latest phase. 'Trendelenburg's Logical Rescarches, published the year before, marked a change in the philosophic tone of the age. But the most characteristic feature of the time was the rise of natural science on the one hand, and the great schism in the Hegrelian school on the other. A few Hegelians were still to be found who clung, with a fair degree of orthodoxy, to the doctrine of the master in its integrity. But they were far outstripped in popularity and influence by the pseudo-Hegelians like Weisse, and by the so-called Young-Hegelian group, which includes the names of Arnold Ruge, Bruno Bauer, Strauss, and Feuerbach. The bond of sympathy between men so dissimilar was their common antipathy to the conventional, the non-natural, and the super-natural, their endeavour to reduce imposing historical authority to its matter-of-fact basis, to eliminate the theological from the field of human history, and to 'paint man, man, man whatever the issue.' Accepting the criticism which history passes upon acts, they used it, not, as Hegel did, to show that the rational is the real, but to tear up the roots of old beliefs and institutions in order to show the sordid materials and base nutriment from which their strength had come. They rejected the idealism which judges a thing's truth and reality by its function and meaning, and adopted the realism which lays main stress on the origin, the means, and machinery.

With these Realists Lotze had little relation. Nor had he very much closer connexion with the realism of Herbart. It is indeed common with those who love to classify philo- 
sophers by schools, after the manner of the ancient grammarians, to eall Lotze a Herbartian. There would be at least as much justification for naming him a IIegelian. He has himself protested against the IIerbartian title: and declared that his realism, such as it is, was not the realism of Herbart, but the realism of the physicist. The very word has been so bandied about as an antithesis that it may almost mean anything. In Ilerbart it refers to the principle that the difficulties in the apparent data of experience postulate for their explanation a true and non-contradictory reality, which under certain relations presents the aspects, the contradictions in which perplex our logical requirements. This reality however is not one: the true reality consists of an indefinite plurality of real beings, each simple, and completely independent of all the others. Still they are 'together,' and they can (not must) stand in relation to one another. In such a case, when the juxtaposition occurs, there may to the eye of a spectator be presented an apparent fusion of their elements, by means of an analysis which substitutes for the two invariable ' reals' two equivalent expressions admitting of comparison. Yet the real beings remain at last as they were at first: any disturbance that may have been threatened is at once annulled by their self-conserving power, "like the trees in a wood, which stand out from each other as they approach the eye and at a distance gather into one mass, whilst they themselves undergo no change.' In psychology Herbart made two important points. The first is his doctrine that the soul, one of these simple and indestructible ' reals,' when brought 'together' with the others, conserves itself under the form of an idea, or object of consciousness; that once the soul has thus acted and produced sensations or ideas, it ceases to be more than a passive scene, on which through the action and reaction of the various 'ideas' upon each other by mechanical laws, and without need of postulating a number

$$
\mathrm{k} \mathbf{k}
$$


of other and higher faculties, there is gradually produced the varied structure of mental life, such as feelings of pain and pleasure, general ideas, volitions, judgments, \&e. The second point carries out this view into the conception of the application of mathematics to psychology: of treating the processes of association according to the principles of mechanical science.

In none of the peculiar doctrines of Herbart has Lotze been his follower. Where he agrees with Herbart is in insisting on analytical investigation instead of constructive imagination, and on the absurdity of beginning with the deduction of everything from one supreme principle; in the important function he attributes to the method of substituting for indivisible totals the analytic expressions derived for them by 'accidental views'; and in the secondary place he assigns to relations instead of inner states of the active elements themselves. But his antagonism is hardly less marked. He refuses, for example, to treat the soul as a mere background for the evolutions of the atom-like 'ideas,' in which they thwart or promote each other, fuse into a homogeneous mass, or are partially disrupted by some new attraction, and where concepts and judgements are mere casual products, collateral results of the fore-play of ideas. According to Herbart attention is merely the strength of an idea driving others before it. According to Lotze thought is activity : the soul directs, watches, and above all criticizes the processes which go on mechanically between ideas: it does voluntarily, with comparison and attention, what the psychical machinery did as it were by chance. Thought in short is an original act of interference with the mechanism of association: the laws which express the general principles guiding that critical interference are the laws of thought, whilst the special forms of thought, such as concept and judgement, are the modes under which the mind forces the results of sense-association to comply with the general conditions of reality, the metaphysical categories. 
If Lotze thus differs from Herbart in denying that thought is a mere occasional result of senses and association, and maintaining' the essential spontaneity of the 'relating' intellect, he no less differs from his view that ideas and sensations are the sole primary elements, giving rise to feelings and volitions in their dynamical effects. For Lotze, the soul is not a simple real: there are nowhere indeed any such simple reals: and the soul, above all others, has something of the infinite in its nature, which needs, indeed, the stimulus of other presenees to unfold, but which is notwithstanding the source of its own internal state. Still less can Lotze be satisfied with the doctrine of independent realities in a mere 'together' - in a vacuity of juxtaposition. We have already seen the antithesis in psychology-where metaphysical differences naturally appear in the most pronounced form: and we have only to substitute for the soul the universe. Here too there is one directing principle, critically guiding the whole of event according to a plan, supplying in each apparent centre of being those states of activity, which, by his eommon purpose, have the power of earrying along with them corresponding states in other centres of activity.

The points at which Hegelianism most repelled Lotze need scarcely be noted. Over and above the common defects of idealism - that it is too much concerned with ends to pay the proper attention to means, and that it begins at the wrong point-a special objection to Hegelianism is its claim to have discovered a movement of thought which is the native movement of the reality : its deification of method, and neglect of realities. 'It is,' he says, 'a philosophy of philosophy, which ceases to occupy itself with the problems and deals only with itself.' He has stated in the beginning of his early Metaphysics his own idea of what philosophy has to do, and of its relation to life. When it first addresses itself to the mind, it enters no vacant ground. The mind as a whole is already there, with truth possessed and exercised, 
though without scientific knowledge of it. An instinctive sense or law within, existing in the shape of opinion, but not formulated in definite rules, serves as a repellent and protective power to negative whatever is out of harmony with it. Though we do not know what or where is the unknown which we seek, we are still able to reject the suggestion that it is this or is here. As each inappropriate suggestion is set aside, the outlines of opinion acquire a fuller definiteness. And so it may almost seem as if the clearness grew by a motor in the ideas themselves, without our interference. But this allusion arises only because of the vagueness of that inward truth, which only comes forward into action when stimulated by the felt disproportion between it and each overt judgment.

The truth in the mind-which carries us beyond the given to something not given, standing as its necessary complement-is an activity of the whole mind. And the mind in so doing is exerting its supreme category-the 'ought to be.' Thus philosophy comes up in consequence of the tendency in the mind to seek for the fragmentary complement needed to clear off the contradictions found in each several phenomenon: and its business is to give a distinct and, as far as may be, a detailed account of this instinctive activity, this real though indefinable opinion, and to make its laws no longer a means only but also an object of knowledge. Nor is it only in this desultory way that we are carried by an indwelling feeling for truth beyond the given fact to the totality of which it forms part. There comes also to every mind a time of longing and ethical emotion, Lotze reminds us, when it is visited by a vision, carried away by an enthusiasm, the burden 'of which is infinitely good and precious-a true reality which is unlimited and unchangeable. In the inward glow of youthful imagination a consciousness grows that beyond the ordinary course of thought there lies another and more real world-no single phenomenon, not 
liable to the limited and transitory conditions of finite things -describable by no words except by the uncertain sounds, 'one, infinite and eternal.' But it is to be added that only

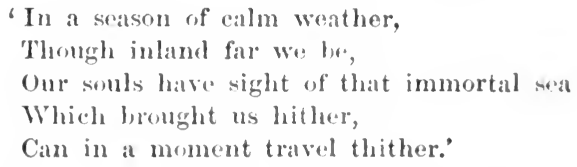

Oftener in duller moods, when this splendid vision fades into common day, we feel the want of some means to give the shadowy outlines permanence, to combine the results of our several questionings of sense and outward things with this feeling of a presence of something which gives the true meaning and purpose to all existence. To give to this conception of true being (and the weight of truth lies in its ethical significance) that persistence and definiteness which as a mere dream of faith and suggestion of passing moods it lacks-to make it a substantive part of our common thought-is the aim of philosophy. Ordinary civilization has done something to establish a comparatively fixed notion of what is real and what only an illusion. To carry this work a stage further is the aim of philosophy. Her aim is primarily formal, she does not propose to ereate ideas, which must be gained by the training of art and experience : but to bring greater unity and system into the vague assumptions which underlie all thinking and action. The aim of the school is therefore to elevate the transient convictions of individuals into a common estate of science. It is reserved for faith and conduct-acting through laws and manners-to make the truth thus ascertained a real and permanent possession of the whole being.

Traced in such words the problem of philosophy has a more human interest than Lotze seemed to find in contemporary systems. If, on the one hand, they cherished aims and employed methods which his scientific studies showed him to be impossible and wrong, on the other hand, they failed 
to supply him with that support for ethieal and aesthetical cravings which had led him to philosophy. He has no liking for the apotheosis of knowledge for its own sake-for the cold intellectualism he found rampant. The resistless movement of self-development in the 'idea,' the evolution which has no further purpose than fullest evolution, were to him meaningless and repulsive-specimens of a curiosity which revelled in its logical dexterity and mastery of method. A mere plan which was carried out inexorably without any regard to the worth of the principle it subserved, he held to be an offer of a stone when one asked for bread. That everything is one vast process without beginning or end, each stage only a preliminary to the next, with no permanent result except the exhibition of certain uniformities of succession and coexistence, sounded to him a vain moekery of human cravings. There must be something somewhere, which has intrinsic value, and that something can only be conseious self-enjoying being. Existence is no mere machinery for working out a logical operation, or illustrating relations of fact. There must be something that can justify the bother and pother of existence-some meaning and purpose, over and above the mere regularity, system, and development. Something must develop as well as be developed, enjoy the order as well as move in submission to it.

The basis of his conviction is embodied in the statement that the root of metaphysic lies in ethics. But he has nowhere given expression to all that is implied in this assertion. It is probably so deeply imbedded in all his thought, both by early influences and by the special form it received through his first philosophic teacher, that it lay beyond the range of introspective criticism. His first writings did not specially discuss the theme. An essay on the idea of Beauty ( 1845 ) touches upon this faith in the ideal. But during the first part of his professorial career he did not deal with specially ethical problems. The lectures 
on 'Practical Philosophy' were first given in 1857 , and those on the 'Philosophy of Religion' in 1858. On ethies the only parts of his published writings that we can refer to are a few chapters in the Microcosmus, and a paper which appeared after his death under the title of 'Principles of Ethies,' but which really traverses only the ground of the old battles between experience and the a priori. One may doubt whether the unwritten last volume of the 'System' would have earried us much further.

Iis point of view has some light thrown upon it by the following words addressed in 1857 to J. H. Fichte (who was his senior by twenty years): "With your illustrious father, most honoured friend, I am associated not merely by the to me pleasant accident of a common Lusatian nationality, but by a fundamental theory of things, to which I bring the same inflexible energy as he showed in its defence: the conviction, to wit, that it is only in what, for want of a sufficiently comprehensive name, I will for the nonce eall the import of the 'idea of the good,' that the adequate motive is to be sought for the whole burthen of existence and event, or, as I have elsewhere described it, that the world of values is also at the same time the key to the world of forms ... I could not agree with your father in the detail of his opinions, neither in his initial subjective idealism, nor in the restrietion by which he exclusively laid stress on action, as the form in which what ought to be is to find its existence, and made it the sole aim and destination of the world to supply the conditions needful for realizing action. For me the quiet bliss of beauty, the sanetity of that disposition which neither does nor desires, the intrinsic self-consistency of truth with the place of its harmonies, were counted elements too essential in the constitution of that postulated ideal world to let me do otherwise than look upon the restlessness of action as merely the means for reaching that higher aim.' 
There is in these words the force of a persuasion which he always reverts to: the belief that movement and progress is not a good for its own sake, but that in the words of Aristotle, schole is the end of all ascholia-self-enjoyment is the truth of work. It is the protest and reaction against an attitude which in the eighteenth century took the shape of a deification of moral and intellectual progress in society, and which, in the logical philosophy of the nineteenth, became a worship of evolution and development. His scepticism anent the cry of progress had started early. One of his theses in 1840 , when he 'habilitated,' was 'that there was no progress in human conduct: that the difference between civilization and its obstacles was a constant quantity.' It seemed to him that in all these matter's men mistook the means for the end; and that the loud self-approbation of material eivilization over its advances was a delusion. As every quality has its defects, so every new instrument and institution calls for a fresh effort to guard against a new series of dangers. People do not realize that nothing can be got for nothing:-a delusion which in various forms, more or less gross, misleads more than half the energy of the world. The deifying of machinery and movement forgets that no machine creates force, but only transfers it to a place where it may be used without being dissipated beforehand.

His general quarrel is with what for want of a better name may be called formalism-the belief that there is a saving virtue in forms, methods, movements, by themselves. It is this which leads him to criticize the Kantian moral principle on the ground that mere conformity to law for the sake of law, as such, ean never be a true motive for the behaviour of a being, who is something more than a mere intelligence, pleased with uniformities for their own sake. It similarly leads him to object to the tendency in Hegelianism, as he understands it, to lay the main emphasis on its method-on the formal symmetry of a movement of 
thought which proceeds more geometrico, and revels in the achievements of mere dialectic. 'It is not a mere blind fate' he says in the last pages of his Metapllyssic $(18+1)$ 'which has appointed a tedious triadie development as the law of this world: but, because the grood is the true substance of the world, and is what it is only by this process (from end proposed by means of instrument to end realized), all being is noulded in the form of the grood.' His metaphysical system is thus named by himself a 'teleological idealism.' The good must be:- such is the initial presupposition, and on that is based the necessity for the machinery of existence and of thought. The so-called categries of metaphysies are conceptions of the nature of being which are rendered necessary, if we accept the conviction that the true cause of events, the very substance of all that is, is a moral meaning or plan. And this assumption-unprovable by logic-is a conviction forced upon the mind as not a mere intelligence, but an intelligence suffused with emotion and inspired by conceptions of what ought to be.

When Lotze gives expression to these ideas, there is no doubt that he believes himself to be carrying out the idea of Plato. From the intellectualism of his own time, Lotze turned not merely to Leibnitz but further still to the philosophy of Greece. There form and law had not yet celebrated their exaltation to supreme power. Duty for duty's sake was subordinated to the dominant influence of the beautiful and the good. It is in aceordance with this origin that Lotze puts in the front of his practical philosophy that idea of a chief good which Kant had deposed from its primacy. When the ancient Greek was asked what this good was, he was perplexed between two answers. The one answer was Pleasure, the other was Intelligence. Sometimes he tried to combine both, more frequently he felt struck by their incompatibility. Lotze does not join in the common hunt which zealots urge against the value of pleasure. 
Though foolish courtiers have profaned her palace, this is no justification for joining the rout of asceties who elamour for her head. And so Lotze finds himself in disagreement with Kant, who allowed no fellowship between pleasure and duty, or between the beautiful and the pleasant: for there is no good which is not pleasure, nothing beautiful which fails to please. He turns away from a theory which finds nothing more in beauty than a formal symmetry, or in virtue than the recognition of universal law.

The question, it may be remarked, is not whether Lotze was correct in so interpreting either Kant or Hegel. That is a question which concerns the study of these philosophers: though it may be said that Lotze came to the task of interpretation with a mind too definitely formed to allow him to do more than observe the salient contrasts or resemblances with his own line of thought. The point for present consideration is the light these antipathies throw on his own point of view. What they evidence is his realism: the realism which cannot suppose an act without an agent, an idea without a thinker, a form without a form-giver. He has no sympathy with the language which uses words like humanity, as if there were a common spirit over and above the forces active and co-operative in the individual men. To him humanity is no mere generic character, still less a mere multitude of individuals only co-existing in our thought. 'It consists,' he says ', ' in that real and living community which comprises in one totality of reciprocal being the temporally separate and disrupted numbers of spirits; a totality in which each, as if they were all numbered, has his peculiar place pre-arranged and reserved.' The personal must never be swallowed up in the impersonal. 'If we had to believe,' he says ', 'that all personal life was employed only as a transition-point for the development of an impersonal absolute, we should either give up the efforts

$$
{ }^{1} \text { Micr. iii. 5r. } 2 \text { P. 4r. }
$$


to do good, since we discover no obligation to co-operate towards the support of a process which is equally uninteresting to itself and to us, or, if we should still hold fast the treasure of love, duty, and sacrifice, which we find within us, we should at the same time admit that a human heart in all its finitude and transiency is a far nobler, richer, and more sublime being than that absolute with all its necessary development.'

To conclude this part of the statement. It is true that Lotze has not given us an ethical philosophy on which his other views can rest. But he has given significant utterance to the conviction that no metaphysical system which does not satisfy the wants of our moral nature will ever be a permanent ereed. And he has put forward with distinctness two points of importance in ethical theory. One is the supremacy of conscience in morals. 'All theoretical knowledge we have conceived to begin from simple truths innate in the nature of the mind, and to apply which the mind is awakened by the force of observation: no knowledge of the actual sprung up without the experiences which supplied those principles with the matter for their estimation. Conversely experience alone could never generate the highest principles, by which it is fain to be estimated. Practical philosophy offers a complete analogy. A moral judgement upon our actions can only proceed from the conseiousness of unconditionally obligatory ideals, to realize which is binding upon us under all circumstances that urge us to action: but similarly these ideas will realize what they command only in the definite shapes rendered possible by the real circumstances to be learned by experience... These ultimate principles we shall seek where we sought the corresponding principles of our knowledge: in our own mind, in that immediate sense of certainty with which our conseience, when interrogated in reference to the simplest forms of our possible actions, utters its irrevocable judgement of 
approval or disapproval. For this beginning we can allow no other: no pretended interpretation of the plan of the world, from which, as if it were possible for us, the obligatory commandments of our behaviour might be deduced; still less that silly and offensive custom which at present plumes itself with so great aplomb on descending into the entertaining incidents of natural history, and-out of a tendeney, which is imagined to have been discovered in the animal world, to ascending development-construing the summit, which logically ought to form the behaviour of humanity. If we could not find in our own conscience the irrevocable criterion of our moral judgement, we should certainly not get it from the beasts : for what observation of them might teach us-that the series of development we suppose we find in them goes upwards to the perfect and not downwards to the bad-we could know, only if it were beforehand eompletely clear to us, which we should regard as the better and the worse end of this scale.'

Such is the expression given to a cardinal truth generally neglected by those moralists who devote their study to the ways and means by which these ideals are gradually realized in the scientific consciousness and in actual life. The other point to which reference has already been made is the rehabilitation of pleasure from the attacks of ascetic formalists. 'Somewhere the mere bringing about of outward events must open into an internal activity of pleasure. Pleasure is the seal set upon perfect life, and we crave for pleasure not in mere selfishness, but because we feel that the world without it would be an incomplete world-an absurdity even, if the good for which generations laboured were lost to them and only the blessing of generations to come. Pleasure must be no longer identified with an egoism which sees everything only as a means to its petty enjoyment: but considered as 'the light in which every objective excellence and beauty of the actual, first 
becomes truly luminous.' No doubt Lotze was aware of the difficulties that arise for ethics and aestheties in trying to reconcile the subjective and apparently variable groundwork of pleasures with the objective universality commonly predicated of the good and the beautiful. IIe has touched in the following passage from the Cieneral Physiology ${ }^{1}$ on the opposition between scientific law and the poetical truth of morals :--

'It is the problem of an ethical philosophy to show how the fabric of the world, though directed to the production of goods, may not seek this end at any cost, but only while maintaining the original sacredness of certain relationshipsor rather to show how from the true conception of the highest good itself there immediately flow certain indispensable forms of existence and development, which in all formations reappear as limits to the range of configuration, and which, without being aimed specially at a result of pleasure, possess an immediate necessity as evidence for the principle of the whole ... Much is still wanting before this problem can be solved and the full cogency of a scientific truth acquired for those ideal interpretations of life, under the influence of which we all unconsciously prosecute our work. Whether we should complain of this, we know not. Even now we have not lost the sense of those dim ideas, and the greater definiteness of theoretically moulded form-the only addition we can expect from science-would scarcely compensate us for the sacrifice of the intuitive vividness of its aesthetic impression. It is not needful that everything should become science. Mueh is completely clear and open which yet shrinks from definition.'

So far all that has been done is to attempt a sketch of Lotze's place in the history of modern philosophy and the general attitude of his speculations. On the whole he executes a retreat from the advanced idealist philosophy of the absolute

$$
\text { 1 P. } 163 .
$$


and to a more generally human ground. But the retreat is not equivalent to a surrender. All that was precious in idealism may still be kept, but kept partly as a faith and a conviction, partly as a series of inferences gradually reached by confronting these ideals with the data of everyday experience, finding in the former a guide through the complications of the latter, getting from the latter real bits of knowledge to piece out the vague suggestions of the former. On the other hand, the truth of science claims her own, and Lotze admits it with no grudging measure. Truth of science must be made independent of truth of poetry. Yet the truth of poetry, when lifted out of the changeful moods in which it usually lives into the stable shape of a philosophic doctrine, is the higher. So that after all what Lotze has done is to carry idealism home to those humbler latitudes where dwell the ordinary men and women, who feel uncomfortable on the cold heights of speculation and find the absolute 'uncanny.' And thus, as was suggested in the beginning, Lotze may perhaps to some be as it were a porch whence they may enter into the Hegelian courts, not so dreary perhaps as they have been represented. 
IT is no easier in Nietzsche's case than in the case of any other 'philosopher' to sum up in a single principle or tendency the general drift or spirit of his writings. When we ask for such a summary, we really ask to see him as he could not see himself. Self-consciousness is no doubt understood to be a foremost quality of thoughtful minds. But what such self-consciousness brings to light is not the total impression of the intellectual and moral self: but rather a series of particular pictures, a set of self-manifestations in a special circle of cireumstances. It is by reflections from other things that the mind, that most pure spirit of sense, sees itself. What is thus revealed by those thoughts or writings which are the self-manifestation of any thinker, is a product of the mind and its circumstances conjoined, and that not in one finished and rounded work, but in a succession of partial efforts at self-expression. Each man's life, as long as its visible utterances last, is a continued but varying attempt to utter his full purpose or achieve his full task. But of that purpose and of that task he has no final and perfect intuition or vision. His essential work, after all, is to be, without knowing it. The work of the historian is, on the contrary, to know what he can scarcely hope to be. And this is true in relation to the 
thinker's efforts and achievements not less than in relation to those of other men.

He too, no less (it may be, even more) than other's, has certain partial revelations of what manner of man he is and of what kind of work he is ultimately doing. But the eompleter objectivity which history requires must take all such autobiographical dicta as mere elements in the problem it seeks to solve-elements of priceless value, oceasionally, but still only factors in the delineation of its object. What a man seemed to himself to be and to do, is perhaps a predominant element in determining what he was and did, but it is not final or complete. History hears his evidence, and, it may be, regards it as supremely important: but its task requires an analysis and a synthesis on a wider scale.

These remarks are suggested by Nietzsehe's own attempts to describe or name his problems or define his task. These problems are, we may expect, more than one, and their names are not always the same. Nietzsche, indeed, is a man of problems. Where the ordinary person sees only a fact to be accepted, Nietzsehe stumbles on a host of difficulties, puzzles, questions. Everything, as it were, sets him thinking on the What and the Why, the Whence and the Whereunto. And at the same time every diseovery and every idea forees into prominence the question of what ultimately is to be done- of what he is by his nature bound to effect or to help in effecting.

Nietzsche was originally and professionally a philologistwhose interests lay in tracing the growth of ideas in literature. and in scrutinizing the documentary evidence for early history. His first literary performances which saw the light were essays on the poems of Theognis, and on the sources of Diogenes Laertius (1867). But philology was in his case only a remedy to check that 'mania for universal knowledge' which he felt as a danger of development, and to stave off the full emancipation of 'disposition 
to refer the individual problem to its deepest and remotest grounds.' And he was not long in finding out that he could no longer stay in any such half-way house, and that scholarship in its ordinary limitations could not finally satisfy his cravings for truth. 'Philology' he finds 'lacking in great ideas;' and in the absence of a grand enthusiasm 'the workers in it have grown like workers in a factory: the interest of the whole is lost to their sight.' 'Our philologists ought,' he adds, 'to give up higgling abont single passages, and take to heart the large methods of philosophy.' For even philology has its final reason of existence in its ministering to human life. 'The dynamic of all research lies in those unknown far-off regions where the results of research are seen to harmonize with those of life.' 'The fruitfulness of philology lies in the points where its studies touch upon humanity at large.' And so there had inevitably to come a time when he would say: 'I have journeyed forth from the house of scholars : too long had my soul sat hungry at their table.' He refused-because his nature refusedto spend life in 'settling the business of the enclitic.'

The love for individual fullness of life which will be content with nothing short of all reality for its province is not however to be identified entirely with a dislike to restraint and discipline. If he loves 'freedom and the air above fresh earth,' it is because of a certain hardness and love of solitude which turns away from everything vulgar and shuns the crowd. Call it pride-the 'pathos of distance'-or by worse names, you must recognize in Nietzsche a coldness and indifferenee to the commonplace ideals of snugness and what is known as happiness. As a student at Bonn (1864) he soon felt himself out of tone with the drinking and smoking habits of the clubs: he grew indignant at the Bier-malerialismus and Bier-gemüthlichkeit which they foster: and found that such company lowers the moral tone and destroys all clearness and singleness of aim. An occasional 
ascetic fit makes him try to harden himself, for example, by shortening his hours of sleep. If other mortals say to him, like carbon to diamond, Why so hard, brother, he replies, Why so soft.

There are, as he says, in a letter to his sister, written at this time, a lot of half-and-half standpoints. But there is notwithstanding a clear bifurcation of paths of life, such as was shown to Herakles: the path to truth and the path to happiness. 'If you would aim at peace of soul and happiness, then believe: if you will be a disciple of truth, then inquire.' And the truth is to be accepted even if it prove ugly and deterrent. Nay, Nietzsche flaunts, as it were, a sort of preference for the sterner and more repellent truth, a certain readiness to esteem more highly the belief that costs most in the loss of ease and vulgar comforts. His critical intelligence in philosophy has ' an earnestness which is never content except in presence of the naked truth, and a fearlessness to meet hard and wicked conclusions, perhaps an affection towards them.' A fatal facility to believe in uncomfortable truths and to distrust everything that is associated with ease and indolence! It seems at times as if life were really to him only a means of knowledge, and knowledge itself the end: and 'with this principle in the heart,' he says, 'we can live not only bravely, but even cheerfully,'-and, as the doubt emerges: 'It may be that in following out this passion of knowledge, humanity will perish ${ }^{1}$,'- still 'even this thought has no power over us.' These are bold words : perhaps also not a little paradoxical.

Two influences had contributed to modify the effect of a purely philological training, one of them was a considerable susceptibility to the aesthetic and artistic side of life, especially a love of music, and some actual achievement both in writing songs and setting them to music. So far as mastery in that direction is concerned, however, he soon came to the conclusion

$$
1 \text { v. } 295 \text {. }
$$


that he had no supreme distinction to hope for. But it was otherwise as regards the general tone and mental attitude which music and perhaps art in general can give. 'Art,' he says in one place ', 'has taught the world to look with interest and pleasure on life in every shape.' 'Art is the supreme task,' he puts it elsewhere, 'and the properly metaphysical activity of this life.' But when he says art, we must remember that the art properly so called, as shown in what are technically called 'works of art', is cnly an appendix of that larger sense to which he extends the term. Without its help-and 'its great, over-great task is to embellish life' by concealing or interpreting away everything that is ugly-pessimism would reign unchecked ${ }^{2}$. Its network is spread over all existence: called sometimes religion, sometimes art, sometimes seience. The homines religiosi may in fact be reckoned among the artists, and considered as their highest order. All in their several degrees, art, religion, and science, are illusions spread over thingsdevices by which human creatures may keep themselves in life: for 'all life,' it is declared ', 'rests on semblance, art, illusion, optic, necessity of perspective and of errors.'

In this there is partly an echo of Schopenhauer, with whose ideas he first made acquaintance in his first term at Leipsic (1865). ' ' I am far from believing,' he writes later, ' that I have correctly understood Schopenhauer: it is only myself that I have learnt to understand a little better through Schopenhauer's means, that is why I owe him most gratitude.' Not in short the specific doctrines or arguments which Schopenhauer uses, but the value of him and his philosophy for life, is the cardinal point on which Nietzsche's interest, turns. Two things there were in Schopenhauer which attracted him, as they did others. The first was the feeling that here at least philosophy was no matter of names and disputation only, but a serious attempt to get at the meaning

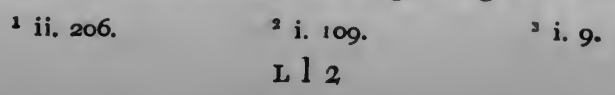


and drift of reality, and to examine into the worth of life. It seemed as if here the 'one thing needful' were the aim, to the exclusion of all side issues and all logomachy. The second was the show of independence of all established and endowed dogma and institution which Schopenhauer exhibited. Philosophy was not only an attempted codification of what was thought and believed, but a criticism of ordinarily accepted values.

And a third-and that, the central idea of Schopenhauerwas the reduction of intelligence to a secondary and derivate rank, combined within the enthronement of Will as the supreme reality. It is perhaps impossible to give to Will in Schopenhauer's pages a clearly consistent meaning: but so much at least is negatively certain, that he meant, in some way, to assert the phenomenal, superficial, and partial character of the reason or thought which philosophers generally put in the front rank or at the very foundation of reality. Intelligence is an exception and a parergon, not the essential being of things. It is at the best a means to an end, the evidence of an imperfection in the organism, a machinery to supply the want of deeper and essential unity. A Spinoza-like treatment of intellect, as only a special phase in a wider animateness or cogitatio which does not want or deserve the epithet 'conscious,' is characteristic of this mood of thought. Human thought-and all animal consciousness which is more or less analogous to it-is a mark of provinciality. The fully free citizen of the universe regards it as a mark of imperfection, a pis-aller.

'The mind counts for us,' says Nietzsche, 'only as a symptom of a relative imperfection of the organism, as a stage of experimenting, feeling about, and missing its aim 1'. The great business of life is for us, as for nature, in general transactcd in silence: it is done, and needs not the intermediary of speech and thinking. 'Consciousness,' he further notes,

' viii. 230. 
' does not properly belong to the individual existence of man, but only to that part in him which is of the nature of community and gregariousness.' It is a social product-and if it be assumed, as Nietzsche does assume that sociality is but an accident of man, due to a weakness which will not let him stand alone-then it too is a result of his infirmities, a part of the great sin of 'herding' and seeking shelter, with its inevitable contaminations, behind others in a mass. "The nature of the animal consciousness, therefore, involves that the world of which we and these gregarious animals are conscious is only a superficial world, a world of signs, a generalized world '.' It is hardly going farther when we are told that 'everything good is instinct': that the 'so-called motive is only a surface-phenomenon of consciousness.' The doom of intellectualism and rationalism could not be pronounced more clearly.

Partly, at least, this is in accord with a wider movement in which physical science has had its part. There is a conviction abroad that we have been imposed upon by names. We have confused the expression and the interpretation, which varies from time to time, with the reality which underlies it and is the same always. Reason, intelligence, logic, is but a receiver and transmitter of a prime reality which is given. We are passive recipients: the only word that properly describes our-individual and conscious-attitude to being is 'pregnancy ', : we turn over again and again a material which we did not create. The home of our true being and of our best wisdom is our body-our spirit and mind is but an interloper, a bleared or at best a one-eyed reduction of that which is all eye and all ear, the universal life. A great deal of our morality and religion is but a misinterpretation of physical or physiological reality. We take a nervous or stomachic uneasiness and describe it in terms of morals and religion, as, e.g., guilt or sin. Call it

$$
1 \text { v. } 293 \text {. 2 v. } 362 .
$$


realism, or materialism, this revolt of naturalism is a protest against some sort of spiritualism which seemed inelined to deny or ignore the matter-of-fact of life, and to substitute the comment and the translation for the original text.

Man, however, as we have seen, lives by these illusionsor, in milder phrase-by these interpretations. The lowest, and apparently the least satisfactory of them is science. The type of the 'scientific' or purely theoretic man according to Nietzsche is Socrates. For Socrates, myth and mystery are standpoints to be left behind: the spirit of science or rationalism will brook nothing short of absolute clearness and intelligibility. Logic-in the vulgar sense-as cutand-dry reasoning, must rule life and reality: dialeetic must prescribe laws to the world. But Socrates-so Nietzsche treats, as a parable, the story of the Phaedobegins to doubt at the close of life whether he has adequately fulfilled the command to make music. Hitherto he had supposed he was carrying out the oracle when he sought, in and out of season, for the reasons and the definitions of things, for was not philosophy 'the greatest musie'? But in the house of prison Socrates begins to see-so Nietzsche methodizes the tale-that perhaps science with its clear-cut distinctions is not all-in-all. Perhaps there is a deeper and truer than science-something nearer the fountain-head of life. Is it art? and above all, music, that art which, according to Schopenhauer and Nietzsche, reveals the whole force of being, the undivided will of reality? Behind science, and even beyond the arts of painting or sculpture, there is the spirit of music, and its child, the tragic drama. That drama-such is the theme of his earliest work-is the revelation, so far as the forms of Apollo the god of light allow, in words and act, of the Dionysiac mystery of being:- the scene which bodies itself out in the eye of the chorus (through whom the poet speaks) to express the 
otherwise unutterable burthen of passion and emotion which surges indefinitely in the musical tones.

What science is unequal to perform, art and religion may in some measure hope to accomplish. The enthusiasm fur Richard Wagner which Nietzsche displayed in his first writings, is comnected with these hopes. In Warner he imagined he had found one who was more of the true artist, and less of the mere rationalist, than other musicians : the promise, if not the performance, of an 'art which knows no longer the opposition of educated and unelucated, and speaks no more the language of a caste.' In Wagner he hears 'the languagre of an art which speaks not to nations, but to man: which is no longer narrowly rational, but human -though it waits for a humanity of the future to give its appropriate audience. 'Wagner,' says Nietzsche, ' is a true poet: he thinks in myths, as the people always have thought.' And what is a myth? It is the complete concrete individuality or fact, of which a theory is only an abstract and mutilated copy. "The myth is not based on a thought, as the children of an artificial education suppose: but is itself a kind of thinking, which imparts a conception of the world: but imparts it in a sequence of events, acts, and sufferings.' 'A myth is a single exemplar of a universal truth which has infinite significance.' In Wagner, in short, Nietzsche fancied he saw the fulfilment of what Schelling demanded ${ }^{1}$, a new mythology in which the ideal (i.e. the truly real) world would no longer be, as it is with the philosopher, subject to limitations and tainted by the weakness of subjectivity. It is the merit of Wagner to have seen, he thinks, that art is no accident on the shores of life, but in intimate connexion with all political, social, and moral activity.

Religion again is a kind of art-perhaps the supreme form of art. It, too, is a bulwark against pessimism : an

\footnotetext{
1 iii. 628 .
} 
instrument which the will to live uses in its struggle against the hostile forces of the universe-the forees deadly to man. As such it has its value, its justifieation. 'To ask if faith is true, is to ask amiss: and to seek to prove the reality and truth of religious belief by pointing to the fervours and vigours of enthusiasm which it inspires, is to be illogieal and absurd '. The sole question in the first instance is, does it sustain life? does it give strength in the struggle for existence? If it does that, it has justified itself as religion, and it were a preposterous demand to ask it to conform to the eanons of science ${ }^{2}$; for 'between religion and genuine seience there subsists neither relationship, nor friendship, nor even hostility: they live on different stars.' Yet, apparently, they cannot be quite so unconnected: for in man they inhere, by man they live: just as, conversely, it is true that according as man lives in one or other of these stars, he rises to different heights of his potentiality of being, and religion and art must give place to a fuller manifestation. 'We must have loved religion and art, as one loves mother and nurse: otherwise one cannot grow wise. But we must look beyond them and outgrow them. If we stay within their confines, we understand them not ${ }^{3}$ ' They are only steps on the upward ladder of humanity, not its goal.

The present age looks with pride upon itself as the historical age par excellence. It is so, however, ehiefly because it is without strength or originality of its own ${ }^{4}$. The historic sense is in its origin a sequel of that mixture of orders and races, of creeds and ideals, into which the democratic progress of modern Europe has turned the modern man. Itself possessed of no intrinsic and characteristic quality, modern Europe is open to receive the stamp of all the ages, and finds in itself a chord which is sensitive to all varieties of opinion.

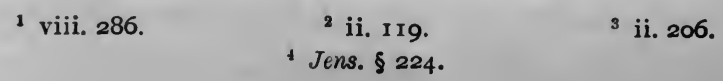


It is liberal and not exclusive in its appreciations. It has plenty of taste for all fashions and phases, and probably cannot be expected to cling to anything so narrow as grood taste. It has no home, no narrow altal of its own, but in cosmopolitan laxity seeks anywhere and everywhere for excellence, for an object of worship.

Man himself maly be said to be par excellence the historical animal. He is not solely the present and the moment. 'He lias to hold himself up against the great and ever greater burden of the past: it weighs him down, or turns him aside, it impedes his walk as an invisible and gloomy load which he may deny, but only in appearance.' The irrevocable and indestructible past, the It was, is the human doom. 'Even the child learns to understand the meaning of that It was, the watchword with which battle, suffering, and vexation draw close to man, to remind him what his existence at bottom is-a never-to-be-completed imperfect.' We walk through life with the consciousness that we are epigoni:'Weh dir, dass du ein Enkel bist:' that things have been said and done which have left us no longer our own masters, and bind us to the authority of the past. "There is much talk of free personality, and in louder tones than were ever before heard:'-but it is the outcry of want and longing. 'Nowhere do we see a personality, still less a free personality - there is nothing but beings concealed under the identical mantle of a generalized humanity.'

In such a condition of affairs the study of history is a fresh danger. We take to it, as the invalid takes to what is most consonant with his own debility. It does not strengthen, but paralyzes or lulls to indolent acquieseence. The useful reading of history belongs only to those who have thrown out their roots and branches widely and strongly in the present. 'It is only from the highest force of the present that you should interpret the past: it is only in the strongest exertion of your noblest qualities that you 
will surmise what in the past is great, and worth knowing and admiring.' 'The greatest men in all ages have been those who have dared to ignore the past: the great epochs of history have been those which acted as if the world was new for them. To act, to aehieve something, it is necessary to be able to forget the past, and to shut yourself up within a limited horizon. It is necessary to wrap yourself in the unhistorical-to throw around you its enveloping atmosphere in which alone is life generated. Annihilate that atmosphere, which gives at least a temporary unity and finality to life, and life itself must vanish. 'For he who cannot stablish himself on the threshold of the present in forgetfulness of all that is past, will never know what happiness is : and worse still, he will never do anything which makes others happy.'

Hence the maxim : Forget once and for all the superstition that you are of the epigoni-one of the later generations. Draw around you the fence of a great and comprehensive hope, of effort embraced in hope. Form within you an image to which the future shall correspond-and work immersed in present actuality. There are, of course, other difficulties, which threaten to break up this isolative effort. Against them you must call in what Nietzsche calls the 'supra-historical' powers. These are Art and Religion. In them the existence has acquired the character of something eternally and uniformly significant: they carry you beyond and above the fluctuations of time and change. These are the antidotes against the disease of history.

'The thing which has most profoundly engaged me,' says Nietzsche, 'is the problem of décadence.' It is the phenomenon of the present, as Nietzsche sees it. The present is an age of deterioration, of degeneration, of descending life. 'The symptoms of decadence,' he declares, 'are an anarchy of the atoms and a disgregation of wills.' The sense of social solidarity and of personal unity have been lost. The con- 
fidence of instinctive life, the strength of undivided will have given way to a distrust of self, a leaning upon suggestions and authorities, and of authorities largely incompatible or contradictory. "We all have values, formulae, words, morals, of opposite descent in our body.' We are ruins, in short, crumbling to pieces, but held together by extraneous supports and foreign ligatures. Like invalids, or neurasthenies, we can only continue to exist on an artificial regimen: our worn-out systems are attracted by what is injurious to them, and have no longer the vigour or resolution which finds nutriment in things hard and dangerous. We can no longer trust our instincts: we can no longer be generous to our passions. And yet 'to be forced to fight against the instincts is the very formula of decadence'; and 'to attack the passions at the root is to assail the roots of life.'

What Nietzsche thus describes as decadence, is not unlike the state of soul and society which Plato was pleased to call democratic. It seemed to him the proper name for a state of affairs which has lost centrality of aim and leading in social and individual life. There have been many who used the term (democracy) as an ideal of a different kind, just as there have been a few who made an ideal of anarchy. To these idealists anarchy meant a condition in which all external and obvious restraint has been removeda sort of self-abolition and idealization of governmental interference, when outward and visible thought is unnecessary because each unit carries out under his individual stimuli all that external means of repression could conceivably secure. So, in the ideal sense, democracy, in contrast to all terms which recognize the limitation of the highest manifestations of political life to a special and numbered order, denotes a state of associated action, in which there is no amorphous mass, set in motion by forces alien to it, but the whole body freely and completely organized, is 
the master of its own movements. But such democracy is not what Plato meant, and such anarchy is not that condemned by Nietzsche. The state of anarchy is one in which the principle of order and unity is reduced to a minimum : and democracy, in Plato's sense, is a sweltering muddle of constitutional forms, in which none has emerged to rule and domination, to a domination, that is, which is based ideally not on force, but on harmony of aim and purpose.

But Nietzsche himself has said elsewhere that ' corruption is only a term of abuse for the autumn time of a nation.' This, too, is only a metaphor: but it may serve to indicate some doubts as to Nietzsche's thorough-going disjunction of periods of ascending and descending life. It is in that respect to be compared with another corresponding distinction between organic and critical periods in history: ages which build up larger unities, and ages which analyze the given into its elements. Loosely taken, perhaps, such distinctions, like the analogous contrasts between the heart and the head, do no great harm. At certain epochs life seems to proceed spontaneously, unconsciously, constructively, as if moved altogether by an inward spring: at other epochs doubts and uncertainties call for reflection, examination, discussion : the forward step seems suspended: there is little apparent action, and much thinking and talking. But it will surely be found, when one looks below the surface, that the so-called organic period owes the secret of the advance to hints and discoveries made in the tentative and abortive efforts of hesitation; and that just as there is not-except when seen from an outlook too distant to permit of close scrutiny -an absence of criticism from an organizing period, so the apparently fruitless movements of criticism really represent those starting-points, which are more than the half of the subsequent progress.

Terms like decadence and deterioration or degeneration savour of a prejudice which is scarcely scientific. They 
are, as Bentham has phrased it, dyslogistic, and have a tone of quasi-disapproval about them. They imply a tacit assumption of the merit of unchangeableness and stability of kind: an assumption which perhaps might be tenable of kinds existing in total independence of their surroundings. 'They imply, perhaps, in addition, a belief in the fallacy of the golden age-of that idealization which raises the past into a contrast against the mixed reality of the present. 'To use them is to show a forgetfulness of the various factors in the situation. It is to assume that instincts have been given as ready-made states, instead of being what they apparently always are, a product of a long series of efforts, gradually succeeding in reaching some unification which, for the time at least, has a certain sufficiency. In a changing world it is unwise to be too trustful of mere instincts. As we look upon the present in its disruptions and chaotic effort, we are apt to forget how rare and how short-lived were those moments of balanced and harmonious activity when the race and people was one and single-minded. We forget, too, how no unification thus attained is perfect: that, such as it is, it has only been achieved by what may be called an arbitrary simplification of the problem: and that at the very moment when success is assured, it becomes apparent that a heavy price has been paid in exclusiveness and partiality. Nietzsehe knows-none better-that all Rechte or rights are in their origin Vorrechte or privileges and distinctions - that liberties always imply a corresponding check upon the action of others. Ascend the stream of history as far as you can, you do not thereby emerge from the range of mixed races. All such 'pure races' as are alleged to exist are apparently only artificial and temporary restrictions, due to special conditions, but powerless to check the general movement of differentiation and integration. Far from being the aboriginal state of society, purity of race is rather a device of dominant classes to thwart 
the tendency of evolution in the interests of a special aggregation of social elements. And when it is elaimed that the order of progress shall rest at some stage in a fixed institution, it is a sign that there are movements which would lead beyond, and which it is deemed desirable to check. But unity is not a datum : it is a goal, or rather a law guiding development.

One should not accordingly lay too much stress on the alleged phenomenon of decadence, as if it stood alone, and were not a part of a complete process. It is, on the contrary, only an aspect of the total phenomenon of evolution. The breaking up of old forms - the disruption of institutions - is only a step in a complete movement, and changes its look according to the environment in which we see it. It is also a necessary step without which progress is impossible. In the tentative efforts which are the concomitants and causes of advance, all kinds of impossible combinations are made, and these must perish. But it is only by such sacrifices that progress is attained. The decadent is an experimenter who fails. And he may fail in various ways, either by precipitancy or by sluggishness: he may fall behind the line of march, or he may rush on to overwhelming dangers. The decadent must have ideas, but they are not adequately co-ordinated with the facts around him. He is unwisely clinging to old rules and beliefs, or he is rashly running on unexplored territory with half-formed plans.

It is not altogether wrong to say that we are all decadents. But in the same way it may be maintained that all walking is a continual falling. It is so: but it is also a continued rectification of the process or falling. To act is always a little tainted by folly and rashness. It cannot wait till everything is certain: if it were to do so, it would hardly be action. The straight course is only the resultant of innumerable divergences on this side and that. The ultraconservative who clings blindly to a passing and falsified ideal carries movement to one extreme: the ultra-radical 
who wishes to unsettle everything drives it in another. Both in relation to the middle course are decadents and degenerates. But both are necessary adjunets to the car of progress. Both are experiments which prove an impasse: safety does not lie in that direction. But in the darkness and blindness through which all discovery and advance is made, no decadent can be considered superfluous. The obstinate survival of old beliefs helps to strengthen and clarify the new rivals to their place, and prevents the steadying influence of the past from passing away without leaving a trace behind. The extravagances of new combinations disclose the variety of eircumstance with which the problem is beset, and the conditions which have to be satisfied.

The problem of decadence, therefore, seems to lie in a failure to recognize its place in the law of existence which we eall development. Man-and it is with him that we are concerned-is in no wise finished. The other creatures represent so many formed types, each adapted to its peculiar circumstances and its province of nature. But man is yet to be made: he is still in the making. As yet he is only a beginner: his true day has not yet come: and before it dawns there must be passage from day to day, between which intervenes the fall of night. 'Man,' says Nietzsehe, -'not only the reason of centuries, but also their frenzy breaks out in him.' We are a bundle of contradictions, just because we are a growing and self-forming creature. Nay, every great step in advance must be bought at terrible cost. 'Almost everywhere it is madness which paves the way for the new thought that breaks through the barrier of revered usage and superstition.' The vast detachment which unlooses the tie of immemorial habit is only possible with a general unsettling which gives its victim a repute of being beside himself.

'To every progress on a large scale a partial weakening 
must be antecedent': the strongest natures keep the type permanent: the weaker help towards its further development. Thus in all evolutionary progress, while there must be, on the one hand, an 'augmentation of the stable force by faith and sense of solidarity,' there must be, on the other, in the 'occurrence of degenerating natures' the possibility of attaining to higher goals.' Such is the law of historythrough night to light.

The man of the future-the man that is yet to bea humanity which shall be to the present as sunlight and moonlight, and as wine unto water, is the goal of development. To bring him forth is-shall we say-the aim of the process of the world-at any rate the aim of all genuine reform. But as things have hitherto gone, the process is singularly unequal and inadequate. Nowhere is there such a failure as man. The higher and the less definite the goal, the greater the risk of complications and collisions in the effort to reach it. History is strewn with wrecks-with possibilities unrealized, experiments that seemed to shut up the way of advance. It seems at times-as Nietzsche himself often appears to think - as if the only fairly successful man were the primitive 'blond beast,' the beast of prey, without a conscience and a faith, save the unhesitating faith in his instincts. But such a primeval man is probably not less of an illusion than many other ideals inhabiting the golden age. Between him and the primeval man of anthropology there is indeed an abyss, a Fall-from the Eden garden of dreams into the earth of gross reality. It is not wrong perhaps to say that to bridge over that interval between the perfect man and the perfect animal-from which he sprung, no means were great enough. Rather at the beginning we should place him whom Nietzsche and others call the decadent. He has fallen-but it is a fall upstairs. The abnormal outburst of reason is simultaneous with 
a disorganization of instinets, or rather-as the term disorganization is question-begging-the elasticity and liberty in his instincts was the curse without which development would have been impossible. And at every step in his future progress the same laxity and differentiation had to be repeated. The attainment of truth is only possible in proportion as you increase the liability to the influence of error.

The common method of training proceeds upon another view. It forgets that 'without the errors which are at work in every pleasure and pain of the soul, a humanity would never have arisen '.' 'The individual is treated by his educators as if, though he was something new, he ought to be a repetition". Whereas, it remains true that 'the terrible energies-what is called the Wicked-are the Cyclopean architects and road-makers of humanity ${ }^{3}$. History speaks almost only of those bad men who have subsequently been visited with approval ${ }^{4}$. The objeet of common education is therefore to dam up individuality and originality under the bounds of the traditional rule.

There is indeed a degeneration (Entartung) which Nietzsche cannot abide: which to him is bad and worst. It is the degeneration which may always be surmised when the giftmaking principle is lacking in the egoistic soul which cries 'Everything for me.' But that is not degeneration which throws itself away in order to gain itself in others; which goes through history, a body in growth and combat, and a spirit which is the herald of its victories ${ }^{5}$, their comrade and their echo ${ }^{6}$.

1 iii. $x 99$.

4 v. 29.

6 This was intended to be the first chapter of a detailed criticism of Nietzsche, which was not completed. Partially to supply what is wanting, I have added the following review from the International Journal of Ethics, which was the latest thing written by Professor Wallace. 
Tuese things are an allegory: and the man who 'spake' them is no kinsman of the Persian Zoroaster. Friedrich Nietzsche, the new wearer of that prophet's mantle, picked it up as he walked one day in January, I883, along the wooded hills around Rapallo and looked on the fairest scenery of the eastern Riviera. He was then in his thirty-ninth year, and had for about seven years been a wanderer in search of health on the uplands of the Engadin and on the shores of the Mediterranean. In 1872 he had begun a career of meteoric brilliancy as a writer and a thinker on man, his aims, ideals, and illusions, and drew upon himself the attention, if not always the approval, of those who, throughout the world, fight under the banners of ' advanced thought.' This career came to an abrupt end in 1889 by a mental and bodily collapse, which has left the daring spirit a complete and apparently hopeless wreck.

The book, called Thus Spake Zarathustra, consists of a series of chapters, composed in a figurative and fantastic prose, which caricatures rather than imitates the style of an Oriental sacred book, and is laden with a varied store of epigrammatic reflections on life and criticisms of morals and religion. It is divided into four parts. The first three, written during the years $1883_{-84}$, were published in 1886 . The fourth part,

1 Thus Spake Zarathustra: a Book for All and None. By Friedrich Nietzsche. Translated by A. Tille. London: Henry \& Co., 1896, pp. xxiii, 488. 
a sort of interlude-or satiric drama following on the trilogy of passion-was printed for circulation among Nietzsche's friends in 1885 (having been written that same year at Mentone), but did not become public till I892. To understand properly the utterances of Zarathustra-Nietzsche some knowledge of the life and letters of the anthor during these years would be almost indispensable, and this biographical material would have to be supplemented by a history of the movements in the world of thought and letters for the last twenty-five years. Some light as regards the personal element in the work may be derived from Lou AndreasSalomé's Fr. Nietzsche in seinen Werken (Wien, I894), but for complete and authentic information more may be expected from the second volume, yet unpublished, of Nietzsche's life by his sister.

When the scene opens, Zarathustra is supposed to have spent from his thirtieth to his fortieth year in the quest of truth, making his home in a mountain cavern, with an eagle and a serpent as his familiars. He has at length resolved to go down from his hermitage and offer men the gifts won in his aerial meditations. These gifts are summed up in a new gospel, the gospel of a new humanity, which, instead of sacrificing the individual to the mass, and the earthly Here to a heavenly Hereafter, shall be realized on earth in a more than human race, which it is the present duty to prepare and make possible, a race for which society shall not be an obstacle, but, as it were, a fostering garden where they may grow in grace and strength, and for which deity shall be the inspiring faith in perfectibility, not a fixed power impending as a menace and a check upon the path of progress. The multitude, however, shows no taste for such revelations of spiritual truth, and prefers the marvels of charlatans. Zarathustra, accordingly, who does not wish 'implieit believers,' but fellow-workers who will ' write new values on new tables'-i. e. will destroy the old misconception of good and barl and create other ideals 
of perfection-turns away from the masses and resolves to sing his song 'to single and to dual recluses.' 'These chants form some eighty chapters, more or less concordant in theme, but far from continuous or systematic: the outpouring of varying moods of gloom and gladness, hope and disgust; often wild and fiery in tone, with many traces of the struggle with self and with old associations, but often also gracious with quaint eharms, and touches of tenderness.

European civilization, as Nietzsche sees. it, is the victim of ideals which mislead it in two directions. On one side it is dominated by a low-toned Utilitarianism, whose watch-words are mass-happiness, comfort, conservation of general and individual welfare. To these ends learning and morality, enlightenment and virtue, are made alike subservient. To-day is the day of the masses and the vulgar. The 'Philister' is supreme, and gives the keynote both to the science of the scholar and to the ethics of the just and good. On another side, civilization is attracted-and distracted-by ascetic and pessimistic ideals, which, according to Nietzsche, have found their typical expression in Christianity. These disparage natural impulses; instead of manly action they preach selfsacrifice, compassion, and, in general, an altruism which leaves no room for healthy self-regard. As against the greatesthappiness idea, Nietzsche insists on the view that self-conservation must not be identified with stagnation, and that the welfare of humanity has yet to be discovered and rightly conceived. Man, far from having surmised or learned his true meaning and drift, is still in the making: he is, as he stands, only 'the rope between the animal and the superhuman.' 'What is great in man is that he is a bridge and not a goal.' His being has yet to be made by effort, suffering, and sacrifice. So far Nietzsche may seem to be an ally of ascetic morality. But he sharply disclaims the connexion. Asceticism has in his eyes treated the body as something extraneous, which hampers, and only hampers, the spiritual 
life; its overstrained spirituality has dehumanized man, and set up a conception of truth and goodness which is hostile to the requirements of hmman nature. 'Everywhere' he cries, 'sounds the voice of the preachers of death.'

'Dead are all grods: it is now our will that the superhuman live, are the words which conclude the first part; and when Zarathustra, after months and years of renewed retirement, again, in Part II, utters his message, it begins with the same refrain: 'The old God is dead,' or, for those who have not yet gone so far, Deus est delendus. 'There was a time,' as he puts it, 'when, as men looked out on far-away seas, they said God,' but the surmise thus uttered was, according to Nietzsche, one which paralyzed man's effort, set up an insurmountable barrier to his progress, and subjected his life to an influence of incalculable instability. Such a deity is-or rather is part of-the inserutable power whom primitive man (if Epicurus and Nietzsche tell us true) saw haunting human life from lonely places and holds of darkness. And, perhaps, if man is to rise above his lower self, such a God must disappear. We may even say that, if this be atheism, such an atheism has many adherents among the followers of the true God. The godhead which is to be, Nietzsche sees as the ideal end, consummating a process whereby the man of to-day, if he fulfils his true mediating position, will build up in many ehildren of glory the kingdom of the superhuman-the as yet undiscovered, but still-to-be-pursued, ' land of his children and his children's ehildren in remotest seas.' But if the gods of primitive tradition are to go and leave man free space to create many exemplars of the godhead which is to be, other fetters on human development must go too. Foremost among these drags is, in Nietzsche's eyes, the dogma of the eternity and immutability of moral rules and of particular moral ideals. All detached ethical precepts, all single and limited ethical ideas, all detailed moral standards, have in them elements arbitrary, provincial, temporary. The law which shall not 
pass away is not written with earthly pens or graven on earthly tables. Nichts ist wahr: Alles ist erlaubt. There is nothing in even the most saered observances and institutions of human life which has not, when tested by history, a tentative and provisional character. Even the best of manners and customs, if allowed to remain for ever, i.e. beyond its implied conditions, would corrupt a world, the distinctive mark of which is to be ever on the march. Hear Nietzsche:

'Oh! my brothers! where lies the greatest danger for all men's future? Is it not from the good and just?

'For they are those who say and feel in their heart, We know already what is good and just; we have it, too. Woe to those who still seek for it!...

'Oh! my brothers! there was once one who saw into the heart of the good and just; and he said, They are Pharisees. But men understood him not.

'The good and just themselves might not understand him : their mind was fast in the stocks of their good conscience. Unfathomably shrewd is the stupidity of the good. . . .

'But the second who discovered their land-land, heart, and world of the good and just-he it was that asked, Whom do they hate most?

' It is the maker of new things they hate most: him who breaks tables and old values, the breaker. Him they call peace-breaker (criminal).

'The good, verily, they cannot make anything new : they are always the beginning of the end. They crucify him who writes new values on new tables: they sacrifice the future; they crucify all men's future. ...

' Break, break in pieces the good and the just.

'Ye flee from me? Ye are scared! Ye tremble at this word!

' Oh! my brothers! when I bade you break in pieces the good and the tables of the good, then first did I put man aboard to sail his high sea. 
'Then only comes there upon him the great terror, the great looking about, the great illness, the great qualm, the great sea-siekness.

'False shores and false securities the good taught you: in good men's lies had ye hirth and bield. Sly and awry have the good made everything to its very heart.

'But he who discovered the land Man, discovered also the land Man's future. So shall ye become my seafarers, valiant, patient.

' Walk upright betimes. Oh! my brothers! learn to walk upright. The sea is in storm, and many will fain hold themselves upright on you.

'The sea is in storm. Everything is in the sea. Up! up! ye old seamen's hearts. Fatherlanl, say ye? Our helm is set thitherwards where is our chillren's land. 'Thither, stormier than the sea, storms our great longing.' . . .

Should any one, stimulated by the call of this patriotism of the future to serve and to create a nobler posterity, be unwilling, like a prudent person, to throw away the old tables until he receives assurance of what is to take their place-should he ask, What is the way? and what are the signs which betoken the approach to truer goals? he will not find, I fear, much comfort from the new prophet. He does not reveal a way; he seeks fellow-travellers who are fellow-seekers. He knows that he is only a forerunner; and not very infallible even at that. If he be 'a bridge unto the future,' he is also-and that is his eross-' a cripple at the bridge.' He knows that the work of self-teaching and self-discipline unto self-growth is a task not to be accomplished at a single stroke; knows, too, that every good quality, every nobility, has its defect and its temptation. "Whoso wisheth to learn to fly one day must first learn to stand and walk and run and climb and dance.' There is no one infallible road either, because there is no single goal: 'noble ones of many kinds are needful, if there is to be nobility.' 'That is my way' is his answer to those 
who question him as to the way. "The way-there is none such.' 'By many ways and modes I have come unto my truth : . . . a trying and questioning of ways was all my going.' Clearly, there are many dangers attending such experimentation in life. It cannot be tried 'on a worthless thing'; the cost of the experiment must be borne by the living experimenter. This has to be borne by every one who, like Nietzsehe, has felt: 'I am of to-day and the past; but something is within me that is of to-morrow and the day after.' Whoso goes on this path is not without his work. If he has broken the tablets of duties, he has still upon him the unwritten law of duty to the Man that is to be. Past and present forms of family may be in his view but provisional inductions; but the ideal of marriage still remains 'the will in pairs to create the one which is more than those who ereated it. Mutual reverence name I marriage-reverence before those who will such a will.'

It was said by Francis Bacon of his Atlantidean sage that his look was of one who pitied men. And so may it be said of Nietzsche. Yet is his a mixed feeling: there is in it pity that men 'bear so many strange things on their shoulders,' and make their ' life so hard to bear'; there is contempt that they sit so complacently resigned under their burden, and regret the irrevocable, and leave their existence a meaningless fragment; but there is also active energy urging to transform the future by a creative will. But of vulgar compassion Nietzsche is impatient. ' What in the world,' he asks, 'has done more harm than the follies of the compassionate?' Setting more importance on relief of momentary pain and of temporary ailments than on the sure but protracted process of rebuilding health and strength, weakly and sentimental pity leads astray, and neglects the one thing needful, the development of the higher man. 'Compassion makes dull and heavy air for all free souls.' Its function in life is entirely secondary; and to allow it to claim more is high treason 
against the majesty of future humanity. So the masterbuilder, who labours for the higher world he surmises and longs for, must often be hard, sparing neither his neighbour nor himself in the rigour of his devotion. "Myself I sacrifice unto my love, and my neighbour as myself; thus runs the speech of all creators.' Niet zsche's protest against the idolization of emotional pity and sympathy, which the sensitive and sentimental have sometimes spoken of as the essential teaching of Christianity, and which Schopenhaner dignified with the title of ethical principle, is not unneeded. And if we remember the extravagances of altruism, we shall better understand his emphatic counterblasts. "There is a wholesome and healthy selfishness which springs from mighty soul - from mighty soul to which belongs the high body, the beautiful, victorious, refreshing body, around which everything is a mirror; the flexible, persuading body, whose image and epitome is the selfjoyous soul.' Such selfishness is not a light thing, any more than true compassion is identical with the gush of sympathetic emotion. 'By all means,' says Nietzsche, 'love your neighbour as yourselves, but let me first see you such as love yourselves.' But 'to learn how to love one's self is the finest and cunningest of arts.'

To hear Nietzsche, one might sometimes think as if all that was needed for the seeker after higher life was to burst the bonds around him by an effort of vigorous will. 'Willing delivers.' But what if will itself be a prisoner? Gods and moral imperatives may be discarded; but the past stands irrevocable, menacing and marring the present, and man can, it seems, only gnash his teeth impotently, and seek in vain anger and vainer punishments to get relief for his vexation. Will beats wildly against its prison-bars and kicks against the pricks; and how is it to unlearn the spirit of revenge? 'Who taught it reconciliation with time, and something higher than all reconciliation?' How is it to unlearn the pessimism which arises as it sees in all the past, in every 'It was,' a 'fragment, 
an enigma, a dismal accident'? Only, replies Nietzsche, "when a creative will saith unto the "It was," 'Thus would I have it be.' But for Nietzsche, at least, the 'It was' has a further signifieance and a deeper horror than to the commonalty. Following out an idea which has again and again in different forms risen up to awe the inquiring spirit, he sees in all existence an eternal recurrence. The burden of the irrevocable past grows heavier as age is added to age. 'A demon,' so he puts it, 'in an hour of utmost solitude thus whispers: This life, as thou now livest and hast lived, thou must live once more and countless times more; and there will be in it nothing new, but each pain and pleasure and each thought and sigh and all the ineffably little and big of thy life must return to thee, and all in the same order and sequence.' And what retort does the tempted will make? Does it curse the demon who so spoke, or fall crushed to the ground in despair? or may there come a moment when it rises to the height of the awful decision and, in full amity with life, affirms its resolve to have this moment once more and countless times over again. From the depth of Nietzsche's pessimism-from the horror in which he shrinks at the ghastly idea of the 'ring of existence,' the 'eternal recurrence'there emerges the final utterance of the world-affirming, lifeascending will. The free spirit-the pioneer on the way to the superhuman-is one who has so accepted the fact of life that ' he will have it again, as it was and is, for ever and ever, insatiably calling da capo, not merely to himself, but to the whole piece and play, and not only to the play, but at bottom to him to whom this play is just what is needed, and who makes it needful, because he always needs himself again, and makes himself needful. How? And-would not-this-becirculus vitiosus Deus'? The problem of life, it seems, has brought us round-by a 'vicious circle,' perhaps-to God. Life, on the assumption of the demonic idea, can only be lived-a paralyzing pessimism can only be escaped-if the 
individual, born, as it appears, to strugghle with an alien and irrernovable sum of antecedents, as a mere incident and single fragment in the stream of time, boldly accepts and asserts his identity, in the root of his being, with the supreme freedom and unchartered spirit of life in all its range and sweep. We are now, it may be said, in the full tide of unverifiable metaphysic; or we have passed from morality-even Nietzsche's morality-into religion. The final and fundamental step is a mystic salto mortale - an act of faith-by which the individual seems to reach what more pensive thinkers call the 'beatific vision' and 'intellectual love of God.'

It is principally in the second and third parts that these vaguely adumbrated ideas find a place: and they are not touched in Nietzsche's other works except in passages such as Aph. 34I, from 'the Gay Science' (publ. I882), and in the 'Other side of the good and bad' (Aph. 57). They are the evidence of the last stages of a 'Titanic struggle - of the struggle which man seems inevitably compelled to make to give himself a secure standing-ground in the battle of life. In Nietzsche's case they seem especially full of terrible pathos. If all life, as he holds, has been hitherto built and taught to rise by illusions; if man in his science, his art, and his morality has only clutched at semblances helping him to keep and foster life; if these creations of his mind are only something spread over existence to cheat or stave off an ineradicable pessimism;-it is hard to find anything solid elsewhere. Then the circle of inference is indeed vicious; and man only steps into the vacant place of God, or simulates the post of conductor in the chariot of life and nature, because otherwise he must perish. But, on the other hand, it may be urged, only by such declaration, of what the old thinker otherwise expressed by saying that all our movement, life, and being was in God, can art, science, and morality be made anything more than illusions and artificial perspectives. The creator of art, science, and morality, if they are to be real and solid elements in a real world, and not 
mere devices and tricks to escape ruin-a mimicry which deccives enemies in the struggle for existence-must be a real superhuman or a real Deity. And by an inverted path Nictzsche would have arrived at the old Greek dogma of man's essential divinity.

But these conclusions were not formulated by Nietzsche; he, at least, has not, like $\mathrm{R}$. Wagner, recited a palinode; and we cannot say that any decided trace exists of the recoil, which the acceptance of a theo-centric, instead of an anthropo-centric, position for man seems to involve, had clearly presented itself to his mind. His hour apparently had come; his sun set when the great noon promised a fruitful evening, and his message hardly goes beyond that awakening of the sleepers, that stimulus to a new step in development, which thorough scepticism, honest and unresting, may give. The fourth part of the book is not properly a continuation of the rest. It is rather a grimly farcical indictment of those specimens of the higher culture and advanced thought, who fancied themselves, and at one time were fancied by Nietzsche himself, to be his comrades and fellow-workers in the emancipation of the human spirit. They are all, on closer inspection, somewhat cranky and ill-favoured instances of the type higher-man-suitable for doing odds and ends of rough work in the wilderness, but hardly genial and hale and gracious enough to enter into the land of promise. Towards the close of the book they are all - the several types of the radical, emancipated, agnostic, and free-thinker-gathered in Zarathustra's cave, where the utmost they arise to is (in allusion to a mediaeval caricature of religion) the worship of the Ass. Whereby, perhaps, is signified that although they have surmounted the gloomier depths of religious dogmatism, and surmised the presence of an ineffable simplicity in things, they have reached but a somewhat jejune and negative conception of the higher truth. But of the interpretation of these scenes, which are evidently not without the spice of direct personal reference, it would be out of 
place to say more than to hint that they occasionally sound a jarring note and offend against the canons of good taste.

In the main, this notice has contented itself with giving a brief exposition of the contents of this volume, without going into criticism or discussion. Some of Nietzsche's opinions are of such obvious extravagance, judged by eomınon standards, that examination of them may be thought unnecessary. But of most, a much longer discussion would be required than could find a place here. Perhaps enough has been said on various points to excite a desire to hear more. Some, indeed, may think that these are poisonous opinions and best left in silence and neglect. But to this it may be rejoined that the growth of such opinion is itself a symptom that certain corners in the fields of ethics and religion have been left to an abandonment which favours the upspringing of strange plants, with both weeds and good grain among them. Nietzsche is at least always honest, pure, and thorough. One of his faults is a natural perversity, if one may so style it, which positively refuses easy and flattering solutions of problems, and would always seek its rest on the hardest and barest of rocks, with inveterate suspicion of any suggestion that happiness and truth can lie down together. Another is a fatal facility to follow the track of epigram, and to wander in the pleasant but devious mazes of verbal conceits. It has been impossible in a bare abstract like this to give much of an idea of his style. Its variety and sparkle naturally tend to disappear in the monotony of a summary statement of his positions:

Of the translation it is difficult to speak favourably; but it may be admitted that to translate Nietzsche well would be a task of no small skill. 
STUDIES IN THE HEGELIAN DIALECTIC ${ }^{1}$

Hitherto, with slight exceptions, the studies in Hegelian philosophy published in this country have been chiefly in the line of exposition. Criticism has in the main been incidental, and found in works dealing with Hegel's views on special questions whose discussion engaged the chief attention. Mr. Me'Taggart's book marks a distinct advance. It is a thoughtful and acute attempt, conducted with marked good taste and ability, to determine what Hegel actually tried to effect and how far he succeeded, to clear away misconceptions as to his method and its relation to ordinary experience, to point out problems which Hegel suggests to reflection but cannot be said himself either to see or to give a solution to, to indicate some directions in which his system seems to need supplement or correction, and to examine the value of his philosophy in general, as well as of certain applications he made of it to the several departments of sociological history. Even for those who are unable to accept all its conclusions it is a stimulating and enlightening book; full of quiet reflectiveness and penetrating remark, and high-toned in its conception of the problem of philosophy.

The seven chapters conjoined under the title of Studies in the Ilegelian Dialectic, if they do not exactly form an organic unity, offer at least a fairly continuous discussion of certain

${ }^{1}$ Studies in the Hegelian Dialectic. By John M. E. McTaggart. M.A., Fellow of Trinity College, Cambridge. 8vo. Cambridge, 1896. Pp. xvi, 259. (Mind, no. 20, 2nd series, 1896.) 
difficulties and corollaries which sooner or later present themselves to the student of Hegelianism. They fall, it may be said, into three or four tolerably distinct groups. In the first of these groups will go the three chapters (i-iii) entitled 'The general nature,' 'Different interpretations,' and 'The validity,'-' of the dialectie.' 'T'oo much should not of course be expected under these somewhat comprehensive headings. The three chapters are written with, on the whole, a definite reference to views taken of IIegel's work by erities of the two generations since his death (e.g. by Trendelenburg, Herr v. Hartmann, and Prof. A. Seth), and offer a line of arguments narrowed (even if it be also pointed) by the occasionally accidental and personal qualities of the objections against which they are directed. Such objections to a large extent are but symptomatic of the course of development in the individual soul which makes them, and to deal with them in a satisfactory way would require (as, obviously, one cannot hope to traverse the endless multitude of single censures) either to assure ourselves that they may safely be taken as typical of the dubieties raised by Hegelianism in the average human mind, or to seek to diseover the fundamental views as to the problem of philosophy, as to the relations or no-relations of thought and reality, to diseover (to put it roughly) the idola of the den and the theatre, which underlie and give growth to the incessant efflorescence of cavils. Instead of this all but impossible method of dealing with objectors, Mr. Mc'Taggart takes the praiseworthy course of testing general demurrers by a patient confrontation of them with the evidence of the original texts, by distinguishing what is valid in their remarks from what is exaggerated for the sake of a thesis. Probably there are other and more penetrating criticisms of the Hegelian principle and method which it would have been desirable for him to tackle. Those of Trendelenburg were written too much in the shade of that reaction which made asceticism in speculation a positive, and perhaps the sole 
intellectual, virtue, and looked back on the speculative epoch as a time of philosophic paganism: Von Hartmann's essay on the 'dialectical method' is but a hasty spoil of the times when he was scouring the domains erewhile held by the three kings of thought who reigned before him, and trying to carve out for himself a new realm; and as for Prof. Seth, perhaps one may venture the hope that he will yet employ his eminent conciliatory talent to bridge over the gulf between the deeprooted instincts of 'personal' life and the 'meditation' of death' which seems to take their place when life is viewed ' under a certain species of eternity,' instead of intensifying the inevitable conflict between them by an appeal ad populum.

Chapters iv and $\mathrm{v}$-which have been already published, 'nearly in their present form ' in Mind 1 - form a second group of different aspect. Chapter iv, entitled 'The development of the Method,' taking the phenomena as presented first in Hegel's Logic, and then in the whole cycle of his philosophy, endeavours to show that in the progress of the Hegelian system the method undergoes a continuous alteration-like an instrument which acquires new capabilities by being used; that in its beginning the element of negation and contradiction takes a more prominent position than it holds later, so that a period of struggle gives place finally to an easy evolution; that, in a way, the conclusion thus serves to show the incorrectness or 'subjectivity' of the process by which it was reached, or, in other words, that 'the dialectic does not give a fully adequate account of its own nature.' This, it must be owned, sounds at first hearing a very awkward doctrine for the 'dialectic,' even though Mr. McTaggart is careful to circumscribe its consequences. He further points out that Hegel might, if he had chosen, have adopted for the relations of Nature and Mind to pure Logic a scheme of movement, analogous to that adopted in the transitions of Being and not-

I N. S. I, 2, 8, 10. 
being, rather than that suggested by the relation of subjective and objective in the 'idea.' To the thesis of this chapter, that Hegel had not himself realized or seen what was implied in the gradual but decisive change from the inadequacy of the earlier eategories to the increasing truth of the later, Mr. Me'laggart attaches much importance: 'it is only,' he remarks, 'by the aid of some such theory' (of a subjective element in the dialectic) 'that we can regard the IIegrelian system as valid at all.'

Chapter v, 'The relation of the dialectic to time,' will be to many the most difficult passage in the book. 'The author is always acute and subtle in argumentation, and the discussion of the place of time in the system of ultimate reality is not a less fertile field of ambiguity now than it was in the days of Augustine. 'That the development in the dialectical system, both pure and applied, is not a development in time (i.e. the story of a growth) may be taken as settled: Hegrel distinctly negatives the suggestion of so treating it; and indeed the confusion between a record of events and an exposition of meaning seems too gross to be deemed possible. But, it is argued, this technical treatment of it does not really abolish the difficulty. If philosophy is the comprehension of what is, if it aims at 'discovering the ultimate nature of all reality,' and does so by showing ' reality' ordinarily so-called to be an inadequate stage or partial truth of what in its fullest 'realization' is an 'idea,' it seems not unnatural to say with Mr. Me'Taggart that the purpose of philosophy is to ' establish the rationality of the universe,' and that all idealism (and Hegel's system is confessedly and professedly a complete or 'absolute' idealism) declares the world or universe to be 'fundamentally rational and righteous throughout.' Does not the veriest tyro know that Hegel asserted that whatever is real is rational, and whatever is rational is real? And if so, is not the actual fact, present anywhere, justified; and is not the 'must be' and 'ought to be' of the 'rationalist' 
invested with a title to existence? Yet ' if all reality is rational and righteous,' how are we to explain the notorious facts of unreason and wrong everywhere protruding? We are, it is obvious, confronted by the 'problem of the origin of evil.' According to Mr. Me'Taggart the solution of the problem lies in accepting both the opposed propositions-that the universe is eternally rational, and that imperfection does exist-and hoping that in some as yet unknown and unsurmiseable way a reconciliation may be found in a higher synthesis. Perhaps this is to throw too hard a task on the divine might of Higher Synthesis, and it may more profitably be asked whether the universe which is eternally rational and righteous is directly identifiable with the universe in which imperfection prevails. Or it may even more profitably be considered what is to be understood by 'eternally reasonable and righteous,' and how far these epithets are clear and unequivocal.

The two concluding chapters (vi. and vii.) treat of 'The final result of the dialectic' and 'The application of the dialectic.' The 'final result' or the terminus of the dialectic is made by Hegel to be Philosophy, and one hardly sees how he could do otherwise in an encyclopaedia, where philosophy is alpha and omega. But philosophy, urges Mr. Mc'Taggart, must be considered to be 'merely a state of knowledge.' Deduct the 'merely,' and the equation seems no great error : but what is the force of the 'merely'? It is the separation of knowledge, first, from the thing known, from the 'this' which we know, and then we have before us the thing-in-itself named knowledge, but to which neither gods nor men can attach any meaning or allow any reality; and, second, its separation from volition and from pleasure and pain-that pure, disinterested knowledge, which human beings at least neither desire nor eare for. Philosophy - so understood as a state of knowledge-cannot (it is further inferred) be regarded as the 'culminating point of reality, or as the 'supreme activity of spirit'; it cannot even form a part in 
that supreme activity, for it is for ever vitiated by its antithesis to volition, and by its dependence upon an 'immediate' and a 'griven' which is alien to it. Philosophy is not 'eapable of acting as a synthesis between art and religion.' It, like them, is 'endeavouring' (says the author) 'to find a harmony' between the individual spirit and the rest of the universe.' But all three alike fall short of their aim. A new synthesis is recuired: 'some state of emscious spirit,' 'as direct as art, as certain and universal as philosophy,' in its faith, vision, and assurance that all things (ourselves inchuled) are in harmony.

Of the essay on the application of the dialectic the drift is briefly to show that the dialectic itself is worth much more than its applieations. 'The really valid part of Hegel's system is his Logie, and not his applications of it.' And if we farther ask what the ralue is of what is thus pronounced valirl, an answer comes that ' the value of philosophy lies more in the domains of religion than in those of science or practice,' and that that value consists in the 'general determination of the nature of true reality' and in the certainty Logic gives that 'all reality is rational and righteous.' The application of the method to portions of the concrete historical field in religion, law, or art is invalidated, according to Mr. Mc'Taggart, by three considerations: first, that we have there no fixed beginning or end as in the Logic, no bare rudiment or 'complete realization' of the 'absolute idea' where we can set our foot down; second, that all real life and history is more than logie, that the dialectic process is continually disturbed by external causes; and third, that a philosopher cannot possibly have the extensive and thorough knowledge of particulars, which the 'rationalization of reality'-particularly if understood to be the 'reconciliation of it with our aspirations'must demand as a pre-requisite. In consequence of the last deficiency it is suggested that a more promising field in which to apply logic will be found by taking abstract (moral) qualities and considering them as thesis, antithesis, 
or synthesis of other qualities (or mixed modes) of the same abstract stamp.

It is a commonplace that every age has its own difficulties and prejudices; and that each individual also has his own. 'The thoughts and interests of a period, a class, a single person, are set in a particular direction, and reflect or construct the world in a special way. An age which in the gross may be called idealistic is replaced by a period where realistic currents prevail. Faith fastens at different dates on widely diverse foci, or calls them at least by widely disparate names. New catchwords are abroad, new aims pursued, new gods worshipped. We ask the philosopher of other days questions which imply a standpoint he would find it difficult to assume. We want to see him from the outside, all round, as a single object, to be, as it may seem desirable, appropriated or rejected, according to its adaptability or inadaptability to our needs. What to him was at least an effort to reconstruct the world in the light of the Absolute, his readers will for practical purposes treat as only a petty contribution to a task (that of rationalizing the mass of things) which each reader must de novo undertake for himself. But so to take stock of themselves - to put themselves in a nutshell-to adjust themselves for consumption by the public jaws-is what the great thinkers have not done, and could not do without self-derogation and self-destruction. Hegel, in the introductory chapters of the Encyclopädie, made an attempt: but it was not more successful than Wordsworth's exposition of the theory of the relations of Nature to Art and to Man which governed his poetry. He had not studied his own method from without: it was not-for him-detachable from his subject-matter, just as, conversely, the subjectmatter was not detachable from it. Such a subject-matter, detached and made a body of dogma, would be but dry bones, suitable for a museum: such a method, reduced to an abstract trick of manipulation, would be but an instrument of logomachy. 
Hegel has spoken more than once of the movement of thought in his argument as that of the matter or fact itself (Ner Sache sells:t). He did not mean that the abstractly objective did or could move: that a selfless world could exert the life of change. The fact itself of which he speaks is the real world, which is a unity of subjective and objective: it is a thought-permeated objectivity, and a subjectivity which has made itself at home in external body, and is no longer a floating will-o'-the-wisp of opinion. When Hegel's Logic begins its dogmatic march and enters on the sicheren Gang der Iriscnschaft, the processes of nature and history-and especially that of mental history (and Mind is always and par excellence the Historical process-das Historische) have been already traversed. It is a fundamental hypothesis of his system that philosophy as self-contained knowledge is a circle - that it returns into itself - and that the beginning has its full force only for him who has gone already through what is called its end. The mind which logicizes is a mind which, if it at its one end grows ont of the organized concretion of space and materiality known as homo sapiens, attempts at its other to raise itself up to, and seek a higher firmament in, that spiritual structure of the Idea, which is the intangible and inapprehensible God, as he may be said to exist (if such being ean be called existence) before the realm of nature and the realm of history (which is freedom and humanity) had emerged. If this be kept in mind-and it is implied in Mr. Me'Taggart's phrase that the process of Hegelian logic is a reconstruction rather than eonstruction-it seems to cut away the ground from some loose talk about 'pure thought,' about the passage from Logic to Nature, and about the relation of philosophy to religion and art. A paralle' case may set this in a clearer light. Just as Kant is sometimes estimated on the basis of an arbitrary restriction of his teaching to the more palpable features of the Criticism of Pure Reason, so Hegel has suffered by the subordination 
of his philosophies of Nature and Mind to the Logic. Nor is it sufficient to say that the Logic presupposes experience: that it is based upon the general nature or " common characteristics of all experience' - an experience which contains within it the 'nature of pure thought' to be elicited or ascertained by dialectic. 'Experience' is but a vague, much-worn word; and, like its neighbour 'reality,' it is employed perhaps a little too much as a conjuror's cry. The speeific experience which philosophy always, according to Hegel, presupposes is an experience which has in it the characters of morality, art, and religion: and the still more specific experience which Hegelianism presupposes is the concentrated ideal life in the Geisterreich or World of Soul, Mind and Spirit, which is the abiding fruit gained from the historic movement of art and religion, and above all of philosophy. The bare shell of experience is and gives nothing: we must know what it is an experience of: for experience is not a reality, a selfsubsistent, nor on the other hand is it so much 'pure thought' combined with so much 'data of sense' or 'matter of intuition.' Data of sense which are 'indispensable and yet negative,' which are 'not positive causes, but conditions,' shrivel up into something very hard to talk about-at least if they are to be talked about with profit.

Mr. Me'Taggart has entitled these interesting and suggestive chapters essays in the Hegelian dialectic. He has spoken freely of categories. He has used as descriptive of the three steps of the logical movement the names thesis, antithesis, and synthesis. He may plead great example for so doing, and may urge the convenience of distinct terms. But something may be said on the other side. The three last names are the literary property of Fichte, and oust a multitude of very untranslateable Hegelian terms, such as setzen and aufhelen, an und für sich, which, with their various shades and-as some may even think-ambiguities, constitute (may one say?) the charm and the stimulus of Hegelianism. The 
others, I think, give a mechanical regularity and discreteness to the process which, as Mr. Me'lagrgart well points out, is or would be continuous and organic. Synthesis, in particular, is misleading. No loubt in some modern uses it denotes a finer, ideal composition-an inner and intimate union of hearts and bodies; but it may be doubted whether the word can fairly bear this meaning, and it is unadvisable so to treat it, in the face of Hegel's relegation of it to a lower level than that of a 'speculative' unity. 'Category,' again, is a name Hegel occasionally introduces: but it is only to facilitate the way of the historical student-(in a similar way to Kant's so calling the Stammbegrifie of intellect), and tends to mix up matters of diverse origin and purport. An elastic term like this has its disadvantages.

'The case is somewhat different with Dialectic. In Hegel's primary use it designates a real, though frequently unnoted, phenomenon in life and knowledge, whereby the thing or concept, which temporarily or ordinarily seemed stable, definite and simple, turns out to be unstable, multiform and contradictory. Common practical life rests upon the assumption of temporarily ultimate points, absolute principles, and the like. It may, if probed, own them to be relative and abstract, but it deals with them as if they were absolute and total. And it is natural and good for it so to act, so long as it is immersed in the necessities of practical life which insensibly and gradually call up the complementary re-action. It is otherwise when it philosophizes and rests in reflection on the single step. Then the context and the complementary is lost sight of; and a series of independent atoms of thought seem to be left as severally real. Theory in its first stage tends to give independent fixity to elements which life keeps flexible and organic. It is the business of a higher philosophy to find a more adequate expression of concrete experience than the ordinary efforts of reflection, divoreed from life and action, are able to supply. 
The business of dialectic, therefore, in its most legitimate sense, is to be the bridge which continually throws itself out to span the abyss between the land of so-called common sense, or first impression of ordinary reflection, and the land of reason or philosophy. It serves to demonstrate that the irrefragable data and solid ground of the theorizing practician are not really so solid and impregnable as they seem. In practice no doubt the impermanence and the interdependence of things is again and again flashed upon even common observation. But in the world of theory which is for ever being built up by man, this truth of observation is forgotten, treated as an extrinsic and accidental phenomenon of things, instead of being recognized as what Plato has called a $\pi \dot{a} \theta 0$ s

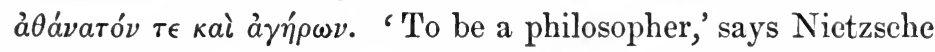
in his drastic way, ' is to be a mummy.' That at least is the common danger of the hasty theorizer. His ideal world leaves out the pathos and the action of life, and converts it into a statuesque collection or a mechanical conjunction of what are called ideas. This is where Hegel pressed his dialectic into service-to show that these ideas, even when hardened into the stability of things, have intrinsic and intestine life and motion. It is directed against the half-and-half measures of popular philosophy-of the philosophy which seeks a comfortable pillow of sound principle to sleep again, and which perhorresces nothing so much as seeing a 'bacchantic intoxication' convulsing the old stolidly respectable ideas. The human mind in its unregenerate nature craves for a $\pi \circ \hat{v}$ $\sigma \tau \hat{\omega}$, some solidly apprehended reality, some impregnable rock of experience, whence it may possibly seek to move other things, or where it may itself rest in tranquillity. Such a rest Hegel does not give:-or if he gives it, he gives it in the 'absolute idea,' where there is room in 'identity' and ' unity' for all transitions and correlations and developments through negation and contradiction; or he gives it in that absolute philosophy which includes all that is true 
in art and religion, and, in including, transcends and transmutes. But the absolute idea and the philosophy are both unlike the rest of sleep: and if they are to be called reality, then reality is that immeasurably far-off divine event to which all things in their finitude move, as from it in their finitude they proceed.

The function of the dialectic is therefore mainly introductory. It is none the less eternally necessary. Here and there, in every tongue and tone, some reflective spirit cries that he has found the solid bit of fact, reality, experience, out of which he will (-if you allow him time enough, and operations sufficiently multiple of memory, construction, generalization, abstraction, and so on-) build you up the real round world you know. Only let him sit on his pateh of the solid earth of present reality and primitive apprehension-even though his datum, or 'given,' be a very little one-, and he will be at ease. Hegel's whole energy is engaged in a contest against this belief in a datum. Make it as small as you like-call it pure being: and his argument tends to show that you have got nothing, You say you do not want a pathological process of knowledge; a knowledge which grows through disturbances and tempests and morbid states: you would like 'pure health,' a normal and natural development. Hegel replies, you are crying for the moon: pregnancy and birth have their morbid features: all life is tainted with sickness: nay, all life is lived only through the victory over perturbing elements; and if the conquest be too thorough, and the struggle collapse through want of antithesis, the life itself is at an end. You would like positive, out-and-out positive, truth. But truth only lives by the side of error: it has its value and validity only in the error which it serves to refute, i.e. to explain: remove the error it lives upon, and the truth hangs flaceid and sere. In ordinary everyday experience this dialectic, as we have seen, goes on quietly enough. But it assumes 
more terrible proportions on the field of history, when ideas have, by eauses not here to be discussed, grown into great conerete powers, and summed up in a single term the result of long processes. Then the phenomena are called disease. But there is no absolutely normal health-except in a visionary standard which only youthful impatience ean expeet to see realized in his own sturdy growth.

But Hegel has not used the term 'dialectic' as the supremely descriptive name of his method, or made it, as Mr. Me'Taggart does, serve to cover the whole process of introducing order and connexion into the mass of terms and forms of thought which are built into the fabrie of reality. Dialectic proper perhaps belongs most to the field of what Hegel at one time ealled Oljective Logic. Objective Logic deals with a number of 'categories' or 'kinds of nameable things' which are taken as, in a way, part of the 'external' universe of fact, bits of reality. There are other categories-more commonly taken as 'forms of thought'which fall within the scope of what Hegel once ealled Subjective Logic. These, such as final cause, and the formulae of judgement and conception, are treated as ideal vestments on reality: ways the human mind has of putting together or disjoining facts which are in the last resort independent of this dressing. Hegel's purpose may be said to be to break down the absoluteness and ultimateness of this distinetion. It was not a new step, but only a systematic prosecution of a view which had come out deeidedly in Kant, been deepened and extended by Fichte and Schelling, but had never been absent when philosophy went vigorously to work in its effort to unify the theory of life. That view had been that the so-called objective is essentially a subjective-objective: that not merely in the modal or properly logical terms, but also in such as put forward a claim to metaphysical, and even materialistic value, there is the pulse and life of subjectivity. With being, you 
suppose. yourself to be on the ground of reality: you fancy that on given qualities you can build as on primitive rock. Causes are valid, you say, even if final eauses are foibles: there is power in number, even if organism be an illcompounded mole of synthesis. But the Itegelian logic claims to show that if you are sufe on being, it is only because it is one plank on the deck of the ship of thought, and that the single solid plank involves and postulates the concrete complexity of the whole structure. If you are in earnest with being, or trust the data of intuition (apprehension), you are committed to the absolute idea, i. e. to the concrete system of correlativity, transition, and development, which is the god of the abstract logical world: and in the long run you are committed to something larger still, to an organic natural realm, and to the omnipresenee of intelligent and volitional life. It was this conviction which in partial and therefore paradoxical shapes led to the Berkeleian theory of vision, to the analysis of the more abstruse ideas by Locke into simpler co-adjusted elements, and to Hume's much maligned interpretation of causality in things as connexion between thoughts. It is the same principle which in Descartes appears in the personal form, cogito, ergo sum, and in his finding the safeguard of each single perception in their eoherence with that supreme harmony of all true or 'perfect' reality which he called God. What merit Hegel has is perhaps only the persistent exploitation of this idea throughout the whole range of terms in which blank and bare reality emerges into name, interrelation, and value. The real world in its essential fabric is a work of ideas: while the admittedly ideal terms are only the development to a further stage of what has come to be commonly taken as real and constitutive of reality.

But dialectic is after all only the negative side of his philosophy: and Hegel does not rest content with the demonstration of the power of negation, even in the highest. 
His own name for his method would be Speculative: and as Speculation he designates the positive and unificatory operation of intelligence which holds contradictions in unity and identity. But the 'unity' and 'identity' of contradictions does not, however erassness or perversity may assert, mean that it is all the same whether we say yes or no. It means rather that the meanest of God's ereatures boasts at least two soul-sides, one to show to the world and the enemy, another to show to the self and the friend. It means that in the view of science or fuller knowledge, the simplicity which is the assumption of practical life is an illusion. The plain man and the practical judge expect a plain answer, yes or no, to a plain question. But the investigator and the criminologist have learned that plain questions and plain answers are only possible for those of hurried and blunted senses; guilty and not-guilty are terms of a limited province and are conditioned in their application by a social convention. The plain answers are neither quite unreal nor quite untrue, be it added: but they are not expressive of the whole truth or the whole reality. The problem which is strictly called speculative is to find a more adequate expression, to formulate the question in terms which will allow a more equitable answer. But it must not be supposed that the speculative simply undoes the effect of the dialectical act: or if we say that it reconciles, reconciliation does not consist in glossing over or ignoring the opposition. We may declare that the disruption is overcome, or cancelled, or suppressed, or transcended: but we shall misinterpret these terms if we think that thereby that which once was has been made as if it were not. The 'new life which rises upon the ruins of the old' is a phrase which, as is the way of metaphors, makes us forget that the new life owes its structural grace and wealth to the fragments and jarring elements which it reconstructed. Mr. Mc'Taggart remarks that 'if we find contradictions in our notion of a thing, we must give up 
its reality.' 'This seems an unnecessarily hard saying. No doubt contradiction is a symptom of incompleteness and therefore of eomparative unreality of defective 'truth.' It is a sign that you are not on the absolutely solid ground. But the ground may be fairly real ground for all that. A pure unreality would hardly be worth the trouble of contradiction. It is only the 'concrete notion,' says the author, which is 'found in the world of reality,' and he tells us that according to IIegrel 'thought can only exist in its complete and concrete form' as absolute illea. Surely there is exaggeration and misconception present or sugrrested here. The world of reality in which the concrete idea is found existent is not the world known as real to ordinary mortals: for them its light is not visible on sea or land: it is a world which for him who has eyes only for the actual (das Wirkliche) is a veiled world. The full and concrete notion-the 'absolute idea'-surely only exists (if the word is even there appropriate) in the totality of nature and of mind, in the universe natural and spiritual. But the absolute truth ('truth' and not 'reality' is the Hegelian term of supreme sweep) does not annihilate partial truths, and seat itself in their place. Apart from their partial reality or truth, it itself were the emptiest reality and the poorest truth, just because the most pretentious. The Absolute must not merely have room for, but must contain all the Relatives: the concrete must contain all the abstracts: the harmonious unity, all the contradictories.

Mr. Mc'Taggart remarks that in the Logic we have fixed points at the two termini: Being at the commencement and Absolute idea at the close. He speaks, it often seems, as if there were two points as realistically defined and locaterl as the two ends of a road. But this may be misleading if we forget that the road leads across the infinite and eternal. The start with being is equivalent, he thinks, to the postulate that 'experience really exists,' or that 'something is': the 
dialectic 'assumes the ralidity of the idea of being.' What precisely is meant by 'validity,' I hardly feel sure: but in any case I do not think the philosophy which characteristically asserts that 'Being and Nothing is the same thing' can have a very high estimate of the idea of being and its validity. It would be truer to say that the dialectic demonstrales the invalidity of the idea of being (-that impregnable stronghold of those who fear the eddying tides of thought) until it has been supplemented by factors which are decidedly idealistic, subjective, thought-born. And 'Is,' whieh is no more than a bare 'Is,' being in its blank purity, far from serving as a solid standpoint, is a tight-rope from which you are incessantly rolling off into nought. It is the beginning of the dialectic, not beeause it is warranted by the common nature of experience-(the common nature of experience, if it can warrant anything, can warrant a great deal more than the bare pin-point of being), but because as mere or pure being it is the pole of truth in closest contact with nonentity, and at an inappreciable distance from it.

But if pure Being is the minimum of reality, what shall be said of the Absolute Idea? One may have the highest respect for the serried array of the dialectic, and feel unable to detect a serious flaw in the links of its chain; one may be amazed at the incompetence which allows some of its crities first to mistranslate and then to misconceive its argument; and yet one may not be clear that here is the absolutely fire-proof structure of thought, embracing all details, and complete for all time to come. Even a disciple may regard his master as human, and be content if he finds in him a light to lighten the past and to convert its chaotic voices into harmony or at least coherent speech, though he fails to prophesy unambiguously of the after-times. As Hegel approaches the terminus-the absolute idea (in Logic) and philosophy (in Mind)-he grows terse and enigmatic. And why? One may say with Mr. MeTaggart that the 'Idea' 
is 'the idea of the human mind, acting theoretically or (and ?) practically.' But this is but a piece of verbal information, till we linow the human mind-know it, as Plato says, not in its erushed and degraded or 'dergenerate' form on these shores of time, but in its pristine or perfect (eternal) nature as revealed in philosophy. And when that knowledge comes, shall we be anxious to retain the epithet 'human' as distinct from 'superhuman' and 'divine'? 'The 'alusolute idea' can have little said of it, because it represents a postulated maximum-just as the other terminus (being) represented a minimum-of truth. Once we get beyond 'Object' in the Iogical order and enter on 'Idea' we cross the Rubicon which separates the philosophie movement, as it was directed by Kant and his successors, from all the past. $U_{p}$ to that point Hegel had been reproducing what may, not irreverently, be called aneient history. In the rest of the Logic he is engaged on the modern fielda much more complex and concrete field. The relation between life and intelligence, between intellect and will, the problems of Schelling and Schopenhauer, the questions of evolution theory, emerge and come to the front. But even if 'organism' and 'vitality' were clear and assured conceptions (and they are far from being so, they are rather battle-grounds of the advanced sciences), it is difficult to surmise how we are to go beyond them, and where we shall find ourselves if we do. We may say with Mr. MeTaggart that 'the universe is a super-organie unity.' But just as 'organic' gets most of its meaning by its antithesis to 'mechanical,' so super-organic is only a plus ultra sort of word, tending to indicate that 'organism' is not the mountain summit, but only a subordinate height of truth 'Absolute idea' therefore can only be regarded as a name for the problem of philosophy, not as a solution: it emphasizes the need of a synthesis. The very title itself (with its epithet alsolute) suggests this: and Hegel's (like 
Kant's) use of 'knowledge' as a genus embracing the two species of theoretical and practical reason hints the same approach to ' undiseovered territory.' When the idea is absolute, it ceases to be only idea.

I cannot agree with Mr. McTaggart therefore when he speaks of the highest category as 'without contradictions.' A nursery rhyme tells of the tumultuous and interesting seenes of life and death that were transacted in relation to the House that Jack built. This House so built is in its way a supreme category: but I think it would be a rather lame affair if all the contradiction and negation of which it was the centre were removed. The pith of the story would be gone. So when we are reminded that in the advance of thought and knowledge 'the presence of negation is a mere accident, though an inseparable one, and that its importance continuously decreases,' one may in a way admit that the later chapters have less of it, and yet seek the causes in other quarters. These causes are partly that this part of the Logic had been treated in the 'Phenomenology of Mind' and comes up again in the discussion of organic and mental phenomena: partly that the battles on this field were largely yet to fight, and that not even a Hegel can anticipate the debates of the future in their detail.

It is Mr. Mc'Taggart's conviction that 'reality is not in its truest nature a process, but a stable and timeless state.' I pass over the antithesis of a process and a timeless state, and its implications : they are perhaps scarcely in accordance with the statements of ehapter v, I must note that Hegel speaks not of reality - which to him is a very subordinate categorybut of the Absolute, when he describes it (if and when he does describe it) as a process. But I think it is impossible to accept the description given by Mr. McTaggart as true to Hegelianism. The absolute-the Hegelian God (if we for a moment adopt language of accommodation which will not improbably mislead) -is at least Life, at least Ego : and if 
these are not process, self-surrendering, self-renewing process, it is difficult to see where we are to look for examples of process. 'To speak of II im or It as the 'supreme beingr' or 'ultimate reality,' as the 'reality which underlies all finite things' is to use expressions, eapable perhaps of profitable interpretation, but which certainly lead, by their obvious suggestions, towards the cave of Spinozan substance, rather than to Hegelian Subjectivity-which is Personality, or rather 'Tri-personality. And there is in Mr. Me'Taugrart's language if not in his thought, a recurrent proclivity in this direction. It shows itself in the pre-supposition of an irredueible minimum of heing as datum, an undeduced and griven This; a reality which lies behind and which 'the inadequacy of our finite thought' never permits us to express completely; a reality 'supplied by sense' - sense without which 'we can perceive nothing of the nature of thought.' It shows itself in the dictum that it is the oflice of thought to mediate, and only to mediate: to 'relate' alien elements, given and apprehended somethings. When it is added that 'thought actually exists, or it could not mediate,' we are face to face with the old mythology of 'efficient' causes, powers which mediate like persons, and are entangled in the inextricable confusion between thought, the thinker, and his thoughts. As against such conceptions there is here only space to say that a thought, which does not do more than mediate, must presuppose and postulate another (if it be another) thought which calls for mediation and submits to it: a thought which, to use language we have already demurred to, is synthesis, antithesis, and thesis - which

'Creates, creator and receiver both.'

Thought mediates: but to do so, it has to be more than a mediator, and must have in it the natures of the two extremes which it reconciles, otherwise its would-be mediation is waste and nullity, or accident. The only ground for holding 
otherwise would scem to lie in a confusion of terms. Say that an unrelated being is as good as nothing, and you are immediately supposed to have been refuted, if it is pointed out that by your own admissions the being must be before it is relatel. The refuter does not take 'unrelated' in all its bitter truth, its absoluteness and utterness : he still leaves it in its comparative sense, indicating the absence of those relations without which the being may still exist and perform its function.

'There is however another feature in Mr. McTaggart's conception of the dialectic process which has to be noted in this connexion. We have seen already how he supposes negation to be banished from the bosom of ultimate reality and contradiction to be removed from supreme truth. He prefers, it is evident, the faith and the historieal event of religion to the triplicity of syllogism into which philosophy dissolves the tale. If it be the declaration of religion, as he says, that 'all things are dependent on a reality' in which our ideals find their embodiment, if religion, as Hegel suggests, keeps in the view of suffering humanity the prospect of a glittering rest which lights up the scene of present toil, philosophy certainly endeavours to 'secularize,' i. e. to reduce to an immanent law of life what revelation presents as an event and a drama. But does philosophy supervene as a new stage, utterly differing from what has gone before? Is it, as we have heard it called, a state of knowledge only? To say so of Hegel's conception of philosophy is-one need not put it more, and one dare not put it less, bluntly-seriously to misconceive Hegelianism. When Hegel says ${ }^{1}$ that 'religion is the general title of the supreme sphere' of intelligence, he only expresses his prevailing tendency to accentuate that religious tone and aspect of the higher mind which he accused even Kant, and still more his predecessors, of unduly neglecting in their systems. Philo- 
sophy no doubt is knowledge; but even distinguished critics have failed to show that it is only knowledge. It is the knowledge of religion: the credlo as intelligo. Philosophy (to Hegel) is that stage of truth-the highest, if evaneseent, vision of reality - which is called religion-turned, or attempted to be turned, into the grip of a pervading prineiple of immanent life and conscious action, not set in antagonism and relief to the present actuality, but read more and more into it, and in its turn steadied and interpreted by it.

I do not think the dialectic intended to teach us that ' matter must be reduced to spirit,' unless that means that in vulgar matter (so to call it) there are promises and potencies which call for revelation or manifestation. It is not the case, I submit, that, in Hegel's view, 'explanation by a higher category relieves us from the necessity of finding a consistent explanation by a lower one.' Hegel had read his Anaxagoras and his Leibniz to better advantage than that, and knew that the supreme Novs never works without the instrumentality of machinery, and that final causes never supersede, but only complete, the laws of mechanical causation. The higher eategories are not thus ungrateful. If theirs is the glorious prerogative of crowning the edifice, it is a prerogative which only the patient and laborious co-operation of many minor craftsmen made possible. No doubt we all feel sympathy with the critic who complains that the three volumes of Hegel's Logie, with their recurrent demonstration of the inadequacy of concepts whose practical reality and use we all accept, are a weary pull up barren steeps. But it isaccording to Hegel-only on the partial truth of these materials of which dialeetie proves the partial ineffieiency tha: the higher and distant stages of the pyramid of knowledge can be reached. And each later category has to keep-transmuted and adjusted-the earlier, not leaving them behind.

$$
\text { o } 02
$$


It is therefore questionable policy to deelare that "philosophy can tell us a priori that nature and spirit do exist.' When it so speaks, philosophy perhaps reveals no more profound secret than M. Jourdain heard when he learnt he had been talking prose all his life. Phrases, like 'a priori' and 'deduction,' are out of place in this phase of method, and serve only as stumbling-blocks. If philosophy can predict nature and spirit, it is because nature and spirit have produced or grown into philosophy.

Lastly, a word on some phrases by which the purpose of philosophy is here described. It 'aims at discovering the ultimate nature of all reality': and its final conclusion, we are informed, is, at least for Hegel, that 'all reality consists of spirits which are individuals' or of self-conscious beings existing only in their connexion with one another-a connexion which is closer than an organism. Such is the ontology; and it has beside it a theology which declares God to be "the reality which underlies all finite beings.' It would have been desirable perhaps to give more definite justification from Hegel for the assertion that he had arrived at the former conclusion, and to supply some indication as to the relation between the reality which underlies appearance and finitude, and the reality which consists of individual self-conscious beings. But when it is stated that, according to Hegel, philosophy is the 'culminating point of reality,' we fall into an almost grotesque bundle of equations, to correlate which will require an interpretation of God, philosophy, and reality involving a portentous effort of reconstructive thought. 'Reality' at least will not help us much in these latitudes, when it has become as empty a term as thing or leing. But I do not linger long on these ontological dogmas: for-as Kant long ago remarked in his 'Dreams'-it is not easy to say how much you commit yourself to when you cross the boundary into Spiritland. 
Philosophy, however, has its less metaphysical side. It 'establishes the rationality of the miverse': and Hegel himself is said to show that 'the universe is fully rational,' 'altogether rational and righteous.' A Cierman pet, Novalis, I think, is reported to have said that though philosophy an bake us no bread, she ean give us (iod, freedom, and immortality. Not on one side only, but on both, this aphorism smacts of the enthusiasm and peudo-idealiom of the Romantic. epoch. Directly philosophy can do the seeond as little as the first: in her place in the organism of intellect she can laclp much both towards better bread, and a worthier life in the light of these three ideas. But let us not be in a hurry t. suppose that a discovery of the harmony of the universe, its rationality and righteousness, will reconcile it with our aspirations or with our ethical needs, at least unless we first make our aspirations and our ethical needs both rational and righteous. Our aspirations are no doubt legitimate in their way, and our ethical needs are possibly eren 'daughters of the voice of God'; and so are in another way the harmonies of art and the consolations of religion. But the righteousness of the true and rational world - of the kingdom which is, in a practical sense, to come, if it be also the kingdom which is within us-exceeds the righteousness of the Scribes and Pharisees. And we are all perhaps in our lower moments to be found in the camp of the Scribes and Pharisees. We are proud of our justice and our benevolence. But Fiat justitia, ruat caelum is but a relatively-worthy flaunt cast at weak-kneed pity. The righteousness and rationality of the intelligible world may not entirely square with our notions borrowed from our earthly jurisprudence and our practical aims. If philosophy therefore seeks to rationalize the world, it does so in continuation of those efforts which in all ages have been made in the direction of realizing the unity and coherence of all being, in carrying ever further the process of discovering 
and constituting the truth of things, the harmony of mind and nature, the synthesis of all the aspects and appearances of experienee. Of ultimate and absolute reality it will say positively and dogmatically but little, though it may hint much of what we have to do in temporal and relative service to further the coming of the kingdom of truth. 
OXFORD

PRINTED AT THE CLARENDON PRESS

BY HORACE HART, M.A.

PRINIER JO THE UNIVERSITY 



\section{Clarendon IDress, Oxford.}

\section{SELECT LIST OF STANDARD WORKS.}

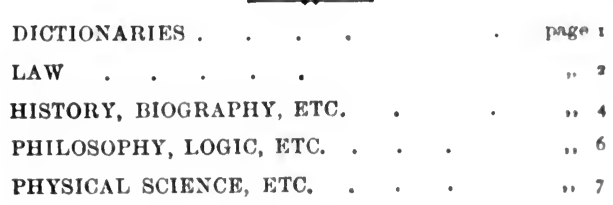

\section{DICTIONARIES.}

\section{A NEW ENGLISH DICTIONARY}

\section{ON HISTORICAL PRINCIPLES,}

Founded mainly on the materials collected by the Philological Society.

$$
\text { Imperial } 4 \text { to. }
$$

Present State of the Work. 6 \&. $d$.

Vol. I. $\left\{\begin{array}{l}\text { A } \\ \text { B }\end{array}\right\}$ Edited by Dr. Murray . . . Half-morocco 2126

Vol. II. C Edited by Dr. Murray . . . Half-moroceo 2126

Vol. III. $\left\{\begin{array}{l}\mathrm{D} \\ \mathbf{E}\end{array}\right\}$ Edited by Dr. Murray and Mr. Hesry Bradefy Half-morocco . . . . . . . . 2126

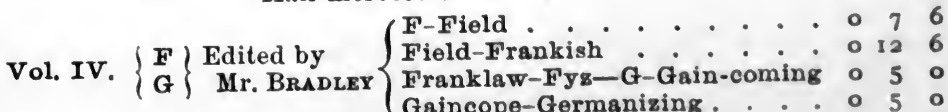

Gaincope-Germanizing . . . 050

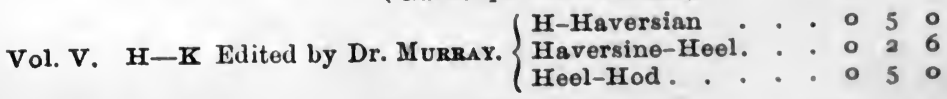

The remainder of the uork, to the end of the alphabet, is in an advanced state of preparation.

* * The Dictionary is also, as heretofore, issued in the original Parts-

Series I. Parts I-IX.

Series I. Part X.

Series II. Parts I-III.

Series III. Part I.

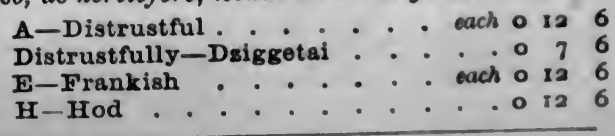

nxford: Clarendon Prees. London: Henky Frowor, Amen Oornet, E C 
A Hebrew and English Lexicon of the Old Testament, with an Appendix containing the Biblical Aramaic, based on the Thesaurus and Lexicon of Gesenius, by Francis Brown, D.D., S. R. Driver, D.D., and C. A. Briggs, D.D. Parts I-VI. Small 4 to, 2s. 6 d. each.

Thesaurus Syriacus : collegerunt Quatremère, Pernstein, Lorsbach, Arnoldi, Agrell, Field, Roediger: edidit R. Payne Smith, S.T.P.

Vol. I, containing Fasciculi I-V, sm. fol., 5l. $5 s$.

** The First Five Fasciculi may also be had separately.

Fasc. VI. $1 l .1 s$. ; VII. $1 l .11 s .6 d$. ; VIII. $1 l .16 s$. ; IX. Il. 5s.; X. Pars. I. Il. $16 s$.

A Compendious Syriac Dictionary, founded upon the above. Edited by Mrs. Margoliouth. Parts I. and II. Small 4to, 8s. 6d. net each. ** The Work will be completed in Four Parts.

A Sanskrit-English Dictionary. Etymologically and Philologically arranged. By Sir M. Monier-Williams, D.C.L. 4to. $2 l .2 s$.

A Greek-English Lexicon. By H. G. Liddell, D.D., and Robert Scott, D.D. Eighth Edition, Revised. 4to. Il. I6s.

An Etymological Dictionary of the English Language, arranged on an Historical Basis. By W. W. Skeat, Litt.D. Third Edition. 4 to. $2 l .4$ s.

A Middle-English Dictionary. By F. H. Stratmann. A new edition, by H. Bradley, M.A. 4to, half-morocco, Il. I Is. $6 d$.

The Student's Dictionary of Anglo-Saxon. By H. Șweet, M.A., Ph.D., LL.D. Small 4to, 8s. 6 d. net.

An Anglo-Saxon Dictionary, based on the MS. collections of the late Joseph Bosworth, D.D. Edited and enlarged by Prof. T. N. Toller, M.A. Parts I-III. A-SÁR. 4to, stiff covers, I 5s. each. Part IV, § I, SÁR-SWİRIAN. Stiff covers, 8s. 6d. Part IV, § 2, SWIP-SNELÝTMEST, I 8 s. $6 d$.

** A Supplement, which will complete the Work, is in active preparation.

An Icelandic-English Dictionary, based on the MS. collections of the late Richard Cleasby. Enlarged and completed by G. Vigfússon, M:A. 4to. $3 l .7 s$.

\section{LAW.}

Anson. Principles of the in its Relation to Contract. By Sir W. R. Anson, D.C.L. Eighth Edition. With Appendix of American Cases. 8vo. Ios. $6 a$.

Law and Custom of the
constitution. 2 vols. 8vo.
Part I. Parliament. Third
Edition. I2s. 6d.
Part II. The Crown. Second
Edition. I4s.

Baden-Powell. Land-Systems of British India; being a Manual of the Land-Tenures, and of the Systems of Land-Revenue Administration prevalent in the several Provinces. By B. H. Baden-Powell, C.I.E. 3 vols. 8 vo. $3 l .3 s$.

Digby. An Introduction to the History of the Law of Real Property. By Kenelm E. Digby, M.A. Fifth Edition. 8vo. I2s. $6 d$. 
Grueber. Lex Aquilia. By Erwin Grueber, Dr. Jur., M.A. 8 vo. IOs. $6 d$.

Hall. International Law. By W. E. Hall, M.A. Fourth Edition. 8vo. $22 s .6 d$.

A'Treutiseonthe Foreign Powers and Jurisdiction of the British Crown. By W. E. Hall, M.A. 8vo. 10s. $6 d$.

Holland. Elements of Jurisprudence. By T. E. Holland, D.C.L. Eighth Edition. 8vo. 10s. $6 d$.

\section{- The European Concert} in the Eastern Question; a Collection of Treaties and other Public Acts. Edited, with Introductions and Notes, by T. E. Holland, D.C.L. 8 vo. $12 s .6 d$.

Studies in International Law. By 'T. E. Holland, D.C.L. 8vo. 1os. $6 d$.

- Gentilis, Alberici, De Iure Belli Libri Tres. Edidit T. E. Holland, I.C.D. Small 4 to, halfmorocco, $21 \mathrm{~s}$.

The Institutes of Justinian, edited as a recension of the Institutes of Gaius, by T. E. Holland, D.C.L. Second Edition. Extra feap. 8vo. $5^{s}$.

Holland and Shadwell. Select Titles from the Digest of Justinian. By T. E. Holland, D.C.L., and C. L. Shadwell, D.C.L. 8 vo. 14 s.

Also sold in Parts, in paper coversPart I. Introductory Titles. 28. $6 d$. Part II. Family Law. Is.

Part III. Property Law. 2s. $6 d$.

Part IV. Law of Obligations (No. 1), 3s. $6 d$. (No. 2), 4s. $6 d$.

Ilbert. The Governmient of India. Being a Digest of the Statute Law relating thereto. With Historical Introduction and
Illustrative Documents. By Sir Courtenay Ilbert, K.C.S.I. 8vo, half-roan. 21 s.

Markby. Elements of Law considered with reference to Principles of GeneralJurisprudence. By Sir Williain Markby, D.C.L. Fifh Edition. Svo. 12s. $6 d$.

Moyle. Imperutoris Iurtiniani Institutionum Libri Quattuor; with Introductions, Commentary, Excursus and Translation. By J. B. Moyle, D.C.I. Third Edition. 2 vols. 8vo. Vol. I. 16s. Vol. II. 6s.

- Contract of Sule in the Ciril Law. By J. B. Moyle, D.C.L. 8vo. 10s. 6d.

Pollock and Wright. $A n$ Essay on Possession in the Common Lav. By Sir F. Pollock, Bart., M.A., and Sir R. S. Wright, B.C.I. 8vo. 8s.6d.

Poste. Guii Institutionum Juris Civilis Commentarii Quattuor ; or, Elements of Roman Law by Gaius, With a Translation and Commentary by Edward Poste, M.A. Third Edition. 8vo. 18 s.

Raleigh. An Outline of the Law of Property. By Thos. Raleigh, M.A. Svo. 7s. $6 d$.

Sohm. Institutes of Roman Laro. By Rudolph Sohm. Translated by J. C. Ledlie, B.C.L. With an Introductory Essay by Erwin Grueber, Dr.Jur., M.A. 8vo. 188.

Stokes. The Anglo-Indian Codes. By Whitley Stokes, LI.D.

Vol. I. Substantive Law. 8vo. 30 s. Vol. II. Adjective Law. 8vo. 358. First and Seeond Supplements to the above, $18 S_{7-1} S_{91}$. Svo. 6r.6d. Separately, No.1, 2s.6d.; No. 2, 4s.6d. 


\section{HISTORY, BIOGRAPHY, ETC.}

Adamnani Vita S. Columbae. Ed. J. T. Fowler, D.C.L. Crown 8 vo, half-bound, 8s. 6 d. net (with translation, 9s. 6d. net).

Aubrey. 'Brief Lives,' chiefly of Contemporaries, set down by John Aubrey, between the Years 1669 and r696. Edited from the Author's MSS., by ANDREw Clark, M.A., LL.D. With Facsimiles. 2 vols. 8vo. 25s.

Baedae Historia Ecclesiastica, etc. Edited by C. Plummer, M.A. 2 vols. Crown 8vo, 2 Is. net.

Bedford (W.K.R.). The Blazon of Episcopacy. Being the Arms borne by, or attributed to, the Archbishops and Bishops of England and Wales. With an Ordinary of the Coats described and of other Episcopal Arms. Second Edition, Revised and Enlarged. With One Thousand Illustrations. Sm. $4^{\text {to, }}$ buckram, 31s. $6 d$. net.

Boswell's Life of Samuel Johnson, LL.D. Edited by G. Birkbeck Hill, D.C.L. In six volumes, medium 8vo. With Portraits and Facsimiles. Half-bound, $3 l$. $3 s$.

Bright. Chapters of Early English Church History. By W. Bright, D.D. Third Edition. Revised and Enlarged. With a Map. 8vo. I2s.

Casaubon (Isaac). I559-I6 I 4 . By Mark Pattison. 8vo. I6s.

Clarendon's History of the Rebellion and Civil Wars in England. Re-edited from a fresh collation of the original MS. in the Bodleian Library, with marginal dates and occasional notes, by W. Dunn Macray, M.A., F.S.A. 6 vols. Crown 8vo. 2l. $5^{s}$.

Hewins. The Whitefoord Papers. Being the Correspondence and other Manuscripts of Colonel Cirarles Whiteroord and Caleb WhITEFOORD, from I 739 to I8Io. Edited, with Introduction and Notes, by IV. A. S. Hewins, M.A. 8 vo. $12.6 d$.

Earle. Handbook to the LandCharters, and other Saxonic Documents. By John Earle, M. A. Crown 8vo. 16 s.

Freeman. The History of Sicily from the Earliest Times.

Vols. I. and II. 8vo, cloth, $2 l .2 s$.

Vol. III. The Athenian and Carthaginian Invasions. $24 s$.

Vol. IV. From the Tyranny of Dionysios to the Death of Agathoklês. Edited by Arthur J. Evans, M.A. $21 s$.

Froeman. The Reign of William Rufus and the Accession of Henry the First. By E. A. Freeman, D.C.L. 2 vols. 8 vo. 1 l. $16 s$.

Gardiner. The Constitutional Documents of the Puritan Revolution, 1628-1660. Selected and Edited by Samuel Rawson Gardiner, M.A. Crown 8vo. 9s.

Gross. The Gild Merchant; a Contribution to British Municipal History. By Charles Gross, Ph.D 2 vols. 8 vo. $24 s$.

Hastings. Hastings and the Rohilla War. By Sir John Strachey, G.C.S.I. 8 vo, cloth, ros. $6 d$.

Hill. Sources for Greek History between the Persian and Peloponnesian $W$ ars. Collected and arranged by G. F. Hill, M.A. 8vo. ros. $6 d$.

Hodgkin. Italy and her Invaders. With Plates and Maps. By T. Hodgkin, D.C.L.

Vols. I-II. Second Edition. 2l. 2s. Vols. III-IV. Second Edition. $\mathrm{Il}$. $\mathrm{I} 6 \mathrm{~s}$.

Vols. V-VI. Il. I6s.

Vol. VII. In the Press. 
Jackson. The Church of St. Mary the Virgin, Oxford. By T. G. Jackson, M.A., R.A. With T'wentyfour full-page Illustrations, and numerous Cuts in the Text. Demy 4 to, half-bound, $36 s$. net; or in vellum, gilt top and morocco labels, \&c., $42 s$. net.

Johnson. Letters of Sumuel Johnson, LL.D. Collected and Edited by G. Birkbeck Hill, D.C.L. 2 vols. half-roan, $28 s$.

- Johnsonian Miscellanies. By the same Editor. 2 vols. Medium 8 vo, half-roan, $28 s$.

Kitchin. A History of France. With Numerous Maps, Plans, and Tables. By G. W. Kitchin, D.D. In three Volumes. Newo Edition. Crown 8vo, each I0s. $6 d$.

Vol. I. to 1453. Vol. II. 14531624. Vol. III. 1624-1793.

Lowis (Sir G. Cornewall). An Essay on the Government of Dependencies. Edited by C. P. Lucas, B.A. 8vo, half-roan. I $4 s$.

Lucas. Introduction to a Historical Geography of the British Colonies. By C. P. Lucas, B.A. With Eight Maps. Crown 8vo. 4s. $6 d$.

Historical Geography of the British Colonies:

Vol. I. The Mediterranean and Eastern Colonies (exclusive of India). With Eleven Maps. Crown 8 vo. $5 s$.

Vol. II. The West Indian Colonies. With Twelve Maps. Crown 8vo. 7s. 6 d.

Vol. III. West Africa. With Five Maps. Crown 8vo. 78.6d.

Vol. IV. South and East Africa. Historical and Geographical. With Ten Maps. Crown 8vo. 9s. 6d.

Also Vol. IV in two Parts-

Part I. Historical, 6s. 6d.

Part II. Geographical, 3s. $6 d$.
Ludlow. The Memoirs of Edmund Ludlow, Lieulenant-General of the Horse in the Army of the Commonwealth of England, $1625^{-1672}$. Edited by C. H. Firth, M.A. 2 vols. 8 vo. 1l. $16 s$.

Machiavolli. Il Principe. Edited by L. Arthur Burd, M.A. With an Introduction by Lord Acton. 8vo. 148 .

Prothoro. Select Statutes and other Constitutional Documents, illustrative of the Reigins of Elizabeth and James I. Edited by G. W. Prothero, M.A. Crown 8vo. 10s. Gd.

- Select Statutes and other Documents bearing on the Constitutional History of England, from A.D. 1307 to 1558. By the same Editor. [In Preparation.]

Ramsay (Sir J. H.). Lancaster and York. A Century of English History (A.D. I 399-1485). 2 vols. 8 ro. With Index, $378.6 d$.

Ramsay (W. M.). The Cities and Bishoprics of Phrygia. By W. M. Ramsay, D.C.L., LL.D.

Vol. I. Part I. The Lycos Valley and South-Western Phrygia. Royal 8vo. 18s. net.

Vol. I. Part II. West and WestCentral Phrygia. 218. net.

Ranke. A History of England, principally in the Seventeenth Century. By L. von Ranke. Trans. lated under the superintendence of G. W. Kitchin, D.D., and C. W. Boase, M.A. 6 vols. 8 vo. 63 s.

Revised Index, separately, Is

Rashdall. The Universities of Europe in the Mriddle Ages. By Hastings Rashdall, M.A. 2 vols. (in 3 Parts) 8vo. With Maps. 2l. 5s., nel. 
Smith's Lectures on Justice, Police, Revenue and Arms. Edited, with Introduction and Notes, by Edwin Cannan. 8vo. Ios. 6d. net. Wealth of Nations. With Notes, by J. E. Thorold Rogers, M.A. 2 vols. 8 vo. 2 Is.

stephens. The Principal Speeches of the Statesmen and Orators of the French Revolution, I 789-1795. By H. Morse Stephens. 2 vols. Crown 8vo. $21 s$.

Stubbs. Select Charter's and other Illustrations of English Constitutional History, from the Earliest Times to the Reign of Edward I. Arranged and edited by W. Stubbs, D.D., Lord Bishop of Oxford. Eighth Edition. Crown 8vo. 8s. $6 d$.

The Constitutional History of England, in its Origin and Development. Library Edition. 3 vols. Demy 8vo. $2 l .8 s$.

Also in 3 vols. crown 8 vo, price I 2s. each.
Stubbs. Seventeen Lectures on the Study of Mediaeval and Modern History. Crown 8vo. 8s. $6 d$.

\section{Registrum Sacrum}

Anglicanum. An attempt to exhibit the course of Episcopal Succession in England. By W. Stubbs, D.D. Small 4 to. Second Edition. Ios. $6 d$.

Swift (F. D.). The Life and Times of James the First of Aragon. By F. D. Swift, B.A. 8vo. I $2 s, 6 d$.

Vinogradoff. Villainage in England. Essays in English Mediaeval History. By Paul Vinogradoff, Professor in the University of Moscow. 8vo, half-bound. I6s.

Woodhouse. Aetolia; its Geography, Topography, and Antiquities. By William J. Woodhouse, M.A., F.R.G.S. With Maps and Illustrations. Royal 8vo, price 2 Is. net.

\section{PHILOSOPHY, LOGIC, ETC.}

Bacon. Novum Organum. Edited, with Introduction, Notes, \&c., by T. Fowler, D.D. Second Edition. 8vo. I5s.

Berkeley. The Works of George Berkeley, D.D., formerly Bishop of Cloyne; including many of his voritings hitherto unpublished. With Prefaces, Annotations, and an Account of his Life and Philosophy. By A. Campbell Fraser, Hon. D.C.L., LL.D. 4 vols. $8 \mathrm{vo}$. $2 l .18 s$.

The Life, Letters, \&c., separately, $16 s$.

Bosanquet. Logic; or, the Morphology of Knowoledge. By B. Bosanquet, M.A. 8vo. 2 Is.

Butler. The Works of Joseph Butler, D.C.L., sometime Lord Bishop of Durham. Divided into sections, with sectional headings, an index to each volume, and some occasional notes; also prefatory matter. Edited by the Right Hon. W. E. Gladstone. 2 vols. Medium 8 vo. I 4 s. each.

Fowler. The Elements of Deductive Logic, designed mainly for the use of Junior Students in the Universities. By T. Fowler, D.D. Tenth Edition, with a Collection of Examples. Extra fcap. 8vo. 3s. $6 d$.

The Elements of Inductive Logic, designed mainly for the use of Students in the Universities. By the same Author. Sixth Edition. Extra feap. 8 vo. $6 s$.

Fowler. Logic; Deductive and Inductive, combined in a single volume. Extra feap. 8vo. 7s. $6 d$. 
Fowler and Wilson. The Principles of Morals. By 'T. Fowler, D.D., and J. M. Wilson, B.D. 8vo, cloth, I $4 s$.

Green. Prolegomena to Ethirs. By 'T. II. Green, M. A. Elited by A. C. Bradley, M.A. Fourth Edition. Crown 8vo. 7s. 6 d.

Hegel. The Logic of Hegel. Translated from the Eneyclopaedia of the Philosophical Sciences. With Prolegomena to the Study of Hegel's Logic and Philosophy. By WV. Wal. lace, M.A. Second Edition, Revised and Augmented. 2 vols. Crown 8vo. Ios. $6 d$. each.

Hegel's Philosophy of Mind. Translated from the Encyclopaedia of the Philosophical Sciences. With Five Introductory Essays. By William Wallace, M.A., LL.D. Crown 8vo. Ios. $6 d$.

Humo's Treatise of Human Nature. Edited, with Analytical Index, by L. A. Selby-Bigge, M.A. Second Edition. Crown 8vo. 8s.

\section{Enquiry concerning}

the Human Understanding, and an Enquiry concerning the Principles of Morals. Edited by L. A. Selby-Bigge, M.A. Crown 8vo. 7s. 6d.

Leibniz. The Monadology and other Philosophical Writings. Translated, with Introduction and Notes, by Robert Latta, M.A., D.Phil. Crown 8vo. 8s.6d.
Locko. An Essay Concerning Iuman Understanding. By John Locko. Collated and Annotated, with Prolegomena, Biographical, Critical, and Historic, by A. Campbell Fraser, Hon. D.C.L., LL.I). 2 vols. Svo. 1\%. $12 s$.

Lotzo's Logir, in 'Three Books; of 'Thought, of Investigation, and of Knowledge. English Translation; edited by B. Bosnnquet, M.A. Second Edition. 2 vols. Cr. 8vo. 128.

Metaphysic, in Three Books; Ontology, Cosmology, and Psychology. English Translation ; edited by B. Bosanquet, M.A. Second Edition. 2 vols. C'r. 8vo. I2s.

Martineau. Types of Ethical Theory. By James Martineau, D.D. Third Edition. 2 vols. Cr. 8vo. 158.

A Study of Religion: its Sourcesand Contents. Second Edition. 2 vols. Cr. 8 vo. $15 s$.

Selby-Bigge. British Moralists. Selections from Writers prin. cipally of the Eighteenth Century. Edited by L. A. Selby-Bigge, M.A. 2 vols. Crown 8vo. 18 s.

Wallace. Lectures and Essays on Natural Theology and Ethics. By William Wallace, M.A., LI.D. Edited, with a Biographical Introduction by Edward Caird, M.A., Hon. D.C.L. 8vo, with a Portrait. 12s.6 1 .

\section{PHYSICAL SCIENCE, ETC.}

Chambers. A Handbook of Descriptive and Practical Astronomy. By G. F. Chambers, F.R.A.S. Fourth Edition, in 3 vols. Demy 8 ro.

Vol. I. The Sun, Planets, and Comets. 21 s.

Vol. II. Instruments and Practical Astronomy. 2 Is.

Vol. III. The Starry Heavens. I 45.
De Bary. Comparative Anatomy of the Vegetative Organs of the Phanerogams and Ferns. By Dr. A. de Bary. Translated by F. 0 . Bower, M. A., and D. H. Scott, B.A. Royal 8vo. Il. 2s. 6d.

De Bary. Comparative Morphology and Biology of Fungi, Mycelosoa 
and Bacteria. By Dr. A. de Bary. Translated by H. E. F. Garnsey, M.A. Revised by Isaac Bayley Balfour, M.A., M.D., F.R.S. Royal Svo, half-morocco, Il. $2 s .6 d$.

DeBary. Lectures on Bacteria. By Dr. A. de Bary. Second Improved Edition. Translated by $\mathbf{H}$. E. F. Garnsey, M.A. Revised by Isaac Bayley Balfour, M.A., M.D., F.R.S. Crown 8 vo. 6 s.

Druce. The Flora of Berkshire. Being a Topographical and Historical Account of the Flowering Plants and Ferns found in the County, with short Biographical Notices. By G. C. Druce, Hon. M.A. Oxon. Crown 8vo, I6s. net.

Goobel. Outlines of Classification and Special Morphology of Plants. By Dr. K. Goebel. Translated by H. E. F. Garnsey, M.A. Revised by Isaac Bayley Balfour, M.A., M.D., F.R.S. Royal 8vo, half-morocco, Il. Is.

Sachs. A History of Botany. Translated by H. E. F. Garnsey, M.A. Revised by I. Bayley Balfour, M.A., M.D., F.R.S. Crown 8vo. Ios.

Fossil Botany. Being an Introduction to Palacophytology from the Standpoint of the Botanist. By $\mathbf{H}$. Graf zu Solms-Laubach. Translated by H. E. F. Garnsey, M.A. Revised by I. Bayley Balfour, M.A., M.D., F.R.S. Royal 8vo, half-morocco, I 8 s.

\section{Biological Series.}

I. The Physiology of Nerre, of Muscle, and of the Electrical Organ. Edited by .J. Burdon Sanderson, M.D., F.R.SS. L.\&E. Medium 8vo. Il. Is.

II. The Anatomy of the Frog. By Dr.Alexander Ecker, Professor in the University of Freiburg. Translated, with numerous Annotations and Additions, by G. Haslam, M.D. Med. 8vo. 2 Is.

IV. Essays upon Heredity and Kindred Biological Problems. By Dr. A. Weismann. Authorized Translation. Crown 8vo.

Vol. I. Edited by E. B. Poulton, S.Schönland, and A.E.Shipley. Second Edition. 7s. 6 d.

Vol.II. Edited by E. B. Poulton, and A. E. Shipley. $5^{s .}$

Elliott. An Introduction to the Algebra of Quantics. By E. B. Elliott, M.A. 8vo. ${ }^{5}$ s

Johnston. An Elementary

Treatise on Analytical Geometry, with Numerous Examples. By W. J. Johnston, M.A. (R.U.I.) Crown 8vo. Price reduced to $6 s$.

Prestwich. Geology; Chemical, Physical, and Stratigraphical. By Sir Joseph Prestwich, M.A., F.R.S. In two Volumes. $3 l$. Is.

Price. A Treatise on the Measurement of Electrical Resistance. By W. A. Price, M.A., A.M.I.C.E. 8vo. 14 s.

\section{Oxford}

\section{AT THE CLARENDON PRESS}

Eondon, Eoinburgb, and Mew Dork

HENRY FROWDE 




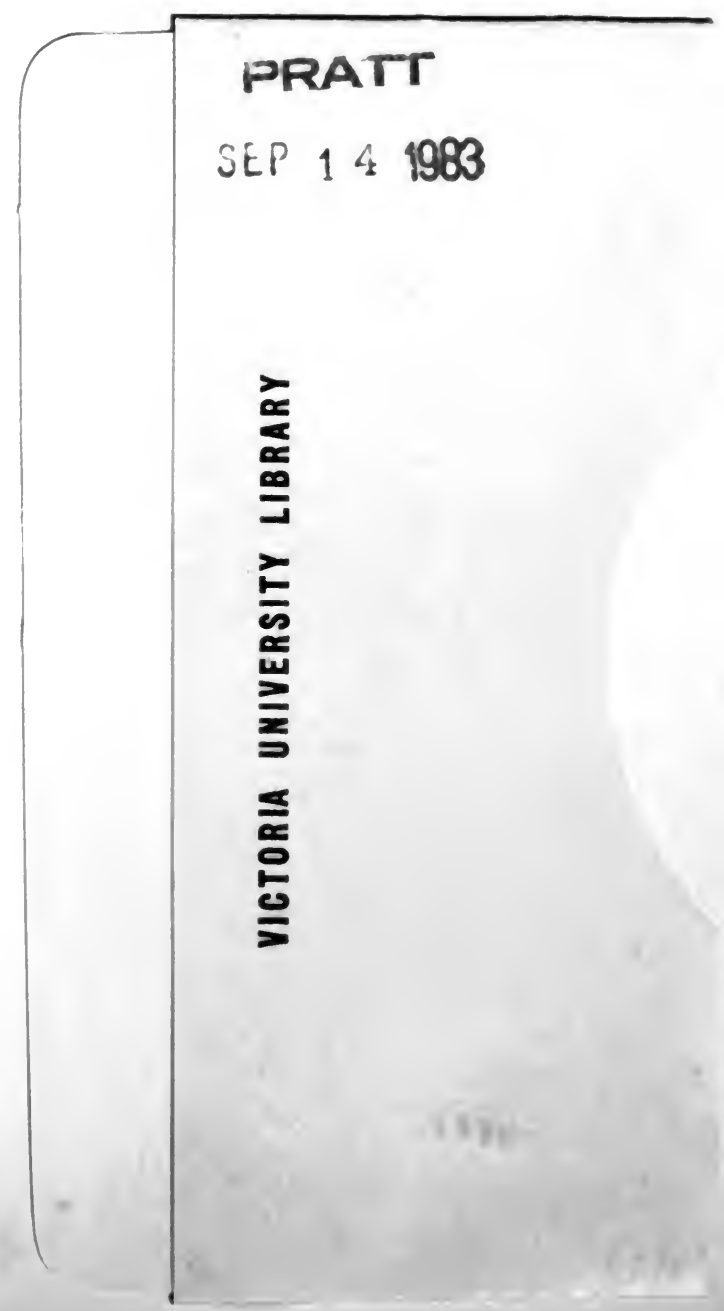


